UNIVERSIDAD POLITÉCNICA DE MADRID. Escuela Técnica Superior de Arquitectura
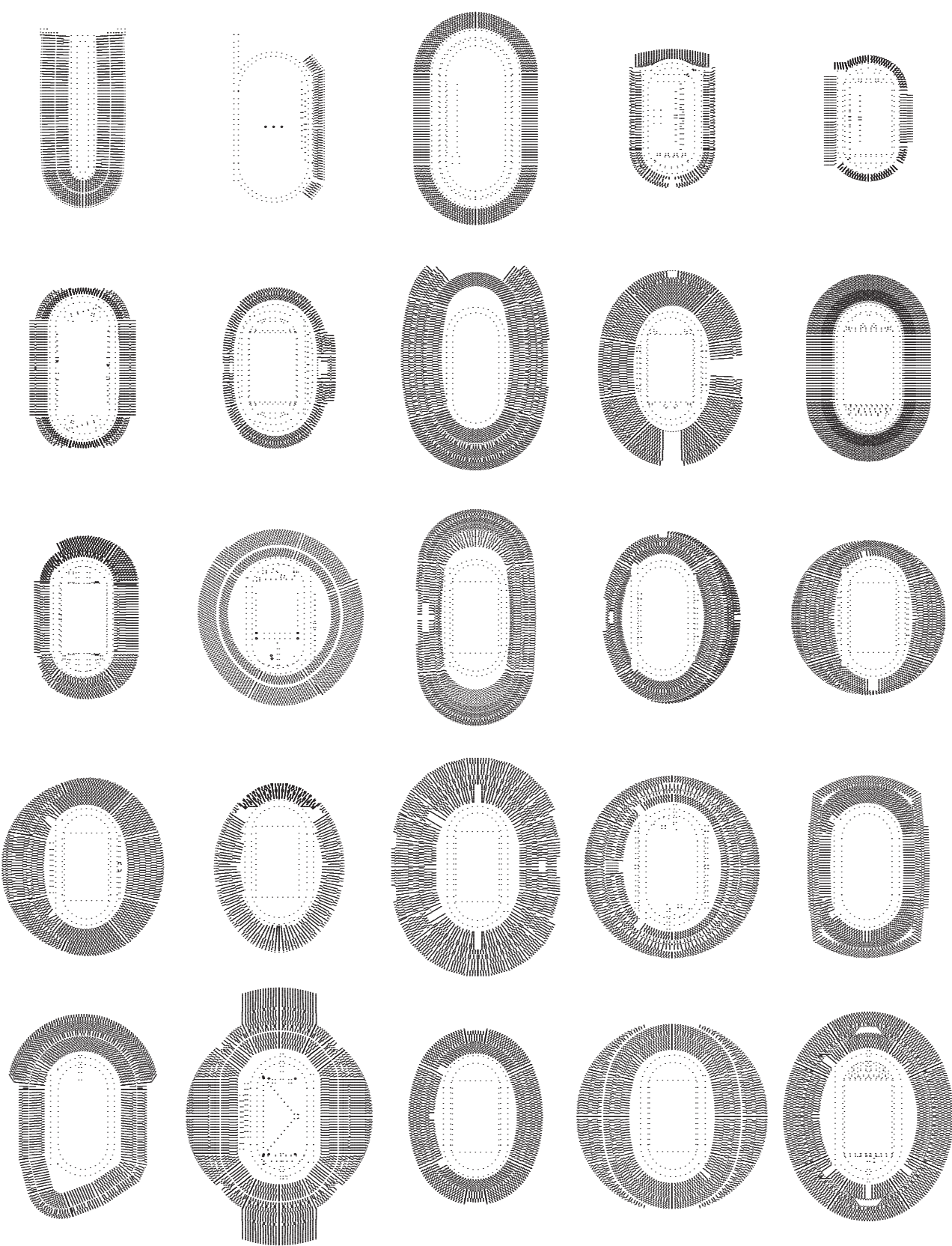

El estadio Olímpico. Sus fundamentos arquitectónicos Alfonso Cano Pintos 
Departamento de Proyectos Arquitectónicos

Escuela Técnica Superior de Arquitectura de Madrid

\section{Autor: Alfonso Cano Pintos. Arquitecto}

Director: Juan Miguel Hernández de León. Doctor Arquitecto

2016 


\section{Universidad Politécnica de Madrid}

Tribunal nombrado por el Magfco. y Excmo. Sr. Rector de la Universidad Politécnica de Madrid, el día de de 2016

Presidente:

Vocal:

Vocal:

Vocal:

Secretario:

Suplente:

Suplente:

Realizado el acto de defensa y lectura de la Tesis el día de 2016, en la Escuela Técnica Superior de Arquitectura de Madrid.

Calificación: 
A la memoria de mi padre, Julio Cano Lasso que nos inculcó la afición y el espíritu deportivo 


\section{El estadio Olímpico. Sus fundamentos arquitectónicos}

Índice de la Tesis

Resumen / Abstract

i. Introducción

i.i. Hipótesis

i.ii. Objetivos

i.iii. Estado de la Cuestión

i.iv. El estadio en la historia y crítica de la Arquitectura

i.v. Metodología

$\mathrm{i}-1$

A. Catálogo

A.1 Estadio Panathinaiko. Atenas. 1896

A.2 Croix Cantelar. Bois de Bolougne. París. $1900 \quad \ldots$

A.3 Francis Field Stadium. St Louis. 1904

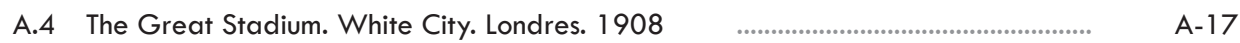

A.5 Estadio Olímpico. Estocolmo. $1912 \quad$............................................................................... A-23

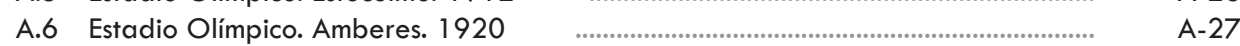

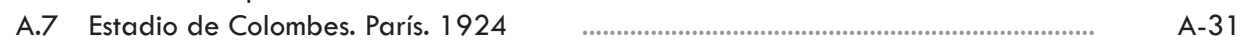

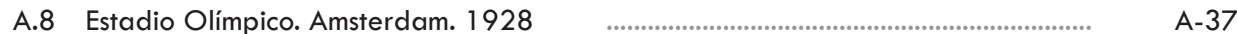

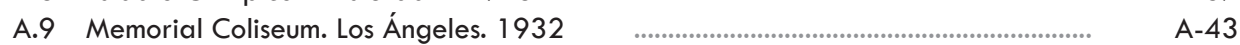

A.10 Reichssportfeld. Berlín. $1936 \quad$................................................................................... A-49

A.11 Wembley. Londres. $1948 \quad \ldots$

A.12 Olympiastadion. Helsinki. $1952 \quad \ldots$........................................................................ A-63

A.13 Cricket Ground. Melbourne. $1956 \quad$ …..................................................................... A-67

A.14 Estadio Olímpico. Roma. $1960 \quad$ ………............................................................... A-73

A.15 Kokuritsu Kasumigaoka Rikujo Kyogijo. Tokio. $1964 \quad$................................................ A-79

A.16 Estadio Olímpico Universitario. México. $1968 \quad$ …….................................................. A-83

A.17 Olympiastadion. Munich. $1972 \quad$ ………......................................................... A-89

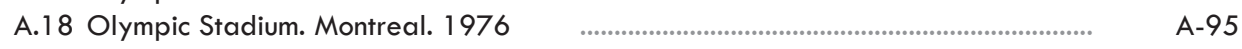

A.19 Estadio Central Lenin. Moscú. $1980 \quad$ ……...................................................................... A-101

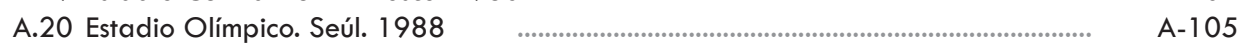

A.21 Estadio Olímpico Montjuic. Barcelona. $1992 \quad$........................................................... A-109

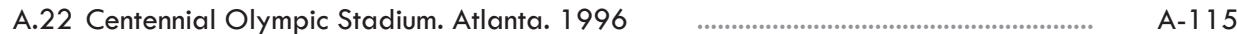

A.23 Olympic Stadium Australia. Sydney. $2000 \quad$............................................................. A-119

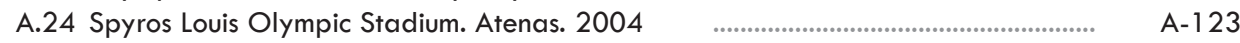

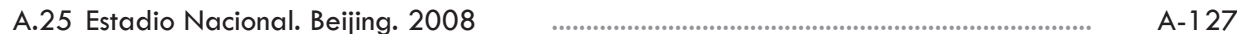

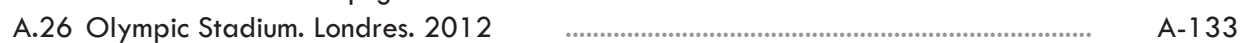

B. Tesis

B.1 El Estadio espacio de especial significación.

La compleja relación entre lo visible y lo evocativo

B.1.1 Espíritu agonal

B.1.2 El "intangible aglutinante"

B.1.3 El origen mítico

B.1.3.1 Origen mítico de los JJ.OO.

B.1.3.1.1 Origen mítico de los Juegos de la Antigüedad

B.1.3.1.2 Origen mítico de los Juegos Modernos

B.1.3.2 Destrucción y olvido

B.1.3.2.1 Destrucción y olvido previos a los Juegos de la antigüedad

B.1.3.2.2 Destrucción y olvido previos a los Juegos modernos

B.1.3.3 Reinstauración

B.1.3.3.1 Reinstauración de los Juegos Olímpicos de la antigüedad

B.1.3.3.2 Reinstauración de los Juegos Olímpicos modernos

B-1

B-2

B-4

B-6

B-7

B-7

B-1 11

$B-13$

B-14

B-15

B-21

B-21

B-22 
B.2 Origen del Estadio Moderno

B.2.1 El colector social _.............................................................................. B-29

B.2.2 Los modelos clásicos. El estadio, el circo y el anfiteatro. $\ldots \ldots \ldots . . . . . . . . . . . . . . . . . . . \quad$ B-34

B.2.2.1 El estadio _........................................................................... B-34

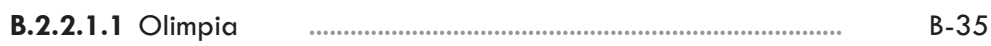

B.2.2.1.2 Atenas $\quad$.............................................................. B

B.2.2.2 El circo romano ............................................................................ B

B.2.2.3 El anfiteatro ........................................................................ B-40

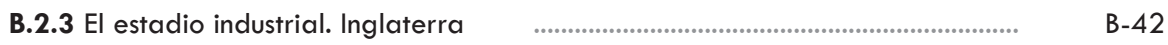

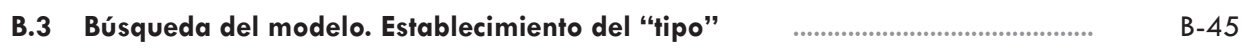

B.3.1 Función ….......................................................................................................... B

B.3.1.1 Decantación del contenido programático $\quad$...................................... B-.

B.3.1.2 Homogeneización y Homologación _.............................................. B-52

B.3.1.2.1 La cuerda y geometría de la pista _............................ B-53

B.3.1.2.2 La orientación ....................................................... B-58

B.3.1.3 Seguridad. Y las consecuencias de la violencia $\quad$.......................... B-. B

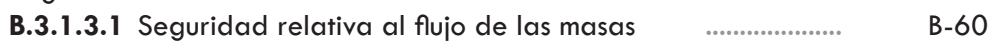

B.3.1.3.2 Consecuencias derivadas de la violencia $\quad$................... B $\quad$ B-64

B.3.1.4 Multifunción _.......................................................................... B-66

B.3.1.5 Nuevas tendencias _.............................................................. B-68

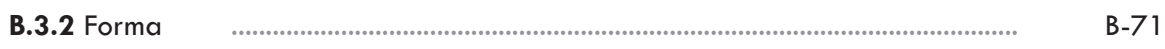

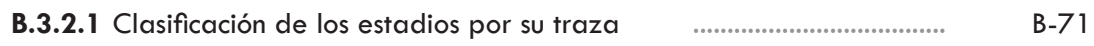

B.3.2.1.1 Herradura $\quad$............................................................... B

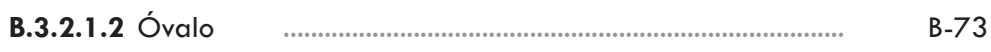

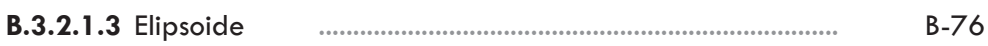

B.3.2.1.4 Extraños _.............................................................. B-8

B.3.2.2 Conclusiones respecto a la traza _............................................... B-8

B.3.3 Significación $\quad$............................................................................................... B-84

B.3.4 Técnica. Mass Media $\quad$..................................................................................... B-86

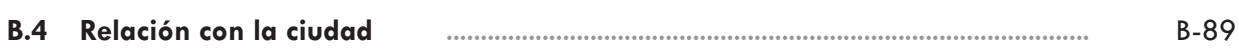

B.4.1 Claro en el bosque _................................................................................... B-93

B.4.2 Oposiciones reconciliadas, el pasado es prólogo _...................................... B-. B

B.4.3 Reto de Coubertin a los arquitectos _....................................................... B-96

B.4.4 Homotopía. Independencia de la ubicación $\quad$................................................... B $\quad$ B-97

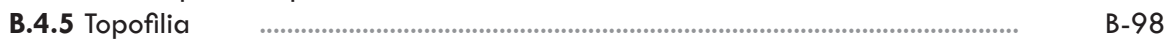

B.5 Geometría ........................................................................................................ B-101

B.5.1 Momentos de cambio en el entendimiento geométrico de los estadios .. B-101

B.5.2 El caso de Pekín _.............................................................................. B-102

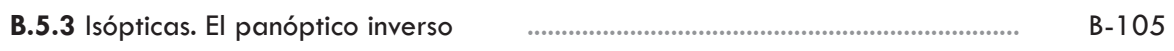

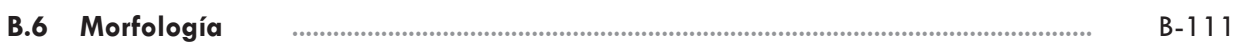

B.6.1 Escala. Proporción y Tamaño. "Lo grande"
y su riguroso requerimiento estructural

B.6.2 La configuración del espacio mediante la estructura.

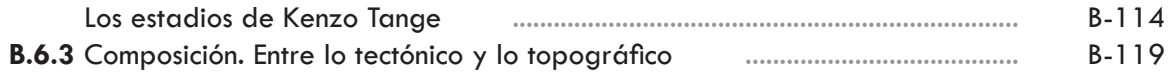

C. Conclusiones

D. Bibliografía 


\title{
El estadio Olímpico. Sus fundamentos arquitectónicos
}

\author{
RESUMEN
}

El estadio Olímpico. Sus fundamentos arquitectónicos El estudio del estadio Olímpico establece sus principales características arquitectónicas, cuáles son sus orígenes, su evolución tipológica y su relación con la ciudad. Se analiza que geometría subyace tanto para sus trazas como para las visuales y su entendimiento espacial, por último los fundamentos relacionados con su morfología. La relación entre el estadio y su usuario, es la historia acerca de la compleja relación entre lo visible y lo evocativo; lo físico y lo emocional. Los estadios no son solo edificaciones de carácter funcional, son, también, espacios de especial significación, lugares de emoción compartida, de mitos y de leyendas. El espíritu agonal que caracteriza el deporte, y que es directo heredero de los ritos de iniciación, crea un halo cuasi mitológico alrededor de los competidores, que transciende $y$, que es capaz de emocionar a los espectadores. Como un "intangible aglutinante" que ha acompañado al hombre desde tiempo inmemorial y es consustancial a las sociedades desarrolladas, encontrando en el estadio su más perfecto acomodo arquitectónico como espacio de reunión y autoafirmación de masas. El origen mítico de los juegos antiguos tiene su eco en los modernos, proporcionándoles un regusto mitológico Se pueden establecer tres antecedentes históricos básicos, para el desarrollo del estadio Olímpico moderno. El "colector social", con la entrada de las masas en la historia a finales del siglo XVIII, con su entusiasmo asambleario, plantea la tarea de producir las condiciones espaciales que apoyen la reunión de individuos en conjuntos de cooperación y contemplación multicéfalos. Esto exige nuevos planteamientos en arquitectura. También los modelos clásicos, el estadio griego, el circo y sobre todo el anfiteatro romano suponen acreditados modelos para grandes concentraciones, cuya perfección formal permite recuperarlos incluso después de una interrupción de más de 1500 años. Y por último el estadio de la Inglaterra industrial del siglo XIX, donde se produce el desarrollo del deporte, primero, como parte integral de la educación más elitista y, posteriormente, mediante su popularización. Paralelamente aparecen nuevos materiales y técnicas constructivas. Se analiza el desarrollo y perfeccionamiento de la serie tipológica, indagando como se ha ido decantando su contenido programático, desde estadios polivalentes hasta la especialización actual, motivada por la necesaria homogeneización para asegurar la igualdad de condiciones de los competidores. Las adaptaciones introducidas para procurar la seguridad y evitar los episodios de violencia, la multifuncionalidad y el análisis de las nuevas tendencias, las cuestiones derivadas de la forma de los estadios fundamentadas en su traza, los elementos significantes y la implicación de los de los medios de comunicación de masas, especialmente la televisión. Los estadios, aun siendo una de las grandes infraestructuras urbanas que destacan por su gran tamaño, mantiene una relación extraña y esquiva con la ciudad, cerrados hacia el exterior, en su interior encierran un fragmento de naturaleza domesticada que establece una relación afectiva con el claro en el bosque, lugar originario de los Juegos en Olimpia. La concepción geometría que subyace y sustenta el carácter de los estadios ha ido variando a lo largo de su secuencia histórica. Hasta los Juegos de Londres 1948, ha domina el equilibrio estático apoyado en la rigurosa aplicación de las simetrías, como mejores garantes de la monumentalidad. Con el estadio de Helsinki se inicia definitivamente el camino de la modernidad, con puntos culminantes en México, Múnich y especialmente Pekín. Y por último sus condiciones morfológicas, relacionadas con la escala, la proporción y "lo grande" con su riguroso requerimiento estructural, la composición, su masividad o ligereza, el equilibrio y la clara y directa relación entre forma, función y estructura. 


\section{Olympic Stadia and their architecture}

ABSTRACT

Olympic Stadia and their architecture The primary architectural characteristics of the stadium will be laid out including its origins, evolution and relationship with the its host city. The underlying geometry of the stadium will be analyzed, along with its visual aesthetics and use of space, and general morphology.. The relationship between the stadium and the spectator is the story of the complex connection between the visible and the evocative, between the physical and the emotional. Stadia are not only functional edifications, but also shared spaces of special significance, shared emotion, myth and legend. The agonistic spirit that embodies sport, that which is the direct heir of ancient ritual, creates a myth-like halo over the competitors, one which is transcendental and capable of exciting the spectators. Like something intangible that has been with mankind and society since time immemorial, the stadium has become society's perfect architectural expression as a place of congregation and public expression. The mythic origin of the ancient games shows itself in modern sport, providing it with a certain mythology. Three historical precedents can be established for the modern Olympic stadium's development. The Social Collector, with the arrival of the masses at the end the 18th century and their eagerness for assembly, necessitated spatial conditions that could accommodate the individual's integration into large groups for purposes of cooperation. This required new thinking in architecture. Surely the classical models, the Greek stadium, the Roman circus and above all the Roman amphitheatre, represent the starting points for consideration as they have been rediscovered after an interruption of 1500 years. And finally, the stadia of 19th century industrial England, where sport development was first introduced, first as an integral part of elite education, and afterwards by popularization. At this time, new ideas in material and construction techniques appear. The development and improvement of stadia will be analyzed, looking at how programming has played a part, from multi-purpose stadia to those with a specific purpose, and how the need for equality among competitors has led to homogenization. Adaptations to improve security and prevent violence will be studied, as will multifunctionality and new trends in stadia construction. The very nature of stadia and their relationship with mass media, especially television will also be studied. Stadia continue to be one of the great public urban infrastructures which stand out for their large size, and for their strange yet elusive relationship with the city which sees them closed on the outside, while their inside contains a fragment of domesticated nature that evokes a sense of a clearing in the woods, the place of the first Olympic Games. The geometric design which underlies the character of stadia has varied throughout its history. Until the 1948 London Games, static equilibrium resting on the rigorous application of symmetries was the name of the game when it came to monumentality. With the stadium at Helsinki, the path to modernity definitely begins, culminating in Mexico, Munich and above all, Bejing. Finally, morphological conditions of stadia related to scale, proportion and how "going large" translates to structural requirements. Composition, size or lack thereof, balance and the clear and direct relation among form, function and structure will be investigated. 


\section{El estadio Olímpico. Sus fundamentos arquitectónicos}

Desde siempre he sentido una gran fascinación por los estadios.

\section{i. Introducción}

Antes de que se iniciara la serie histórica de estadios Olímpicos modernos, Goethe, cuando describe la impresión que le produce el anfiteatro de Verona durante su viaje a Italia en 1786, adelanta certeramente unas características que posteriormente se han mostrado como sus fundamentos básicos.

El anfiteatro es el primer monumento importante de la Antigüedad que veo, iy está tan bien conservado! Cuando entré, mejor dicho, cuando empecé a pasearme por el borde superior, me pareció raro contemplar algo tan grande y al mismo tiempo tan vacío. Ciertamente se trata de un monumento que merece visitarse repleto de gente, tal como se llenó en tiempos recientes en honor a José Il y a Pío VI. El emperador, pese a estar acostumbrado a la contemplación de grandes masas de gente, debió de quedar asombrado ante semejante espectáculo. No obstante, sólo en tiempos pretéritos, cuando el pueblo era más pueblo que ahora, producía el anfiteatro todo su efecto. Puesto que un anfiteatro se construye para que el pueblo se impresione de sí mismo y se ría de sí mismo.

Siempre que se celebra algo digno de atención en un lugar llano y todo el mundo acude allí, los que están detrás intentan por todos los medios elevarse por encima de los que están delante: se suben a los bancos, traen toneles, vienen en coche, colocan tablas en diversos sentidos, ocupan un cerro próximo, y rápidamente se forma una especie de cráter.

Si el espectáculo se repite con frecuencia en el mismo sitio, se construyen pequeñas tribunas para los que puedan pagarlas, y el resto de la gente se las arregla lo mejor posible. Satisfacer la necesidad general es tarea del arquitecto, que crea una construcción de planta elíptica, con gradas alrededor, lo más sencilla posible, con objeto de que el mismo pueblo constituya el ornamento. Al verse así congregado, el pueblo, acostumbrado a una imagen desordenada de sí mismo, andando de acá para allá, habituado a la sensación de que en una multitud no hay ni orden ni concierto, por fuerza sentiría admiración ante este cuadro. En el anfiteatro, en cambio, este animal de múltiples cabezas y sentidos que se mueve desorientado de un lado a otro percibe por primera vez que está reunido en un cuerpo noble, 
destinado a una unidad, agrupado y afianzado en una masa, como una sola figura, animada de un único espíritu. La simplicidad de la forma ovalada es percibida de manera muy agradable por el ojo, y cada cabeza sirve de medida para hacerse cargo de lo descomunal que es el conjunto. Ahora, al contemplarlo vacío, no disponemos de referencias para determinar si la construcción es grande o pequeña. Debemos alabar a los veroneses por lo bien que conservan este monumento. Construido con un mármol rojizo constantemente expuesto a los agentes atmosféricos, las gradas se van sustituyendo a medida que se desgastan y ahora casi todas parecen muy nuevas. Una inscripción recuerda a un tal Jerónimo Maurigenus y los increíbles cuidados que consagró a este monumento. Del muro exterior no hay más que un lado, y dudo que éste se haya llegado a terminar nunca. Las arcadas inferiores, que dan a la gran plaza llamada il Brà, están alquiladas a artesanos: resulta divertido que estos antros estén de nuevo llenos de vida.'

La arquitectura del estadio está dominada por un gran vacío interior y su razón de ser es el público y su trazado permite y potencia que el espectador sentado de manera enfrentada comparta un sentimiento de unidad, orden y pertenencia. Es un tipo edificatorio que se distingue por su claridad conceptual y gran escala.

El conjunto de estadios modernos y contemporáneos conforman una tipología arquitectónica claramente definida y diferenciada. Y dentro de ellos, los Olímpicos mantienen unas características de uniformidad que los hacen más fácilmente comparables. Cuentan con antecedentes históricos de gran antigüedad e interés y abarcan un amplio periodo, desde finales del siglo XIX hasta nuestros días. Su desarrollo en el tiempo es coincidente con el de la arquitectura moderna ${ }^{2}$.

Creemos que es pertinente esta investigación porque en los estudios acerca de la historia de la arquitectura la atención prestada a la crítica y análisis de los estadios en su globalidad, es mínima, casi inexistente, a pesar de ser los estadios piezas muy reconocibles por la visibilidad que les proporcionan los Juegos por el alto interés que suscitan ${ }^{3}$.

Los estadios modernos comparten características derivadas tanto del estadio griego como del anfiteatro romano.

Dieciséis años antes del viaje de Goethe el emperador austrohúngaro José Il había visitado Verona, en 1771, el Gobernador de la ciudad italiana preparó una sorpresa especial para el monarca: una corrida de toros en el antiguo anfiteatro romano. El emperador fue dirigido por las galerías interiores hasta su sitio y de repente al ir a ocupar su asiento; el ovalo del arena se descubrió ante su vista y los miles de espectadores se pusieron en pie y le aplaudieron, como cuenta una fuente contemporánea, "dejó sin respiración al emperador" . Recibió una impresión abrumadora, a pesar de que seguramente estuviera acostumbrado a las multitudes. Algo nuevo había pasado en las viejas ruinas.

Goethe que nos relata éste hecho, a su vez, se extrañó al ver cerca del anfiteatro a una multitud de cuatro o cinco mil personas viendo un partido de pelota entre dos equipos de cuatro jugadores ${ }^{5}$, preguntándose en su diario por qué no utilizaban la antigua arena. Los Veroneses habían cuidado y preservado el monumento que desde hacía siglos había perdido su función, mientras que los deportes y los juegos habían encontrado otros medios para ser vistos; la arena física y los juegos habitaban en mundos distintos. Goethe fue un adelantado en entender la conexión entre el espectáculo de masas, con su modelo arquitectónico más eficaz, y el deporte.

La arquitectura del estadio está en intima relación con la competición deportiva que en él se desarrolla, incluso su propio nombre se confunde con el de la primera y principal prueba disputada en él. Constituye un espacio organizado en torno a dos polos ideológicos que controlan la actividad que en él se desarrolla, el de la justicia y el de la igualdad. Constituye un "espacio de excepción", acotado y

1. GOETHE, Johann W. Viaje a Italia. Ed. Zeta. ISBN 978-84-9872-263-5

2. Frank Lloyd Wright, en 1893, tres años antes de la primera edición de los Juegos Olímpicos modernos, deja el despacho de Adler y Sullivan, tras discutir con este último y abre su propio estudio en Chicago e inicia el camino de la modernidad

3. Por ejemplo, la audiencia televisiva de la ceremonia de inauguración de los últimos Juegos Olímpicos, de 2012 , en Londres, fue de aproximadamente 900 millones y en los Juegos de Beijing 2008, los espectadores totales se estiman en más de 4.000 millones de personas

4. The Stadium and the City. Editado por John Bale y Olof Moen. Keele University Press. ISBN 1853311103. Primera edición 1995. B. ACP

5. El tradicional juego del pallone

6. HERNÁNDEZ DE LEÓN, Juan Miguel. El espacio de la excepción. Sobre el carácter de la arquitectura deportiva. AV: 
prohibido, un claro en el bosque sagrado.

El anfiteatro es un mecanismo arquitectónico deudor del entretenimiento y del espectáculo en el que lo fundamental es el espectador y su capacidad para seguir adecuadamente la acción, constituyendo lo que Michel Foucault ${ }^{1}$ ha venido a denominar como Panóptico Inverso, en contraposición al modelo arquitectónico propuesto por el filósofo Jeremy Bentham, a fines del siglo XVIII, en el que las visuales constituyen el principio básico de su diseño, pero siendo su elemento más significativo el efecto que produce el público sentado frente a sí mismo que Elías Canetti describió en el capítulo titulado "La Masa como Anillo" de su ensayo de 1960, "Masa y Poder". Por su parte, Peter Sloterdijk en la tercera entrega de su trilogía "Esferas", titulada "Espumas, Esferología plural", de 2004, añade el concepto de la condición sonosférica.

Pese a que inicialmente el carácter de las actividades desarrolladas en el estadio y en el anfiteatro son esencialmente distintas, ambos tipos arquitectónicos convergen y dan como resultado el Estadio Olímpico Moderno, que constituye lo que califica Hernández de León² como "espacio de la excepción", en relación con el concepto de "heterotopía" propuesto por Foucault en su conferencia Espacios Otros, de 1967. Parece fácil "encontrar" y "reconocer" las características del estadio en los principios de los espacios heterotópicos enumerados en dicha conferencia.

Es evidente que se puede establecer una relación directa entre la estructura formal del tipo arquitectónico inferido de los diferentes estadios olímpicos modernos y del modelo clásico por excelencia de anfiteatro romano, el Coliseo. Lo que permite poner en relación arquitecturas de épocas y estilos muy diferentes, de manera análoga a como lo hizo Colin Rowe, en 1947, es decir, estableciendo una atrevida vinculación entre la Malcontenta, de Palladio, y la villa Stein-de-Monzie de Le Corbusier evidenciando que una estructura formal muy similar subyace en ambos edificios.

\section{i.i. Hipótesis}

La tesis pretende evaluar el perfeccionamiento del tipo estadio olímpico moderno y sí se mantiene la directa relación con el modelo romano, el Coliseo, a pesar de los profundos cambios de carácter funcional y técnico experimentados en los estadios a lo largo de más de un siglo de desarrollo.

\section{i.ii. Objetivos}

La tesis persigue un doble objetivo: por una parte constituir lo que podríamos denominar tesis de carácter enciclopédico, en la que se investiga y reúne todo un material disperso, mediante unos criterios de catalogación unitarios y procediendo a dibujar con las mismas escalas y medios expresivos todos los estadios olímpicos desvelando sus geometrías generadoras, su carácter topográfico o tectónico, cuestiones de dimensión y escala y su relación con la ciudad. Por otra parte, plantear una tesis de carácter científico por la que con el análisis comparado de los diferentes estadios en relación con su desarrollo tipológico y a sus fundamentos arquitectónicos pretende desentrañar el contenido de la hipótesis de partida.

\section{i.iii. Estado de la Cuestión}

La bibliografía disponible con un nivel científico adecuado es escasa. Existen dos monografías que incluyen el estadio como elemento principal de sus respectivos estudios y que abarcan la globalidad de la arquitectura Olímpica hasta el momento de su publicación.

El primero de ellos publicado es:

WIMMER, Martin. (1976). Olympic Buildings. Ed. Leipzig. Lic 600/34/75. 5938721

Martin Wimmer, es arquitecto, nacido en 1928. Se doctoró con la tesis sobre los Edificios Olímpicos (1975). Ejerció como arquitecto en las ciudades Eisenhüttenstadt y Hoyerswerda de la Alemania Oriental y como teórico e investigador en el Instituto de Construcción Industrial de la Deutsche Bauakademie (Academia de Arquitectura de la RDA) con sede en Berlín. Entre 1965 y 2002, fue miembro del grupo de trabajo Deportes y Ocio de la UIA. Ha sido profesor visitante en varias universidades, Dresden,

Monografías, ISSN 0213-487X, № 33, 1992 (Ejemplar dedicado a: Cultura física), p. 4-7

1. FOUCAULT, Michel. (1975). Vigilar y Castigar, nacimiento de la prisión. Ed Siglo XXI. Buenos Aires. 20003. ISBN 987-98701-4-X

2. En su artículo El espacio de la excepción: Sobre el carácter de la arquitectura deportiva AV. n³3 1992. ISSN 0213 487-X 

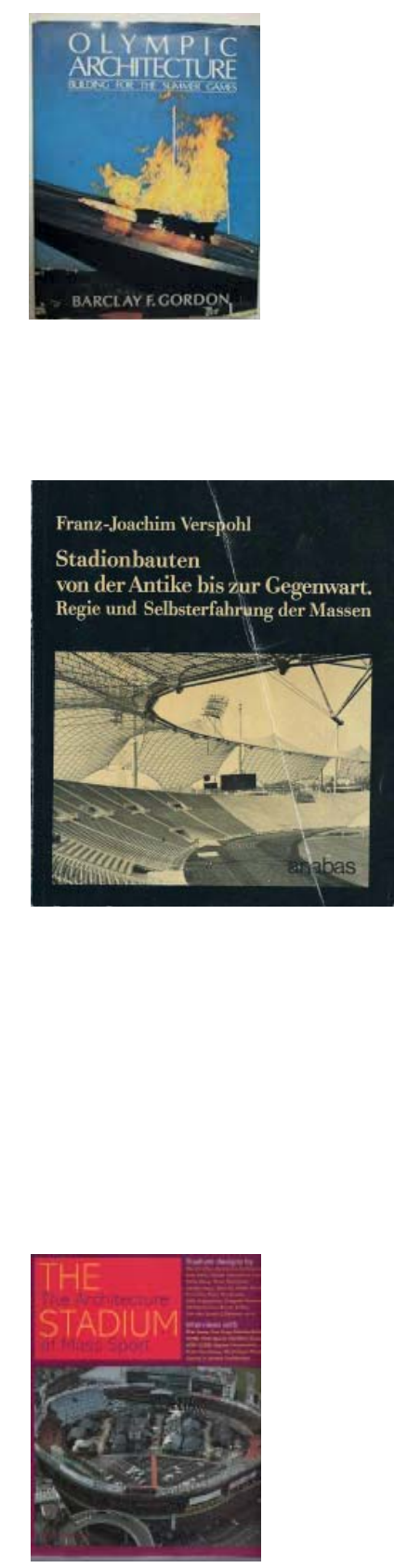

Moscú y Ulan Bator'.

Su estudio pretende dar detallada cuenta de los edificios e instalaciones de los Juegos, con una descripción muy somera de los mismos. Y, comparando los diferentes ejemplos, evalúa el desarrollo y los cambios que se han producido para ir adaptándose, paulatinamente, a las nuevas necesidades. También destaca los elementos y logros más destacados. El libro representa una clara visión de conjunto, desde las Olimpiadas Clásicas hasta los Juegos de Múnich de 1972.

La segunda publicación, en el tiempo, es:

GORDON, Barclay F. (1983). Olympic Architecture. Building for the summer games. Ed. John Wiley \& Sons. Nueva York. ISBN 0-471-06069-0

Establece una serie de etapas en el desarrollo de la arquitectura olímpica, desde Atenas 1896 hasta Los Ángeles 1984, agrupando los Juegos en diferentes grupos de características homogéneas y omitiendo, los que no considera relevantes desde el punto de vista arquitectónico.

No podemos dar ningún dato sobre su autor, aunque su libro es ampliamente conocido y citado en estudios posteriores.

Otro estudio relevante sobre estadios, con un campo de investigación más amplio que el estrictamente Olímpico, es:

VERSPOHL, Franz-Joaquim. (1976). Stadionbauten von der Antike bis zur Gegenwart. Regie und Selbsterfahrung der Massen. Ed. Anabas. ISBN 3-87038-043-8. (Estadios desde la antigüedad hasta nuestros días. Control y autoafirmación de las masas.

Franz-Joaquim Verspohl, nacido en 1946 en Altenberge, Alemania. Estudia historia del arte, sociología, filosofía y arqueología en Múnich, Colonia y Marburgo. Desde 1976 es profesor ayudante de la Universidad de Osnabrück.

En la contraportada del libro se dice:

El estadio es uno de los temas más interesantes y complejos de la arquitectura del siglo $X X$, sin embargo, no cuenta con trabajos de investigación importantes.

Este libro presenta por primera vez un estudio básico sobre su desarrollo histórico y su función social desde la antigüedad hasta nuestros días.

Se divide en tres partes.

La primera aborda el estudio desde el punto de vista de las masas, de estas y su relación con la ciudad, de las experiencias para su concentración y como el estadio es el elemento adecuado para ello y por tanto el lugar en el que se manifiestan todas sus contradicciones sociales.

En la segunda parte, recorre el desarrollo de la historia del estadio desde la Edad Media hasta principios del siglo $X X$.

La tercera, se centra en la historia del estadio moderno, aunque no de una forma global. Dedica un capítulo a la importancia que ha tenido el Ideario Olímpico como fuerza impulsora de los estadios. Luego, desarrolla, fundamentalmente, los casos alemanes y americanos, para acabar con un análisis detallado de la arquitectura de los Juegos Olímpicos de Múnich en 1972.

En verano del año 2000 el Netherlands Architecture Institute, organizó la exposición The Stadium. The architecture of Mass Sport (El Estadio. La arquitectura de los deportes de masas) y con el mismo título publicó un interesante estudio recogiendo el contenido de la exposición:

The Stadium. The Architecture of Mass Sport. (2000). Ed. Michelle Provoost. NAl Publishers Rotterdam. ISBN 90-5662-145-9

En su prólogo Kristin Feireiss, directora del Nai, se pregunta por la relación entre deporte, arquitectura y cultura. Considera que los estadios tienen la capacidad de constituirse piezas importantes de la arquitectura, la ingeniería y del desarrollo urbano.

$Y$ también afirma que:

la arquitectura deportiva que tiene su particular historia, al igual que otros objetos arquitectónicos tales como puentes, túneles, diques o la arquitectura industrial.

Es curiosa esta equiparación que, más adelante, nos permitirá reflexionar sí el lugar que han ocupado los estadios para el mundo de la crítica, lo ha sido en el campo de la arquitectura o en el de la ingeniería. La publicación contiene una introducción por parte de los comisarios de la exposición, Matthijs Bouw y Michelle Provoost, además de reseñas, entrevistas y cuatro ensayos.

El más interesante para el presente estudio es el primero, a cargo de Camiel van Winkel (escritor y profesor de teoría del arte y filosofía del arte). Es el titulado Dance, discipline, density and death. The crowd in the stadium (Danza, disciplina, densidad y muerte. La multitud en los estadios). Una interesante

1. Acaba de publicar, en 2015, el libro Stadium Buildings: Construction and Design Manual, editado por DOM Publishers ISBN-10: 3869224150 
reflexión sobre las masas, su psicología y el estadio como contenedor funcional de las mismas.

Existen una serie de libros sobre estadios en los que predominando la imagen su nivel científico es escaso, como por ejemplo,

LLORELLA, Anja. (2006). Stadium Design. Ed. Daab. Colonia, Londres, Nueva York. ISBN 3-93 7718-38-9

Y otra serie más interesante de publicaciones promocionales de grandes ingenierías dedicadas a la arquitectura deportiva, como puede ser el libro de Rod Sheard de HOK LOBB, en el que los estadios proyectados por esta firma, incluido el Olímpico de Sydney, son los elementos centrales su línea argumental.

SHEARD, Rod. (2001). Sports architecture. Ed. Spon Press. Londres, Nueva York. ISBN 0-419-21 220-5

En revistas, catálogos y publicaciones periódicas se pueden encontrar algunos artículos interesantes, como en las publicaciones de CIO (Comité Olímpico Internacional), Documents of the Museum, o en la revista británica Stadia, aunque esta tiene un marcado carácter informativo y comercial.

Con motivo de los Juegos de Barcelona, la desaparecida revista barcelonesa Arquitecturas Bis dedicó un número doble al estudio de los estadios.

Revista Arquitecturas Bis. $n^{\circ} 46$ y 47. Barcelona 1992.

Por otra parte, existe una amplia bibliografía de carácter parcial, dedicada a la arquitectura de algunos estadios Olímpicos.

Y para acabar con el repaso de la bibliografía disponible debemos mencionar los interesantes documentos publicados después de cada edición de los Juegos, por los comités organizadores, conocidos, en francés, como los Rapport, o Report en inglés. En ellos se levanta acta de lo realizado en y para los juegos y suelen contar con un capitulo acerca de las infraestructuras $y$, en particular, de su estadio.

En busca de más información se han visitado un buen número de estadios Olímpicos y en cada una de sus ciudades los archivos correspondientes. Igualmente se ha viajado en repetidas ocasiones a Lausana, Suiza, para consultar el archivo del $\mathrm{ClO}$. También se ha investigado en los archivos de la Academia Olímpica Internacional, en Olimpia, Grecia y en las bibliotecas de la Escuela Técnica Superior de Arquitectura de Madrid, del Instituto Nacional de Educación Física, del Colegio Oficial de Arquitectos de Madrid.

Durante los muchos años de estudio se ha ido reuniendo una amplia colección de libros versados en el olimpismo y su arquitectura.

\section{i.iv. El estadio en la historia y crítica de la Arquitectura.}

Si repasamos algunos de los tratados, ensayos o investigaciones publicadas sobre la historia de la arquitectura moderna, vemos que los estadios no han sido tenidos en consideración como un elemento arquitectónico relevante, ni como ejemplo de arquitectura que en algún caso pudiera destacar, ni tampoco ha sido considerado como secuencia tipológica.

Es más, ni tan siquiera en el primer tratado de arquitectura que conservamos, De Architectura', escrito en el siglo I dC. por el arquitecto e ingeniero romano Marco Vitrubio, se considera al estadio y al anfiteatro como tipos arquitectónicos dignos de reseña dentro del grupo de los edificios públicos:

Así pues, oh César, en el tercer y cuarto volúmenes he expuesto las proporciones de los templos y en éste pasaré a explicar la disposición o estructura de los lugares públicos.

Y en el libro desarrolla los siguientes temas:

El foro y las basílicas, en el capítulo primero

El erario, la cárcel y la curia, capítulo segundo

La ubicación del teatro, capítulo tercero

La armonía, capítulo cuarto

Los vasos del teatro, capítulo quinto

Trazado del teatro, capítulo sexto

Los teatros griegos, capítulo séptimo

La acústica, capítulo octavo 


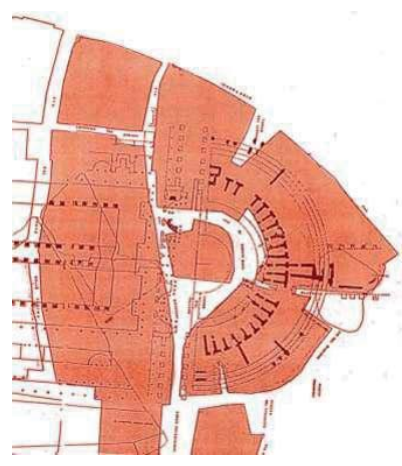

Los pórticos y paseos detrás del escenario, capítulo noveno

Los baños, capítulo décimo

La palestra, capítulo décimo primero

Los puertos y astilleros, capítulo décimo segundo

Resulta extraño que Vitrubio no se ocupe de elementos arquitectónicos tan importantes en la ciudad romana como el anfiteatro, el circo o, en menor medida, el estadio.

Al estadio solo lo menciona dos veces, de una manera tangencial y circunstancial. La primera en el Libro Quinto, capitulo noveno:

Detrás del escenario deben disponerse unos pórticos para que el público pueda recogerse desde el teatro, si una lluvia repentina interrumpe las representaciones; y además unos vestuarios o soportales espaciosos para ubicar los decorados y las máquinas. Como son los pórticos de Pompeyo, en Roma, y en Atenas los pórticos de Eumene; el Templo de Baco y el Odeón, situado a la izquierda según se sale del teatro, con unas columnas de piedra que levantó Temístocles y recubrió con antenas y mástiles de naves procedentes de los despojos obtenidos sobre los persas. El rey Ariobarzanes lo reconstruyó, ya que fue incendiado en la guerra contra Mitrídates. En Esmirna podemos ver los pórticos de Estratónice. En Trales hay también unos pórticos a ambos lados del teatro, como si fueran escenas, sobre el mismo estadio.

Y otra vez, también en el Libro Quinto, capitulo décimo primero, cuando describe la Palestra y los pórticos complementarios de la misma y, más adelante solo cita al estadio como complemento arquitectónico de todo ello:

Fuera de la palestra se abrirán tres pórticos: uno, para quienes salen del peristilo y los otros dos, situados a derecha e izquierda, para que se ejerciten los atletas; de estos dos pórticos, uno quedará orientado hacia el norte, tendrá dobles columnas y una anchura extraordinaria; el otro pórtico será simple; entre la parte próxima a la pared y entre la que está al lado de las columnas se trazarán unos lindes, a modo de senderos, excavados en su parte intermedia, cuya anchura no será menor de diez pies. Los escalones para descender a la plataforma tendrán unos márgenes de pie y medio y la plataforma no menos de doce pies; así quienes vayan paseando vestidos por los márgenes no serán molestados por los atletas, ungidos con aceite. Los griegos llaman xystos a este pórtico, ya que los atletas se entrenan en estadios cubiertos, durante el invierno. Cerca del xisto y del pórtico doble se dispondrán unos paseos al aire libre -en griego, paradromídas- que nosotros llamamos xistos: durante el invierno los atletas se ejercitan en estos paseos, si hace buen tiempo. Los xistos deben construirse siguiendo el siguiente plan: entre los dos pórticos se plantarán unos plátanos y a través de ellos se trazarán paseos y lugares de reposo, construidos con "mortero de Signia». Detrás del xisto se construirá un "estadio", donde un gran número de espectadores, sin apreturas, pueden observar las competiciones de los atletas. He descrito con todo detalle los edificios que parecen necesarios dentro de las murallas de una ciudad, con el fin de distribuirlos convenientemente.

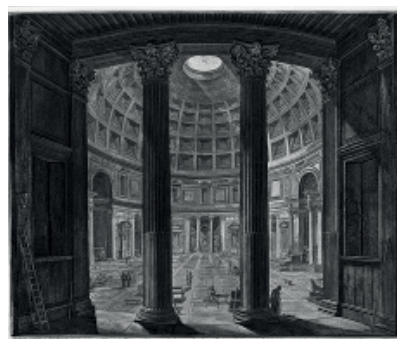

El libro publicado por Bruno Zevi en 1948 con el título en italiano "Saper vedere l'architettura", en español, Saber ver la Arquitectura', gira en torno al concepto de espacio interior como elemento sin el cual no existe la arquitectura, aunque ésta pueda tener otros valores y sin ellos, quizás tampoco pueda considerarse arquitectura. Ejemplo de no-arquitectura para Zevi es el Partenón, del que dice que no posee espacio interno, ya que sólo se pensó en la envolvente, lo que según Zevi lo convierte en un elemento con valor escultural y urbanístico, pero no propiamente arquitectónico. Tal vez, siguiendo esta línea de pensamiento, los críticos hayan considerado al estadio como una categoría en la que se manifiestan muchos elementos de la arquitectura, pero que no es puramente un elemento arquitectónico, por carecer de espacio interior cerrado, puede que sea considerado más como una infraestructura, perteneciente al mundo de la ingeniería, aunque cuente con atributos propios de la arquitectura. Ya hemos visto anteriormente como Kristin Feireiss, directora del Nai, equipara los estadios con elementos edificatorios que siempre se han considerado ajenos a la competencia del arquitecto y pertenecientes al mundo de la ingeniería.

Zevi, en el capítulo titulado "El espacio, protagonista de la arquitectura" primero define lo que es para él la arquitectura

La definición más precisa que se puede dar hoy de la arquitectura, es aquella que

1. ZEVI, Bruno. (1948). Saber ver la arquitectura. Ed. Poseidon. Barcelona 1981. ISBN 84-85083-01-6 
tiene en cuenta el espacio interior. ... Un obelisco, una fuente, un monumento aunque de proporciones enormes, un arco de triunfo, son todos hechos de arte que encontramos en las historias de la arquitectura y pueden ser obras cumbres de poesía, pero no son arquitectura. La escenografía, la arquitectura pintada o dibujada, no es arquitectura; ni más ni menos que un poema todavía no desarrollado en verso y solamente narrado en sus grandes líneas no es un poema, o lo es meramente en intención. En otras palabras, la experiencia espacial no está dada, hasta que la expresión mecánica y concreta no haya realizado la intuición lírica.

A continuación advierte del riesgo que se puede derivar de la aplicación estricta de su definición

Ahora bien, si nosotros tomamos cualquier historia de la arquitectura y entresacamos rigurosamente todas las partes en que se detiene en la descripción de hechos no arquitectónicos, podremos estar seguros de que en cien páginas llegaremos a suprimir ochenta por lo menos.

Pero aquí pueden surgir dos gravísimas equivocaciones que no sólo anularían el valor del razonamiento precedente, sino que harían francamente ridícula la interpretación espacial de la arquitectura. Estas son:

1) que la experiencia espacial de la arquitectura tan sólo se puede tener en el interior de un edificio, es decir, que prácticamente no existe, o no tiene valor el espacio urbanístico;

2) que el espacio no es solamente el protagonista de la arquitectura, sino que agota la experiencia arquitectónica, y que, por consiguiente, la interpretación espacial de un edificio es suficiente como instrumento crítico para juzgar una obra de arquitectura.

Estas equivocaciones deben ser disipadas inmediatamente.

La experiencia espacial propia de la arquitectura tiene su prolongación en la ciudad, en las calles y en las plazas, en las callejuelas y en los parques, en los estadios y en los jardines, allí donde la obra del hombre ha delimitado "vacíos", es decir, donde ha creado espacios cerrados."

Zevi cita al estadio entre los parques y los jardines y lo hace después de las calles, plazas y callejuelas. Y aclara que la experiencia espacial de la arquitectura tiene su prolongación...en los estadios. Esto parece que es restarles valor. No es que se lo niegue pero tampoco los incluye en lo que anteriormente ha definido como arquitectura "aquella que tiene en cuenta el espacio interior". A los estadios solo les reconoce que comparten con la arquitectura "la experiencia espacial".

En cualquier caso, incluir a los estadios como salvedad, dentro de la aclaración de errores que puede producir su razonamiento nos indica el rango de importancia que les asigna.

Aunque después en lo que denomina "índice de ilustraciones fuera de texto" incluye fotografía aérea del anfiteatro de Verona (s. I-III d. C.)

Pero hay un concepto, que queremos resaltar de lo que dice:

La experiencia espacial propia de la arquitectura tiene su prolongación...en los estadios ..., allí donde la obra del hombre ha delimitado "vacíos", es decir, donde ha creado espacios cerrados.

En otra de sus publicaciones, Espacios de la Arquitectura Moderna, que es una revisión, de carácter predominantemente visual, de su muy citado libro editado en 1950, Historia de la Arquitectura Moderna, repasa numerosísimos ejemplos de arquitectura y algunos de ingeniería, diseño o pintura, desde el tiempo de los iluministas Boulle y Ledoux, hasta los años 70. En un total de 680 páginas, con una media de cuatro o cinco ejemplos por página, solo incluye un estadio, el de 20.000 espectadores de Tony Garnier, en Lyon, de 1913/16 y lo hace con dos pequeñas fotos y el comentario "se convierte en prototipo europeo".

De otras arquitecturas deportivas, solo menciona el Palazzetto dello Sport de Pier Luigi Nervi, en Roma, de 1957 y el centro Olímpico de Yoyogi en Tokio de 1963, entre las obras destacadas de Kenzo Tange y sin más cometarios.

Renato de Fusco (1929), en la edición española, revisada en 1981, de su obra Historia de la Arquitectura Contemporánea, vuelve a citar al estadio de Garnier en Lion, como único ejemplo de estadio. Y lo hace, no por su especial interés arquitectónico, sino como parte de los equipamientos de la nueva ciudad ...el arquitecto vuelve a Lion, su ciudad natal, donde entre 1905 y 1919 realiza Les grands trabaux de la ville de Lyon, apoyado por el alcalde radical E. Herriot. Constan
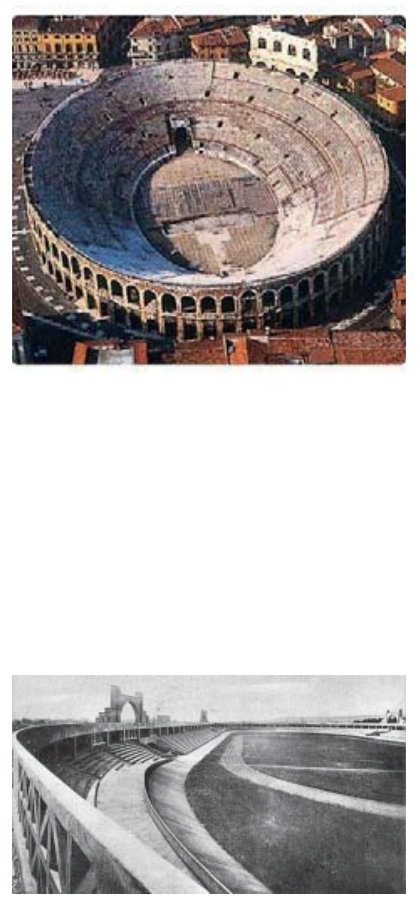


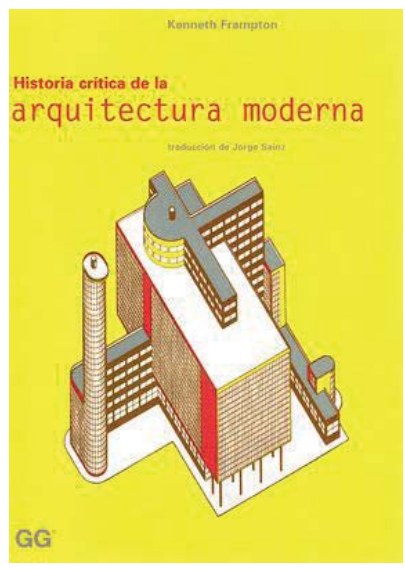

Kenneth Frampton (1930), en su muchas veces reeditada Historia crítica de la arquitectura moderna, cuando habla del constructivismo, reproduce en una de las ilustraciones una sección de un estadio imposible, con una estructura extraordinariamente sugerente, proyecto de Korschev. Menciona a Frei Otto, pero no al estadio Olímpico de Múnich. Cuando habla de Kenzo Tange, lo ilustra con dos fotos de los estadios de natación y baloncesto en Yoyogi, sedes de los Juegos Olímpicos de Tokio, 1964. Y en la parte dedicada a España, habla de los Juegos de Barcelona 1992 y destaca el Palacio de Deportes de Badalona y el Velódromo de Horta, de Esteban Bonell y Francesc Rius, de 1984,

ambos se cuentan con seguridad entre los estadios más elegantes levantados en todo el mundo en los últimos cincuenta años. La fuerza del "parti" o esquema esencial del velódromo se basa en una oposición entre la forma pura del círculo de delimitación y el trazado elíptico de la pista peraltada, y todavía más, por supuesto, en una estrecha correspondencia entre la función, el volumen, los materiales y la estructura. Esto último, tan característico de la mejor tradición moderna española, se menciona explícitamente en la descripción que hace Bonell del proyecto.

Y podríamos seguir poniendo ejemplos del escaso interés que ha suscitado para los críticos e historiadores de la arquitectura, el estadio Olímpico.

\section{i.v. Metodología}

Se propone una investigación de carácter científico. Es decir;

1. Sistemática y controlada, que está en todo momento sometida a una estricta disciplina.

Basada en datos empíricos. En cuestiones de carácter teórico-conceptual se recurre a teorías suficientemente contrastadas, de fuentes fiables $\mathrm{y} / \mathrm{o}$ prestigiosas.

2. Crítica, apoyada en juicios objetivos. Con dos vertientes, la crítica analítica y la descriptiva.

3. Relacional. Comparando y relacionando los fenómenos semejantes para asignarles la valoración adecuada.

4. Hipotética, se conduce y comprueba a través de objetivos e hipótesis. Se elabora un plan estratégico de actuación.

El largo periodo de elaboración, de la presente tesis, ha propiciado una serie de cambios y fluctuaciones en los objetivos de la tesis, en función de las inquietudes personales y del ambiente cultural. También el proceso de investigación ha ido produciendo un apasionado interés por algunos aspectos de la investigación y una cierta frialdad hacia otros. Por lo cual se ha ido reconduciendo el objetivo desde cuestiones más genéricas y sobre todo de relación entre la arquitectura Olímpica y la ciudad, hacia cuestiones más propias del estadio, como objeto arquitectónico, y fundamentalmente del espacio contenido en su interior, de ese "vacío, espacio cerrado" al que se refiere Bruno Zevi, con todas sus cualidades.

Entendiendo que el carácter principal del estadio es el que emana de la relación que se produce entre el público y el espectáculo.

El gran reto de los arquitectos, al enfrentarse con la tarea de proyectar un estadio, está en la capacidad de propiciar mediante la arquitectura la conexión de la tensión del espectáculo con los espectadores y también en el sentido inverso, configurando un gran espacio interior.

El plan estratégico ha ido evolucionando hasta el punto actual, en el que se ha definido con precisión para la redacción final de la tesis.

Una vez fijados los objetivos, se ha procedido a elaborar un catalogo con los 26 estadios Olímpicos, en el que se recogen los datos de la manera más uniforme posible. Además se han dibujado, todos y cada uno de ellos, con las mismas escalas y los mismos criterios gráficos, atendiendo a las cuestiones que nos han parecido más relevantes para la posterior su comparación y posibilidad de relación. 

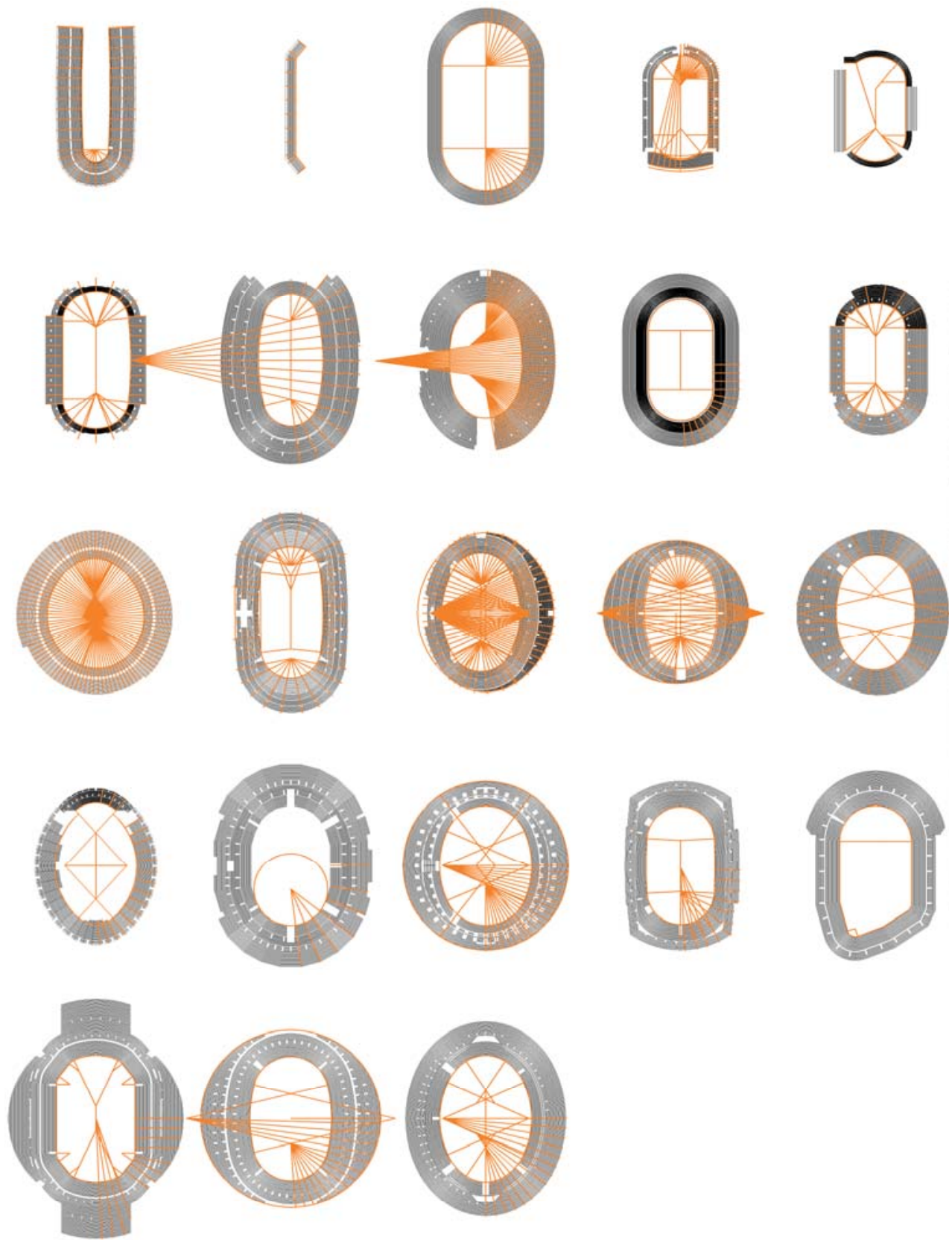

A- Católogo

El estadio Olímpico. Sus fundamentos arquitectónicos 
1896. ATENAS

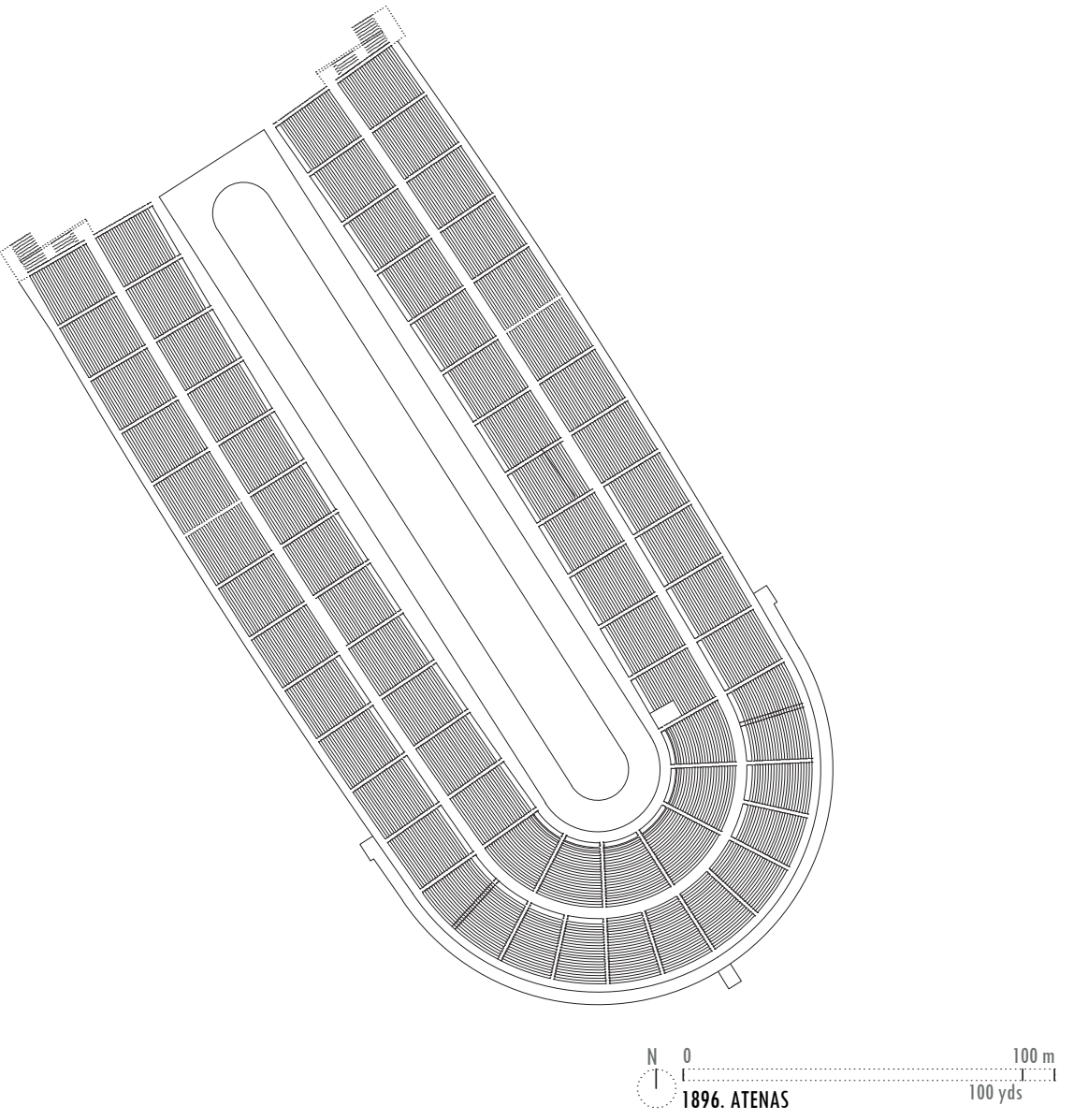

1896.0. Nombre del Estadio

Panathenaikó Stadion

1896.1. Situación

Avenida Vasileos Konstantinou. Atenas 116 35. Grecia

\subsection{Fechas}

329 aC. Construcción del estadio impulsado por Licurgo (Lykourgos).

144dC. Intervención impulsada por Herodes Ático (Atticus). Mejora del estadio y sus materiales, recubriéndolo en mármol pentélico.

1836. Primera excavación arqueológica que descubre sus trazas.

1869. Restauración llevada a cabo por Ernst Ziller bajo el patronazgo del fallecido en 1865 Evangelis Zappas. Anastasios Metaxas participa como colaborador.

1870. Primer festival Olímpico celebrado en el estadio. Organizado y financiado siguiendo las instrucciones dejadas por Zappas

1875. Segundo festival Olímpico celebrado en el estadio.

1894. Congreso de Paris, reinstauración de los Juegos Olímpicos, se designa Atenas como ciudad anfitriona de los primeros Juegos Olímpicos de la edad moderna, a celebrar en 1896.

1895. El estadio se encontraba abandonado y cubierto de maleza. Metaxas es encargado de su rehabilitación. El generoso benefactor George M. Averoff se hace cargo de los gastos.

1896. El 24 de marzo, se inaugura el estadio y la estatua dedicada a Averoff en frente del mismo.

1896. El 25 de marzo, apertura de los Juegos.

1896. El 3 de abril, clausura de los Juegos.

1906. Finalización de las obras de restauración del estadio.

1906. El 22 de abril, se inauguran los Juegos "intercalados" de Atenas, que no se han considerado oficiales.

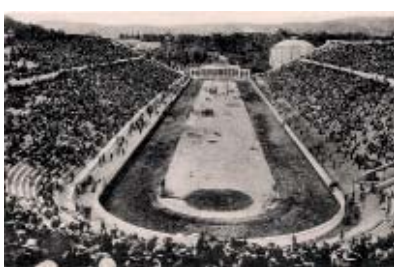

Postal de los JJ.00. 1896 

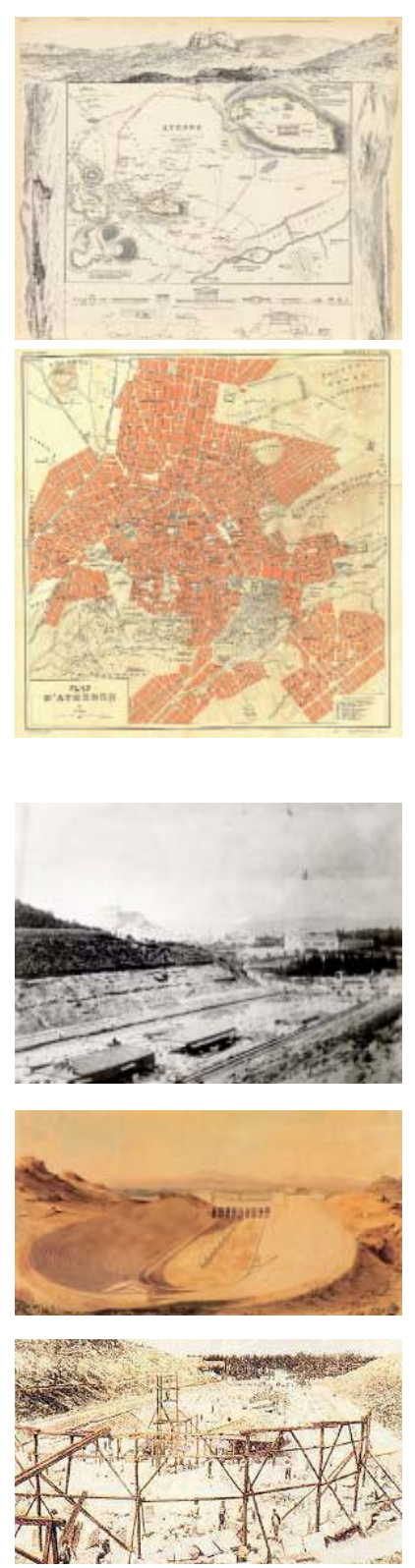

Plano de Atenas, 1832. Society for Diffusion of Useful Knowledge. GB.

Plano de Atenas y sus alrededores, 1896. Guide Joanne

Fotografía de la reconstrucción del estadio s/f

Dibujo de Ernst Ziller, hacía 1865
2004. Competiciones de tiro con arco y línea de llegada de los Marathones masculino y femenino de Juegos de la XVIII Olimpiada.

\subsection{Preexistencias en el lugar}

Situado en la orilla izquierda del río llissos en el lugar llamado Agra, de la "demo" (circunscripción administrativa ateniense) Agrylis, en el lugar había un barranco entre dos cerros con caída desde el sudeste a noroeste, en la línea perpendicular al lecho del río. La colina occidental, llamada Ardettos, era el lugar donde los Heliastas (magistrados del tribunal de rango inmediatamente inferior al Areópago) realizaban su juramento (Juro por Júpiter, por Neptuno y por Ceres a quienes ruego que si violo mis juramentos envíen su castigo sobre mí y mi familia, pero también les suplico, que si cumplo mis promesas me concedan toda clase de prosperidades).

El lugar no podría haber sido mejor elegido para la construcción de un Estadio, ya que su topografía de manera natural ofrecía cabida para varios miles de espectadores.

\subsection{Relación con la ciudad. Posición respecto al centro urbano}

En el momento de su fundación en el 330 aC. el lugar se encontraba fuera de los limites de la ciudad. En la era moderna ha quedado incluido dentro de la urbe.

Situado a 1.200 metros de la Acrópolis, a 850 de la plaza Sintagma y a 930 del barrio La Placa, origen de la ciudad.

\subsection{Breve relato de la historia del Estadio}

En la Atenas clásica, los juegos y las carreras de carros significaban el punto culminante de las Panateneas, que era el más importante de todos los festivales de la región Ática.

Y esto se venía produciendo desde los tiempos más remotos, cuando el Ática estaba gobernada por reyes, y su población eminentemente agrícola honraba en los festivales a la diosa tutelar y pedía su favor para obtener una abundante cosecha.

Como demuestran las representaciones en algunas vasijas arcaicas encontradas en la necrópolis cercana a la puerta Dipylon

Pero ¿̇dónde se celebraban estos festivales?. Antes del siglo IV a. de C. debió haber existido un hipódromo, donde se desarrollaban no sólo las carreras de carros, sino también los juegos deportivos. Es evidente, pero no podemos determinar con certeza su localización. Existen varias opiniones. Algunos arqueólogos creen que el lugar más probable debió de ser una planicie triangular cerca de Nuevo Phaleron, el lugar donde la topografía favorable de las tres colinas de Munychia forma un recinto de unas grandes dimensiones, capaz de albergar a miles de espectadores.

Se cree que allí se celebraron los primeros los Juegos Panatenaicos.

En las excavaciones arqueológicas, no se han encontrado, en ese lugar, rastros de construcciones en piedra. Lo cual indica que no debía existir una instalación permanente, como en el caso de Olimpia, solamente unas gradas de madera para los notables de la ciudad; los Arcontes (Magistrados) y Athlothetes (organizadores de las Panateneas). Sin que se dispusiera de lugar alguno reservado para el público general. Que muy probablemente tenía que permanecer de pie y con dificultades para la visión del desarrollo de las pruebas.

El público, al no tener un espacio asignado y diferenciado del propio de la competición, y llevado por la emoción y el ansia de ver, muchas veces dificultaría el propio desarrollo de la competición al invadir su espacio.

Esta relación no acotada entre publico y competición, también se refleja en el tratado sobre la caballería de Jenofonte (431 a. C. - 354 a. C. ), titulado Hipárquico, en el que indica como situar a los jinetes delante de la multitud en las paradas y las carreras, dejando suficiente espacio para su libre circulación y así evitar posibles incidencias con el público. Instrucciones innecesarias si los espectadores tuvieran acotado un espacio o estuvieran sentados.

En el siglo IV Pericles promovió la construcción del Odeón para los concursos musicales, al mismo tiempo se levantaban, en otros lugares de Grecia, edificaciones específicas para las competiciones atléticas y ecuestres. Mientras tanto, en Atenas se continuaron desarrollando, con la mayor sencillez, en un espacio abierto con una topografía favorable.

Hasta que un siglo después, Licurgo (396/323 a. C.) el famoso orador, propuso e impulsó la idea de construir un Estadio, donde dar un mejor acomodo a espectadores y competidores. La obra, ejecutada bajo la dirección de Licurgo, consistió fundamentalmente en la elevación del terreno, en su lado sur, hasta el nivel de las colinas, cerrando así el barranco por tres lados. El terreno en el interior, destinado para la competición se hizo horizontal. Las laderas de las colinas fueron perfiladas para conseguir una pendiente uniforme en forma de herradura. Además, se separó la arena de competición con respecto al público por medio de un parapeto y se marcó las líneas de salida y llegada con una hilera de piedras.

Significó un considerable esfuerzo en tiempo y dinero. Como demuestra el decreto, datado 
en el tercer año de CXII (329 a.C.), en el que Eudemos (originario de Platea con ciudadanía ateniense) es mencionado con honores por aportar 1.000 yuntas de bueyes para la construcción del Estadio y del Teatro Panatenaico.

Detrás del parapeto había un deambulatorio que recorría todo el perímetro de la pista y bajo su pavimento corría un conducto abovedado, que recogía el agua de lluvia. Algunos restos de este conducto siguen existiendo. En ese periodo las laderas no estaban cubiertas de gradas de mármol, los espectadores se sentaban en el suelo, como muy probablemente se hacía en Olimpia en la antigüedad. Sólo los sacerdotes, arcontes, generales, embajadores y representantes de ciudades extranjeras, así como los que presidían los juegos y los huérfanos, cuyos padres habían muerto luchando por Atenas, tenían reservados bancos de madera.

En el siglo III a. C. se realizaron algunas reparaciones en el Estadio. Cómo muestra la inscripción que dice "el estadio fue reparado por Heracleitos en una "forma acorde"".

En tiempos del emperador Adriano, en el siglo II d. C. el estadio fue completamente restaurado y suntuosamente decorado por Herodes Ático. El sofista ateniense, que destinó su inmensa fortuna para el embellecimiento de espléndidos edificios y estructuras de uso público, y no sólo repartió su generosidad en Atenas y en varias ciudades de Grecia, sino también de Italia y Asia.

En el 139 d.C. Herodes Ático fue elegido athlothete, organizador de las Panateneas, en el periodo de su mandato las fiestas llegaron a su mayor esplendor y magnificencia. Sirva como ejemplo el detalle de la participación en las fiestas de un barco sobre ruedas, con toda su arboladura, arrastrado por bestias de tiro y dotado de un mecanismo oculto que simulaba los movimientos de la navegación.

Cuando, Herodes Ático agradeció a sus conciudadanos por el honor conferido, terminó diciendo: "Será en un Estadio de mármol en el que espero recibiros, oh atenienses, a vosotros, así como a los Atletas y a los extranjeros, que luego serán nuestros invitados».

El retórico Filostrato, biógrafo de Herodes nos dice: "no hay otro teatro que pueda ser comparado con el estadioll.

Pausanias nos asegura, que su visión "era magnifica, indescriptiblel, y en su admiración fue hasta el punto de añadir que esta obra había agotado casi las canteras de mármol del Pentélico.

La actuación de Herodes Ático sobre el Estadio supone, además, una transformación del mismo, por razón del cambio de su función. En tiempo de los romanos, además de los Juegos Atléticos, en el Estadio, se llevaban a cabo espectáculos de gladiadores y caza de animales salvajes. Como atestigua el historiador Spartianos, cuando relata que el emperador Adriano donó en una ocasión 1.000 animales salvajes, para ser cazados en el Estadio.

Estas razones funcionales, llevaron a la modificación de la barrera entre la pista y los espectadores, $y$, también, la relación entre la primera fila y la pista.

\subsection{Descripción del Estadio; Graderío}

En forma de herradura, correspondería con un teatro helenístico al que se han estirado, desmesuradamente, los dos extremos de su cávea. En su primera versión, en el Estadio de Licurgo, la primera fila de asientos estaba más cerca de la barrera que en el de Herodes. La distancia hasta la pista era muy parecida a la del espectador hasta los actores del teatro de Epidauro, es decir, un poco más de 2 metros. Esta distancia es también semejante, en el punto de los puestos de honor, a la del teatro de Dionisio, aunque en el resto de la alineación va variando. Esta variación también debió de existir en el Estadio de Licurgo, siguiendo una ley óptica, con el fin de que los espectadores de las gradas largas tuvieran una mejor visibilidad. La alineación de la primera fila de asientos no discurría paralela al eje de la pista, sino que seguía una directriz curva. El radio de esa curvatura debió ser de aproximadamente 2.000 metros.

Cuando Herodes renovó el Estadio, el corredor perimetral se amplió mediante la demolición de las filas inferiores de las gradas de la construcción antigua, y se elevó, (como se mencionó anteriormente) la primera fila de asientos a una altura de 1,66 metros. Apoyándose sobre un muro de mármol, con basa y cornisa. El pasillo-corredor que rodeaba la pista no tenía en todas partes la misma anchura, en su parte semicircular y en los extremos, era de 2,82 metros de anchura, y en la mitad de las dos partes largas de 5,00 metros.

La zona del público, a la que se llamaba theatron (lugar desde el que se contempla), estaba dividido en graderíos de 23 filas cada uno, separados por la diazoma, por un pasillo de 3,04 metros de ancho. La primera fila del graderío superior estaba levantada respecto a la diazoma 2,03 metros. La diazoma tenia acceso directo desde los extremos, por medio de dos escaleras. En la primera fila se disponían asientos con respaldo, llamados tronos, que ocupaban el espacio de dos filas normales. 

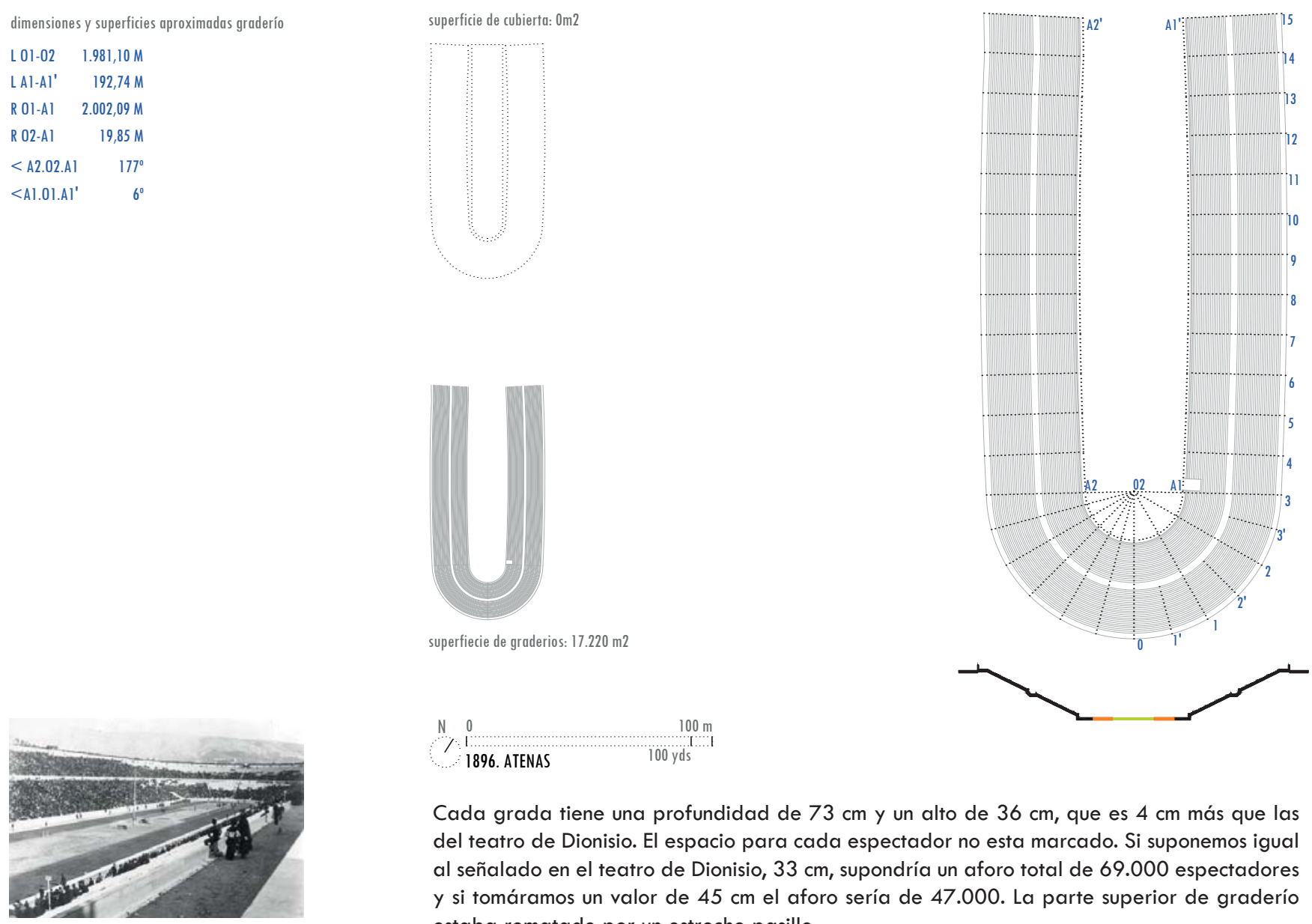

$\begin{array}{ll}0 & 100 \mathrm{~m} \\ 1 & 1\end{array}$

Cada grada tiene una profundidad de $73 \mathrm{~cm}$ y un alto de $36 \mathrm{~cm}$, que es $4 \mathrm{~cm}$ más que las del teatro de Dionisio. El espacio para cada espectador no esta marcado. Si suponemos igual al señalado en el teatro de Dionisio, $33 \mathrm{~cm}$, supondría un aforo total de 69.000 espectadores y si tomáramos un valor de $45 \mathrm{~cm}$ el aforo sería de 47.000 . La parte superior de graderío estaba rematado por un estrecho pasillo.

El graderío estaba dividido en 30 sectores, llamados kerkides, por medio de 31 escaleras de 1,07 $\mathrm{m}$ de anchura. La parte semicircular (sphendone) estaba dividida en 6 sectores en la grada baja y 12 en la alta. Los primeros peldaños de cada escalera se proyectaban sobre el pasillo. El primer asiento de cada fila desde la escalera estaba ornamentado con el relieve de una cabeza de búho.

En la ladera izquierda, en el punto de encuentro entre el tramo recto y el semicírculo, se abría un vomitorio, que cortaba las ocho primeras filas. Sus dimensiones eran 7 metros de profundidad y 4,75 metros de anchura, en sus restos se puede apreciar los espacios necesarios para alojar los elementos de fijación y giro de unas puertas. El vomitorio daba acceso a una galería abovedada de 3,96 metros de alto y 3,69 metros de ancho, revestida de piedra del Pireo. Que penetraba considerablemente en la colina y después de una pronunciada curva salía detrás de la colina. Existen dos teorías sobre la razón de este pasadizo. La primera lo relaciona con la entrada secreta de los Estadios de Olimpia y de Epidauro, como Pausanias nos dice que en los atletas de Olimpia y los árbitros eran llevados al Estadio por un pasaje secreto, también podemos suponer que la bóveda a la entrada del Estadio Panatenaico hubiera servido para el mismo propósito. La segunda, tal vez mas plausible, que fue construido por Herodes Ático, para permitir la introducción de animales salvajes en la arena.

Esto nos lo relaciona con las entradas abovedadas a los teatros romanos, "ábsides" y nos lleva a pensar que la entrada al Estadio de Olimpia al principio fue descubierta "hypaethral" y que en tiempo de los romanos se cubrió con una bóveda

El graderío, koilon, esta apoyado en los dos extremos del lado Norte sobre grandes hastiales de piedra que contienen el terreno. En estos hastiales se apoyan las escaleras que rematan la diazoma.

El graderío estaba rematado en la parte semicircular, Sphendone, por una Stoa, un gran pórtico dórico de 32 metros de longitud y 10 metros de ancho.

Además se supone, por los restos encontrados, que el lado Norte del Estadio estaría cerrado 
por unos Propileos.

En lo alto de la colina occidental que rodea el Estadio, Herodes Ático, erigió un templo a la Fortuna de la ciudad. Y en la cima de la colina oriental los atenienses erigieron más tarde sobre su tumba un monumento de agradecimiento a su memoria, y en el que grabaron la siguiente inscripción, tan elocuente en su concisión: "Aquí yace Herodes Ático de Marathón, digno de toda alabanza. Que todo lo que le rodea, es su propia obra".

\section{Definiciones:}

El "koilon" era el conjunto de gradas donde se asentaban los espectadores. Ocupaba la ladera de la montaña, y recibió también el nombre de "theatron", cuyo significado es "lugar desde el que se mira", que más tarde pasó a referirse a todo la construcción. Tenía forma semicircular y los asientos estaban situados en gradas. Estaba dividido en sectores (kerkís): dividido verticalmente, por escaleras y en horizontalmente por pasillos (diazoma).

En el Teatro Dionisio, al principio los asientos de las primeras filas estaban hechos de madera, y el resto de la gente se sentaba directamente sobre la tierra; pero alrededor de 499 a. C. se comenzaron a construir líneas de bloques de piedra en la ladera de la colina para crear asientos permanentes y estables, que se fueron haciendo cada vez más comunes; los de la primera fila fueron llamados "prohedria", eran de mejor calidad y estaban reservados para los sacerdotes y para los ciudadanos más respetados. Entre el koilon y la orchesta había un murete llamado balteus

\subsection{Descripción del Estadio; Pista}

La arena contaba con una longitud de 205 metros y una anchura de 33,55 metros, su suelo estaba 30 centímetros por encima del corredor perimetral, el radio del sphendone era de 16,76 metros. Hay que destacar que tanto el Estadio de Olimpia como el de Epidauro no contaban con sphendone, sino que estaban rematados en dos lados rectos cortos. Respecto a la cuerda de la pista, en los Juegos de 1896, los textos suelen fijarla en 333,33 metros, pero dibujándola se aprecia que su longitud debía ser mayor, alrededor de los 400 metros. Las curvas eran muy cerradas, la mejor descripción de su efecto sobre el corredor la podemos obtener de las memorias publicadas por George Robertson, atleta de Oxford que compitió en tenis y en los lanzamientos de disco y peso: "el brusco giro al final de cada recta, hace imposible tiempos rápidos... los corredores parecían literalmente pararse al llegar a la curva, en comparación con el ritmo anterior".
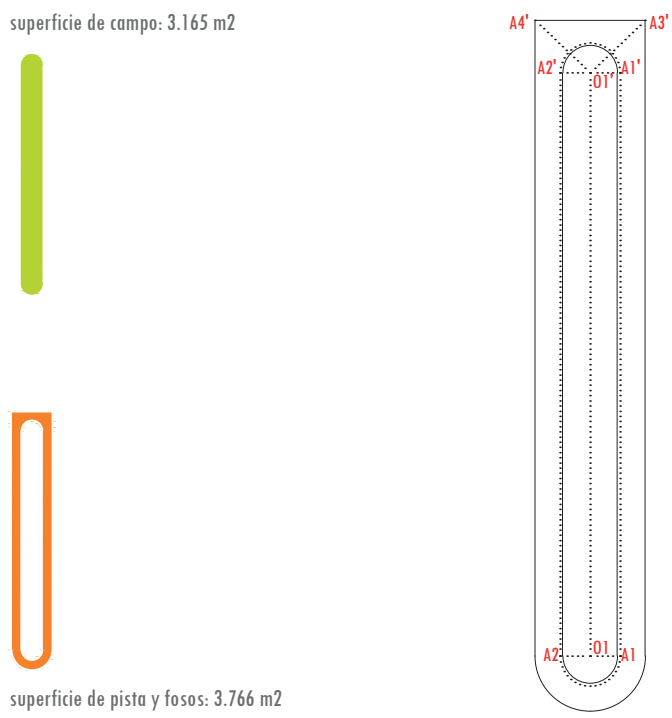

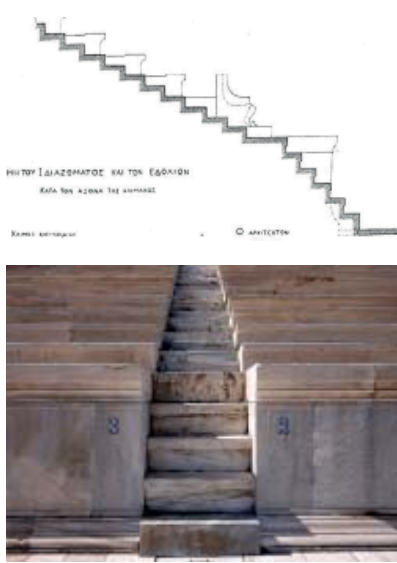

dimensiones y superficies aproximadas pista CUERDA $\quad 409,23 \mathrm{M} \quad 447 \mathrm{yds} \quad \mathrm{l}^{\prime} 7 \frac{27}{64}$

L O1-AI $\quad 177,60 \mathrm{M}$

L A3-A4 $33,52 \mathrm{M}$

ROI-Al $\quad 8,60 \mathrm{~N}$

ROI'-A3' 23,17 M

$<$ Al.01.A2 $\quad 180^{\circ}$

$<A 3^{\prime} .01^{\prime} \cdot A 4^{\prime} \quad 93^{\circ}$

El estadio clásico, aunque es difícil definir claramente su límite norte, por donde queda abierto, podemos pensar que su longitud sería la habitual en los Estadios Griegos, 600 pies griegos, lo que significa 177,6 metros, puesto que el pie griego ateniense es de 0,296 metros.

En lo que era la salida, "aphesis" debió de haber habido cuatro grandes estelas verticales de mármol pentélico, de 2,58 metros de altura coronados por dos cabezas de 43 centímetros de altura mirando, cada una, en sentido contrario. Una de ellas representa al dios Hermes, con barba. El himno homérico invoca a Hermes como el "de multiforme ingenio (polytropos), de astutos pensamientos, ladrón, cuatrero de bueyes, jefe de los sueños, espía nocturno, guardián de las puertas, que muy pronto habría de hacer alarde de gloriosas hazañas ante los inmortales dioses). La otra representa a un juvenil Apolo, severo y majestuoso al mismo tiempo. Las cuatro estelas encontradas son muy parecidas, prácticamente iguales, la primera apareció en 1870, 


$\begin{array}{lrr}\text { marca del ganador } & \text { Hombres } & \text { Mujeres } \\ 100 \mathrm{~m} & 12 " 0 \\ 400 \mathrm{~m} & 54 " 2 \\ 800 \mathrm{~m} & 2,11 " 0 \\ 1500 \mathrm{~m} & 4,33 " 2 \\ 100 \mathrm{mv} & 17 " 6 \\ \text { Altura } & 1,81 \mathrm{~m} \\ \text { Pértiga } & 3,30 \mathrm{~m} \\ \text { Longitud } & 6,35 \mathrm{~m} \\ \text { Triple } & 13,71 \mathrm{~m} \\ \text { Peso } & 11,22 \mathrm{~m} \\ \text { Disco } & 29,15 \mathrm{~m} \\ \text { Marathón } & 2 \mathrm{~h} .58,50 "\end{array}$

las otras a finales del s. XIX. El trabajo del artista deja visibles deliberadamente las marcas de cincel. Es evidente que fueron hechas en un período en el que a los artistas les gustaba imitar el arte arcaico, y esto coincide, precisamente, con los tiempos en que Herodes restaura el Estadio. $Y$ es probable que sea una copia de una escultura del siglo $V$ a.C. Estas estelas seguramente formarían parte del mecanismo de salidas, como parecen indicar los taladros y acanaladuras que muestran. Dos copias de estas piezas se recolocaron en la restauración del estadio.

Material, ceniza. "La pista estaba blanda", según información de la época del periodista Lawrence Levy del Birmingham Post, recogida por David Randall en su libro electrónico publicado en 2012 , "1896 The first modern Olympics", el especialista inglés Charles Perry, de la Amateur Athetic Association, que había prescrito la construcción la pista fue incapaz de obtener en Atenas suministros de ceniza de la clase correcta, por lo que tuvo que utilizar los que tenía disponibles. También, para regar la pista solo disponían de cubos.

La pista se termina de construir demasiado tarde y no tuvo el suficiente tiempo para asentarse. Según lo escrito por el anteriormente mencionado atleta Robertson "La pista parecía estar en el fondo dura, mientras que la superficie estaba suelta y peligrosa."

Programa Deportivo: Atletismo, Gimnasia, Halterofilia, Lucha y la entrega de premios de todos los deportes.

\subsection{Elementos significantes}

\subsection{Avances técnicos}

\subsection{Autores. Tipo de encargo}

Anastasis Metaxas (1863/1937). Arquitecto y deportista, participó en tiro con rifle en los Juegos de Atenas 1896, quedando en cuarta posición, también participó en los intermedios de 1906 y en Londres 1908, donde parece ser que obtuvo la medalla de bronce. Como arquitecto participó en las excavaciones que llevó a cabo Ernst Ziller en 1869, además construyó numerosas mansiones en Atenas, como la que ahora es el Museo Benaki, o la embajada francesa. Amplió el Museo Arqueológico Nacional en su ala este y otros edificios de carácter público, como el Banco lonian.

Ernst Ziller (1837/1923) Arquitecto sajón, nacionalizado griego, fue el arquitecto de referencia de la familia real griega, para los que construyó varias residencias entre ellas el Palacio de Tatoi. Otras obras suyas son, el Teatro Nacional de Atenas, el Museo de Olimpia, la casa del arqueólogo, aventurero y descubridor de Troya, Heinrich Schliemann. Ziller fue sin duda el arquitecto que mejor representa el periodo de reinado de Jorge l, sus obras tuvieron una gran influencia en su tiempo.

Charles Perry. Encargado de la preparación de la pista. Fue un pionero en cuanto a composición y cuidado de las pistas de atletismo, gracias a sus experiencias en las instalaciones del London Athletic Club en Stamford Bridge.

Además fue cronometrador de las pruebas.

Tipo de encargo. Metaxas, tal vez por su condición de deportista y arquitecto, estuvo desde el principio involucrado en la organización de los Juegos, formando parte del subcomité de obras.

1896.11. Edificios coetáneos:

Louis Sullivan publica el articulo titulado "El gran edificio de oficinas considerado desde el punto de vista artístico" (1896).

Frank Lloyd Wright abandona el estudio de Sullivan en 1893 y realiza su primera obra entre 1893 y 1894 , la casa William H. Winslow, (River Forest, Illinois)

En este año Otto Wagner estaba realizando sus estaciones de metro en Viena y un año después, 1897, fundaría junto con Gustav Klimt, Joseph Maria Olbrich, Josef Hoffmann y Koloman Moser el grupo artístico llamado la "Secesión de Viena».

\subsection{Hechos históricos relevantes}

Wilhelm Roentgen descubre un tipo de radiación electromagnética conocida como rayos $\mathrm{X}$ y Henri Becquerel anuncia el descubrimiento de una radiación emitida por el uranio.

1895. En Francia los hermanos Lumière realizan la primera proyección cinematográfica: 'Salida de los obreros de la fábrica'

1896. Henry Ford comienza a fabricar coches.

El 2 de noviembre de 1896 muere en inglaterra Charles Henry Mackintosh. 
Bibliografía Atenas 1896:

LAMBROS Sp. P., POLITES N. G. (1896). The Olympic Games B.C. 776. - A. D. 1896. Official Report of the Games of the I Olympiad, Athens, 1896. Ed. Central Committee in Athens

WIMMER, Martin. (1976). Olympic Buildings. Ed. Leipzig. Lic 600/34/75. 5938721

GORDON, Barclay F. (1983). Olympic Architecture. Building for the summer games. John Wiley \& Sons. Nueva York. ISBN 0-471-06069-0

GIRARDI, Wolfgang (1971). Las Olimpiadas. Titulo Original Olympia Ruft!. Ed. Noguer Barcelona. Deposito Legal B-5.160-72

David Randall (2012). 1896 The first modern Olympics. Libro electrónico

http://www.panathenaicstadium.gr 
1900. PARIS

1900.0. Nombre del Estadio

Croix Cantelan

1900.1. Situación

Chemin de la Croix Catelan, Bois de Boulogne 75016 París. Francia

1900.2. Fechas

1894. El 1 de septiembre, el gobierno de Francia decide incorporar a las actividades de la Exposición Universal que se habría de celebrar en Paris en 1900 un programa deportivo. Nombra una comisión para su desarrollo de más de 70 miembros, entre los que se encuentra Pierre de Coubertin como Secretario General de la Unión Francesa de Deportes Atléticos.

1899. Se decide que los Juegos Atléticos se celebren en los terrenos cedidos al Racing Club de Francia en el Boix de Boulogne.

1900. El 14 de mayo, se inicia programa deportivo de la Exposición de Paris 1900.

1900. El 28 de octubre, terminan.

1900.3. Preexistencias en el lugar

El Racing Club de France ha sido una pieza clave para el desarrollo del movimiento olímpico. Su origen está en un grupo de alumnos del Liceo Condorcet ( 8 rue du Havre), muy próximo a la estación de Saint Lazare, que acostumbraban a entrenar en la propia estación, y en esa misma estación en el año 1882 fundan el Racing Club, al poco tiempo trasladan sus entrenamientos al Boix de Boulogne. En 1885 cambia el nombre por Racing Club de France. En 1886, después de muchas negociaciones, obtienen del Consejo Municipal de París la concesión de un espacio de unas 7 has, llamado la Croix Catelan, en el Bois de Boulogne, era una pradera arbolada con una pista de hierba de un poco menos de 500 metros y un chalet que serviría de vestuario y guardarropa.

1900.4. Relación con la ciudad. Posición respecto al centro urbano

En 1900 el Bois de Boulogne se encontraba a las afueras de París y sin medios de transporte públicos próximos, lo cual, causó que la afluencia de público fuera escasa. La mayor entrada estuvo entre los 2.000 y 3.000 espectadores, mientras que en Atenas las mayores asistencias estaban alrededor de los 40.000 espectadores.

A 3.120 metros de la torre Eiffel, 3.135 del Arco del Triunfo, a 6 kilometros del Louvre, a 7,2 de Notre Dame y a 7,3 del Ayuntamiento.

1900.5. Breve relato de la historia del Estadio

Habría que preguntarse si fueron realmente unos Juegos Olímpicos. En los RAPPORTS oficiales, no los califica como tales. Solo menciona al movimiento Olímpico cuando describe la afluencia de participantes y dice:

"Se agradece la labor de captación de participantes europeos realizada por los Comités Olímpicos de Pierre de Coubertin".

Se desarrollaron en paralelo a las actividades de la Exposición Universal Internacional de 1.900 de Paris. Se organizaron una serie de concursos y festivales que incluían todas las ramas de la Educación Física:

"respondiendo a las nuevas ideas y movimientos de opinión que surgieron a finales de siglo (XIX)". (Rapport Oficial 1900).

La idea de establecer un programa general de Concursos relacionados con el ejercicio físico como apéndice de la Exposición Universal de 1900, se comenzó a gestar en el Ministerio de Comercio, Industria, Correos y Telégrafos en 1894. Y a propuesta del Comisario General de la Exposición se nombró una comisión de 74 personas. En esta lista formada por políticos, militares y personas relacionadas con el deporte, aparecía Pierre de Coubertin en el lugar 63 en función de su cargo de Secretario General de la Unión Francesa de Deportes Atléticos. La comisión propone un presupuesto de 5 millones de francos y la creación de una serie de subcomités;

Deportes Atléticos (amalgama que incluye 1. Carreras a pie, 2. Concursos Atléticos, 3. Marcha, 4. Foot-ball Rugby, 5. Foot-ball Association, 6. Lawn-tennis (Real-tennis se jugaba en pista cubierta y la pelota podía dar en las paredes), 7. Juego de Pelota, 8. Hockey, 9. Croquet, 10. Cricket, 11. Golf, 12, Juego de Bolos, 13, Base-ball, 14. Boxeo, 15. Lucha) Por otra parte estaban los diferentes subcomités de: Gimnasia, Esgrima, Tiro, Hípica, 


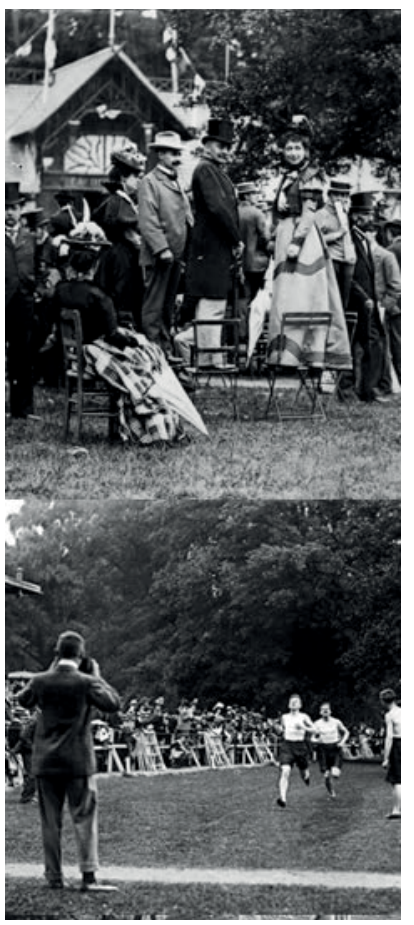

1900.6. Descripción del Estadio; Graderío

Se dispusieron dos graderíos provisionales de madera de 600 plazas cada uno. No se han podido encontrar más datos.

\subsection{Descripción del Estadio; Pista}

La pista para las carreras era en forma de ovalo, de aproximadamente $500 \mathrm{~m}$ de cuerda. La recta de $100 \mathrm{~m}$ tenía una pequeña inclinación y su firme era irregular. Los lanzamientos de disco y jabalina se realizaron en una pradera con árboles, que aunque estos fueron podados, los artefactos, en alguna ocasión, incidieron con ellos y además impedían la vista completa de los concursos.

Material, Hierba, y superficie irregular.

Programa Deportivo: Atletismo.

1900.8. Elementos significantes

\subsection{Avances técnicos}

1900.9. Autores. Tipo de encargo

Arquitectos: Desconocido.

Tipo de encargo: Desconocido.

1900.11. Edificios coetáneos

1899. Estaciones de Metro de Paris de Hector Guimard.

1900. Antoni Gaudí comienza los trabajos del Parque Güell, que se completarían catorce años después.

1900. La Estación d'Orsay, actual Musée d'Orsay, en París, de Victor Laloux.

1902. Flatiron Building, Nueva York, proyectado por Daniel Burnham y Frederick Dinkelberg. 1903. Bolsa de Amsterdam de Hendrik Berlage.

\subsection{Hechos históricos relevantes}

El conde Ferdinand Zeppelin hace volar su dirigible de 128 metros de largo, a 400 metros de altitud en un recorrido de 6 kilómetros, sobre el lago Constanza en Alemania.

Una fuerza expedicionaria de todas las potencias extranjeras termina con el sitio de los "55 días en Pekín". El gobierno chino es obligado a indemnizar a los países afectados.

En la reunión de la Sociedad Alemana de Física, Max Planck lee su trabajo titulado "La teoría de la ley de distribución de energía del espectro normal", abriendo la física a nuevos horizontes al ser el precursor de la física cuántica, la rama de la Física que explica el comportamiento de la materia y la energía. 
Bibliografía·París 1900:

1 Concours Internationaux D'exercices Physiques Et De Sports. Rapports. (1901) Edición a cargo de M. D. MÉRILLON. Paris. Exposition Universelle Internationale De 1900. Ministère du Commerce, de l'Industrie des Postes et des Télégraphes 


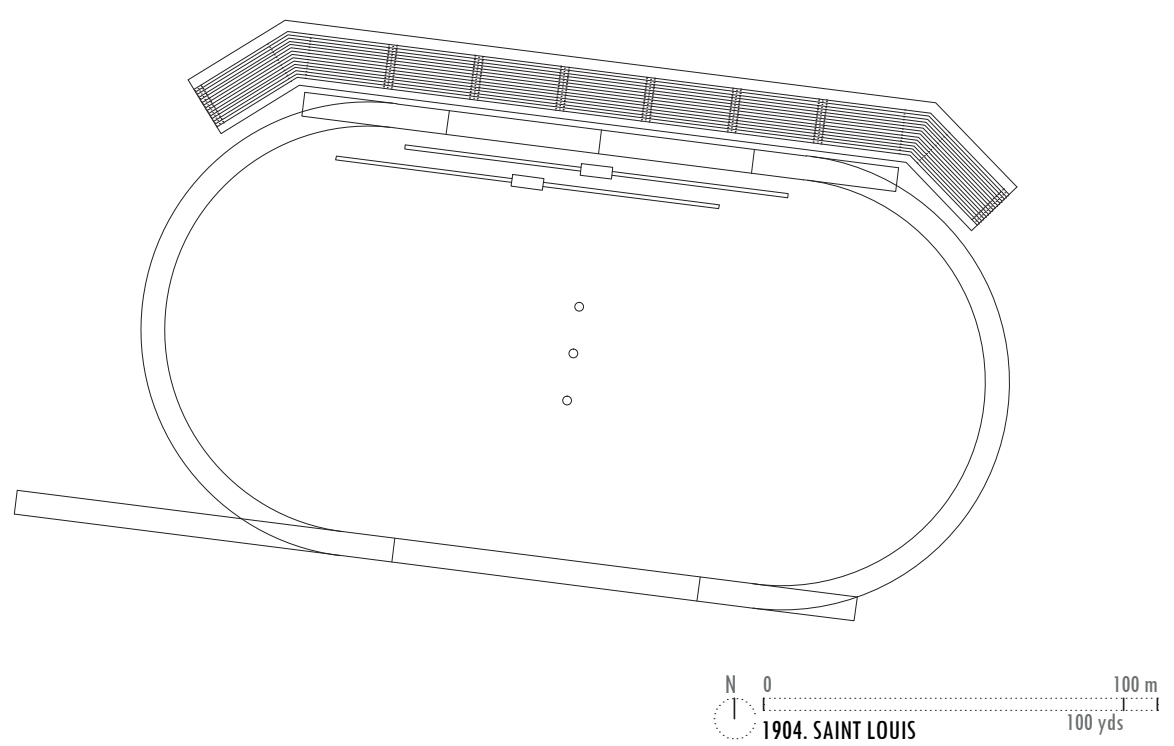

1904.0. Nombre del Estadio

Francis Field.

1904.1. Situación

Campus Danforth, Washington University. St. Louis. Missouri. Estados Unidos de América.

1904.2. Fechas

1899. Concurso de arquitectura para la construcción de los edificios del Campus Universitario de Hilltop (desde 2006 denominado Danforth) que había sido trazado por Olmsted para la Washington University de St. Louis.

1900. El Comité Olímpico Internacional decide conceder los Juegos de la III Olimpiada a Chicago.

1902. Construcción del estadio y del gimnasio adyacente.

1903. En febrero, Chicago renuncia a la organización de los Juegos en favor de St. Louis

1903. La Organización de la Feria Mundial St. Louis 1904, se hace cargo de las instalaciones del Campus Universitario, para apoyo a las vecinas instalaciones de la Feria.

1904. Mayo, se inician las competiciones deportivas de la Feria Mundial no incluidas en los Juegos.

1904. El 29 de agosto, se inician las pruebas de los Juegos Olímpicos.

1904. El 3 de septiembre último día de las competiciones.

1914. Se construye de puerta conmemorativa a los diez años de la celebración de los Juegos, según proyecto del arquitecto James Jamieson. Probablemente desde esa fecha el estadio pasó a denominarse Francis Field, en honor de David R. Francis (1850/1927), empresario, político y promotor de la St. Louis World's Fair 1904 y presidente de la Lovisiana Purchase Exposition Co. Francis declaró la apertura de los Juegos.

1984. Primera modificación. Se demuelen los brazos en ángulo del graderio, reduciéndose el aforo en 4.000 personas. Se redujo la pista a 400 metros con 8 calles de material sintético.

2003. Segunda renovación importante, se amplió, se hizo accesible a personas discapacitadas y se mejoraron sus instalaciones.

2004. Se cambió la superficie de juego por hierba artificial.

\subsection{Preexistencias en el lugar}

A finales del siglo XIX la Washington University de St. Louis, que estaba ubicada en el centro urbano, decide la construcción del nuevo campus universitario, denominado Hilltop a las afueras de St. Louis. Encargando su trazado, de carácter paisajista, al arquitecto Frederick L. Olmsted (1822/1903). Coautor, en 1857, de Central Park en Nueva York.

1904.4. Relación con la ciudad. Posición respecto al centro urbano

Al este del centro urbano a 10 kilómetros y 390 metros del Ayuntamiento, a 11, 390 de donde, en 1963, se construiría el Arco Puerta hacia el Oeste de Eero Saarinen y a un poco más de distancia del río Mississippi.
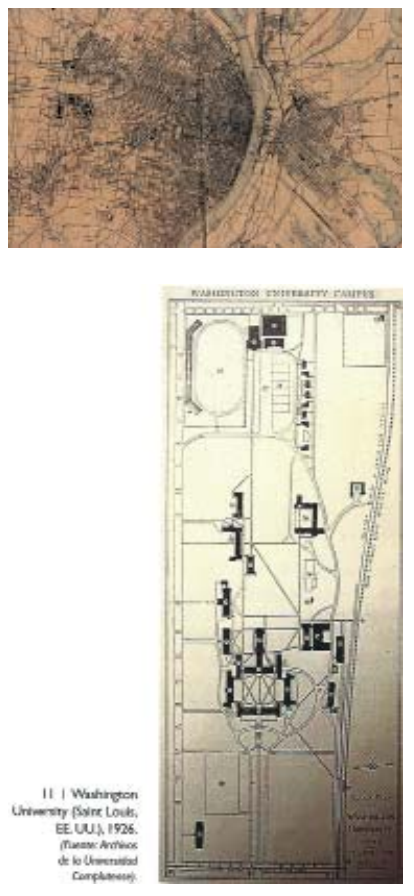
La pequeña población de Clayton queda a tan solo 2 kilómetros hacia el oeste.

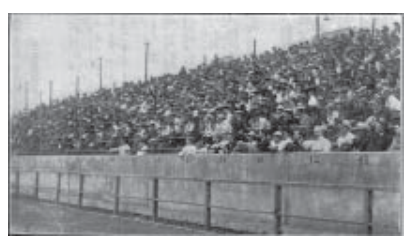

\subsection{Breve relato de la historia del Estadio}

El estadio forma parte de las dotaciones deportivas de la Washington University, al igual que el gimnasio. Durante su proceso de construcción y antes de puesta en uso del recinto universitario, la vecina Feria Mundial utilizó sus instalaciones para sus propios fines, destinando el estadio y el gimnasio como sede de los Juegos y de todas las otras actividades deportivas asociadas a la Feria.

James E. Sullivan era el director del Comité Organizador y jefe del Departamento de Cultura Física de la Exposición. Anteriormente había sido secretario del área económica de la Amateur Athletic Union de los Estados Unidos (AAU/USA) y había participado como consultor del Departamento de Cultura Física en los Juegos de Paris 1900.

El estadio, después de los Juegos, ha sido la sede del equipo de fútbol americano de la universidad, que tuvo su apogeo entre los años 20 y 40 . Ya en ese tiempo se le había dotado con focos, algo bastante novedoso, y construido en su lado norte una grada de madera para ampliar su aforo.

Se ha celebrado en el estadio la Primera y Segunda edición de los Juegos Olímpicos Nacionales para Mayores, también, en 1985 el Campeonato de Fútbol NCAA Tercera División Nacional y en 1986, los denominados AAU/USA Juegos Olímpicos Nacionales Júnior.

Y en julio de 1994, sirvió como una pieza central para el Festival Olímpico de los Estados Unidos, con 3.000 atletas alojados en el Campus.

En 1984, se redujo la cuerda de la pista del tercio de milla a una de 400 metros y material sintético. Al graderío desproporcionado para la nueva pista le fueron recortadas sus dos alas abiertas en ángulo respecto a la tribuna principal, que acompañaban los inicios de las curvas. En 2003, fue sometido a una renovación importante. Revistiéndose su graderío con un semihormigón continuo. Mediante la adición de dos rampas se hizo accesible a personas con movilidad reducida. Y se construyó en la tribuna una cabina cubierta para el control y la prensa.

En 2004, se cambió la superficie de juego a hierba artificial.

Actualmente en uso como sede de los equipos de fútbol americano, soccer y de atletismo de la universidad.

\subsection{Descripción del Estadio; Graderío}

Graderío de hormigón, aprovechando la topografía del terreno, formado con una sola tribuna acompañando a recta norte con dos terminaciones en ángulo siguiendo el inicio de las curvas de la pista. El publico de pie podía deambular alrededor de la pista

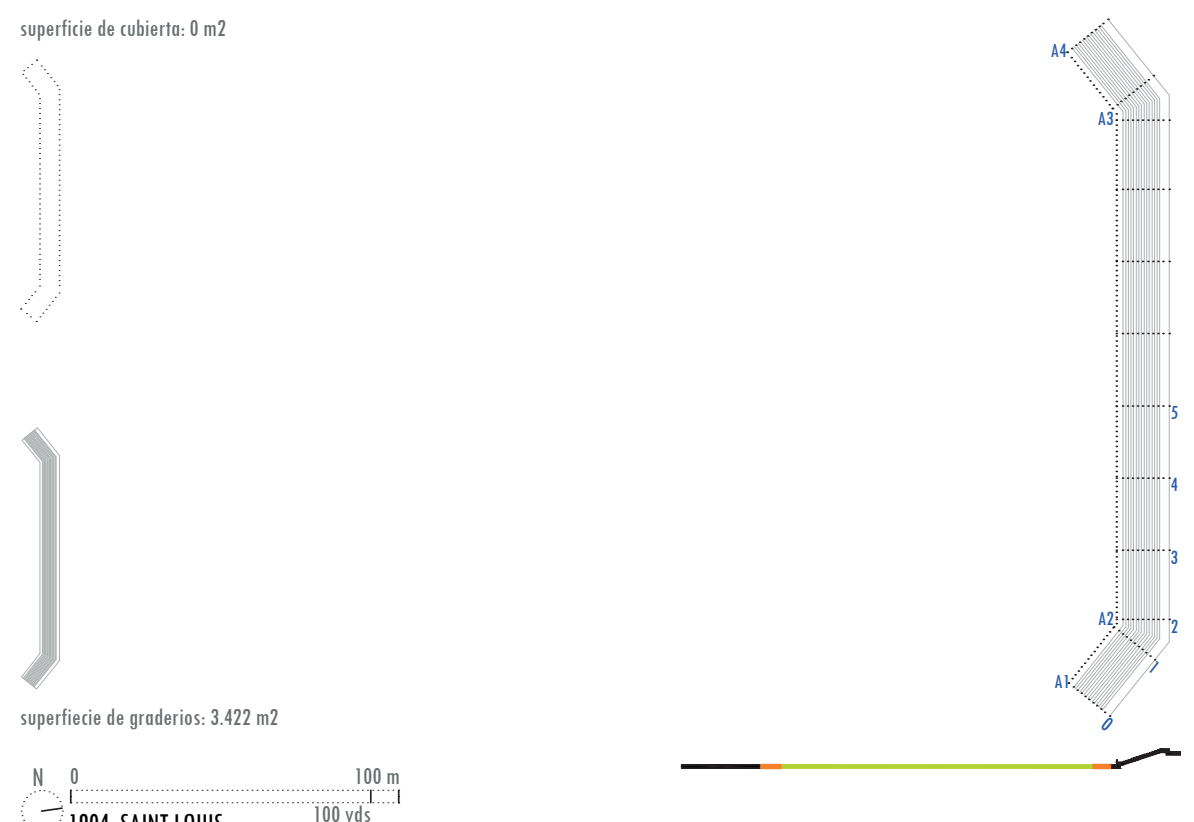

\subsection{Descripción del Estadio; Pista}

La pista de atletismo por primera vez en los Juegos era de forma oval, de un tercio de milla de cuerda, aproximadamente 536,45 metros. La recta sur se extendía fuera del ovalo 
hasta completar la distancia necesaria para la celebración de carreras de hasta 200 metros, en las que cada atleta corría por su propia calle sin riesgo de interferencia con los otros participantes (en Atenas ya fue así, en Paris no tenemos constancia de ello).
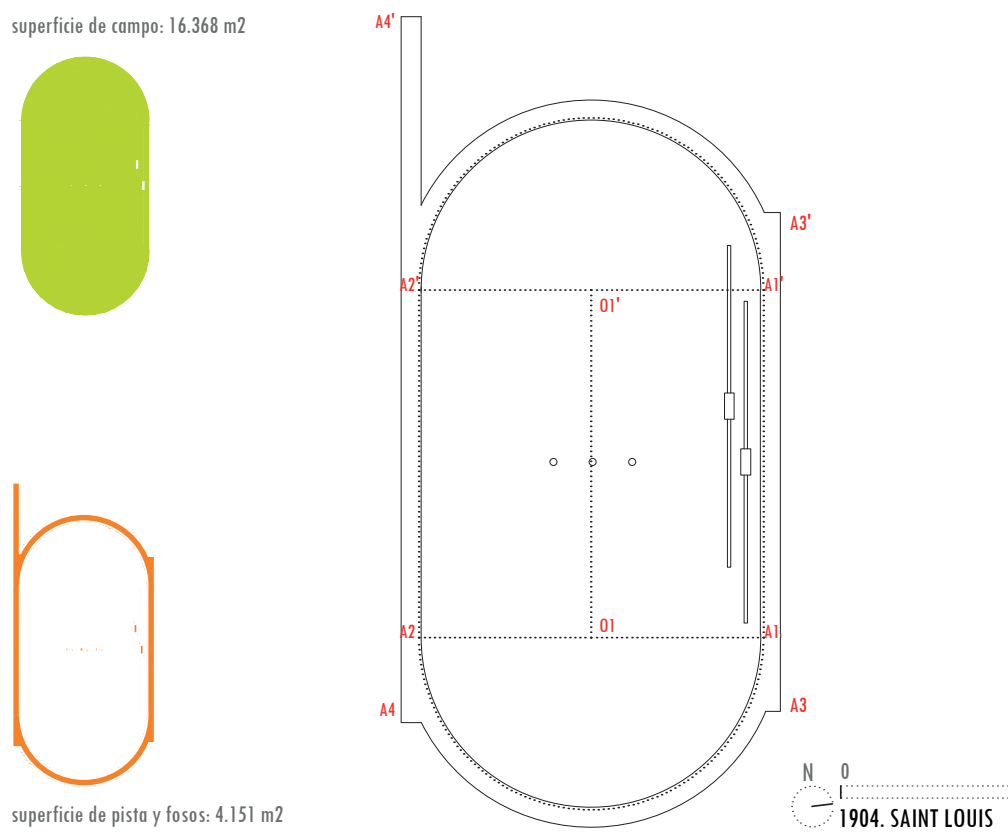

El ancho de la pista era de 20 pies $(609,6 \mathrm{~cm})$, lo que permitió que las carreras de 800 y 400 metros se realizarán a una sola manga. Los concursos estaban organizados de tal manera que permitieran la mayor simultaneidad posible.

Material:

Tierra batida y buena planimetría en la pista y hierba natural en el terreno de juego.

Programa Deportivo:

Atletismo, Gimnasia, Arco, Fútbol, Lacrosse, Tira de Cuerda, Lucha, Halterofilia.

\subsection{Elementos significantes}

\subsection{Avances técnicos}

Los aparatos y artefactos utilizados eran del más moderno diseño. Para facilitar el seguimiento de las competiciones por parte de los espectadores se utilizó por primera vez en los Juegos la megafonía que anunciaba los resultados de las pruebas. Además, se pusieron marcadores en todas los concursos para que los espectadores pudieran seguir la marcha de la competición. Además se marcaron, también por vez primera círculos concéntricos con referencias de distancia.

\subsection{Autores. Tipo de encargo}

Arquitectos: Cope \& Stewardson, de Filadelfia. Formado en 1885 por Walter Cope (1860/1902) y John Stewardson (1858/1896), en 1887 se incorpora Emlyn Srewardson, hermano de John, que pasará a ser socio a la muerte de este. Siendo uno de los más prestigiosos despachos de arquitectura de Filadelfia de finales del XIX y principios del XX. De estilo fundamentalmente neogótico y especializados en arquitectura universitaria. A ellos se deben los Campus del Bryn Mawr College, de la Universidad de Princeton, el campus de las Universidad de Pennsylvania y de la propia Universidad Washington en St. Louis, entre otras. Se distinguieron también por la labor de formación de nuevos arquitectos que pasaron por su estudio, donde se gestó toda una generación de arquitectos de Filadelfia.

Tipo de encargo: Ganadores del concurso nacional para la construcción de los diferentes edificios e instalaciones del nuevo Campus Hilltop de la Washington University de St. Lovis. El concurso fue por invitación a seis equipos de arquitectos de reconocido prestigio a nivel nacional.

1904.1 1. Edificios coetáneos

1904. Larkin Building de Frank Lloyd Wright en Buffalo, New York. dimensiones y superficies aproximadas pista

$\begin{array}{lr}\text { CUERDA } & 536,44 \mathrm{M} \\ \text { L 01-01' } & 105,85 \mathrm{M} \\ \text { L A3-Al } & 22,51 \mathrm{M} \\ \text { L A3-A3' } & 151,95 \mathrm{M} \\ \text { L A4-A2 } & 25,84 \mathrm{M} \\ \text { L A4-A4' } & 214,97 \mathrm{M} \\ \text { R 01-Al } & 51,98 \mathrm{M} \\ \text { < A1.01.A2 } & 180^{\circ}\end{array}$

marca del ganador

Hombres Mujeres

$7 " 0$

$200 \mathrm{~m} \quad 21 " 6$

$400 \mathrm{~m} \quad 49 " 2$

$800 \mathrm{~m} \quad 1,56 " 0$

$1500 \mathrm{~m} \quad 4,05 " 4$

$110 \mathrm{mv} \quad 16 " 0$

$200 \mathrm{mv} \quad 24 " 6$

$400 \mathrm{mv} \quad 53 " 0$

3000 obst $\quad 7,39 " 6$

Altura $\quad 1,80 \mathrm{~m}$

Pértiga $\quad 3,50 \mathrm{~m}$

Longitud $\quad 7,34 \mathrm{~m}$

Triple $\quad 14,35 \mathrm{~m}$

Alt parado $\quad 1,60 \mathrm{~m}$

Long parado $\quad 3,47 \mathrm{~m}$

Trip parado $\quad 10,54 \mathrm{~m}$

Peso 14,81 m

Disco $\quad 39,28 \mathrm{~m}$

Martillo $\quad 51,23 \mathrm{~m}$

Peso $25,4 \mathrm{Kg} \quad 10,46 \mathrm{~m}$

Triathlon $35,7 \mathrm{p}$

(long/peso/100 yds)

4 millasxequipos 27 p

Marathón (40 Km) 3h.28,53"

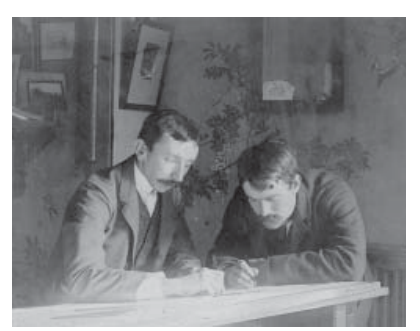


1904. Apartamentos de la rue Franklin, París, de Auguste y Gustave Perret. Edificio pionero en el uso de estructura vista de hormigón armado.

1904. Casa Batlló, en Barcelona, de Antoni Gaudi.

\subsection{Hechos históricos relevantes}

El 8 de febrero de 1904 se inicia la guerra ruso-japonesa.

El 3 de marzo se promulga en España la ley que establece el descanso dominical.

Durante este año, Estados Unidos se hace con la concesión del canal de Panamá e inicia los trabajos.

Bibliografía St Louis 1904:

LUCAS, Charles. The Olympic Games, 1904. (1905). Ed. Woodard \& Tiernan Co. St Louis Missouri. EE.UU.

Spalding's Official Athletic Almanac for 1905. Olympic Games Number. Vol. XVIII N 217 (1905). Ed. James E. Sullivan. American Sports Publishing Co. Nueva York. EE.UU.

MATTHEWS, George. MARSHALL, Sandra. St. Lovis Olympics 1904. Images of American Series. (2003).Ed. Arcadia Publisher SC. ISBN-13: 9780738523293

National Register of Historic Places. Inventory-Nomination Form. United States Departament of the Interior. National Park Service. (Form No. 10-300 <R «v. 09-77). 


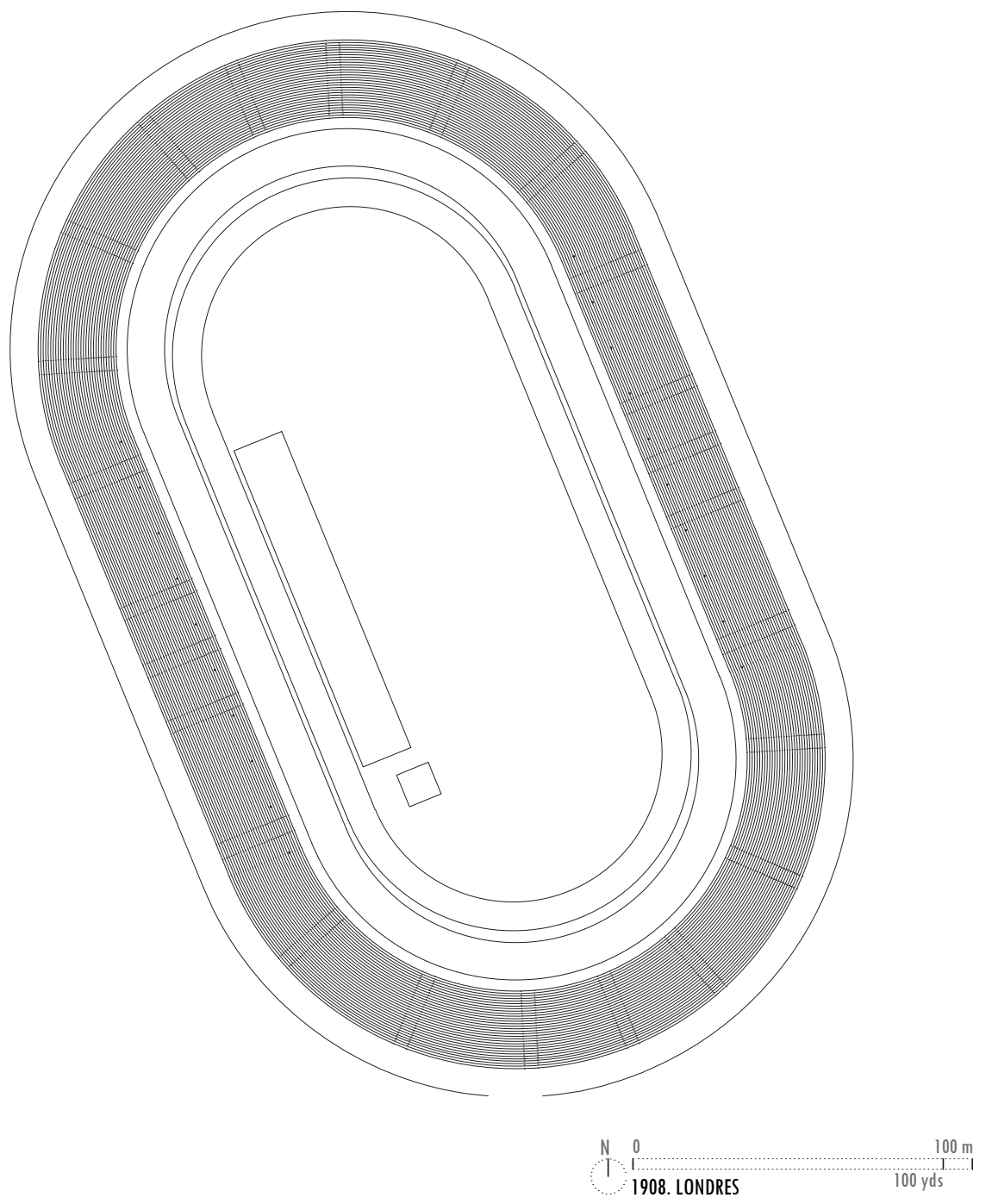

1908.0. Nombre del Estadio

The Great Stadium, Shepherd's Bush. Posteriormente conocido como White City Stadium.

1908.1 Situación

Shepherd's Bush, Hammersmith. Al oeste de Londres. Demolido.

\subsection{Fechas}

1906. Londres se hace cargo de la organización de los Juegos de la IV Olimpiada ante la renuncia de Roma.

1907. El 31 de mayo, se inicia la construcción del estadio, que dura diez meses.

1908. El 14 de mayo, el príncipe de Gales lo inaugura en la Exposición Franco Británica, ante 123.000 personas.

1908. El 30 de mayo, la AAA celebra los trials para seleccionar los participantes británicos a los Juegos.

1908. El 13 de julio. Inauguración de los Juegos.

1908. El 25 de julio. Ceremonia de clausura.

1926. Se rehabilita y se cubre todo el graderio.

1932. Se reduce la pista de atletismo. Nueva cuerda 440 yardas.

1971. Dejan de realizarse competiciones de atletismo de alto nivel, que se trasladan a Crystal Palace.

1985. Es demolido. En su solar se han construido diferentes dependencias de la BBC.
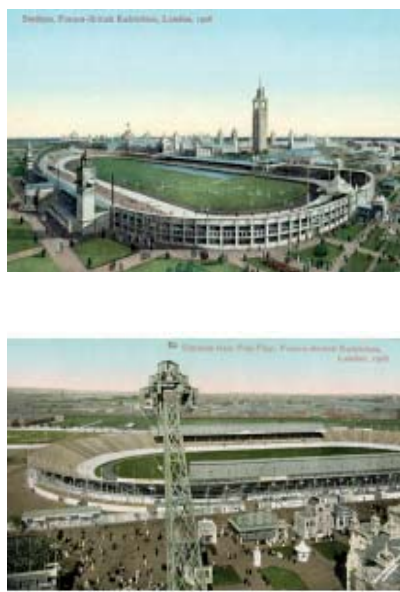


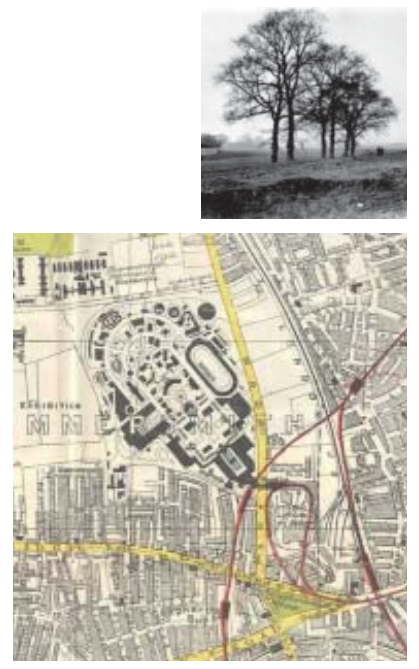

1908.3. Preexistencias en el lugar

Típica campiña inglesa (foto 1904). Resto intersticial que quedó rodeado por los nuevos desarrollos urbanos de Londres.

Proximidad de la prisión Wormwood Scrubs.

1908.4. Relación con la ciudad. Posición respecto al centro urbano

Espacio libre en el borde de la ciudad, pero buscando su cercanía al centro. Distancia al centro urbano: $9 \mathrm{~km}$ en línea recta a la Catedral de San Pablo, a $6 \mathrm{~km}$ de Buckingham Palace y $6,5 \mathrm{~km}$ de Piccadilly Circus.

Integrado en recinto de la Exhibición Franco-Británica de 1908. La exposición conmemoraba la firma del tratado conocido como "Entente Cordiale" que firmaron franceses y británicos en 1904, que dejaba atrás sus disputas territoriales en las colonias y auguraba un siglo de paz. Recinto cerrado, independiente y autónomo con respecto a la ciudad.

Para la ocasión, el 1 de mayo de 1908, se abrió la nueva estación Wood Lane Exhibitión STN, en la que confluían dos líneas; la Metropolitan Ry y la Central London Ry.

Aprovechando la proximidad de las cocheras de la Central London Ry, durante la Exposición se abrió una estación de carácter temporal en las mismas.

Con dos nuevas líneas de metro, tranvía, autobuses y trenes, en horario laboral, podían acceder a White City 75.000 personas por hora.

\subsection{Breve relato de la historia del Estadio}

Los Juegos de la IV Olimpiada habían sido adjudicados a Roma. Pero la catástrofe producida por la erupción del Vesubio el 7 de abril de 1906, que destruyó Boscotrecase y causó serios daños a Ottaviano, obligó a los italianos a desistir. Londres tomó el relevo, con tan solo dos años para preparar los Juegos.

El potente motor organizativo y económico que suponía la Exhibición Franco-Británica que se estaba preparando, y tenía previsto incluir competiciones deportivas en su programa, posibilitó la organización de los Juegos en tan corto periodo de tiempo. El acuerdo entre el presidente de la British Olympic Association, Lord Desborough y Imre Kiralfy, promotor del Exposición Franco Británica, fue considerado muy ventajoso para los organizadores de los Juegos. La organización de la Exposición, además de comprometerse a construir y poner a disposición un moderno Estadio para 110.000 espectadores, completamente equipado, con un presupuesto previsto de $£ 44.000$ (actualizado a $2006 £ 3,1$ millones), se hacía cargo, también, de toda la publicidad del evento y adelantaría $£ 2.000$ para otros gastos organizativos a cuenta de los futuros ingresos. A cambio la organización de la Exposición adquiría el derecho sobre el $75 \%$ de las ganancias totales. (Fuente: British Olympic Association, Council Minutes, December 20, 1906, BOF Archives)

La exhibición abarcaba 140 acres (más de 56 ha) y contaba con plazas, paseos, jardines, lago artificial y un importante número de extravagantes edificios de diferentes dimensiones, estilos y formas. Todos ellos estaban acabados en estuco blanco, de ahí el apelativo de White City. Contaba, además, con un parque de atracciones. Fue visitada por más de 8 millones de personas.

Durante los Juegos no se cubrieron las expectativas de venta de entradas, resultó un fracaso económico. Podemos considerar el White City Stadium como el primer "Elefante Blanco" como un legado problemático. Después de terminar los Juegos el estadio tuvo poco uso.

El White City Stadium es un claro ejemplo de como la construcción de una instalación sin atender a su relación con el contexto social, cultural de una región, ciudad o país, puede derivar en su falta de uso postolímpico.

Poco después de los Juegos se pensó en su demolición, pero sin embargo permaneció en estado latente, casi olvidado, solo utilizado esporádicamente y sin una labor de conservación y mantenimiento. En 1926, el estadio casi en ruinas, pasó a depender de la Greyhound Racing Assotiation, que lo reutilizó para carreras de galgos y para speedway, deportes en los que la incidencia económica de las apuestas en muy fuerte. Gracias a la previsión de beneficios se cubrió todo el graderío y se construyeron restaurantes. En 1932 la pista de atletismo fue reacondicionada reduciéndose su cuerda hasta las 440 yardas (402,34 metros), volviendo a acoger competiciones de atletismo. En 1934, en él, se celebraron los II Juegos del Imperio Británico, actuales Juegos de la Commonwealth. Su revivir atlético duró hasta 1971 en el que las competiciones atléticas de alto nivel celebradas en Londres se trasladaron a Crystal Palace, volviendo a caer en el abandono hasta su demolición en 1985.

\subsection{Descripción del Estadio; Graderío}

"La idea es que los Juegos Olímpicos se realicen ahí (en el estadio). Para ese propósito se necesitaba una superficie de hierba suficientemente grande para poder celebrar un partido de Lacrosse, rodeada de una pista para carreras y un velódromo. Y alrededor de todo asientos para 


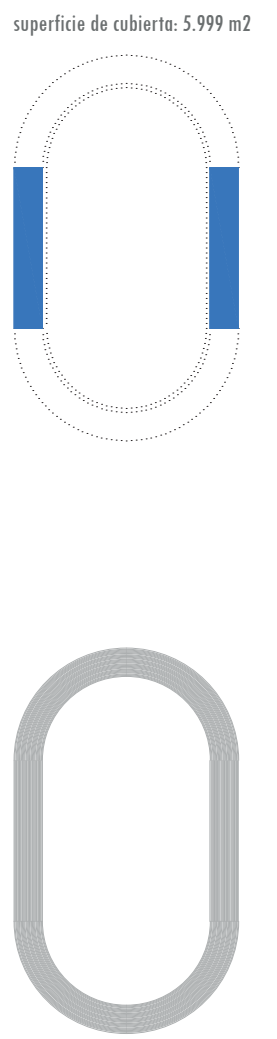

superfiecie de graderios: $17.281 \mathrm{~m} 2$

$$
\begin{array}{lll}
N & 0 & 100 \mathrm{~m} \\
/ & 1 & 1
\end{array}
$$

"Una importante obra de ingeniería" The Builder 18 Julio 1908, vol.95, p.62 y "realmente una gran obra en acero y hormigón" The Builders' Journal and Architectural Engineer

The Builder (9 Mayo 1908, vol.94, p533) elogió "el majestuoso gesto del graderío del estadio" y predijo que "posiblemente sea el principal centro de interés para la mayoría de los futuros visitantes ".

Construcción aérea sobre el terreno de sección continua, estructura de entramado metálico y superficie del graderío de hormigón.

El espacio de sección triangular debajo de las gradas, se destina a vestuarios, diferenciados por deportes, delegaciones para cada uno de los países participantes, oficinas para los organizadores, espacios para la prensa, aparcamiento para ambulancias, accesos al palco real, kioscos de bebidas y otras dependencias.

Cubiertas a dos aguas y estructura metálica, únicamente en las fracciones de grada delante de las dos rectas.

\subsection{Descripción del Estadio; Pista}

Pista de atletismo de un tercio de milla (586 yardas y 2 pies) $(536,45 \mathrm{~m})$ de cuerda. Un ancho de 24 pies $(7,32 \mathrm{~m}$.$) .$

Terreno central de hierba, de forma ovalada, de 700 pies $(213,36 \mathrm{~m}$.) de largo por 300 pies $(91,44 \mathrm{~m}$.) de ancho, en donde se realizaría la mayor parte del programa olímpico.

Rodeando exteriormente la pista de atletismo se situaba la pista para el ciclismo, con firme de hormigón y curvas peraltadas, de 35 pies $(10,67 \mathrm{~m}$.) de ancho y una cuerda de tres octavos de milla, 660 yardas, $(603,50 \mathrm{~m}$.).

La gran novedad es que en el interior de la pista de atletismo se situaba una enorme piscina de 100 metros de largo por 50 pies $(15,24 \mathrm{~m}$.) de ancho, con una profundidad de 1,20 metros en los extremos y 3,70 metros en el centro. La piscina contaba con una torre, que era abatible, para los concursos de saltos de trampolín y palanca. dimensiones y superficies aproximadas graderío
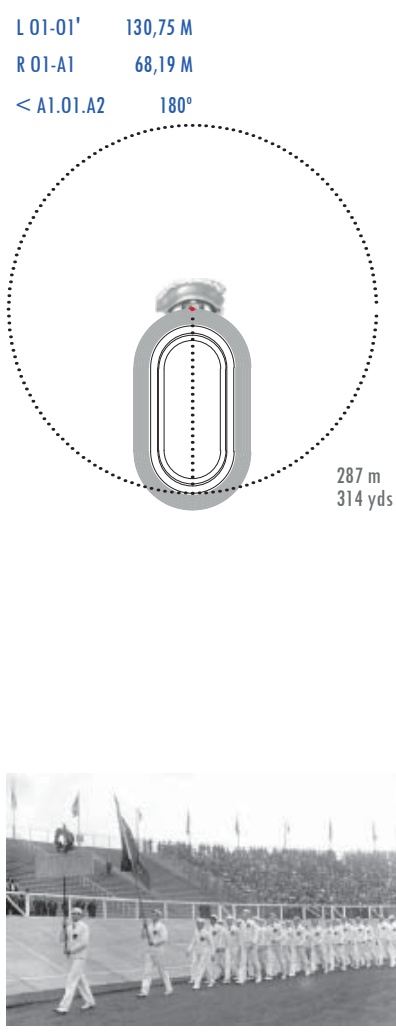


\begin{tabular}{|c|c|c|}
\hline CUERDA 1 & $602,01 \mathrm{M}$ & $658 \mathrm{yds} \quad \mathrm{I}^{\prime} \quad 1 \frac{3{ }^{\prime \prime}}{16}$ \\
\hline CUERDA 2 & $530,78 \mathrm{M}$ & $580 y d s \quad l^{\prime} 4 \frac{27 " \prime}{32}$ \\
\hline L $01-0 I^{\prime}$ & $126,55 \mathrm{M}$ & \\
\hline L $02-02^{\prime}$ & $130,75 \mathrm{M}$ & \\
\hline L $01-02$ & $2,10 \mathrm{M}$ & \\
\hline R OI-Al & $44,19 \mathrm{M}$ & \\
\hline R 02-A3 & $54,19 \mathrm{M}$ & \\
\hline$<$ Al.01.A2 & $180^{\circ}$ & \\
\hline$<$ A3.02.A4 & $180^{\circ}$ & \\
\hline$<$ A3.01.A4 & $176^{\circ}$ & \\
\hline
\end{tabular}
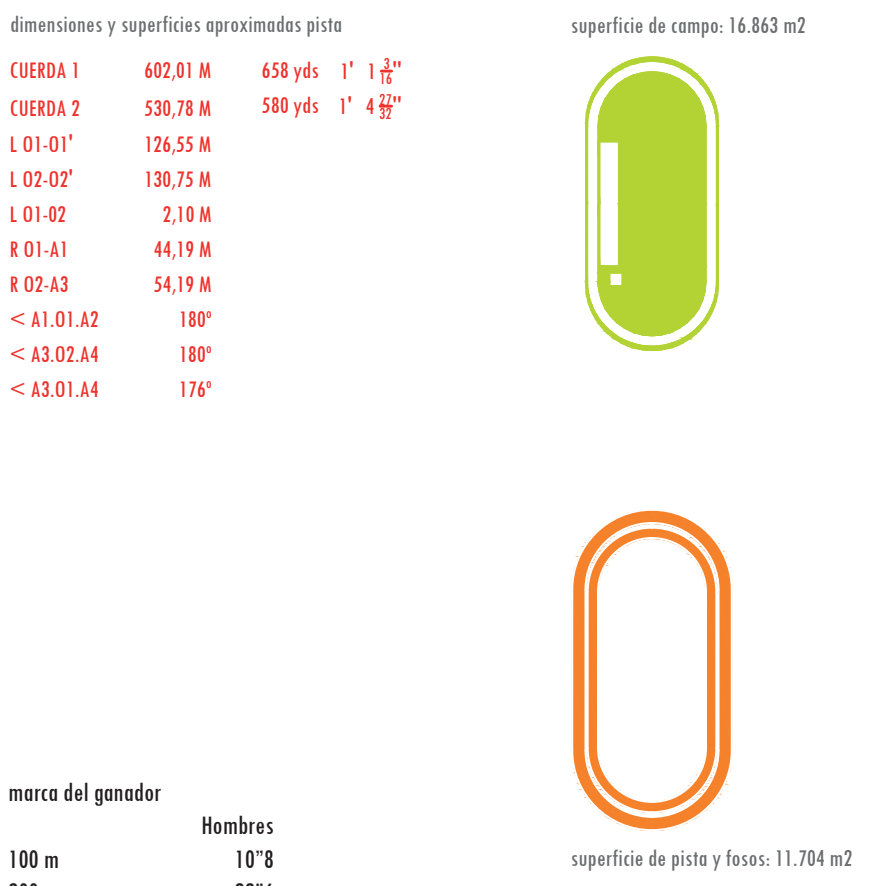

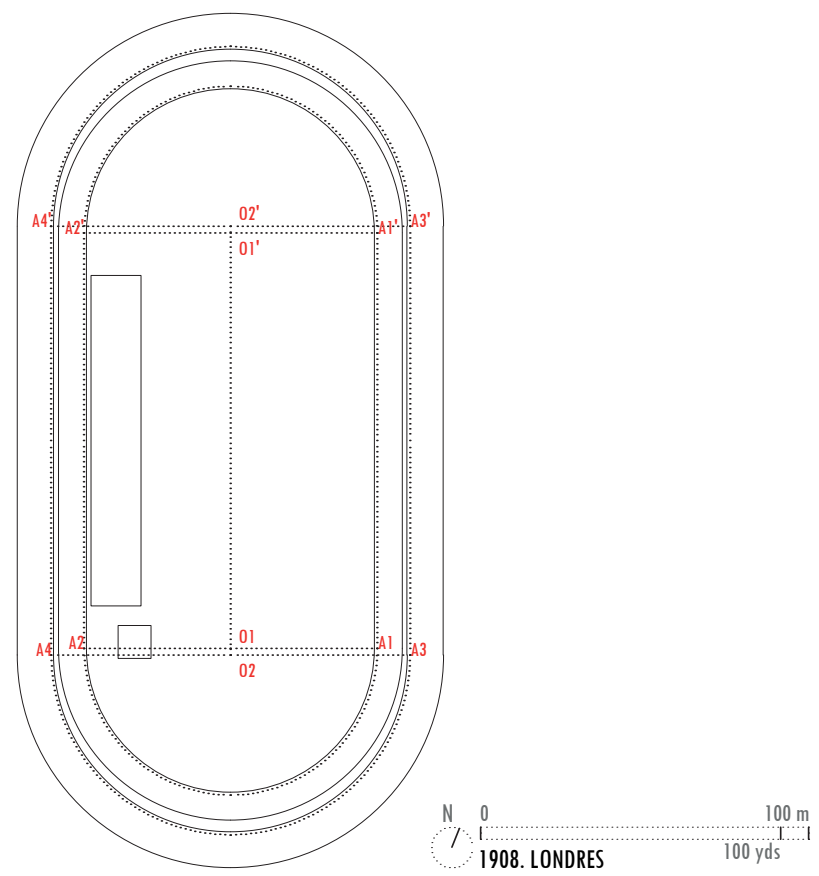

El sistema métrico decimal fue el utilizado en las competiciones. Como ya había ocurrido en las anteriores ediciones de los Juegos.

Material: Pista de atletismo de ceniza. Terreno central de hierba. Velódromo y piscina de hormigón armado.

Programa Deportivo: Atletismo, Ciclismo, Natación, Salto de trampolín, Waterpolo, Tiro con arco, Fútbol, Rugby, Gimnasia, Hockey hierba, Lacrosse, Lucha y las Ceremonias de apertura y clausura.

\subsection{Elementos significantes}

En los primeros Juegos Olímpicos modernos celebrados en Atenas en 1896, surgió la idea de conmemorar la hazaña de Filípes (490 A.C), el mensajero que recorrió la distancia entre Maratón y Atenas, para anunciar la victoria sobre los Persas que amenazaban la ciudad. El primer maratón olímpico recorrió la distancia desde la llanura de Maratón hasta el estadio olímpico de Atenas, aproximadamente, 40 kilómetros. Pero en Londres para que la carrera pudiera comenzar en el Castillo Windsor (para que la Reina pudiera observar la salida) y terminar en el Estadio Olímpico, los organizadores se vieron obligados a extender la distancia hasta los extraños 42.195 metros (26,2 millas). En 1921 la Asociación Internacional de Federaciones Atléticas fijó de forma definitiva esta distancia para todas las carreras de Maratón.

\subsection{Avances técnicos}

\subsection{Autores. Tipo de encargo}

John James Webster, ingeniero.

Para saber quien fue nos remitimos al obituario publicado por la Institution of Civil Engineers, de la que era destacado miembro, poco después de su fallecimiento.

John James Webster murió de repente en su residencia de Streatham Hill, el viernes 30 de octubre de 1914, a la edad de 69 años.

Había nacido en Warrington el 9 de junio de 1845.

Completó su formación práctica como ingeniero civil en E.T. Bellhouse \& Company en Manchester, donde llegaría a jefe de proyectos y subdirector. Durante este periodo colaboró en el diseño y construcción de numerosos grandes puentes.

En 1871 fue contratado por la Ashbury Carriage \& Iron Company para el diseño de puentes en la India y otros trabajos. Al final de ese mismo año se cambió de trabajo, pasando a ser jefe del departamento de puentes de Thos Brassey Company, donde fue responsable de muchas importantes estructuras repartidas por todo el mundo, entre ellas los muelles de Liverpool siguiendo el diseño de G.F. Lyster.

Desde 1876 a 1880 trabajó sucesivamente para W. D. Cay como ingeniero del puerto de Aberdeen y para R.A. Marillier en la Hull Dock Company. 
En 1881 se establece por su cuenta en Liverpool, trasladándose posteriormente a Westminster. Realiza una gran variedad de importantes trabajos, como los puentes de Belford, Cambridge, Northwich, asi como en la India y en Australia, también la reconstrucción del puente colgante de Conway, el puente basculante de Portsmouth, el puente giratorio de Littlehampton, etc. También diseñó los muelles de Dover, Bangor, Minehead, Llanduduo, Penmaenmawr, Menai Bridge, Egremont y otros incluyendo en Sudamérica. Realizó teleféricos en España ( $\dot{\imath}$ ?), maquinaria para Alexandra Dock, Hull, etc. Diseños para la Lyndhurst Gas \& Water y otros muchos trabajos.

Entre sus últimos trabajos cabe destacar el puente trasbordador entre Widnes y Runcorn, diseñado en colaboración con J. T. Wood, el Estadio y otras estructuras en Shepherd's Bush, la gran noria de Earl's Court y el diseño de un gran puente transbordador en Sudamérica. Su último trabajo fue el puente de hormigón armado en Warrington.

En numerosos concursos de carácter abierto obtuvo primeros y segundos premios, como el caso de la Watkin Tower y del puente de puerto de Sydney.

La evidencia de la gran importancia y variedad de las actividades que realizó se plasman en los Minutes of the Proceedings (Institution of Civil Engineers), como los titulados; "Hierro y Acero a bajas temperaturas", "Operaciones de ampliación y dragado", "Construcciones resistentes al fuego" y "El puente transbordador entre Widnes y Runcorn". Por los cuales obtuvo reconocimientos en los premios Telford, siendo merecedor de su prestigiosa medalla.

Sus servicios fueron requeridos por la Board of Trade y también en algunos asuntos parlamentarios. En sus últimos años trabajó asociado con $\mathrm{H}$. W. FitzSimons.

En 1879, fue elegido miembro asociado de la Institution of Civil Engineers y en 1886 como miembro de número.

Fuente: Minutes of the Proceedings. Volumen 199. Publicado 1915. Pag 455-456. DOI: 10.168/imotp 1915.16237. E-ISSN: 1753-7843

Construido por la empresa local de George Wimpey.

Diseño de la pista de atletismo a cargo Charles Perry. Perry, tambien fue el encargado de la construcción de la pista del Estadio Panathinaiko para los Juegos de la primera Olimpiada de la época moderna en Atenas 1896.

Aunque Barclay F. Gordon asigna la autoria del estadio a James Fulton, no hemos podido encontrar referencia de ello en ninguna otra publicación, aunque sí de su participación como arquitecto en la Exposición Franco Británica, con el Palacio de Artes Aplicadas Británicas y otros cuatro edificios menores. Parece obvio que existió un proyecto de una arquitectura de tipo colonial, calificada por algún crítico como Hindú Mahometana, de un carácter semejante al resto de edificaciones de la Exposición, como queda reflejado en imágenes de la época. $Y$, tal vez el autor de dicho proyecto o anteproyecto pudiera ser uno de los arquitectos que trabajara en otros encargos de la Exposición y, ese, pudo ser James Fulton.

Tipo de encargo: Desconocido.

\subsection{Edificios coetáneos:}

1909. Casa Robie, Frank Lloyd Wright.

1910. La pedrera de Antoni Gaudi.

1910. Nave de turbinas AEG, Peter Behrens.

\subsection{Hechos históricos relevantes:}

El 26 de mayo William Knox d'Arcy descubre el primer gran yacimiento de petróleo de Oriente Medio en Masŷed Soleimán (en Juzestán, al sudoeste de Irán). Los derechos de explotación serán rápidamente adquiridos por el Reino Unido.

El 21 de junio, en Hyde Park (Londres) 250000 sufragistas se reúnen para reclamar el derecho al voto femenino.

El 1 de octubre sale a la venta en el mercado norteamericano, el primer modelo "T" de la compañía Ford, resultado de cinco años de esfuerzos de Henry Ford y sus ingenieros para fabricar un tipo de automóvil fiable y barato.

En este año Adolf Loos publica "Ornamento y Delito" y Antonio Machado "Cantares". 
Bibliografía Londres 1908:

COOK, Theodore Andrea. (1908). The Fourth Olympiad. The Official Report. Ed. The British Olympic Association. DAVIS, David. Showdown at Shepherd's Bush. The 1908 Olympic Marathon and the three runners who launched a sporting craze. Ed. Thomas Dunne Books. NY. 2012. Primera edición Junio 2012

ISBN 978-0-312-64100-9

PROVOOST, Michelle (Editado por) (2000). The Stadium. The Architecture of Mass Sport. Ed. Nai Publisher, Rotterdam. ISBN 90-5662-145-9

WIMMER, Martin. (1976). Olympic Buildings. Ed. Leipzig. Lic 600/34/75. 5938721

GORDON, Barclay F. (1983). Olympic Architecture. Building for the summer games. John Wiley \& Sons. Nueva York. ISBN 0-471-06069-0

CARDEN, Robert W. "The Franco-British Exhibition.." Architectural Review. 1908 July, v. 24, p. [32]-37; 1908 Sept., p. [108]-1 11

DUMAS, F.G. The Franco-British Exhibition: illustrated review. London: Chatto and Windus, 1908.

FINDLING, John E., editor, Historical Dictionary of World's Fairs and Expositions, 1851-1988. New York: Greenwood Press, 1990. p. 203-205.

GREENHALGH, Paul. Art, politics and society at the Franco-British Exhibition of 1908. Art History. 1985 Dec., v.8, no.4, p.434-452.

Fuente: British Olympic Association, Council Minutes, December 20, 1906, BOF Archives

The Building News. 23 agosto de 1907. Vol 93. P.239. (Copyright: RIBA Library Books and Periodicals Collection)

The Building News, 10 Julio 1908, vol.95 (Copyright: RIBA Library Books and Periodicals Collection)

The Builders' Journal and Architectural Engineer, 29 Enero 1908, vol.27, p.102 (Copyright: RIBA Library Books and Periodicals Collection)

The Builders' Journal and Architectural Engineer, 22 Julio 1908, vol.28, p.57. (Copyright: RIBA Library Books and Periodicals Collection)

Architectural Review, Julio-Diciembre 1908, vol.24, p.32-37. Biblioteca RIBA, Londres

The Builder, 9 Mayo 1908, vol.94, p533. Biblioteca RIBA, Londres

The Builder 18 Julio 1908, vol.95, p.62. Biblioteca RIBA, Londres

DARCY, Simon; TAYLOR, Tracy. "Managing the Olympics". Editado por Stephen Frawley y Daryl Adair. 2013

Tesis doctoral Filosofía:

LLEWELLYN, Matthew P. (2010) Rule Britannia: Nationalism, Identity, and The Modern Olympic Games. The Pennsylvania State University. The Graduate School. College of Health and Human Development 


\section{ESTOCOLMO}

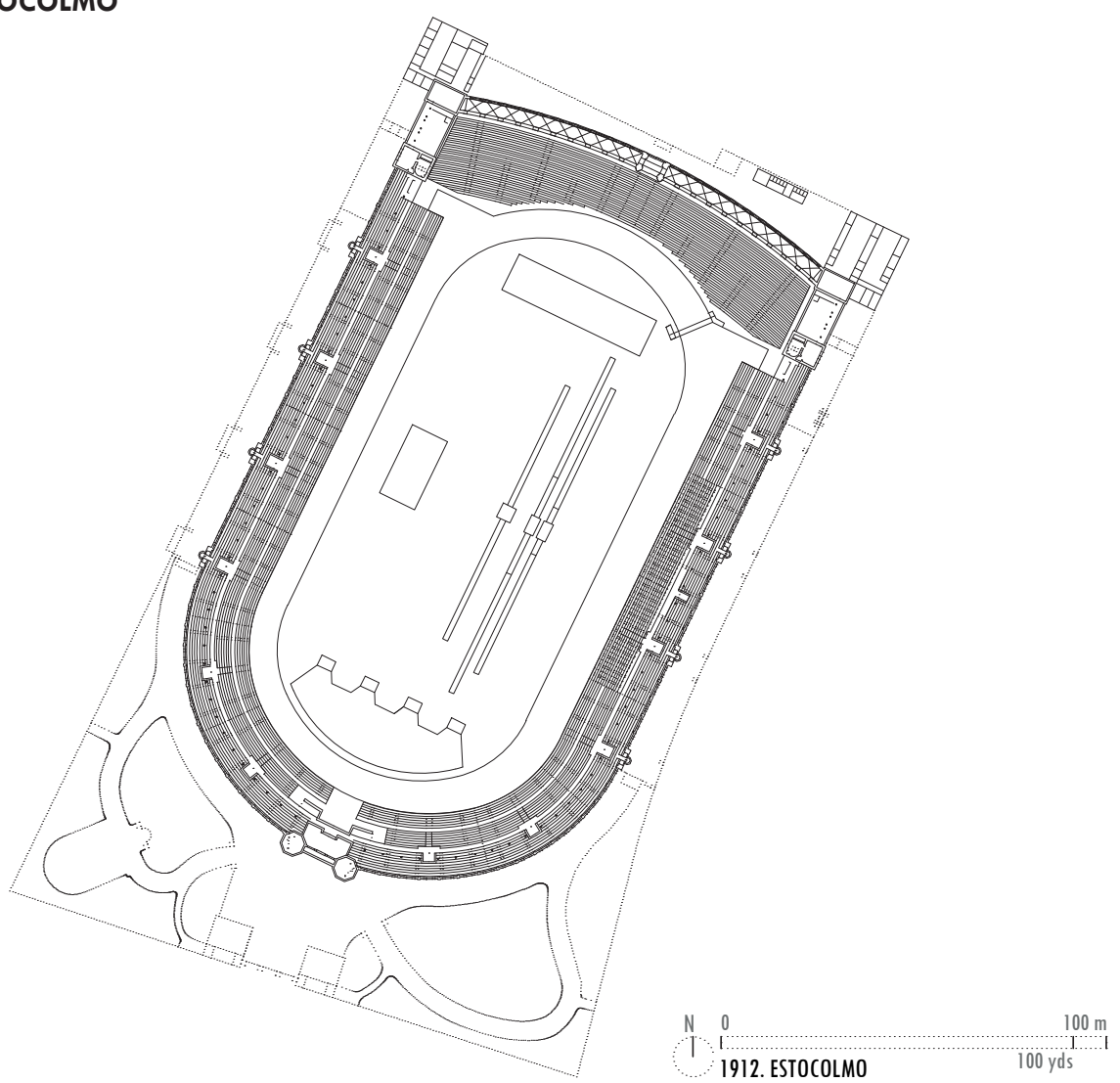

1912.0. Nombre del Estadio

Stockholms Olympiastadion. Aunque en las rotulaciones oficiales aparece como Stockholms Stadion y es conocido comúnmente como, simplemente, Stadion.

\subsection{Situación}

Lidingövägen, 11433 Stockholm, Suecia.

\subsection{Fechas}

1909. 28 de mayo, en Berlín se designa Estocolmo como Sede Olímpica.

1909. 7 de octubre, primera reunión del Comité Organizador.

1910. 10 de julio, se constituye el Comité para la Construcción del Estadio.

1910. 2 de noviembre, el Comité aprueba el proyecto de Torben Grut.

1910. 23 de noviembre, se inicia la construcción del estadio.

1912. 1 de junio, inauguración del estadio.

1912. 6 de julio, inauguración de los Juegos.

1967. Restauración integral el estadio.

1979. Se declara edificio de interés histórico. Actualmente continua en uso.

\subsection{Preexistencias en el lugar}

Idrottsparken Stockholm. En la parcela se hallaba un parque atlético-deportivo construido en 1896.

\subsection{Relación con la ciudad. Posición respecto al centro urbano}

Situado al norte de Estocolmo, cercano al centro y en la proximidad de la mejor zona residencial de Estocolmo. Bien comunicado mediante tranvía. Inmediatamente al norte de la parcela se encuentra el Östermalm Idrottesplats, centro deportivo, dotado de pista de tenis cubierta, pista deportiva, centro ecuestre, golf. Al noreste, está el gran parque urbano Ladugårdsgärdet. Además en las proximidades se encuentran otros espacios abiertos para la práctica deportiva y varios cuarteles y escuelas.

Espacio libre en el borde norte de la ciudad, pero buscando su cercanía al centro. Distancia al centro urbano: 1940 metros en línea recta al Palacio Real, 1950 metros a la Estación Central

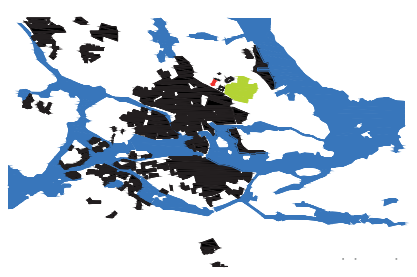
y 980 metros a Stureplan.

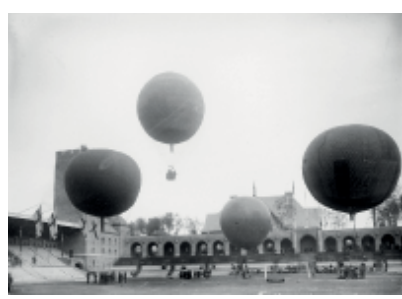




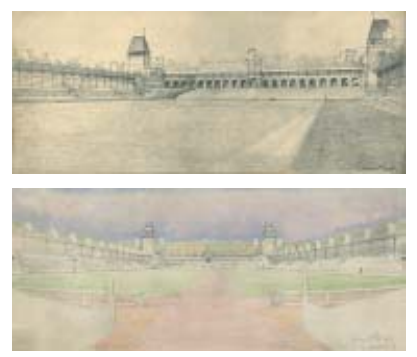

1912.5. Breve relato de la historia del Estadio

Su historia comienza, en Berlín el 28 de mayo de 1909, con la inesperada designación de Estocolmo como sede de los Juegos de la $\vee$ Olimpiada. La gran favorita era la propia Berlín, pero en el último momento retiró su candidatura, por la súbita muerte de su máximo impulsor. Una vez constituido el Comité Organizador se reúne por primera vez el 7 de octubre de 1909. Su primera idea, respecto al estadio, fue la de ampliar y modernizar el Östermalms Idrottesplats, construido en 1906. El coste estimado de la operación rondaría las 235.000 coronas. En 1910 se cambio la idea, decidiendo la realización de un nuevo estadio en el vecino Idrottsparken Stockholm, parque deportivo construido en 1896, situado inmediatamente al sur de la primera posible localización. Cuestiones prácticas como la disponibilidad del suelo y su facilidad de gestión, pudieron estar en el origen de este cambio de decisión.

Se designó al arquitecto Torben Grut para su diseño.

Primero se planteo un Estadio construido enteramente en madera, con un coste estimado de 385.000 coronas. Motivado por el importante desembolso económico que suponía, Torben Grut, propuso su realización en ladrillo y piedra, lo cual, aunque aumentaba sensiblemente el coste, suponía la perdurabilidad de la obra. Después de consultas el Comité aprobó el cambio, estimándose el coste del nuevo proyecto en 820.000 coronas.

El estadio fue inaugurado el 1 de junio de 1912 con un coste final de 1.187 .880 coronas.

Pero, ¿̇cómo fue posible la financiación y construcción del estadio, con sus aumentos presupuestarios, en tan corto espacio de tiempo?

Por una parte los éxitos de los deportistas suecos en las anteriores ediciones olímpicas, hizo aumentar el interés general de la sociedad sueca en los Juegos.

Por otra parte, la atmósfera fuertemente nacionalista que se respiraba en el país después de la separación de Norvega en 1905, encontró en la organización de los Juegos una oportunidad única para el reconocimiento internacional, basado en los éxitos deportivos y organizativos que propiciaba la organización de los Juegos.

El apoyo de la corona y el gobierno fue total y directo, se obvió la necesidad de consulta al parlamento, que de haber sido así hubiera retrasado la toma de decisiones. El presupuesto Olímpico se financió gracias a la realización de ocho sorteos especiales de lotería.

1912.6. Descripción del Estadio; Graderío

"... muy medida, a la cual su sencillez y unidad le confieren grandeza.

Está cuidadosamente integrado en las características naturales del terreno y correctamente orientado, respecto a los puntos cardinales" Rapport Oficial.

dimensiones y superficies aproximadas graderío

\begin{tabular}{|c|c|}
\hline L $01-01^{\prime}$ & $68,20 \mathrm{M}$ \\
\hline L 02-02' & $88,46 \mathrm{M}$ \\
\hline L $04-01$ & $54,70 \mathrm{M}$ \\
\hline L A3-A $7^{\prime}$ & $108,70 \mathrm{M}$ \\
\hline R O1-Al & $47,75 \mathrm{M}$ \\
\hline R $02-A 3$ & $34,54 \mathrm{M}$ \\
\hline R 04-A6' & $165,74 \mathrm{M}$ \\
\hline$<$ Al.01.A3 & $80^{\circ}$ \\
\hline$<\mathrm{A} 2.02 . \mathrm{Al}$ & $50^{\circ}$ \\
\hline$<A 5^{\prime} .04 . A 6^{\prime}$ & $29^{\circ}$ \\
\hline
\end{tabular}
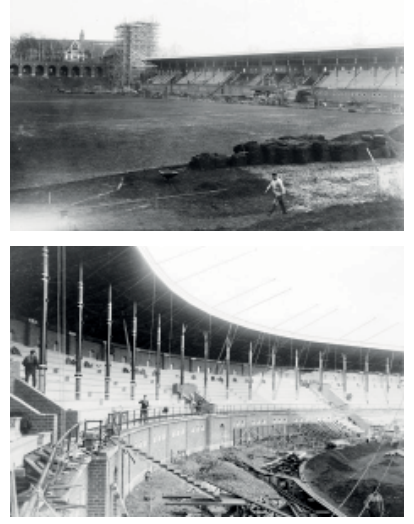

Dibijos originales de Torben Grut. Archivo: Museo de Arquitectura de Estocolmo superficie de cubierta: $3.143 \mathrm{~m} 2$
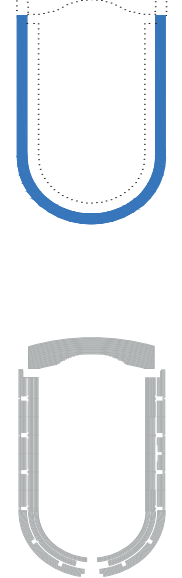

superfiecie de graderios: $7.218 \mathrm{~m} 2$
$\begin{array}{llll}N & 0 \\ N & 1\end{array}$
1912. ESTOCOLMO
$100 \mathrm{~m}$
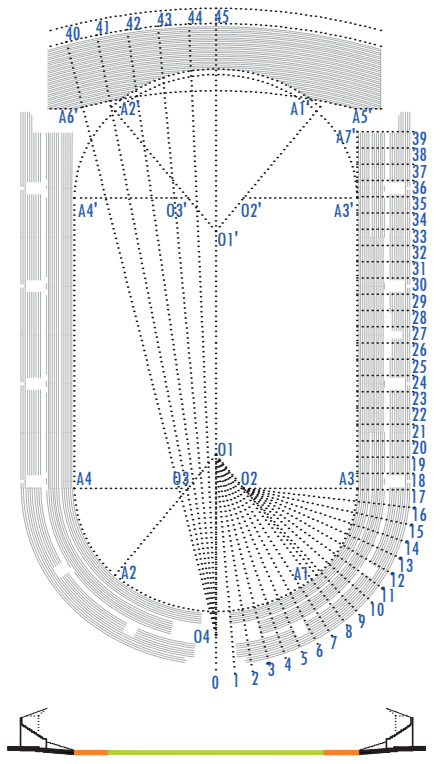

Graderío en forma de herradura que se abre a la ladera sur de pequeña colina situada al norte de la parcela. La cual queda enmarcada por dos masivas torres de ladrillo. La situada más al este es conocida como la torre del reloj. La entrada principal se encuentra en el centro de la curva sur, en el eje del estadio y esta flanqueada por dos potentes torres.

La masividad exterior contrasta con la escala menuda de las gradas, que con sus repeticiones 
sucesivas de la forma de herradura, confieren a la composición un gran dinamismo.

La cubierta de madera se inspira en la arquitectura vikinga.

"...se levantan con orgullo por encima de la arena; (y resulta necesaria por nuestro clima del norte), proporciona, con un coste pequeño, interesantes efectos de sombra y majestuosidad al conjunto, que la pequeña dimensión de los graderíos, no podían haber conferido".

El propio arquitecto nos describe sus intenciones en el artículo publicado en el número 7 de la revista Arkitektur de 1912:

“La arquitectura del Estadio es una aplicación constructiva moderna de las fabricas artesanales de ladrillo de la Edad Media, tal como se mostraba en las antiguas murallas, fortalezas, monasterios e iglesias suecas.

Cada parte del proyecto se integra de una manera natural y orgánica en el conjunto. No existen adicciones decorativas, la construcción se muestra pura y directa, como en un barco o un puente, la belleza depende de los materiales y de las proporciones"

Estas intenciones se alinean claramente con los ideales del movimiento arquitectónico denominado Nacional Romántico.

Inicialmente se proyecto solo una parte alta de la grada, que debajo alberga los servicios, dejándose un espacio de pelouse entre la misma y la pista, en semejanza a los hipódromos, para los juegos y ya de manera definitiva se realizó una grada baja, de sección parabólica, que con el tiempo fue sustituida por una de fabrica. Capacidad total aproximada de 37.000 espectadores.

\subsection{Descripción del Estadio; Pista}

Pista de atletismo de ceniza, con una cuerda de 384, 10 metros. Con un ancho de 10,5 metros en la recta de llegadas y 7,5 metros en el resto. El responsable del trazado y de las instrucciones para su realización fue el experto inglés Charles Perry, de Stamford Bridge en Londres, que estuvo en Estocolmo entre octubre y diciembre de 1911 y también inmediatamente antes del inicio de los Juegos. La pista tiene un grosor de $45 \mathrm{~cm}$ y está compuesta por tres capas, la inferior un macadam de granito y ladrillo triturado de $18 \mathrm{~cm}$, la intermedia de $12 \mathrm{~cm}$ de escoria y la de acabado de $15 \mathrm{~cm}$ de ceniza.

El terreno central de hierba está realizado sobre una cuidada base drenante.
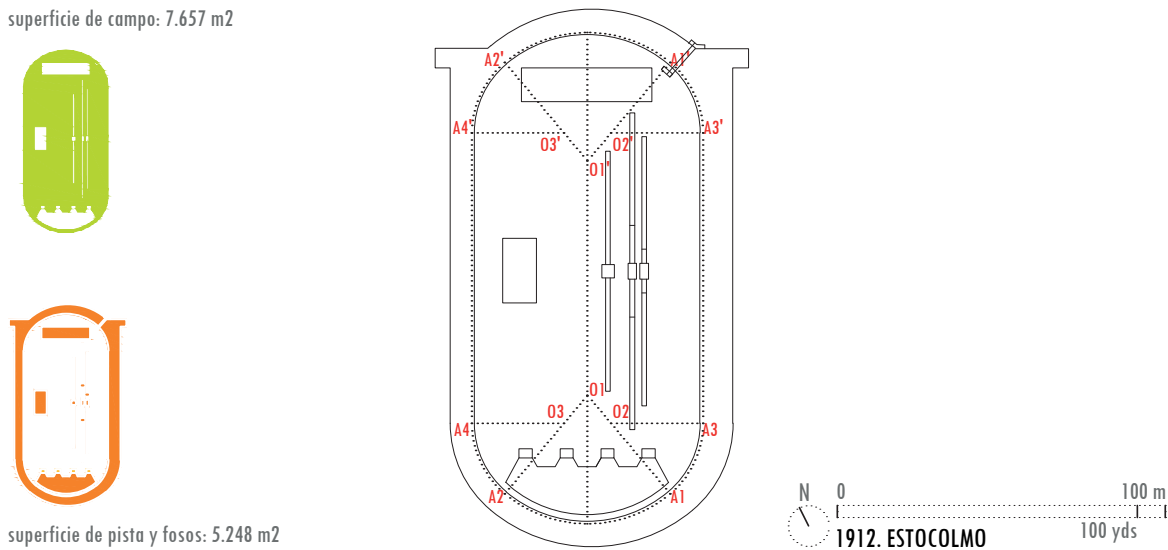

Programa deportivo: Atletismo, Gimnasia, Fútbol, Lucha, Penthalon moderno, salida y meta de carrera cross country, Hípica, Tira de soga y las Ceremonias de apertura y clausura.

1912.8. Elementos significantes

Puerta ceremonial de Maratón, en forma de arco.

\subsection{Avances técnicos}

De forma experimental y sin ser oficial se realiza por primera vez el cronometraje electrónico y la photofinish. También por primera vez se dota de sistema de megafonía para avisos. Se crea un túnel por debajo de la pista para acceso a su interior sin interferir en las carreras

\subsection{Autores. Tipo de encargo}

Torben Grut, arquitecto y responsable del proyecto y obra. Formó parte desde el principio del Comité para la Construcción del Estadio y fue, junto a su presidente el Colonel V. G. Balck, de los miembros más activos del mismo.

Torben Andreas Grut, nació en Tuns, Västergötland, el 2 de junio de 1871 y murió en Frederiksberg, Dinamarca, el 24 de diciembre de 1945. De familia de origen danés.

Estudió en el Real Instituto de Tecnología (KTH) de Estocolmo, en donde el profesor Isak Gustaf

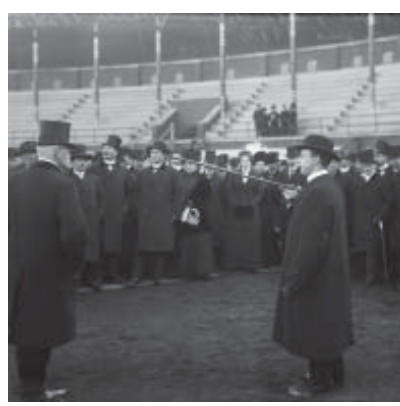

dimensiones y superficies aproximadas pista

CUERDA $384,10 \mathrm{M}-420 \mathrm{yds} 0^{\prime} 2$ -

L 01-01' $\quad 71,37 \mathrm{M}$

L 02-02' $\quad 44,46 \mathrm{M}$

R OI-Al $\quad 38,65 \mathrm{M}$

R 02-A3 27,49 M

$<$ A1.01.A2 $\quad 80^{\circ}$

$<$ A3.02.Al $\quad 50^{\circ}$

marca del ganador

$100 \mathrm{~m}$.

$400 \mathrm{~m}$

$5000 \mathrm{~m}$.

Altur

Longitud

Alt parado

Peso

Jab 2 manos

2 manos

$4 \times 100 \mathrm{~m}$.

Marathon

8412,95 ptos

2h36,54"8

$09,42 \mathrm{~m}$

$27,70 \mathrm{~m}$

$82,86 \mathrm{~m}$

$3,16 " 6$

1 ptos

$(40,5 \mathrm{~km})$ 
Clason fue una influencia fundamental en su formación. Posteriormente se fue a Copenague a trabajar y continuar sus estudios en la Academia de Arte. Completó sus estudios en la Academia de Artes Sueca, en Estocolmo, obteniendo la distinción de la Medalla Real y bolsa de viaje.

Sus primeros trabajos, después de su viaje iniciático por Europa, estuvieron influenciados por la secesión vienesa. Como en su propia casa villa Sunnanlid en Djurgarden (1905), de volumen cúbico y grandes aleros.

Fue editor de la revista Arkitektur entre 1904 y 1907, desde donde defendió e impulsó el nuevo estilo denominado Nacional Romanticismo, que invocaba una arquitectura austera, potente y a la vez sensible, con una gran carga poética. Con referencia a modelos de la arquitectura medieval sueca.

En el estadio, que es su principal obra, desarrolla la fuerza expresiva del ladrillo, sintetizando la arquitectura de las antiguas arenas y la arquitectura fortificada medieval, e incluso, detalles en madera y decorativos de la antigua arquitectura Norse de la época vikinga.

O. Biörlin, Lcdo., fue el responsable de la construcción y mantenimiento de la pista y la pradera. Se recurrió al consejo experto de Charles Perry, de Stamford Bridge Grounds de Londres, que ya fue el responsable de la composición y puesta en obra de las superficies de competición en Atenas 1896 y Londres 1908.

Además participaron en la dirección de la obra:

Henrik Kreuger, Ingeniero de Construcción, fue contratado el 2 de noviembre de 1910 para el control de los materiales. Además, entre otras cosas, fue responsable de las construcciones en hormigón y de las cimentaciones.

Emil Lindkvist, tambien fue contratado como oficial de control, el 6 de febrero 1911.

A. Lindegren, llevó el control económico de la obra.

E. Cederpalm, se encargó de la supervisión de la jardinería.

W. Andersson y W. Dahlgren, dirigieron la realización de las instalaciones mecánicas. Y Nilson y Svensson las eléctricas.

La construcción fue llevada a cabo por la empresa Kreuger \& Toll. El granito era de Oscarshamn y fue suminstrado por Carl J. Schylander's Granite Co. y los ladrillos hechos a mano por Helsingborg Steam Brickmaking Co.

Tipo de encargo. Encargo directo, por parte de Viktor Gustaf Balck (1844-1928), Presidente del Comité Organizador y responsable en conseguir los Juegos para Estocolmo. Era oficial del ejército sueco, profesor de gimnasia y miembro fundador del Comité Olímpico Internacional.

\subsection{Edificios coetáneos}

Casa Batlló, La pedrera y La Sagrada Familia de Antoni Gaudi. Casa Robie, Frank Lloyd Wright. Nave de turbinas AEG, Peter Behrens.

\subsection{Hechos históricos relevantes}

1912. Hundimiento del Titanic. Final del Imperio Chino, se transforma en republica. Faltan dos años para el comienzo de la $1^{a}$ Guerra Mundial.

Bibliografía Estocolmo 1012:

ARHEM, Barbro. Stadion, byggnadshistorisk dokumentation inför byggnadsminnesförklaring. Ed Estocolmo: Stockholms Stadsmuseum, 1989

ARHEM, Barbro. Stockholms Stadion. Ed. Estocolmo: Byggnadsminne i stockholms län, 1979. ISBN 91-87088-04-5 JÖNSSON, Ake. Solskens olympiaden, vägledning till. Ed: Klocktornet Media AB, 2012. ISBN 978-91-637-0085-9 The 1912 Stockholm Olympics, Essays on the competitions, the people, the city. Ed: Yttergren, Leif; Bolling, Hans, 2012. ISBN 978-0-7864-7131-7

ÖSRBERG, Ragnar; GRUT, Torben. Stockholms Stadion. Arkitektur, 1912, n7

The Official Report of the Olympic Games of Stockholm 1912. Ed: The Swedish Olympic Committee, 1913

Fuentes:

Arkitekturmuseet. Museo de la Arquitectura y el Diseño. Estocolmo.

Skeppsholmen, 11149 Stockholm.

Sveriges Centralförening för Idrottens Främjande

Klocktornet, 3 tr. Olympiastadion. 11433 Stockholm. http://www.scif.se/ 


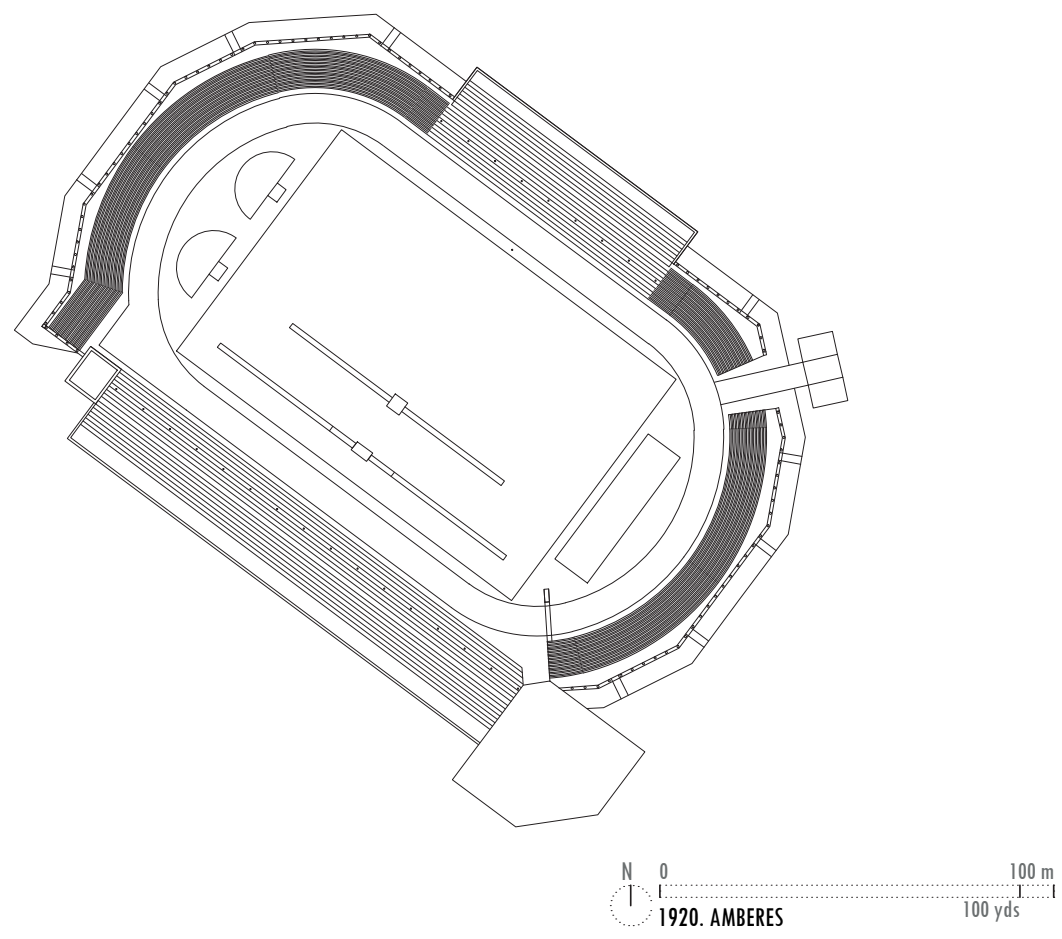

1920.0. Nombre del Estadio

Olympisch Stadion, también conocido popularmente como Kielstadion o Beerschotde Stadion.

1920.1. Situación

Atletenstraat 80, 2020 Amberes-Kiel, Bélgica. Actualmente demolido.

\subsection{Fechas}

1912. Bélgica presenta su intención de organizar los juegos de 1920.

1913. Bélgica elige a Amberes como ciudad candidata.

1914. Presenta candidatura. Se edita un folleto de intenciones "Aurons-nous la Vllème Olympiade à Anvers?" (¿̇Tendremos la VII Olimpiada en Amberes?) que se presenta en el $6^{\circ}$ Congreso Olímpico de París. En el que además presentaron su candidatura Ámsterdam, Roma y Budapest, que era la favorita. El proceso quedó interrumpido al iniciarse la Primera Guerra Mundial.

1919. Confirma su candidatura, una vez acabada la guerra y pese a estar Bélgica en estado de ruina.

1919. El 5 de abril, en Lausana, Amberes es designada ciudad sede de los Juegos de la VII Olimpiada.

1919. El 17 de junio, se constituye el Comité Organizador presidido por el conde Henri de Baillet-Latour.

1919. El 4 de julio, comienza la construcción del estadio.

1920. El 23 de mayo, se inaugura oficialmente, con un festival gimnástico y cultural.

1920. El 27 de junio, atletas belgas realizan un ensayo general de cara a los juegos.

1920. El 14 de agosto, se celebra la inauguración de los juegos.

1920. El 12 de agosto, ceremonia de clausura.

1999. Es demolido para la construcción de un nuevo estadio de fútbol.

1920.3. Preexistencias en el lugar

En 1895 Ernest Grisar, un acaudalado aficionado al deporte, compró 19 Ha de terrenos en Kiel al sur de Amberes en los que había un antiguo hipódromo. En 1901 se funda el Royal Beerschot Athetic Club. En 1913 se construye un estadio de fútbol para 20.000 espectadores.

\subsection{Relación con la ciudad. Posición respecto al centro urbano}

Al sur de la ciudad, fuera del limite de las murallas defensivas, que en 1920 aún estaba en pie. A 4.200 metros del centro urbano, a 1.600 de la muralla, a 2.150 tanto del río Scalda como de la estación de tren. A $5 \mathrm{~km}$ al norte está el importante puerto de Amberes.

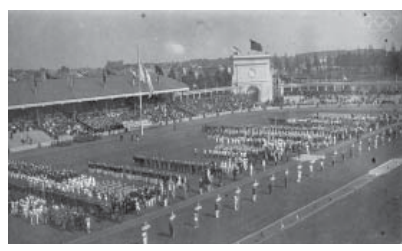



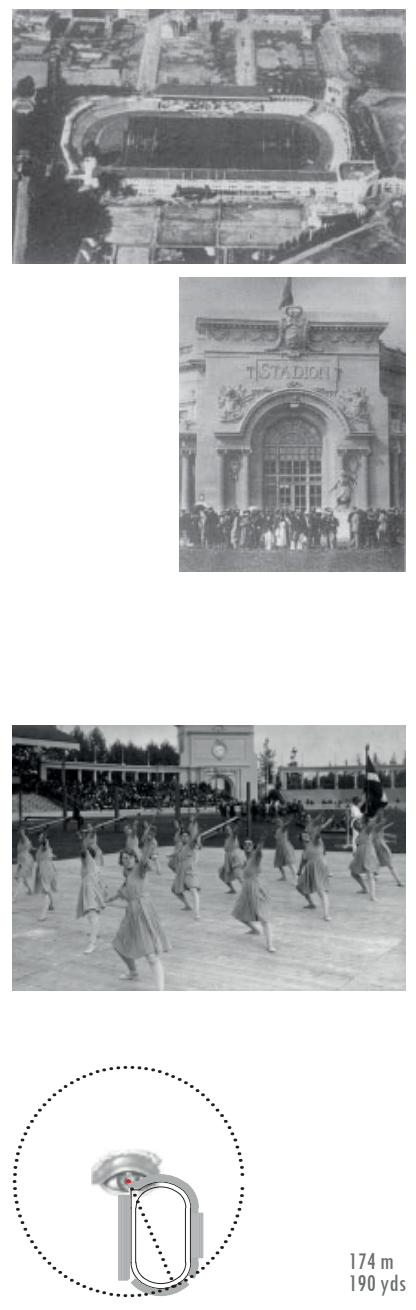

$174 \mathrm{~m}$
$190 \mathrm{yds}$

dimensiones y superficies aproximadas graderío

L $01-01$ ' $61,40 \mathrm{M}$

L $01-02 \quad 14,54 \mathrm{M}$

L 02-02' $\quad 83,99 \mathrm{M}$

L $01 '-04 \quad 57,11 \mathrm{M}$

L A2'-A4' 18,38 M

LA7-A8 $\quad 127,05 \mathrm{M}$

L A3-A3' $\quad 83,98 \mathrm{M}$

R OI-Al $52,46 \mathrm{M}$

R 02-A3 37,92 M

$<$ Al.01.A2 $78^{\circ}$

$<$ A3.02.Al $51^{\circ}$

$<$ A3.02.A4 $30^{\circ}$

$<$ A5.02.Al $6^{\circ}$

$<01.04 .2^{\prime} \quad 17^{\circ}$

$<$ A3.02.Al $\quad 51^{\circ}$

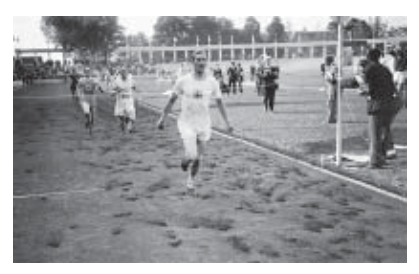

Amberes, en 1920, contaba con aproximadamente 300.000 habitantes.

1920.5. Breve relato de la historia del Estadio

Existe muy poca información publicada sobre este estadio, no hemos sido capaces de encontrar ningún plano o dibujo del mismo. Al carecer de los fondos necesarios, el Comité Organizador no publicó un informe oficial después de los Juegos. En 1927, el Comité Olímpico Nacional belga sin embargo publicó un informe escrito a máquina que data en 1920, disponible sólo en francés, titulado "VIlème Olympiade Anvers 1920". Una segunda edición de este informe fue publicado en 1957 con el título "Rapport officiel des Jeux de la Vllème Olympiade Anvers 1920". Pero, en ninguna de las dos ediciones, aporta dato alguno sobre el estadio.

La idea inicial de postular a alguna ciudad belga para la organización de los Juegos, parte del equipo que participó en Estocolmo en 1912, del que formaba parte Fernand de Montigny, arquitecto y miembro destacado del activo Royal Beerschot Athelic Club, puede que esto tuviera alguna relación con el cómo se desarrollaron los acontecimientos posteriormente. Una vez designada Amberes ciudad sede, después de la renuncia de Lyón y en competencia con Ámsterdam y Budapest, comienzan con urgencia los trabajos. Se quiso aprovechar el prácticamente recién construido campo de fútbol del R. Beerschot $A C(1913)$ para mediante reforma y ampliación construir el nuevo estadio Olímpico. Al añadir la pista de atletismo solo es posible el aprovechamiento de un lado del graderío. Podemos pensar que, tal vez, el graderío norte fue el único remanente del antiguo estadio en el moderno.

Hay que destacar los cortos plazos de tiempo para toma de decisiones, proyecto y construcción, todo ello fue llevado a cabo en tan solo un año y un mes.

Los costes fueron totalmente financiadas por el Comité Ejecutivo de la VII Olimpiada, que se estimaron inicialmente en un millón de francos (precios de 1920), pero finalmente ascendieron hasta los 2.280.479 francos. Esto en parte fue debido a la rampante inflación de la posguerra. Supusieron alrededor de la mitad del gasto total de la organización del evento. El balance económico global de los Juegos resultó muy negativo.

En 1999 el estadio fue demolido. Resulta extraña tal decisión, obviando todo su valor sentimental e histórico.

\subsection{Descripción del Estadio; Graderío}

De pequeña escala, sencillo y austero, en consonancia con la difícil situación de Bélgica, y de buena parte de Europa, después de la finalización de la Primera Gran Guerra, en la que muchas de sus ciudades todavía estaban en ruinas.

Barclay F. Gordon, en Olympic Architecture, building for the summer games, lo califica: "en su planificación, una expresión tardía del estilo Beaux Arts. Sus formas son producto de un delirante Eclecticismo, con elementos de estilo y ornato pertenecientes a muchos periodos históricos. Sólo un Henry Higgins' de la arquitectura, podría interpretar todos estos leguajes".

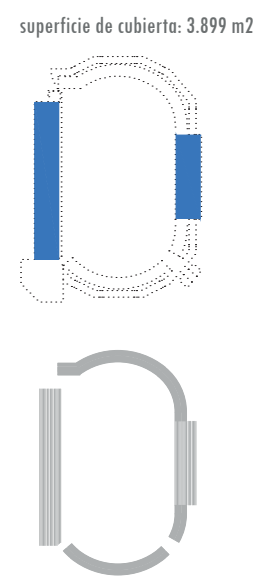

superfiecie de graderios: $6.836 \mathrm{~m} 2$
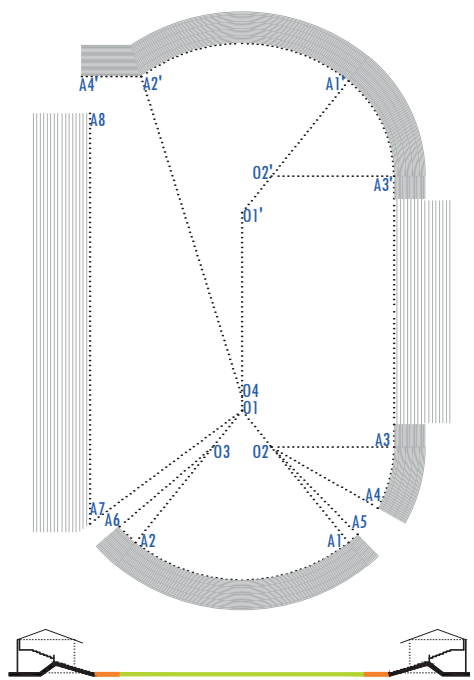

$$
\begin{gathered}
N \quad 100 \mathrm{~m} \\
\hline 1 \\
1920 . \text { AMBERES }
\end{gathered}
$$

En sus dos rectas contaba con tribuna cubierta, dividida en dos partes diferenciadas cada una de ellas, en las superiores se encontraban los palcos. La de la recta principal era más larga, 105 metros, rematándose en su extremo de llegadas con un pabellón de acceso, formando 
chafan y en el lado de las salidas con una pequeña torre. El graderio de la recta opuesta tiene una longitud de 70 metros. En las dos curvas se desarrolla un graderio de pendiente muy tendida para público de pie, el remate superior de dicho graderio, acotando el espacio del estadio, formaba una alineación de columnas dóricas enlazadas por un arquitrabe. Detrás de la salida del 100, en la construcción del graderío se respetaron cuatro árboles que existían en el lugar, quedando integrados en el mismo. En el lado de levante del estadio se interrumpe el graderio y se erige un arco del triunfo, entrada ceremonial del estadio. Debajo de las tribunas había espacio habitable, mientras que el graderio de las curvas estaba asentado sobre terreno aportado. Las tribunas tienen capacidad para 10.000 espectadores sentados y el graderio de pie para 20.000 , haciendo un aforo total de 30.000 personas.

Cubierta, dos fragmentos rectos, cerchas a dos aguas biapoyada en sus extremos.

\subsection{Descripción del Estadio; Pista}

Dimensiones: Cuerda de la pista de 389,8 metros y seis calles.

Material: Debió de ser tierra batida o ceniza. Aunque no hemos podido encontrar datos que lo confirmen. Interior, pradera de hierba.

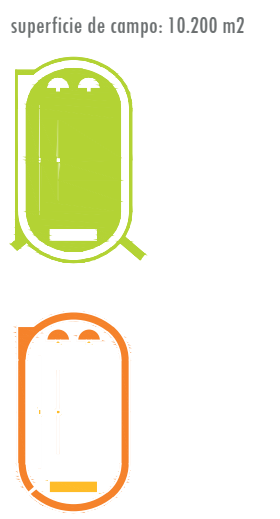

superficie de pista y fosos: $4.155 \mathrm{~m} 2$

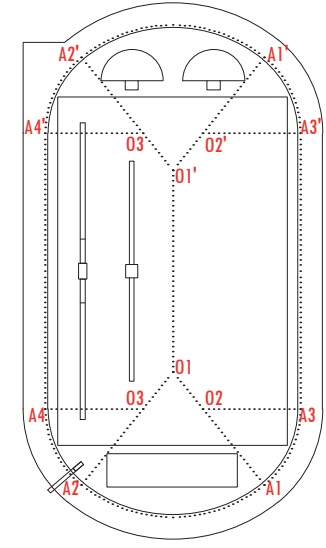

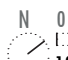
1920. AMBERES

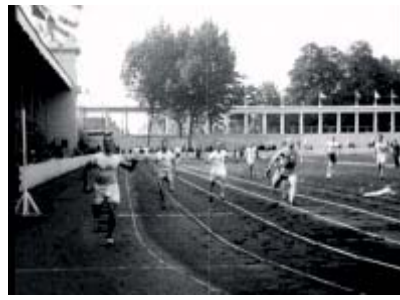

dimensiones y superficies aproximadas pista

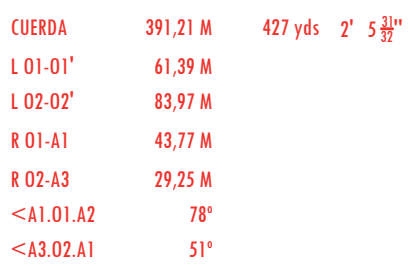

marca del ganador

$\begin{array}{lr} & \text { Hombres } \\ 100 \mathrm{~m} . & 10 " 8 \\ 200 \mathrm{~m} & 22 " 0 \\ 400 \mathrm{~m} . & 49 " 6 \\ 800 \mathrm{~m} . & 1,53 " 4 \\ 1500 \mathrm{~m} . & 4,01 " 8 \\ 5000 \mathrm{~m} . & 14,55 " 6 \\ 10000 \mathrm{~m} . & 31,45 " 8 \\ 110 \mathrm{mv} & 14 " 8 \\ 400 \mathrm{mv} & 54 " 0 \\ 3000 \mathrm{obst} & 10,00 " 4 \\ \text { Altura } & 1.93 \mathrm{~m} \\ \text { Pértiga } & 4.09 \mathrm{~m} \\ \text { Longitud } & 7.15 \mathrm{~m} \\ \text { Triple } & 14.50 \mathrm{~m} \\ \text { Peso } & 14.81 \mathrm{~m} \\ \text { Disco } & 44.69 \mathrm{~m} \\ \text { Martillo } & 52.87 \mathrm{~m} \\ \text { Jabalina } & 65.78 \mathrm{~m} \\ \text { 4x100 } & 42 " 2 \\ \text { 4x400 } & 3,22 " 2 \\ \text { 3000xEquipos } & 10 \mathrm{ptos} \\ \text { 3000m marcha } & 13,14 " 2 \\ \text { 10000m marcha } & 48,06 " 2 \\ \text { Decathlón } & 6804 \mathrm{ptos} \\ \text { Marathón } & 2 \mathrm{~h} .32,35 " 8 \\ & \end{array}$

Programa Deportivo: Atletismo, Hípica, Fútbol, Rugby, Gimnasia, Hockey hierba, Pentathlón Moderno, Halterofilia, Tira de Soga y las Ceremonias de apertura y clausura.

\subsection{Elementos significantes}

Por primera vez se realiza el izado de la bandera Olímpica. En el estadio se sitúa un gran mástil, en el eje de la tribuna principal, dentro de la pista de carreras, próximo a la recta de contrameta. También como elemento novedoso se construye un arco de triunfo como entrada ceremonial de atletas y de la carrera de Marathon. Además se hace por primera vez el juramento olímpico y la suelta de palomas con mensajes de paz.

\subsection{Avances técnicos}

\subsection{Autores. Tipo de encargo}

Ferdinand de Montigny. (1885/1974) Nació en Anzegem. Además de arquitecto, fue un deportista relevante, participó en cuatro ediciones de los juegos y, también, en los no oficiales de Atenas 1906. En dos deportes diferentes, ganando en esgrima las medallas de bronce en Londres, oro en Estocolmo y dos de plata en París. Además de bronce en hockey en el estadio que el mismo diseño en Amberes.

Louis Somers. (1871/í?). Nacido en Mortsel, es un personaje con muy pocos datos conocidos. Montigny y Somers, se destacan por su eclecticismo, trabajan juntos en la región de Amberes entre 1912 y 1938, realizando, fundamentalmente, edificios de viviendas y casas de muy variados estilos. Como la Résidence La Pépinière en el número 4 de la calle Koningin Elisabethlei, que es típicamente beaux arts, las viviendas de la calle Doornelei, art decó, la villa en Vijverlaan 8, neorural, o la mansión en Faillelaan, neorococo, etc.

Archibald Leitch. (1865/1939). El historiador británico del deporte y su arquitectura, Simon Inglis en su publicación de 2005, Engineering Archie: Archibald Leitch - Football Ground Designer, atribuye a este renombrado especialista escocés en estadios de fútbol algún tipo de participación en el estadio Olímpico de Amberes, ya que parece que están documentados varios viajes a la ciudad flamenca durante el periodo de construcción del estadio. Archie se inició en la practica de la arquitectura construyendo edificios industriales. En 1899 le fue encargado el estadio de los Glasgow Rangers, el lbrox Park. Ahí se inicia una larga y

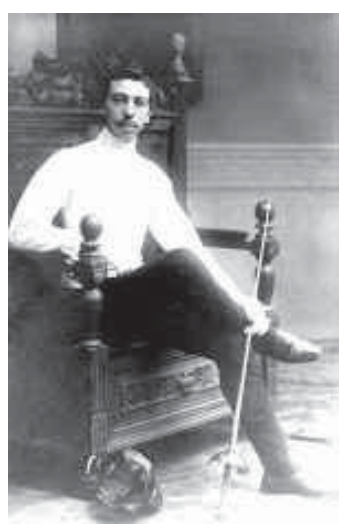


fructífera carrera, que no se vio empañada por el desastre de 1902, en el que la parte trasera de la tribuna oeste del recién construido lbrox Park, cedió durante la celebración de un partido entre Escocia e Inglaterra, cientos de espectadores cayeron desde 12 metros de altura, muriendo 25 personas y resultando heridas 517 . Desde ese momento las gradas de madera sobre estructura metálica quedaron en entredicho, siendo mayoritariamente sustituidas por gradas de hormigón o graderíos sobre el terreno. Entre los muchos estadios construidos por Leitch podemos destacar: Anfield, Arsenal Stadium, Celtic Park, Old Trafford, Stamford Bridge, Villa Park, West Ham, White Hart Lane.

Charles Perry. Martin Polley en su libro The British Olympics: Britain's Olympic Heritage 1612 2012, dice en su pagina 97 que Perry preparó la pista de Amberes, además de las de Atenas, Londres y Estocolmo. De Perry sabemos muy poco, solo que pertenecía al London Atheletic Club que tenia sus instalaciones en Stamford Brigde, seguramente fuera entrenador y además era cronometrador.

Humphreys \& Co., prestigiosa compañía londinense especialista en la construcción de instalaciones deportivas, fue la contratistas de las obras. Posiblemente Leitch pudo ejercer de asesor de esta empresa y Perry tal vez también, aunque es posible que su conexión este más en relación con una imposición directa de Pierre de Coubertin.

Tipo de encargo. Directo, la idea de postular a Amberes para los juegos, se inició en Estocolmo 1912 con los miembros del equipo olímpico belga entre los que se encontraba Fernand de Montagny, que fue medalla de oro. El arquitecto era además miembro activo del Beerschot Athetic Club y el tiempo para la organización de los juegos era escasísimo.

\subsection{Edificios coetáneos}

Mies van der Rohe, en 1921, presenta su propuesta de rascacielos de vidrio para el concurso de la Friedrichstrasse, en Berlín.

Enrich Mendelsohn, entre 1919 y 1921, construye la torre Einstein en Postdam.

Capilla del Bosque, 1920, de Gunnar Asplund, en el Cementerio Sur de Estocolmo, que estaba desarrollando con Sigurd Lewerentz desde 1915.

1920.12. Hechos históricos relevantes

Entre 1919 y 1920 se firman todos los tratados que fijan las condiciones de paz y que suponen el final de la Primera Guerra Mundial.

Se constituye la Sociedad de Naciones, con el objetivo de evitar futuras guerras.

En la India, Gandhi inicia el movimiento no violento en defensa de los derechos.

En EEUU entra en vigor la conocida como ley seca y una enmienda constitucional reconoce el voto a las mujeres.

El 4 de enero muere Benito Pérez Galdós.

Bibliografía Amberes 1920:

RENSON, Roland (1996). The Games Reborn. The Vllth Olympiad Antwerp 1920. Antwerp. Ed. Pandora. ISBN $90-$ 5325-051-4

INGLIS, Simon (2005). Engineering Archie: Archibald Leitch - Football Ground Designer. English Heritage. ISBN 1-85074-918-3

GORDON, Barclay F. (1983). Olympic Architecture. Building for the summer games. John Wiley \& Sons. Nueva York. ISBN 0-471-06069-0

POLLEY, Martin (2011). The British Olympics: Britain's Olympic Heritage 1612-2012. Ed. English Heritage. ISBN 978 1848020580

http://home.scarlet.be/ fhermans/antwerpen 1920/stadion.html 


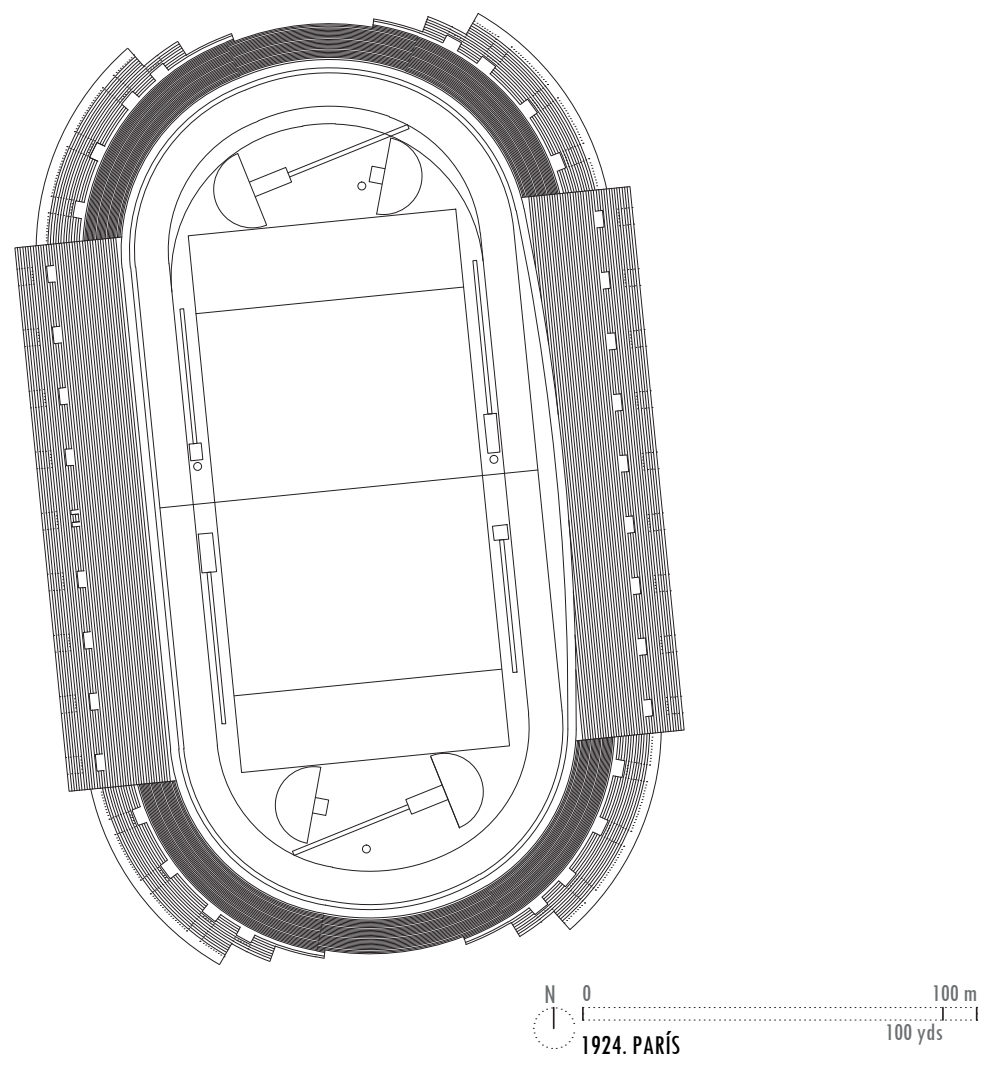

1924.0. Nombre del Estadio

Stade Olympique de Colombes. Desde 1928 Stade Olympique Yves-du-Manoir

1924.1. Situación

12 rue Francois Faber. 92700 Colombes. Hauts-de-Seine . Francia.

\subsection{Fechas}

1920. El Stade du Matin, en Colombes a las afueras de Paris, pasa a estar gestionado por el Racing Club de Francia

1921. El 2 de junio, el Comité Olímpico Internacional designa Paris como sede de los Juegos de la VIII Olimpiada.

1921. A partir de junio, Frantz Reichel, Secretario General del Comité Ejecutivo de los Juegos, prepara un informe con posibles sedes y previsiones económicas.

1921. El 8 de octubre, el arquitecto municipal de Paris Léopold Bévières presenta un estudio con ocho propuestas de estadio.

1921. El 31 de octubre, Bévières presenta su propuesta de estadio terraplenado.

1921. A finales del año, convocatoria de un concurso de arquitectura para seleccionar el proyecto de la nueva ciudad olímpica.

1922. El 3 de febrero, el jurado presidido por Paul Leon, director de BeuaxArts, designa ganador al proyecto presentado por Louis Faure-Dujarric.

1922. El 11 de febrero, exposición de los trabajos presentados al concurso.

1922. El 12 de marzo, el ayuntamiento de Paris se desentiende de la organización de los Juegos, pero pone a disposición el estadio Pershing, sus terrenos aledaños y 1 millón de francos.

1922. El 12 de abril, después de muchas dudas acerca de la ubicación de la Ciudad Olímpica, el Comité Olímpico Francés decide aceptar la oferta del Racing Club de Francia que cedía su estadio y sus terrenos en Colombes.

1922. El 21 de julio, se firma el acuerdo entre el Comité Olímpico Francés y el Racing Club de Francia, por el cual este último se comprometía a la construcción de los estadios de atletismo, natación y tenis, con un coste global de 4 millones de francos, que debería recuperarlos con la venta de entradas.

1922. En agosto, comienzan las obras del estadio. 

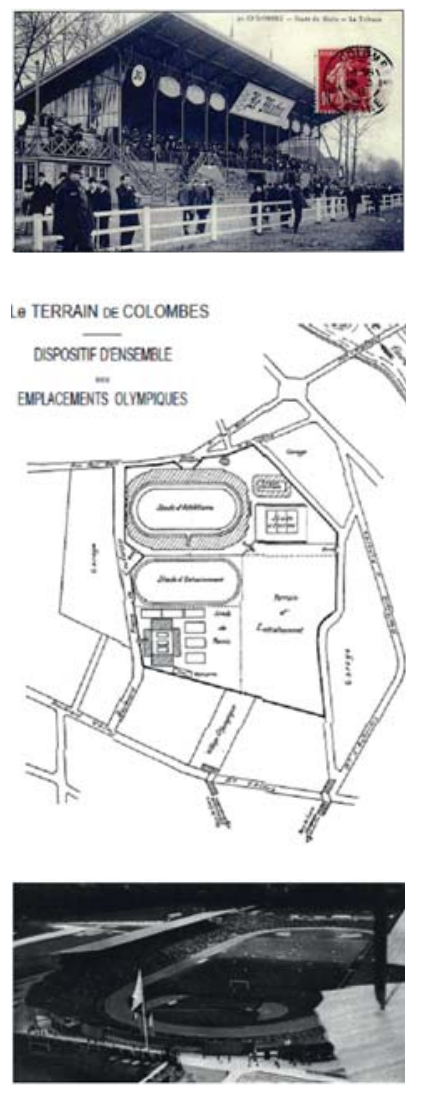

1924. El 1 de enero, el estadio estaba terminado.

1924. El 4 de mayo, inauguración del estadio con un partido de rugby entre Francia y Rumania.

1924. El 5 de julio, ceremonia de apertura de los Juegos de la VIII Olimpiada.

1924. El 27 de julio, clausura de los Juegos.

1924. Desde este año las selecciones francesas de rugby y fútbol juegan sus partidos internacionales en este estadio.

1938. Campeonato de Europa de Atletismo

1938. El 11 de junio, se disputa la final del Mundial de Fútbol, ganando Italia a Hungría 4 goles a 2.

1972. El 18 de junio, combate entre Bouttier y Monzón disputándose el titulo de Campeón del Mundo de Boxeo de los pesos medios, ante 40.000 espectadores.

1972. Dejan de disputarse los encuentros internacionales de rugby y fútbol que se trasladan al Parque de los Príncipes.

1982. Renovación de las instalaciones

1988. La nueva norma que prohíbe espectadores de pie deja sin posibilidad de uso las tribunas de las curvas.

1993. Demolición de la tribuna de Marathon, la del trescientos y de buena parte de las curvas conocidas como Argenteuil y Colombes.

2003. El 1 de enero, el Racing Club de Francia vende la propiedad del estadio a el Consejo General de Hauts-de-Seine.

2009. Construcción de un nuevo graderio, en el espacio vacío, para 5.000 espectadores.

\subsection{Preexistencias en el lugar}

Antigua llanura inundable en la orilla de río Sena, convertida en hipódromo en 1883 por la Société des Courses de Colombes. A partir de 1893, también, la Société du Sport de France organiza sus reuniones hípicas en Colombes. Desde 1903 la Compagnie des Tramways mécaniques des environs de Paris realiza un servicio de transporte especial entre la estación y el hipódromo los días de carreras.

En 1907, el hipódromo es comprado por el periódico parisiense "Le Matin», que lo transforma en estadio para acoger competiciones de atletismo, rugby y fútbol, denominando al nuevo recinto deportivo como "Stade du Matin». Su capacidad era de 20.000 espectadores.

\subsection{Relación con la ciudad. Posición respecto al centro urbano}

Al noreste del centro de Paris y también del centro de Colombes, del que está a 900 metros y a 1.050 de su estación de tren. El río Sena discurre a tan solo 400 metros del estadio. El arco del triunfo esta a $7 \mathrm{Km}$ y el Louvre a 10, Notre Dame y el Ayuntamiento de Paris a 11,2 Km.

\subsection{Breve relato de la historia del Estadio}

Desde el mes de junio de 1921, a la continuación de la carta de Pierre de Coubertin dando a conocer que el Comité Olímpico Internacional había decidido elegir a Paris como sede de la VIII Olimpiada, la administración de la ciudad fue invitada a presentar en el Consejo Municipal sus estudios en lo que concierne la elección del lugar y el gasto que conllevarían los trabajos que había que realizar. Una comisión mixta y dos subcomisiones fueron instituidas para el estudio de proyectos relativos a la organización de los Juegos Olímpicos y el examen de las cuestiones técnicas y financieras. Fue pedido un informe a Frantz Reichel, secretario general del Comité Ejecutivo de los Juegos de la VIII Olimpiada, sobre el programa exacto de los Juegos y sobre los equipamientos necesarios. Entre las diferentes instalaciones descritas por Reichel, las más importantes consistían en la realización de un vasto estadio de 100.000 espectadores, para atletismo, fútbol, rugby, gimnasia y los deportes ecuestres. Además, un estadio náutico, para la natación y el waterpolo, y otro para el tenis $y$, eventualmente, para las competiciones de lucha.

Paris contaba en esos momentos con el estadio de Pershing construido por los estadounidenses en 1919, para los Juegos Interaliados, pero se consideraron insuficientes sus 29.000 espectadores, aunque se estudió la posibilidad de su ampliación e incluso su demolición y reconstrucción. Lo mismo pasaba con los 20.000 del Estadio du Matin. también se estudiaron diferentes emplazamientos para un nuevo estadio en el limite de la ciudad, en su periferia y también en el centro. Louis Bonnier, inspector general de la Dirección de la Extensión de Paris, y Hermant, arquitecto al mando encargaron a Léopold Bévières (1864/1937), arquitecto municipal, realizar una serie de estudios exploratorios. Desarrollo ocho hipótesis de un altísimo interés. Propuestas simples, razonables, pero dotados de una gran fuerza e intensidad. Especialmente destaca el denominado Stade Reichel por su monumentalidad y ligereza a la vez. Presenta todo el graderio cubierto y en el bajograda, además de las dotaciones habituales, pretendía situar habitaciones para 2.000 atletas, que después de 
los Juegos funcionarán como hotel. Exteriormente un volumen rotundo que evoca, a la vez, las construcciones de las antiguas termas, los grandes edificios industriales de la época de difícil encaje con la escala humana e incluso con el coetáneo estadio de la Universidad de Ohio. Los trabajos de Bévières fueron presentados a la Comisión el 15 de octubre de 1921, que los recibió con extraña frialdad, tal vez asustados por la gran escala de propuesta, encargando que se buscarán opciones más económicas basadas en los estadios terraplenados de los Estados Unidos. Solo dos semanas después, el 31 de octubre, Bévières presenta una interesantísima solución terraplenada, en el que se aprecian ciertas semejanzas con el Stade Gerland de Tony Garnier, de 1914 en Lyon y que, también, tiene algo de la arquitectura funeraria de Boullée.

Posteriormente se organiza un ambicioso concurso de arquitectura en el que se designa ganadora la propuesta presentada por Louis Faure-Dujarric.

Por cuestiones financieras el objeto del concurso no fue llevado a termino. En sesión celebrada los días 11 y 12 de marzo de 1922 el Ayuntamiento de París decide que;

desea la celebración de los Juegos Olímpicos, pero la situación financiera obliga a que su organización sea menos costosa.

... su celebración supone un prestigio para la ciudad de París; pero considerando la situación financiera y los recortes que deben ser realizados sobre los gastos sociales, que son los más necesarios, se impone más que nunca una política de prudencia y de economía;

... considerado, en consecuencia, que deben ser afectado el presupuesto de los Juegos Olímpicos reduciéndose su dotación y haciéndolos menos costosos.

Por lo cual decide poner a disposión del Comité Olímpico Francés el Estadio de Pershing en el Bois de Vicennes y sus terrenos aledaños, así como una subvención de 1.000.000 de Francos. Esta postura de desentendimiento por parte del Ayuntamiento de París, pone en crisis la celebración de los Juegos. Hay que recordar, además, que son las ciudades las que organizan los Juegos.

En este punto, se produce el ofrecimiento del Racing Club de Francia, dirigido por antiguos deportistas, entre los que se encontraba el arquitecto L. Faure-Dujarric, ganador del concurso de arquitectura de la Ciudad olímpica. El RCF y el Comité Nacional de Deportes acuerdan, inicialmente, construir en los terrenos en Colombes del RCF:

Una pista de Atletismo de 500 metros de cuerda, con un campo de rugby reglamentario en su interior. Todo rodeado de tribunas y graderíos con capacidad para 60.000 espectadores, 10.000 sentados y a cubierto, 10.000 sentados y descubiertos y 40.000 de pie y descubiertos. Además, de vestuarios para 1.500 deportistas y oficinas.

Un estadio de Natación de dimensiones reglamentarias con gradas fijas para 3.000 espectadores y provisionales para 7.000 .

Estadio de Tenis con graderío provisional para 10.000 espectadores.

Los terrenos de Colombes contaban con 16,5 hectáreas. Lo que se consideró suficiente para el desarrollo de las instalaciones deportivas y la organización del flujo de los espectadores.

Louis Faure-Dujarric es el arquitecto encargado de llevar a cabo el proyecto. Por cuestiones económicas y de calendario, no es posible desarrollar la propuesta ganadora del concurso y se ve obligado a redactar una solución mas ajustada..

Para la construcción del Estadio se aprovecha una pista existente con graderío de madera para 30.000 espectadores, que debía seguir utilizándose durante la construcción de la obra. Entre noviembre de 1922 y marzo de 1923, periodo en el que no se utilizaba la pista, se procedió a su modificación, cambiando el trazado de las curvas y ampliando su anchura.

En el período agosto-octubre 1922 se construyeron las gradas en terraplén sobre el terreno, con excepción de los 150 metros delante de la tribuna de honor del estadio du Matin; esta antigua tribuna que se mantuvo hasta la finalización de la nueva de Marathon en junio de 1923, en ese momento la tribuna de Maratón se convirtió en la tribuna de honor provisional, procediéndose entonces a la demolición de la antigua tribuna principal y la construcción de la nueva, que se terminó a finales de noviembre de 1923. El 1 de enero 1924 se dan por concluidas las obras.

\subsection{Descripción del Estadio; Graderío}

Capacidad 45.000 espectadores. Graderíos construidos con dos sistemas distintos, las gradas bajas de hormigón armado, apoyadas en el terreno y sobre relleno de tierras en terraplén y las gradas altas con estructura aérea de hormigón armado.

En las dos curvas destinadas a publico de pie, prácticamente la totalidad del graderio es del primer tipo, con una pendiente de $1 / 3$ y con gradas de $11 \mathrm{~cm}$ de alto y $33 \mathrm{~cm}$ de fondo. Solo en su parte alta en el encuentro con las dos tribunas tiene 4 sectores de graderío aéreo, cada uno con diez gradas de $24 \times 66 \mathrm{~cm}$ para publico sentado.

En las dos rectas se desarrollan las tribunas, ambas con una longitud de 144 metros y una anchura de 26,73 m. Aproximadamente el tercio inferior construidas en terraplén y la superior
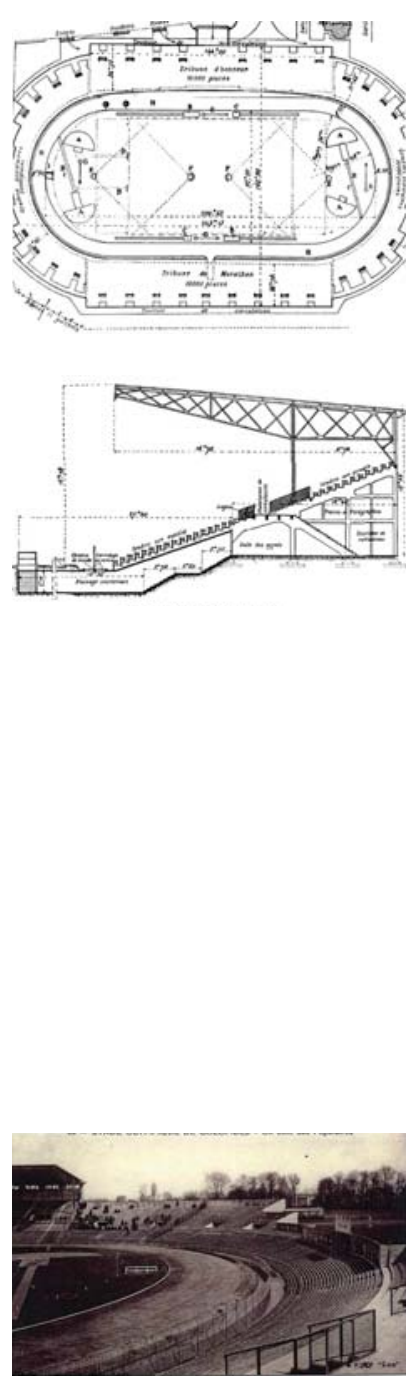


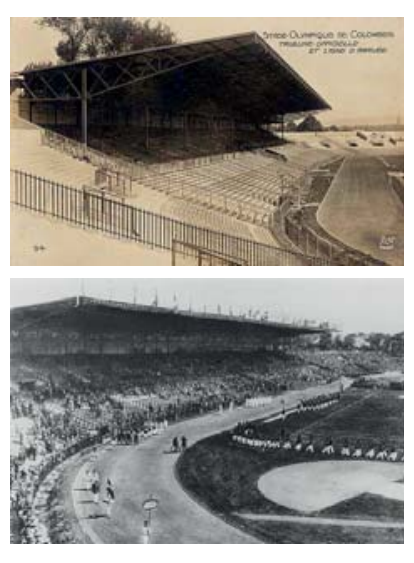

dimensiones y superficies aproximadas graderío

\begin{tabular}{|c|c|}
\hline L01-01' & $103,35 \mathrm{M}$ \\
\hline L 02-02' & $122,81 \mathrm{M}$ \\
\hline R 01-Al & $57,54 \mathrm{M}$ \\
\hline R 02-A3 & $46,78 \mathrm{M}$ \\
\hline R 03-A4 & $48,84 \mathrm{M}$ \\
\hline R 04-A3 & $620,41 \mathrm{M}$ \\
\hline$<$ Al.01.A2 & $42^{\circ}$ \\
\hline$<$ A3.02.Al & $59^{\circ}$ \\
\hline$<A 3.02 . A 1$ & $73^{\circ}$ \\
\hline$<$ A3.04.A3' & $12^{\circ}$ \\
\hline
\end{tabular}

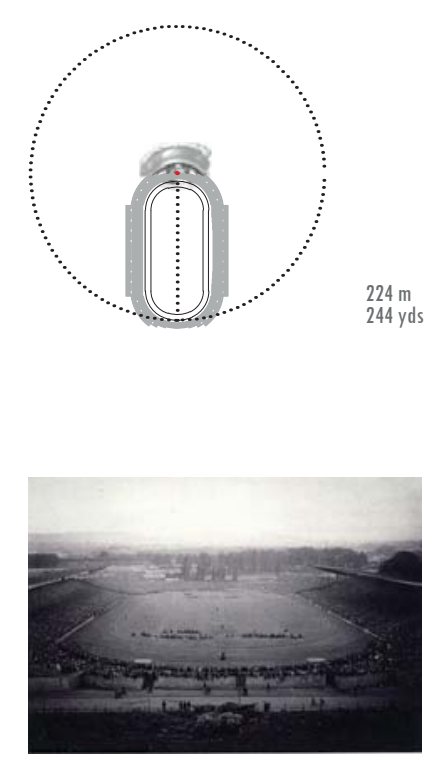

en entramado aéreo de hormigón

La tribuna de la recta de llegadas se denomina de Honor y la opuesta de Marathon (por su eje se produce la entrada de los corredores de la marathon a la pista). Cuentan con 42 filas de gradas de $66 \mathrm{~cm}$ de profundidad y alturas de 22 en la parte inferior, coincidiendo con su estructura apoyada en el terraplén, $24 \mathrm{~cm}$ en la parte media y $26 \mathrm{~cm}$ en las diez filas superiores.

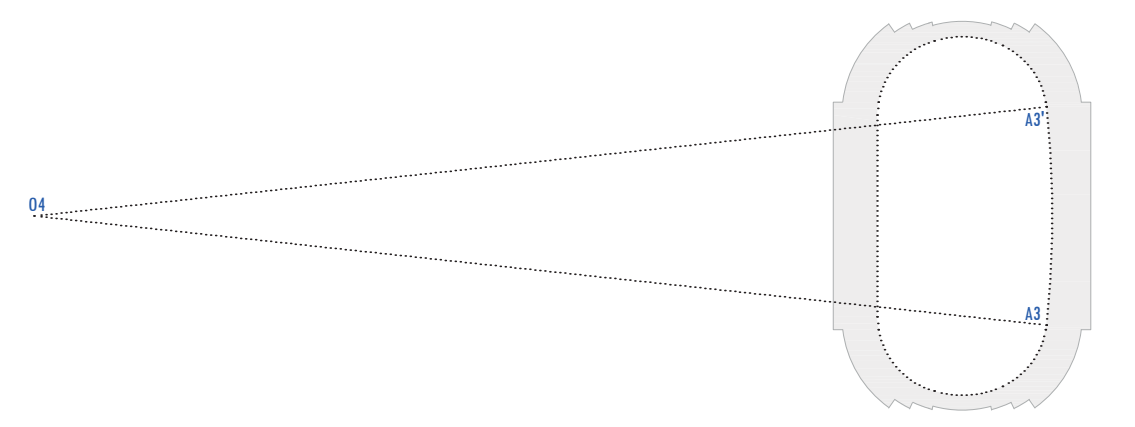

superficie de cubierta: $7.163 \mathrm{~m} 2$
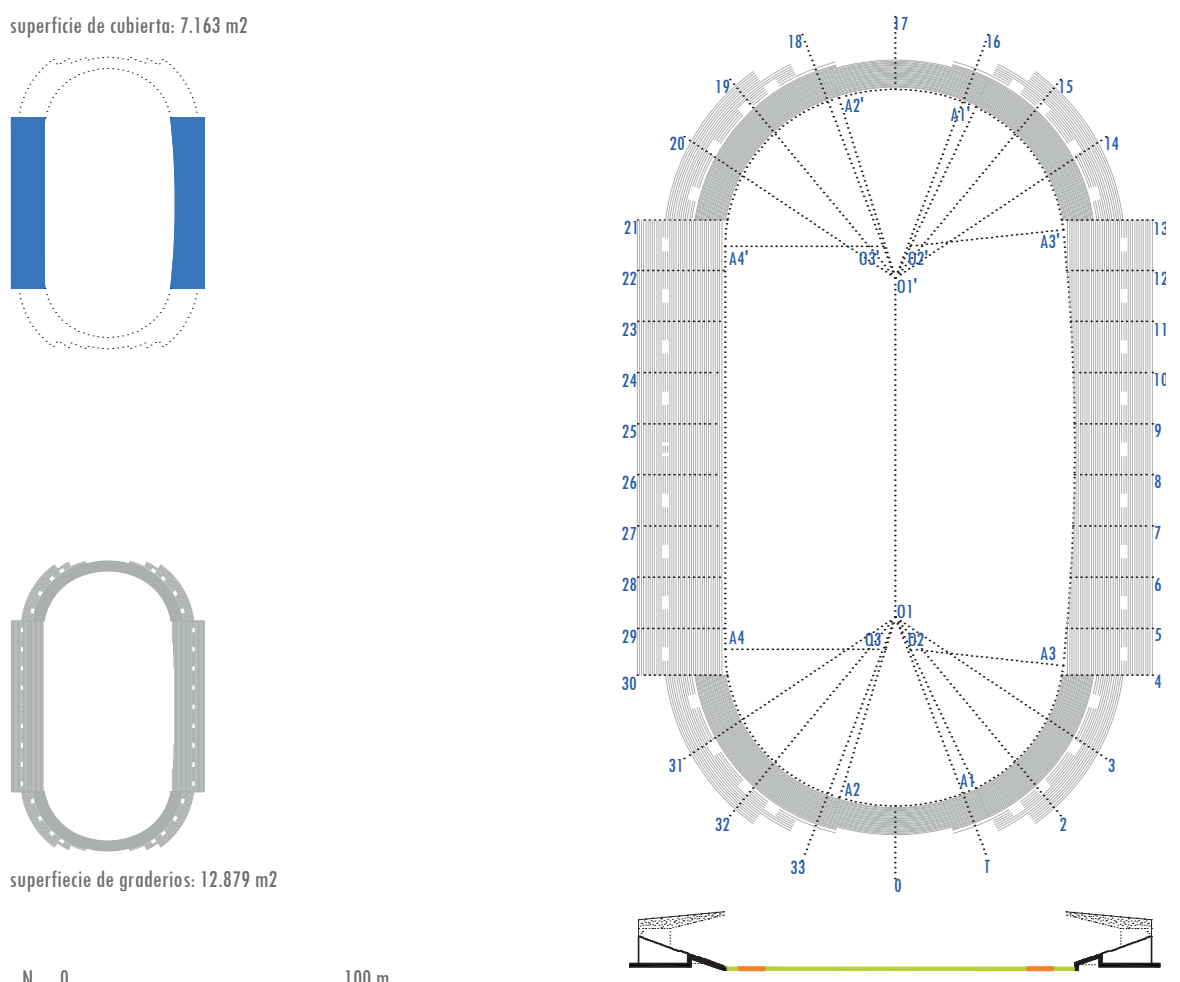

superfiecie de graderios: $12.879 \mathrm{~m} 2$

público accede a las gradas por los vomitorios servidos por escaleras. Ocho en cada uno de las tribunas rectas y cuatro en cada una de las curvas. Es decir treinta y dos vomitorios, con una capacidad de evacuación media de 2.000 espectadores aproximadamente. Con el estadio lleno, se vacía completamente en menos de un cuarto de hora.

Los vomitorios desembarcan en la parte media del graderío, estando enlazados por un corredor de distribución, que permite a los espectadores llegar a sus plazas mediante peldañeados transversales cada 5 metros. Los asientos son de madera corridos, con patas metálicas embutidas en el hormigón. Cada 16 metros, barreras transversales delimitan las gradas en tantos sectores como el numero de vomitorios, 32.

Justo al lado del corredor de distribución, por su parte inferior, se sitúan una fila de palcos con capacidad de 5 personas, ocupando dos filas de gradas.

La grada más alta esta a 9 metros de altura sobre la pista

Cubierta de la tribuna. - Ambas tribunas están cubiertas en toda su longitud por un techo ondulado, con el apoyo de una estructura de metal. La mayor preocupación en el diseño de esta estructura era reducir al mínimo el número de puntos de apoyo ( 10 unidades cada 16 m. Longitud total de la cubierta $144 \mathrm{~m}$.) y darles la sección más pequeña posible, a fin de no dificultar la visibilidad.

Cerchas trianguladas metálicas muy ligeras con voladizo de 17,78 metros y distancia entre 
apoyos de 9,74 metros.

\subsection{Descripción del Estadio; Pista}

Dimensiones: Cuerda de la pista de 500 metros y seis calles de 8,50 metros de ancho y curvas trazadas con tres centros. Espacio libre interior en el que se puede marcar un campo de rugby de 140 x 70 o de fútbol de $103 \mathrm{~m} . \times 73,20 \mathrm{~m}$.

La pista y la grada están separadas por un foso, de muy poca profundidad y una valla metálica, que imposibilita la invasión del espacio de competición por el público

Material: Pista de Atletismo, clinker recocido machacado y cribado. En diferentes capas y granulometrías, cama de drenaje de escoria de tamaño grande, espesor $40 \mathrm{~cm}$., una primera capa de $20 \mathrm{~cm}$ con áridos de tamaño mediano, capa intermedia de $12 \mathrm{~cm}$ de polvo de clinker y ultima capa de acabado de $6 \mathrm{~cm}$ formada por una mezcla de polvos muy finos de clinker, hollín y arcilla.

Campo de juego, pradera de césped, con tubería enterrada para el riego y mantenimiento.
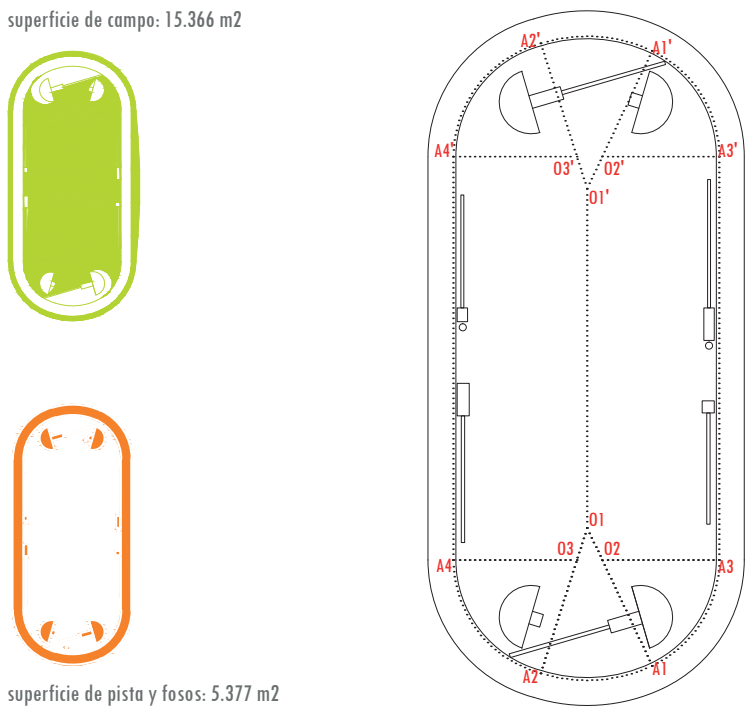

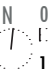

1924. PAR dimensiones $y$ superficies aproximadas pista

\begin{tabular}{|c|c|c|}
\hline CUERDA & $500,00 \mathrm{M}$ & 546 yds \\
\hline L01-01' & $103,36 \mathrm{M}$ & \\
\hline R 0I-Al & $45,94 \mathrm{M}$ & \\
\hline R 02-A3 & $35,18 \mathrm{M}$ & \\
\hline R 03-A4 & $37,14 \mathrm{M}$ & \\
\hline$<$ A1.01.A2 & $43^{\circ}$ & \\
\hline$<\mathrm{A} 3.02 . \mathrm{Al}$ & $65^{\circ}$ & \\
\hline$<$ A2.03.A4 & $72^{\circ}$ & \\
\hline
\end{tabular}

marca del ganador Hombres

$10 " 6$

$21 " 6$

$47 " 6$

$1,52 " 4$

$3,53 " 6$

14,31"2

$30,23 " 2$

$15 " 0$

$52 " 6$

9,33"6

$1,98 \mathrm{~m}$

$3,95 \mathrm{~m}$

$7,445 \mathrm{~m}$

$15,525 \mathrm{~m}$

$14,995 \mathrm{~m}$

$46,155 \mathrm{~m}$

$53,295 \mathrm{~m}$

$62,96 \mathrm{~m}$

$41 " 0$

$\begin{array}{ll}4 \times 400 & 3,16 " 0 \\ 3000 \times \text { Equipos } & 8 \text { ptos }\end{array}$

$\begin{array}{ll}4 \times 400 & 3,16 " 0 \\ 3000 \times \text { Equipos } & 8 \text { ptos }\end{array}$

10000 m marcha $47,49 "$

Pentathlon 14 ptos

Decathl. $\quad 7740,775$ ptos

Marathón 2h.41,22"

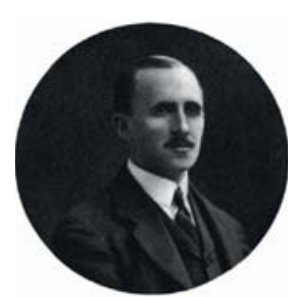
Argentina los primeros años del siglo XX, donde realizó el hipódromo de Palermo, Buenos Aires, además de diversas obras como el Oratorio Inmaculada Concepción en Mar del Plata, monumento histórico Nacional Argentino. En París realizó edificios de viviendas, los grandes almacenes Trois Quartiers, en el Boulevard de la Madeleine (magnifico edificio de lenguaje moderno) y la pista central en Roland Garros en 1928. Fue capitán del equipo de rugby del Racing Club de Francia en los años 90 del siglo XIX además participaba habitualmente en carreras de atletismo. Fue vicepresidente del RCF

Tipo de encargo. Concurso de Arquitectura para la Ciudad Olímpica.

Concurso por invitación a arquitectos con experiencia previa en estadios deportivos.

Las bases fueron redactadas por; los Servicios de Arquitectura de la Ciudad de París y por el Secretario General del Comité Olímpico Francés, M. Frantz- Reichel. En las que se detallaban las necesidades de la Ciudad Olímpica, que debía de constar de :

- Estadio de Atletismo, para 100.000 espectadores, con 2.000 habitaciones para atletas 

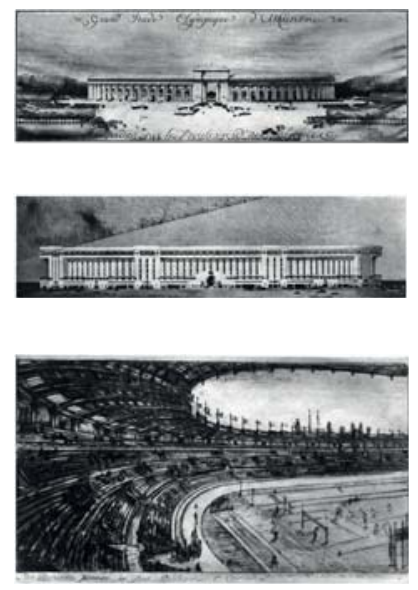

Arriba, vista exterior del gran estadio del proyecto ganador de Faure-Dujarric En medio, fachada del estadio (longitud de $300 \mathrm{~m}$ ) Brandon, Bard y G. De Saint.Cyr Abajo, interior del estadio de Tronchet debajo del graderío.

- Estadio de Tenis, para 15.000 espectadores

- Estadio Náutico, para 15.000 espectadores

- Arena para deportes de combate (boxeo, esgrima, lucha, levantamiento de pesas) para 5.000 espectadores

- Frontón de Pelota Vasca, deporte de demostración.

Fueron invitados once arquitectos o equipos de arquitectos::

Faure-Dujarric; Brandon, Bard y Guillaume de Saint-Cyr; Tronchet; Loysel, Redon y Sue; Hébrard y Dumail; Marozeau: Blum y Brochon; Hesse; Humphreys; Ferrier; Boileau.

El jurado valoró notablemente los proyectos por la novedad de sus diseños y por la inclusión de nuevos dispositivos técnicos, que ayudarían a mejorar la organización y el disfrute de los espectadores..

Sus proyectos fueron expuestos públicamente, primero en los locales del Grand Palais, luego en una de las salas de la Escuela Bellas Artes.

En el jurado participaban los arquitectos: RI. Plumet, designado por M. Paul-León, Director de las Bellas Artes; M. Ménager, Profesor en la Escuela Politécnica de Construcción metálica y hormigón armado. $Y$ las Federaciones Deportivas fueron consultadas para dar su opinión técnica.

Fue elevado un informe de valoración de los proyectos al Comité Ejecutivo que emitió el fallo el 3 de febrero de 1922.

Estableciéndose la siguiente clasificación, asignándose los premios establecidos en las bases del concurso:

$1^{\circ}$ L. Faure-Dujarric Fr. 10.000

$2^{\circ}$ Brandon, Bard et G. de Saint-Cyr 10.000

$3^{\circ}$ Tronchet $\quad 5.000$

$4^{\circ}$ Loysel, Redon et Sue $\quad 5.000$

$5^{\circ}$ Hébrard et Dumail $\quad 5.000$

$6^{\circ}$ Marozeau $\quad 5.000$

$7^{\circ}$ Blum et Brochon $\quad 5.000$

$8^{\circ}$ Hesse $\quad 5.000$

\subsection{Edificios coetáneos}

El concurso de la Ciudad olímpica de Paris, es casi coetáneo con el concurso que se celebró en la otra orilla del atlántico para la nueva sede del diario Chicago Tribune. Que fue, quizás, el primer concurso en el que ensayan las nuevas ideas de arquitectura que empezaban a emergen en aquellos años. Varios maestros del Movimiento Moderno, como Gropius y Meyer, Bruno y Max Taut, Hugo Häring y Eliel Saarinen que obtuvo el segundo premio con un proyecto de corte neoyorquino, que bien lo podría haber sido dibujado Hugh Ferries. El primer premio fue para Raymond Hood y John Mead Howells con un rascacielos de reminiscencias neogóticas. Hay que recordar que la Bauhaus fue fundada en 1919 y que en 1922 Le Corbusier esta preparando su proyecto par el pabellón de "L'Esprit nouveaul" que se inauguraría en julio de 1925 en la Exposición de las Artes Decorativas, Industriales y Modernas de París.

\subsection{Hechos históricos relevantes}

El 6 de marzo, y con gran expectación en el Valle de los Reyes, el gobierno egipcio permite la apertura del sarcófago de la momia del faraón Tutankhamon, que gobernó Egipto en el siglo XIV antes de Cristo, cuya tumba llena de bellos tesoros fue descubierta en noviembre de 1922, por el arqueólogo británico Howard Carter.

Se constituye en Madrid la Compañía Telefónica Nacional de España (CTNE), actual Telefónica. En esta año se publica; La montaña mágica de Thomas Mann, Veinte poemas de amor y una canción desesperada de Pablo Neruda y el Manifiesto del surrealismo por André Breton. izquierda a derecha los proyectos de Gropius y Meyer, Saarinen y el del ganador.
Bibliografía París 1924:•

PIZZORNI ITIÉ, Florence. (1993). Les Yeux du Stade. Colombes, temple du Sport. Ed. L'Albaron. ISBN 2908528452

FAURE-DUJARRIC (Louis), Architecte. L'œuvre. Préface de Jacques Lacretelle. S.I., l'Auteur, 1933, in-folio. 60 planches

Les Jeux De La VIII Olympiade. Paris 1924. Rapport Officiel. Ed. Comité Olympique Français

WIMMER, Martin. (1976). Olympic Buildings. Ed. Leipzig. Lic 600/34/75. 5938721

GORDON, Barclay F. (1983). Olympic Architecture. Building for the summer games. John Wiley \& Sons. Nueva York. ISBN 0-471-06069-0 
1928. AMSTERDAM

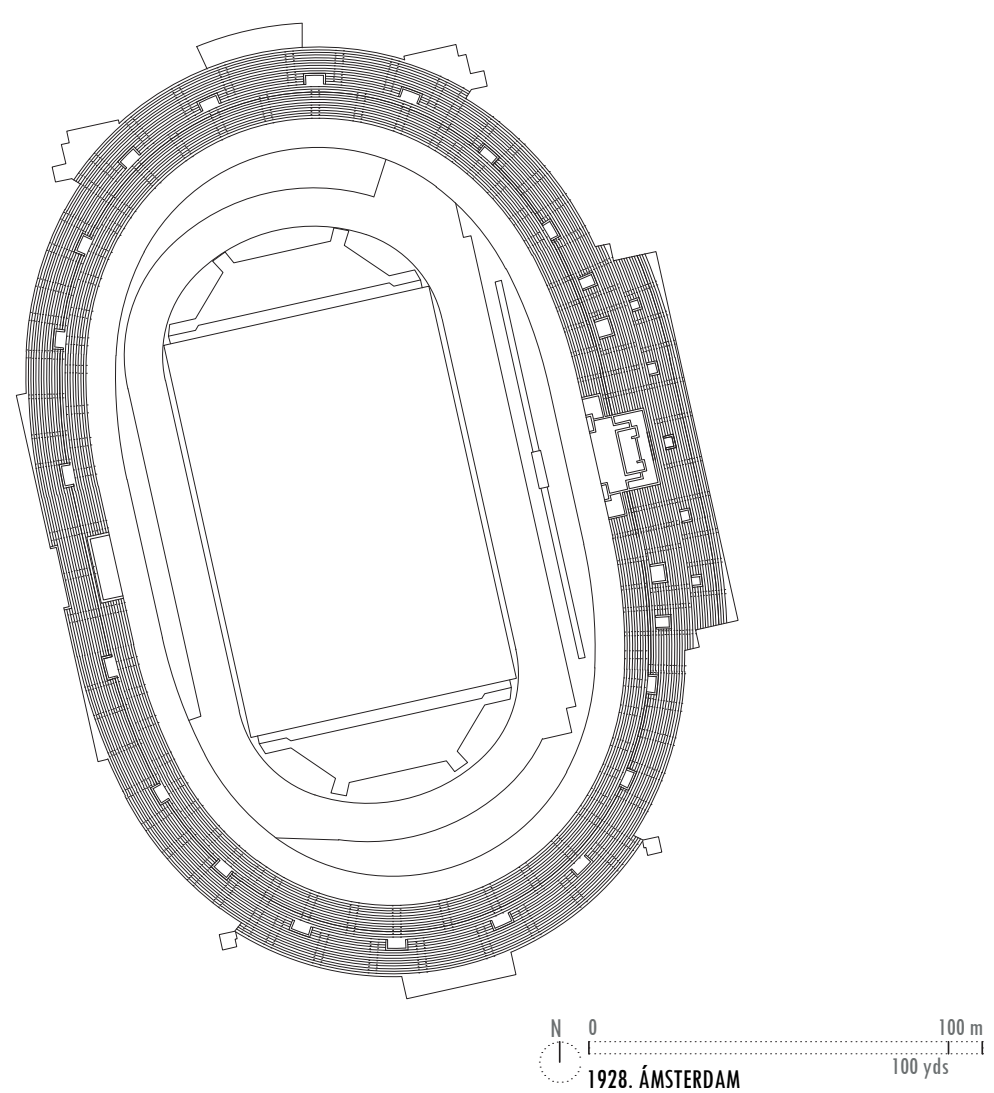

1928.0. Nombre del Estadio

Olympisch Stadion Amsterdam.

\subsection{Situación}

Olympisch Stadion 21, 1076 DE Amsterdam, Holanda

\subsection{Fechas}

1912. Rechazada su candidatura a los Juegos de la $\vee$ Olimpiada, presentada a titulo personal por el Barón van Tuyll miembro del Comité Olímpico Internacional.

1920. Había presentado candidatura, esta vez el Comité Olímpico Holandés, siéndole concedidos los Juegos a Amberes.

1921. El 2 de abril, Amsterdam, a petición del Barón de Coubertin, retira su candidatura para los Juegos de 1924 a cambio de su apoyo para la candidatura de 1928.

1921. El 2 de junio, el CIO expresa su voluntad de conceder los Juegos de la IX Olimpiada a Amsterdam.

1921. El 10 de octubre, se constituye el Provisional Comite Organizador, presidido por el Barón van Tuyll.

1922. En junio se presenta al Comité Olímpico Internacional, esquema de las instalaciones previstas, aprovechando el Estadio Nacional de 1914 del arquitecto Harry Elte, que es rechazado por sus disfuncionalidades. Entonces se baraja la posibilidad de levantar un nuevo estadio de madera detrás del existente. Requiriéndose una serie de bocetos que fueron presentados a finales de 1920.

1923 El 9 de abril, el ClO confirma definitivamente a Amsterdam como sede de los Juegos de la IX Olimpiada

1923. En diciembre el Comité Organizador hace público un borrador con las normas que han de regir la organización de los Juegos.

1924. Muere el Barón van Tuyll, sustituyendole como presidente del Comité Organizador el Baron Schimmelpenninck van der Oye.

1925. Mayo, para el Congreso Olímpico de Praga, se había pedido a Jan Wils que presentará bocetos con posibles opciones y costes. Aunque el proyecto presentado tuvo una muy favorable acogida, se mostro insuficiente el espacio exterior circundante para el manejo de flujo de las masas y el estacionamiento de coche y bicicletas. En vista a esto, el Ayuntamiento decidió poner a disposición del comité organizador
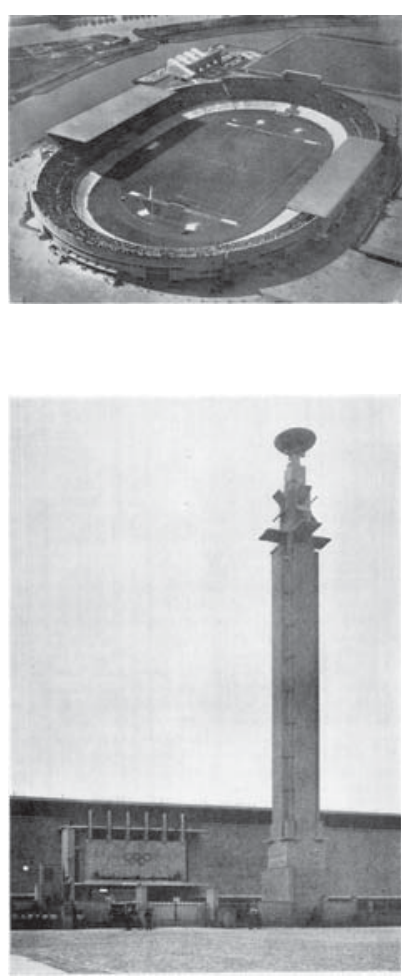

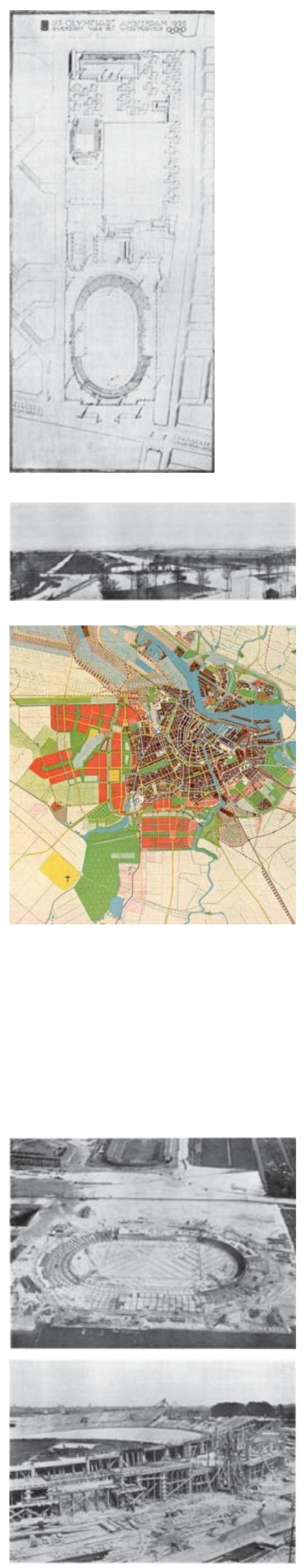

más terreno. La segunda propuesta de Wils supone toda una actuación urbanística, adecuando los flujos y los espacios públicos alrededor del estadio, atendiendo a peatones, tranvías, bicis, coches y barcos. Y también una organización integral de todas las dependencias e instalaciones para todos los deportes y servicios.

1927. El 18 de mayo, se coloca la primera piedra

1928. El 17 de mayo, se estrena el estadio y se inician los Juegos con la competición de Hockey.

1928. El 28 de julio, se celebra la ceremonia de inauguración de los Juegos

1928. El 12 de agosto, ceremonia de clausura.

1937. Se añade un segundo graderio de hormigón que supone un aumento de la capacidad del estadio hasta los 64.000 espectadores.

1987. Declarado Monumento Nacional.

1996. El Ayax AC se traslada al Amsterdam Arena, y se inicia una profunda remodelación que busca recuperar el espíritu original del estadio, despojándolo de todos sus añadidos posteriores.

2000. Se reinaugura el estadio destinándose fundamentalmente para el atletismo.

\subsection{Preexistencias en el lugar}

Estadio Nacional que llevaba en funcionamiento desde 1914. Fue proyectado por Harry Elte, después de un concurso en 1912 en el cual su propuesta con el lema Barnardes resulto ganadora sobre las 24 presentadas. El jurado estaba presidido por Berlage. Se dió la incomoda circunstancia que Elte trabajó para el maestro holandés entre 1899 y 1909 . Para los Juegos, se descartó su uso porque, siendo un estadio principalmente destinado al futbol, el espacio central encerrado por el graderío era demasiado pequeño para poder albergar la pista de atletismo y velódromo. Para haberlo conseguido hubiera sido necesaria la reducción del aforo desde los 29.000 a los 17.000 , lo que se consideró insuficiente. Convivió con el Estadio Olímpico, al cual complementó y fue derribado un año después de los Juegos. El estadio estaba explotado en régimen de concesión por la StadiumCompanyLtd, que posteriormente se hizo cargo de la gestión del Estadio Olímpico. Para la construcción del nuevo estadio fue necesaria la utilización de los terrenos pantanosos situados al sur del estadio antiguo que fueron cedidos por Ayuntamiento

\subsection{Relación con la ciudad. Posición respecto al centro urbano}

Al sur de la ciudad, en el limite suroeste del Plan Zuid de Berlage de 1914, extensión de la ciudad que se destaca por su excelente arquitectura y espacios urbanos en el que destaca el uso del ladrillo. A 4.100 metros del centro urbano, a 5 km de la Estación Central y del Puerto. En la proximidad de una línea de tranvía que conecta con el centro urbano y de un canal navegable, enlazado con la red de canales de la ciudad.

\subsection{Breve relato de la historia del Estadio}

Para el Congreso Olímpico de Praga en 1925, se había pedido a Jan Wils que presentará bocetos con posibles opciones y costes. Aunque el proyecto presentado tuvo una muy favorable acogida, se mostro insuficiente el espacio exterior circundante para el manejo de flujo de las masas y el estacionamiento de coche y bicicletas. En vista a esto, el Ayuntamiento decidió poner a disposición del comité organizador más terreno. La segunda propuesta de Wils supone toda una actuación urbanística, adecuando los flujos y los espacios públicos alrededor del estadio, atendiendo a peatones, tranvías, bicis, coches y barcos. Y también una organización integral de todas las dependencias e instalaciones para todos los deportes y servicios.

Finalmente fue redactada una tercera versión definitiva del proyecto, que desarrollaba lo recogido por la segunda.

El estadio se edificó en un terreno pantanoso, que hubo que mejorar y elevar con $750.000 \mathrm{~m} 3$ de arena provenientes del dragado del puerto.

Después de los Juegos el estadio ha tenido un uso importante e intenso. Ha sido el campo del Ayax hasta 1996. La selección de fútbol holandesa ha disputado 77 partidos. Se celebró la final de la copa de Europa en 1962 en la que el Real Madrid perdió ante el Benfica de Eusebio por 5 goles a 3 .

\subsection{Descripción del Estadio; Graderío}

Por primera vez los criterios de la modernidad están en el trasfondo del diseño del estadio. Lenguaje moderno, parco en elementos decorativos, adecuación a la función y ciertos guiños expresionistas. Según Martin Wimmer, en su libro publicado en 1976 Olympic Buildings, el estadio esta considerado como una verdadera pieza maestra de la arquitectura. 
La fachada de ladrillo en su composición, horizontalidad y elementos decorativos refleja la cierta influencia de Frank Lloyd Wright, pero también de Berlage y de Dudok.

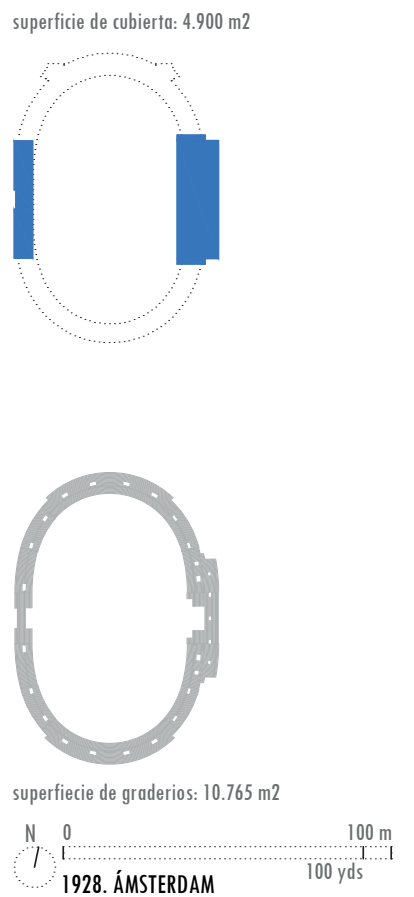

Tras la cuidada fachada aparece un estadio completamente funcional. El terreno de juego circundado por la pista de atletismo y en el exterior un velódromo de $500 \mathrm{~m}$. Las gradas se adaptan a la forma del velódromo hasta completar un aforo de 40.000 espectadores. Las piezas utilizadas para asientos eran desmontables por lo cual se podía ajustar la capacidad de espectadores sentados y de pie, según la necesidad desde los 21.537 sentados y 12.618 de pie a los 16.197 sentados y 25.236 de pie.

En los laterales gradas cubiertas de 60 metros de largo, en el oeste la grada principal, en el este la llamada grada de Marathon con la puerta de acceso para la mitica carrera de gran fondo. Las cubiertas, en fuerte voladizo, están armónicamente integradas en la composición general.

La clara horizontalidad de la composición sólo se ve alterada por el hito vertical de la Torre Marathon. En lo mas alto de la misma a 42 metros de altura se sitúa el pebetero con la llama olímpica. Es el elemento de carácter mas expresionista del conjunto.

La estructura del graderio es de hormigón armado. El velódromo era totalmente independiente de las gradas. Las cubiertas son estructuras trianguladas de acero con un potente voladizo, quedando los soportes de la grada principal a 10,56 metros del cerramiento y una luz libre en ménsula de 17,60 metros y en la grada de Marathon a 6,30 y 11,31 metros respectivamente. Los soportes están a intervalos de 19 metros. superficie de campo: $12.570 \mathrm{~m} 2$
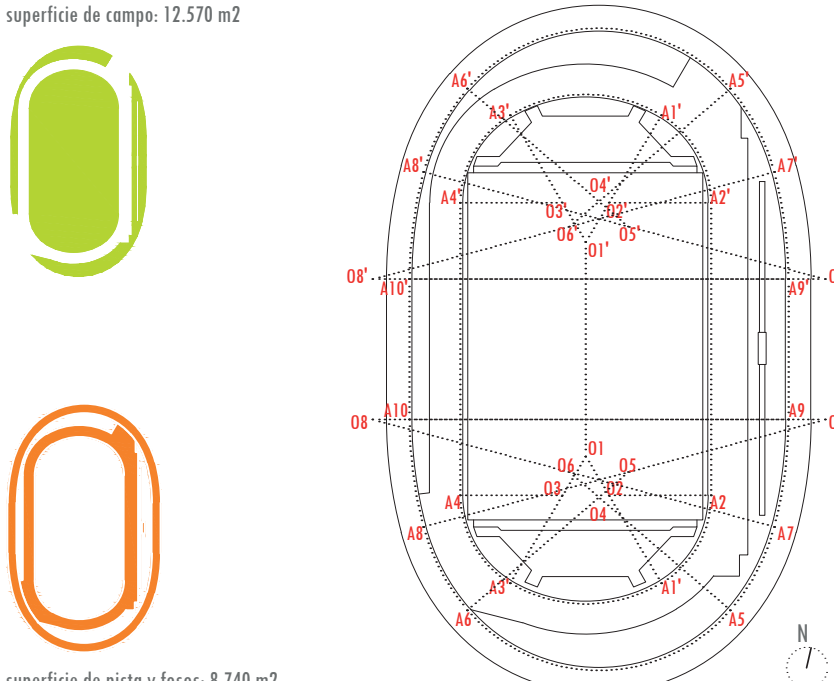

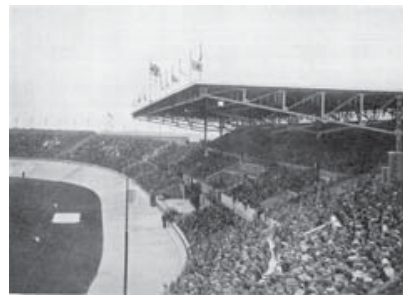

dimensiones y superficies aproximadas graderío

L $01-01 \quad 86,92 \mathrm{M}$

L 02-02' 72,09 M

L 04-04' 21,11 M

R 01-Al $58,21 \mathrm{M}$

R 02-A3 $\quad 69,60 \mathrm{M}$

R 04-A5 129,29 M

L A5-A6 $\quad 125,96 \mathrm{M}$

$<$ Al.01.A2 $99^{\circ}$

$<$ A3.02.Al $26^{\circ}$

$<$ A5.04.A3 $15^{\circ}$

$<03.01 .02 \quad 99^{\circ}$

marca del ganador
Mujeres

$100 \mathrm{~m}$

$100 \mathrm{~m}$.

$400 \mathrm{~m}$.

$800 \mathrm{~m}$.

$1500 \mathrm{~m}$.

$5000 \mathrm{~m}$.

$10000 \mathrm{~m}$

$110 \mathrm{mv}$

$400 \mathrm{mv}$

3000 obst

Altura

Pértiga

Longitud

Triple

Peso

Disco

Martillo

Jabalina

$4 \times 100$

$4 \times 400$

3000 por Equipos

$3000 \mathrm{~m}$. marcha

$10000 \mathrm{~m}$. marcho

Decathlón

Marathón

8053 ptos

2h. $32,357 " 0$

Hombres

$12 " 2$

$21 " 8$

$47 " 8$

$1,51 " 8$

3,53 "2

14,38 "0

$30,18 " 8$

$14 " 8$

$53 " 4$

$9,21 " 8$

$1.94 \mathrm{~m}$

$4.20 \mathrm{~m}$

$7.73 \mathrm{~m}$

$15.21 \mathrm{~m}$

$15.87 \mathrm{~m}$

$47.32 \mathrm{~m}$

$51.39 \mathrm{~m}$

$66.60 \mathrm{~m}$

$41 " 0$

$3,14 " 2$

dimensiones y superficies aproximadas pista

$\begin{array}{lrl}\text { CUERDA } & 400,00 \mathrm{M} & 437 \text { yds I' } 4 \frac{11}{32} \\ \text { CUERDA } & 511,72 \mathrm{M} & 559 \text { yds I' } 10 \frac{29}{64} \\ \text { L 01-01' } & 65,41 \mathrm{M} \\ \text { L 02-02' } & 89,14 \mathrm{M} \\ \text { L 04-04' } & 90,15 \mathrm{M} \\ \text { L 05-05' } & 74,59 \mathrm{M} \\ \text { L 07-07' } & 42,76 \mathrm{M} \\ \text { R 01-A1 } & 44,37 \mathrm{M} \\ \text { R 02-A2 } & 30,55 \mathrm{M} \\ \text { R 04-A5 } & 52,20 \mathrm{M} \\ \text { R 05-A6 } & 64,01 \mathrm{M} \\ \text { R 07-A8 } & 126,07 \mathrm{M} \\ \text { < A1.01.A3 } & 62^{\circ} \\ \text { < A2.02.A1 } & 59^{\circ} \\ \text { < A5.04.A6 } & 99^{\circ} \\ \text { < A5.06.A7 } & 26^{\circ} \\ \text { < A7.08.A9 } & 15^{\circ}\end{array}$




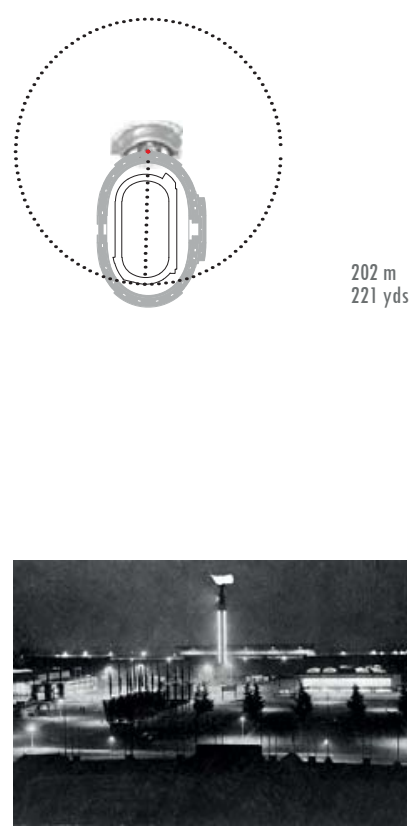

1928.7. Descripción del Estadio; Pista

Dimensiones: Cuerda de la pista de 400 metros y seis calles de 8 metros de ancho total. Velodromo de 500 metros y un ancho de 9 metros más un metro de respeto. Espacio libre para campo de juego interior de $120 \times 80$ yardas $(109,73 \times 73,15$ metros)

Material: Pista de Atletismo, de ceniza. Con el fin de evitar blandones se construyó una subbase muy pesada a base de bloques de piedra sobre la que se extendió tres capas de cenizas. La capa superficial con una profundidad de aproximadamente $7 \mathrm{~cm}$, consistía en una mezcla de cenizas y polvo de ladrillo.

Pradera, césped. Sub-base de $40 \mathrm{~cm}$ de turba y acabado con tepes de césped.

Velódromo, Hormigón, con curvas peraltadas, espacio de respeto y vallas de protección entre pista y espectadores.

Programa Deportivo: Atletismo, Equitación, Fútbol, Rugby, Gimnasia, Hockey hierba, Pentahlón Moderno, Halterofilia, Tirasoga y las Ceremonias de Apertura y Clausura

\subsection{Elementos significantes}

Puerta de Marathon, en el eje del estadio en el lado opuesto de la grada principal. La torre de Marathon, indicando donde está la entrada de la agónica carrera, con cuatro balcones para trompetistas que anunciarían la aproximación de los corredores, altavoces para comunicar los resultados y coronando un pebetero que durante el día una columna de humo y por la noche el resplandor del fuego, harían visible donde se estaban celebrando los Juegos desde la distancia. Es la primera vez que se utiliza el fuego olímpico como elemento significativo en la composición del estadio.

1928.9. Avances técnicos

En el Official Report, por primera vez, aparece justificada la orientación del estadio, prácticamente norte-sur, en función de su insolación y de la protección de los vientos dominantes (pág. 181). También se pone como condición que la totalidad del aforo del estadio pueda evacuar en menos de 10-12 minutos (pág. 185).

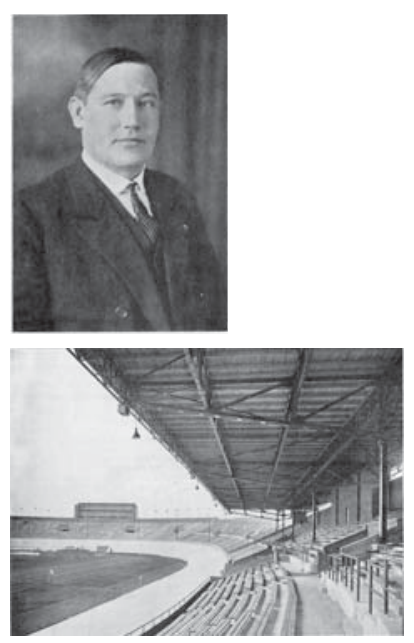

1928.10. Autores. Tipo de encargo

Jan Wils (1891 / 1972) fue una figura relevante de la arquitectura moderna de los Países Bajos del período de entreguerras. Nacido en Alkmaar donde inició sus estudios, para acabarlos en el Politécnico de Delft. De 1914 a 1916 trabajó en la oficina de Hendrik Petrus Berlage en La Haya, donde conoció la obra de Frank Lloyd Wright que le dejó profundamente marcado. En 1917 se hizo miembro, junto con Jacobus Oud, del grupo "De Sphinx", que había fundado Theo Van Doesburg. Jan Wils colaboró con Doesburg en numerosos proyectos, viviendas en Alkmaar (1917) y St. Antoniuspolder (1918), y el hotel-restaurante De Dubbele Sleutel (1918). En 1917 llegó a ser uno de los miembros fundadores de De Stijl y desde este mismo año tuvo su propia oficina en Voorburg. Al año siguiente firmó el primer manifiesto Stijl junto a Van Doesburg, Robert van 't Hoff, Vilmos Huzar, Antony Kok, Piet Mondriaan y Georges Vantongerloo, pero se separó de este grupo en el año 1919. Desde entonces hasta 1921, colaboró con Vilmos Huszár y Piet Zwart, quien trabajaba entonces en su oficina, y realizó importantes proyectos en los que fue notable la influencia de Stijl, por ejemplo, el diseño de una fábrica Bruynzzel en Zaandam (1920), la construcción de una escuela de baile en La Haya (1921), así como el diseño de una residencia para mujeres solteras en La Haya. En 1920 le fue encomendado el diseño del complejo habitacional Daal en Berg, Papaverhof, donde incorpora a su arquitectura imbuida en la influencia de la escuela de Berlage y por la obra de Frank Lloyd Wright, conceptos del incipiente movimiento neoplasticista. A partir de este trabajo, Wils es valorado como uno de los arquitectos más importantes de la nueva escuela Holandesa.

Otras obras de Wils son; El Ayuntamiento de La Haya (1926), la Escuela Superior de Educación Física de Ámsterdam (1929), el Garage Citroen en Ámsterdam (1931) y el establecimiento de la OLVEH en La Haya (1932).

Kreisgsman se encargó del tratamiento final de la pista de atletismo después de que suscitarán dudas sobre el resultado de lo inicialmente prescrito por Wils

Para la pradera Wils buscó el asesoramiento de Koning, responsable de los jardines municipales.

La construcción se realizó por paquetes de obra, siendo Kruithof \& Scholten la adjudicataria de todos menos uno, el que correspondía a graderío y cubierta que fue realizado por G.B. Sanders \& Son.

Tipo de encargo. Le fue encargado directamente a Jan Wils fue después de pasar la prueba favorable por la calidad de sus dos primeras propuestas. Esta decisión perteneció al comité organizador conjuntamente con el Ayuntamiento de Ámsterdam y de la sociedad gestora del estadio. Pero ipor qué se recurrió a Wils para los estudios preliminares?, podemos encontrar 
para esta decisión cuatro motivos fundamentalmente. Primero, en el Report Official lo justifican por su conocimiento en la materia, a la vista del libro publicado por Wils en colaboración con P. W. Scharroo titulado "Buildings and Grounds for gymnastics, games and sports". Segundo, durante los Juegos de París, varios meses antes de su designación, había conocido a varios miembros del Comité Olímpico holandés pues fue miembro del jurado en el Concurso Olímpico de Arte. Tercero, ya era un arquitecto de prestigio gracias a sus viviendas Papaverhof y a su activa participación en los movimientos intelectuales, pese a edad de 33 años. Cuarto, era un gran apasionado del deporte.

1928.11 Edificios coetáneos

Pabellón de Barcelona de Mies van der Rohe, 1928-29

Villa Savoye de Le Corbusier

Dudok inicia las obras del Ayuntamiento de Hilversum, donde ya había realizado la escuela Juliana entre 1926 y 27

Entre 1927 y 34 Alvar Alto realiza la biblioteca de Viipuri.

\subsection{Hechos históricos relevantes:}

Alexander Fleming descubre la penicilina, uno de los descubrimientos mas importantes para el bienestar humano.

La Comisión Federal de Radio (EE.UU.) concede la primera licencia de televisión.

En 1927 se estreno en Nueva York el Cantante de Jazz, la primera película comercial con el sonido sincronizado a la imagen.

\section{Bibliografía Amsterdam 1928:}

The Ninth Olimpiad. Being the Official Report of the Olimpic Games of 1928 celebrated at Amsterdam. Publicado por The Netherlands Olympic Committee (Committee 1928) Amsterdam

GORDON, Barclay F. (1983). Olympic Architecture. Building for the summer games. John Wiley \& Sons. Nueva York. ISBN 0-471-06069-0

LANGMEAD, Donald. JOHNSON, Donald Leslie (2000). Architectural excursions: Frank Lloyd Wright, Holland and Europe. Ed. Greenwood Press. USA. ISBN 0-313-30567-6

WIMMER, Martin. (1976). Olympic Buildings. Ed. Leipzig. Lic 600/34/75. 5938721

Jan Wils / het Olympisch stadion (1978). Monografieën van de Stichting Architectuur Museum. ISBN 9060123999 Onward to Olympics. Historical perspectives on the Olympics Games. (2007) Ed. SCHAUS, Gerard P. WENN Steven R. Wilfrid Laurier University Press. ISBN 9780 88920-505-5

The Stadium. The Architecture of Mass Sport. (2000). Ed. Michelle Provoost. NAI Publishers Rotterdam. ISBN 90-5662$145-9$

http/:olympichstadion.nl

http://en.nai.nl/collection 


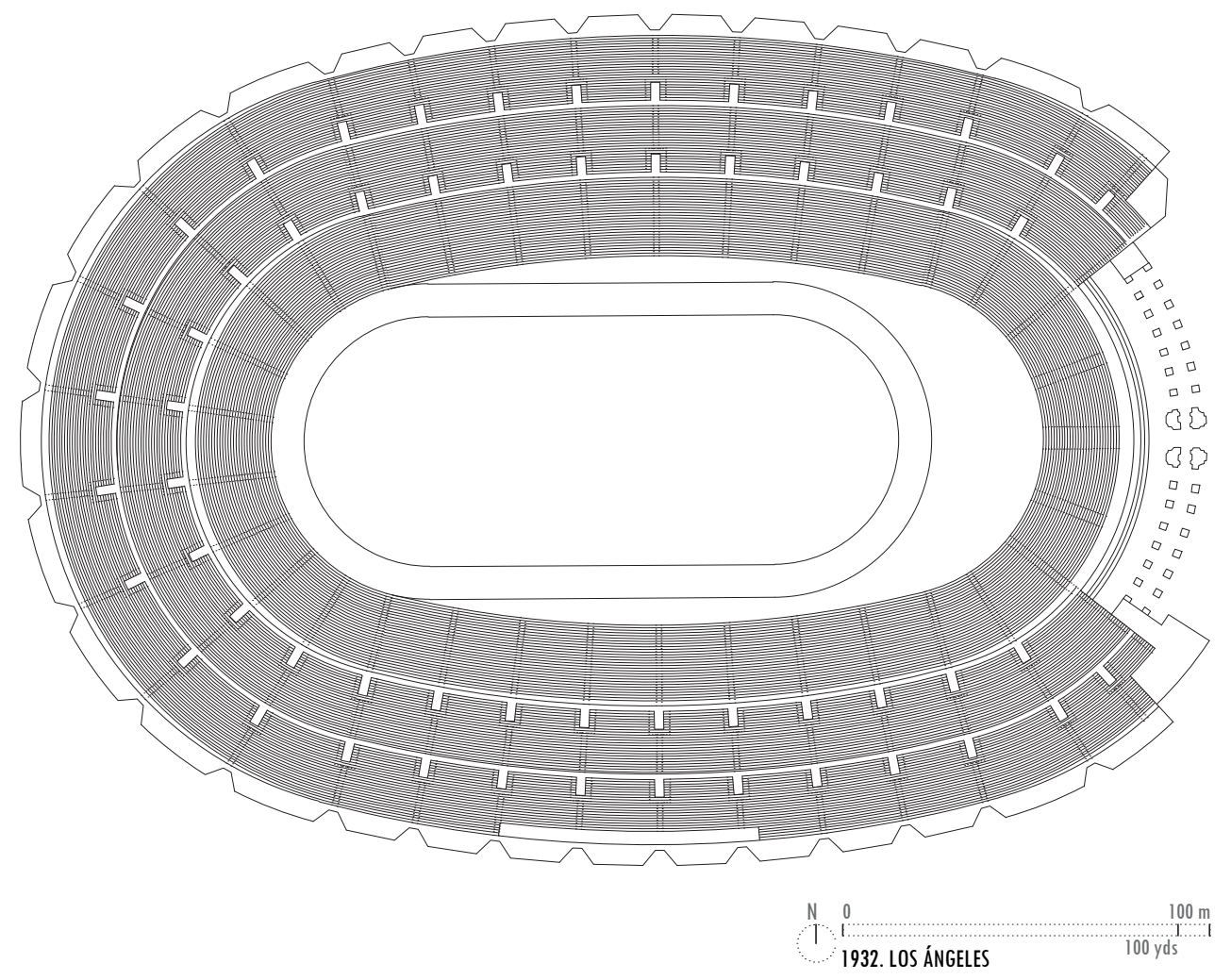

1932.0. Nombre del Estadio

Los Angeles Memorial Coliseum. (Olympic Stadium)

1932.1. Situación

3911 S Figueroa St, Los Angeles, CA 90037, Estados Unidos

\subsection{Fechas}

1919. A instancia de los editores de prensa se constituyó la California Fiesta Association (CFA), con el objetivo de revivir las viejas fiestas españolas tradicionales en la ciudad y en el estado. Para estas fiestas se pensó en la necesidad de un estadio.

1919. En la CFA se propone la posibilidad de presentar candidatura a los Juegos.

1920. Se disuelve la CFA y parte de sus miembros forman la sociedad civil sin animo de lucro Community Development Association. Esta asociación convenció al ayuntamiento y al condado de Los Angeles de la necesidad de ayuda para la financiación del estadio, que se levantaría en Exposition Park.

1920. Los Angeles presenta su candidatura en Amberes.

1921. El 21 de diciembre, se inicia la construcción del estadio.

1923. El 1 de mayo, se finalizan las obras.

1923. Designada ciudad sede de la X Olimpiada, en el Congreso Olímpico de Roma.

1923. El 6 de octubre. Primer partido de fútbol americano entre los Trojans de USC y Pomona College, al que asisten 12.836 espectadores

1927. Se aprueba la ley conocida como California Olimpiad Bond Act, en la que se establece emitir bonos de estado de California, por 1 millón de dólares, para financiar los Juegos.

1928. El 10 de febrero, se constituye el comité organizador con el nombre de Xth Olympiade Committee of the Games of Los Angeles U.S.A. 1932 Ltd, presidido por William May Garland y siendo secretario general ejecutivo Zack J. Farmer.

1928. Análisis pormenorizado de la organización de los Juegos de Ámsterdam y se establece un espíritu de cooperación con su comité organizador, que pasará a asesorar al americano.

1928. El 6 de noviembre, en las elecciones el pueblo de California da validez al Olympiad Bond Act.

1929. Crack económico. Pese a la incertidumbre en cuanto a participación y patrocinios, no se modifica el plan previsto.

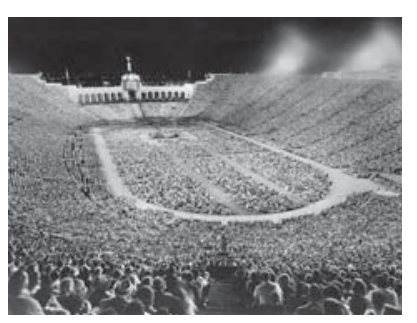


1930. Adecuación del estadio para los Juegos, se amplia su aforo hasta los 101.574 espectadores.

1932. El 30 de julio, se inauguran de los Juegos.

1932. El 14 de agosto, ceremonia de clausura.

1939. Se crea el Southern California Committee for the Olympic Games, con el objetivo de promover una nueva candidatura para albergar los Juegos. A partir de esta fecha Los Ángeles se presenta a todas las convocatorias.

1945. Se contrata a los arquitectos Bennett para el desarrollo de las obras de mantenimiento y puesta al día del estadio

1948. Se instala la iluminación artificial, que permite su uso nocturno.

1964. Fueron renovadas sus instalaciones.

1977. Los Ángeles renovó su intención de presentar candidatura a los Juegos de 1984.

1977. El 31 de octubre, el presidente del ClO confirma que L.A. es la única ciudad candidata. Se inicia un largo proceso de negociación ante la imposición de los organizadores en relación a que la financiación fuera enteramente privada y que serían unos Juegos "espartanos".

1979. El 26 de marzo, una vez constituido el comité organizador, LAOOC, y solventada la financiación, se inician los trabajos para preparatorios de los Juegos.

1980. El 19 de noviembre, el LAOOC y Los Angeles Coliseum Commission anuncian que el Los Angeles Memorial Coliseum, volverá a ser la sede de las ceremonias de apertura, clausura y de las competiciones de atletismo.

1982. El 7 de abril, se inician las obras de adecuación para los Juegos, fundamentalmente nuevo material para la pista y renovación de la pradera de hierba con su sistema de riego.

1984. El 27 de julio, es declarado Federal Historial Landmark.

1984. El 28 de julio, se celebra la inauguración de los Juegos de la XXIII Olimpiada

1984. El 12 de agosto, ceremonia de clausura.

1993. Se elimina la pista de atletismo, se rebaja el nivel del terreno de juego 11 pies consiguiéndose 8.000 nuevas plazas adicionales.

1994. Se interviene para reparar los daños causados por el terremoto de Northridge y se ajusta su estructura a los estándares antisísmicos.
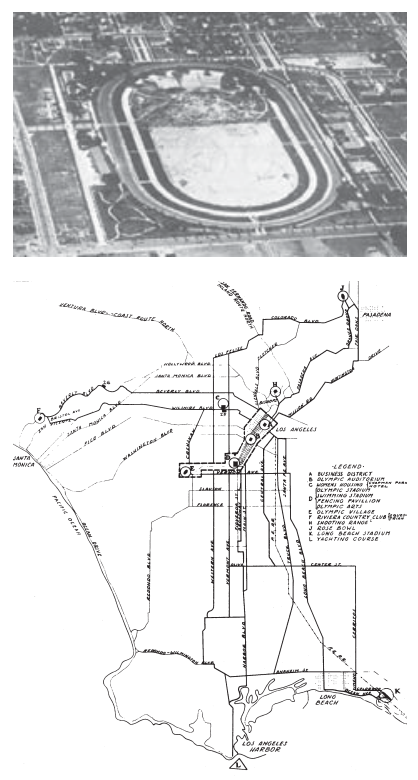

\subsection{Preexistencias en el lugar}

En 1870 se instaló en el área del futuro estadio una feria estable de productos agrícolas y ganaderos, llamado Agricultural Park. En la cual se trazó una pista para carreras de galgos, caballos y trotones, que se celebraban los días festivos. Hacia 1910 ya casi no se realizaban carreras y el lugar se convirtió en lo que se llamaba Exposition Park, un espacio de paseo y recreo, en el que eran habituales los conciertos de bandas de música. Sucesivamente se fueron añadiendo más instalaciones, como el Museo de Historia, Ciencia y Arte de Los Angeles, pabellones para exposiciones, etc. La localización definitiva del estadio fueron los terrenos de una gran gravera que existía en la zona.

\subsection{Relación con la ciudad. Posición respecto al centro urbano}

En el momento de su construcción quedaba a las afueras del entramado urbano, a $6 \mathrm{~km}$ del ayuntamiento. En es momento la ciudad contaba con menos de 600.000 habitantes. En 1932 la población había ascendido hasta el millón de personas. En 1984 con Los Angeles convertida en una megalópolis, el estadio se encontraba en una zona indiferenciada del vasto tejido urbano, justo al sur de la University of Southern California (USC)y a $16 \mathrm{~km}$ del aeropuerto internacional, LAX.

\subsection{Breve relato de la historia del Estadio}

Cuando se proyecta el estadio, con sus 76.000 plazas, la población de los Angeles era de 576.673 personas, la apuesta parecía excesiva. Por aquellos años se habían construido en Estados Unidos estadios de semejantes dimensiones pero asentados en ciudades de una mayor población, Chicago 2,7 millones y Filadelfia 1,8 millones. Pero el fuerte crecimiento del sur de California llevo a que solo 9 años después de su construcción se consideró necesario ampliar su capacidad hasta los 105.000 espectadores.

Gracias a que su utilización ha sido constante y muy activa el estadio se ha conservado, en esencia, inalterado desde su construcción y posterior ampliación en sus casi 100 años de historia. Solo se habían introducido las adiciones y cambios necesarios para adaptarlo al paso de los tiempos, a las nuevas necesidades técnicas, estándares deportivos y a las crecientes necesidades de confort de los espectadores. Pero en el año 1993 se produce un cambio sustancial, se elimina la pista de atletismo para acercar mas las gradas al terreno de juego del fútbol americano, para ello se rebaja el nivel 3,35 metros añadiéndose unas nuevas 
filas de graderio.

En el Coliseum, además de 2 Juegos Olímpicos se han disputado una Final del campeonato americano de baseball, World Series 1959. Dos finales de la Super Bowl, la I edición en 1967 y la VII en el 73. Es la sede habitual de Los Trojanos, equipo de fútbol americano de la Universidad del Sur de California, USC. Además de otros deportes en el estadio han tenido lugar actos de muy diferente tipo, como el discurso de aceptación como presidente de los Estados Unidos de América de John F. Kennedy, en 1960, misa del Papa Juan Pablo Il en el 87 o el macro concierto. "Human rights now", en el que participan Sting, Bruce Springsteen, Peter Gabriel, Tracy Chapman, Joan Báez y otros, un año mas tarde. Su aforo máximo se produjo en 1963 con la asamblea evangelista organizada por Billie Graham a la que asistieron 134.254 personas.

\subsection{Descripción del Estadio; Graderío}

Gran estructura, de hormigón armado, adaptada a la topografía artificial en forma de gigante cuenco elíptico con unas longitudes en sus ejes de $1.038 \times 738$ pies $(316,38 \times$ casi 225 metros), dejando libre un campo interior de $684 \times 345$ pies (aproximadamente 208 x 105 metros). El terreno de juego esta 32 pies $(9,75 \mathrm{~m}$.) por debajo de nivel de las tierras circundantes. El graderío mantiene su continuidad de arriba hasta abajo, pero se divide en tres segmentos, en el inferior de desarrollan 29 gradas y está asentado sobre la propia excavación, el segundo nivel de 27 pies de altura $(8,23 \mathrm{~m}$.) y 25 gradas, se apoya en una berma de terreno compactado proveniente de la propia excavación. El último tramo, añadido para los Juegos de 1932, es una estructura aérea de pórticos de hormigón armado, tiene un desarrollo de 25 gradas, de las cuales las últimas cuatro se encuentran en voladizo.
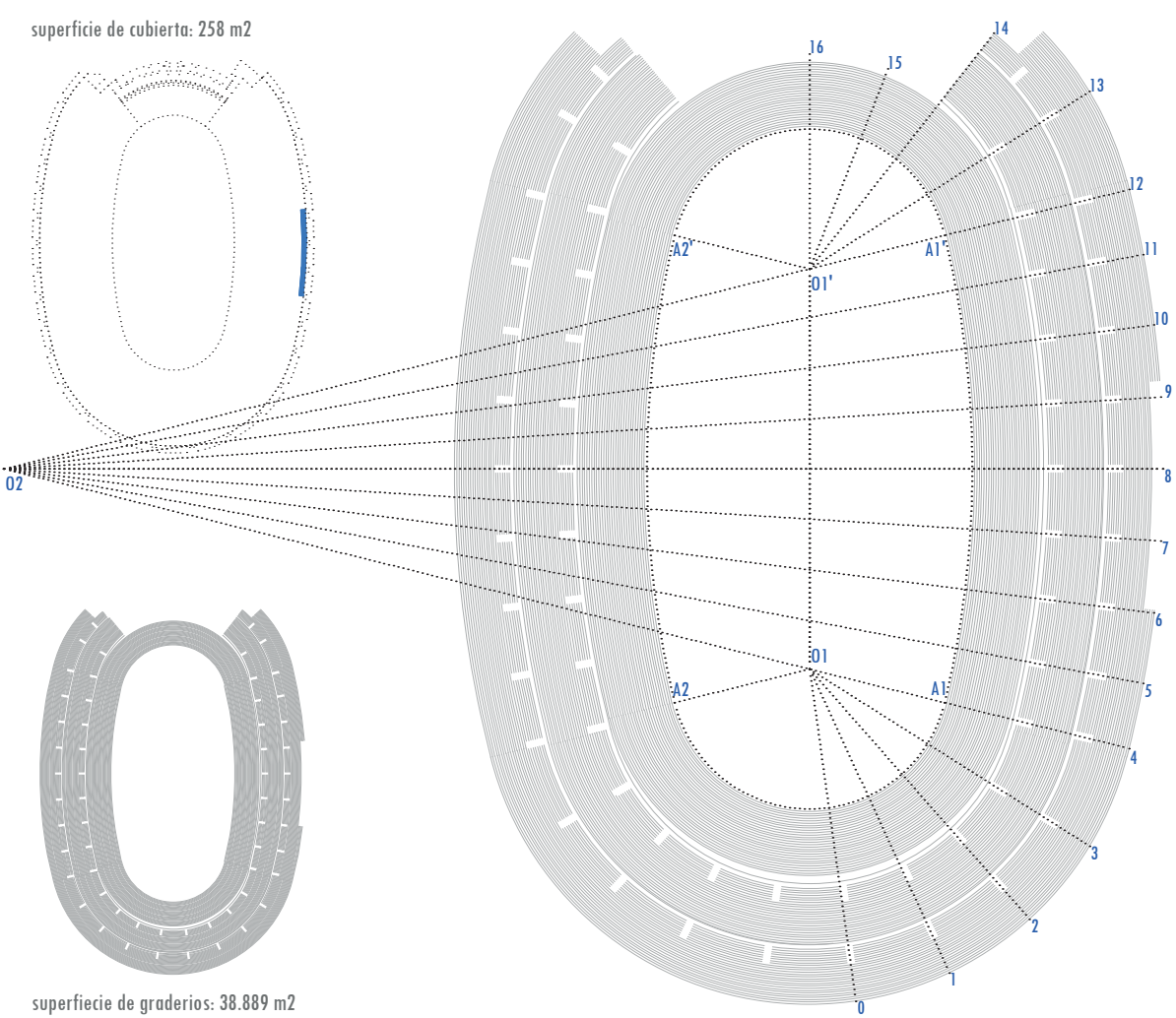

superfiecie de graderios: $38.889 \mathrm{~m} 2$

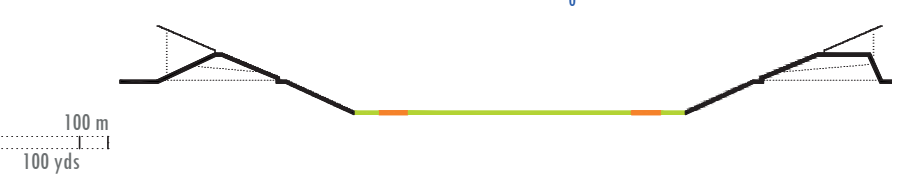

$N \quad 0$
-1

1932. LOS ÁNGELES

$$
100 \mathrm{yds}
$$

En el extremo este del eje largo solo tiene continuidad el graderio inferior, quedando parcialmente abierto el estadio en esta dirección, formando una herradura, Un peristilo compuesto por un arco principal y siete menores a cada lado, cierran dicha abertura. Inicialmente construido en hormigón y carente de toda ornamentación, aunque en el Informe para la solicitud de su catalogación como Monumento Histórico' menciona que el proyecto
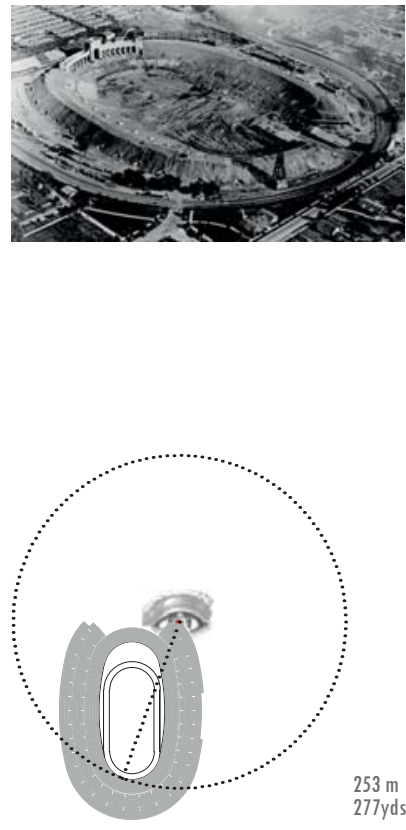

dimensiones y superficies aproximadas graderío

$$
\begin{array}{lr}
\text { L 01-01' } & 123,89 \mathrm{M} \\
\text { L 01-02 } & 256,96 \mathrm{M} \\
\text { R 01-Al } & 43,07 \mathrm{M} \\
\text { R 02-Al } & 300,03 \mathrm{M} \\
\text { < Al.02.Al' } & 28^{\circ} \\
\text { < A1.01.A2 } & 28^{\circ}
\end{array}
$$
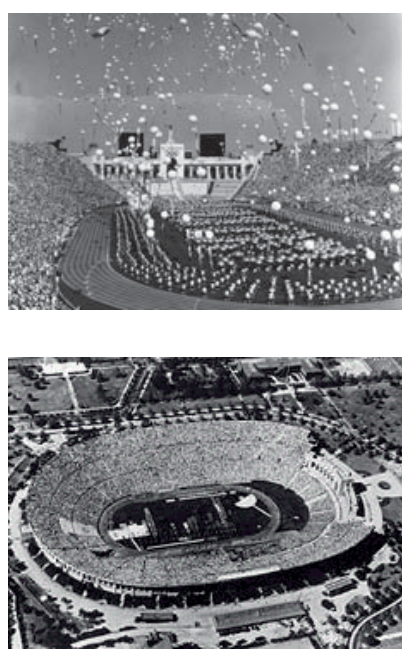

1. National Register of Historic Places. Inventory-Nomination Form. United States Departament of the Interior. 
1932. marca del ganador

\begin{tabular}{lrr} 
& Hombres & Mujeres \\
$100 \mathrm{~m}$ & $10 " 3$ & $11 " 9$ \\
$200 \mathrm{~m}$ & $21 " 2$ & \\
$400 \mathrm{~m}$ & $46 " 2$ & \\
$800 \mathrm{~m}$ & $1,49 " 8$ & \\
$1500 \mathrm{~m}$ & $3,51 " 2$ & \\
$5000 \mathrm{~m}$ & $14,30 " 0$ & \\
$10000 \mathrm{~m}$ & $30,11 " 4$ & \\
$110 / 80 \mathrm{mv}$ & $14 " 6$ & \multicolumn{1}{c}{$11 " 7$} \\
$400 \mathrm{mv}$ & $51 " 8$ & \\
3000 obst & $10,33 " 4$ & \\
Altura & $1,97 \mathrm{~m}$ & $1,67 \mathrm{~m}$ \\
Pértiga & $4,315 \mathrm{~m}$ & \\
Longitud & $7,64 \mathrm{~m}$ & \\
Triple salto & $15,721 \mathrm{~m}$ & \\
Jabalina & $72,71 \mathrm{~m}$ & $43,68 \mathrm{~m}$ \\
Peso & $16,00 \mathrm{~m}$ & \\
Disco & $49,49 \mathrm{~m}$ & $40,58 \mathrm{~m}$ \\
Martillo & & $53,92 \mathrm{~m}$ \\
4x100 & $40 " 0$ & $47 " 0$ \\
4x400 & $3,08 " 2$ & \\
50km marcha & $4 h .50,10 "$ & \\
Decathlón & $8462,23 \mathrm{ptos}$ & \\
Marathón & $2 \mathrm{~h} .31,36 "$ & \\
& &
\end{tabular}

1984. marca del ganador

Hombres Mujeres

$100 \mathrm{~m} \quad 9 " 99$

$200 \mathrm{~m} \quad 19 \times 80$

$400 \mathrm{~m} \quad 44 " 27$

$800 \mathrm{~m} \quad 1,433^{\prime 200}$

$1500 \mathrm{~m} \quad 3,32 " 53$

$5000 \mathrm{~m} \quad 13,05 " 59$

$10000 \mathrm{~m} \quad 27,47 " 54$

$110 / 100 \mathrm{mv} \quad 13 " 20$

$400 \mathrm{mv} \quad 47775$

3000 obst $\quad 8,11 " 80$

$3000 \mathrm{~m}$

Altura

Pértiga

Longitud

Triple

Jabalina

Peso

Disco

Martillo

$4 \times 100$

$4 \times 400$

$20 \mathrm{~km}$ marcho

$50 \mathrm{~km}$ marcha

Decathlón

Heptathlón

Marathón
$10 " 97$

$21 " 81$

$48 " 83$

$1,57 " 60$

$12 " 84$

$45 " 61$

$8,35 " 96$

$2,02 \mathrm{~m}$

$5,75 \mathrm{~m}$

$8,54 \mathrm{~m}$

$17,26 \mathrm{~m}$

$86,76 \mathrm{~m}$

$21,26 \mathrm{~m}$

$66,60 \mathrm{~m}$

$78,08 \mathrm{~m}$

$37 " 83$

2,57 "91

1h.23,13"

$3 \mathrm{~h} .47,26 "$

8.798 ptos

$\begin{array}{rr} & 6.390 p \text { ptos } \\ 2 \mathrm{~h} 09,21 " & 2 \mathrm{~h} 24,52^{\prime \prime}\end{array}$

$69,56 \mathrm{~m}$

$20,48 \mathrm{~m}$

$65,36 \mathrm{~m}$

$41 " 65$

$3,18 " 29$

dimensiones y superficies aproximadas pista

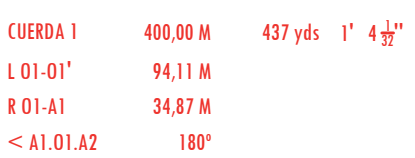

contaba con elementos decorativos de reminiscencia egipcia, mediterránea y española, pero que no llegaron a ejecutarse, seguramente por cuestiones económicas. El peristilo fue lo primero que se construyó y a cota del terreno existente, para luego proceder al movimiento de tierras y demás. Para los Juegos del 32 se añadió encima del arco central del peristilo el pebetero con la antorcha olímpica y se reforzó el eje significante este-oeste con la colocación del mástil de la bandera olímpica sobre el mismo eje en la curva oeste.

Los accesos se producen a los ínterespacios de los graderíos, el inferior mediante túnel en la berma y el superior con una escalera apoyada en la misma.

Gradas de hormigón con asiento de madera. Todos los asientos son de la misma categoría, para los Juegos del 32 hubo que realizar ciertas modificaciones para instalar el palco de autoridades con 809 butacas y los puestos de prensa, 706 en el lugar de 2000 plazas.

Ninguna parte del graderio del estadio está cubierto.

\subsection{Descripción del Estadio; Pista}

1932. Desde su construcción el estadio contaba con una pista de 440 yardas que hubo que reducir para los Juegos de 1932 a los 400 metros, establecidos desde Ámsterdam 1928 como la dimensión de cuerda obligatoria, produciéndose un desajuste entre pista y graderio. Ancho de 6 calles. Material, ceniza.

Programa Deportivo: Atletismo, Gimnasia, Hípica, sólo el Premio de las Naciones, Hockey hierba, finales, Lacrosse, Fútbol Americano, deportes de demostración, Ceremonias de Apertura y Clausura y la entrega de medallas de todos los deportes.

1984. Se renovó completamente para los Juegos, en la pista se instaló el mismo material que fue utilizado en Munich 72, "Rekortan", se renovó la pradera y su sistema de riego y drenaje. De 400 metros de cuerda y 8 calles. Radio de curvatura 36,5 m., para este nuevo ancho fue necesaria la modificación de las primeras filas del graderio. En el interior del anillo; dos pasillos de longitud y tripe en la recta sur, dos de pértiga en la norte, tres áreas de salto de altura y calle de jabalina en la curva este, dos círculos de peso en la oeste, circulo de disco y martillo en la esquina noreste.

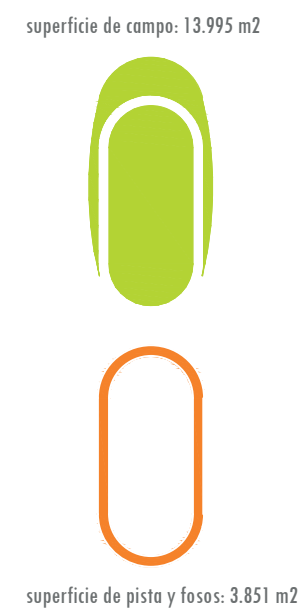

superficie de pista y fosos: $3.851 \mathrm{~m} 2$
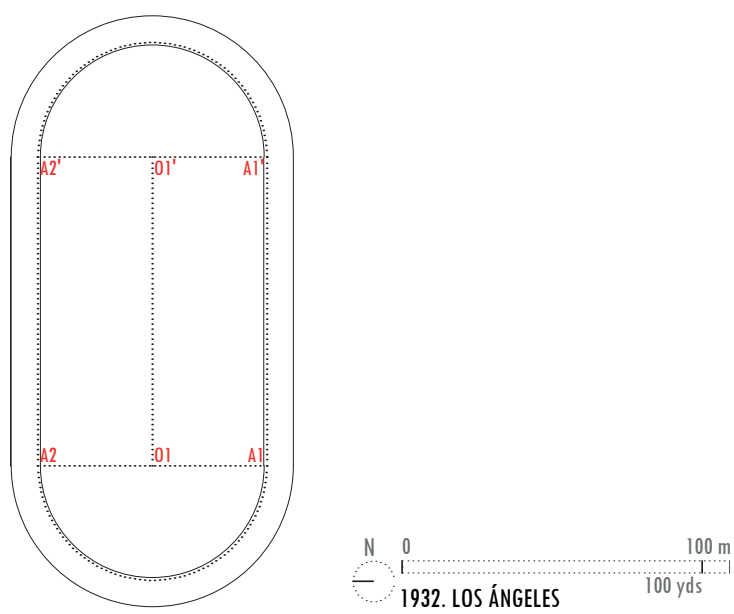

Programa Deportivo: Atletismo, Equitación,. solo el Premio de las Naciones y las Ceremonias de Apertura y Clausura

\subsection{Elementos significantes}

Peristilo con un arco central de mayor dimensión acompañado por siete vanos menores a cada lado. Encima del arco principal se añadió para los Juegos de 1932 un elemento vertical de hormigón de 107 pies de altura, aproximadamente 32,61 metros, coronado por un pebetero de bronce, en el cual ardería de una forma estable y duradera el fuego olímpico. Para los Juegos de 1984 se añadió encima del vano central los aros olímpicos. El graderio en la zona de la arcada es un tercio menor que en el resto del estadio, proponiendo un eje longitudinal significante, en referencia al estadio clásico de Atenas, en forma de herradura. En la curva contraria se situaba el mástil con la bandera olímpica.

Encima del marcador se dispusieron tres mástiles para el izado de las banderas en el momento de la entrega de premios de los tres primeros clasificados. 


\subsection{Avances técnicos}

1932. Panel de resultados de $13,40 \times 6,70$ metros, encima de arco central del peristilo, lugar de especial visibilidad y significación. Sistema eléctrico de megafonía para anunciar los resultados, 23 enormes altavoces distribuían de una manera equilibrada el sonido por todo el estadio.

1984. Dos marcadores convencionales y un videomarcador de 4,45 x 3,35 metros.

\subsection{Autores. Tipo de encargo}

John Parkinson (1861/1935) y Donald Parkinson (1895/1945). Eran padre e hijo. John era inglés, formado en Bolton, probó fortuna en Estados Unidos. Como arquitecto trabajo primero en Seattle entre 1889 y 1894 construyendo y publicando sus obras en publicaciones especializadas con cierta asiduidad. Además se lanzó a promover el Seattle Athletic Club Building justo antes de la fuerte depresión de 1893, sumiéndole en la bancarrota. En 1894, plena crisis y sin expectativas de trabajo en Seattle, se trasladó Los Ángeles iniciando ese mismo año la construcción de lo que ahora se conoce como la Brewery Art Colony, uno de los complejos de producción artística más grandes del mundo. En 1896 construyó el Homer Langhlin Building con la primera estructura metálica protegida al fuego de LA. Su obra Casa y Granero de Susana Machado (1901) está catalogada como Monumento Histórico Cultural en el Registro Nacional de Sitios Históricos. El Bradley Block (1904) fue el primer rascacielos de LA. De 1905 a 1915 estuvo asociado con G. Edwin Bergstrom formando el estudio mas importante de la ciudad en edificios de gran estructura, entre ellos el Metropolitan Building. En 1920 se asocia con su hijo Donald, realizando una muy relevante obra. Entre las que se encuentra el Master Plan y varios edificios del Campus de la Universidad del Sur de California (USC)(1919-39). En 1928 realizan el edificio más icónico de Los Angeles, su ayuntamiento. Un año después construye el potente y expresivo Bullock Wilshire Department Store. Su arquitectura era ecléctica y de formación beauxardiana. Cuando John falleció en 1935 Los Angeles Times publicaron como epitafio "Ias futuras generaciones tendrán solo que andar a través de las calles de Los Angeles para que les recuerde cuanto John Parkinson contribuyó al desarrollo de la ciudad que ha crecido de su mano"'.

Las adaptaciones que sufrió el estadio para adaptarlo a las necesidades olímpicas, según el Informe oficial fue redactado por una oficina técnica que consultó con una prestigiosa firma de arquitectura, pero en ningún momento menciona expresamente a los Parkinson, aunque en el informe de propuesta para que sea declarado Monumento Histórico ${ }^{2}$ parece que dejan claro que lo fueron.

después de la Segunda Guerra Mundial fueron contratados para las futuras obras de adición - cambios en el estadio a los arquitectos de Pasadena, Cyril Bennett (1890/1957) y su hijo Robert E. Bennett (1915/2003) de la firma Bennett \& Haskell. Sus intervenciones en Coliseum no han afectado sensiblemente a su arquitectura, solo destacamos el chapado en mármol del peristilo y la torre de comunicación con las cabinas de prensa, en el exterior.

En tres las obras as destacadas de Cyril Bennett se encuentra el Templo Masónico de Pasadena de 1926 y la Glenarm Power Plant de 1932.

Tipo de encargo. No hemos podido encontrar esa información. En cualquier caso los Parkinson formaba uno de los estudios de arquitectura más prestigiosos del Los Ángeles, parece lógico que recurrieran a ellos. A principios de 1920 John prepara los planos del futuro estadio, con el compromiso que si es aprobada la propuesta se le encargaría su ejecución del mismo al costo, renunciando a los beneficios.

Desconocemos las razones de la contratación de los Bennett.

\subsection{Edificios coetáneos}

VDL Research House: Richard Neutra. Los Ángeles, 1932.

El 9 de febrero se inaugura la exposición titulada: Modern Architecture - International Exhibition, en el Museum of Modern Art de Nueva York, MOMA. Philip Johnson y Henry-Russell Hitchcock publican The International Style.

En 1932, Manuel Sánchez Arcas y Eduardo Torroja construyen la Central Térmica de la Ciudad Universitaria de Madrid, recibiendo ese mismo año el Premio Nacional de Arquitectura.

\subsection{Hechos históricos relevantes}

En España, en 1931 se había instaurado la II Republica.

1. GEE, Stephen. (2013). Iconic Vision. John Parkinson Architect of Los Angeles. Ed Angel City Press. Santa Monica, CA. ISBN 9781626400085

2. National Register of Historic Places. Inventory-Nomination Form. United States Departament of the Interior. National Park Service 
En 1932, Hitler gana sus primeras elecciones en Alemania.

Franklin D. Roosevelt es elegido, por primera vez, presidente de los EE.UU. posteriormente será reelegido en otras tres ocasiones más.

Bibliografía Los Ángeles 1932/1984:

Xth Olympiad. Los Angeles 1932. Official Report. (1933). Ed.Xth Olympiade Committee of the Games of Los Angeles. U.S.A. 1932 LTD

Official Report of the Games of the XXIIIrd Olympiad Los Angeles, 1984. (1985). Ed. Los Angeles Olimpic Organizating Committee.

GEE, Stephen. (2013). Iconic Vision. John Parkinson Architect of Los Angeles. Ed Angel City Press. Santa Monica, CA. ISBN 9781626400085

GORDON, Barclay F. (1983). Olympic Architecture. Building for the summer games. John Wiley \& Sons. Nueva York. ISBN 0-471-06069-0

The Story Behind the Largest and Finest Stadium in America. 1952. Biblioteca CIO. Id: 206777 jo-1932SStade.

WIMMER, Martin. (1976). Olympic Buildings. Ed. Leipzig. Lic 600/34/75. 5938721

National Register of Historic Places. Inventory-Nomination Form. United States Departament of the Interior. National Park Service. Form No. 10-306 <Rıv. 10-74) 11 de mayo de 1984. 


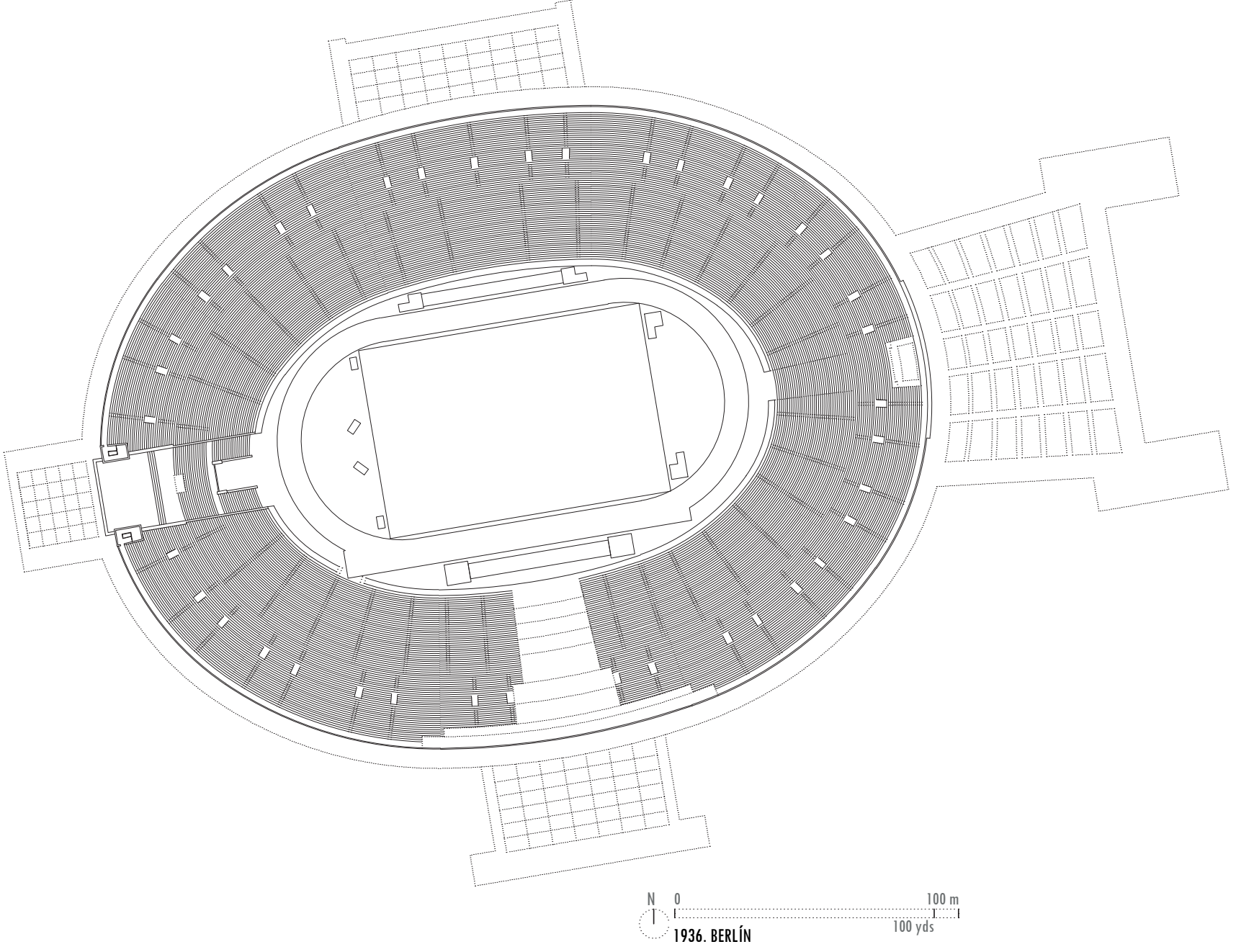

1936.0. Nombre del Estadio

Reichssportfeld. Desde 1950 Olympiastadion

1936.1. Situación:

Olympischer Platz 3, 14053 Berlín, Alemania

\subsection{Fechas}

1925. Los hermanos Werner y Walter March ganan el concurso para la construcción del Deutsches Sportforum, Escuela Alemana de Educación Física y Deportes, en terrenos aledaños al estadio.

1925. El 18 de octubre, se celebra el acto de puesta de primera piedra, aunque el proyecto arquitectónico no estaba finalizado y las obras languidecen por falta de presupuesto.

1929. Werner March, realiza un proyecto de ampliación del Deutsches Stadion hasta los 65.000 espectadores. La gran depresión económica frustra el proyecto.

1930. Berlín presenta candidatura para los Juegos de 1936.

1931. El 13 de mayo, el ClO concede a Berlín la organización de los Juegos de la XI Olimpiada, ganado en la votación final a Barcelona por 43 a 16 votos.

1933. Se reestudia el proyecto para el estadio y se prevé una dotación económica suficiente.

1933. El 14 de diciembre, Hitler decide que se desarrolle la denominada Opción B, presentada por los hermanos Werner. En la que se incluían las directrices de todas las nuevas instalaciones del Reichssportfeld.

1934. En marzo, se inicia la demolición del estadio antiguo y la construcción del nuevo.

1936. El 1 de agosto, se inauguran los Juegos.

1936. El 16 de agosto, se celebra la ceremonia de clausura.

1936. A partir de esta fecha, se celebran al año en el estadio de 20 a 25 acontecimientos de gran escala.

1937. El 20 de junio, final de la Copa de Alemania de fútbol. 
1940. Durante la II Guerra Mundial, los sótanos del estadio se amplían y se convierten en refugio y en fabrica de componentes electrónicos para las armas antiaéreas.

1944. La radio Nacional Alemana se traslada a los sótanos del estadio para protegerse de los bombardeos.

1945. El 1 de julio, el ejercito Británico ocupa el Reichssportfeld y a partir de ese momento hace uso exclusivo de sus instalaciones.

1946. El 7 de septiembre, se reabre al público por primera vez, con motivo de los Juegos de las 8 Naciones.

1947. El 15 de febrero, el ejercito británico demuele la torre de la campana que se encontraba en ruinas por un devastador incendio producido durante la guerra. La campana cae al suelo y se raja.

1949. El 12 de junio, los británicos ceden la gestión del estadio a las autoridades de la ciudad.

1950. El 12 de junio, se cambia el nombre de Reichssportfeld por el de Olympiastadion.

1962. Se finaliza la reconstrucción de la torre de la campana, acción impulsada por Werner March desde 1956.

1966. Catalogado como Monumento Protegido de Berlín Oeste.

1966. En noviembre, se instala un sistema de iluminación artificial, aunque de poca potencia.

1969. Se cambia el material de la pista de atletismo a Rekortan, nuevo material que es probado de cara a los Juegos de Munich en 1972.

1974. Para la Copa del Mundo de Fútbol los arquitectos Dübbers y Krahe cubren parcialmente las tribunas norte y sur, quedando 26.000 asientos protegidos de la lluvia. También se modernizan las tribunas de prensa y los aseos. La grada y el foso de prensa previo a la pista se separan con una pantalla de plexiglás.

1989. En noviembre, Berlín presenta su candidatura a los Juegos del 2000, presentando un plan de modernización integral del estadio.

1994. El 8 de septiembre, el ejercito británico se retira definitivamente del área del antiguo Reichssportfeld.

1998. El 26 de mayo, el senado de Berlín decide renovar el vetusto estadio y convertirlo en un recinto deportivo multifuncional. Descartando la posibilidad de su demolición.

1998. El 1 de diciembre, el senado de Berlín proclama ganadores del concurso de arquitectura a von Gerkan, Marg y Asociados.

2000. El 9 de mayo, la empresa Walter Bau-AG gana el contrato de explotación del estadio, debiéndose hacer cargo de los gastos de su renovación y modernización, por un precio de 242 millones de euros.

2000. El 3 de julio, se pone la primera piedra de la nueva obra que se desarrolla hasta 2004, manteniendo en uso el estadio durante todo este periodo. Se dividió el estadio en 19 sectores de obra sucesivos. El nivel del terreno se descendió 2,65 metros, añadiéndose graderio para acerca mas el publico al espectáculo. Se añadió una cubierta ligera que respeta la apertura hacia la puerta de Marathon, preservando la visión de la torre desde el interior del estadio. La nueva cubrición se apoya en 20 finas columnas metálicas e incorpora iluminación y sonido ( 150.000 watios).

2004. El 31 de julio se celebró con una fiesta la finalización de las obras. El nuevo aforo del estadio es de 74,475 espectadores

2005. En abril, la UEFA le da la calificación de estadio 5 estrellas.

2006. El 9 de julio, final de la Copa del Mundo de Fútbol en la que Italia se impone a Francia en la tanda de penaltis.

2009. En agosto, Campeonato de Mundo de Atletismo.

2015. Se mantiene en uso, albergando un gran numero de actividades deportivas, culturales, etc. Además, mas de 150.000 personas al año visitan sus instalaciones.

\subsection{Preexistencias en el lugar}

En febrero de 1907 la organizadora de carreras de caballos, Union Klub, se hace con el arrendamiento por 30 años de unos terrenos situados al norte de Grunewald, en el denominado Parque del Pueblo, espacio público cedido por el emperador Guillermo II en 1868. El lugar era una meseta rodeada de densos bosques de pinos.

El 23 de mayo de 1909 se inaugura el hipódromo de Grunewald, proyectado por el arquitecto Otto March (1845/1913) padre de Werner y Walter. Tenia una capacidad de 40.000 espectadores y su superficie interior superaba los $85.000 \mathrm{~m} 2$.

En 1912 se concede a Berlín la organización de los Juegos de la VI Olimpiada. Victor von Podbielski (1844/1916) miembro de la junta del Unión Klub, jefe del equipo olímpico alemán en los Juegos Olímpicos de Estocolmo, presidente del Comité del Reich Alemán para Juegos Olímpicos, fue decisivo, primero para el desarrollo del hipódromo y después para buscar la financiación necesaria para la construcción del estadio, denominado Deutsches Stadion 
- Grunewaldstadion, con capacidad para 11.500 espectadores sentados y 18.500 de pie, pista de atletismo de 400 metros rodeada de velódromo de 666 metros y su graderio norte estaba interrumpido y desplazado por la inclusión de una gran piscina.

Estaba situado en el área central del gran hipódromo y para permitir una visión completa de toda la pista de carreras, el nuevo estadio estaba totalmente excavado en el terreno. Un gran túnel debajo de la pista de caballos enlazaba los dos graderíos.

En agosto de este mismo año se inician las obras dirigidas por Otto March, que fallece el 1 de abril de 1913, mes y medio antes de la inauguración del estadio.

Durante la construcción del estadio se protege y conserva un impresionante ejemplar de roble que pasa a formar parte del estadio presidiendo su eje longitudinal en la parte alta del graderío.

Con el estallido de la Primera Guerra Mundial se suspende la preparación de los Juegos y se cierra el estadio que es usado durante la guerra como hospital militar.

1936.4. Relación con la ciudad. Posición respecto al centro urbano

Al oeste, en un área boscosa y en la proximidad del eje Este-Oeste sobre el que pivota el entramado urbano. A 6,4 Kilómetros del Tiergarten, a 9,25 de la Puerta de Brandenburgo, a 10,9 del Altes Museum y 11,8 de Alexanderplatz.

Se llevó a cabo toda una actuación integral de infraestructuras para conectar el estadio con la trama urbana. Una amplia red de circulación fue construida alrededor del estadio para facilitar el tránsito de la enorme cantidad de visitantes que se esperaba. Esta red incluía: amplias calles enlazadas a las principales vías de la ciudad, aparcamientos para coches, estaciones de tranvía y tren, líneas de autobuses y vías peatonales especiales entre el estadio y las estaciones de tren.

\subsection{Breve relato de la historia del Estadio}

En 1920 se crea la Escuela Alemana de Educación Física. Propuesta e impulsada por Carl Diem, hombre fundamental en la historia del deporte en Alemania y del olimpismo en general. Inicialmente se ubica en el Deutsches Stadion. En 1925 se convoca el concurso de arquitectura para la construcción de sus instalaciones permanentes, en la proximidad del estadio. Participan arquitectos renombrados como Hans Poelzig (1869/1936), Hermann Dernburg (1868/1935) y Bruno Taut (1880/1938), venciendo los hermanos Werner y Walter March, hijos de Otto March, arquitecto del Deutsches Stadion.

Werner March en el proceso del proyecto colabora activamente con Carl Diem y comienzan a estudiar alternativas para la ampliación de estadio de cara a la candidatura Olímpica de Berlín. El estadio no tenía aforo suficiente, la cuerda de sus pistas era excesiva y con la gran piscina situada en la recta opuesta a la tribuna principal se perdían muchas posibles plazas de espectadores. Además, se encontraba cercado y limitado por la pista de carrera de caballos. Se llevó a cabo un estudio muy profundo del estadio de Ámsterdam, de Jan Wils.

Finalmente, el 13 de mayo de 1931, el ClO concede a Berlín la organización de los Juegos de la XI Olimpiada.

March prepara una propuesta en 1933, en el que se bajaba el nivel de la pista, reduciéndose su dimensión y aumentando su aforo hasta los 80.000 espectadores. La piscina se posiciona en la curva oeste, integrada en la grada alta. Se conserva el gran roble, respetado por su padre durante la construcción del estadio.

Entonces, entra Hitler en escena desbaratando los "modestos" planes para la remodelación y ampliación del antiguo estadio de Grunewald y pidiendo al arquitecto que

lo que ahora se necesitaba era una construcción que por su poder y majestuosidad hiciera justicia con la gloria del Reich alemán.

como recoge Barclay F. Gordon en Olympic Architecture, building for the summer games, de 1983, haciendo referencia a lo citado por Franz-Joachim Verspohl en Stadionbauten von der Antike bis zur Gegenwart, publicado por Anabas, Verlag, Giessen, en 1976.

El panorama ha cambiado radicalmente, el ámbito de actuación se amplia, se prescinde del preexistente hipódromo que ahogaba cualquier posible solución y la dotación económica se amplia de manera considerable.

March presenta varias propuestas y finalmente el 14 de diciembre de 1933 Hitler decide que se desarrolle la denominada Opción B, en la que se incluían las directrices de todas las nuevas instalaciones del ahora denominado Reichssportfeld. Alrededor de 36 millones de Marcos se pusieron a disposición del Comité organizador. Se impone como condición; que todos los materiales utilizados procedan del propio país.

El modelo que sirvió de referencia a March fue el Praterstadion de Viena del arquitecto Otto Ernest Schweizer (1890/1965). Basado en un detallado análisis del Anfiteatro Romano: en su vertiente puramente funcional, destinada a descubrir el método mas eficiente de acceso y evacuación de las gradas, consiguiendo que se lograra en tan solo siete u ocho minutos, y

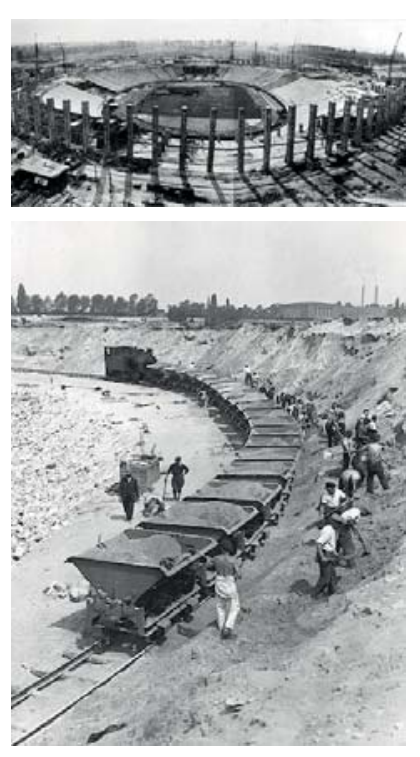


las dimensiones óptimas del campo de juego en relación a la visión de los espectadores. De carácter abierto, luminoso, funcional y sensible. En intima relación con el paisaje circundante por escala y continuidad espacial. Utiliza el graderio partido en dos anfiteatros que proporciona una vista ininterrumpida de espectadores y una posición cercana de los mismos a la pista o terreno de juego. Que había sido experimentado por primera vez por Johannes Brinkman (1902/1949) y Leen Van der Vlugt (1894/1936) en el estadio Feyenoord de Rótterdam, de 1937. Aunque contaban con los antecedentes del campo de fútbol rectangular y con grada en los lados largos de Highbury en Londres, de Archibald Leitch, de 1913. Y también, del estadio de baseball de los Yankees en Nueva York, de Osborne Engineering Corp, de 1923.

Pero mientas el estadio de Rótterdam esta construido con acero, vidrio y hormigón, el de Viena lo esta solo con hormigón armado y vidrio. Constituyendo una delicada muestra de funcionalismo y relación con la naturaleza.

En marzo de 1934 se inicia la demolición del viejo estadio Grunewald y la construcción del nuevo.

En más de una ocasión durante los meses posteriores, el entusiasmo de Hitler chocó abiertamente con March. En su libro de memorias Albert Speer recuerda que en una ocasión fue llamado urgentemente a presentarse en las dependencias de Hitler después de que el Führer hubiese visitado las obras. estaba muy enfadado. Se quejaba de que las construcciones de March eran poco potentes y además su estilo era demasiado moderno. Discrepó especialmente con el cerramiento de vidrio que March había diseñado para el exterior del estadio.

Speer modificó los planos de March, reforzando su cornisa con ménsulas de piedra y eliminando por completo el vidrio en sus fachadas. En la búsqueda de una arquitectura que tuviera la capacidad, en un futuro lejano, de convertirse en una noble ruina, en sintonía con su teoría del valor de la ruina. La arquitectura de March se mostraba demasiado ligera y endeble, incapaz de soportar el paso de los siglos, manteniendo su nobleza y dignidad aunque hubiera perdido capacidad de uso.

El 1 de agosto de 1936, se inauguran los Juegos.

dimensiones y superficies aproximadas graderío

$\begin{array}{llll}\text { L 02-02' } & 47,96 \mathrm{M} & <\text { A4.03.A5 } & 35^{\circ} \\ \text { L 03-03' }^{\prime} & 94,53 \mathrm{M} & <\text { A4'.03'.A5' } & 42^{\circ}\end{array}$

L $01-02 \quad 150,83 \mathrm{M}$

L $02-03 \quad 33,06 \mathrm{M}$

R OI-Al 229,08 M

R 02-A2 $\quad 78,24 \mathrm{M}$

R 03-A4 45,20M

$<02.01 .02^{\prime} \quad 18^{\circ}$

$<03.01 .03^{\prime} \quad 31^{\circ}$

$<$ Al.01.Al' $17^{\circ}$

$<$ A2.02.A3 $33^{\circ}$

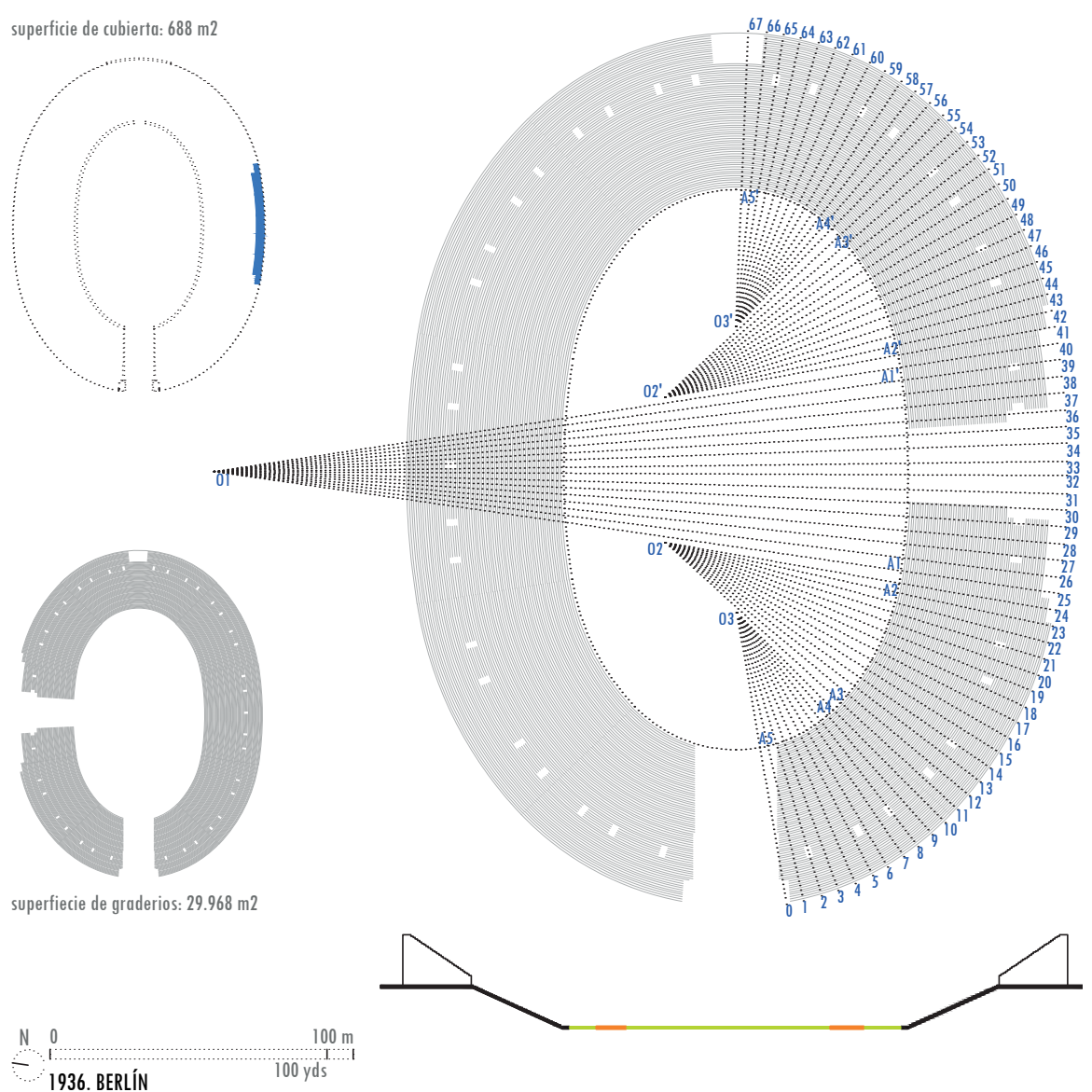

1936.6. Descripción del Estadio; Graderío

Capacidad para 100.000 espectadores. Graderio de planta elíptica en el que su sección con 71 gradas conforman una parábola para asegurar la correcta visibilidad, como expresamente queda reflejado en el Informe Oficial de los Juegos. 
El graderío en sección esta dividido en dos partes, la inferior excavada en el terreno, con una profundidad de 45 pies (13,70 m.) y la superior, una construcción aérea, de 54 pies (16,46 m.) de altura. Un corredor de distribución central reparte el flujo de espectadores, de una manera diferenciada, mediante 20 vomitorios con escaleras a la parte alta y otros 20 vomitorios a nivel a la grada inferior, permitiendo un acceso y evacuación muy fluido. Se diferencian las circulaciones de público y de autoridades, jueces y atletas, estos últimos cuentan con un acceso diferenciado mediante un túnel subterráneo, que además conecta con las diferentes instalaciones del Reichssportfeld. El acceso directo a la pista, sin interferir al flujo de gente alrededor del estadio, se produce por la puerta y túnel de Marathon. Encima de los cuales el graderio se abre al denominado Campo de Mayo, interrumpiéndose el graderío superior, permitiendo la visión de la torre con la campana Olímpica. La grada inferior se convierte en una escalinata ceremonial coronada por el pebetero en el que arde el fuego Olímpico.

En el eje de la grada sur se dispone la tribuna de honor y encima de la misma la tribuna de prensa para 1.000 plazas, rematada en su parte superior por las 20 cabinas cerradas de radio.

El marcador esta situado en la parte superior del eje de la curva este.

Construido en hormigón armado revestido por potentes bloques de piedra caliza de sedimento marino de Franconia, con una labra severa.

No tenía ningún tipo de cubierta.

El estadio forma, por primera vez, desde el punto de vista arquitectónico y compositivo parte de un conjunto perfectamente diseñado y organizado.

La principal consideración para la disposición de los diferentes edificios en el Reichssportfeld fue la necesidad de garantizar el libre acceso y la salida de los espectadores, los invitados de honor, los competidores, para todas las personas relacionadas con la organización y para la prensa. El Estadio Olímpico, como eje principal de los Juegos, se encuentra en el medio, y muy cerca de los principales accesos desde el este y el sur, y desde las estaciones de metro y ferrocarril municipal. La Puerta olímpica, la entrada principal del Estadio Olímpico cuenta con 52 tornos para el público de pago y de las dotaciones necesarias para la recepción y la atención de los espectadores. ... Además la entrada sur cuenta con 28 tornos más, por lo que en una hora los 100.000 espectadores pueden comprar sus entradas y acceder al estadio. Del Report Official. El espacio alrededor del estadio es dos veces la superficie de sus graderíos, para poder asegurar una fácil evacuación y acceso a los diferentes sistemas de transporte.
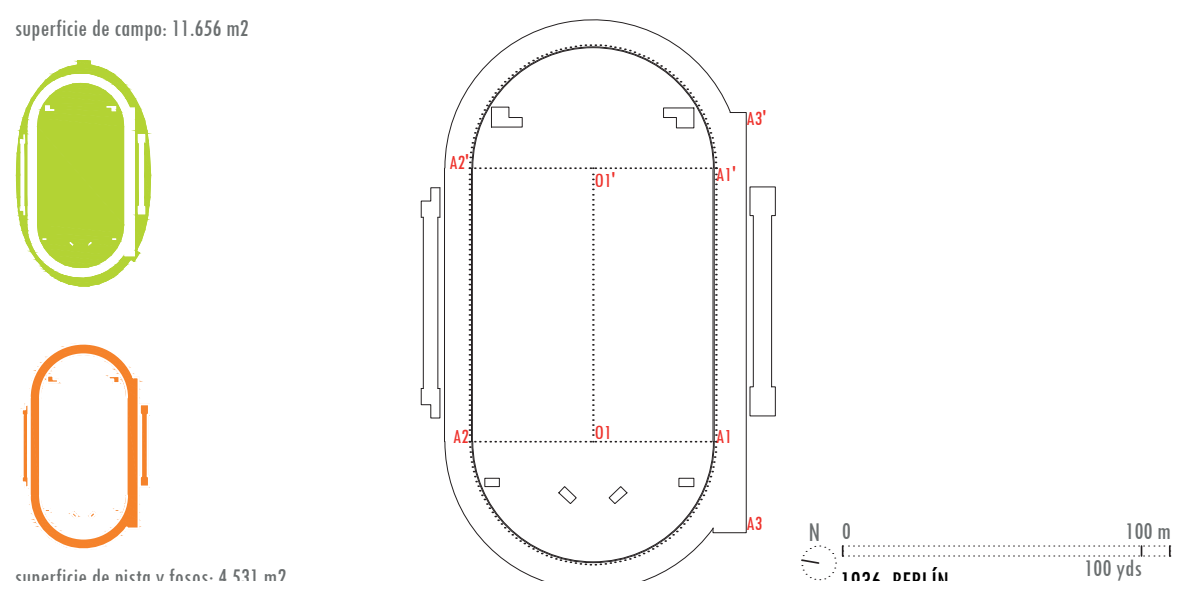

\subsection{Descripción del Estadio; Pista}

Dimensiones: Cuerda de la pista de 400 metros y siete calles de 4 pies de ancho $(1,22 \mathrm{~m}$.) y un ancho total de 28 pies $(8,53 \mathrm{~m}$.) con una inclinación hacia el interior en las rectas de 1,5\% y en las curvas del $3 \%$. Orientada este-oeste. La recta sur cuenta con 8 calles para las carreras de velocidad pura, alargándose en 8 pies $(2,44 \mathrm{~m}$.) para las salidas y 56 pies $(17,07 \mathrm{~m}$.) más allá de la línea de meta, con una longitud total de 142 yardas $(129,84 \mathrm{~m}$.). Fosos de saltos en el exterior de ambas rectas. Espacio libre interior de 115 yardas $(105,16 \mathrm{~m}$.) de largo por 76 yardas $(69,49 \mathrm{~m}$.) de ancho en el que se puede marcar un campo de fútbol.

La pista y la grada están separadas por un foso para prensa.

Material: Su composición es la siguiente:

Pista.

$8,0 \mathrm{~cm} .80 \%$ de escoria gruesa y $20 \%$ de arcilla de 20 a $30 \mathrm{~mm}$ de granulometría. $5,5 \mathrm{~cm} .70 \%$ de escoria fina y $30 \%$ de arcilla de $12 \mathrm{~mm}$.

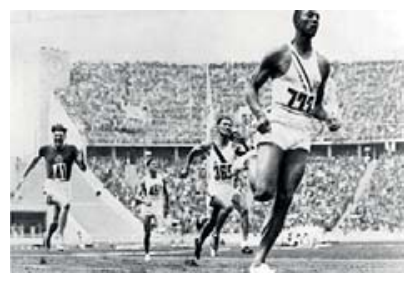




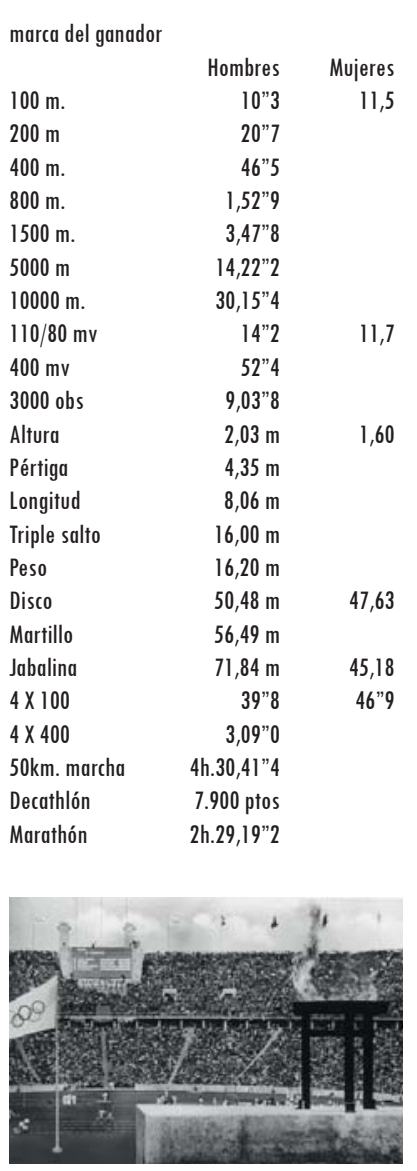

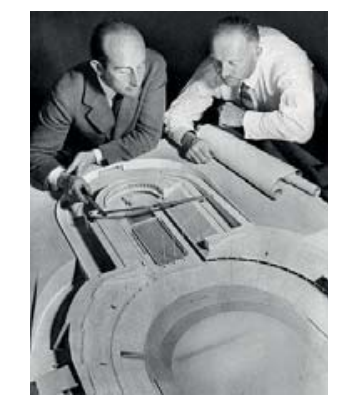

Pebetero

Werner March, a la izquierda, con Carl Diem
$2,5 \mathrm{~cm} .75 \%$ tierra roja y $25 \%$ de arcilla de 1 a $10 \mathrm{~mm}$.

$2,0 \mathrm{~cm} .50 \%$ tierra roja y $50 \%$ de arcilla de $0.3 \mathrm{~mm}$.

$0,5 \mathrm{~cm}$. limo.

El césped de 12 pulgadas (30,48 cm.) de buen suelo sembrado de la siguiente manera: $25 \%$ pradera de césped, $25 \%$ hierba festuca, $20 \%$ hierba de pasto alemán, el $27 \%$ cresta de gallo hierba, y el $3 \%$ de trébol blanco. (datos sacados directamente de Informe oficial, por un lado no suman el $100 \%$ y por otro la cresta de gallo, cockscomb grass, no parece una especie adecuada para una pradera).

1,7 Programa Deportivo: Atletismo, Hípica Premio de las Naciones, Fútbol semifinales y finales, Balonmano semifinales y finales y las Ceremonias de apertura y clausura

\subsection{Elementos significantes}

El eje formado por la puerta, la escalinata, el túnel y las dos torres de Marathon, con el pebetero del fuego Olímpico como elemento central de la composición.

\subsection{Avances técnicos}

Los juegos de Berlín fueron el primer evento televisivo a gran escala; emitido en 27 salas de televisión distribuidas por la ciudad donde la gente podía seguir las competiciones. Además, el complejo deportivo contaba con los más modernos medios de comunicación, tanto para seguridad como para fines periodísticos.

\subsection{Autores. Tipo de encargo}

Werner March (1894/1976) y su hermano Walter (1898/1969) a título de colaborador según aparece en los planos. Hijos del también arquitecto Otto March (1845/1913), autor del preexistente Deutsches Stadion. Werner inició sus estudios de arquitectura en la Universidad Técnica de Dresde, en 1914 se alisto de soldado en la Primera Guerra Mundial, acabando como oficial. después de la guerra acaba sus estudios en la Universidad Técnica de Berlín. Siendo alumno de German Bestelmeyer (1874/1942) colabora con él supervisando dos de sus obras, la Reichsschuldenverwaltung en Berlín y un banco en Gotha.

En 1923 se titula como arquitecto y trabaja para el Reichsbank en el diseño y construcción de un conjunto de viviendas para sus empleados en Schmargendorf, Berlín. Abre estudio propio en 1925 y con su hermano Walter ganan el concurso para el Deutsches Sportforum.

Entre 1934 y 1936 proyecta y dirige las obras del Reichssportfeld, con todas sus instalaciones. Desde 1936 a 1938 es profesor en la Universidad de Berlín.

Participa en la Segunda Guerra Mundial como oficial. Disfrutando de algunos periodos de excedencia para la supervisión de las obras públicas o la realización de proyectos, como el Aldolf Hitler Stadion en Lepzig, 1942.

Al acabar la guerra, con su casa y estudio en Berlín destruidos, se traslada a Minden donde dirige la reconstrucción de la Catedral y del Ayuntamiento.

En 1946 proyecta y construye la embajada de Yugoslavia en Berlín. En 1951 proyecta la primera de su Iglesias, la Apostólica Güntersloh, Wrederanfbau. En 1952 inicia sus trabajos en Bagdad, con el proyecto del Museo Arqueológico. En 1957, un gran complejo deportivo en el Cairo con un gran estadio. En 1960, Instituto Técnico de la Universidad de Berlín.

En el archivo de la Universidad de Berlín se encuentra una propuesta suya para el estadio de Munich fechado en 1964, tres años antes del concurso que ganaría Behnisch.

Realiza también varios trabajos de urbanismo y en 1953 volvió a la Universidad Técnica de Berlín. Continuando como profesor emérito después de su retiro en 1960.

Paisajista, Heinrich Wiepking-Jürgensmann (1891/1973)

Construido por la Reichsneubauamt.

Albert Speer (1905/1981), hijo y nieto de arquitectos. Se gradúa en 1927 en la Escuela Técnica Superior de Arquitectura de Berlín-Charlottemburg, donde había sido alumno y asistente de Heinrich Tessenow (1876/1950). En 1931 ingresa en el partido nacional socialista, para el que pasa a trabajar. En 1934 se convierte en primer arquitecto del partido. Obras suyas son; el Ministerio de Propaganda en la Wihemplatz de Berlín, 1933. La escenografía en Nuremberg del Zeppelinfeld, 1934. Plan integral de reforma de Berlín, 1936. Nueva Cancillería, 1939.

Tipo de encargo. Es un encargo directo, quizás, derivado de posición ventajosa del arquitecto como ganador del concurso para la construcción del Sportforum en esa misma localización, y ser el Grunewaldstadion una obra de su padre, Otto March.

Por estos motivos colabora con Carl Diem (1882/1962) en el estudio de alternativas de estadio olímpico de cara a la candidatura de Berlín. Diem fue un gran impulsor de deporte en Alemania y del olimpismo, desde su faceta de organizador y pensador. Werner fue miembro del comité organizador de los Juegos de 1936. 


\subsection{Edificios coetáneos}

En este año se terminan de construir la Casa Bloc de Josep Lluís Sert en Barcelona y la Casa del Fascio en Como de Giuseppe Terragni. De un año antes son la Casa de la Cascada de Frank Lloyd Wright y la biblioteca de Viipuri de Alvar Aalto. Y de uno después el Golden Gate de San Francisco.

El 30 de octubre de 1936 un pavoroso incendio destruye el Crystal Palace de John Paxton.

\subsection{Hechos históricos relevantes:}

El 17 de julio se inicia la guerra civil española.

\section{Bibliografía Berlín:}

The XI th Olympic Games Berlin, 1936. Official Report. Volume I. (1937) Ed. Organisationskomitee Für Die Xi. Olympiade Berlín 1936 E. V. Responsable de contenidos Dr. Carl Diem. Editor Dr. Friedrich Richter. llustraciones Wilhelm Reetz, Berlín. Copyright 1937 Wilhelm Limpert-Verlag, Berlín Sw 68, Ritterstrasse 75

GORDON, Barclay F. (1983). Olympic Architecture. Building for the summer games. Ed. John Wiley \& Sons. Nueva York. ISBN 0-471-06069-0

KLUGE, Volker. ZIMMERMANN, Harf, fotografias. (1999) Olympiastadion Berlín. Steine beginnen zu reden. Olympia Stadium : stones are beginning to talk. Ed. Parthas. Berlín. ISBN $10 \quad 3932529286$ KRAUSE, Gerhard (1936). Das Reichssportfeld. llustrado por STRACHE, Wolf. Ed. Reichssportverl. Berlín. MALLWITZ, Artur (1909). Das deutsche Stadion im Grunewald. Verlag f. Volkshygiene und Medizin. MARCH, Werner. ROHRBACH, Charlotte (Fotografias) (1936). Bauwerk Reichssportfeld. Ed. Deutscher Kunstverlag, Berlín. Biblioteca CIO. MA 3465

VERSPOHL, Franz Joachim. (1976) Stadionbauten Von Der Antike Bis Zur Gegenwart: Ed. U. Selbsterfahrung D. Massen, 1 st Edition (Illustrated). Anabas-Verlag. ISBN 3-87038-043-8

WIMMER, Martin. (1976). Olympic Buildings. Ed. Leipzig. Lic 600/34/75. 5938721

The Stadium. The Architecture of Mass Sport. (2000). Ed. Michelle Provoost. NAI Publishers Rotterdam. ISBN 90-5662-145-9

Archivo CIO. Das Reichssportfeld. (1937). llustraciones, Herbert Leinbaum. Ed. A. Gallus Druckerei, Berlín Archivo ClO. Id 10427. ClO JO1936S-STADE. SDI. Plans des Installations Sportives et du Stade Olympique, 1936

Archivo ClO. Id 10021. ClO JO1936S_STADE. Das Deutsche Stadion. Sport und Turnen in Deutschland, 1913. August Reher's Verlag Charlottenburg

http://architekturmuseum.ub.tu-berlin.de

http://www.olympiastadion-berlin.de 


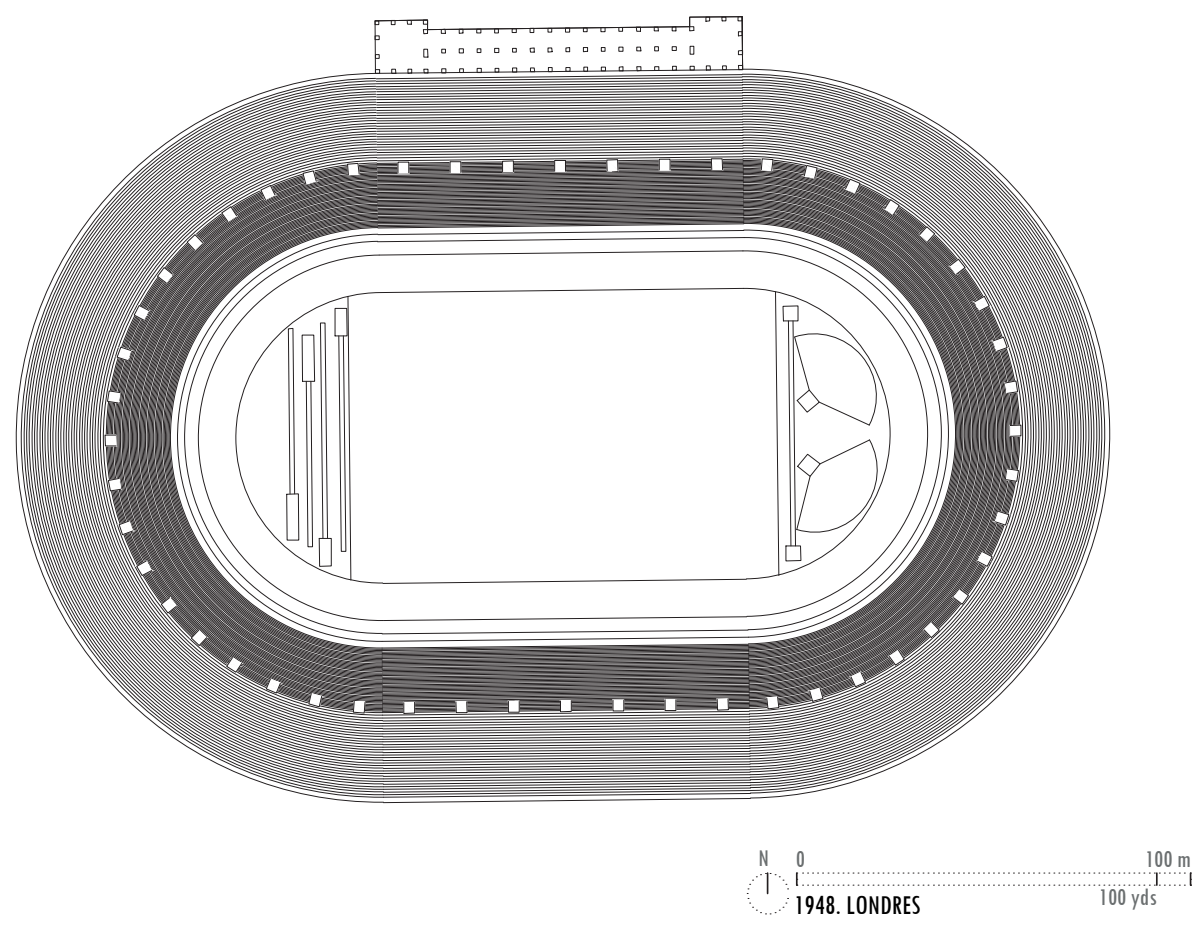

1948.0. Nombre del Estadio

Empire Stadium en Wembley

1948.1. Situación

Wembley Stadium. Wembley. London. Inglaterra.

1948.2. Fechas

1919. Se inician los trabajos preparatorios de la Exposición del Imperio Británico, que tenia por objeto mostrar la capacidad industrial y los recursos naturales del Imperio.

1921. Se eligen los terrenos de un antiguo parque de recreo en Wembley, un terreno vacante y bien comunicado por tren con el centro de Londres.

1922. En enero, se inicia la construcción del estadio.

1923. El 8 de abril, se inaugura el estadio con la final de la FA Cup. A partir de esta fecha se han celebrado en Wembley 78 finales de la FA Cup, 258 partidos internacionales de la selección inglesa de fútbol, 40 finales de la copa de la Liga y 6 finales de la Copa de Europa de fútbol.

1924. El 23 de abril, el rey Jorge $V$ inaugura oficialmente el estadio y la Exposición del Imperio Británico, que tuvo dos años de desarrollo.

1929. Desde este año se celebra en Wembley la final de la Copa Challenge de la Liga inglesa de Rugby.

1944. Los Juegos que habían de ser celebrados en Londres fueron suspendidos por el estallido de la Segunda Guerra Mundial.

1945. En octubre, el presidente del British Olympic Council, Lord Burghley pregunta al $\mathrm{ClO}$ si les corresponde organizar los próximos Juegos, en 1948. A partir de ese momento, Londres prepara un plan detallado para llevarlos a cabo, con unos criterios de gran austeridad.

1946. A principios de marzo, en CIO vota a favor de celebrar los Juegos de la XXIV Olimpiada en Londres.

1946. Se constituye el Comité Organizador y se consigue el apoyo económico del gobierno.

1947. A finales de 1947 se comenzó la adecuación del estadio, incluyendo la construcción de una pista de ceniza para las pruebas de atletismo. Terminandose a dos meses de la fecha de inauguración.

1948. Los Juegos se inauguraron el 29 de Julio, cuando el Big Ben marcaba las 4 en punto, según se muestra en el cartel anunciador. Se clausuraron el 14 de Agosto

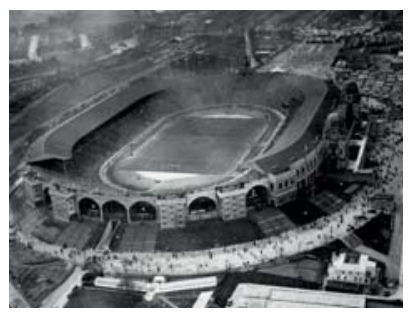




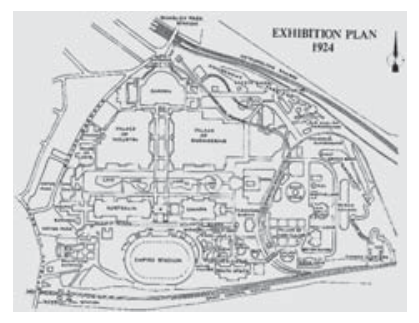

y a mediados de septiembre todas las instalaciones añadidas temporalmente ya habían sido retiradas para ser vendidas o subastadas.

1966. Se celebra en Wembley la final de la Copa del Mundo de Fútbol.

1982. Gran celebración del Papa Juan Pablo II.

1985. Concierto con motivo de Liv Aid.

1986. Concierto de Queen.

1988. Concierto de Michael Jackson.

1990. Concierto de los Rolling Stones.

1996. Final de la Eurocopa de Fútbol.

2002. Demolición e inicio de la construcción del nuevo Wembley, que se inauguró en 2007. proyecto de Foster and Partners y HOK Sport (Populous desde 2009).

\subsection{Preexistencias en el lugar:}

En la zona, una de las más ricas de Harrow, densamente arbolada y situada al norte de la Harrow Road, parece que existieron, a finales del Siglo XVII algunas pequeñas construcciones, pero lo que marca la preexistencia en el lugar es una casa solariega que perteneció a la familia Page durante un par de siglos, hasta finales del XVIII.

En 1837, el ferrocarril entre Londres y Birmingham, ahora parte de la West Coast Main Line, se abrió desde London-Euston, a través de Wembley hasta Hemel Hempstead, y después hasta Birmingham un año después. Los nombres cambiantes de la estación local ponen de manifiesto la creciente importancia del lugar, así, la estación de Sudbury que abrió sus puertas en 1845 fue rebautizada en 1882 como "Sudbury y Wembley", en 1910 como "Wembley para Sudbury" y en 1948 como "Wembley Central", en el momento de los Juegos Olímpicos.

En la década de 1880 el lugar era utilizado para jugar al fútbol. Posteriormente la compañia Ferrocarril Metropolitano, presidida por sir Edwin Watkins, inició la construcción, en el mismo lugar, la denominada Torre Watkins, también conocida como la "Locura de Watkins"), un intento de erigir un rival en Londres a la Torre Eiffel. La visión de sir Edwin Watkins no llegó a realizarse completamente debido a la falta de fondos, fue abandonada a media altura y demolida en 1907.

La idea de crear una Exposición del Imperio Británico ya había sido debatida antes del estallido de la Primera Guerra Mundial y fue resucitada en 1919 con el objetivo declarado de I... permitir, a todos los que le deben lealtad a la bandera británica, reunirse en un terreno común y aprender a conocerse unos a otros».. Este fue el lugar elegido, situado al noroeste del centro de Londres y bien comunicado.

Existieron tres motivos esenciales para la elección del lugar:

El carácter de "espacio abierto". Wembley Park no tenía los inconvenientes de un parque público central.

La existencia de dos líneas de ferrocarril metropolitano que discurrían por las proximidades y facilitarían el acceso a los visitantes.

El desarrollo urbano que, en las primeras décadas del siglo XX estaba protagonizando la ciudad de Londres.

\subsection{Relación con la ciudad. Posición respecto al centro urbano}

El Empire Stadium de Wembley se sitúa al noroeste de Londres, a $18 \mathrm{~km}$. del centro y al norte de la Harrow Road, notable vía de comunicación.

No fue necesaria la implantación de nuevas y extraordinarias infraestructuras de comunicación pues todas las necesarias se habían ejecutado 25 años antes para la Exposición. Aparte de eso, quizá no hubiera sido posible realizarlas tan solo tres años después de finalizada la guerra mundial. En esta situación, Londres se aprestó a celebrar la que sería conocida como "la olimpiada de la austeridad", alojando a los deportistas en recintos cuartelarios, con un mínimo de gasto y la incomodidad de los desplazamientos hasta los lugares donde se celebrarían las pruebas deportivas. En el apartado económico y, lógicamente, debido a la escasa inversión, los juegos olímpicos fueron un éxito.

\subsection{Breve relato de la historia del Estadio}

El Empire Stadium formaba parte de las infraestructuras realizadas para la Exposición del Imperio Británico que se celebró entre 1924 y 1925, tras finalizar la Primera Guerra Mundial. Fue una exposición innovadora, en la que participaron los países que habían pertenecido al Imperio Británico y sus actuales colonias. Correspondía con un momento de gran optimismo, los felices 20, asistieron 27,1 millones de visitantes.

El parque de la Exposición contenía un conjunto de edificios, muchos de ellos construidos como estructuras permanentes, con contenidos diferenciados (agricultura, industria, ingeniería, 
...). Para dar una idea de su magnificencia, diremos que el Palacio de Ingeniería fue, en su momento, el mayor edificio de hormigón armado en el mundo. Cubrió 13 acres $(5,26$ Has) y contó con cinco líneas de ferrocarril internos para ayudar a mover los objetos expuestos. El estadio era una de las piezas principales y focalizadora de la organización general. Fue proyectado por los arquitectos John Simpson y Maxwell Ayrton y del Ingeniero Owen Williams, su coste de construcción fue de 750.000 libras.

En su arquitectura de carácter industrial destacan exteriormente sus dos torres gemelas de lenguaje colonial mogol.

Aunque no fue inaugurado oficialmente, por el rey Jorge V. hasta el 23 de abril de 1924, en el estadio se jugó la final de la Copa el 28 de Abril de 1923, con la asistencia de unas 200.000 personas hacinadas en sus graderíos.

El estadio debía ser demolido al final de la exposición, pero se salvó por sugerencia del presidente del comité organizador, sir James Stevenson. Poco después el estadio se declaró económicamente inviable y fue subastado, haciéndose con él la Wembley Company.

Para los Juegos Olímpicos de 1948 sólo se realizaron las modificaciones necesarias para la adecuación de la pista.

El estadio se mantuvo sin variaciones reseñables hasta 1963, que se añadió el marcador electrónico y se cubrió el graderío en su totalidad con vidrio translúcido. Las distintivas Torres Gemelas se mantuvieron como icono de referencia.

El estadio se cerró en octubre de 2000, y la demolición se inició en diciembre de 2002, completándose en 2003 para construir el estadio actual, proyecto de Foster and Partners y HOK Sport (Populous desde 2009).

1948.6. Descripción del Estadio; Graderío

El Estadio de Wembley Park, construido en origen para la Exposición del Imperio Británico, debía mostrar la magnificencia que el evento requería. Reconvertido para su utilización en los Juegos Olímpicos era capaz de albergar a no menos de 126.500 personas, de las cuales 25.000 estaban sentadas bajo cubierta, otras 10.000 en asientos de graderío y al menos 91.500 de pie. Todos ellos disfrutando de una visión completa del terreno de juego.

Circundando a la pista de atletismo se disponen 5 filas de asientos ( 11 pies) con la capacidad de ser ampliado al doble invadiendo la pista de atletismo.

superficie de cubierta: $11.860 \mathrm{~m} 2$
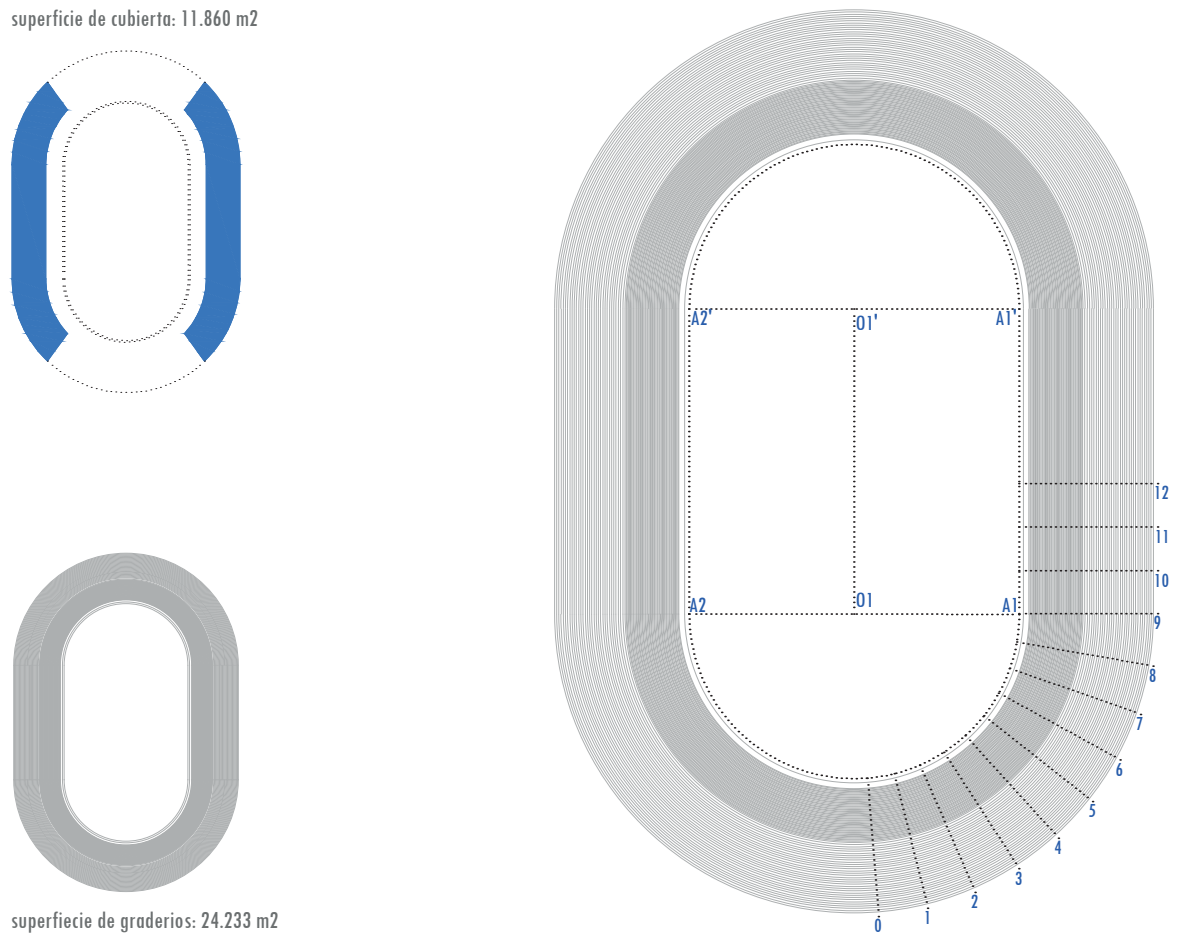

superfiecie de graderios: $24.233 \mathrm{~m} 2$

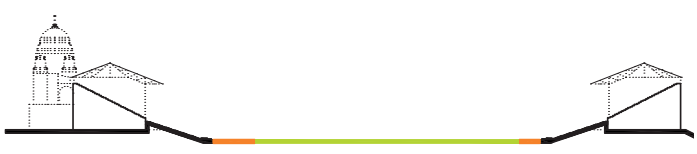

dimensiones y superficies aproximadas graderío

L 01-01' 92,99 M

R OI-Al $\quad 50,33 \mathrm{M}$

$<$ Al.01.A2 $180^{\circ}$
$N \quad 0$
$-\quad 1$
- 1948. LONDRES 

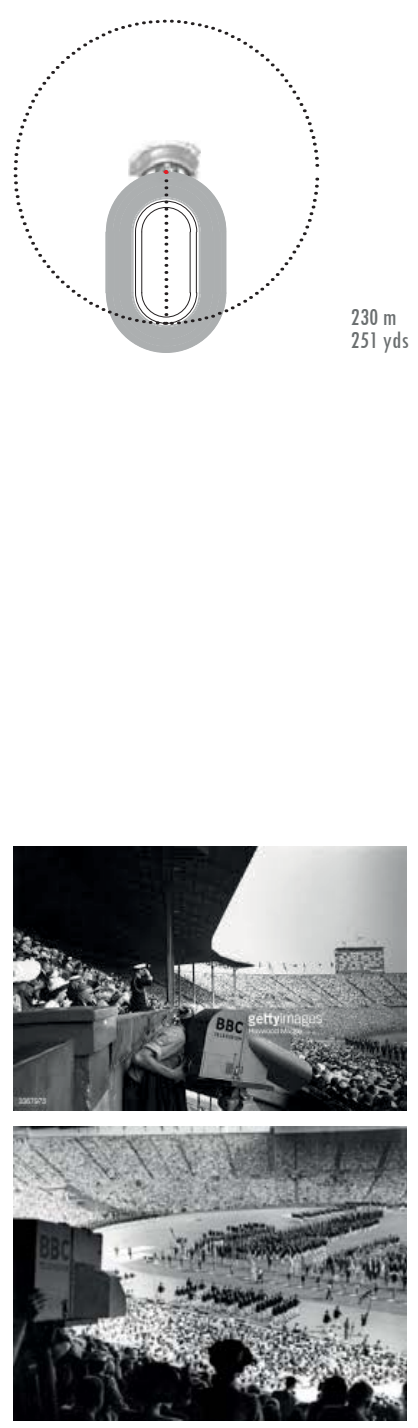

Hacia su exterior, comienzan el graderío descubierto, para público de pié, 48 filas, separadas en cuatro franjas longitudinales por barandillas antiavalanchas, cada grada tiene una anchura promedio de 1 pie y dos pulgadas $(36 \mathrm{~cm}$ ) hasta una anchura total de 56 pies y cuatro pulgadas $(17,17 \mathrm{~m})$. Con una diferencia de en altura total de poco más de 16 pies y 6 pulgadas $(5,04 \mathrm{~m})$. Para acceder a este graderío existen cuarenta y nueve vomitorios a nivel del terreno exterior. Un túnel principal comunica directamente el exterior con el terreno de juego.

Este primer graderío está apoyado en rellenos realizados con terrenos escogidos del lugar, terrenos arcillosos, de forma que se realizó un movimiento de tierras de unas 120.000 yardas cúbicas $\left(91.750 \mathrm{~m}^{3}\right)$.

Tras esta fase de adecuación y aprovechamiento del terreno, finalizada en febrero de 1922, comienza la verdadera construcción tectónica del edificio con la creación de un muro de hormigón armado, alrededor del graderío descrito, para contrarrestar el empuje de las tierras y para apoyar la estructura metálica de gradas y cubiertas. Esta nueva fase de construcción llevará poco más de un año.

El graderío alto esta constituido por de 31 gradas de 2 pies y 2 pulgadas de ancho 166 $\mathrm{cm}$ ) por 1 pie y una pulgada de alto $(33 \mathrm{~cm})$, prefabricadas en hormigón, se apoyan en un forjado, inclinado $(2 \times 1)$ respecto a la horizontal, conformado por viguetas de acero laminado en "Ll" de $14 \times 6$ pulgadas $(36 \times 16 \mathrm{~cm}$ ) espaciadas 14 pies y 4 pulgadas $(4,37 \mathrm{~m})$. Estas viguetas apoyan su extremo más bajo sobre el muro de hormigón citado anteriormente y su extremo más alto en pilares de hormigón armado, de sección cuadrada de $20 \times 20$ pulgadas $(52 \times 52 \mathrm{~cm})$ situados el muro de cerramiento exterior del estadio. En tres puntos intermedios de su longitud están atadas (remachadas) por sendas vigas de celosía que se apoyan, cada tres viguetas, en pilares metálicos, formados por cuatro canales de acero y barras de cordón, de distintas alturas (16, 24 y 32 pies) en función de la pendiente del forjado que soportan. La distancia radial entre estos pilares es de 17 pies y 4 pulgadas $(5,29 \mathrm{~m})$. Los dos pilares más altos de cada "radio" están atados, entre sí y al muro exterior, por cerchas ligeras, sobre las cuales se apoya un forjado de hormigón de 4 pulgadas $(12 \mathrm{~cm}$ ) de espesor que genera un pasillo elevado en todo el perímetro del estadio para acceder a las gradas más altas.

En los lados norte y sur del estadio las gradas están cubiertas en una longitud de 650 pies (200 m). Los asientos, en estas zonas son de madera, abatibles y más cómodos. En el resto no cubierto los asientos están formados por unas simples tablas cepilladas fijadas a los peldaños prefabricados de hormigón. Las cubiertas están formadas por cerchas triangulares sobre las que apoyan unas placas de fibrocemento corrugado. Las cerchas principales de apoyan, por el lado del terreno de juego, en sendos pilares prefabricados de hormigón, de sección octogonal y 32 pies de altura $(9,75 \mathrm{~m})$, que nacen en la cabeza del muro de contención y por el otro lado en el propio cerramiento perimetral del estadio.

En el lado Sur existen 16 de esos pilares prefabricados mientras que en el lado Norte sólo existen 12, dejando un vano central de unos $40 \mathrm{~m}$. para facilitar la visión desde el palco de autoridades y desde las tribunas de prensa. En este lado Norte, donde la edificación se adosa al estadio, también la tipología constructiva es diferente. En la parte inferior de las gradas, a 21 pies $(6,40 \mathrm{~m})$ de la arena y apoyado en el muro de contención se encuentra el palco (the Royal Box), con acceso directo desde el exterior a través de la Sala de Banquetes, una enorme sala diáfana de 215 pies $(65,50 \mathrm{~m})$ de larga por 70 pies $(21,30 \mathrm{~m})$ de ancha cuyas puertas, con arcadas de medio punto, conducen a una amplia terraza que se extiende a lo largo de la cara norte del edificio.

\subsection{Descripción del Estadio; Pista}

El rectángulo central, con extremos redondeados, tiene unas dimensiones de 492 pies (150 m) de largo por 260 pies $(79,25 \mathrm{~m}$ ) de ancho. El césped ha sido seleccionado en diferentes lugares de la propia finca. Está rodeado por una pista de ceniza, para pruebas de atletismo, de 42 pies de ancho $(12,80 \mathrm{~m})$. Las dimensiones son tales que una línea trazada, a un pie de distancia hacia el exterior del terreno de juego, tiene una longitud de un cuarto de milla, por lo que cuatro vueltas completan un recorrido de una milla (1.609,34 m).

Para los Juegos, ya que el estadio no había sido usado para competiciones atléticas durante más de 20 años, fue necesaria la instalación de una nueva pista de atletismo. Se investigaron diversos materiales a fin de obtener la mejor superficie posible.

Marcadores. El marcador gigante que se utilizó para todos los eventos en este estadio fue construido en el extremo este del estadio directamente detrás de la última grada de espectadores. Fue diseñado por sir Owen Williams \& Partners, los arquitectos, y fue operado por un grupo de la armada cedido por el Almirantazgo. Además del marcador principal, cuatro cuadros de indicadores, uno en cada esquina del terreno de juego, mostraban el avance de los acontecimientos al momento.

Equipo de Eventos en campo. Dados los altos estándares exigidos para las pruebas de salto 
de longitud, salto de altura y salto con pértiga, fue necesario incorporar unas escalas de medición precisas para que fuesen utilizadas por los jueces y funcionarios.

Para el salto de longitud se diseñó un brazo deslizante, en forma de triángulo que se desplazaba sobre el foso, de forma que un "cepillo" en uno de los lados se encargaba de "peinar» la arena y borrar las huellas que pudiesen dar lugar a confusión. El elemento triangular se deslizaba a lo largo de unos carriles de rodadura situados a ambos lados de la fosa, de modo que la línea del pelo podría ser colocada con precisión en el lugar deseado y marcar, sobre una escala situada en un lateral, la longitud del salto realizado. Para detectar un salto nulo cuando el atleta pisaba la línea de salto, se utilizó una bandeja poco profunda de plastilina. El sistema resultó fiable, sencillo y eficaz.

Se instalaron indicadores especiales para estas pruebas, de forma que pudiera conocerse en todo momento el número del competidor y la altura que se estaba intentando. Estos indicadores eran útiles sobre todo cuando en el campo estaban ocurriendo al mismo tiempo otros eventos.

Para los lanzamientos de martillo y disco se utilizaron líneas de referencia circulares concéntricas con el círculo de lanzamiento de forma que, utilizando un brazo especial provisto de una cinta métrica metálica, (indeformable), se pudieran obtener rapidamente las marcas obtenidas.
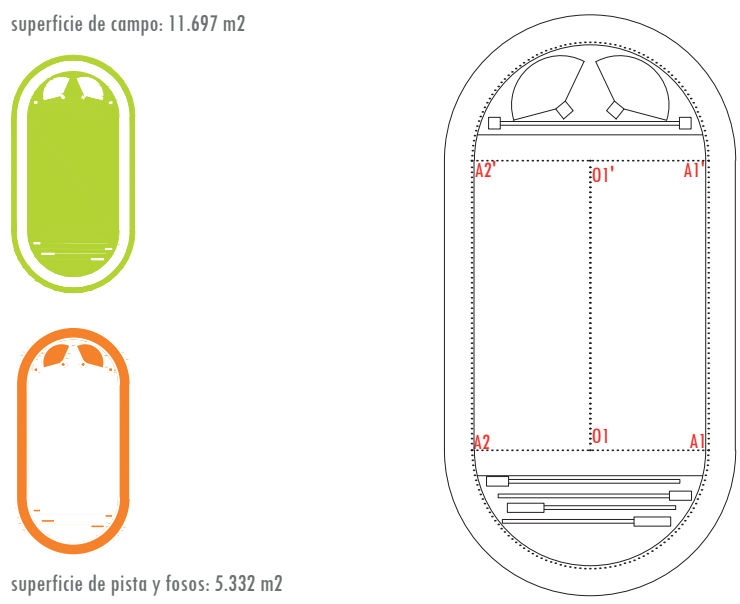

Programa Deportivo: Atletismo, futbol (semifinales y finales), hockey sobre hierba (final), equitación (saltos) y las Ceremonias de Apertura y Clausura.

1948.8. Elementos significantes

El edificio en el lateral Norte, la fachada porticada con las dos torres cupulares en los extremos.

\subsection{Avances técnicos}

El nacimiento del cronometraje moderno, con la utilización de la célula fotoeléctrica (Omega) aplicada a una cámara fotográfica para determinar el orden de llegada a la meta y eliminar las salidas antes de tiempo.

En 1948, los resultados registrados por los dispositivos de sincronización automática no se utilizaron oficialmente. El primer equipo photo finish sólo sirvió para ayudar a los jueces. Sólo 20 años después, en las Olimpiadas del 68, en México, los tiempos automáticos empezarían a ser oficiales.

\subsection{Autores. Tipo de encargo}

John William Simpson (1858/1933) y su socio Ormrod Maxwell Ayrton (1874/1960), con el apoyo del ingeniero Evan Owen Williams (1890/1969), el peso del diseño correspondió a los dos últimos.

John William Simpson nació en Escocia, hijo del arquitecto Thomas Simpson, pero se educó en Brighton. Comienza a trabajar con su padre en 1875. En 1878 se traslada a Londres para estudiar en la Royal Academic School, tenia una gran ambición y era un dibujante capaz y trabajador.

En 1881 inicio su colaboración con Michael Prendergast Manning. El 6 de noviembre de ese año fue admitido en el RIBA. En esos tiempos había viajado por Francia y Bélgica.

En 1887 Simpson se asocia con Edmund J. Milner Allen, un compañero de estudios algo menor

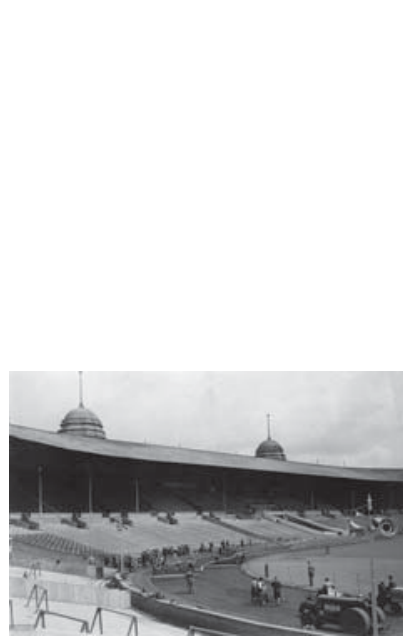

dimensiones y superficies aproximadas pista

$\begin{array}{lr}\text { CUERDA I } & 400,00 \mathrm{M} \quad 437 \mathrm{yds} \text { I' } 4 \frac{1}{32} " \\ \text { L O1-01' } & 88,26 \mathrm{M} \\ \text { R 01-Al } & 35,57 \mathrm{M} \\ \text { < A1.01.A2 } & 180^{\circ}\end{array}$

$\begin{array}{lrr} & \begin{array}{r}\text { marca del ganador } \\ \text { Hombres }\end{array} & \text { Mujeres } \\ 100 \mathrm{~m} . & 10 " 3 & 11 " 9 \\ 200 \mathrm{~m} & 21 " 1 & 24 " 4 \\ 400 \mathrm{~m} . & 46 " 2 & \\ 800 \mathrm{~m} . & 1,49 " 2 & \\ 1500 \mathrm{~m} . & 3,49 " 8 & \\ 5000 \mathrm{~m} & 14,17 " 6 & \\ 10000 \mathrm{~m} . & 29,59 " 6 & \\ 110 / 80 \mathrm{mv} & 13 " 9 & 11 " 2 \\ 400 \mathrm{mv} & 51 " 1 & \\ 3000 \text { obst } & 9,04 " 6 & \\ \text { Altura } & 1,98 \mathrm{~m} & 1,68 \mathrm{~m} \\ \text { Pértiga } & 4,30 \mathrm{~m} & \\ \text { Longitud } & 7,83 \mathrm{~m} & 5,70 \mathrm{~m} \\ \text { Triple } & 15,40 \mathrm{~m} & \\ \text { Peso } & 17,12 \mathrm{~m} & 13,75 \mathrm{~m} \\ \text { Disco } & 52,78 \mathrm{~m} & 41,92 \mathrm{~m} \\ \text { Martillo } & 56,07 \mathrm{~m} & \\ \text { Jabalina } & 69,77 \mathrm{~m} & 45,57 \mathrm{~m} \\ 4 \text { X 100 } & 40 " 6 & 47 " 5 \\ 4 \times 400 & 3,10 " 4 & \\ 50 \mathrm{~km} . \text { marcha } & 4 \mathrm{~h} .41,52 " 0 & \\ \text { Decathlón } & 7.139 \mathrm{ptos} & \\ \text { Marathón } & 2 \mathrm{~h} .34,51 " 6 & \\ & & \end{array}$

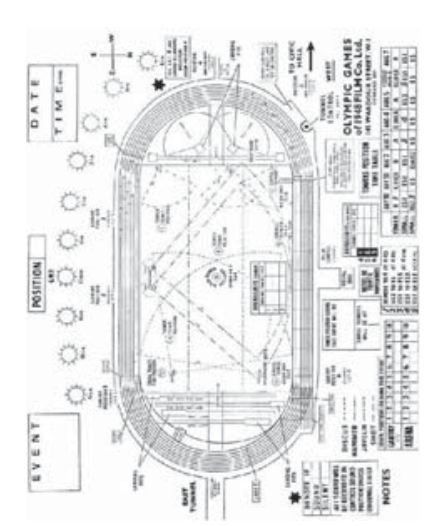


que él e hijo del pintor John Milner Allen. Esta asociación se permitió acceder a importantes concursos. Obteniendo un tercer premio en los edificios municipales de Edimburgo y el primero en el hospital de la ciudad de Liverpool, ambos en 1887. Ganó también los concursos para el Instituto Victoria, Worcester, 1890; Glasgow Art Gallery, 1891; y el Manchester Royal Infirmary, 1896.

En 1905 se incorporó al equipo Maxwell Ayrton, pasando a ser socio en 1910. Tras la muerte Milner, en 1912, Ayrton se responsabilizó más de la parte de diseño mientras que Simpson se involucro intensamente en sus responsabilidades en el RIBA, del que fue presidente entre 1919 y 1921 y vicepresidente de su Comité Internacional desde 1927 hasta su muerte.

Maxwell Ayrton, aunque era escocés, se había formado como arquitecto en Londres, donde trabajó para Edwin Luytens. Por su parte Owen Williams, era un ingeniero especializado en hormigón armado, había trabajado para la Trussed Concrete Company desde 1912 hasta 1919 que funda su propia empresa, la Williams Concrete Structures. Con el tiempo acabó trabajando como arquitecto, consideraba que arquitectura e ingeniería eran una misma disciplina, en 1930 proyectó en muy interesante edificio industrial Boots D10 Building en Nottingham, que está catalogado con el grado 1 desde 1971.

Diseñan el trazado general de la Exposición del Imperio Británico en Wembley (1924/1925), y sus piezas principales, los Palacios de Industria, Artes, Ingeniería y Horticultura, además del estadio para la práctica de los deportes nacionales de los países del imperio. Por razón de este trabajo a Simpson se le concedió el título de caballero.

Ayrton y Williams, colaborarían posteriormente, en el diseño de puentes en Escocia.

En 1928 se disolvió la asociación de Simpson y Ayrton. Sin embargo, Simpson siguió trabajando hasta la edad de 70 años, colaborando con Frank W. Knight y Henley Cornford. Enfermó en el invierno de 1932 y murió en marzo de 1933. Fue descrito como un hombre con una "lcapacidad de organización inusual ... con una mente sutil y penetrante, hombre de buen corazón y gran sentido del humor ...ll. Fue uno de los pocos arquitectos británicos de ese tiempo que apreciaba el valor de mantenerse IIen contacto con las ideas, los objetivos y el trabajo de los hombres de otras tierras.ll

Tipo de encargo. Encargo directo.

\subsection{Edificios coetáneos}

Iglesia parroquial del Espiritu Santo (Capilla del CSIC) Miguel Fisac. Madrid.

Maison Curutchet, Le Corbusier

Consolidación de la "ciudad" de Kowloon, en Hong Kong, la manzana más densamente poblada del planeta.

\subsection{Hechos históricos relevantes}

Asesinato de Mahatma Gandhi.

Invención del transistor.

Entrada en vigor del Plan Marshall para Europa.

Creación de la República Popular de Corea del Norte y del Estado de Israel.

Bibliografía Londres 1948:

XIV Olympiad London. 1948. The Official Report of the Organissing Committee for the XIV Olympiad . London (1948). GORDON, Barclay F. (1983). Olympic Architecture. Building for the summer games. John Wiley \& Sons. Nueva York. ISBN 0-471-06069-0

WIMMER, Martin. (1976). Olympic Buildings. Ed. Leipzig. Lic 600/34/75. 5938721

The Stadium. The Architecture of Mass Sport. (2000). Ed. Michelle Provoost. NAI Publishers Rotterdam. ISBN 90-5662$145-9$

Revista "The Engineer». 06-Abril-1923. "The Stadium in Wembley Park».

Exposiciones Internacionales y Urbanismo. Fco. Javier Monclús Fraga. Universidad Politécnica de Cataluña, 2006. 


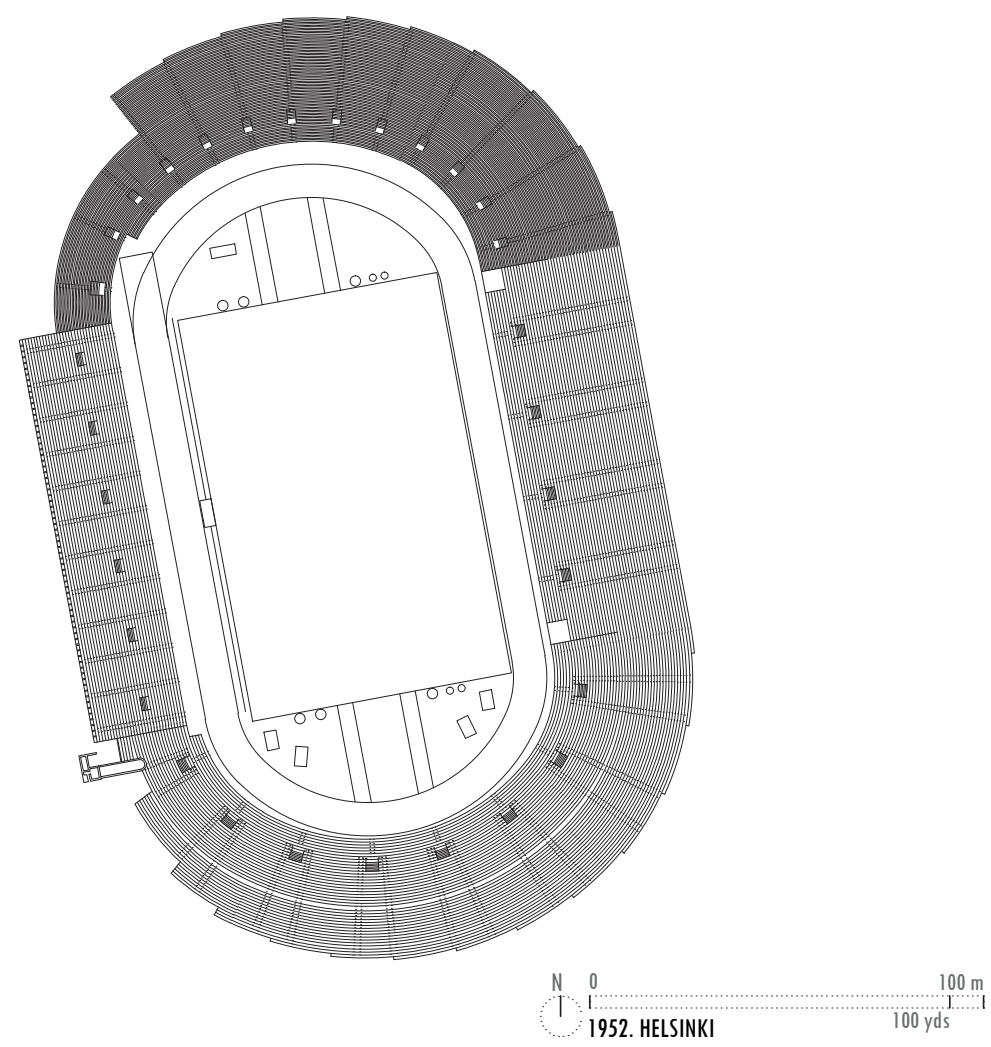

1952.0. Nombre del Estadio

Estadio Olímpico de Helsinki (en finés Helsingin Olympiastadion).

1952.1. Situación

Paavo Nurmen tie 1, 00250 Helsinki, Finlandia

\subsection{Fechas}

1927. Una Fundación formada por las principales asociaciones deportivas de Helsinki y más tarde se incorpora el propio Estado, representado por el Ministerio de Educación, promueve la construcción del Estadio. El objetivo es dotar a la ciudad de un estadio que pueda servir para acoger los Juegos Olímpicos de verano.

1933. Yriö Lindegren y Toivo Jäntti ganan el concurso de arquitectura celebrado para elegir el proyecto del nuevo estadio.

1934. El 12 de febrero, se inicia la construcción del estadio.

1938. El 12 de junio, es inaugurado por el presidente de la nación Juho Kusti Paasikivi.

1938. Tras la renuncia de Japón a organizar los Juegos de 1940, el ClO recurre a Helsinki, al haber sido la finalista del proceso de selección. Finalmente se suspenden definitivamente por el inicio de la Segunda Guerra Mundial.

1943. Se construye el Museo de Deportes de Finlandia dentro del propio Estadio.

1947. El 21 de junio, el CIO designa a Helsinki como sede de los Juegos de la XII Olimpiada en 1952.

1948. Campeonato del Mundo de Patinaje de Velocidad.

1952. Ampliación y adecuación del estadio para los Juegos.

1952. El 19 de julio, Inauguración de los Juegos.

El 3 de agosto, Ceremonia de Clausura.

1961. Se construye un albergue juvenil en el Estadio.

1970. Concierto de los Rolling Stones.

1983. Campeonato Mundial de Atletismo.

1991. Renovación y rehabilitación integral del estadio, que concluye en 1994.

1994. Campeonato de Europa de Atletismo.

1997. Concierto de Michael Jackson.

2005. Campeonato de Europa de Atletismo.

2006. Se cataloga como bien histórico del patrimonio de la nación.
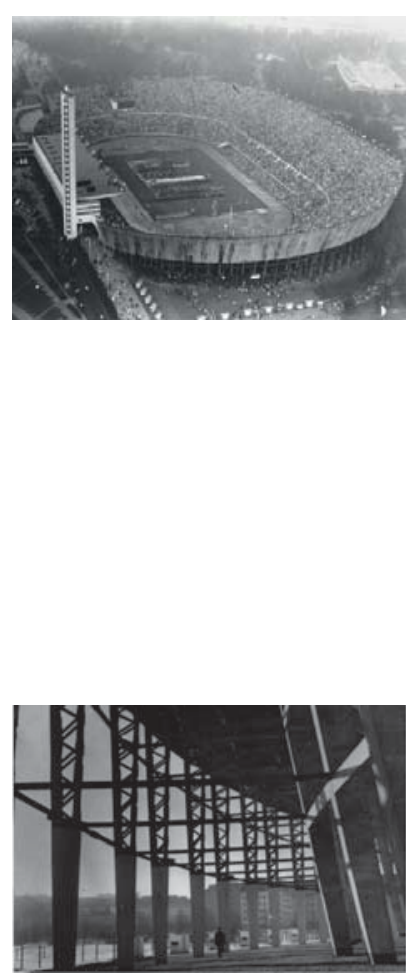

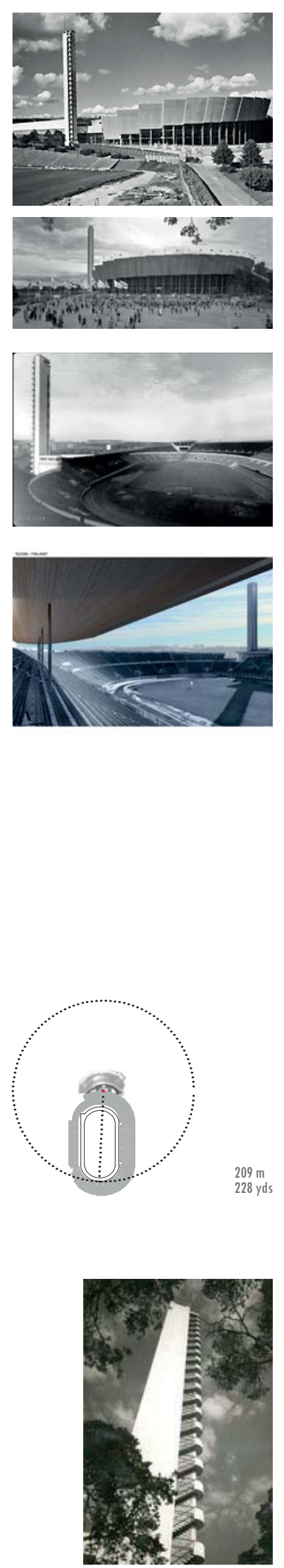

2007. Campeonato de Europa de fútbol.

2008. Concierto de Iron Maiden.

2009. Campeonato Europeo de Fútbol Femenino.

2010. Concierto de U2.

\subsection{Preexistencias en el lugar}

Área denominada Töölö compuesta por un total de 25 parcelas rurales entre humedales, bosques y praderas, adyacentes al centro de urbano y destinada a ser el Parque Central de la ciudad

\subsection{Relación con la ciudad. Posición respecto al centro urbano}

En el distrito de Töölö, a 2 kilómetros del centro de Helsinki.

\subsection{Breve relato de la historia del Estadio}

El lugar de ubicación fue objeto de un animado debate. Mientras que unos arquitectos criticaban la propuesta de la Fundación de ubicarlo en Töölö porque se temía la implicación del trafico que produciría en la zona del Parque Central y además porque el lugar no proporcionaba oportunidades para que el nuevo edificio tuviese un aspecto monumental, otros justificaban esta ubicación por su viabilidad económica, ya que se trataba de un lugar céntrico.

Yrïö Lindegren y Toivo Jäntti ganaron el concurso, celebrado en 1933 para el proyecto del Estadio Olímpico y antes de terminar el diseño, los autores gozaron de una beca para viajar durante seis semanas visitando edificios olímpicos en los diferentes países.

El Estadio Olímpico de Helsinki comenzó a construirse, en una primera fase, en 1934 y fue inaugurado el día 12 de junio en 1938. De hormigón visto, en color blanco y de líneas puras fue exaltado como un símbolo de la independencia. De estética arquitectónica práctica, funcional y racional.

Los ciudadanos aportaron su apoyo al patriótico proyecto mediante la compra de los productos que llevaban la marca Stadium. En una segunda fase, en 1940, se construyó la esbelta e imponente torre de hormigón armado, de 72,71 metros de altura (exactamente la misma longitud que necesitó el lanzador de javalina Martti Jarvinen para proclamarse campeón olímpico en Los Ángeles 1932).

La guerra supuso una pausa obligada en la ejecución del proyecto y no se pudo continuar hasta los últimos años de la década de 1940, con el impulso de la nueva concesión de los Juegos de 1952. Las necesidades de posguerra y la carencia de materiales dificultaban la construcción. Para los Juegos se amplió el graderío en 20.000 personas, mediante la adicción de gradas provisionales de madera a lo largo de todos sus lados exceptuando la parte de la tribuna principal y al acabar fueron desmontadas.

\subsection{Descripción del Estadio; Graderío}

El eje principal del estadio es norte sur. La longitud del edificio del estadio es de $243 \mathrm{~m}$ con una anchura máxima de $159 \mathrm{~m}$. El área que ocupa, junto con las instalaciones perimetrales, calles y zonas de aparcamiento es alrededor de 4,9 has.

Fue construido por fases, entre 1934 y 1952. En primer lugar se levantaron los graderíos, en 4 etapas diferentes. Las primeras que se construyeron, de hormigón armado para cerrar el óvalo, fueron las del oeste, las tribunas y algunas gradas de la parte este. Más tarde, cuando se conoció que los Juegos Olímpicos de 1940 se celebrarían en Helsinki, se construyeron soportes de madera temporales que elevaron la capacidad a 62.000 espectadores, 48.123 sentados y el resto de pie.

La Segunda Guerra Mundial retrasó los juegos hasta 1952 y las gradas de madera, que pretendían ser una medida temporal y serían derribadas una vez terminados los Juegos, se mantuvieron en su posición durante casi una década, pero acabaron pudriéndose. Un par de años antes del inicio de los Juegos se desmantelaron y se sustituyeron por otras de hormigón armado que podían alojar a 50.000 espectadores. El Comité Olímpico lo consideró insuficiente, que las localidades deberían superar las 60.000. A tal efecto se construyeron, en el lateral sur, con curvatura, nuevas gradas de madera que elevaban el posible aforo a más de 70.000. En los días secos, durante los Juegos, las gradas de madera se rociaban con agua antes del inicio de las actividades deportivas para evitar el riesgo de incendio. De hecho, permanecieron intactas durante todo el evento y la decisión de desmantelarlas se retrasó un año más.

La cubierta del lado oeste forman un rectángulo de $105 \mathrm{~m}$ de largo por $24 \mathrm{~m}$ de ancho, sustentada por 12 pilares de acero de $9 \mathrm{~m}$ de longitud. La cubierta es también de hormigón armado. 
superficie de cubierta: $2.397 \mathrm{~m} 2$
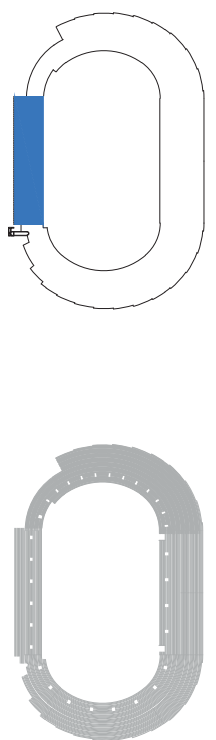

superfiecie de graderios: $16.126 \mathrm{~m} 2$

$\begin{array}{lll}N & 0 & 100 \mathrm{~m} \\ \mid & 1952 . \text { HELSINKI } & 100 \mathrm{yds}\end{array}$
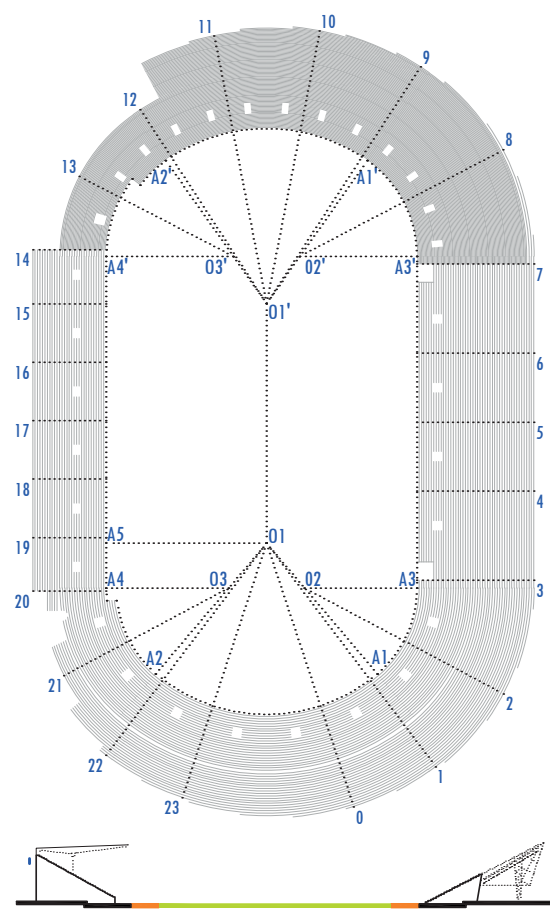

dimensiones y superficies aproximadas graderío

L $01-01^{\prime} \quad 73,00 \mathrm{M}$

L $01-02 \quad 17,93 \mathrm{M}$

L 01-A5 48,82 M

R O1-Al $52,17 \mathrm{M}$

R 02-Al $34,25 \mathrm{M}$

R 03-A2 37,22 M

$<$ Al.01.A2 $\quad 81^{\circ}$

$<$ A3.02.Al $\quad 50^{\circ}$

L $01^{\prime}-02$ ' 17,64 M

R O1'-Al' $53,32 \mathrm{M}$

R 02'-Al' $\quad 35,68 \mathrm{M}$

R 03'-A2' 38,65 M

$\angle A 1^{\prime} .01^{\prime} . A 2^{\prime} \quad 70^{\circ}$

$<3^{\prime} .02^{\prime} . \mathrm{Al}^{\prime} \quad 55^{\circ}$

Los asientos son de $40 \mathrm{~cm}$ de alto y $75 \mathrm{~cm}$ de profundidad. Cuando tienen respaldo, su profundidad se aumenta hasta los $85 \mathrm{~cm}$. En la zona con localidades "de piel, los peldaños tienen una altura de $21 \mathrm{~cm}$ y una profundidad de $37,5 \mathrm{~cm}$. En la zona con pendiente natural del terreno, los asientos tienen una profundidad de $75 \mathrm{~cm}$ y su altura es creciente con la pendiente.

Un túnel que une el campo de juego con los vestuarios de los competidores.

\subsection{Descripción del Estadio; Pista}

El campo de hierba central mide $100 \times 66,5 \mathrm{~m}$. Rodeado por una pista de atletismo de 400 $\mathrm{m}$ de longitud, con una superficie de competición de polvo de ladrillo rojo. Dicha pista cuenta con 7 carriles, 8 en la recta situada al oeste, junto a la tribuna, con una anchura total de 10,80 $\mathrm{m}$.

En invierno, la pista se transforma para las carreras de patinaje sobre hielo.

superficie de campo: $11.557 \mathrm{~m} 2$

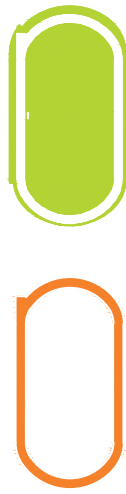

superficie de pista y fosos: $3.684 \mathrm{~m} 2$

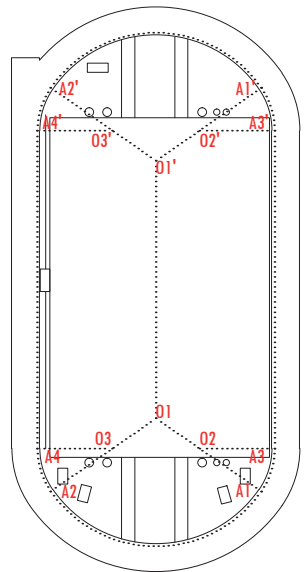

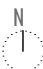

1

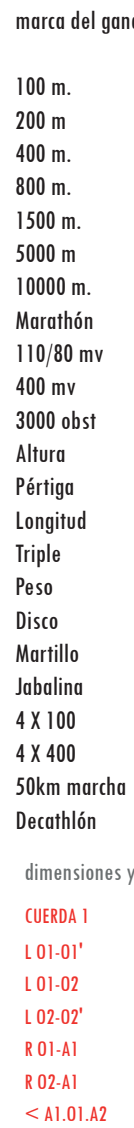$$
\begin{array}{lr}
\text { R 02-Al } & 22,30 \mathrm{M} \\
<\text { Al.01.A2 } & 111^{\circ} \\
<\text { A3.01.Al } & 35^{\circ}
\end{array}
$$ 
1952.9. Avances técnicos:

Nacimiento del cronometraje electrónico.

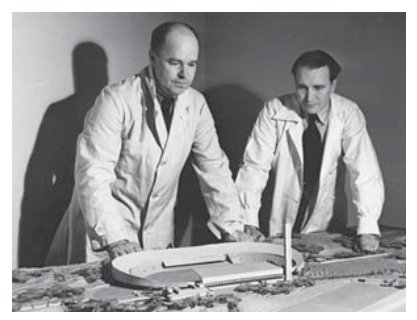

1952.10. Autores. Tipo de encargo:

Yrio Lindegren (1900/1952) Nacido en Tampere, se graduó como arquitecto en 1925, en la Universidad Tecnológica de Helsinki, estableciendo su propia oficina en ese mismo año. Su diseño exterior para el edificio de la compañía de seguros en Glenvara, construido en 1928, está influenciado por el funcionalismo alemán de su tiempo. Al inicio de la década de 1930, su proyecto de Estadio Olímpico supone un referente del funcionalismo internacional. A mediados de la década de 1940, trabajó junto con Alvar Aalto y Viljo Revell, redactando planes urbanísticos de postguerra. También diseñó la Casa Serpentina (en finlandés: Käärmetalo), un complejo de edificios de apartamentos en Makelankatu en el distrito Käpylä, Helsinki, que debe su nombre a su característica forma sinuosa. La Casa Serpentina aparece en Docomomo como un ejemplo significativo de la arquitectura moderna en Finlandia. También proyectó edificios públicos e industriales.

Lindegren ganó el gran Premio de Arquitectura en la feria mundial de 1937 en París y en 1948 ganó la Medalla de Oro en las Olimpiadas Culturales, celebradas por última vez en el marco de las olimpiadas de Londres de ese año.

Inició el proyecto de remodelación del centro de la ciudad de Helsinki, que fue completado por Alvar Aalto (1898-1976) a causa de su temprano fallecimiento en 1952. Poco tiempo antes había sido nombrado profesor universitario.

Toivo Jäntti (1900/1975 Helsinki) además del proyecto del Estadio Olímpico, junto con Yrio Lindegren, realizó las remodelaciones del mismo posteriores a 1952, como las salas de oficinas en la curva sur del estadio (construidas en 1955) y las habitaciones del albergue en la curva norte (1961), así como la primera ampliación del Museo del Deporte de Finlandia (1963).

Nacido en Helsinki realizó sus estudios en la Finland High School y se graduó como arquitecto en la Universidad de Helsinki en 1928. Realizó viajes de estudio por varios países europeos. Durante los años 1928/1930, en su primera etapa, influenciado por el funcionalismo alemán, colaboró como experto en ingeniería estructural en el diseño de grandes edificios urbanos: edificios deportivos, museos, centros comerciales y hospitales, muchos de los cuales nunca llegaron a materializarse a causa de la recesión económica.

Trabajó después como arquitecto independiente desde 1930 hasta 1955. Su primer encargo importante fue la rehabilitación del hospital psiquiátrico de Kellokosken y de los edificios adyacentes. Este trabajo le mantuvo ocupado desde 1932, justo antes de ganar el concurso para el Estadio Olímpico, hasta 1942..

Entre 1943 y 1954 proyectó casas de madera, aplicando modernos e innovadores sistemas de construcción. Entre ellas cabe destacar (1949) la compuesta por 26 apartamentos adosados con instalación común de calefacción, sauna y lavandería. En 1955 funda su propio estudio. La obra de Jäntti es un compendio de historia de la arquitectura finlandesa que busca la aplicación de las ideas modernas a los elementos tradicionales. Era un arquitecto valorado dentro de la profesión, como lo demuestra el hecho de que trabajara con frecuencia para la Asociación Finlandesa de Arquitectos y que fuera miembro de la Asociación Finlandesa de artistas.

Tipo de encargo. Fue producto de un concurso público, al que asistieron los mejores arquitectos finlandeses, entre ellos Alvar Aalto.

\subsection{Edificios coetáneos}

El día 14 de octubre de 1952 se inaugura la Unité d'Habitation de Marsella. Casa de la Marina. José Antonio Coderch.

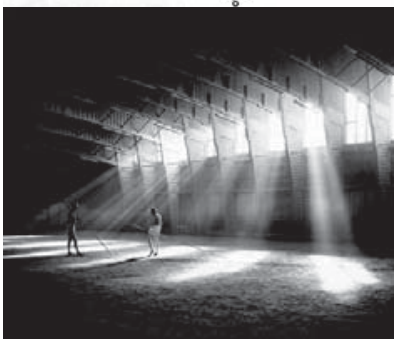

1952.12. Hechos históricos relevantes

En enero, en Estados Unidos, Jonas Salk desarrolla la primera vacuna contra la polio.

El 10 de septiembre, en Europa, primera reunión de la Asamblea de la Comunidad Europea del Carbón y del Acero (CECA), antecesora del Parlamento Europeo.

El 7 de octubre se inventa el código de barras.

El 31 de octubre, Estados Unidos, hace detonar la primera bomba de hidrógeno.

Bibliografía Helsinki 1952:

XV OLYMPIAD HELSINKI 1952. The official Report of the Organising Committee for the Games. 1955 WIMMER, Martin. (1976). Olympic Buildings. Ed. Leipzig. Lic 600/34/75. 5938721

GORDON, Barclay F. (1983). Olympic Architecture. Building for the summer games. John Wiley \& Sons. Nueva York. ISBN 0-471-06069-0

The Stadium. The Architecture of Mass Sport. (2000). Ed. Michelle Provoost. NAI Publishers Rotterdam. ISBN 90-5662145-9 


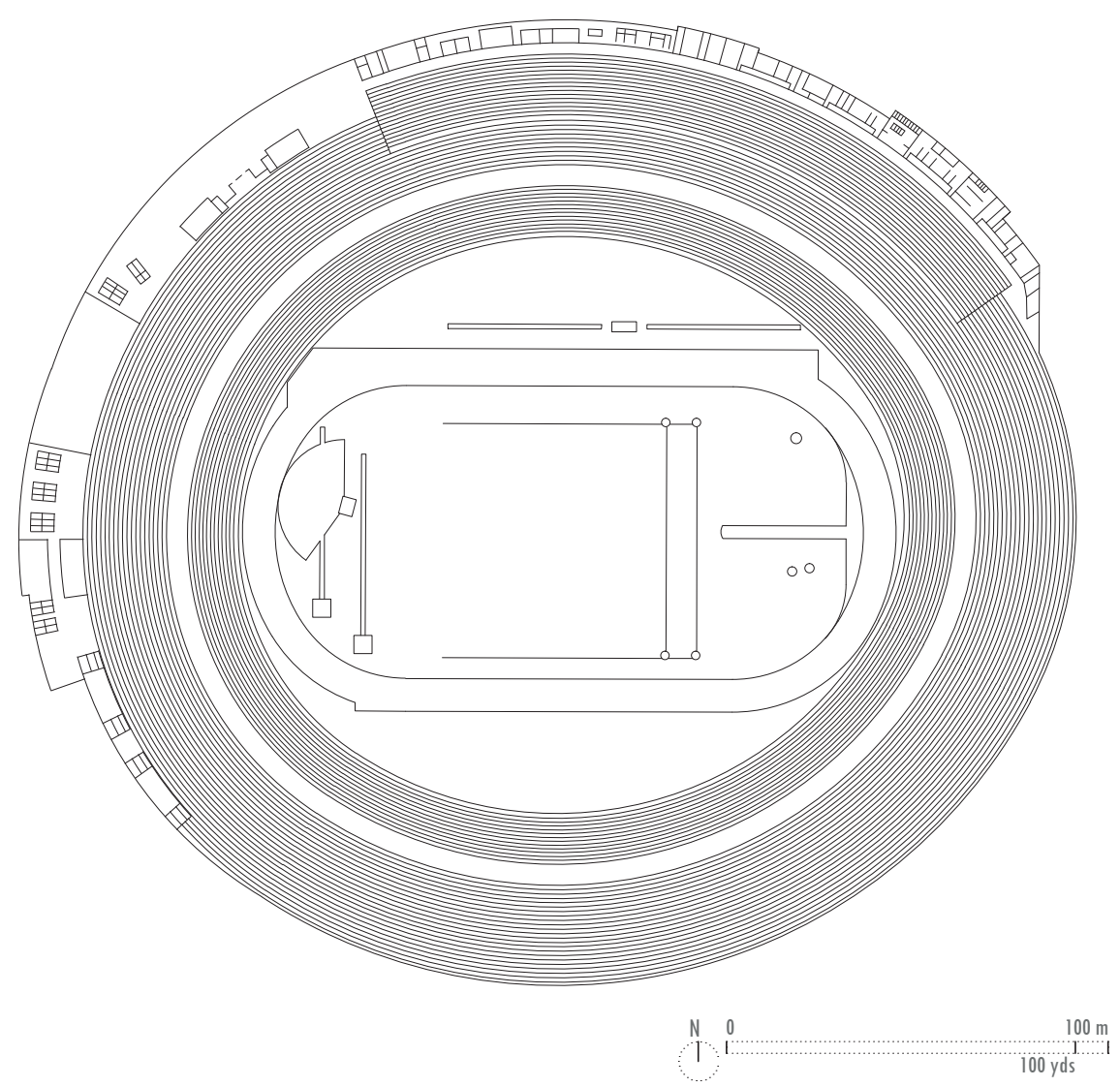

1956.0. Nombre del Estadio

Melbourne Cricket Ground.

1956.1. Situación

Brunton Avenue East Melbourne, Melbourne City, 3002 Victoria, Australia.

1.2. Fechas

1838. Fundación del Melbourne Críquet Club.

1853. En septiembre, el gobierno concede al Melbourne Críquet Club el uso del terreno de 10 acres ( 4 has) cerca de Richmond Park.

1854. Construcción de grada de madera para los socios.

1861. Juegos de Caledonia.

1900. Luz eléctrica en el Estadio.

1927. Se reconstruye la grada de socios, proyectada por Stephenson y Meldrum.

1933. El Gobierno permite que Estadio se utilice para otros usos, aparte de la práctica del cricket.

1942. Durante la Guerra el gobierno lo requisa para uso militar.

1948. Melbourne presenta su candidatura a los Juegos Olímpicos de 1956.

1949. El 28 de abril, el ClO concede a Melbourne la organización de los Juegos de 1956.

1953. Enero, el comité del MCC dio todo su apoyo al gobierno para el uso del MCG para los Juegos Olímpicos de 1956. Se constituye el Sub-Comité de Construcción, que tuvo la responsabilidad de adecuar el estadio a los requisitos Olímpicos.

1954. Visita de la Reina Isabel II.

1956. Se completa la construcción de la grada Olímpica Norte, por A.W. Purnell.

1956. El 22 de noviembre, Inauguración Juegos Olímpicos de Melbourne El 8 de diciembre, Ceremonia de Clausura.

1959. Un evento religioso, la cruzada evangélica de Billy Graham en 1959, logra reunir a más de 140.000 personas en el Estadio.

1968. Se completa la construcción de la Grada Occidental, proyectada por Tompkins, Shaw \& Evans.

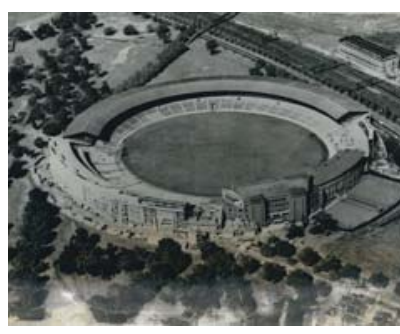




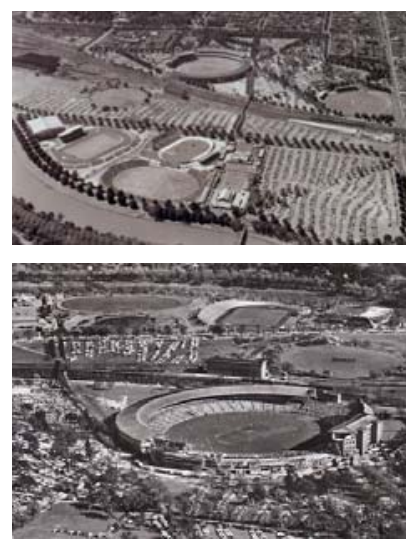

1974. Primer concierto celebrado en el Estadio. David Cassidy.

1978. Concierto de David Bowie.

1984. Se instalan las seis Torres de lluminación.

1986. Eucaristía celebrada por El Papa Juan Pablo II.

1992. Se completa la construcción de la Gran Grada Sur, diseñada por Daryl Jackson.

1992. Final de la Copa del Mundo de Cricket.

1993. Conciertos de Paul McCartney, U2 y Madonna.

1995. Concierto de los Rolling Stones.

1996. Concierto de Michael Jackson.

1997. Concierto de Los Tres Tenores.

1998. Conciertos de Elton John y Billy Joel.

2005. Se incluye al Estadio en el listado de bienes del patrimonio nacional.

2006. Juegos de la Commonwealth.

2008. Concierto de The Police celebrando el Día de Australia.

2009. Concierto de Sound Relief en favor de la Cruz Roja.

\subsection{Preexistencias en el lugar}

Paraje virgen utilizado por los aborígenes hasta 1835. Entre 1835 y 1853 se utilizó como prados de alquiler para caballos coloniales "troopers". A partir 1850 se destina para el recreo de la población.

\subsection{Relación con la ciudad. Posición respecto al centro urbano}

El Melbourne Cricket Ground está situado en Yarra Park a 10 minutos a pie del centro de la ciudad y es servido por la estación de tren de Richmond y la Estación de tren de Jolimont, East Melbourne.

1956.5. Breve relato de la historia del Estadio

Lo que, en sus inicios, era una pradera para la practica deportiva con una modesta edificación y tribuna, el Melbourne Cricket Ground ha evolucionado y se ha visto ampliado a través de un proceso de remodelación por fases.

La primera tribuna del MCG se construyó en madera en 1854, para albergar a los miembros del Club.

En 1860 se construyó un graderío con una longitud de 275 metros, capaz de albergar a 6000 personas.

A mediados de la década de 1860 la fortaleza económica del Club empezó a decaer hasta que, a finales de la misma, se tuvo que construir una pista de atletismo alrededor del campo para atraer a otro tipo de público. Parece que la estrategia no produjo los resultados previstos.

Coincidiendo con el resurgir del críquet entre 1873 y 1874 , cuando la selección inglesa realizaba una gira por Australia, se decidió instalar en el campo una tribuna permanente capaz de albergar más de 2000 espectadores.

El Melbourne Football jugaba en un campo situado inmediatamente al norte $y$, excepto los vestuarios, no tenían nada en común. Sin embargo, cuando se dieron cuenta de que el fútbol atraía a varios miles de personas en cada partido, los dirigentes del MCC contrataron al arquitecto George Browne, quien tuvo la ingeniosa idea de modificar los asientos de las gradas y hacerlos reversibles, de forma que se pudieran usar para ambos deportes. A esta grada se la llamó la "Lillywhite Tower».

En 1881, la tribuna de socios originales con estructura de madera se cambió por otra de ladrillo. Fueron consideradas entonces como las mejores instalaciones de críquet del mundo, incluso se instalaron un teléfono $y$, un año más tarde un marcador que informaba del desarrollo del juego.

El seguimiento del fútbol, sin embargo, decayó en la década de 1880 y las gradas reversibles dejaron de utilizarse, para acabar destruidas por un incendio. Fueron sustituidas por una nueva capaz de acoger a 4500 espectadores de pago y a 450 socios. En 1897, se le añadieron unas alas aumentando su capacidad a 9000.

Desde 1900 el estadio contaba con luz eléctrica. En 1904 se construye una grada de madera en el lado sur del terreno de juego y, posteriormente se levanta la grada Grey Smith Stand en 1906, con capacidad para 2084 espectadores sentados.

La grada Harrison Stand en el lado sur fue construida en 1908 para 4000 espectadores, seguida por la Wardill Stand en 1912 para 8000.

En los 15 años después de 1.897 la capacidad de aforo del Estadio aumentó a casi 20.000 espectadores, siempre por medio de actuaciones de carácter parcial.

En 1927 fue reemplazado el pabellón de ladrillo para los socios del Club. En 1936 los graderíos denominados Harrison y Wardill fueron demolidos para dar paso a la Grada 
Sur, que se completó en 1937, que acogía sentados bajo techo a 18200 espectadores y en abierto a 13000 más.

La grada llamada Olímpica Norte fue construida para los Juegos en 1956, reemplazando al Gran Stand,. Diez años más tarde, el Grey Smith Stand y la grada descubierta de hormigón que estaba a su lado, fueron reemplazados por la Grada Occidental, completándose en 1968

\subsection{Descripción del Estadio; Graderío}

Las gradas han sido construidas en varias secciones durante muchos años. Para los Juegos decidieron eliminar las gradas más antiguas y reemplazarlas por otras de hormigón, de tres niveles, con capacidad para 40.000 espectadores, lo que elevó el total del aforo a 104.000. Las dimensiones del terreno de juego eran $171 \times 146$ m y estaba conformado por un óvalo de hierba.

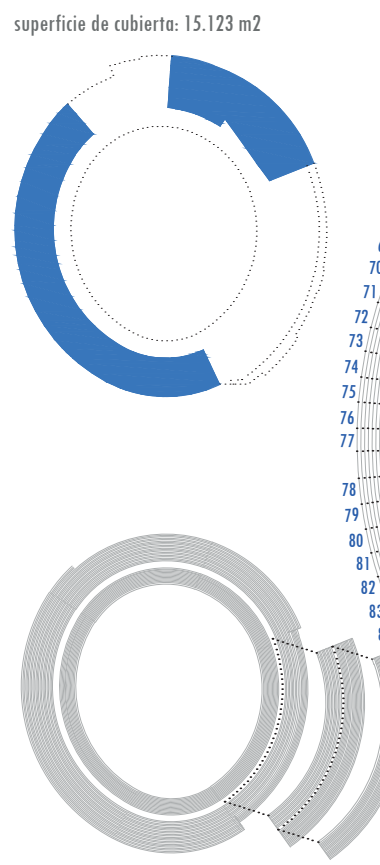

superfiecie de graderios: $35.053 \mathrm{~m} 2$
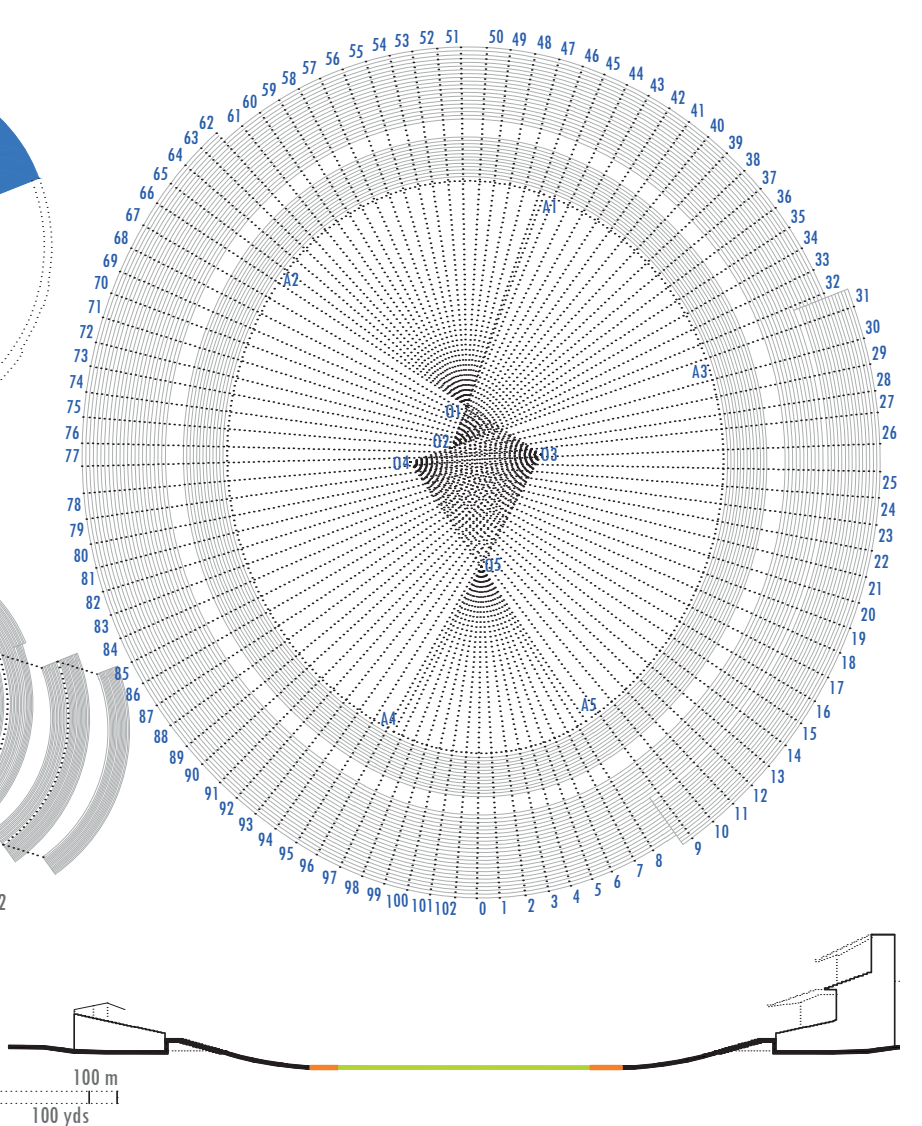

N 0

- 1956. MELBOURNE

$$
\begin{gathered}
100 \mathrm{~m} \\
100 \mathrm{yds}
\end{gathered}
$$

\subsection{Descripción del Estadio; Pista}

En los estudios previos a la celebración, se encontró que la planta tenía un desnivel próximo a los 8 pies $(2,44 \mathrm{~m})$ de norte a sur y puesto que las normas internacionales permiten unos desniveles máximos del 1:1.000 en longitud y del 1:100 en anchura, fue necesario rehacerla. Al tiempo que se realizaban las obras de acondicionamiento del campo de juego, se rehacía la pista de $400 \mathrm{~m}$ de longitud con 7 carriles y uno más en la recta norte, de llegadas. La superficie de la pista se completó justo antes del inicio de los Juegos.

Se prestó especial atención al diseño de los fosos de concursos para asegurarse de que los saltadores no lo hicieran frente al sol, tuvieran algún impedimento por los vientos dominantes o tuvieran que correr o saltar a través de zonas con sombras. Siempre que era posible, se evitó que las pruebas se realizaran demasiado próximas a los espectadores. Una innovación fue el uso de dobles zonas de salto con pértiga, áreas de lanzamiento de peso y salto de longitud en la competición de decatlón, lo que aseguraba que todas las pruebas terminasen con la luz del día.

La pista tiene dos rectas de 93 yardas $(85,04 \mathrm{~m})$ y fácilmente se puede marcar en su interior un campo de fútbol o de hockey.

Composición de la pista.

La cimentación de la pista fue colocada en noviembre de 1955 y después volvió a quedar

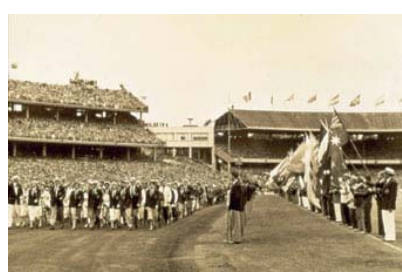

dimensiones y superficies aproximadas graderío

$\begin{array}{lr}\text { L 01-02 } & 13,50 \mathrm{M} \\ \text { L 01-03 } & 26,97 \mathrm{M} \\ \text { L 02-04 } & 13,27 \mathrm{M} \\ \text { L 03-05 } & 38,69 \mathrm{M} \\ \text { L 04-05 } & 38,50 \mathrm{M} \\ \text { R 01-Al } & 68,63 \mathrm{M} \\ \text { R 02-01 } & 82,14 \mathrm{M} \\ \text { R 03-A2 } & 95,60 \mathrm{M} \\ \text { R 04-A3 } & 95,41 \mathrm{M} \\ \text { R 05-A4 } & 56,91 \mathrm{M} \\ \text { < A1.01.A2 } & 77^{\circ} \\ \text { < A3.02.A1 } & 51^{\circ} \\ \text { < A2.03.A4 } & 95^{\circ} \\ \text { < A3.04.A5 } & 75^{\circ} \\ \text { < A5.05.A4 } & 62^{\circ}\end{array}$
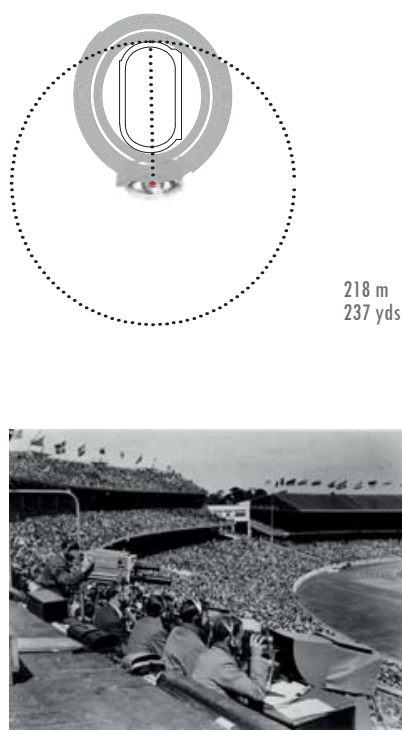


$\begin{array}{lrr}\text { marca del ganador } & & \\ & \text { Hombres } & \text { Mujeres } \\ 100 \mathrm{~m} . & 10 " 5 & 11,5 \\ 200 \mathrm{~m} & 20 " 6 & 23 " 4 \\ 400 \mathrm{~m} . & 46 " 7 & \\ 800 \mathrm{~m} . & 1,50 " 0 & \\ 1500 \mathrm{~m} . & 3,41 " 2 & \\ 5000 \mathrm{~m} & 13,39 " 6 & \\ 10000 \mathrm{~m} . & 28,45 " 6 & \\ 110 / 80 \mathrm{mv} & 13 " 5 & 10 " 7 \\ 400 \mathrm{mv} & 50 " 1 & \\ 3000 \mathrm{obst} & 8,41 " 2 & \\ \text { Altura } & 2,12 \mathrm{~m} & 1,76 \mathrm{~m} \\ \text { Pértiga } & 4,56 \mathrm{~m} & \\ \text { Longitud } & 7,83 \mathrm{~m} & 6,35 \mathrm{~m} \\ \text { Triple } & 16,35 \mathrm{~m} & \\ \text { Peso } & 18,57 \mathrm{~m} & 16,59 \mathrm{~m} \\ \text { Disco } & 56,36 \mathrm{~m} & 53,69 \mathrm{~m} \\ \text { Martillo } & 63,19 \mathrm{~m} & \\ \text { Jabalina } & 85,71 \mathrm{~m} & 53,86 \mathrm{~m} \\ 4 \text { X 100 } & 39 " 5 & 44 " 5 \\ 4 \text { X 400 } & 3,04 " 8 & \\ 20 \mathrm{~km} \text { marcha } & 1 \mathrm{~h} 31,27 " 4 & \\ 50 \mathrm{~km} \text { marcha } & 4 \mathrm{~h} 30,42 " 8 & \\ \text { Decathlón } & 7.937 \mathrm{ptos} & \\ \text { Marathón } & 2 \mathrm{~h} .25,00 " & \\ & & \\ & & \end{array}$

tapada para permitir la práctica del cricket, lo que permitió un terreno de juego perfectamente consolidado. La mezcla de cenizas que formaba la superficie de la pista fue importada de Inglaterra. Su colocación se inició el 17 de septiembre de 1956, y se terminó a mediados de octubre.

11,5

$23 " 4$

0"7

$1,76 \mathrm{~m}$

$6,35 \mathrm{~m}$

$6,59 \mathrm{~m}$

$53,69 \mathrm{~m}$

$53,86 \mathrm{~m}$

$44 " 5$ superficie de pista y fosos: $4.859 \mathrm{~m} 2$

superficie de campo: $15.700 \mathrm{~m} 2$
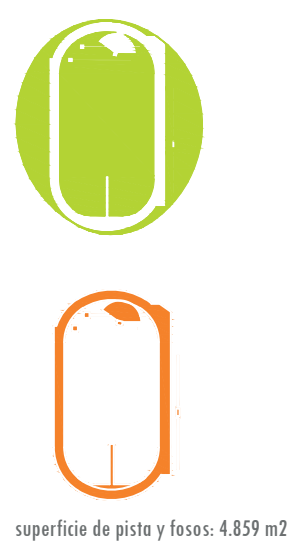

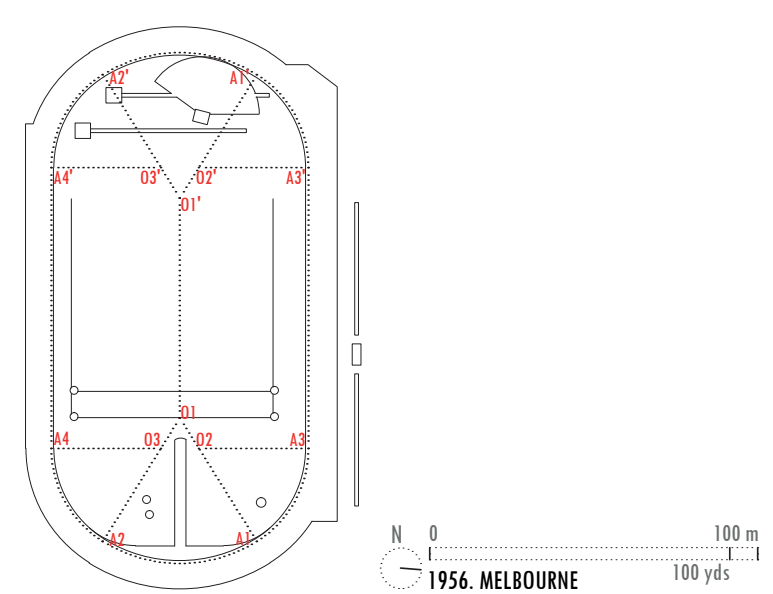

Programa Deportivo: Atletismo, Hockey sobre hierba (final), Fútbol (final) y las Ceremonias de Apertura y Clausura de los Juegos

\subsection{Elementos significantes}

\subsection{Avances técnicos}

\subsection{Autores. Tipo de encargo:}

Stephenson y Meldrum. Arquitectos.

Sir Arthur George Stephenson (1890/1967), arquitecto. Nació en Box Hill, Victoria. En 1907 Stephenson trabajó para Swansson Brothers mientras estudiaba construcción en el Working Men's College. Se unió a la Fuerza Imperial australiana en 1915 como teniente, ascendido a capitán y fue condecorado con la Cruz Militar. Después de la Primera Guerra Mundial, Stephenson se quedó en Londres y estudió en la Architectural Association School (AA) y se unió al Royal Institute of British Architects (RIBA) en 1920. Volvió a Melbourne asociandose con Meldrum en 1921 y especializandose en el diseño de hospitales y en arquitectura industrial. Stephenson también dio conferencias, escribió ampliamente y fue miembro de numerosos comités, entre ellos la Federación de Hospitales Internacionales, el Consejo Asesor del Hospital de Melbourne y un fideicomisario del Museo Nacional de Victoria. En 1954 Stephenson fue nombrado caballero por sus servicios a la arquitectura y fue el primer australiano en recibir la Medalla de Oro del RIBA en 1964. El Real Instituto Australiano de Arquitectos (de RAIA) le otorgó la Medalla de Oro en 1963 y fue nombrado miembro honorario por el Instituto Americano de Arquitectos en 1964.

Percy Meldrum (1887/1968), arquitecto. Nació en Casterton, Victoria y estudió en la universidad de Ballarat. En 1907 estudió arquitectura y escribió para el Melbourne Architect AA Fritsch desde 1907 hasta 1913. ganó la medalla de Bronce del Royal Victorian Institute of Architects.

En 1913 Meldrum viajó a Chicago. Admiraba la arquitectura de Frank Lloyd Wright. Luego viajó a Inglaterra en 1914 donde trabajó en el Ministerio de la Guerra diseñar hangares. En 1919 Meldrum se unió a la AA, donde conoció y enseñó a Arthur Stephenson y Donald Turner. Fue un dibujante y acuarelista extraordinario. Meldrum fue director artístico y colaboró con algunos de los artistas destacados de Melbourne, incluyendo Napier Waller, cuyo mosaico destaca en la fachada de la Newspaper House de Melbourne (1933). Su asociación con Stephenson terminó en 1937, pasando a trabajar con Arthur Noad, para formar Meldrum y Noad.

Remodelación del Melbourne Cricket Ground: Grada Norte:

Arthur William Purnell (1878/1964), arquitecto. Nació en una familia de arquitectos y constructores afincada en Geelong, Victoria. Estudió Arquitectura en Gordon College (ahora Universidad Deakin) y Dibujo en la Escuela de Artes de Geelong antes de incorporarse a la empresa familiar Purnell \& Sons, en 1895. Después de pasar los exámenes de Geelong y Melbourne como requisito imprescindible, aprobó los exámenes públicos victorianos de 
arquitectura, construcción de edificios y dibujo en perspectiva en 1896. Ganó numerosos premios por sus dibujos en varias exposiciones, entre ellas la Exposición Universal de París. Después de un viaje de estudios por el mundo en 1899, Purnell vivió y trabajó en China durante una década, de 1900 a 1910. Allí estuvo diseñando edificios en Shameen (ahora Shamian), una pequeña isla gestionada por el gobierno chino de Canton (Guangzhou) para que los extranjeros pudieran trabajar y vivir. Su firma, Purnell y Paget (Charles Souders Paget era un ingeniero civil estadounidense, de Bethlehem).

Purnell y Paget desarrollaron una extensa producción arquitectónica en China, entre otros, la rehabilitación y ampliación del Club Social de Cantón, el edificio Arnhold-Karberg \& Company, la Casa Imperial de Aduanas y una gran cantidad de locales comerciales para empresas europeas que deseaban establecerse allí. Especialmente diseñó la Fábrica de Cementos de China Meridional, situada en la estratégica isla de Honam, próxima a las ciudades de Hong Kong y Macao. La fábrica fue utilizada en 1917 por el primer presidente democráticamente elegido de China, el Dr. Sun Yat-Sen, como su Palacio Presidencial.

De regreso a Melbourne, Purnell se estableció por su cuenta y después trabajó con diferentes socios. Realizando proyectos de casas suburbanas, escaparates de tiendas, fábricas, oficinas y almacenes. Purnell, en ocasiones, introdujo elementos de diseño adoptados de sus años de inmersión en la cultura china. Los trabajos de Purnell reflejan con frecuencia sus propios intereses. Como amante del deporte, por ejemplo, diseñó una sorprendente variedad de instalaciones deportivas, incluyendo el Club de Golf de Clifton Springs (1926), la tribuna Oval Occidental (1929), una pista de galgos en Tottenham (1927), la Piscina Olympia Mar en South Melbourne (1937) y el Rosebud Yacht Club (1939). Uno de sus últimos encargos fue la grada Olímpica para la remodelación del Melbourne Cricket Ground (desde 1953 hasta 1955).

Purnell fue un arquitecto ecléctico. Creció en el último período victoriano y fue educado en los estilos de construcción populares del siglo 19, siempre con ganas de avanzar con los tiempos, se adaptó al Modernismo, al Art Deco, y al final de su carrera, al Estilo Internacional. Tipo de encargo.

Fue un encargo directo, probablemente derivado de su prestigio, de su gran experiencia en arquitectura deportiva y por ser vecino del lugar.

\subsection{Edificios coetáneos:}

Se inaugura el Crown Hall, de Mies van der Rohe, en el campus de Illinois Institute of Technology. Edificio en dos plantas que alberga la escuela de arquitectura.

Comienza a construirse la ciudad de Brasilia, con trazados urbanos de Lúcio Costa y edificios de Oscar Niemeyer.

Concurso abierto para el diseño del Edificio de la Ópera de Sydney, ganado por Jorn Utzon.

\subsection{Hechos históricos relevantes}

26 de julio. El presidente egipcio Nasser nacionaliza el Canal de Suez.

26 de octubre. Tropas del Pacto de Varsovia invaden Hungría.

14 de diciembre. España ingresa en la ONU.

Bibliografía Melbourne 1956:

XVI OLYMPIAD. MELBOURNE 1956. The Official Report of the Organizing Committee for the Games of the XVI Olympiad. Melbourne 1958

WIMMER, Martin. (1976). Olympic Buildings. Ed. Leipzig. Lic 600/34/75. 5938721

GORDON, Barclay F. (1983). Olympic Architecture. Building for the summer games. John Wiley \& Sons. Nueva York. ISBN 0-471-06069-0 


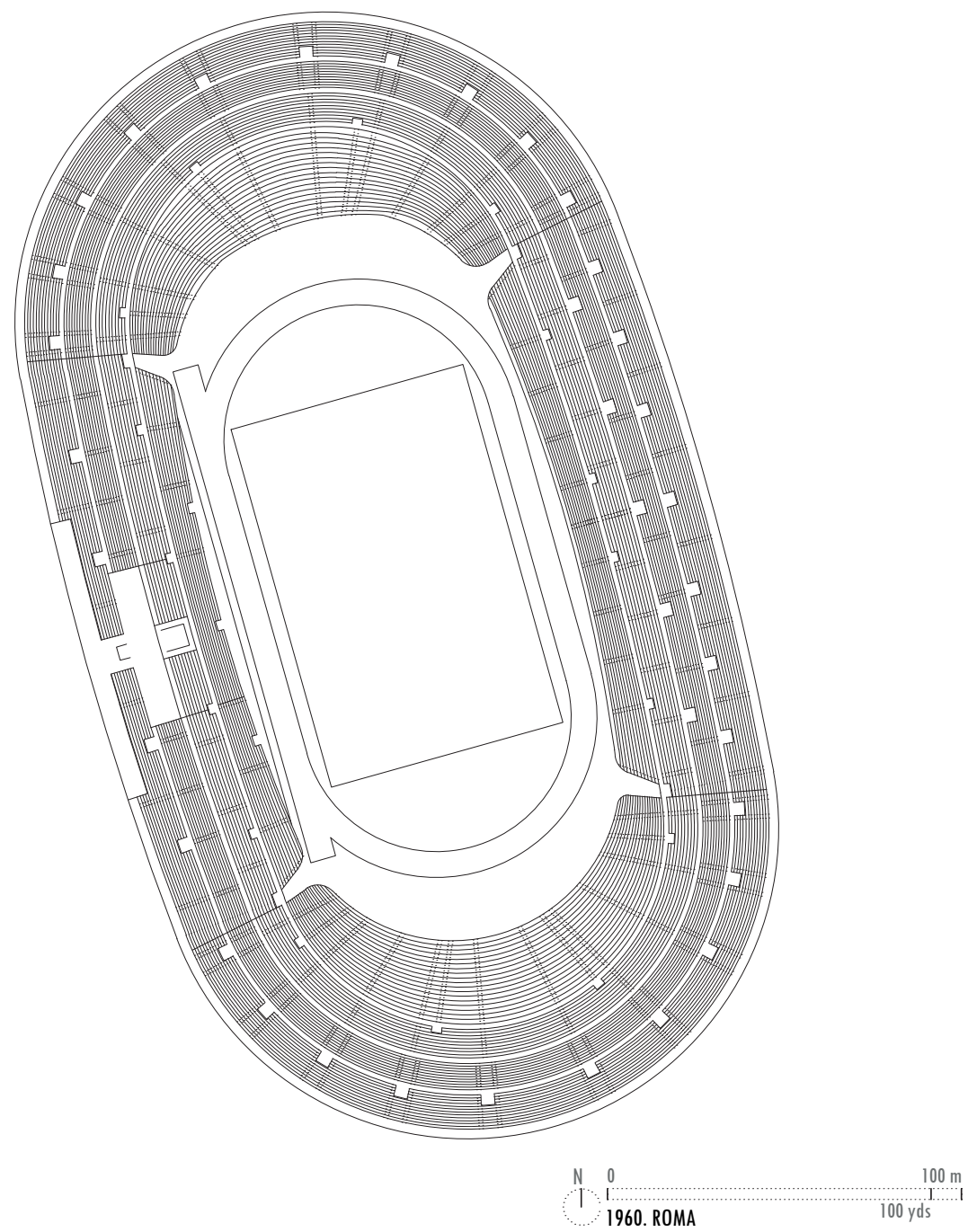

1960.0. Nombre del Estadio

El estadio original (1937) se conocía como "Stadio dei Cipressi". Tras su reconstrucción en 1950 fue nombrado como "Stadio dei Centomila". Desde 1960 Stadio Olimpico

1960.1. Situación

Viale dello Stadio Olimpico, Foro Itálico, Roma

\subsection{Fechas}

1909. Edmund Sanjust Teulada traza los primeros planos para la construcción de un complejo multideportivo en la zona.

1927. Renato Ricci, presidente de la Commissione dell'Opera Nazionale Balilla, impulsa la idea de crear un gran complejo educativo, el Foro Mussolini

1927. Comienzan las labores de construcción del Stadio dei Cipressi.

1928. El 5 de febrero se celebra una solemne ceremonia para la colocación de la primera piedra de la Academia de Educación Física, primera costrucción del Foro Itálico.

1932. Inauguración (parcial) del Stadio dei Cipressi.

1936. Desde este año y hasta 1941, el arquitecto Luigi Moretti elabora un proyecto expansivo del Foro hacia Tor di Quinto, insertandolo en el plan urbanístico de Enrico Del Debbio, aunque nunca llegó a realizarse.

1937. Reanudación de las obras de ampliación y mejora del Stadio dei Cipressi.

1940. Con el estallido de la Segunda Guerra Mundial se detienen toda construcción del Foro Mussolini

1950. En diciembre se reanudan los trabajos de construcción del estadio bajo la dirección de Carlo Roccatelli.

1951. Con el fallecimiento del arquitecto Carlo Roccatelli, la dirección de la obra pasa a
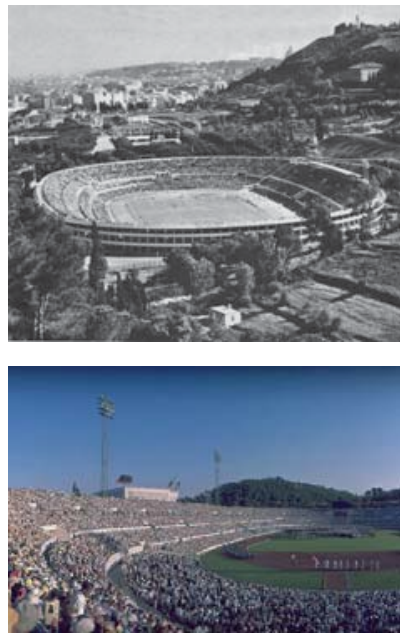
manos de Annibale Vitellozzi.

1951. El Stadio dei Cipressi pasa a conocerse como Stadio dei Centomila.

1953. El 17 de Mayo se inaugura el Stadio dei Centomila con un partido de fútbol entre las selecciones de Italia y Hungría.

1960. Debido a las modificaciones realizadas con motivo de la celebración de los Juegos Olímpicos de Roma, el estadio pasó a conocerse como Stadio Olimpico.

1964. Partidos de la Eurocopa

1968. Partidos de la Eurocopa (Tercer puesto, final y partido de desempate)

1977. 25 de mayo, Copa de Campeones 1976-1977

1984. 30 de mayo, Copa de Campeones 1983-1984

1980. Partidos de la Eurocopa

1987. Del 28 de agosto al 6 de septiembre, campeonato mundial de atletismo.

1987. Comienza una intervención radical de renovación.

1990. Mundial de Fútbol de Italia' 90

1991. Concierto de Miles Davis

El 22 de mayo, el Stadio Olimpico fue sede de la final de la Champions

1997. League entre el Juventus y Ajax

1998. 7 de julio, concierto de Tina Turner

2000. Agosto, Tosca de Giacomo Puccini

2001. 7 de julio, concierto de Sting

2005. 23 de julio, concierto de U2

2006. 16 de junio,concierto de Madonna

2007. Comienza una nueva remodelación para adaptarse a la normativa de la UEFA.

2007. 6 de julio, concierto de Rolling Stones

2009. El 27 de mayo se celebra la final de la Liga de Campeones.

2012. 12 de junio, concierto de Madonna

2015. 5 de septiembre, concierto de Antonio Venditti

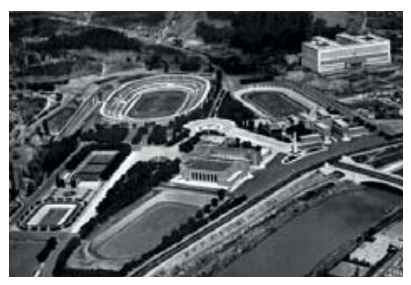

\subsection{Preexistencias en el lugar}

El área designado para levantar el Foro Mussolini se situaba entre el Ponte Silvio ( $115 \mathrm{aC}$.), el Tíber, Villa Manama (1525, Rafael Sandio) y las laderas de Monte Mario, era en gran parte una propiedad militar. Con topografía ascendente desde el río hasta el Monte Mario.

El Foro constituye un gran complejo educativo orientado al deporte, que se hace eco del mundo clásico griego y romano. Entre sus edificaciones se destacan, el gran Obelisco, el Stadio dei Marmi, con sus estatuas de mármol de carrara que describen los diferentes deportes olímpicos, y el Stadio dei Cipressi

\subsection{Relación con la ciudad. Posición respecto al centro urbano}

El Stadio Olimpico se encuentra al noroeste del casco histórico de la ciudad, cruzando el rio Tevere (en la misma orilla que la Ciudad del Vaticano y a $3,48 \mathrm{~km}$. de este), a pocos kilómetros de algunos de las construcciones más emblemáticas de la ciudad como son el Coliseo Romano $(5,74 \mathrm{~km}$.), el panteón de Agripa (4,32km.), la Fontana de Trevi (4,37km.), y la Piazza Navona $(4,14 \mathrm{~km}$.). Sin embargo, a pesar de la aparente cercanía de la ciudad, la comunicación con cualquiera de estos puntos no es muy fluida por carretera ni transporte público (el único medio es el autobús).

El estadio está construido dentro del Foro Itálico, a $400 \mathrm{~m}$. del "Parco del Foro Itálico" y junto a otras tres instalaciones deportivas: el Stadio dei Marmi $(240 \mathrm{~m}$.), el Stadio della Farnesina (712m.) y el Stadio Flaminio, donde también se realizaron parte de los Juegos Olímpicos de 1960 ( $1,60 \mathrm{~km}$.).

En las inmediaciones del Stadio Olimpico destacan algunos edificios como el Auditorium Parco della Musica, obra de Renzo Piano y el "MAXXI" (Museo Nacional de Arte del Siglo XXI de Roma), diseñado por Zaha Hadid.

\subsection{Breve relato de la historia del Estadio}

En 1909, Edmund Sanjust Teulada dibujó el primer proyecto de un complejo multideportivo en el área comprendida entre la Villa Madama y el río Tiber.

En diciembre de 1925, en función del ordenamiento general de la ciudad se establece la necesidad de crear un espacio amplio, cerca del casco histórico, de carácter cultural y deportivo para la ciudad, poniéndose en marcha lo que se llamaría Foro Mussolini (y que tras la Segunda Guerra Mundial sería rebautizado como Foro Itálico)

Una de las piezas más importantes del Foro era el Stadio dei Cipressi, cuya obra comenzó en 1927; proyectado por el arquitecto Enrico Del Debbio, fue inaugurado parcialmente en 1932, las obras se fraccionaron en etapas, lo inaugurado correspondía con la parte topográfica de la actuación, y probablemente la primera fase aérea, aunque no completa del todo. 
En 1937 se reanudaron las obras para la realización de la pista de atletismo, a cargo de los ingenieros Frisa y Pintonello. El estadio quedo incompleto, el estallido de la a Segunda Guerra Mundial en 1940 paralizó definitivamente los trabajos.

En diciembre de 1950 comienzan de nuevo las obras para la conclusión del estadio. En esta ocasión, el proyecto fue confiado a Carlo Roccatelli, miembro de la Junta de Obras Públicas, y a su muerte en 1951, la dirección de la obra fue tomada por Annibale Vitellozzi. Aunque en un primer momento se decidió construir una estructura compleja, la escasez de fondos y las características de la zona llevaron a una edificación menos ambiciosa; aún así la capacidad del nuevo estadio llegó a los 100.000 asistentes por lo que su nombre se cambió a stadio dei Centomila (estadio de los cien mil). La reinauguración del estadio se celebró el 17 de mayo de 1953 con motivo del partido de fútbol entre las selecciones de Italia y Hungría y la llegada a Roma del Giro de Italia.

Con motivo de los Juegos Olímpicos de verano de 1960 tuvieron que realizarse varias modificaciones en el estadio, que dieron lugar a la supresión de algunas plazas de pie, con lo que la capacidad del mismo se redujo a 65.000 espectadores, pasando a llamarse Stadio Olimpico.

Con vistas al Mundial de Fútbol de Italia '90, que se jugaría principalmente en el Stadio Olimpico, se previó una intervención radical de renovación. La obra fue realizada por equipo de diseñadores entre los que se encontraban los arquitectos Annibale Vitellozzi y Maurizio Clerici, y los ingenieros Paul Teresi y Antonio Michetti. Entre 1987 y 1990, el proyecto sufrió tantos cambios que el excesivo aumento de los costos supuso que, en última instancia, se optara por la demolición de la práctica totalidad del complejo y su reconstrucción en hormigón armado; con la excepción de la Tribuna Tevere que fue ampliada mediante la incorporación de varios niveles adicionales. Esta nueva versión contaba con 82.922 asientos, íntegramente protegidos mediante una cubierta blanca de fibra de vidrio sobre estructura metálica.

En 2007 se puso en marcha un nuevo proceso de remodelación del interior del estadio, en esta ocasión para ajustarse a las normas de la UEFA, y que pudiera celebrarse la final de la Liga de Campeones el 27 de mayo de 2009. Este trabajo, que terminó en 2008, consistió en una serie de mejoras en la seguridad reduciéndose su capacidad a 73.261 espectadores.

\subsection{Descripción del Estadio; Graderío}

Capacidad para 65.000 espectadores. El graderío se encaja en la topografía apoyando su graderío en el Monte Mario, en planta tiene forma de anillo ovalado y simétrico respecto a ambos ejes (el mayor con una dimensión de $319 \mathrm{~m}$. hasta su cara externa y 205,80 hasta la interna, y el menor con unas dimensiones de $186 \mathrm{~m}$. y $94,40 \mathrm{~m}$. respectivamente).

Los asientos de madera miden $0,80 \mathrm{~m}$. de ancho y $0,40 \mathrm{~m}$. de altura y se disponen formando cuatros anillos de entre 10 y 13 filas cada uno, separados entre sí por pasillos distribuidores. La finalidad de este diseño era asegurar una excelente visibilidad desde cualquier sección. La longitud total de la grada, colocada en disposición lineal recorrería una distancia aproximada de $30 \mathrm{~km}$. El graderío en sección esta dividido en dos partes, la inferior excavada en el terreno, con una profundidad de 4,50m. y la superior, una construcción aérea, de $20,50 \mathrm{~m}$. de altura.

El público accede al estadio a través de las 10 puertas exteriores que dan acceso a un total de 59 vomitorios, los cuales comunican, ya en el interior, con una red de corredores que conducen a los asistentes a su asiento correspondiente y permiten la evacuación completa del estadio en un tiempo máximo de 11 minutos.

Se diferencia ésta de la circulación de autoridades, jueces y atletas, los cuales cuentan con cuatro entradas, a nivel de suelo, que dan acceso directo al campo.

La "Curva Sud" y la "Curva Nord" están destinadas al público en general, con espacios para espectadores tanto de pie (en la zona más próxima al campo) como sentados (en la construcción aérea); mientras que en los lados este y oeste se encuentran la tribunas Tevere y Monte Mario respectivamente. En esta última se localiza el único espacio cubierto del estadio: la zona de prensa que durante los Juegos Olímpicos vio aumentados los habituales 572 asientos reservados a periodistas a 1.126 y que consistía en 40 cabinas construidas en aluminio y vidrio, donde, además de despachos para la prensa, había una sala de trabajo, varias salas de espera y de instalaciones y una oficina de telégrafos.

\subsection{Descripción del Estadio; Pista}

Dimensiones: Cuerda de la pista de 400 metros y seis calles de 4 pies de ancho $(1,22 \mathrm{~m}$.) y un ancho total de 24 pies $(7,32 \mathrm{~m}$.). Orientada norte-sur, la recta oeste se prolonga en ambos extremos hasta alcanzar una longitud total de 142 yardas (129,84 m.). Espacio libre interior de 115 yardas $(105,16 \mathrm{~m}$.) de largo por 76 yardas $(69,49 \mathrm{~m}$.) de ancho en el que se puede marcar un campo de fútbol. 
dimensiones y superficies aproximadas graderío

\begin{tabular}{|c|c|}
\hline L01-01' & $116,56 \mathrm{M}$ \\
\hline L $01-02^{\prime}$ & $95,16 \mathrm{M}$ \\
\hline L $04-01$ & $444,72 \mathrm{M}$ \\
\hline R O1-Al & $46,84 \mathrm{M}$ \\
\hline R $02^{\prime}-A 3^{\prime}$ & $66,96 \mathrm{M}$ \\
\hline$<$ Al.01.A2 & $167^{\circ}$ \\
\hline$<A I^{\prime} .01$ '.A2 & $53^{\circ}$ \\
\hline$<A 3^{\prime} .01^{\prime} . A 4$ & $60^{\circ}$ \\
\hline$<A 3^{\prime} .02^{\prime} . A 4$ & $42^{\circ}$ \\
\hline$<$ Al.04.Al & $15^{\circ}$ \\
\hline
\end{tabular}

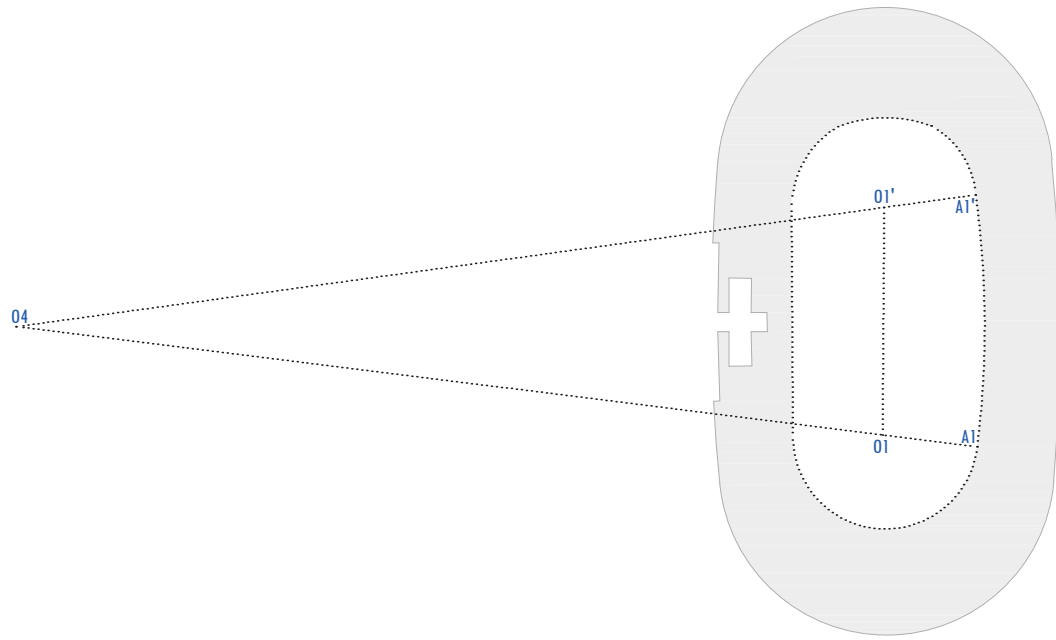

superficie de cubierta: $468 \mathrm{~m} 2$
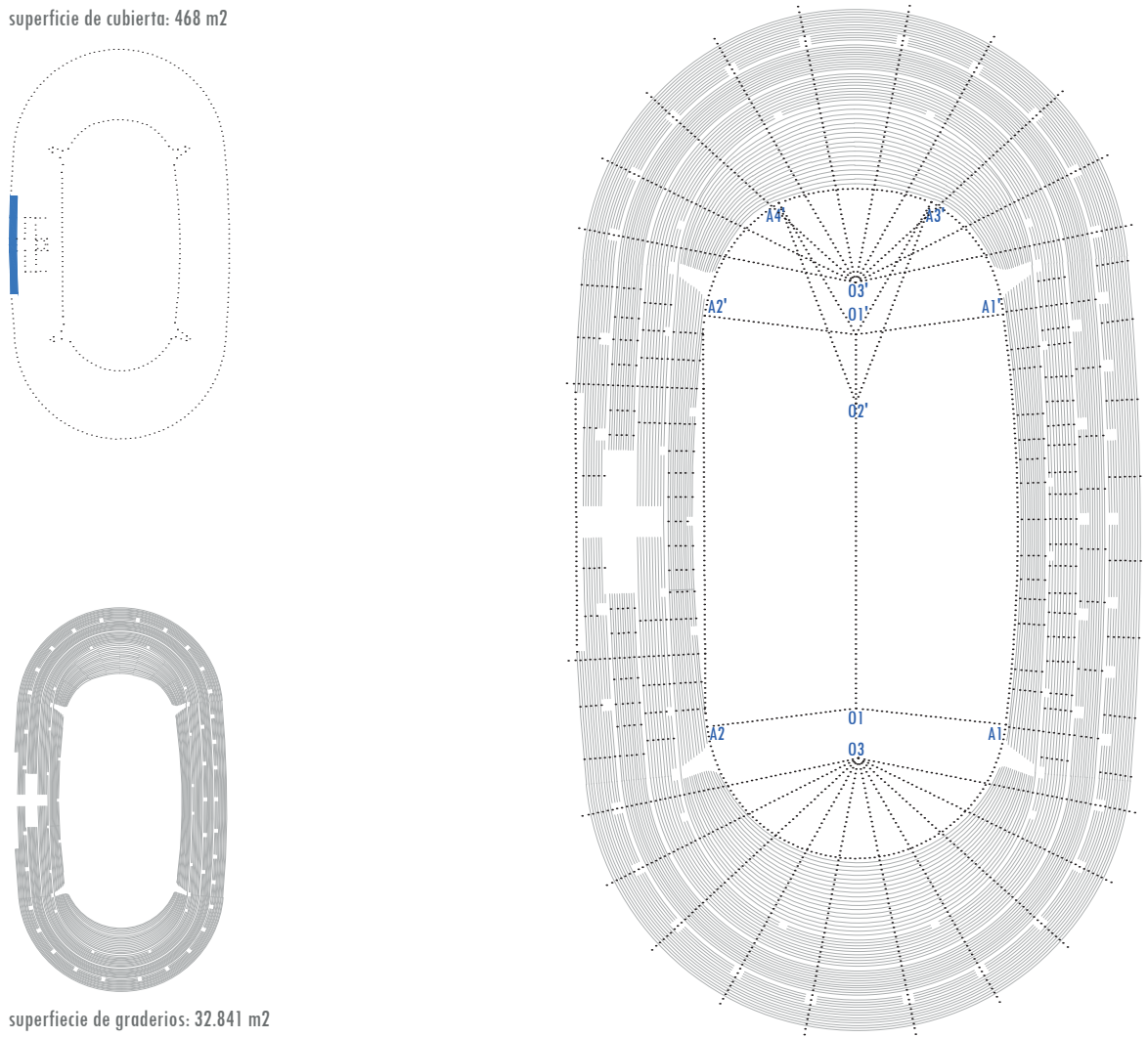

superfiecie de graderios: $32.841 \mathrm{~m} 2$

$\begin{array}{lll}N & 0 & 100 \mathrm{~m} \\ 1 & 1 & 1\end{array}$

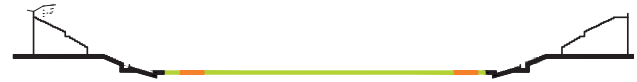

El campo y la pista se encuentran a 4,50m. por debajo del nivel de suelo y permanecen separados del graderío por un foso $2 \mathrm{~m}$. de ancho, 1,90m. de profundidad. El campo de hierba, la pista y las otras instalaciones para el atletismo poseen un sistema de drenaje especial para proporcionar el grado de humedad necesario; así como una instalación moderna y eficiente que permite realizar el riego necesario en un corto período de tiempo.

$246 \mathrm{~m}$

\subsection{Elementos significantes:}

\subsection{Avances técnicos:}

Se empleó por primera vez en estos juegos un sistema de grabación magnética de señales de televisión, cuya ventaja principal frente al kinetoscopio empleado hasta entonces (dispositivo 
que captaba con una cámara cinematográfica las escenas y las presentaba en un monitor de televisión) era, además de la calidad, que las imágenes se podían grabar y reproducir, dando la posibilidad al emisor, pero también al receptor, de revivir las experiencias una y otra vez.

Fueron además los primeros Juegos emitidos en directo por las televisiones de Europa y, gracias al empleo del magnetoscopio, los primeros con retransmisiones internacionales. En total, 18 países europeos recibieron las señales en directo a través de Eurovisión (red permanente de circuitos de radioenlace establecido por la Unión Europea de Radiodifusión para permitir el intercambio de programas entre sus miembros y la distribución a destinos múltiples de programas de interés común) mientras que para los otros continentes, las retransmisiones se realizaban al día siguiente, en versión diferida, cuando las cintas magnéticas grabadas con los programas de los juegos llegaban avión a Estados Unidos, Canadá y Japón).

Cabe también destacar que en estas Olimpiadas tuvo lugar la primera edición de los juegos paralímpicos y sonó por primera vez el himno oficial de los Juegos.

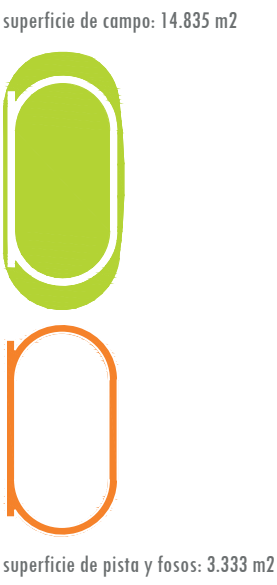

superficie de pista y fosos: $3.333 \mathrm{~m} 2$

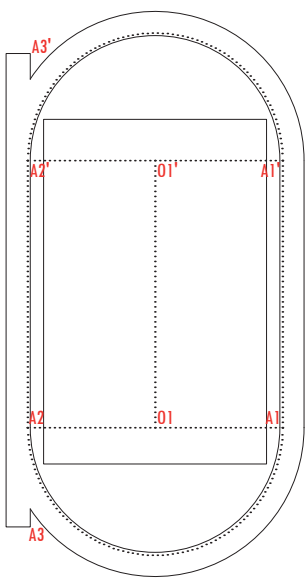

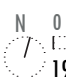
1960. ROMA dimensiones y superficies aproximadas pista

\begin{tabular}{|c|c|c|}
\hline CUERDA & $400,00 \mathrm{M}$ & $437 \mathrm{yds}$ \\
\hline $01-01 '$ & $81,45 \mathrm{M}$ & \\
\hline A3-A2 & $30,10 \mathrm{M}$ & \\
\hline A3-A3' & $144,16 \mathrm{M}$ & \\
\hline ૨ $01-A 1$ & $38,33 \mathrm{M}$ & \\
\hline$<$ Al.01.A2 & $180^{\circ}$ & \\
\hline
\end{tabular}

marca del ganador

$\begin{array}{lrr} & \text { Hombres } & \text { Mujeres } \\ 100 \mathrm{~m} . & 10 " 2 & 11 " 0 \\ 200 \mathrm{~m} & 20 " 5 & 24 " 0 \\ 400 \mathrm{~m} . & 44 " 9 & \\ 800 \mathrm{~m} . & 1,46 " 3 & 2,04 " 3 \\ 1500 \mathrm{~m} . & 3,35 " 6 & \\ 5000 \mathrm{~m} & 13,43 " 4 & \\ 10000 \mathrm{~m} . & 28,32 " 2 & \\ \text { Marathón } & 2 \mathrm{~h} .15,16 " 2 & \\ 110 / 80 \mathrm{mv} & 13 " 8 & 10 " 8 \\ 400 \mathrm{mv} & 49 " 3 & \\ 3000 \mathrm{obst} & 8,34 " 2 & \\ \text { Altura } & 2,16 \mathrm{~m} & 1,85 \mathrm{~m} \\ \text { Pértiga } & 4,70 \mathrm{~m} & \\ \text { Longitud } & 8,12 \mathrm{~m} & 6,37 \mathrm{~m} \\ \text { Triple } & 16,81 \mathrm{~m} & \\ \text { Peso } & 19,68 \mathrm{~m} & 17,32 \mathrm{~m} \\ \text { Disco } & 59,18 \mathrm{~m} & 55,10 \mathrm{~m} \\ \text { Martillo } & 67,10 \mathrm{~m} & \\ \text { Jabalina } & 84,64 \mathrm{~m} & 55,98 \mathrm{~m} \\ 4 \text { X 100 } & 39 " 5 & 44 " 5 \\ 4 \text { X } 400 & 3,02 " 2 & \end{array}$
con Castellazzi y el Ingeniero Pascoletti.

En 1947, construyó la estación de Roma Termini (un ejemplo importante del Racionalismo Italiano) después de ganar el concurso junto con los arquitectos Castellazzi-Fatigati y el ingeniero Pintonello, ex-aequo con el ingeniero Calini y el arquitecto Montuori, junto a quienes ejecutaron el proyecto.

De sus obras de carácter deportivo destacan, además del estadio Olímpico, el Palazzetto delo Sport de Roma (1957) y de Turín (1961), ambos en colaboración con Pier Luigi Nervi, la Escuela Nacional de Atletismo 'Bruno Zauli' en Formia (entre 1956 y 1958) y el complejo deportivo de Acqua Acetosa de Roma (entre 1956 y 1963). Estas dos últimas obras se caracterizan por su sinceridad estructural, la supresión de todo lo superfluo y la exaltación de los materiales pobres.

Tipo de encargo.

Del Debbio: encargo directo, por ser director de la Oficina Técnica de la Opera Nazionale Balilla

Vitellozzi: encargo directo, derivado del puesto que ocupó en la Dirección General de

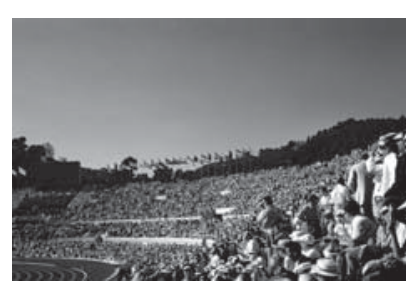



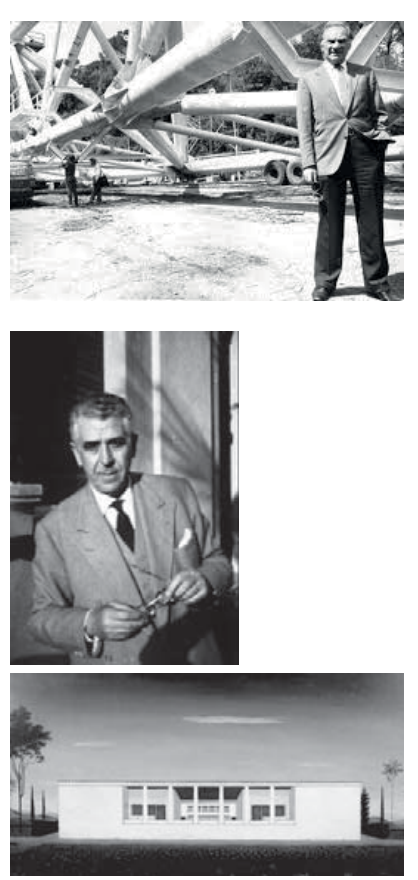

Annibale Vitellozzi Enrico del Debbio Villa Brizzi de del Debbio, 1939
Ordenación del Territorio del Ministerio de Obras Públicas desde comienzos de la posguerra. En 1949 se decide su traslado al al Comité Olímpico con el fin de llevar a cabo las tareas de planificación, diseño, desarrollo y construcción de algunas de las obras necesarias para la celebración de los juegos

\subsection{Edificios coetáneos:}

1932, Sanatorio de Paimio, de Alvar Aalto, plan Obus en Argel de Le Corbusier.

1952, Ayuntamiento de Säynätsalo, de Aalto,

1953, Unidad de Habitación de Marsella de Le Corbusier.

1960, La Chemosphere house, de John Lautner, en Hollywood, la Torre Pirelli, de Gio Ponti, en Milan, el Hotel SAS, en Copenhagen, de ARNE Jacobsen, la Tourette de Le Corbusier.

\subsection{Hechos históricos relevantes:}

El 21 de abril, aunque aún permanece en construcción, Brasil estrena su nueva capital: Brasilia. Se independizan de Francia Togo (27 de abril), la República Malgache (postriormente conocida como República Democrática de Madagascar, 26 de junio), Costa de Marfil (7 de agosto) y el Chad ( 11 de agosto). El Congo Belga alcanza la independencia de Bélgica bajo el nombre de República Democrática del Congo (30 de junio)

El 11 de julio se publica la novela de la escritora estadounidense Harper Lee "Matar un ruiseñor".

El 20 de julio en Ceilán, se elige a la primera mujer Primer Ministro del mundo: Sirimavo Bandaranaike

El 26 de septiembre tiene lugar en Estados Unidos el primer debate electoral televisado, entre los candidatos a la presidencia del país John F. Kennedy y Richard Nixon. 
1964. TOKIO

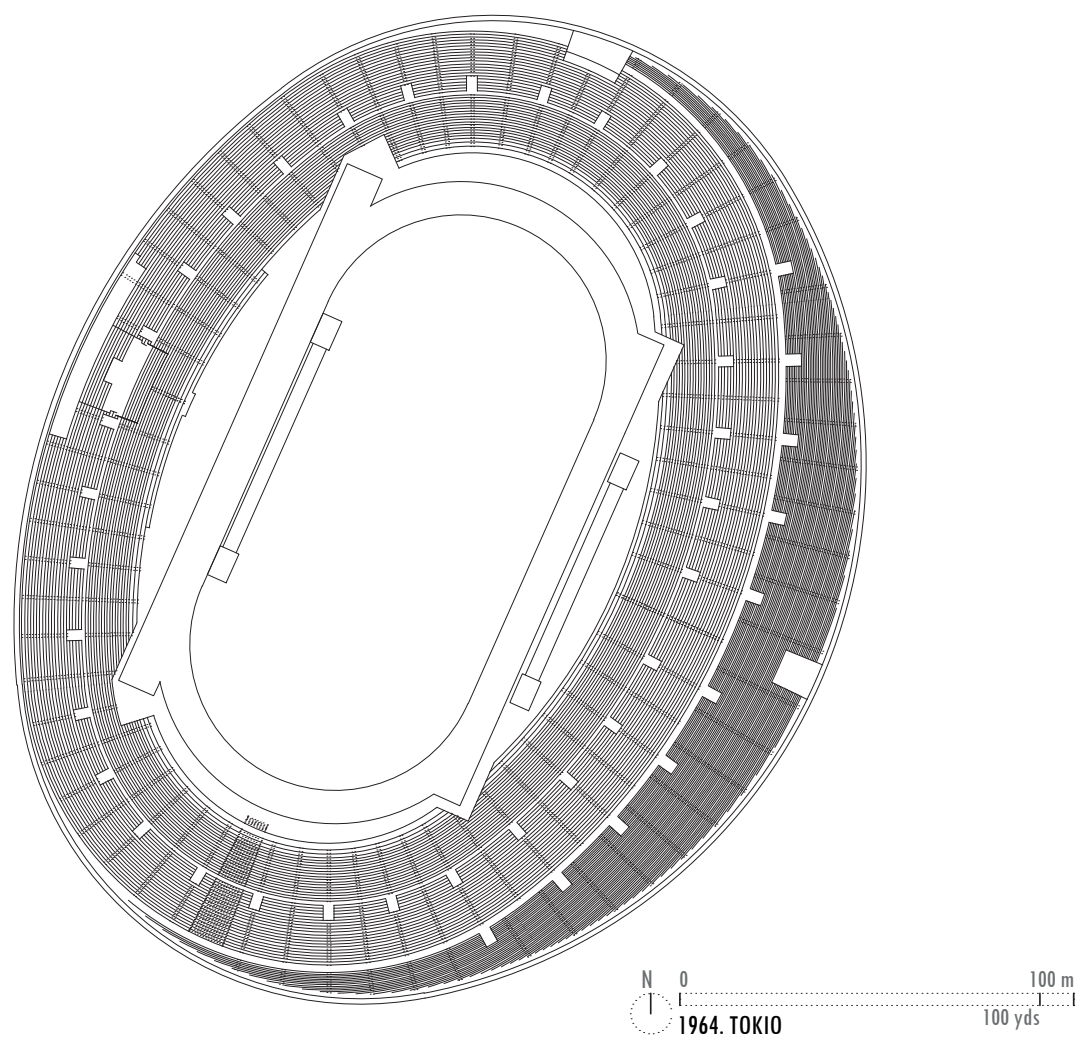

1964.0. Nombre del Estadio

Estadio Olímpico de Tokio o Estadio Nacional de Japón.

(Kokuritsu Kasumigaoka Rikujo Kyogijo).

1964.1. Situación

10-2, Kasumigaokamachi, Shinjuku, Tokio 160-0013, Japón

\subsection{Fechas}

1936. En agosto, en Berlín, el Comité Olímpico Internacional designa a Tokio como sede de los XII Juegos Olímpicos de 1940, aunque posteriormente fueron cancelados por motivos de la guerra.

1952. En mayo, Tokio decide volver a presentar su candidatura para la organización de los Juegos.

1957. Enero, inicio de la construcción del estadio

1958. Marzo, finalización de las obras.

1958. El 20 de noviembre, inauguración del estadio, con los Juegos Asiáticos.

1959. El 26 de mayo, el ClO concede a Tokio la organización de los Juegos de la XVIII Olimpiada a celebrar en 1964

1959. El 19 de octubre, se constituye el Comité Especial para las Instalaciones Deportivas.

1962. En febrero empiezan las obras para aumentar el aforo de 55.000 a 75.000 espectadores. Finalizando el 30 de junio

1963. Semana Internacional Deportiva de Tokio, ensayo general de los Juegos

1964. El 10 de octubre, inauguración de los Juegos.

El 24 de octubre, ceremonia de clausura.

1967. Celebración de la V Universiada.

1968. Copa del $47^{\circ}$ Emperador. Más tarde sería celebrada cada año.

1973. Se instala pista de atletismo con superficie sintética.

1975. Final campeonato de rugby. Anual a partir del 2004.

1979. Copa mundial de Fútbol Juvenil.

1979. Primer Marathón de Tokio. Anual a partir del 2008.

1980. Copa Intercontinental.

1991. Campeonato Mundial de Atletismo.

1993. Final de la Liga de Fútbol Japonesa.

1996. Concierto de los Tres Tenores.

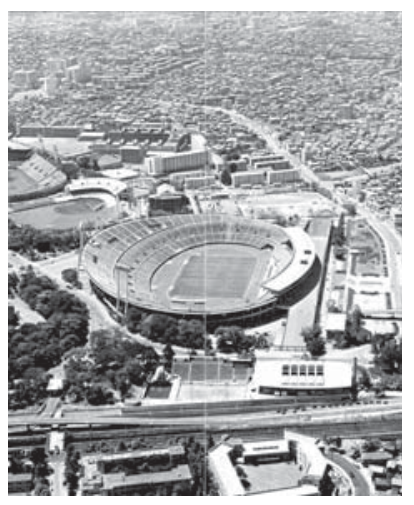




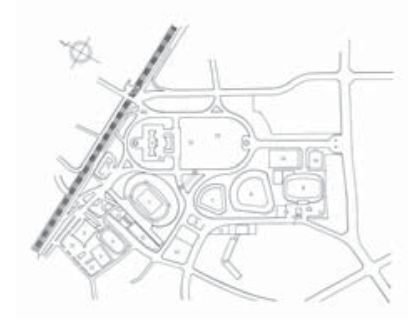

1964.3. Preexistencias en el lugar

Jardín exterior del Santuario de Meiji. Durante los cuarenta años de reinado del emperador Meiji Tenno (1878/1912) era el lugar en el que el pueblo podía reverenciarlo. En 1924 se construye el estadio Meiji Jingu, que es demolido para la construcción del Estadio Nacional, en 1956.

1964.4. Relación con la ciudad. Posición respecto al centro urbano

En el casco urbano, a unos $2,5 \mathrm{~km}$ al oeste del centro de la ciudad, a $1,5 \mathrm{~km}$ del Santuario Meiji, a $0,9 \mathrm{Km}$ del Palacio Akasaka, a 2,0km de la estación de tren Shinjuku, la más concurrida del mundo.

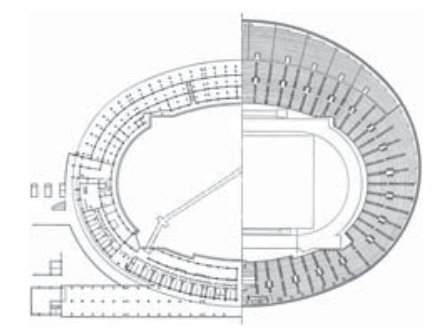

1964.5. Breve relato de la historia del Estadio

Para poder contar con un estadio para la celebración de competiciones internacionales en la ciudad de Tokio, con la vista puesta en los Juegos Asiáticos, en 1957. se iniciaron los trabajos de demolición del antiguo Estadio del Santuario de Meiji, que duró tres meses y a finales de marzo de ese año comenzaron las obras de edificación de lo que sería el Estadio Nacional. 2.000 personas trabajaron día y noche para conseguir terminar la construcción el 30 de marzo de 1958, un año después de su inicio.

Se invirtieron 1.400 millones de yens, aproximadamente 3.972 millones de dólares en la construcción de un estadio, de forma ovalada, con capacidad para 50.000 espectadores. La estructura se preparó para añadir 30.000 localidades más en el caso de que la ciudad de Tokio fuese escogida para celebrar los Juegos Olímpicos.

Así ocurrió a partir de 1961. En muchos textos, pero no hemos podido constatarlo en las fuentes, se atribuye el encargado del estudio urbanístico para la creación del Parque Olímpico y la ampliación del Estadio a Kenzo Tange, en colaboración con los ingenieros Yoshikatsu Tsuboi y Uichi Inve.

Las obras de ampliación del Estadio, para adecuarlo a los requerimientos de los Juegos Olímpicos, comenzaron en marzo de 1962 y se completaron en agosto de 1964. Se ampliaron las gradas, para aumentar el aforo desde 52.000 hasta 75.000 localidades, adosando un nuevo graderío en forma de media luna a las gradas opuesta a la tribuna principal. En entorno fue remodelado, y se realizaron mejoras en las instalaciones y se ampliaron los sistemas de transporte público.

La designación de la ciudad de Tokio como sede para la celebración de los Juegos Olímpicos de 1964 supuso un gran escaparate para mostrar al mundo el cambio radical que se había producido en el país. Se trazaron múltiples líneas de tren y metro. Se construyeron autopistas entrecruzando las áreas metropolitanas. Se ampliaron los aeropuertos. El tren bala, el más rápido del mundo que con la más moderna tecnología, unía Osaka con Tokio. Un monorail acercaba el aeropuerto al centro de la ciudad.

\subsection{Descripción del Estadio; Graderío}

Grada continua, con capacidad para 71.556 espectadores, numero de filas creciente de forma asimétrica en su eje corto. Pequeña cubierta en la tribuna principal. Material Hormigón armado y cubierta de hormigón armado aligerado y estructura de perfiles de acero. En la ampliación se instalaron además cuatro potentes torres de iluminación.

Situado en la ladera de una colina (la cota de apoyo de la grada principal es 10 metros inferior que la grada opuesta) la edificación se adapta en su arranque a la topografía. Dimensión exterior total del estadio: $213 \times 262 \mathrm{~m}$. Dimensiones de los asientos: $72-90 \mathrm{~cm} \times 42$ $\mathrm{cm}$. Ancho máximo de las gradas: $61 \mathrm{~m}$. Altura máxima de las gradas: $31 \mathrm{~m}$. (sobre el nivel del campo)

\subsection{Descripción del Estadio; Pista}

Pista de $400 \mathrm{~m}$. de cuerda, curvas de un solo radio. Ocho calles con una anchura total de 10 m.

Material, ceniza coloreada NeoH-Brick, de $3 \mathrm{~cm}$ de espesor

Campo de $105 \times 68 \mathrm{~m}$. de Hime-Korai, una variedad de césped japonés

Programa Deportivo: Atletismo, Final del torneo de fútbol, Competiciones de hípica y las Ceremonias de Apertura y Clausura de los Juegos. 


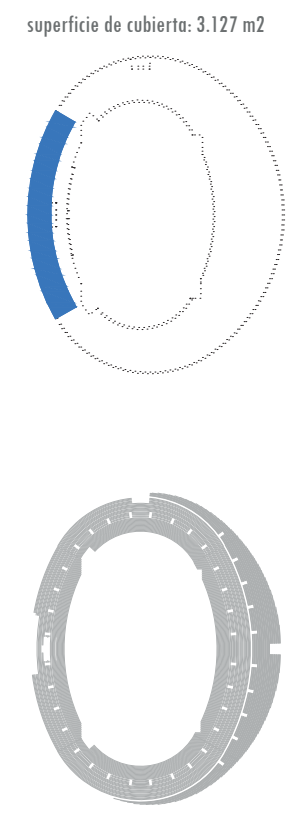

superfiecie de graderios: $23.117 \mathrm{~m} 2$

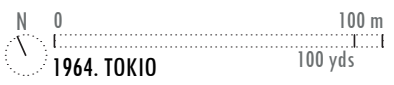

superficie de campo: $12.997 \mathrm{~m} 2$
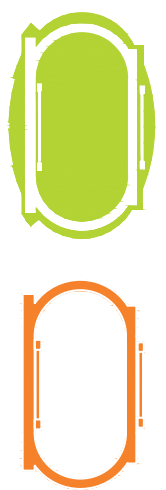

superficie de pista y fosos: $4.663 \mathrm{~m} 2$
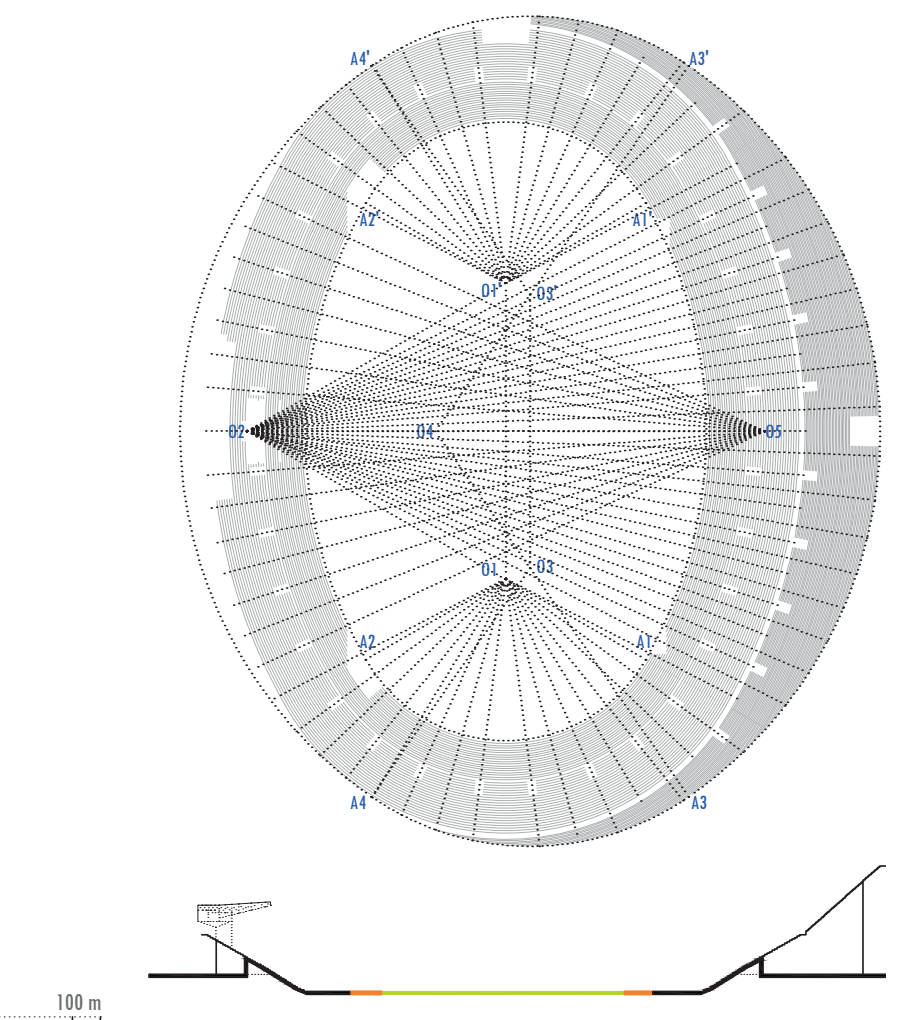

dimensiones y superficies aproximadas graderío

L 01-01' $\quad 90,26 \mathrm{M}$

L $01-02 \quad 90,85 \mathrm{M}$

L 03-03' 83,31 M

L 03-04 50,69 M

R O1-Al 49,13 M

R 02-Al 139,97M

R 03-A3 84,82 M

R 04-A3 135,51 M

$<$ A1.01.A2 $\quad 60^{\circ}$

$<$ Al.02.Al $\quad 60^{\circ}$

$<$ A3.03.A4 $\quad 69^{\circ}$

$<$ A3.04.A3' $111^{\circ}$

\subsection{Elementos significantes}

El pebetero, colocado en la parte superior del graderío recrecido en forma de media luna enfrente de la tribuna principal. Fue realizado con las técnicas de la calderería tradicional japonesa de la ciudad de Kawaguchi.

\subsection{Avances técnicos}

Juegos olímpicos televisados en color y en directo, vía satélite para América del Norte y Europa.

Primera vez que se utilizó la cámara lenta.

La mayor innovación en atletismo fue la incorporación de las pértigas de fibra de vidrio, en lugar de las rígidas de aluminio que se venían usando hasta entonces, ello dio lugar a que el estadounidense Fred Hansen batiera el récord mundial por 40 centímetros.

\subsection{Autores. Tipo de encargo}

Mitsuo Katayama nace el 27 de septiembre de 1918 en la prefectura de Aichi, Nagoya. Estudió en el Departamento de Arquitectura de la Universidad Imperial de Kyoto, donde se graduó con un estudio sobre la "Casa de la Cascada" de Frank Lloyd Wright en 1943.

dimensiones y superficies aproximadas pista

$$
\begin{aligned}
& \text { CUERDA } \quad 400,00 \mathrm{M} \quad 437 \mathrm{yds} \quad \mathrm{I}^{\prime} 4 \frac{1}{32} \\
& \text { L 01-01' } \quad 78,95 \mathrm{M} \\
& \text { L 03-03' 127,95 M } \\
& \text { ᄂ } 03-01 \quad 24,50 \mathrm{M} \\
& \text { L 04-04' 143,45 M } \\
& \text { L 04-02 30,50 M } \\
& \text { R OI-Al } \quad 37,76 \mathrm{M} \\
& <\text { A1.01.A2 } \quad 180^{\circ}
\end{aligned}
$$

marca del ganador

$\begin{array}{lrr} & \text { Hombres } & \text { Mujeres } \\ 100 \mathrm{~m} . & 10 " 0 & 11 " 4 \\ 200 \mathrm{~m} & 20 " 3 & 23 " 0 \\ 400 \mathrm{~m} . & 45 " 1 & 52 " 0 \\ 800 \mathrm{~m} . & 1,45 " 1 & 2,01 " 1 \\ 1500 \mathrm{~m} . & 3,38 " 1 & \\ 5000 \mathrm{~m} & 13,48 " 8 & \\ 10000 \mathrm{~m} . & 28,24 " 4 & \\ 110 / 80 \mathrm{mv} & 13 " 6 & 10 " 5 \\ 400 \mathrm{mv} & 49 " 6 & \\ 3000 \text { obst } & 8,30 " 8 & \\ \text { Altura } & 2,18 \mathrm{~m} & 1,90 \mathrm{~m} \\ \text { Pértiga } & 5,10 \mathrm{~m} & \\ \text { Longitud } & 8,07 \mathrm{~m} & 6,52 \mathrm{~m} \\ \text { Triple } & 16,85 \mathrm{~m} & \\ \text { Peso } & 18,85 \mathrm{~m} & 18,14 \mathrm{~m} \\ \text { Disco } & 61,00 \mathrm{~m} & 57,27 \mathrm{~m} \\ \text { Martillo } & 69,74 \mathrm{~m} & \\ \text { Jabalina } & 82,66 \mathrm{~m} & 60,54 \mathrm{~m} \\ 4 \text { X 100 } & 39 " 0 & 43 " 6 \\ 4 \text { X 400 } & 3,00 " 7 & \\ \text { 20km marcha } & 1 \mathrm{~h} 29,34 " 0 & \\ 50 \mathrm{~km} \text { marcha } & 4 \mathrm{~h} 11,29 " 4 & \\ \text { Decathlón } & 7.887 \mathrm{ptos} & \\ \text { Hepthalón } & & 5.246 \mathrm{ptos} \\ \text { Marathón } & 2 \mathrm{~h} .12,11 " 2 & \\ & & \end{array}$




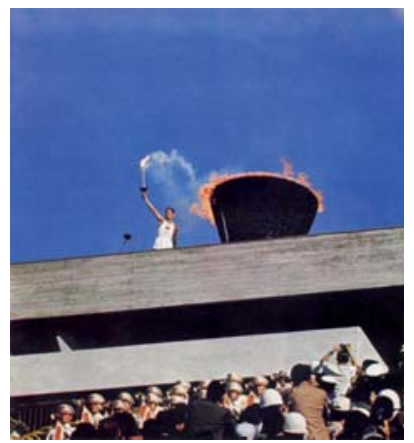

Después de la Guerra trabajó como Arquitecto para la Administración hasta 1973, en el Ministerio de Construcción, primero en la Oficina Regional de Kinki y después en Oficina Regional de Kanto. Posteriormente trabajó en el estudio de arquitectura de la Corporación Naito.

Desde 1983 hasta su fallecimiento el 16 de agosto de 1985, en Kyoto, se dedicó al estudio de la Arquitectura Sostenible en el Instituto de Investigación Archigreen de Arquitectura Bioclimática.

Sus obras más importantes son, además del estadio, el Hospital Kansai de Osaka, el Edificio de la Delegación del Gobierno de la Prefectura de Nara, el Museo de Arte de la Prefectura de Nara y el Centro Cultural de la Prefectura de Nara.

Diferentes fuentes atribuyen la ampliación del estadio Kenzo Tange, aunque no hemos podido constatar fehacientemente el hecho, por la confusión que produce que su actuación en Yoyogi, para los Juegos, se denominen también estadios. $Y$ además de su presumible participación en la planificación urbanística de los Juegos desde su posición como el más prestigioso arquitecto y urbanista Japonés, recordemos que en 1960 había presentado su plan para el crecimiento de Tokio.

Construcción: Taisei Construction Co., Ltd.

Tipo de encargo. Para su construcción fue objeto de un concurso público restringido a arquitectos japoneses, ganado por Mitsuo Katayama. De la ampliación no disponemos de datos.

\subsection{Edificios coetáneos}

Palacio de la Asamblea de Chandigarh, ciudad patrimonio de la humanidad, diseñado por Le Corbusier.

Biosfera de Montreal, de Buckminster Fuller.

Estadios en Yoyogi, de natación y Baloncesto para los Juegos de 1964 de Kenzo Tange

\subsection{Hechos históricos relevantes}

7 de abril, la empresa IBM presenta su primer modelo de la computadora serie 360 .

14 de mayo, en Egipto se inaugura la presa de Asuán.

12 de junio, en Sudáfrica se condena a cadena perpetua a Nelson Mandela.

Diseño del lenguaje de programación BASIC. Este lenguaje facilitaba la programación de ordenadores a cualquier persona, aunque no hubiese estudiado ciencias. Hasta entonces, el uso de un ordenador requería codificar software hecho a medida, lo que restringía enormemente el número de usuarios.

Bibliografía Tokio 1964:

The Games of the XVIII Olympiad. Tokio 1964. The Official Report of the Organizing Committee WIMMER, Martin. (1976). Olympic Buildings. Ed. Leipzig. Lic 600/34/75. 5938721

GORDON, Barclay F. (1983). Olympic Architecture. Building for the summer games. John Wiley \& Sons. Nueva York. ISBN 0-471-06069-0 


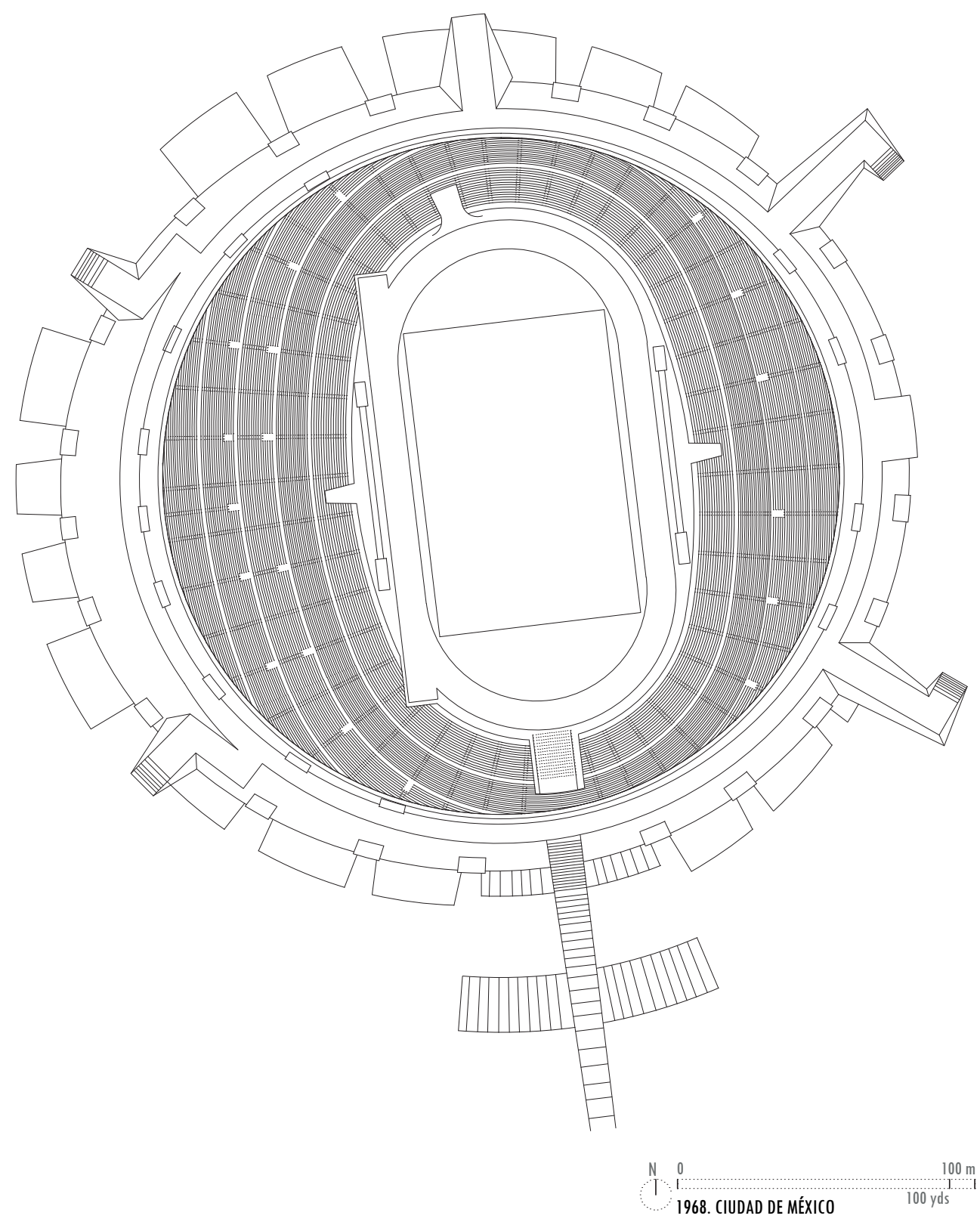

1968.0. Nombre del Estadio

Estadio Olímpico Universitario.

Antes de los Juegos era solamente Estadio Universitario.

1968.1. Situación

Av. de los Insurgentes Sur S/N,

Universidad Nacional Autónoma de México C.U.,

Coyoacán, 04510 Ciudad de México, D.F., México

\subsection{Fechas}

1950. El 7 de agosto, inicio de las obras del Estadio.

1952. El 20 de noviembre, inauguración del estadio con los II Juegos Juveniles Nacionales y la Orquesta Sinfónica de la Universidad.

1954. Juegos Deportivos Centroamericanos y del Caribe. Constituyeron la primera gran competición deportiva internacional celebrada en México.

1955. Juegos Deportivos Panamericanos.

1956. Campeonato Panamericano de Fútbol.

1968. Celebración de la XIX Olimpiada.
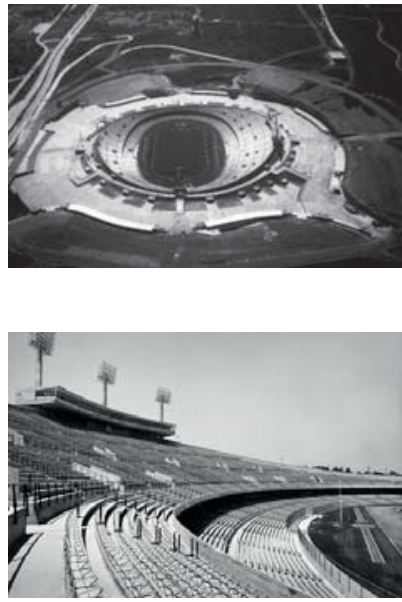


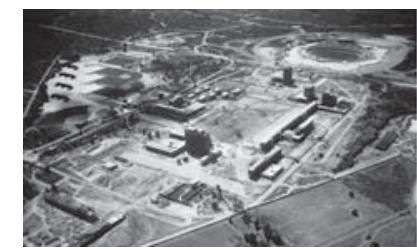

12 de octubre Inquguración.

27 de octubre Clausura.

1970. Campeonato Mundial de Fútbol.

1975. Juegos Deportivos Panamericanos

1977. Juegos deportivos Estudiantiles Centroamericanos y del Caribe.

1979. Universiada Mundial.

1986. Campeonato Mundial de Fútbol.

1990. XVI Juegos Deportivos Centroamericanos y del Caribe.

2003. Gran Prix de México de Atletismo.

\subsection{Preexistencias en el lugar}

El estadio es parte integrante de la Ciudad Universitaria y sus orígenes se deben a la misma. En 1943, se eligió el sitio adecuado para construir la Ciudad Universitaria: el Pedregal de San Ángel, zona de terrenos predominantemente volcánicos, producto de erupciones de varios volcanes, entre ellos el Xitle, ocurridas hace más de dos mil años, ubicada al sur del Valle de México.

En 1946 se expropiaron los terrenos elegidos, aproximadamente setecientas hectáreas. Creándose una comisión para formular los programas generales de los edificios que compondrían la Ciudad Universitaria, entre los que se encontraba el estadio, convocar los concursos de planificación urbanística y proyectos y proponer el plan financiero.

En 1948 iniciaron las primeras obras de infraestructura, del conjunto.

En marzo de 1950 se creó la entidad denominada Ciudad Universitaria de México. El arquitecto Carlos Lazo, actuando como gerente, asumió la tarea de convertir en realidad los proyectos que se iban finalizando.

Para el desarrollo y ejecución de toda la obra de la Ciudad Universitaria se contó con más de 70 arquitectos e ingenieros, 200 jefes de obra contratistas y supervisores y más de 10.000 obreros, en algunos momentos trabajando las 24 horas del día. El conjunto total de las obras se concluyó en un plazo inferior a tres años.

1968.4. Relación con la ciudad. Posición respecto al centro urbano

Al sur del centro urbano, en la proximidad al eje norte sur de la ciudad, la avenida de los Insurgentes. Forma parte de la Ciudad Universitaria.

Situado a 12,8km del Centro Histórico, 12,7km del Zócalo, Pza. Constitución, a 5,4km del Estadio Azteca y a $16,8 \mathrm{~km}$ del Aeropuerto Internacional Benito Juárez:.

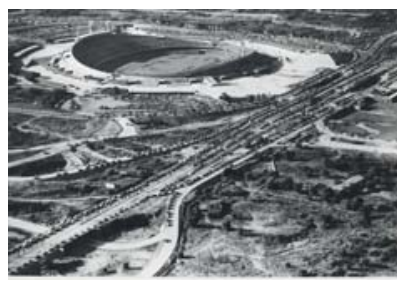

\subsection{Breve relato de la historia del Estadio}

En marzo de 1950, una vez designado el equipo de arquitectos que proyectaría el estadio y estaba formado por Augusto Pérez Palacios, Raúl Salinas Moro y Jorge Bravo Jiménez, Pérez Palacios visita por el mundo algunos estadios, además analiza otros a través de las publicaciones disponibles, especialmente los de Berlín (1936), proyectado por Werner March; Florencia (1931), de Pier Luigi Nervi, o París (1937), de Le Corbusier, y la propuesta de Niemeyer para Maracaná (1941), estos dos últimos se quedaron en el papel.

Pérez Palacios dibujó numerosos croquis analíticos que mostraban su preocupación respecto al funcionamiento, la forma, la isóptica, la iluminación, las gradas o la estructura.

También le impactaron otros estadios, como los de las universidades de Yale, Denver, Providence y Cornell, en Estados Unidos, por las soluciónes arquitectónicas basadas en el diagrama del estadounidense Gavin Hadden (Stadium Design, Ed. American Society of Civil Engineers. Nueva York. 1925). Tal esquema proponía que la forma de los estadios debía responder al acomodamiento natural de los espectadores, analizando cual es el proceso de ocupación en función de las preferencias lógicas de los espectadores. Dicho estudio supone un cambio sustancial en el trazado de los estadios, donde el público, tradicionalmente, se colocan en igual número de filas concéntricas en torno al óvalo que rodea el campo y las pistas. Después de su análisis comparativo, Pérez Palacios opta por el planteamiento de Hadden, como lo demuestra el croquis inicial que realizó, descrito por él mismo: "l...a base de dos grandes valvas desiguales para alojar en una forma natural y espontánea pero eminentemente lógica a los espectadoresil. Este dibujo muestra además una zona de graderías a cubierto bajo un balcón volado «....buscando la yuxtaposición de las gradas en un nivel intermedio entre campo y últimas filas de asientos. Accesos en forma de rampa, eliminando las escaleras, posibilidad de varias rampas y accesos a diferentes niveles... con una disposición de gradas dejando dos espacios, las cabeceras del campo, con menor número de asientos para evitar la sensación de encierroll.

El croquis inicial se acompaña de dos secciones que representan soluciones para los graderíos superiores: estadio sobre terraplén (estereotómico) o estadio con estructura de hormigón armado (tectónico). Las dos propuestas comparten la grada baja excavada en el terreno. 
Para fundamentar la elección fue solicitado a los arquitectos un estudio comparativo. El sistema en talud aprovecha el perfil resultante de la excavación para levantar las gradas superiores, mientras que la grada construida en hormigón armado permite una gran penetrabilidad entre los dos graderías, resultando mas flexible en su funcionamiento al poderse conformar una galería de distribución debajo de la misma, pero suponía un gran consumo de materiales caros y escasos, el acero y el hormigón.

Finalmente se impuso el aspecto económico y Carlos Lazo, gerente de la Entidad Ciudad Universitaria, decidió que se utilizaría el terraplenado como sistema básico arquitectónico y a partir del 2 de octubre de 1950 los arquitectos iniciaron los planos definitivos. Entre los argumentos que Carlos Lazo esgrimió en su respuesta se decía: "los primeros planos del proyecto para el gigantesco Estadio Olímpico especificaban hormigón y otros conocidos materiales usados en estadios de los Estados Unidos, pero México es un país pobre. Tenemos pocas plantas productoras de cemento, sin embargo, tenemos una técnica para construir presas empleando arcilla, que es famosa en el mundo de la ingeniería. Nuestras presas pueden ser comparadas favorablemente con las presas de hormigón siendo mucho más económicas»l.

Los arquitectos aprovecharon las técnicas construcción de presas, Empleando arcilla como materia prima y la maquinaria utilizada en la construcción de presas y carreteras. El resultado ha sido una verdadera y original aportación a la arquitectura. Pérez Palacios escribiría después: "Creo que la solución a la que llegamos es la mejor demostración de que procedimos de forma lógica, porque el Estadio Olímpico es una de las estructuras más hermosas de Ciudad Universitaria. Para la economía en construcción, una de las reglas principales es tener el material lo más cerca posible. En la construcción del estadio Olímpico empleamos el magnífico material que teníamos a la mano, la misma tierra en donde iba a ser levantadoll.

La construcción comenzó oficialmente, según la correspondencia, llel lunes 7 del actual (agosto de 1950), a las 12 horas, en los terrenos del Pedregal de San Ángel donde se construye la Ciudad Universitaria de México..."

El Estadio se localiza al noroeste de Ciudad Universitaria. El eje longitudinal de composición del campo de juego, con orientación norte-sur, se sitúa paralelamente y a 270 metros de la avenida de los Insurgentes, el otro eje de composición, con orientación este-oeste, coincide con el eje principal de composición del campus universitario. En el ensayo de la coordinadora del Archivo Arquitectos Mexicanos de la UNAM, la doctora Lourdes Cruz González Franco, titulado El Estadio Olímpico Universitario del Pedregal. Permanencia y vigencia, nos revela algunos de los fundamentos del proyecto

Además de su favorable localización dentro de Ciudad Universitaria, el terreno se eligió porque tenía cierto hundimiento natural que se aprovechó para excavar y remover la roca fija, producto del crestón de roca basáltica, la tierra y el tepetate (terreno endurecido, de color amarillento y de origen volcánico).

La forma del hundimiento era la de un tronco de cono de base elíptica, allí se ubicó el campo de juego y además se aprovechó para apoyar una parte de las gradas. La tierra excavada se volteó para construir un terraplén circular alrededor del campo con el talud o pendiente exterior con base en el ángulo de fricción o reposo natural del material, el cual se recubrió para evitar el deslizamiento, con la misma piedra de origen volcánico que se extrajo del lugar. En el interior del terraplén se apoyaron las graderías superiores.

Las óptimas condiciones físicas del terreno permitieron la compactación del terraplén utilizando la maquinaria de movimiento de tierras conveniente, al igual que en los ocho estacionamientos que circundan al Estadio. Se movieron más de 100.000 metros cúbicos de tierra y piedra para lograr la forma proyectada. Este procedimiento constructivo se combinó eficazmente con las estructuras de hormigón armado necesarias para el balcón perimetral, los túneles, la caseta de prensa y los mástiles.

El balcón perimetral forma un voladizo de nueve metros de luz. Por un lado, funciona como trasdós de las gradas, para que los últimos espectadores no estén demasiado lejos; y por el otro, la sombra que proyecta permite alojar los palcos y aproximadamente 14 mil localidades bajo cubierta que son las más cotizadas.

El talud exteroir cuenta con un gran mural del artista mejicano Diego Rivera $(1886 / 1957)$ realizado con piedras de diversos colores: el rojo tezontle, el ámbar del tecali, el mármol blanco, las piedras verdes y rosas, y las piedras de río.

A raíz de la designación de México como sede olímpica, el Comité indicó la necesidad de aumentar la capacidad en 20.000 espectadores más. El Departamento de Obras Públicas presentó, sin contar con Pérez Palacios, un proyecto en la prensa nacional el 26 de junio de 1966, que además de ser muy costoso, deformaba la apariencia del Estadio. De inmediato Pérez Palacios propuso otro proyecto respetuoso con el carácter de la edificación. Suplementando una grada elevada a modo de un gran aro sobre el estadio topográfico existente. Afortunadamente ninguna de las dos propuestas se levaron a termino. 

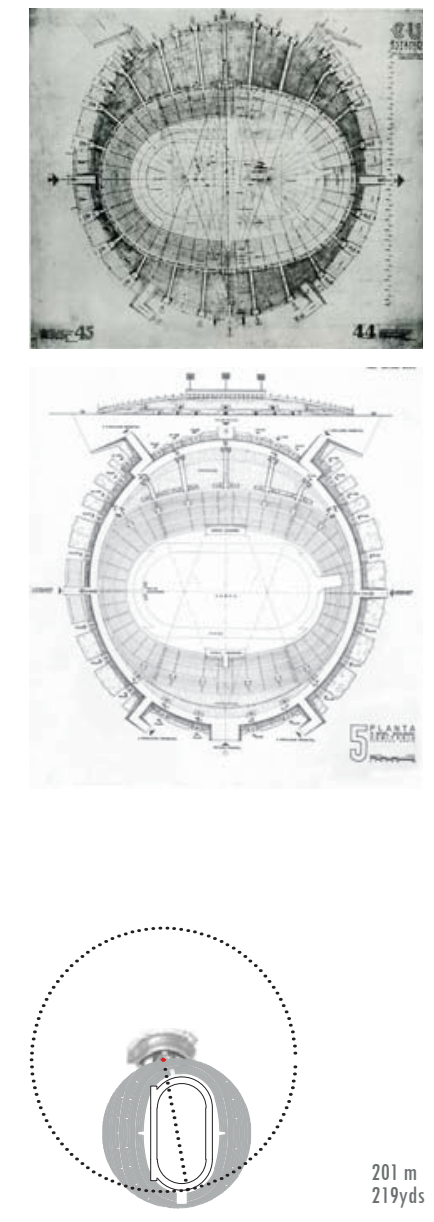

dimensiones y superficies aproximadas graderío

$\begin{array}{lr}\text { L 01-01' } & 77,69 \mathrm{M} \\ \text { L 01-02 } & 135,58 \mathrm{M} \\ \text { L 02-03 } & 260,27 \mathrm{M} \\ \text { L 03-04 } & 123,01 \mathrm{M} \\ \text { R 01-A1 } & 51,02 \mathrm{M} \\ \text { R 02-A2 } & 187,00 \mathrm{M} \\ \text { R 04-A3 } & 113,77 \mathrm{M} \\ \text { < A1.01.A2 } & 147^{\circ} \\ \text { < A2.02.A2 } & 33^{\circ}\end{array}$

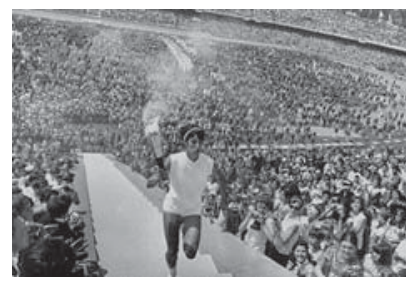

\subsection{Descripción del Estadio; Graderío}

Graderío encajado en la topografía formado por dos gradas una resultado de la excavación y la alta del terraplenado, con capacidad para 80.000 personas. Todos los accesos y circulaciones se producen por rampas que a través de 42 túneles de hormigón armado que atraviesan los terraplenes acceden al interior del estadio en un nivel intermedio. Este diseño permite una rápida distribución de los espectadores, lográndose su desalojo, en tan sólo 20 minutos.

El volumen del edificio presenta una curva convexa en las caras este y oeste, donde se encuentran las gradas que alojan a la mayor parte del público además de las torres de iluminación. Estas gradas son asimétricas, la del poniente mayor que la de oriente, debido a que así se resuelve la protección solar para la mayoría de los espectadores, ya que los espectáculos suelen celebrarse por la tarde. Además, de disfrutar de las vistas hacia el conjunto universitario.

Encima del graderío destaca el volumen elevado de $70 \mathrm{~m}$. de longitud, para la prensa llamado "el Palomar", que ingrávido se despega y flota.

Su traza en planta esta compuesta por un delicado juego de elipses que dibuja de un modo asimétrico el graderío, rompiendo esquemas clásicos y favoreciendo la visibilidad de la mayor parte del público.

superficie de cubierta: $1.073 \mathrm{~m} 2$
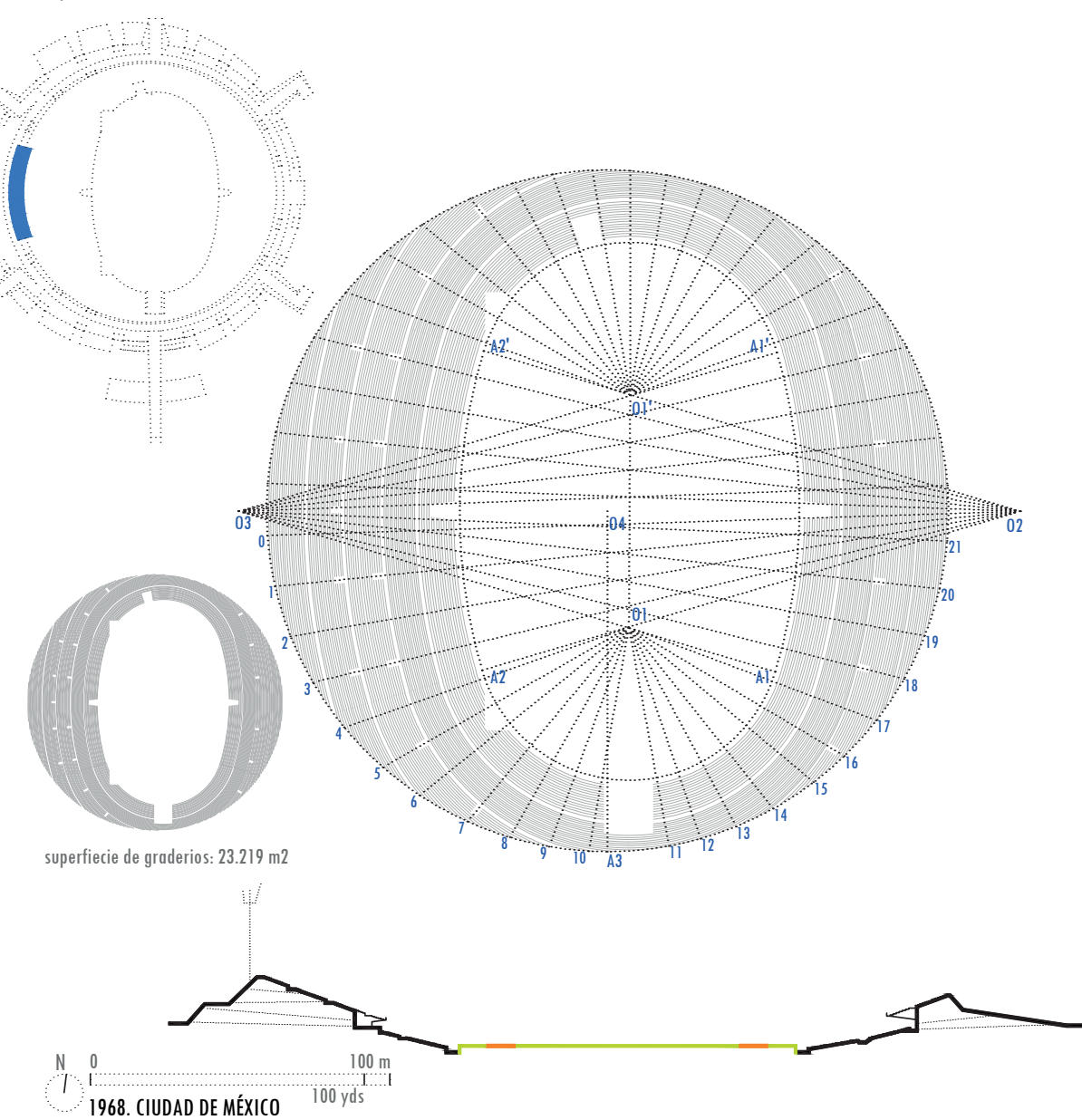

\subsection{Descripción del Estadio; Pista}

Tiene una cuerda de 400 metros formada por dos rectas de 80.62 metros y dos curvas de 119.38 metros. La pista tiene ocho carriles de 1.25 metros de ancho y la recta, situada al frente de las tribunas del lado poniente, que se prolonga en ambos extremos para permitir las pruebas de 100 metros, y 80 y 110 metros vallas.

Fue el primer estadio Olímpico en contar con una pista fabricada con material sintético llamado Tartán, polímero de $25 \mathrm{~mm}$ de espesor, compuesto por caucho y resinas sintéticas que forma una superficie elástica, antideslizante, resistente y apropiada para cualquier competición bajo cualquier condición climática. 
El Estadio cuenta con un moderno sistema de desagüe (con filtros y drenes) en el campo de juego.
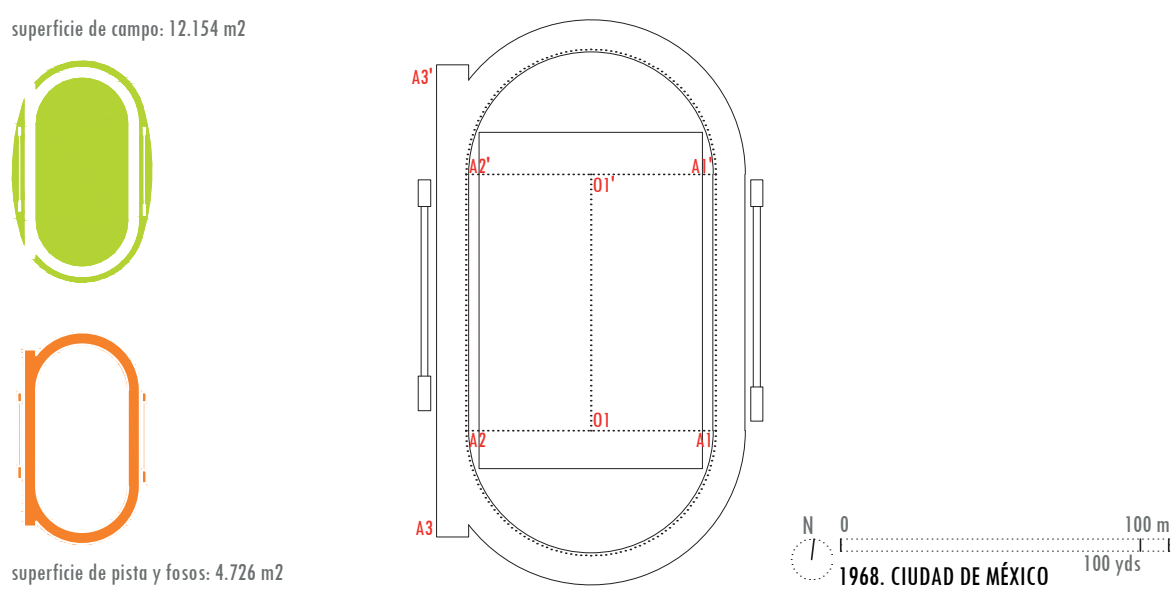

Programa Deportivo: Atletismo, Gran Premio de las Naciones de Hípica y las Ceremonias de Apertura y Clausura de los Juegos.

\subsection{Elementos significantes}

\subsection{Avances técnicos}

Superficie de competición sintética, sus beneficios unidos a la menor densidad de la atmósfera a causa de la gran altitud de México, supuso una autentica revolución en las marcas de las pruebas relacionadas con la velocidad, pudiéndose destacar a Bob Beamon que saltó unos extraordinarios 8,90 metros en longitud

La mejora de los fosos de saltos permite la evolución técnica de las especialidades, que queda ejemplarizada en el nuevo estilo de salto de altura ejecutado por Richard Douglas Fosbury, o la mejora del materia de las pértigas que permitió una mejora sustancial del récord Olímpico, iniciada por nuestro saltador Ignacio Sola $(5,20 \mathrm{~m})$ entrenado por el querido y carismático José Luis Torres.

Primera vez que se utilizó la cámara lenta basada en técnicas de disco magnético.

Aunque ya se había empleado en Roma de forma no oficial, el cronometraje de las pruebas que se desarrollaron en los Juegos de México fue exclusivamente electrónico. El tiempo se unió a la imagen y nació el cronometraje deportivo moderno. Con este sistema se eliminaba el tiempo de reacción de los cronometradores manuales estimado en 0,23 segundos. Bajo la presión de las cadenas de televisión, los jueces cronometradores desaparecieron del borde de la pista y su ayuda nunca más volvió a ser requerida.

\subsection{Autores. Tipo de encargo}

Augusto Pérez Palacios, Raúl Salinas Moro y Jorge Bravo Jiménez.

Augusto Pérez Palacios (1909/2002). Estudió en la Escuela Nacional de Arquitectura de México DF. Su arquitectura se asienta en principios funcionalistas, en la búsqueda de una plástica mexicana propia y un profundo conocimiento de construcción y del cálculo estructural. Su logro principal fue haber fundido el lenguaje moderno y la tradición arquitectónica mexicana.

Obra Arquitectónica: Vivienda popular y edificios hospitalarios. Estadio Alberto "Chivo" Córdoba(estadio talud, inscrito en un circulo) en la ciudad de Toluca, de la Universidad Autónoma del Estado de México (UAEM) en 1954 (dos años después de la inauguración del Estadio Universitario). Secretaría de Comunicaciones y Obras Públicas de México DF (1954). Conjunto habitacional Belén de las Flores, México DF (1954).

Tipo de encargo. Concurso de ideas entre los profesores y alumnos de la Escuela Nacional de Arquitectura.

\subsection{Edificios coetáneos}

Iglesia Evangélica Luterana St. Stephen «Stephanuskirche». Wolfsburg, Alemania. Alvar Aalto.

Neue Nationalgallerie. Berlín, Alemania. Mies van der Rohe.

Finaliza la construcción del edificio Torres Blancas, de Francisco Javier Sáenz de Oíza.

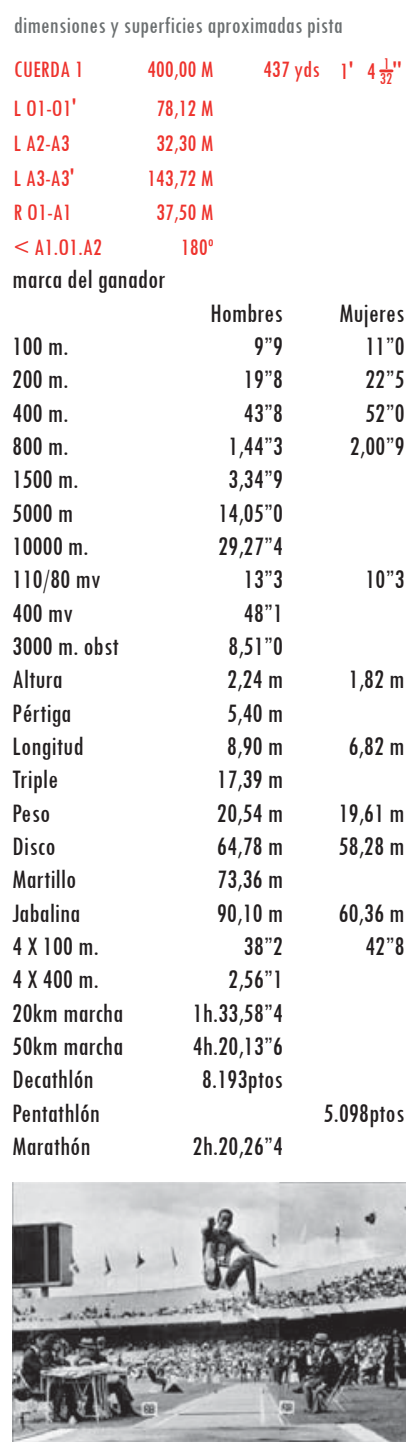

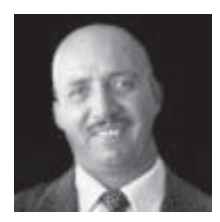


1968.12. Hechos históricos relevantes

20 de agosto, en Checoslovaquia las tropas del Pacto de Varsovia invaden el país y acaban con la Primavera de Praga.

12 de octubre, Guinea Ecuatorial, Fernando Poo y Río Muni se independizan de España.

24 de diciembre, el Apollo 8 se convierte en la primera nave espacial en orbitar la Luna.

Bibliografía México 1968:

MEXICO 68. The Official Report 1968. Ed. Organizing Committee of the Games of the XIX Olympiad. 1969.

WIMMER, Martin. (1976). Olympic Buildings. Ed. Leipzig. Lic 600/34/75. 5938721

GORDON, Barclay F. (1983). Olympic Architecture. Building for the summer games. John Wiley \& Sons. Nueva York. ISBN 0-471-06069-0

Archivo de Arquitectos Mexicanos de la Facultad de Arquitectura de la UNAM: retrospectiva y compromiso. CRUZ GONZÁLEZ FRANCO, Lourdes. El Estadio Olímpico Universitario del Pedregal. Permanencia y vigencia 


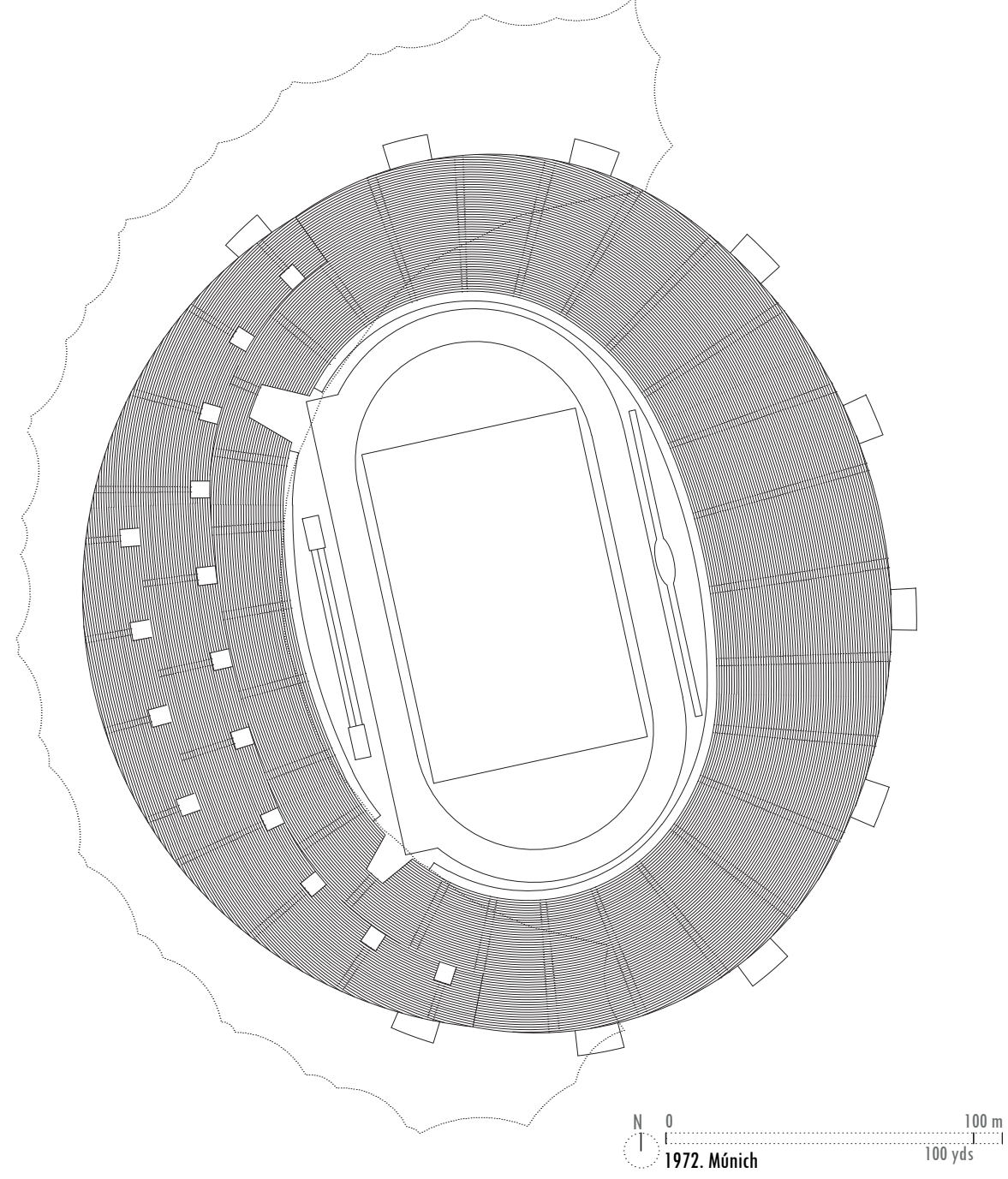

\subsection{Nombre del Estadio}

Estadio Olímpico de Múnich

(Münchner Olympiastadion).

1972.1. Situación

Spiridon-Louis-Ring 21

80809 Múnich, Alemania

1972.2. Fechas

1966 El 26 de abril el COI en Roma concede a Munich la celebración de los Juegos de la XX Olímpiada.

1966 El 2 de diciembre, celebración del concurso para el diseño y desarrollo del Parque Olímpico.

1967 El 3 de noviembre comienzan las obras generales de movimiento de tierras.

1968 El 28 de octubre se inician las obras del Estadio.

1971 En primavera comienza la instalación de la cubierta.

1971 A finales de este año comienza la plantación de los 3.100 árboles del Parque Olímpico.

1972 El 26 de agosto, inauguración Juegos Olímpicos de Múnich.

1972 El 11 de septiembre, ceremonia de Clausura de los Juegos.

1974 El 13 de junio, X Copa Mundial de Fútbol.

1979 El 30 de mayo, Final de la Copa de Campeones de Europa.

1988 El 10 de junio, VIII Eurocopa de Fútbol.

1989 El 2 de septiembre, sede de la final mundial del "Motorcycle speedway"

1993 El 26 de mayo, Final de la Liga de Campeones de la Uefa.

1997 El 28 de mayo, Final de la Liga de Campeones de la Uefa.

1999 El 27 de junio Michael Jackson ofrece un concierto solidario en beneficio de la Cruz Roja teniendo como invitados a Steve Wonder, Andrea Bocelli, Montserrat Caballé, Ringo Starr y Rod Stewart entre otros.

2006 El 31 de diciembre se convierte en la primera sede en acoger el Tour de Esquí 


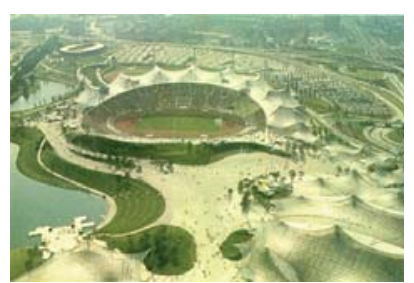

1972.3. Preexistencias en el lugar

La zona de Oberwiesenfeld, originariamente una planicie. Aparece mencionada por primera vez en 1792 cuando la artillería del ejército bávaro realizaba allí sus prácticas de tiro, sirviendo además como patio de armas de algunos cuarteles situados en los alrededores. A partir de 1909 se utilizó también como campo de aviación. Hasta 1938 fue el lugar en el que se encontraba el aeropuerto comercial de Múnich-Oberwiesenfeld y donde el primer ministro francés Édouard Daladier y el primer ministro británico Neville Chamberlain firmaron el Acuerdo de Múnich poco antes del inicio de la Segunda Guerra Mundial. En en área se contruyeron una estación de mercancias y una central térmica. En 1939 se amplió y pasó a denominarse MunichRiem, un aeropuerto utilizado por la Luftwaffe durante la contienda.

Después de 1945, fue segregada del Oberwiesenfeld una zona entre HeavyReiterStraße y Nymphenburg Canal, la cual se utilizó entre 1947 y 1958 como vertedero de los escombros provenientes de la destrozada ciudad de Múnich, que había sido fuertemente azotada por bombardeos durante la guerra. Se generaron dos auténticas montañas: una de ellas, la que después se convertiría en la colina olímpica, Olympiaberg, llegó a tener 60 metros de altura y contenía 10.000.000 de metros cúbicos de escombros; la otra, la del Luitpoldhügel en el Luitpoldpark, a poca distancia de la anterior y situada hacia el este, fue movida durante la construcción de la línea del metro olímpico U3. El Olympiaberg es una de las elevaciones más altas de Múnich y en su cima, una cruz de aluminio recuerda a las víctimas civiles de la Segunda guerra Mundial.

Hasta poco antes del inicio de las obras para los Juegos Olímpicos, la parte norte del campo de aviación preexistente seguía siendo utilizada por pilotos amateurs (el último avión despegó en marzo de 1968); la parte sur fue, de 1954 a 1967 el lugar donde se celebraba la Feria Anual de la Construcción (Bauma).

1972.4. Relación con la ciudad. Posición respecto al centro urbano

Se localiza dentro del Olympiapark (Parque Olímpico), al nornoroeste del Casco Histórico pero incluido en el actual centro urbano.

Situado a 4,6km de la Marienplatz (el centro de Múnich), a 25,8 km del Aeropuerto Internacional de Múnich-Franz Josef Strauss, a 3,8km de Hauptbahnhof (Estación Central de Ferrocarriles), a $4,7 \mathrm{~km}$ de Sendlinger Tor (la torre más antigua de la ciudad), a $4,4 \mathrm{~km}$ de Frauenkirche (La Catedral de Nuestra Señora) y a $4,9 \mathrm{~km}$ de Viktualienmarkt (mercado de alimentos)

1972.5. Breve relato de la historia del Estadio

El 30 de diciembre de1965, la ciudad de Múnich presenta su candidatura ante el C.O.I. para la celebración de los XX Juegos Olímpicos. Acompaña a la solicitud un informe con una relación detallada de las instalaciones deportivas con las que cuenta la ciudad para realizar el evento. Entre ellas no aparece ningún equivalente a un estadio olímpico, sin embargo, y como se describe en dicho informe "lestaban a punto de finalizar los planes para la construcción de un gran estadio con un aforo de entre 90.000 y 100.000 espectadores, 70.000 de los cuales estarán sentados y 50.000 de ellos bajo cubierta. Este estadio, futuro centro deportivo de la ciudad de Múnich, estará equipado con instalaciones para casi todos los deportes y será por tanto perfectamente adecuado para albergar los importantes eventos deportivos internacionales que se prevénn.

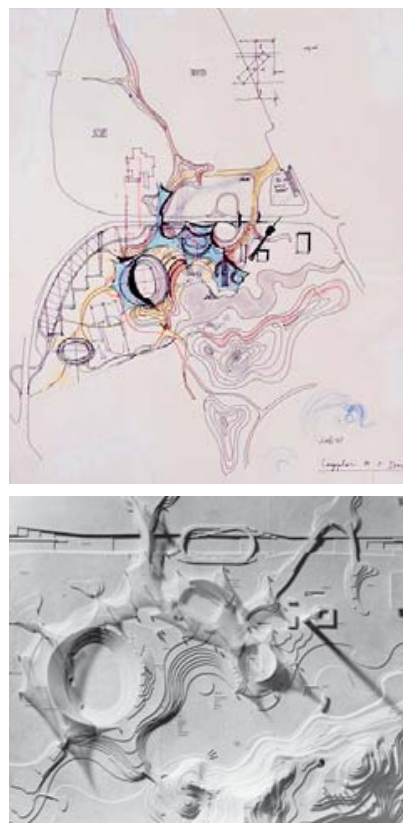

Cuando el 26 de abril de 1966 el C.O.I. otorgó en Roma la celebración de los XX Juegos Olímpicos a Múnich, las ideas sobre la nueva planificación urbana de la zona ya estaban muy desarrolladas, sólo faltaba materializarlas. Para ello, el 2 de diciembre de ese mismo año se anunció un concurso de ámbito nacional, para que arquitectos e ingenieros realizaran sus propuestas: "El objetivo del concurso es obtener propuestas, desde un contexto digno, para la planificación urbana del Oberwiesenfeld y para el diseño arquitectónico de los lugares de competición, además de hallar la mejor solución económica y funcional para la posterior utilización de esas instalaciones.l)

El concurso fue ganado por Behnisch \& Associates, de Stuttgart. El jurado tuvo en cuenta "Los esfuerzos realizados por los autores para obtener la solución del problema a través de la alteración artificial del terreno». Se valoró además "la inclusión, en la configuración del complejo olímpico, de la colina formada por el antiguo vertedero de escombros. El modelado del terreno, como se propone en el proyecto, es la base para resolver el problema de acomodar el complejo olímpico en un sitio que no está dotado de características naturales es encomiable, no sólo desde el punto de vista económico, sino también urbanístico.ll

En octubre de 1967 se realizaron los estudios geológicos y las obras generales de movimiento de tierras dieron comienzo el 3 de noviembre. Las obras propias del Estadio, como una de las parte del conjunto del Parque Olímpico, comenzaron el 28 de octubre de 1968.

1972.6. Descripción del Estadio; Graderío

La forma del Estadio Olímpico es un círculo casi perfecto, situado en la pendiente occidental de la meseta central. Existe un único graderío que recorre todo el círculo del Estadio, como una carcasa interior, soportada en sus $2 / 3$ inferiores por el propio terreno y en el tercio superior por la estructura del edificio. 
El eje longitudinal mide $260 \mathrm{~m}$. y el eje transversal, de $245 \mathrm{~m}$., está desviado $10^{\circ}$ hacia el oeste respecto de la alineación norte - sur.

El borde superior de la grada presenta un escalonamiento para adaptarse a la forma circular. La pendiente de las escaleras se planteó para seguir el mismo trazado en sección de las gradas de forma que no obstaculizara la visión del espectador. La distancia máxima desde cualquier localidad al punto más alejado del terreno de juego es de $218 \mathrm{~m}$. El escalonamiento de las gradas varía entre 20 y $48 \mathrm{~cm}$. en función de la altura del lugar respecto a la cota del campo de juego. Debido a la exigencia del C.O.I. de instalar asientos especiales en algunos lugares de las gradas, la capacidad del Estadio se vió reducida de 81.000 a 77.000 espectadores. Todos los vomitorios para acceso y evacuación de las gradas se encuentran al mismo nivel.
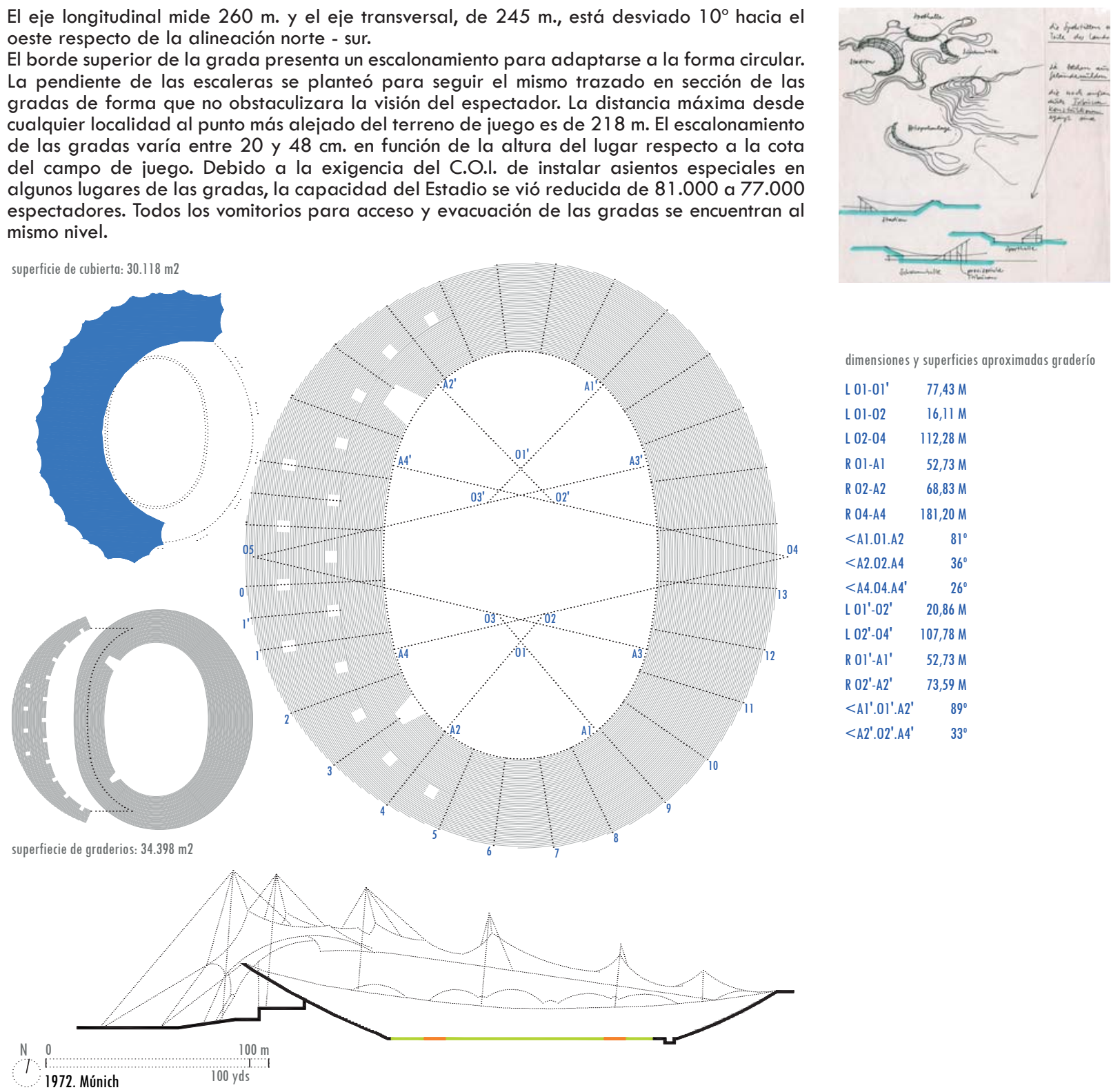

La estructura de la tribuna, situada en el lado oeste está conformada por más de 24.700 $\mathrm{m}$. de perfiles metálicos que soportan un total de 1.280 placas prefabricadas. Estas placas generan el escalonamiento de las gradas y tienen una longitud máxima de 16,05 m. La estructura mencionada posee una altura total de $34 \mathrm{~m} ., 18$ de los cuales están situados por debajo de la superficie del terreno, antigua escombrera que circunda el estadio, y que soporta tres forjados en los cuales están situadas las dependencias auxiliares. Cada uno de estos forjados, con forma de arco, encastra por un lateral, en una capa de $30 \mathrm{~cm}$. de hormigón vertido sobre el terraplenado y por el otro en la carcasa que soporta los graderíos. Un pasillo inferior conecta las dependencias de los atletas.

El estadio se integra en la red viaria del Parque Olímpico. En todo el recinto existe una separación estricta entre las zonas de tráfico de vehículos y de peatones. El primero está restringido al lado occidental del Estadio y sólo a personas autorizadas. Finalizadas las Olimpiadas, estas zonas serán ocupadas por los espectadores que accedan en coche al Estadio.

En transporte público:

Al norte del Parque Olímpico se encuentran las estaciones de metro y las paradas del tranvía. Una estación de autobuses para desplazamientos interiores está situada al sur del Estadio. También existen caminos y pasarelas de acceso rápido para los peatones.

Dos bloques de iluminación, cada uno con 144 focos, están montados en mástiles de celosía a los lados de la tribuna este.

En cuanto a la cubierta, el jurado del concurso expresó sus dudas sobre la viabilidad. Se recabó la opinión de «expertos», selecionandorse la propuesta de Frei Otto. La idea básica

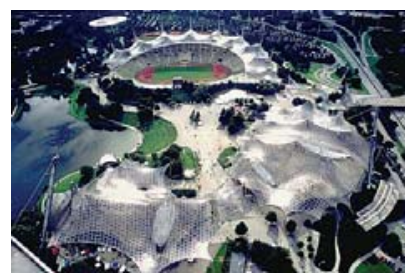

dimensiones y superficies aproximadas graderío

L $01-01 ' \quad 77,43 \mathrm{M}$

L $01-02 \quad 16,11 \mathrm{M}$

L 02-04 112,28 M

R 01-Al $\quad 52,73 \mathrm{M}$

R 02-A2 $68,83 \mathrm{M}$

R 04-A4 181,20 M

$<$ A1.01.A2 $\quad 81^{\circ}$

$<$ A2.02.A4 $36^{\circ}$

$<$ A4.04.A4' $26^{\circ}$

L $01^{\prime}-02^{\prime} \quad 20,86 \mathrm{M}$

L 02'-04' 107,78 M

R Ol'-Al' $\quad 52,73 \mathrm{M}$

R 02'-A2' $\quad 73,59 \mathrm{M}$

$<$ Al'.O1'.A2' $89^{\circ}$

$<$ A2'.02'.A4' $33^{\circ}$

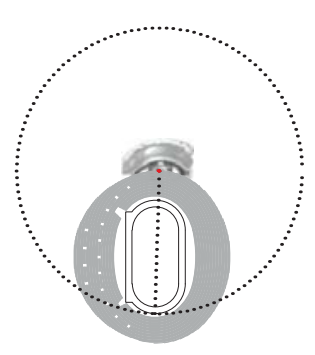




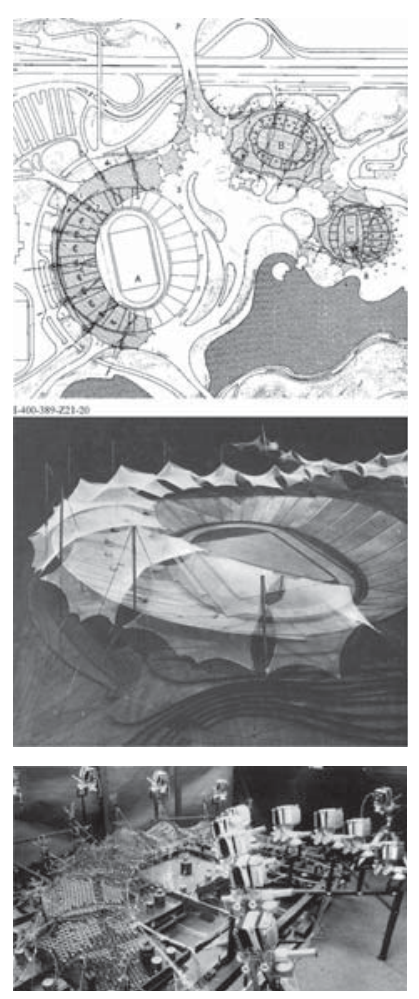

dimensiones y superficies aproximadas pista

CUERDA $\quad 400,00 \mathrm{M} \quad 437 \mathrm{yds}-1$ -

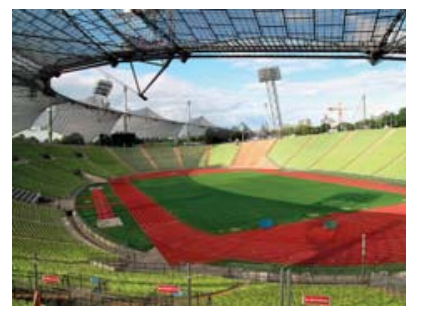

de diseño era que, para que una cubierta de $75.000 \mathrm{~m} 2$ de superficie tuviera un aspecto ligero, sólo podría ser construida a partir de una malla de cables pretensados, aplicando la experiencia previa del pabellón de Alemania Occidental en la Exposición Mundial de 1967 celebrada en Montreal.

Los estudios de Frei Otto demostraban que la curvatura necesaria de los tensores principales se podía conseguir con la incorporación de válvulas de neopreno. Las superficies serían de doble curvatura, similares a las de una silla de montar, con una tensión tal que prevenga el aleteo producido por las ráfagas de viento y el pandeo producido por las cargas de nieve. Siguiendo este patrón se consigue que la red adopte cualquier forma deseada y que además pueda cubrir grandes áreas sin apoyos. Los cables del tejido de red canalizaban los esfuerzos transmitiendo las cargas recibidas a los cables principales y estos bien a los mástiles o a los anclajes en el terreno.

La televisión en color, que empezaba a dominar el panorama informativo, requirió que los soportes de la cubierta del lado oeste produjeran la menor cantidad de sombras posible, lo que se consiguió, sustituyendo los apoyos proyectados, por un simple cable frontal de 440 $\mathrm{m}$. de longitud que, puesto en tensión adquiriría una forma semicircular que ataría todos los extremos de las mallas.

La longitud de los mástiles va de 11 a $81 \mathrm{~m}$. con diámetros de hasta 3,5 m. Calcular la altura de un mástil es relativamente fácil, sin embargo, la longitud exacta de un cable sólo se obtiene a partir de la buena planificación matemática que proporciona un ordenador. La cubierta del Estadio se divide en nueve secciones continuas que exigen el diseño de nuevos componentes y hasta nuevas técnicas de soldadura.

Frei Otto se lamentaba a veces de que la cubierta del estadio olímpico no hubiera podido ser mas ligera, debido a la necesidad de adaptarse a una forma previamente diseñada por el arquitecto Günter Behnisch.

El deseo fue conseguir el mínimo impacto sobre el parque, como un velo tendido sobre la colina.

La cubierta está suspendida de 12 mástiles de acero articulados, de diferentes alturas. Tiene una superficie de $74.800 \mathrm{~m} 2$ y está constituida por una red de malla rectangular de cables pretensados, espaciados en ambos sentidos $75 \mathrm{~cm}$ y con ángulo de intersección variable, lo que le permite acomodarse a cualquier curvatura.

El cerramiento de la estructura es una lámina de poliéster revestida de PVC, de 2,9 x $29 \mathrm{~m}$. y $4 \mathrm{~mm}$. de espesor que, para evitar deformaciones a causa de la temperatura, descansa sobre válvulas de neopreno.

\subsection{Descripción del Estadio; Pista}
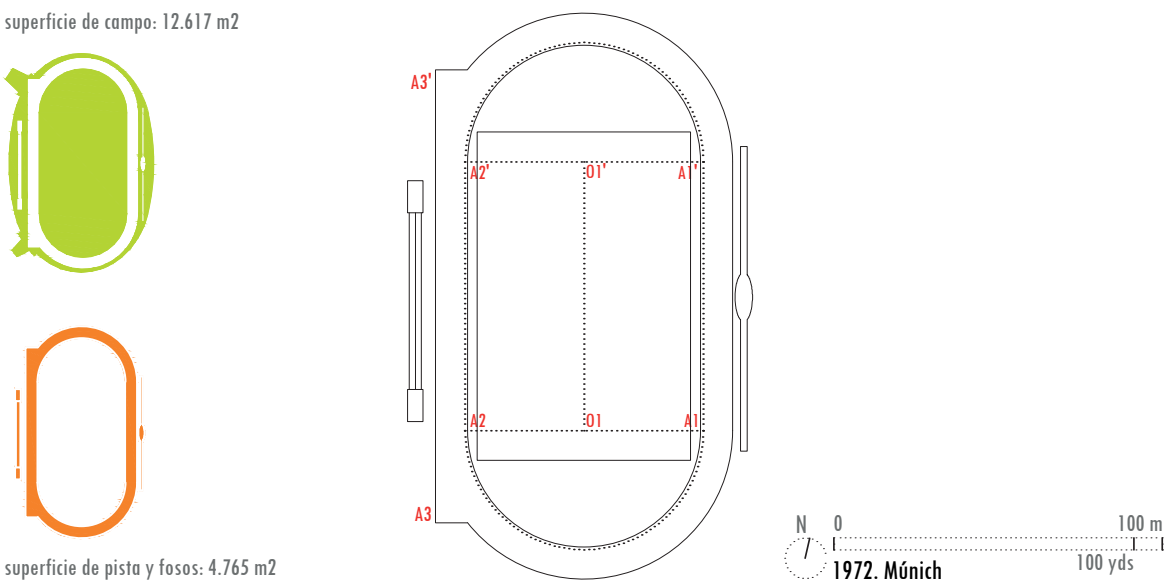

Tiene una cuerda de 400 metros formada por dos rectas de 83.58 metros y dos curvas de 116.42 metros. La pista tiene ocho carriles de 1.22 metros de ancho y la recta del lado poniente se prolonga en ambos extremos para permitir las pruebas de 100 metros, y 100 y 110 metros vallas.

La pista está fabricada con poliuretano macizo mediante un sistema de 3 capas (denominado "rekortan") ejecutado "in situ" con un espesor total de $15 \mathrm{~mm}$., compuesto por una capa base autonivelante, una capa intermedia de micro-espuma para reducción de impacto y un acabado de gránulos de EPDM resistentes a los rayos UV embebidos en una capa de poliuretano de alta pureza. Se trata de una superficie elástica, impermeable, antideslizante, resistente y apropiada para la competición bajo cualquier condición climática.

El campo de juego consta de una superficie de césped que se compone (en orden ascendente) de una capa drenante de $20 \mathrm{~cm}$. de grava, una capa filtrante de $16 \mathrm{~cm}$. de espesor de arena y una capa soporte de $10 \mathrm{~cm}$. de compost, musgo y arena. En cuanto al tipo de hierba es una mezcla de $70 \%$ poa pratensis "Merion", $15 \%$ Phleum nodosum "S 50 " y $15 \%$ cristatus Cynosurus "Credo".

Programa Deportivo: Atletismo, Gran Premio de las Naciones de Hípica, pentatlón moderno, final del torneo de fútbol y las Ceremonias de Apertura y Clausura de los Juegos. 
1972.8. Elementos significantes

El propio concepto del diseño constituye el elemento de mayor significación. Mediante el tratamiento del terreno que establece una integración entre arquitectura y naturaleza. La propuesta propone unos juegos "verdes" y abiertos a sus visitantes. Su cubierta evanescente, como una nuble suspendida sobre el graderío, refuerza ésta intención.

1972.9. Avances técnicos

El material de la pista de atletismo, que permite a los atletas mejorar las marcas.

Los tacos de salidas incluye altavoces en miniatura incorporados que indican a los atletas cuando salir y un microinterruptor que se activa en caso de que el corredor comience demasiado pronto.

Otra novedad es la aparición de pequeñas miras electrónicas, situadas cada 10 metros a lo largo del recorrido de la pista, que irradian un haz de luz y permiten obtener información de la carrera a tiempo real gracias a un procesador Siemens.

Por primera vez se utilizaron cámaras robotizadas y magnetoscopios de banda ancha para la grabación en color, así como generadores de caracteres para perfeccionar la información en las pantallas de televisión. Se consiguió además una retransmisión de los Juegos a nivel mundial gracias al desarrollo de los satélites ya que, con una sola transmisión hacia el satélite se pueden cubrir muchos países o regiones.

Los centros de prensa estaban equipados con ordenadores que permitían a los periodistas obtener los resultados oficiales o cualquier información sobre alguno de los participantes en el momento.

1972.10. Autores. Tipo de encargo

Behnisch \& Partner (Günter Behnisch, Fritz Auer, Winfried Büxel, Erhard Tränkner, Carlo Weber mit Jürgen Joedicke.

Paisajista: Günther Grzimek

Cubierta: Frei Otto y Jörg Schlaich (Leonhardt + Andrä)

Günther Behmisch (1922/2010). Se alistó voluntario en la Marina a los 17 años, y tras ser capturado por las fuerzas británicas, permaneció como prisionero de guerra en Inglaterra entre 1945 y 1947. Finalizado su cautiverio, comenzó los estudios de arquitectura en la Universidad de Stuttgart. Tras obtener el título en 1951, diseñó numerosas escuelas en la zona sur de Alemania en las que cada vez era mayor el nivel de prefabricación y estandarización (su Escuela Técnica de Ulm, de 1963, fue el primer edificio de la República Federal de Alemania enteramente prefabricado). Su aportación al desarrollo industrial de la arquitectura alemana se vio reconocida con su nombramiento como profesor de diseño en la Escuela Técnica de Darmstadt (sucediendo a Ernst Neufert).

Obra Arquitectónica: las escuelas Schäfersfeld en Lorch (1973), la residencia de ancianos en Reutlingen (1977), el Centro de estudios para la Iglesia Evangélica en Birkach (1979), el edificio del Instituto Hysolar para la Universidad de Stuttgart (1987). Más recientemente, destaca la Asamblea del Gobierno Federal de Bonn, finalizada en 1992 (veinte años después de la celebración del concurso); la Academia de las Artes de Berlín, inaugurada en 2005 y el State Clearing Bank-Landesgirokasse, en Stuttgart (1997).

Frei Otto (1925/2015). Comenzó sus estudios de arquitectura en la Universidad Técnica de Berlín antes de enrolarse como piloto en la Luftwaffe (Wehrmacht) durante los últimos años de la Segunda Guerra Mundial. Tras ser capturado, fue internado en un campo de concentración en Francia durante dos años. Posteriormente estudió en Norteamérica, comenzó a desarrollar su carrera en Alemania en 1952 tras graduarse como ingeniero civil y en 1954 publica su tesis doctoral sobre cubiertas suspendidas, llegando a convertirse en la mayor autoridad en estructuras tensadas y de membrana de bajo peso, encabezando avances en matemática estructural e ingeniería civil. En 1964 fundó el Instituto para estructuras ligeras de la Universidad de Stuttgart.

Obra Arquitectónica: Pabellón para la exposición de Jardines Federales BUGA (1955), Iglesia de San Lucas en Bremen (1963), Pabellón Alemán para la Exposición Universal en Montreal (1967), Bonhoeffer-Gemeindezentrum en Bremen (1971), Centro de conferencias en La Meca (1974, junto a Rolf Gutbrod), Multihalle en Mannheim (construcción temporal, 1975), pajarera del zoológico de Hellabrunn (1980), Palacio Tuwaiq (centro de Autoridades y Cultura en Riad, Arabia Saudita, 1985), Pabellón japonés para la Expo 2.000 en Hannover (en colaboración con Shigeru Ban).

Tipo de encargo. Concurso nacional entre arquitectos e ingenieros para la propuesta de la planificación urbana del Oberwiesenfeld, el diseño arquitectónico de los lugares de competición y la solución (económica y funcional) al posterior uso de las instalaciones.

Como miembro más destacado del jurado figura el prestigioso arquitecto alemán Egon Eiermann.

1972.11. Edificios coetáneos

Aldo Rossi gana el concurso para el diseño del "Cementerio de San Cataldo", cuya construcción comenzaría en 1978.

Peter Eisenman comienza a desarrollar el proyecto "Casa Vl". Que concluiría en 1975.

Entre 1965 y 1971 Louis Kahn diseña y construye el comedor y la Biblioteca para la comunidad de la escuela preparatoria de la Phillips Exeter Academy. Un año más tarde, abre sus puertas el Museo de Arte Kimbell.

marca del ganador

$\begin{array}{lrr} & \text { Hombres } & \text { Mujeres } \\ 100 \mathrm{~m} . & 10 " 14 & 11 " 07 \\ 200 \mathrm{~m} & 20 " 00 & 22 " 40 \\ 400 \mathrm{~m} . & 44 " 66 & 51 " 08 \\ 800 \mathrm{~m} . & 1,45 " 86 & 1,58 " 55 \\ 1500 \mathrm{~m} . & 3,36 " 33 & 4,01 " 38 \\ 5000 \mathrm{~m} & 13,26 " 42 & \\ 10000 \mathrm{~m} . & 27,38 " 35 & \\ \text { Marathón } & 2 \mathrm{~h} .12,19 " 8 & \\ 110 / 100 \mathrm{mv} & 13 " 24 & 12 " 59 \\ 400 \mathrm{mv} & 47 " 82 & \\ 3000 \mathrm{~m} . \text { obst } & 8,23 " 64 & \\ \text { Altura } & 2,23 \mathrm{~m} & 1,92 \mathrm{~m} \\ \text { Pértiga } & 5,50 \mathrm{~m} & \\ \text { Longitud } & 8,24 \mathrm{~m} & 6,78 \mathrm{~m} \\ \text { Triple salto } & 17,35 \mathrm{~m} & \\ \text { Peso } & 21,18 \mathrm{~m} & 21,03 \mathrm{~m} \\ \text { Disco } & 64,40 \mathrm{~m} & 66,62 \mathrm{~m} \\ \text { Martillo } & 75,50 \mathrm{~m} & \\ \text { Jabalina } & 90,48 \mathrm{~m} & 63,88 \mathrm{~m} \\ 4 \text { X 100 m. } & 38 " 19 & 42 " 81 \\ 4 \text { X 400 m- } & 2,59 " 80 & 3,23 " 00 \\ 20 \text { kmmarc } & 1 \mathrm{~h} .26,44 " 4 & \\ 50 \text { kmmarc } & 3 \mathrm{~h} .56,11 " 6 & \\ \text { Decathlón } & 8.454 \mathrm{ptos} & \\ \text { Pentathlón } & & 4.801 \mathrm{ptos}\end{array}$
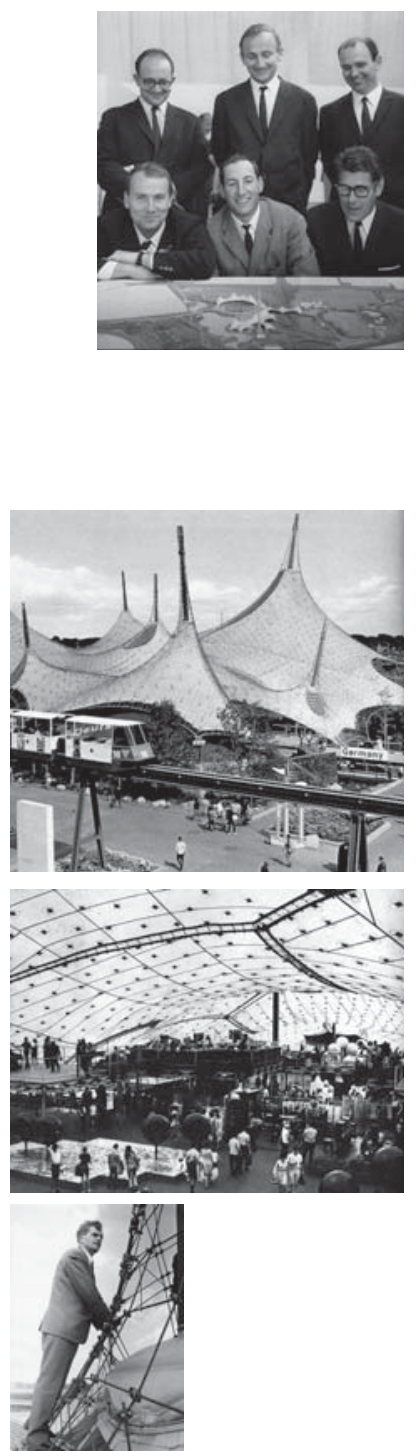


\subsection{Hechos históricos relevantes}

El 15 de marzo se estrena la película "El Padrino", de Francis Ford Coppola

El 30 de mayo el presidente estadounidense, Richard Nixon, y el Secretario General del Comité Central del Partido Comunista de la Unión Soviética, Leonid Brézhnev, firman en Moscú los acuerdos SALT (Strategic Arms Limitation Talks) sobre limitación de armas nucleares, que estará en vigor durante 30 años.

El 5 de septiembre, durante la celebración de los Juegos Olímpicos de Múnich, terroristas palestinos atacan los aposentos de la delegación israelí en la villa olímpica, asesinando a dos miembros del equipo y secuestrando a otros nueve. Tras las negociaciones y un intento fallido de rescate el saldo final será de 17 víctimas. A pesar de lo ocurrido, y tras suspenderse durante veinticuatro horas, los Juegos seguirán con normalidad.

El 22 de diciembre son rescatados los 16 supervivientes del avión uruguayo con 45 pasajeros siniestrado en plena cordillera de los Andes, después de haber estado 72 días aislados del mundo.

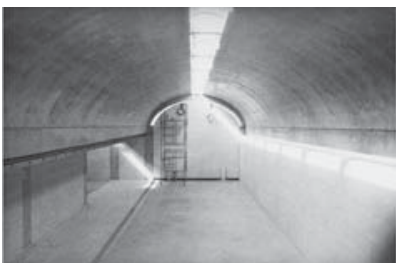




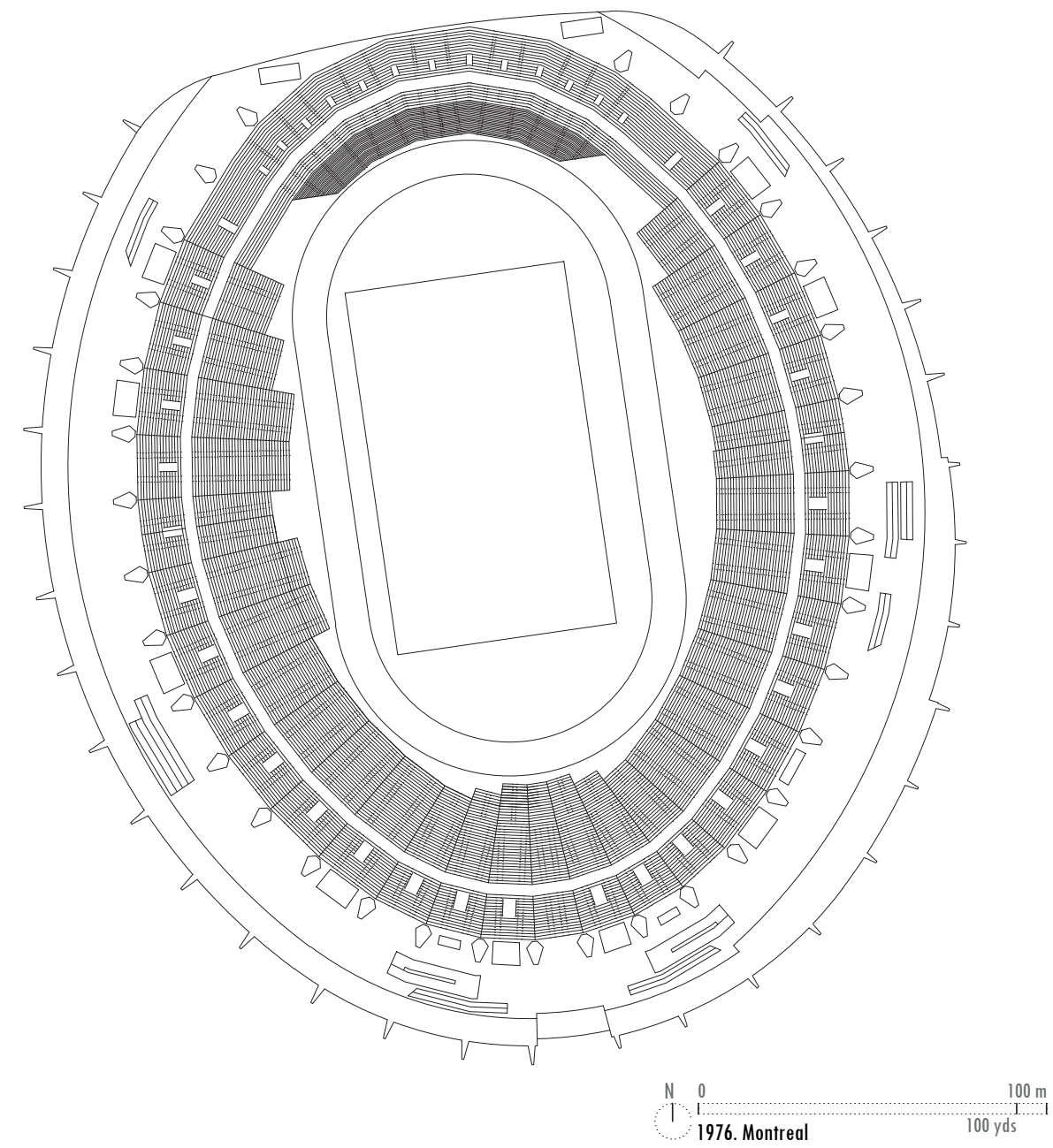

1976.0. Nombre del Estadio

Estadio Olímpico de Montreal. Stade Olympique de Montréal.

1976.1. Situación

4545, avenue Pierre-de-Coubertin. Montréal, Quebec H1V 3N7, Canadá

\subsection{Fechas}

1939. Primera candidatura de Montreal para los Juegos de 1944

1949. Segunda candidatura para 1956

1965. Tercera para 1972

1968. Cuarta para los Juegos de 1976

1970. Designación por parte del ClO, de Montreal como ciudad sede de los Juegos de la XXI Olimpiada.

1972. La alcaldía de Montreal encarga a Roger Taillibert el proyecto del estadio

1973. Crisis del petróleo que dispara la inflación en la mayor parte de las economías, produciendo una fuerte recesión.

1974. Conflictos laborales entre el gobierno y los sindicatos de la construcción que provocan una larga serie de huelgas.

1976. Inauguración del estadio.

1976. El 17 de julio, inauguración Juegos Olímpicos de Montreal.

1976. 1 de agosto, ceremonia de Clausura

1977. Se jugó el primer partido de béisbol en el Estadio. Con una afluencia de 57.592 espectadores.

1977. Conciertos de Pink Floid y de Emerson Lake \& Palmer.

1981. Entre 1981 y 1983 , el estadio fue la casa del Montreal Manic, equipo de futbol.

1984. el Papa Juan Pablo II participó en una reunión juvenil celebrada en este recinto. Se 

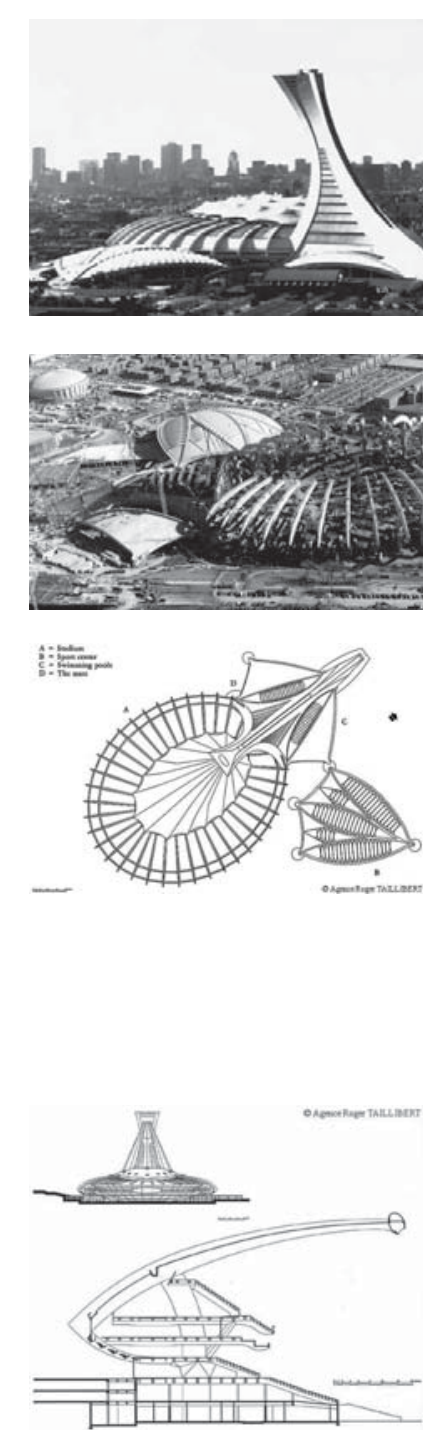

registró la asistencia de unas 55.000 personas.

1987. Se instala la cubierta retráctil.

1987. Concierto de U2.

1988. La cubierta retráctil entra en funcionamiento con más de 11 años de retraso. Incluso entonces, el diseño no era perfecto y con vientos superiores a los $40 \mathrm{~km} / \mathrm{h}$ se impedía su utilización.

1988. Representación de la ópera Aída, de Verdi.

1989. Concierto de los Rollig Stones.

1991. Entre 1991 y 1992, el estadio fue la casa del Montreal Machine de la World League of American Football.

1994. Nuevo concierto de Pink Floid.

1998. Se sustituye la cubierta retráctil de kevlar por otra permanente.

2007. Se disputan varios partidos de la Copa Mundial de Futbol Sub-20.

2010. Multitudinaria misa por la canonización del hermano André Bessette.

2014. Se disputa la final de la Copa Mundial Femenina de Fútbol Sub-20.

2015. Se celebraron algunos partidos de la Copa Mundial de Fútbol Femenino.

\subsection{Preexistencias en el lugar}

El terreno elegido para la ubicación del Parque Olímpico una zona situada al noreste del centro de la ciudad que desde 1912 había sido destinada al recreo. En ese año, la Ciudad de Maisonneuve, posteriormente un distrito de Montreal, había destinado 204 hectáreas de tierra para el desarrollo de un área recreativa y deportiva conocida como Parque Maisonneuve. Hacia el año 1932, algo más de la mitad de esta superficie se convirtió en un campo de golf municipal y hacia 1938 se construyó un Jardín Botánico en una buena parte del terreno restante. Quedaron unas 46 hectáreas reservadas para el futuro desarrollo de un gran complejo deportivo.

En 1954 se desarrolló un plan maestro, fruto del cual nacieron el Centro Deportivo Maisonneuve, más tarde conocido domo el Centro Pierre Charbonneau, y el Maurice Richard Arena.

1976.4. Relación con la ciudad. Posición respecto al centro urbano:

El estadio está directamente conectado a la estación de metro Pie IX en la Línea Verde del Metro Montreal.

El Parque Olímpico se encuentra al 6,5 km. al norte del centro de la ciudad y a $18 \mathrm{~km}$. del aeropuerto Pierre Elliott Trudeau.

\subsection{Breve relato de la historia del Estadio}

El diseño de este enorme centro deportivo tuvo que satisfacer una multitud de necesidades, con el frío clima de la ciudad, para su uso posterior era necesaria la cubrición del estadio, pero la Federación Internacional de Atletismo Amateur requería que las competiciones se desarrollen al aire libre. Los arquitectos se debían enfrentar al desafío de diseñar un estadio en el que, además de las pruebas olímpicas, se pudieran celebrar posteriormente partidos de béisbol y de fútbol americano.

En 1972, en una conferencia de prensa, se presentó un proyecto para diseñar un estadio con estructura de hormigón armado y capacidad para 60.000 espectadores, ampliable a 70.000 durante el desarrollo de los Juegos Olímpicos. En un lateral del estadio, de forma elíptica y abierto en el centro, destacaba una torre inclinada, de $165 \mathrm{~m}$. de altura. En ella estaban anclados unos tensores que sostenían una serie de elementos textiles, ligeros y fácilmente desplegables con los que se pretendía cubrir la zona central del campo cuando fuese necesario. De esta forma podrían celebrarse actividades al aire libre o bajo cubierta. La construcción del recinto deportivo se programó originalmente para ser finalizada en 1975, pero la inauguración tubo que cancelarse debido a una huelga de obreros de la construcción. Otros retrasos deben achacarse al diseño inusual del estadio y a que Taillibert, el arquitecto, se empeñó en llevar a cabo su concepción original, sin modificaciones, lo que produjo un extraordinario aumento en los costos. El gobierno provincial de Quebec finalmente perdió la paciencia y en 1974 dejaron a Taillibert fuera del proyecto. Como resultado de ello, la apertura de los Juegos Olímpicos se realizó con el estadio y la torre sin terminar.

\subsection{Descripción del Estadio; Graderío}

La estructura básica del estadio estaba formada por un conjunto de 34 costillas, arcos volados de hormigón armado, prefabricadas, con el interior hueco, y cuatro arcos más, truncados, para el apoyo de la torre. La línea que unía sus anclajes en el terreno era una elipse y una vez situadas, servían de apoyo a todos los elementos secundarios; forjados, gradas, escaleras, corredores y a un "anillo técnicol" de $480 \mathrm{~m}$. de longitud que ataba las costillas por su extremo volado. 
Una vez terminado, el Estadio tendría unas dimensiones de $305 \mathrm{~m}$. de largo por $250 \mathrm{~m}$. de ancho y una altura de $55 \mathrm{~m}$. desde el nivel del campo de juegos, y sería capaz de alojar a más de 70.000 espectadores (en las ceremonias de apertura y clausura de los Juegos se calculó un aforo promedio de 76.400 espectadores).

Las costillas y la cubierta permanente.

Cada vez que se terminaba la cimentación de una de las costillas y se retiraban los encofrados, una hilera de camiones suministraba las dovelas prefabricadas que la componían. En la obra se erigían y unían unas a otras por medio de cables postensados. Una vez que las costillas se encontraban en su lugar, comenzaban los trabajos de armado de las vigas y forjados que las ataban. El último elemento a instalar era el "anillo técnico».
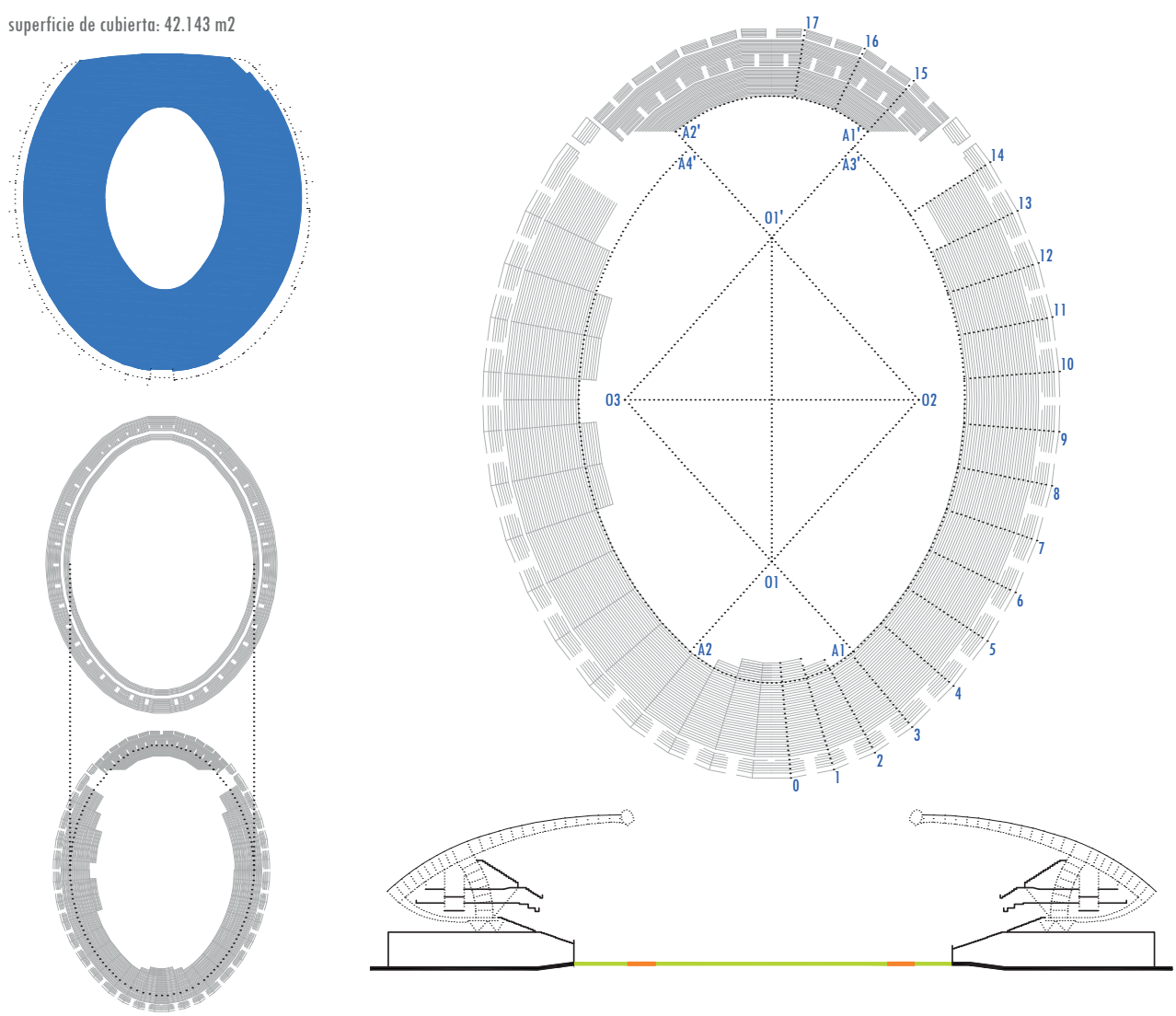

superfiecie de graderios: $30.717 \mathrm{~m} 2$

$\begin{array}{lll}N & 0 \\ 1 & 1976 . \text { Montreal } & 100 \mathrm{mds}\end{array}$

La cubierta permanente del estadio estaba dividida en dos secciones: la parte inferior, formada por una delgada carcasa de hormigón que ejercía de cerramiento y tapaba las canalizaciones de evacuación de aguas pluviales, y la parte superior, un blindaje metálico que cubría el "anillo técnico" o corona. La estructura metálica de la parte superior del techo fue conformada en frío doblando unas chapas metálicas de 1,2 m de ancho y uniéndolas entre sí, por medio de tornillos de presión, para formar unas vigas estándar en forma de «H». Después de la cubrición con chapa se instalaba el resto de elementos situados debajo: gradas, rampas, escaleras, zonas de acceso, etc.

Para la fabricación de los 12.000 elementos se utilizaron $71.500 \mathrm{~m} 3$. de hormigón y alrededor de $1.000 \mathrm{~km}$. de cables postensados.

De la torre que aparecía en el proyecto original, inclinada sobre el terreno de juego y con una altura de 165 m., se terminó poco más de la cuarta parte antes de comenzar el evento. Estaba diseñada para cumplir tres objetivos principales: cubrir parcialmente la Piscina Olímpica, servir de área de almacenamiento para la cubierta retráctil del estadio y generar una superficie utilizable de $27.000 \mathrm{~m} 2$., en un total de 18 alturas, en la que poder albergar instalaciones para la práctica del voleibol, baloncesto, balonmano, esgrima, gimnasia y tenis de mesa, además de vestuarios, servicios técnicos y oficinas para la administración deportiva. La cubierta retráctil, fabricada con materiales sintéticos muy duraderos y resistentes a la pudrición, se podría subir o bajar en menos de 20 minutos, lo que permitiría que el estadio

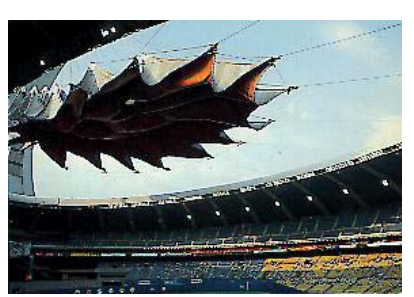

dimensiones y superficies aproximadas graderío

L 01-01' 107,21 M

L $01-02 \quad 72,40 \mathrm{M}$

L $02-03 \quad 97,15 \mathrm{M}$

ROI-Al 40,25 M

R Ol'-Al' 47,21 M

R 02-A2 112,52 M

$<$ A1.01.A2 $\quad 84^{\circ}$

$<$ A2.02.A2 $\quad 96^{\circ}$

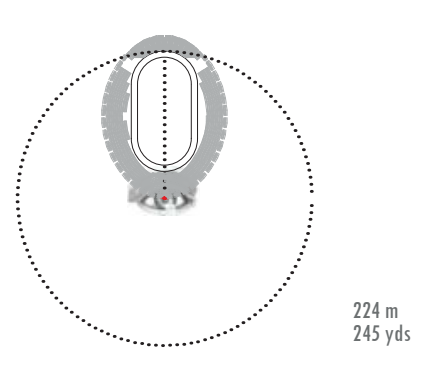




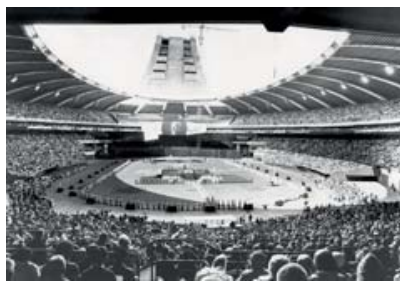

dimensiones y superficies aproximadas pista

\begin{tabular}{|c|c|c|}
\hline CUERDA & $400,00 \mathrm{M}$ & $437 y d s \quad l^{\prime} 4 \frac{1}{32} "$ \\
\hline L $01-01^{\prime}$ & $77,78 \mathrm{M}$ & \\
\hline R 01-Al & $38,90 \mathrm{M}$ & \\
\hline$<$ Al.01.A2 & $180^{\circ}$ & \\
\hline
\end{tabular}

marca del ganador

\begin{tabular}{|c|c|c|}
\hline & Hombres & Mujeres \\
\hline $100 \mathrm{~m}$. & $10 " 06$ & 11"08 \\
\hline $200 \mathrm{~m}$ & $20 " 23$ & $22 " 37$ \\
\hline $400 \mathrm{~m}$. & $44 " 26$ & $49 " 29$ \\
\hline $800 \mathrm{~m}$. & $1.43 " 50$ & $1.54 " 94$ \\
\hline
\end{tabular}

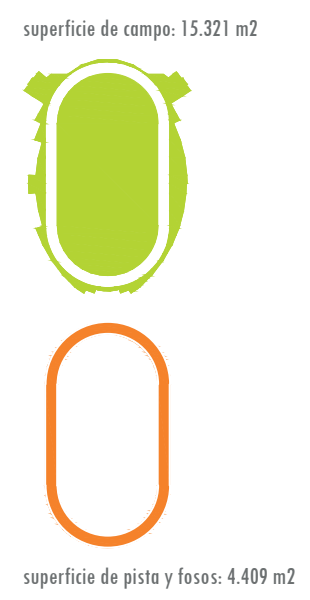

$1500 \mathrm{~m} . \quad 3,39 " 17 \quad 4,05 " 48$

$5000 \mathrm{~m} \quad 13,24 " 76$

$10000 \mathrm{~m} . \quad 27,40 " 38$

$110 / 100 \mathrm{mv} \quad 13 " 30$

$400 \mathrm{mv} \quad 47 " 64$

3000 obstv $\quad 8,08 " 02$

Altura $\quad 2,25 \mathrm{~m}$

Pértiga $\quad 5,50 \mathrm{~m}$

Longitud $\quad 8,35 \mathrm{~m}$

Triple 17,29 m

Peso $\quad 21,05 \mathrm{~m}$

Disco $\quad 67,50 \mathrm{~m}$

Martillo $\quad 77,52 \mathrm{~m}$

Jabalina $\quad 94,58 \mathrm{~m}$

$4 \times 100$

$4 \times 400 \quad 2,58 " 65$

$20 \mathrm{~km}$ marcha 1h.24,40"6

Decathlón 8.618ptos

Pentathlón 4.745ptos

Marathón 2h.09,55"0 mantiene en la actualidad.
$1,93 \mathrm{~m}$

$6,72 \mathrm{~m}$

$21,16 \mathrm{~m}$

$69,00 \mathrm{~m}$

$65,94 \mathrm{~m}$

$42 " 55$

$3,19 " 23$

\subsection{Elementos significantes}

\subsection{Avances técnicos} en blanco y negro.

fuese utilizado en todas las épocas del año y en todas las condiciones climáticas. Una vez instalada, debería cubrir un espacio abierto de unos $18.000 \mathrm{~m} 2$.

Lamentablemente el diseño se quedo plasmado sólo en el papel puesto que durante la construcción del estadio, una huelga laboral originó un retraso mayor de lo previsto en la construcción de la torre y esta no se construyo hasta 1987, pasados ya diez años del evento deportivo.

La cubierta había permanecido guardada en un almacén, en Francia, hasta el momento de su puesta en obra. Estaba fabricada con $6.000 \mathrm{~m} 2$ de kevlar y pesaba más de 65 toneladas. Nunca funcionó como estaba planeado porque resultó difícil de desplegar y el sistema no podía ser operado en presencia de vientos de más de $40 \mathrm{~km} / \mathrm{h}$. Poco después de su instalación, la cubierta se rasgó en varias ocasiones debido a imperfecciones del diseño y en los meses siguientes sufrió más rasgaduras que provocaban goteras en tiempos de lluvia. En 1992 se decidió mantenerla siempre recogida. La cubierta retráctil fue retirada en mayo de 1998 y sustituida más adelante por otra opaca, de color azul y no desplegable que se

\subsection{Descripción del Estadio; Pista}

El terreno de juego tiene un perímetro de $551 \mathrm{~m}$. y las dimensiones de los ejes mayores son $181,6 \mathrm{~m}$. de largo por 141,7 m. de ancho. La altura libre en el centro del campo prevista hasta la cubierta sería de $50 \mathrm{~m}$. Esta altura libre, posteriormente, cuando la cubierta retráctil fue instalada, resultó escasa pues en los torneos de beisbol algunas bolas la golpeaban.

Estaba cubierto por césped natural, excepto las áreas de salto y la pista de $400 \mathrm{~m}$. Ocupaba una superficie de unos $25.700 \mathrm{~m} 2$ y fue implantado a la manera tradicional, sobre una cama de arena para facilitar el drenaje. Fue una operación crítica, ya que había que dar suficiente tiempo a la hierba para echar raíces y esto restringió el movimiento de maquinaria en el Estadio. Posteriormente se sustituyó por hierba artificial
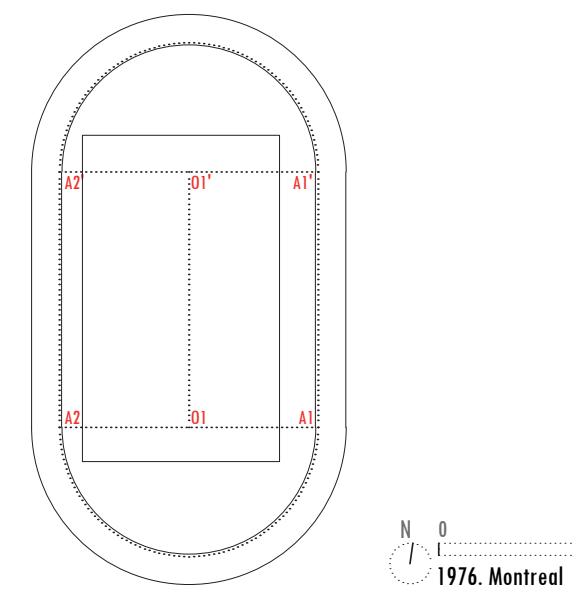

Programa Deportivo: Atletismo, Final del torneo de fútbol, Hípica y las Ceremonias de Apertura y Clausura de los Juegos.

La utilización de un tejido elástico, retráctil y flexible en la formación de la cubierta constituía un nuevo concepto de tensoestructuras, completamente diferente del utilizado en Munich. Tan novedoso que, se puede decir que no pudo llevarse a cabo por la inexistencia de medios y maquinaria adecuada para su puesta en funcionamiento.

La primera pantalla de video matricial complementaba a los marcadores tradicionales. En ella, además de los tiempos logrados por los atletas, se podían mostrar los puntos y las clasificaciones, en cualquier idioma y alfabeto. También podía mostrar grabaciones de video

El sistema Intelsat cubría ya todo el mundo y se utilizaron los satélites del Atlántico, del Pacífico y del Índico para la distribución general de la información.

1976.10. Autores. Tipo de encargo:

Roger Taillibert (1926) natural de Châtre-sur-Cher, Francia., Estudia en la Escuela de Bellas 
Artes de Paris, trabajó unos meses como becario en el estudio de Alvar Aalto. Posteriormente en la KTH de Estocolmo se interesó por la vertiente mas constructiva de la arquitectura. Ya en Francia su primer proyecto fue una piscina de forma y estructura bastante audaz con clara referencia ala arquitectura de Félix Candela. A partir de ésta obra fue contratado para diseñar, en un tiempo récord, el centro de preparación preolímpica de Font Romeu. Después realizó otra obra excepcional, el Estadio del Parque de los Príncipes, una pieza interesante del constructivismo expresionista, cuya fama cruzó el Atlántico y antes incluso de estar finalizada le valió el encargo directo, por parte de la alcaldía de Montreal, de la ejecución del Complejo Olímpico que se iba a construir en esa ciudad.

Roger Taillibert, que había estado trabajando en el Instituto Politécnico de Stuttgart en la investigación y desarrollo de las estructuras pequeñas y móviles, desarrolló, con Frei Otto la cubierta de la piscina de Carnot, en París. Fue una de las primeras estructuras móviles producidas en el mundo, con un sistema capaz de cubrir, bajo un ligero arco tensado y en pocos minutos, superficies de hasta $4.000 \mathrm{~m} 2$. Esta cubierta experimental, cuya patente presentó en 1967, fue la que le inspiró el diseño de la cubierta del Estadio Olímpico de Montreal.

Durante la década de 1970 se involucró en la investigación de estructuras de hormigón prefabricado reforzado para instalaciones deportivas y desarrolló diferentes sistemas de construcción basados en la combinación de armaduras tensionadas.

Tipo de encargo.

Encargo directo por, por la pericia demostrada al remodelar el Parque de los Príncipes en Paris

"I... la gran marquesina elíptica de cincuenta metros de vuelo apoyada sobre costillas compuestas por elementos de hormigón prefabricado que usted ha diseñado para responder al desafío del Estadio, es suficiente, aún antes de finalizar la obra, para convencer a la Alcaldía de Montreal de que debe ser usted quien proyecte nuestro Estadio Olímpicoll.

\subsection{Edificios coetáneos}

Fallece Alvar Aalto. Su última obra, el Auditorio Finlandia de Helsinki, se inauguró un año antes de su muerte. Su obra póstuma, la Ópera de Essen, fue finalizada en 1988.

La Biosfera de Montreal, de Buckminster Fuller, es destrozada por un incendio.

Casa White-U de Toyo Ito.

\subsection{Hechos históricos relevantes}

1 de abril. En Estados Unidos, se funda Apple Computers.

24 de junio. la Asamblea Nacional de Vietnam anuncia la reunificación del país y fija la capital en Hanói.

20 de julio. La nave estadounidense Viking 1 realiza el primer aterrizaje en Marte.

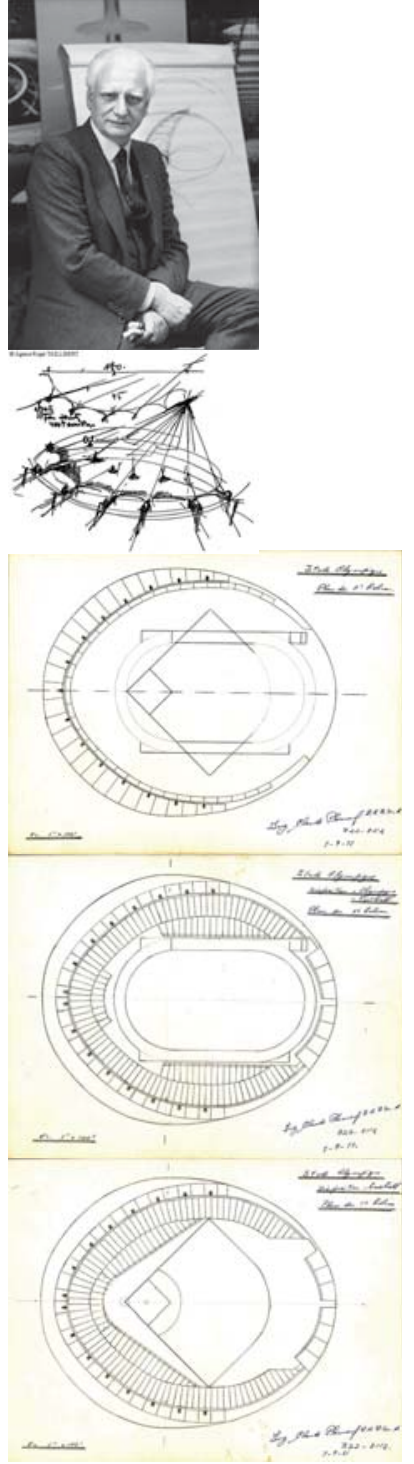

Roger Taillibert.

Croquis de la cubierta retráctil Planta 2 nivel

Planta 1 nivel para los Juegos Planta 1 nivel para baseball 


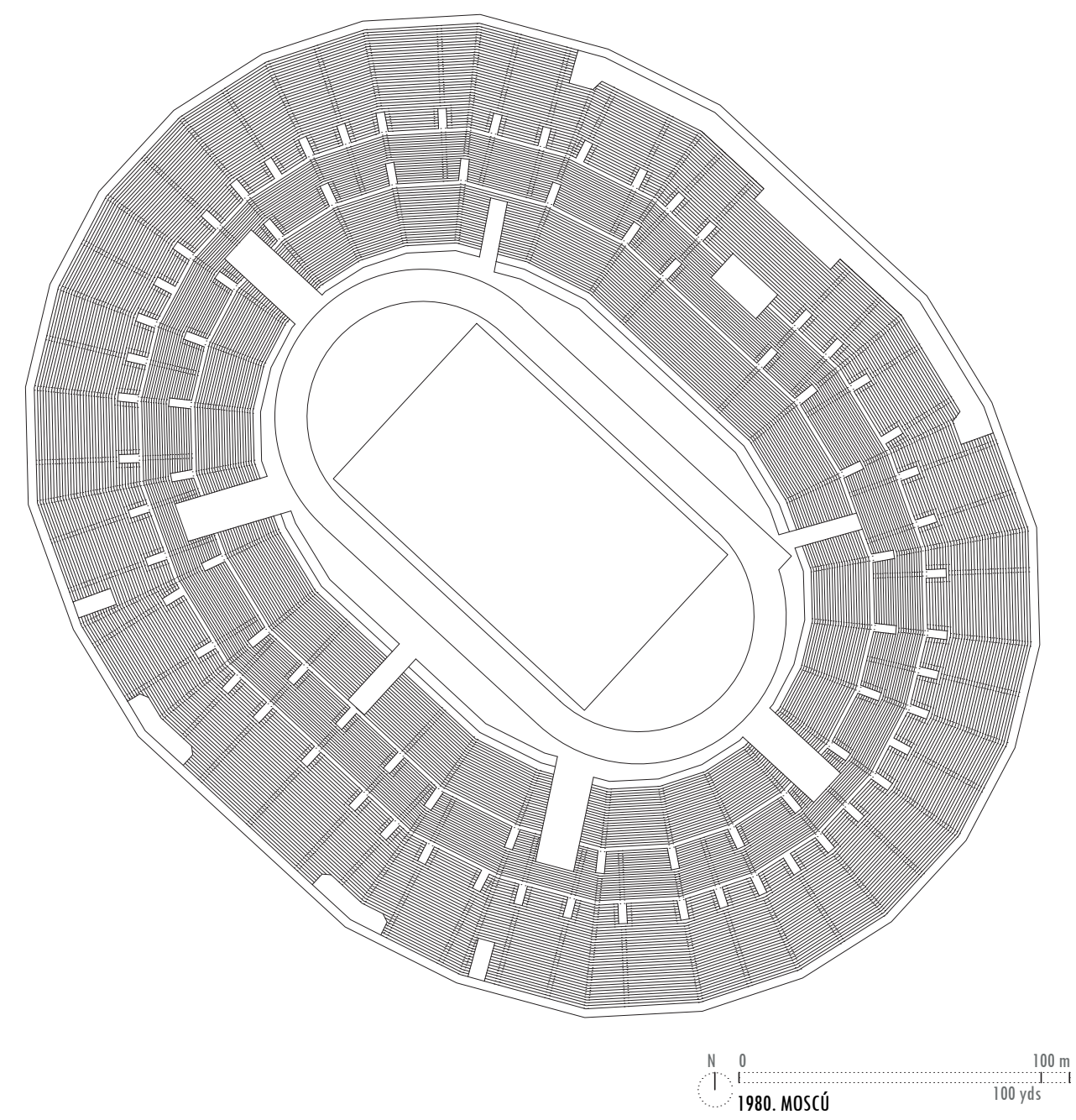

1980.0. Nombre del Estadio:

"Estadio Central Lenin", tras el final de la Unión Soviética pasa a denominarse "Gran Estadio Deportivo del Complejo Olímpico Luzhniki".

\subsection{Situación}

Luzhniki, 24, Moscú, Rusia.

\subsection{Fechas:}

1954. El 23 de diciembre el gobierno de la URSS decide la construcción de un gran centro deportivo, incluido un estadio en el área de Luzhniki.

1955. En enero se inicia el proyecto, que se desarrolla en 90 días.

1956. Dias antes de la inauguración oficial se celebra la primera edición de las Spartakiadas. Posteriormente ha acogido seis ediciones más.

1956. El 31 de julio, se inaugura el estadio, construido en tan solo 450 días.

1974. El 23 de octubre, en la $75^{\circ}$ Sesión del Comité Olímpico Internacional en Viena, se designa Moscú ciudad anfitriona de los Juegos de la XXII Olimpiada.

1975. En marzo, se constituye en Moscú el Comité de Organización.

1975. A finales de año, el Comité de Arquitectura e Ingeniería Civil, junto con la Unión de Arquitectos de la URSS y el Ministro de Arquitectura y Planeamiento de Moscú organizan un concurso para el diseño del complejo deportivo e instalaciones principales para las Olimpiadas en el que participarían unos 500 arquitectos e ingenieros.

1976. En septiembre, el Comité de Organización junto con la Cámara de Comercio e Industria de la URSS y Glavsportprom llevan a cabo la primera exhibición internacional "Tecnología para las Olimpiadas".

1976. Inicio de las obras de acondicionamiento del Estadio Lenin de cara a los Juegos 

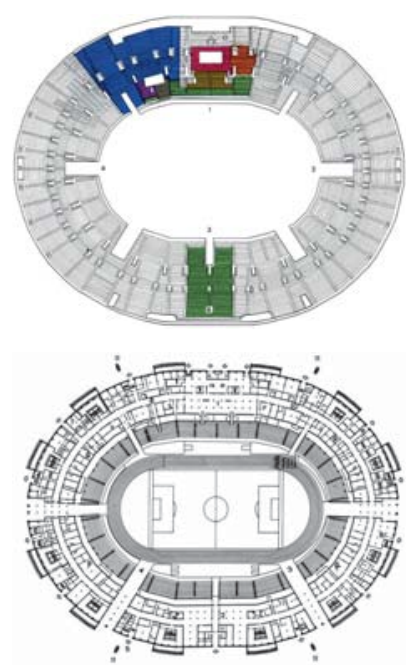

dimensiones y superficies aproximadas graderío

L Al-Al' $\quad 190,42 \mathrm{M}$

L A1-A2 15,68 M

L Al-A3 I4,39 M

L A3-A5 $\quad 14,60 \mathrm{M}$

L A5-A7 15,73 M

L A7-A9 $\quad 22,34 \mathrm{M}$

L A9-All 21,45 M

R OI-Al $\quad 58,01 \mathrm{M}$

$<$ Al.01.A3 $14^{\circ}$

$<$ Al.A3.A5 $\quad 166^{\circ}$

$<$ A3.A5.A7 $165^{\circ}$

$<$ A5.A7.A9 $162^{\circ}$

$<$ A7.A9.All $169^{\circ}$
Olímpicos que finalizarían en 1979.

1978. En abril, el Comité de Organización, la Cámara de Comercio e Industria de la URSS y Glavsportprom llevan a cabo la segunda exhibición internacional, esta vez sobre "equipamiento deportivo".

1980. El 19 de julio. Ceremonia de inauguración.

1980. El 3 de agosto. Ceremonia de clausura.

1982. 20 de octubre, tragedia de Luzhnikí con 300 muertos oficiales y 61 heridos, por una avalancha.

1997. Se rehabilita y se cubre todo el graderío. También se cambia su nombre al actual, se mejoró la calidad de las gradas reduciendo el número de asientos (aproximadamente 84.400) y se cubrió totalmente.

1998. Concierto de los Rolling Stones

2002. Por razones climáticas se sustituye el campo por hierba artificial FieldTurf.

2008. 21 de mayo, final de la liga de Campeones de fútbol. Para este partido se volvió a colocar la hierba natural temporalmente.

2015. Para el Mundial de fútbol 2018 el estadio será remodelado, perderá su pista olímpica de atletismo permitiendo aumentar la capacidad a 88.000 espectadores.

1980.3. Preexistencias en el lugar

Gran superficie con pastos cerca del río, en un territorio verde relativamente cercano al centro de la ciudad.

\subsection{Relación con la ciudad. Posición respecto al centro urbano}

En el barrio de Luzhnikí a unos $5 \mathrm{~km}$ al sudoeste del Kremlin, en una curva del río Moskva, cerca del dique Luzhnetskaya y bien conectada con otras áreas de la capital mediante transporte público.

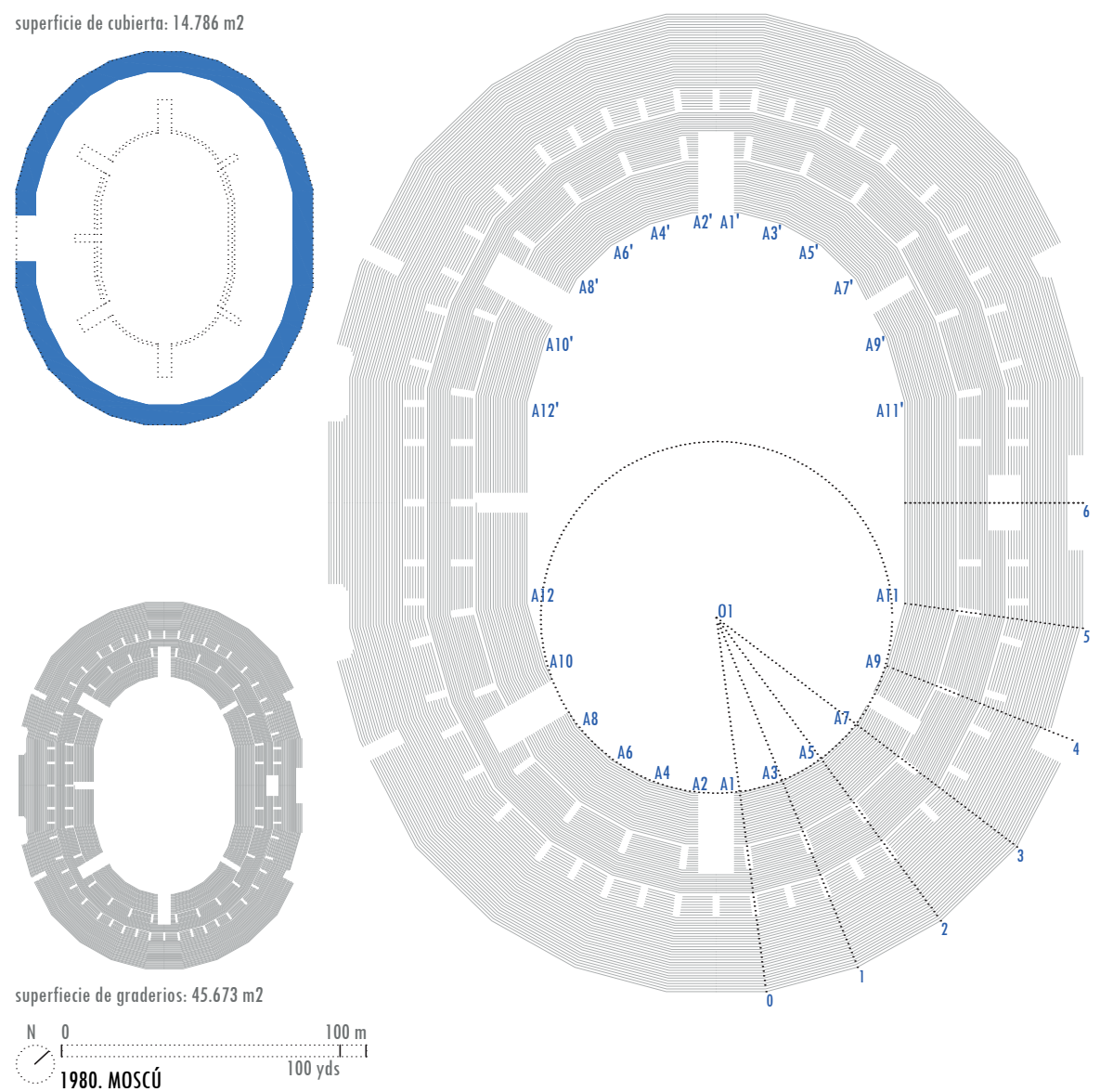

1980.5. Breve relato de la historia del Estadio

En los Juegos de Helsinki 1952 los deportista de la URSS se reincorporan a los Juegos. En diciembre de 1954, el gobierno de la Unión Soviética decidió la construcción de un gran estadio en Moscú. Las nuevas instalaciones deportivas tendrían que cumplir los estándares 
mundiales modernos y servir de campo de entrenamiento para los equipos nacionales y ser sede de grandes competiciones tanto nacionales como internacionales.

El grupo de arquitectos I. Rozhin, N. Ullas, A. Khryakov dirigidos por A. Vlasov y de ingenieros V. Nasonov, N. Reznikov, V. Polikarpov, una vez decidida la ubicación del complejo, redactaron el proyecto en tan solo 90 días.

El 31 de julio de 1956 se inaugura el Estadio Central que fue construido en el tiempo récord de 450 días.

Después de 20 años de uso intensivo, las instalaciones deportivas del Estadio Central Lenin necesitaban una modificación y renovación que se llevó a cabo durante la preparación de los Juegos de la XXII Olimpiada, siguiendo las instrucciones y recomendaciones del Comité Olímpico Internacional, para asegurar la correcta adecuación del estadio a los deportes olímpicos.

\subsection{Descripción del Estadio; Graderío}

El estadio es elíptico, con un eje mayor de 301,4 m de largo. Con un aforo de 100000 espectadores en 73 a 78 filas. Las filas superiores estaban resguardadas por un voladizo de $10 \mathrm{~m}$.

\subsection{Descripción del Estadio; Pista}

Pista de atletismo de $400 \mathrm{~m}$. con 8 calles y cuatro áreas bien equipadas para concursos. En su pradera interior se puede marcar un campo de fútbol de $105 \times 68 \mathrm{~m}$.

Programa Deportivo: Atletismo, Finales de Fútbol, Gran Premio de las Naciones de Hípica y las Ceremonias de Apertura y Clausura.

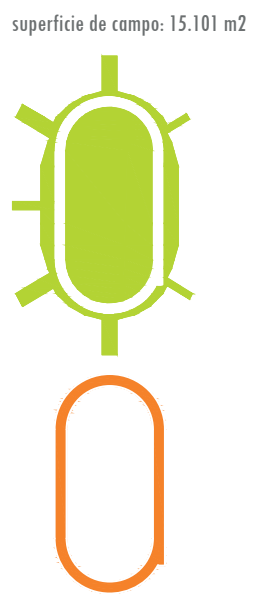

superficie de pista y fosos: $4.216 \mathrm{~m} 2$
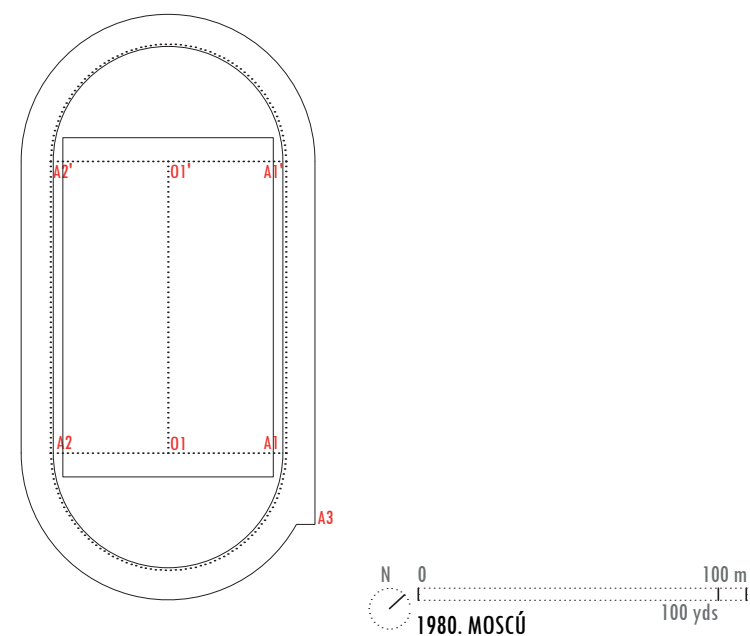

\subsection{Elementos significantes}

\subsection{Avances técnicos}

1980.10. Autores. Tipo de encargo:

Arquitectos I. Rozhin, N. Ullas, A. Khryakov dirigidos por A. Vlasov.

Ingenieros V. Nasonov, N. Reznikov, V. Polikarpov.

Tipo de encargo: Desconocido.

\subsection{Edificios coetáneos:}

En 1977 se inaugura el Centro Pompidou de Renzo Piano y Richard Rogers.

1980, concurso IBA en Berlín.

1980.12. Hechos históricos relevantes:

Se funda en Gdansk (Polonia) el sindicato Solidaridad.

Es asesinado John Lennon en Nueva York. 
Bibliografía Moscú 1980:-

Games of the XXII Olympiad Moscow 1980. The Official Report. Organizing Committee of the Games of the XXII Olympiad, Moscow. (1981).. Ed. Fizkultura i Sport Publishers.

1st Century Project (2000). The XXII Olympiad: Moscow 1980, Sarajevo 1984. Ed. World Sport Research \& Publications. ISBN 1888383003, 9781888383003

PROVOOST, Michelle (Editado por) (2000). The Stadium. The Architecture of Mass Sport. Ed. Nai Publisher, Rotterdam. ISBN 90-5662-145-9

FINDLING, John E., PELLE, Kimberly D. (1996). Historical dictionary of the modern Olympic movement. Ed. Greenwood Press. ISBN 0-313-28477-6 
1988. SEÚL.

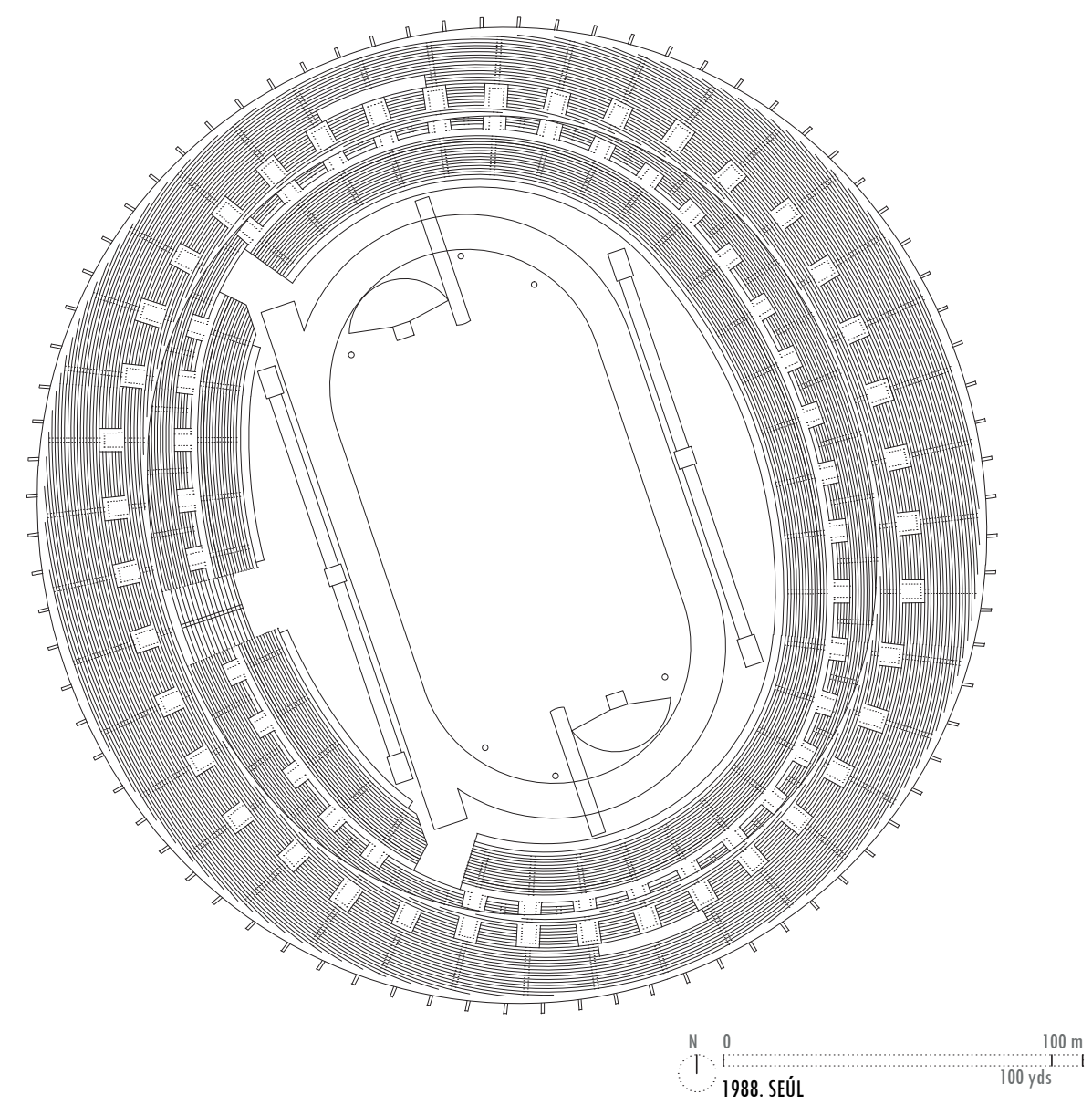

1988.0. Nombre del Estadio

Estadio Olímpico de Seúl o Estadio Jamsil (anteriormente romanizado como Chamshil).

1988.1. Situación

10 Jamsil-dong, Songpa-gu, Seoul, Corea del Sur

1988.2. Fechas

1973. En julio, se aprueba el plan de desarrollo de la zona de Chamshil, que reserva un gran área para un futuro Complejo Deportivo.

1973. El 28 de septiembre se presenta el plan de construcción del Complejo Deportivo de Seúl.

1976. El 1 de noviembre, el gobierno de la ciudad de Seúl aprueba la construcción del Complejo Deportivo.

1977. El 28 de noviembre comienzan las obras del Estadio.

1979. El 3 de septiembre se decide presentar la candidatura de Seúl para las Olimpiadas, decisión que se formalizaría el 8 de octubre.

1981. El 29 de septiembre, Seúl es designada ciudad anfitriona de los Juegos de la XXIV Olimpiada.

1984. El 29 de septiembre, se finalizan las obras del Estadio Olímpico.

1986. Se celebran en el Estadio Olímpico los X Juegos Asiáticos.

1988. Del 17 de agosto al 5 de octubre, se celebra el Festival de Artes Olímpico de Seúl.

1988. Del 21 de agosto al 8 de septiembre, se celebra la Conferencia Académica Internacional de la Olimpiada' 88 .

1988. El 17 de septiembre, Ceremonia de Inauguración de la $24^{\circ}$ Olimpiadas.

1988. El 2 de octubre, Ceremonia de Clausura.

1996. Del 11 al 13 de octubre, Concierto de Michael Jackson.

2015. 2 de mayo, Concierto de Paul McCartney. 

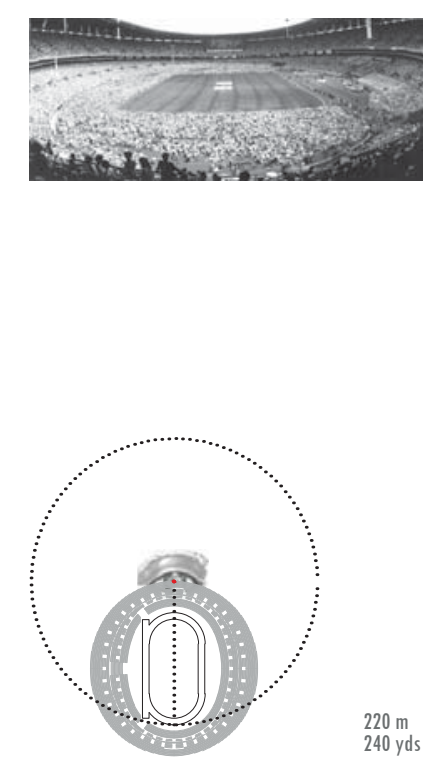

dimensiones y superficies aproximadas graderío

\begin{tabular}{|c|c|}
\hline L $01-01^{\prime}$ & $58,50 \mathrm{M}$ \\
\hline L $01-02$ & $73,48 \mathrm{M}$ \\
\hline L $02-03$ & $134,81 \mathrm{M}$ \\
\hline R Ol-Al & $65,98 \mathrm{M}$ \\
\hline R 02-A2 & $139,46 \mathrm{M}$ \\
\hline$<$ Al.01.A2 & $133^{\circ}$ \\
\hline$<$ A2.02.A2' & $47^{\circ}$ \\
\hline L $04-04^{\prime}$ & $38,00 \mathrm{M}$ \\
\hline L $04-05$ & $23,95 \mathrm{M}$ \\
\hline L $05-06$ & $29,15 \mathrm{M}$ \\
\hline R 04-A3 & $117,61 \mathrm{M}$ \\
\hline R 05-A4 & $141,56 \mathrm{M}$ \\
\hline$<$ A3.04.A4 & $58,50 \mathrm{M}$ \\
\hline$<A 4.05 . A^{\prime}$ & $58,50 \mathrm{M}$ \\
\hline
\end{tabular}

marca del ganador

\begin{tabular}{|c|c|c|}
\hline & Hombres & Mujeres \\
\hline $100 \mathrm{~m}$ & $9 " 22$ & $10 " 54$ \\
\hline $200 \mathrm{~m}$ & $19 " 75$ & $21 " 34$ \\
\hline $400 \mathrm{~m}$ & $43 " 87$ & $48 " 65$ \\
\hline $800 \mathrm{~m}$ & l'43"45 & $1 ' 56 " 10$ \\
\hline $1500 \mathrm{~m}$ & 3'35"96 & 3'53"96 \\
\hline $5000 \mathrm{~m} 3000 \mathrm{~m}$ & 13"וו'ו'ו & $8 ' 26 " 53$ \\
\hline $10000 \mathrm{~m}$ & $27 ' 21 " 46$ & $31 ' 05 " 21$ \\
\hline $110 / 100 \mathrm{mv}$ & $12 " 98$ & $12 " 38$ \\
\hline $400 \mathrm{mv}$ & $47 " 19$ & $53 " 17$ \\
\hline 3000 m obst & 8'05"51 & \\
\hline $4 \times 100 \mathrm{~m}$ & $38 " 19$ & $41 " 98$ \\
\hline $4 \times 400 \mathrm{~m}$ & $256 " 16$ & 3'15"18 \\
\hline Altura & $2,38 \mathrm{~m}$ & $2,03 \mathrm{~m}$ \\
\hline Pértiga & $5,90 \mathrm{~m}$ & \\
\hline Longitud & $8,72 \mathrm{~m}$ & $7,40 \mathrm{~m}$ \\
\hline Triple & $17,61 \mathrm{~m}$ & \\
\hline Peso & $22,47 \mathrm{~m}$ & $22,24 \mathrm{~m}$ \\
\hline Disco & $68,82 \mathrm{~m}$ & $72,30 \mathrm{~m}$ \\
\hline Martillo & $84,80 \mathrm{~m}$ & \\
\hline Jabalina & $84,28 \mathrm{~m}$ & $74,68 \mathrm{~m}$ \\
\hline $20 \mathrm{~km}$ marcha & & lh19'57" \\
\hline $50 \mathrm{~km}$ marcha & & $3 \mathrm{~h} 38^{\prime} 29^{\prime \prime}$ \\
\hline Decatlón & 8488 ptos & \\
\hline Heptatlón & & 7291 ptos \\
\hline Maratón & $2 \mathrm{~h} 10^{\prime} 32^{\prime \prime}$ & $2 \mathrm{~h} 25^{\prime} 40^{\prime \prime}$ \\
\hline
\end{tabular}

1988.3. Preexistencias en el lugar

Parcela vacía destinada a equipamiento deportivo en el proyecto de desarrollo urbano del distrito de Chamshil.

1988.4. Relación con la ciudad. Posición respecto al centro urbano

En Chamshil, en el Distrito Songpa-gu, en el sureste de la ciudad de Seúl, al sur del río Han y a unos $13 \mathrm{~km}$ del centro

El Tren Olímpico comunica directamente con el aeropuerto y el centro de la ciudad, además es accesible en metros y mediante varias líneas de autobús.

Situado el Complejo Deportivo de Seúl, el complejo incluye cinco grandes instalaciones deportivas.

1988.5. Breve relato de la historia del Estadio

En enero de 1973, mientras se desarrollaba el plan de implementación territorial del distrito de Chamshil, el gobierno de la ciudad de Seúl reservó $330508 \mathrm{~m}^{2}$ para el desarrollo de un complejo deportivo que cumpliese los estándares internacionales.

El diseño del Estadio Olímpico corrió a cargo de Kim Swoo-geun del Grupo SPACE de Korea, destacada figura de la arquitectura coreana.

Las obras del estadio principal se iniciaron en noviembre de 1977. La construcción duró casi 7 años hasta la inauguración el 29 de septiembre de 1984.

\subsection{Descripción del Estadio; Graderío}

El Estadio Olímpico, posee una capacidad para 100000 espectadores. Los asientos se distribuyen en tres niveles. Está cubierta casi la totalidad del graderío.

Su perfil estructural imita las curvas de los jarrones de la Dinastía Coreana Chosun.

Sus ejes tienen una longitud de $280 \mathrm{~m}$ y $245 \mathrm{~m}$ respectivamente y una altura de $47 \mathrm{~m}$ en el punto más alto.

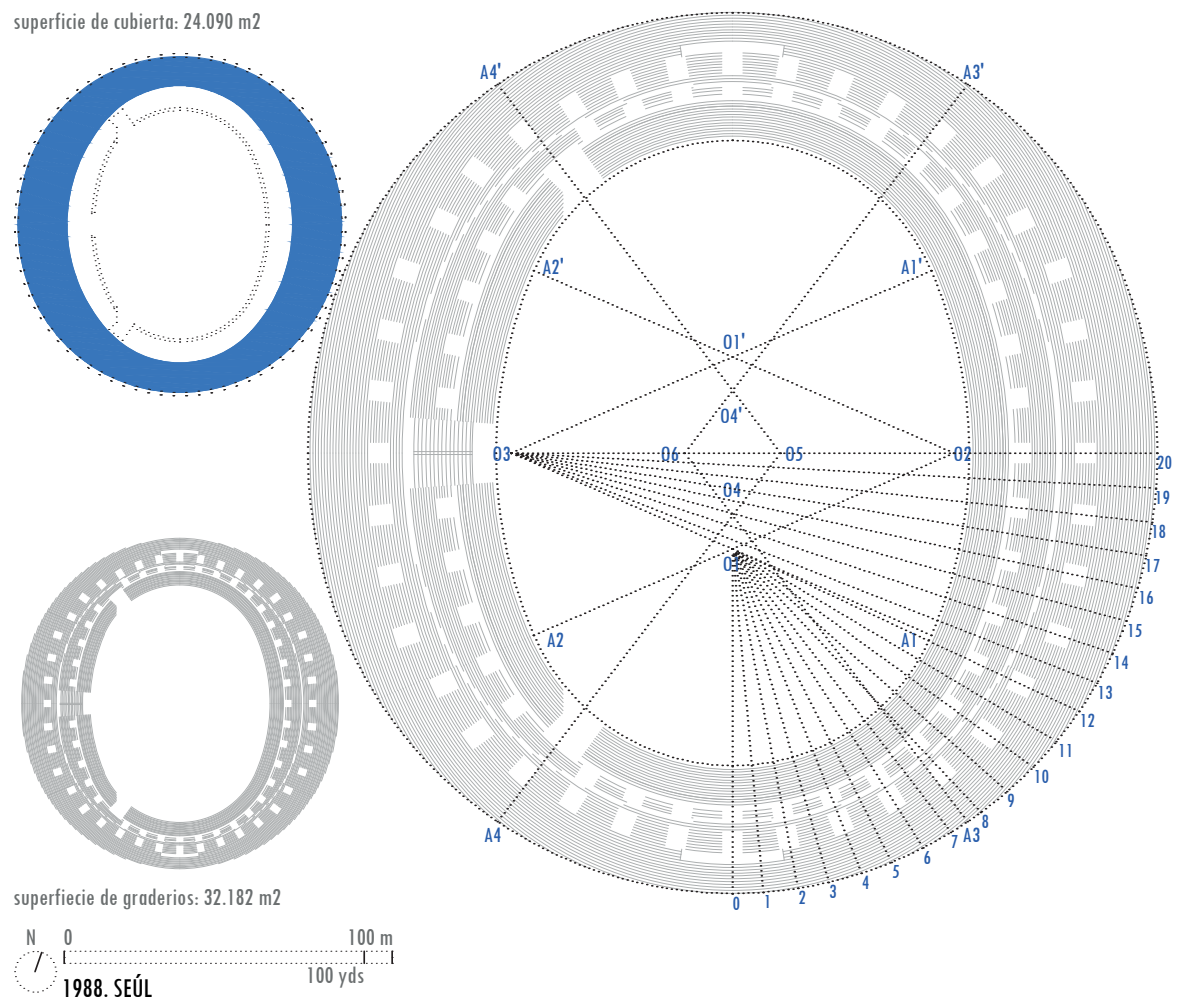

\subsection{Descripción del Estadio; Pista}

Pista de atletismo de $400 \mathrm{~m}$. y 8 calles y un campo de juego de 105 por $67 \mathrm{~m}$.

Programa Deportivo: Atletismo, Finales de fútbol, Hípica(Gran Premio de las Naciones) y las Ceremonias de Apertura y Clausura

1988.8. Elementos significantes 


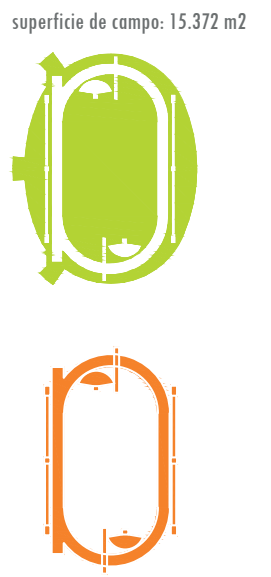

superficie de pista y fosos: $6.169 \mathrm{~m} 2$

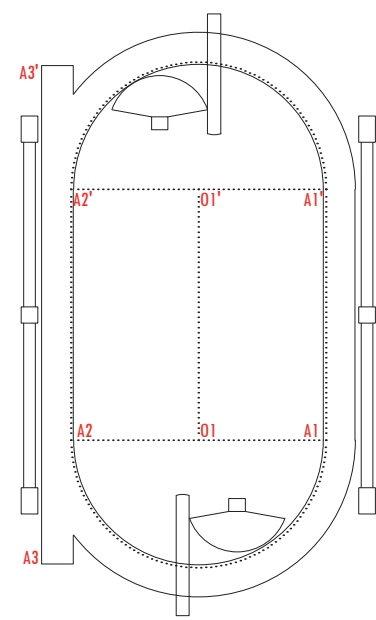

dimensiones y superficies aproximadas pista

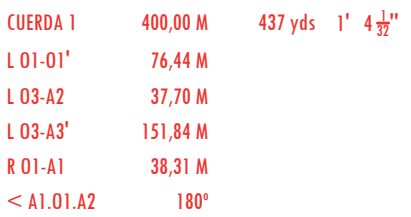

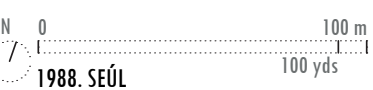

1988.9. Avances técnicos

1988.10. Autores. Tipo de encargo:

Kim Swoo Geun (1931/1986) fue un prominente arquitecto surcoreano. Nacido en el distrito de Sinap, Chongjin, en la provincia de Hamgyong Norte. Comienza sus estudios en la Universidad Nacional de Seúl. En 1952, durante la Guerra Coreana, viaja a Japón, donde acaba la carrera y comienza a trabajar..

En 1959, gana el concurso para el Edificio de la Asamblea Nacional de Corea del Sur, pero su propuesta no se construye debido a la situación política del momento. En 1960, vuelve a Corea, abre estudio e inicia su labor docente.

Es autor de más de 200 proyectos dentro y fuera del país, entre los que se incluyen el edificio para el grupo SPACE, la Iglesia Católica de Masan Yangdeok, el Museo Nacional de Jinju y el Estadio Olímpico de Seúl.

Desde 1966 es editor de la revista mensual SPACE, publicación de arte en general que contribuyó a difundir la cultura coreana.

También participaron en el diseño y construcción del Estadio:

Diseño Estructural: Instituto de la Asociación de Arquitectos de Seúl e Ingenieros Estructurales. Diseño de maquinaria: Sam Shin Ingenieros. Instalaciones eléctricas: Moon Y.H. Ingenieros consultores. Ingeniería Civil: Yoo Shin Corporación de Ingenieros.

Tipo de encargo: Desconocido.

\subsection{Edificios coetáneos}

1987. Centro Mundo Islamico, en Paris de Jean Nouvel

1988. Museo Hedmark en Hamar, de Sverre Fehn

\subsection{Hechos históricos relevantes}

Termino de la guerra entre Irán e Irak

Mijail Gorvachev es elegido presidente del Presidium del Soviet Supremo

Se funda Al Qaeda

Bibliografía:

SOOC, The Seoul Olympic Organizing Committee. (1989). Games of the XXIVth Olympiad Seoul. The Official Report. Ed. Korea Textbooks Co.

HAEOE, Kongbogwan (1991). 100 questions and answers on the Seoul Olympiad Ed. Korean Overseas Imformation Service.

IAF, International Athletic Foundation. (1990). Scientific Research Project at the Games of the XXIVth Olympiad IOC, International Olympic Committee. (actualizado en octubre de 2013) Factsheet the games of the Olympiad. TESIS DOCTORAL: JUNG, In Kim. (1992). Constructing a "miracle", Architecture, National Identity and Development of the Han River. A critical exploration of Architecture and Urbanism: Seoul, 1961-1988. UMI Number 3353391 
A-108 


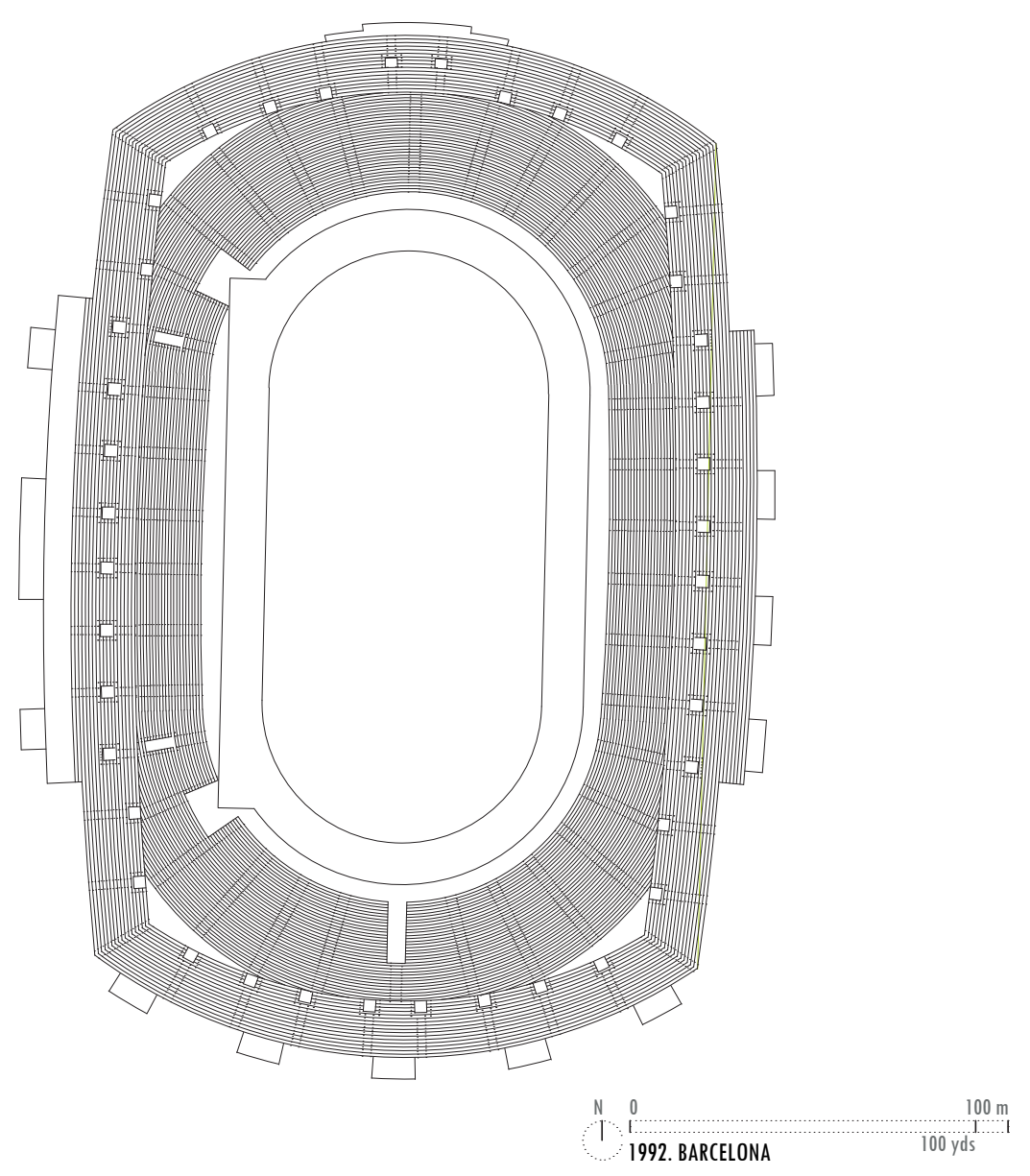

1992.0. Nombre del Estadio

Estadio Olímpico de Montjuïc. Desde 2001, Estadio Olímpico Lluís Companys.

1992.1. Situación

Paseo Olímpico 17-19, 08038 Barcelona, España

\subsection{Fechas}

1920. Barcelona hace el primer intento para organizar unos Juegos Olímpicos, los de 1924. Las otras ciudades candidatas fueron Ámsterdam, Roma, Los Ángeles, Praga y París.

1926. Barcelona vuelve a cumplimentar solicitud para ser anfitriona de unos Juegos. Esta vez, los de 1936.

1927. Se coloca la primera piedra para la construcción del Estadio de Montjüic. Fue un proyecto realizado por Pere Doménech i Roura como instalación deportiva principal de los Juegos y que al mismo tiempo, serviría para demostrar la grandeza de Barcelona en la Exposición Internacional de 1929.

1929. 5 de abril. Finalización de la construcción del Estadio.

1929. 20 de mayo. Se inaugura la Exposición Internacional de Barcelona, localizada en la montaña de Montjüic, con una superficie de 118 hectáreas. Participaron numerosos países europeos y algunos expositores privados estadounidenses y japoneses y sirvió para remodelar la ciudad y dar a conocer los adelantos tecnológicos e industriales catalanes en el exterior.

1929. 20 de mayo. El rey Alfonso XIII inaugura también el Estadio Olímpico de Montiuïc y las Piscinas de Montjuïc.

1931. 24 de abril. Se decide cuál sería la ciudad organizadora de los Juegos de 1936. Debido a la mala situación política de España, la elegida es Berlín.

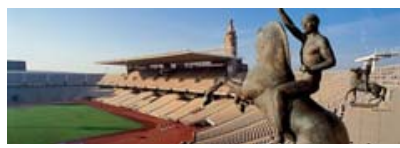

1932. Barcelona presenta candidatura para los Juegos de 1940. 
1936. 18 de julio. Comienza la Guerra Civil Española. Las Olimpiadas populares previstas en Barcelona justo para el día siguiente son suspendidas.

1951. Barcelona acoge los II Juegos Mediterráneos, celebrándose en el Estadio las ceremonias de inauguración y clausura y las pruebas de atletismo, fútbol, hockey hierba y equitación.

1965. 30 de diciembre. Candidatura conjunta de Madrid y Barcelona para los Juegos Olímpicos de 1972, pero la ciudad elegida es Múnich.

1980. Narcís Serra, alcalde de Barcelona y los tenientes de alcalde comienzan a estudiar la posibilidad de llevar los Juegos Olímpicos a la ciudad.

1981. 31 de enero. El alcalde de Barcelona Narcís Sierra anuncia la candidatura para los Juegos de 1992.

1983. Concurso para el Anillo Olímpico. Algunos de los elegidos son Ricardo Bofill, Federico Correa, Alfonso Milà, Juan Margarit, Carlos Buixadé, Francisco Sáenz de Oiza, Rafael Moneo, Vittorio Gregotti o Arata Isozaki.

1984. 16 de enero. Se anuncian los resultados del concurso. Federico Correa, Alfonso Milà, Juan Margarit, Carlos Buixadé y Vittorio Gregotti se encargan de la restauración del Estadio Olímpico.

1985. Febrero. Comienzan los trabajos de remodelación del Estadio Olímpico.

1986. 17 de octubre. Se decide en Lausana que Barcelona sea la sede de los Juegos de 1992.

1989. Se reinaugura el Estadio con motivo de la Copa del Mundo de Atletismo.

1992. 25 de julio a 9 de agosto. Se celebran los Juegos Olímpicos en Barcelona. El Estadio de Montjuïc acoge las ceremonias de inauguración, clausura y las pruebas de atletismo.

1992. 3 de septiembre a 14 de septiembre. Se celebran los Juegos Paralímpicos.

2001. 31 de marzo. El Estadio de Montjǘc pasa a denominarse Estadio Olímpico Lluis Companys.

2014. Se anuncia la reconversión del Estadio en un parque temático dedicado al deporte, "Open Camp"

2016. Primavera. Inauguración del parque temático Open Camp.
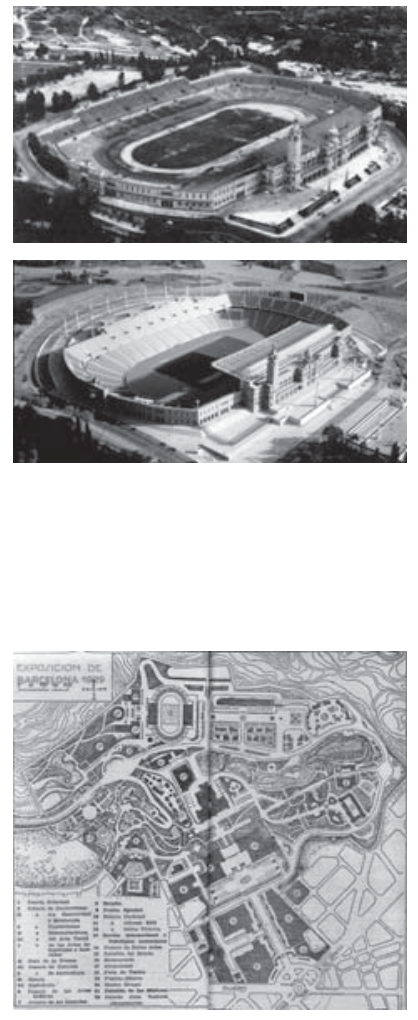

\subsection{Preexistencias en el lugar:}

Montaña de 190 metros de altura, en la que se han encontrado restos de asentamientos íberos del siglo VI aC. A principio de los años veinte se construyó en la proximidad al emplazamiento del futuro estadio el campo de deportes Foixarda.

1992.4. Relación con la ciudad. Posición respecto al centro urbano:

La organización de los Juegos permitió a la ciudad realizar una amplia restruccturación urbana, con el efecto mas llamativo de volver abrir la ciudad al mar

El Estadio está situado a: $3 \mathrm{~km}$ de la Plaza de España, a $1 \mathrm{~km}$ del puerto, a $14 \mathrm{~km}$ del aeropuerto: $14 \mathrm{~km}$; a 30 minutos a píe de la Estación de FFCC de Sants.

\subsection{Breve relato de la historia del Estadio:}

En 1929 Barcelona acogería la Exposición Internacional, a la que asistieron numerosos países europeos y también inversores privados estadounidenses y japoneses. Como ya había ocurrido en otras ocasiones, la Exposición y la propuesta de candidatura para los Juegos de 1936, sirvieron para que la ciudad se transformara, en un interés por mostrar al resto del mundo su grandeza.

Se planteó la reestructuración de la zona de Montjüc, para que ésta quedara como zona deportiva y de exposición, lo que significó una mejora en sus comunicaciones (sobre todo por tranvía y metro) y la ampliación de sus instalaciones deportivas, culturales y de ocio.

Una de estas nuevas instalaciones sería el nuevo Estadio Olímpico, que sustituiría al de la Foixarda (1923), puesto que este quedaba demasiado escaso según la afluencia de personas que se preveía. El encargado de realizar el proyecto fue Pere Doménech i Roure y el 5 de abril de 1927, tras la aprobación del proyecto por parte del presidente de 1OC, fue colocada la primera piedra. La inauguración del Estadio fue llevada a cabo el 20 de mayo de 1929 por el Rey Alfonso XIII, coincidiendo con la apertura de la Exposición Internacional. La estructura presente del Estadio es resultado de la reconstrucción realizada con motivo de la candidatura olímpica de Barcelona para los Juegos de 1992. La construcción fue financiada por el Consejo Superior de Deportes y el COOB'92. Constituia la rehabilitación del viejo estadio que había simbolizado el espíritu y la tradición deportiva de la ciudad. Un proyecto confiado a los arquitectos Federico Correa, Alfonso Milà, Juan Margarit, Carlos Buixadé y Vittorio Gregotti, ganadores del concurso promovido en agosto de 1983 y cuya intención principal fue preservar las fachadas neoclásicas del proyecto inicial y las esculturas originales de Pau Gargallo, tan representativas de la arquitectura catalana. No obstante, la fachada 
oeste hubo de ser reconstruida siguiendo la misma estética debido a su mal estado y las esculturas hubieron de ser restauradas antes de volver a colocarse.

El interior fue modificado completamente para aumentar la funcionalidad, lograr mejores accesos, mejores circulaciones y más capacidad y así poder ser totalmente aprovechado en eventos futuros de diversa índole.

En febrero de 1985 comenzó la primera etapa de la reconstrucción, empezando por la protección de las fachadas y la demolición de todas las estructuras del interior. Al mismo tiempo se rebajó el nivel del suelo interno 11 metros para poder aumentar el número de asientos, hasta completar un aforo total de 60000 espectadores y asegurando una buena visión de la zona central desde cualquier punto de la grada, reduciéndose la cuerda de la pista de los 500 metros originales a los 400 reglamentados.

\subsection{Descripción del Estadio; Graderío}
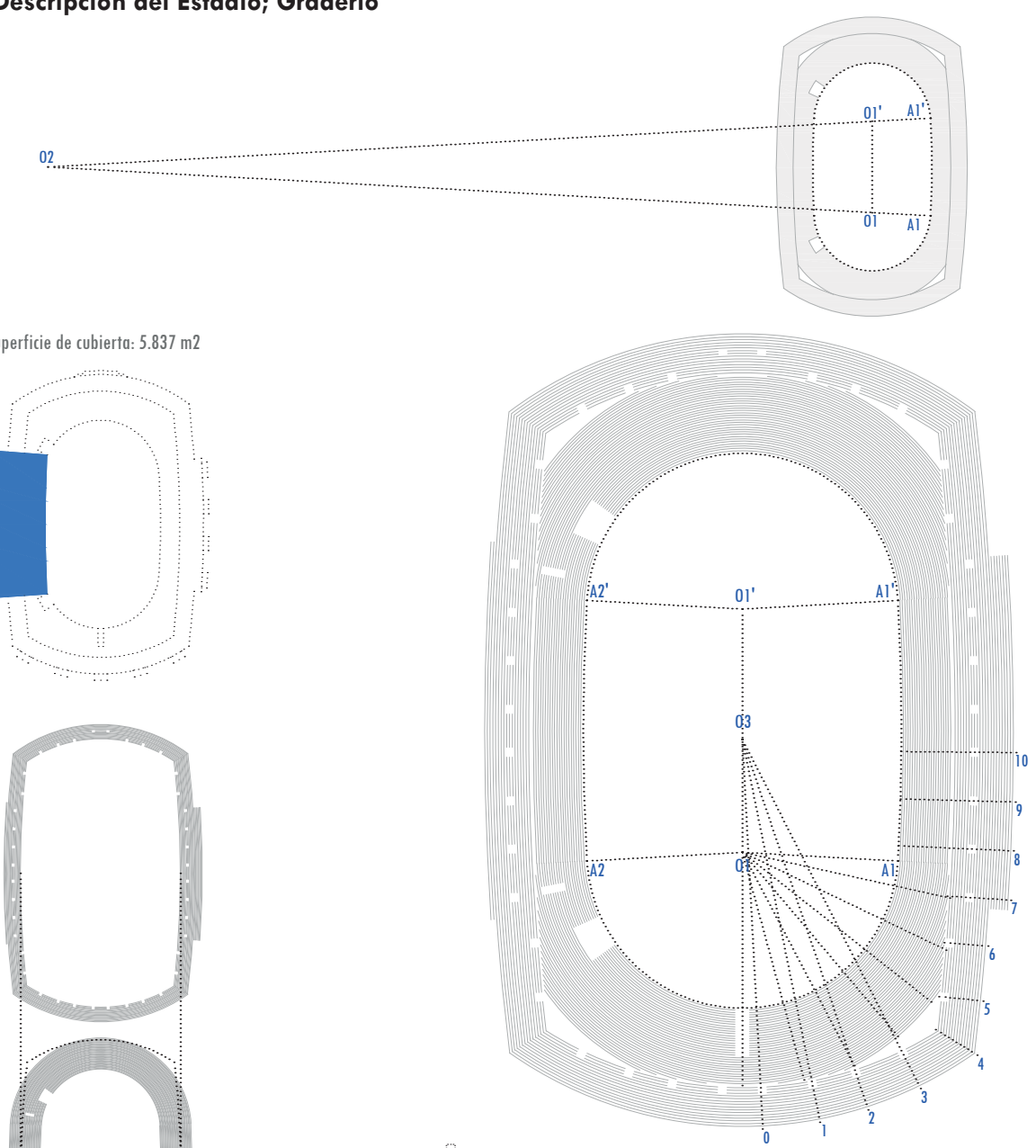

dimensiones y superficies aproximadas graderío

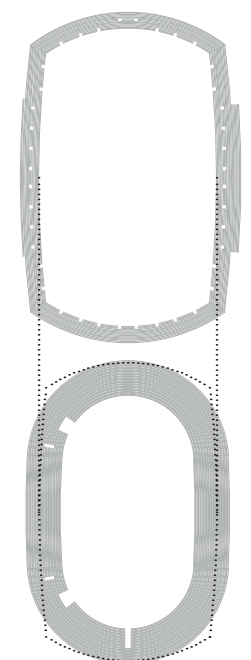

superfiecie de graderios: $27.569 \mathrm{~m} 2$

$$
\begin{array}{llr}
\mathrm{N} & 0 & 100 \mathrm{~m} \\
1 & 100 \mathrm{yds}
\end{array}
$$

Capacidad para 60.000 espectadores. Las nuevas gradas se construyen completamente de nueva planta, teniendo en cuenta la correcta inclinación para tener una buena visibilidad de la pista en cualquier lugar de las mismas. Las gradas inferiores están definidas siguiendo la forma de la pista de atletismo y las superiores son paralelas a las fachadas.

El plan de rehabilitación mantuvo las entradas originales al estadio pero se mejoró el sistema de circulaciones. Bajo las gradas se establecieron todos los servicios necesarios y también las circulaciones de atletas, organizadores, mantenimiento y servicios técnicos, de manera que no obstruyeran el acceso de los vehículos por los túneles de los lados este y oeste.

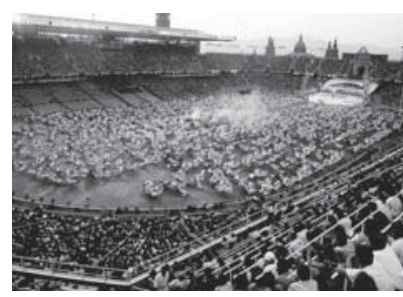

$\begin{array}{lr}\text { L 01-01' } & 82,35 \mathrm{M} \\ \text { L 01-02 } & 745,80 \mathrm{M} \\ \text { R 01-Al } & 52,77 \mathrm{M} \\ \text { R 02-Al } & 798,57 \mathrm{M} \\ \text { < A1.01.A2 } & 174^{\circ} \\ \text { < Al.02.Al' } & 6^{\circ}\end{array}$

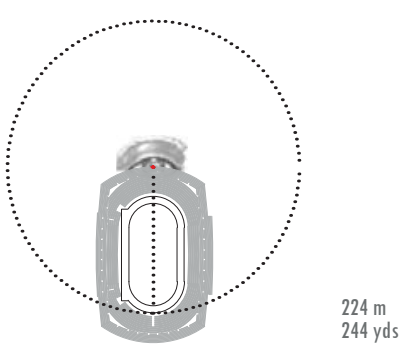


1925-29. Edificios de la Bauhaus de Dessau, de Walter Gropius

1929. Villa Saboya de Le Corbusier

1929. Pabellón Alemán de la Exposición de Barcelona de Mies Van der Rohe

1987. Instituto del Mundo Árabe de París, de Jean Nouvel.

1988. Facultad de Arquitectura de Oporto, de Álvaro Siza.

1992.12. Hechos históricos relevantes:

1929, el "Crack" del mercado de mercado de valores de Nueva York, produciendo una crisis que se extendió rápidamente a todas las áreas del mundo.

1985, adhesión de España y Portugal a la Unión Europea.

1992, el gobierno de Sudáfrica deroga las leyes de discriminación racial y acuerda un gobierno de transición con Nelson Mandela y la celebración de elecciones libres.

\section{Bibliografía Barcelona 1992:}

CORNUDELLA, J; FERRER, J; LÓPEZ, E; MELERO, J; RIAMBAU, J.- Official Report of the Games of the XXV Olympiad Barcelona 1992. Volume I. (1992) ISBN: 84-7868-108-6

CORNUDELLA, J; FERRER, J; LÓPEZ, E; MELERO, J; RIAMBAU, J.- Official Report of the Games of the XXV Olympiad Barcelona 1992. Volume II. (1992) ISBN: 84-7868-109-4

CORNUDELLA, J; FERRER, J; LÓPEZ, E; MELERO, J; RIAMBAU, J.- Official Report of the Games of the XXV Olympiad Barcelona 1992. Volume III. (1992) ISBN: 84-7868-110-8

CORNUDELLA, J; FERRER, J; LÓPEZ, E; MELERO, J; RIAMBAU, J.- Official Report of the Games of the XXV Olympiad Barcelona 1992. Volume IV. (1992) ISBN: 84-7868-106-X

CORNUDELLA, J; FERRER, J; LÓPEZ, E; MELERO, J; RIAMBAU, J.- Official Report of the Games of the XXV Olympiad Barcelona 1992. Volume V. (1992) ISBN: 84-7868-283-X

BENÉVOLO, L.- Historia de la Arquitectura Moderna. Barcelona, Ed. Gustavo Gili, 1994.

BRU, E.- y MATEO, J.L.- Arquitectura europea contemporánea. Barcelona, Gustavo Gili, 1987.

CHUECA GOITIA, F.- Historia de la arquitectura occidental. VI El siglo XX, las fases finales y España. Madrid, Editorial Dossat, 1980.

FRAMPTON, K.- Historia Crítica de la Arquitectura Moderna. Barcelona, Ed. Gustavo Gilli, 1994

Barcelona Arquitectura y Ciudad, 1980-1992. "Remodelación del Estadio Olímpico. Palacio de Deportes y Complejo Deportivo Municipal de pelota en La Vall d'Hebrón." Editorial Gustavo Gili.

Arquitecturas Olímpicas. Barcelona 92. Rafael Vila Rodríguez Fabricio Bianchetti. "El anillo Olímpico y el Estadio Olímpico." Frames Libri.

Revista ON Diseño, núm. 116. "Remodelació de l'Edifici del Rellotge de Barcelona y remodelació de l'Estadi Olímpic de Montjü̈." Edita Aram Ediciones. 


$$
\text { A-114 }
$$




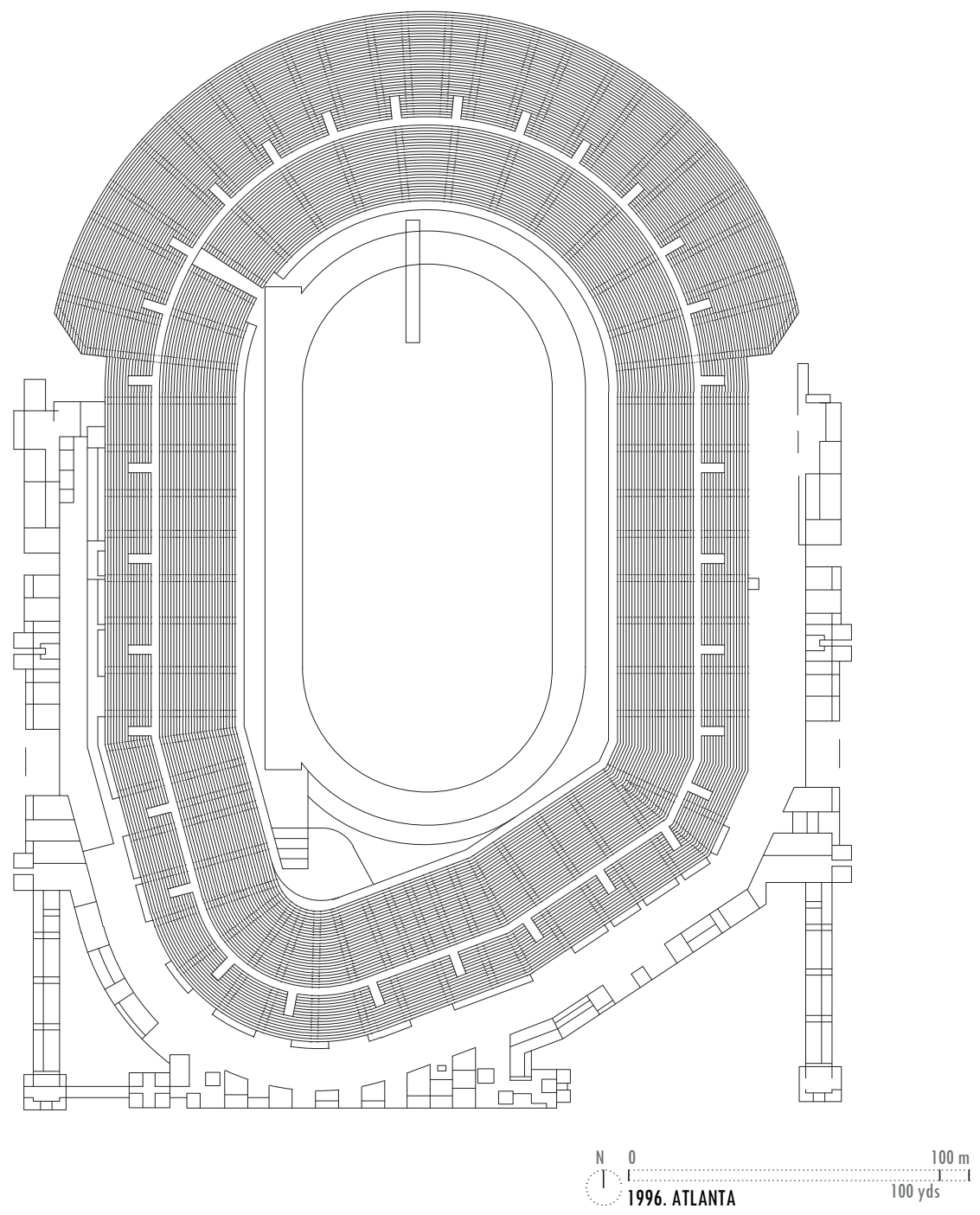

1996.0. Nombre del Estadio

Centennial Olympic Stadium. En 1997 fue parcialmente demolido para convertirlo en un estadio de béisbol, pasando a llamarse Estadio Turner Field.

1996.1. Situación

755 Hank Aaron Dr, SE. Atlanta, GA, 30315 . Estados Unidos.

1996.2. Fechas

1987. En septiembre, Atlanta presenta su candidatura al Comité Olímpico Estadounidense (USOC) entre otras 14 ciudades de los Estados Unidos para organizar los Juegos Olímpicos de 1996.

1988. 9 de abril. Atlanta es seleccionada por el USOC como la candidata estadounidense. Finalmente las competidoras son cinco: Atenas, Belgrado, Manchester, Melbourne y Toronto.

1990. 18 de septiembre. Por una votación de 51 a 35, el COl selecciona a Atlanta como ciudad anfitriona de los Juegos Olímpicos de 1996.

1992. Octubre. Empieza todo el proceso de diseño del proyecto del Estadio.

1993. 9 de marzo. Se aprueba el plan para construir el Estadio Olímpico junto al AtlantaFulton County Stadium y se aprueba también que cuando las Olimpiadas acaben, el proyecto deberá adaptarse para convertirse en el campo del equipo de béisbol de Los Atlanta Braves y que el viejo Atlanta-Fulton sea demolido.

1995. 13 de marzo. Comienza la construcción del Centennial Olympic Park.

1996. Marzo. Finaliza la construcción del Estadio. 

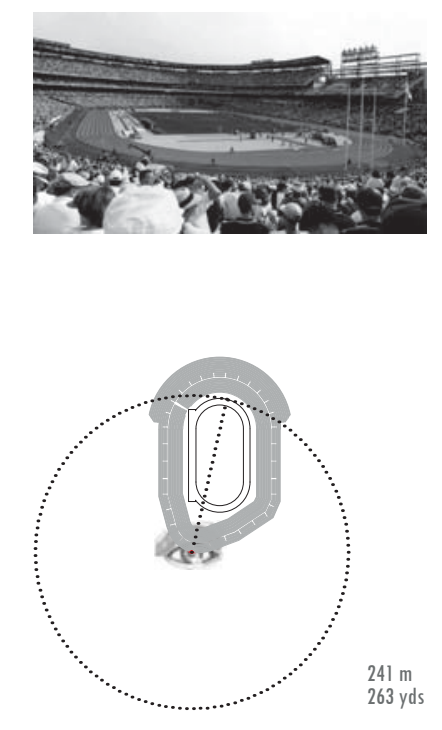

dimensiones y superficies aproximadas graderío

$\begin{array}{lr}\text { L A1-A8 } & 102,90 \mathrm{M} \\ \text { L A2-A3 } & 98,44 \mathrm{M} \\ \text { L A3-A4 } & 46,48 \mathrm{M} \\ \text { L A5-A6 } & 43,07 \mathrm{M} \\ \text { L A6-A7 } & 47,85 \mathrm{M} \\ \text { L A7-A8 } & 8,08 \mathrm{M} \\ \text { R 01-Al } & 56,12 \mathrm{M} \\ \text { R 02-A4 } & 12,58 \mathrm{M} \\ \text { < A2.A3.A4 } & 165^{\circ} \\ \text { < A5.A6.A7 } & 167^{\circ} \\ \text { < A6.A7.A8 } & 148^{\circ} \\ \text { < A7.A8.A1 } & 155^{\circ}\end{array}$

1996. 18 de mayo. Inauguración del estadio.

1996. 19 de julio al 4 de agosto. Se celebran los Juegos Olímpicos de Atlanta. El Centennial Olympic Stadium acoge las ceremonias de inauguración, clausura y las pruebas de atletismo.

1996. 16 de agosto al 24 de agosto. Se celebran los Juegos Paralímpicos de Atlanta 1996.

1996. 27 de agosto. Comienza la demolición parcial del Centennial Olympic Stadium para adaptarlo a las necesidades de un campo de béisbol. Su nombre es modificado y pasa a llamarse Turner Field.

1997. Verano. El Atlanta-Fulton County Stadium es demolido.

2005. Renovación significativa de Turner Field. Se instala la pantalla de alta definición más grande del momento.

2016. Finaliza el contrato con el equipo Atlanta Braves. El futuro del estadio queda ahora en el aire.

\subsection{Preexistencias en el lugar}

El Centennial Olympic Stadium fue construido en una parcela de aproximadamente 30 acres (unas 12 hectáreas), localizada justo enfrente del Atlanta-Fulton County Stadium. Éste era un estadio multiusos (eventos culturales, deportivos y musicales) construido en la década de los sesenta, sede de los Atlanta Braves, Atlanta Falcons y Atlanta Chiefs.

\subsection{Relación con la ciudad. Posición respecto al centro urbano}

El estadio están muy cerca del centro urbano de Atlanta., a 1,5km,y a $14 \mathrm{~km}$ del aeropuerto.

\subsection{Breve relato de la historia del Estadio}

Atlanta necesitaba un nuevo estadio de béisbol puesto que el Atlanta-Fulton County Stadium se había quedado obsoleto. En uno de sus aparcamientos se decidió construir para los Juegos el Centennial Olympic Stadium, con pista de atletismo. Una vez finalizados los Juegos se demuele parcialmente y se completa un estadio apto para el béisbol con capacidad para 45.000 espectadores. Una vez concluida la remodelación y puesto en uso, se procede a la demolición del antiguo estadio.

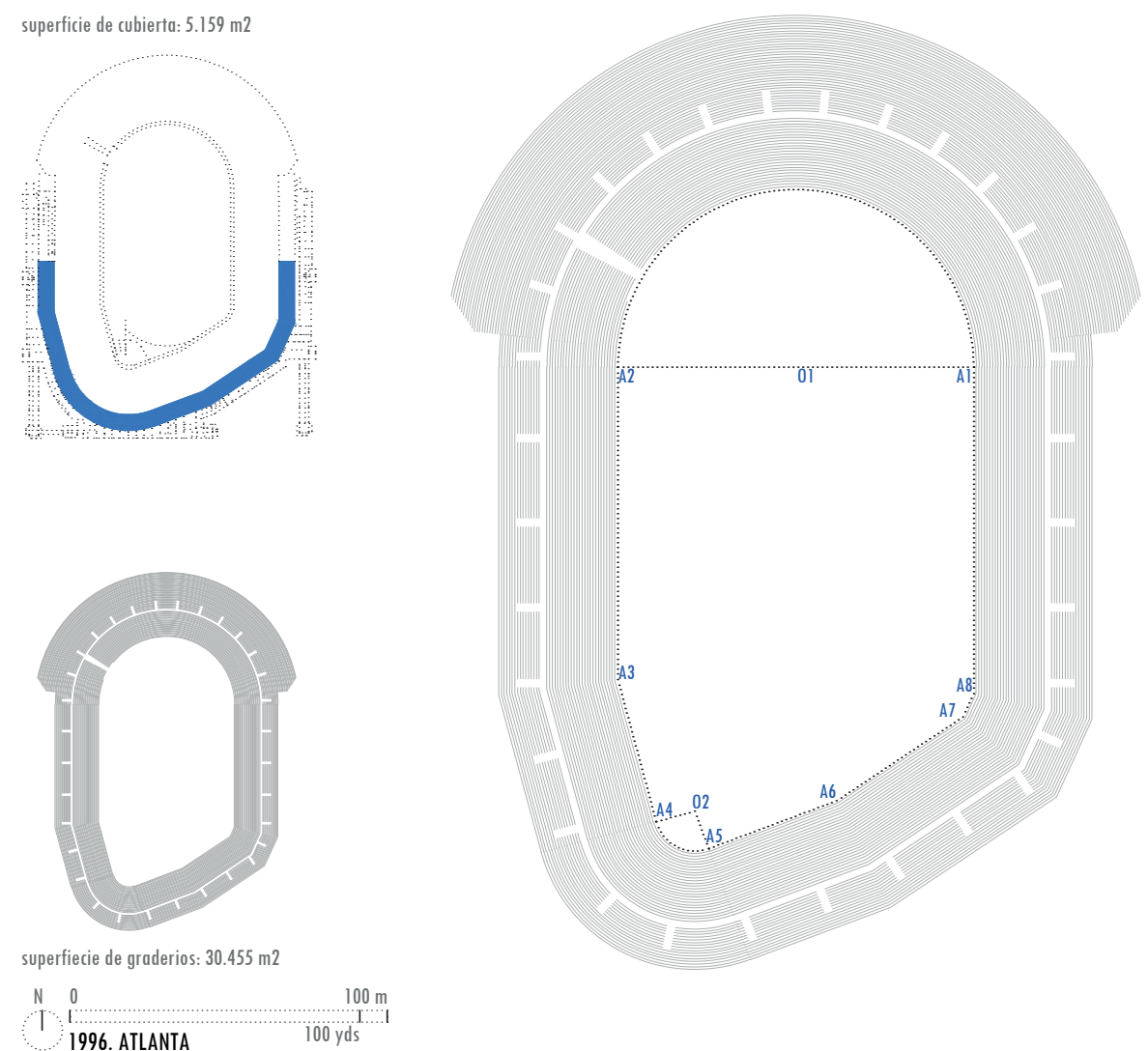

1996.6. Descripción del Estadio; Graderío

Aforo de 85000 espectadores para los Juegos. 
El anfiteatro norte del Estadio fue construido con elementos prefabricados de hormigón para facilitar su posterior reconversión.

La forma del graderío responde a las necesidades del futuro estadio de béisbol.

1996.7. Descripción del Estadio; Pista:

Dimensiones: Cuerda de la pista 400 metros, con ocho calles de cuatro pies $(1,22 \mathrm{~m})$, cada una y un noveno carril en la recta de llegadas. El material sintético de la pista fue el más duro permitido para favorecer las pruebas de velocidad.

Campo interior de hierba.

Programa Deportivo: Atletismo y las Ceremonias de Apertura y Clausura
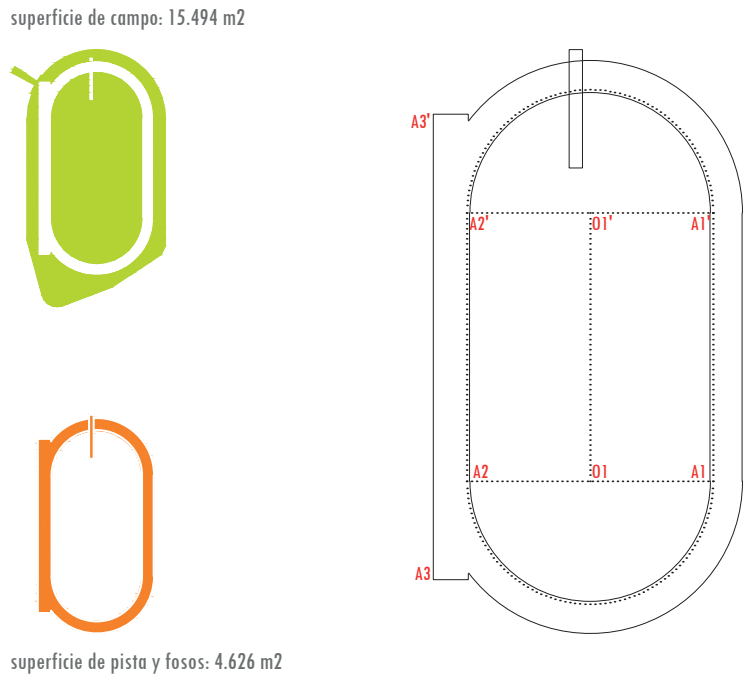

superficie de pista y fosos: $4.626 \mathrm{~m} 2$

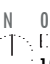

1996. ATLANTA marca del ganador

$100 \mathrm{~m}$.

$200 \mathrm{~m}$

$400 \mathrm{~m}$.

$800 \mathrm{~m}$.

$1500 \mathrm{~m}$.

$5000 \mathrm{~m}$

$10000 \mathrm{~m}$

$110 / 100 \mathrm{mv}$

$400 \mathrm{mv}$

3000 m obst

Altura

Pértiga

Longitud

Triple

Peso

Disco

Martillo

Jabalina

$4 \times 100$

$4 \times 400$

$20 \mathrm{~km}$ marcha

$10 \mathrm{~km}$ marcha

$50 \mathrm{~km}$ marcha

Decatlón

Heptatlón

Maratón

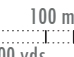

100 yds

dimensiones y superficies aproximadas pisto

\begin{tabular}{|c|c|c|}
\hline CUERDA & $400,00 \mathrm{M}$ & 437 yds \\
\hline L $01-01$ ' & $81,73 \mathrm{M}$ & \\
\hline LA3-Al & $30,00 \mathrm{M}$ & \\
\hline L A3-A3' & $141,73 \mathrm{M}$ & \\
\hline R Ol-Al & $36,96 \mathrm{M}$ & \\
\hline$<$ Al.01.A2 & $180^{\circ}$ & \\
\hline
\end{tabular}

1996.8. Elementos significantes:

El pebetero que, posteriormente, se ha conservado como parte de la fachada del nuevo estadio.

1996.9. Avances técnicos:

1996.10. Autores. Tipo de encargo:

Proyecto dividido entre varias firmas: Heery International, Rosser Fabrap International, Williams-Russell \& Johnson y Ellerbe Becket (hoy día AECOM).

Los equipos encargados de la construcción del edificio fueron: Beers Construction, H. J. Russell Construction y C. D. Moody Construction.

1996.11. Edificios coetáneos:

Fundación Cartier de Arte Contemporáneo de París, de Jean Nouvel (1994)

Estación de Bomberos de Vitra, de Zaha Hadid (1994)

Iglesia de Marco de Canaveses, de Álvaro Siza (1996)

Museo de Arte Contemporáneo de Niterói, de Óscar Niemeyer (1996)

1996.12. Hechos históricos relevantes:

1995, entrada en vigor del Acuerdo de Schengen, que permite la libre circulación entre los países firmantes del mismo.

1996, la instauración del Régimen Talibán en Afganistán y el nacimiento en Edimburgo de la oveja Dolly, el primer animal clonado de la historia.

En 1997, la firma del Tratado de Ámsterdam, una revisión del Tratado de Maastricht de 1993, con el objetivo fundamental de crear un espacio de libertad, seguridad y justicia común. 
Bibliografía Atlanta 1996:

THE ATLANTA COMMITTEE OF THE CENTENNIAL OLYMPIC GAMES.- Official Report of the Centennial Olympic Games. Volume I (1997) ISBN: 1-56145-168-1

THE ATLANTA COMMITTEE OF THE CENTENNIAL OLYMPIC GAMES.- Official Report of the Centennial Olympic Games. Volume II (1997) ISBN: 1-56145-151-7

THE ATLANTA COMMITTEE OF THE CENTENNIAL OLYMPIC GAMES.- Official Report of the Centennial Olympic Games. Volume I (1997) ISBN: 1-56145-169-X

SIMON, L.- All about the Atlanta Braves Including the History, Turner Field, Recent Seasons, Awards, and Records. BiblioBazaar, 2011.

CARUSO, G.- Turner Field: Rarest of Diamonds. Longstreet Press, 2001.

http://www.atlantaga.gov 


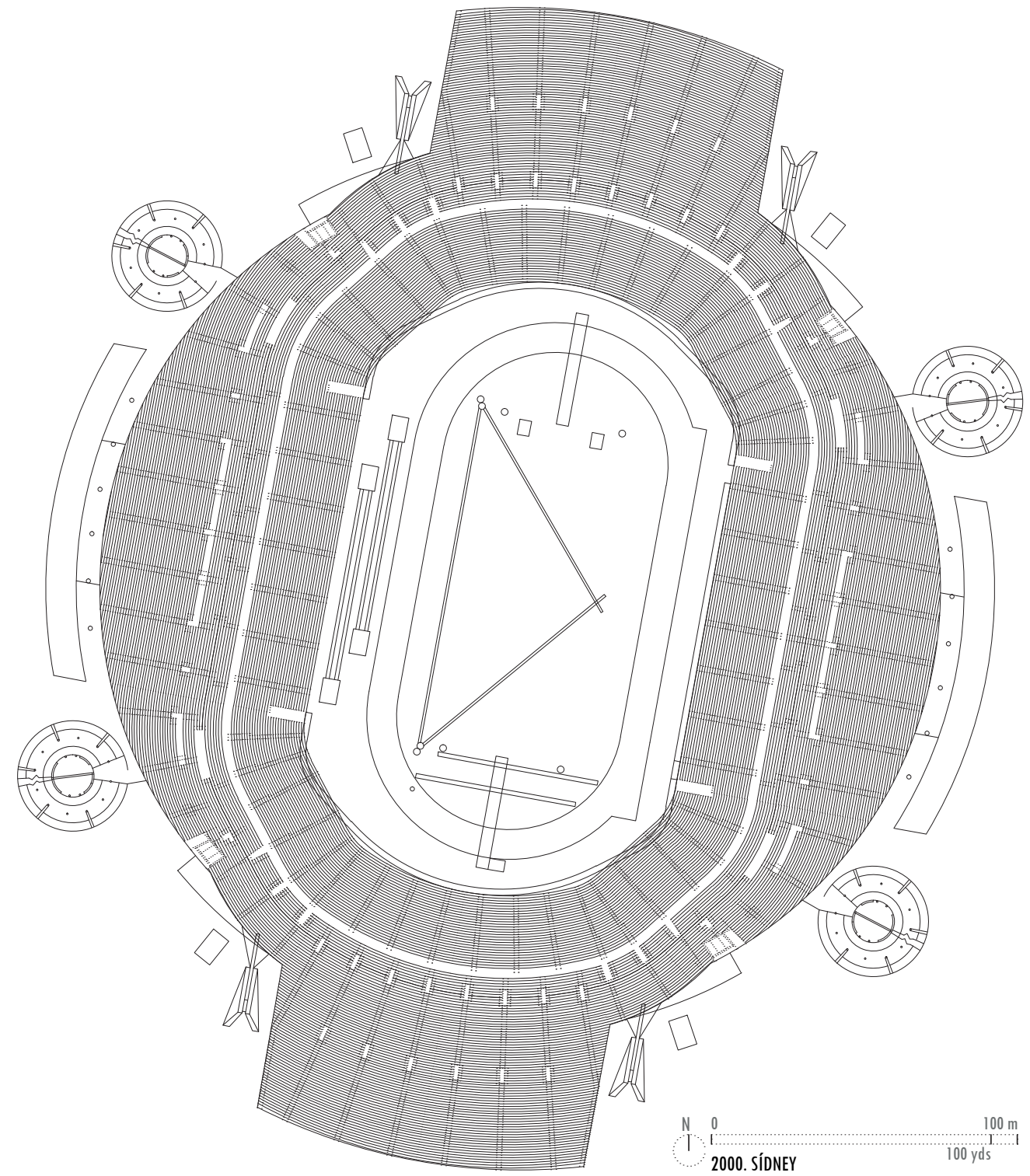

2000.0. Nombre del Estadio

Stadium Australia. Conocido por motivos de patrocinio como ANZ Stadium, y anteriormente Telstra Stadium. (2002/2007)

\subsection{Situación}

Edwin Flack Ave, Sydney Olimpic Park NSW 2127. Situado en el interior del Parque Olímpico de Sidney en el distrito suburbano de Homebush, Australia.

\subsection{Fechas}

1970. El gobierno de Nueva Gales del Sur identificó Homebush Bay como posible sede olímpica.

1988. Se inicia el desarrollo urbanístico Parque Bicentenario, en Homesbush.

1990. El 23 de octubre se constituye el Comité para impulsar la candidatura de Sidney para albergar los Juegos.

1990. El noviembre el Comité Olímpico Australiano presenta la candidatura de Sydney a los Juegos del 2000

1993. El 23 de septiembre, el CIO designa Sydney sede de los Juegos de la XXVII Olimpiada

1995. En marzo se redacta el proyecto

1996. El 9 de Septiembre empezó la construcción del estadio.

1999. En junio, se terminan las obras.

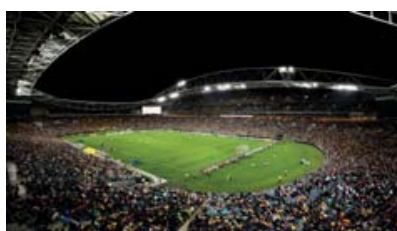




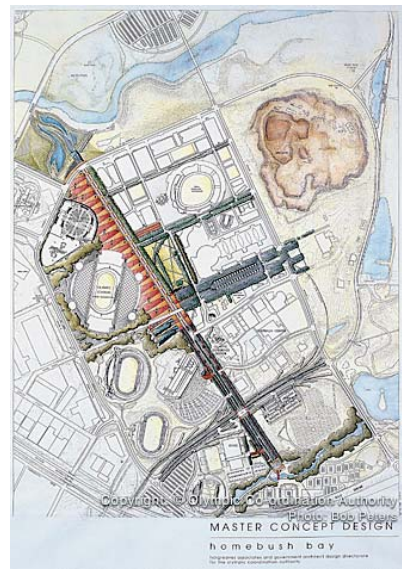

1999. El 12 de Junio, inauguración oficial.

2000. El 15 de septiembre tiene lugar la ceremonia de apertura de los JJOO.

2001. Remodelación del Estadio después de los Juegos, de octubre de 2001 a octubre de 2003

2003. Reinauguración.

2003. Copa Mundial de Rugby.

2015. Copa de Asia de Rugby

\subsection{Preexistencias en el lugar}

Homebush Bay, era originariamente un enclave de exuberante vegetación y fauna, pero que la contaminación en las últimas décadas lo había ido degradando. En el lugar se encontraban industrias obsoletas.

superficie de cubierta: $29.657 \mathrm{~m} 2$
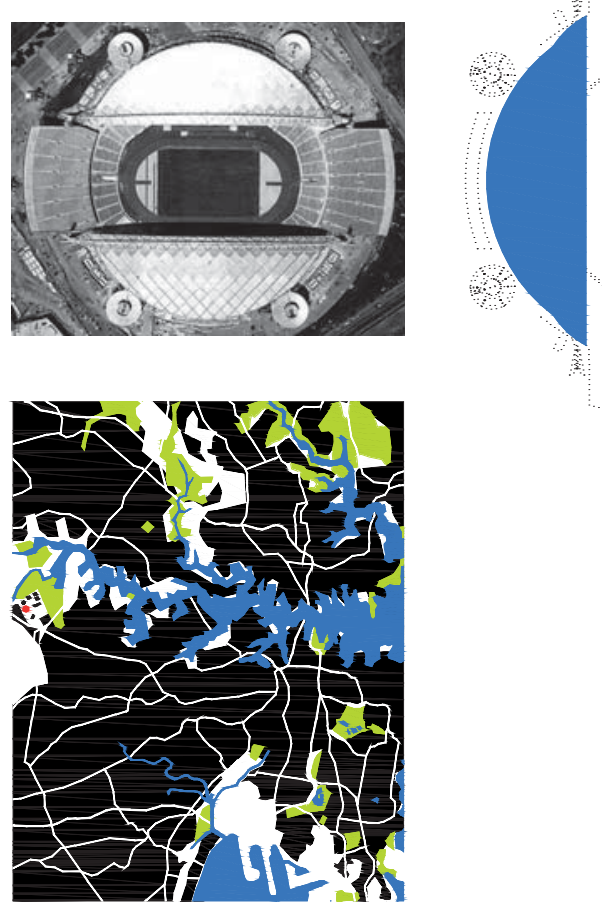

dimensiones y superficies aproximadas graderío

\begin{tabular}{|c|c|}
\hline L 01-01' & $38,79 \mathrm{M}$ \\
\hline L 01-02 & $62,11 \mathrm{M}$ \\
\hline L $02-02^{\prime}$ & $151,95 \mathrm{M}$ \\
\hline L 04-04' & $108,65 \mathrm{M}$ \\
\hline L $01-06$ & $19,39 \mathrm{M}$ \\
\hline R Ol-Al & $81,32 \mathrm{M}$ \\
\hline R 02-Al & $18,80 \mathrm{M}$ \\
\hline R $04-05$ & $21,00 \mathrm{M}$ \\
\hline$<$ A1.01.A2 & $50^{\circ}$ \\
\hline$<A 1.02 . A 3$ & $27^{\circ}$ \\
\hline$<A 5.04 . A 7$ & $38^{\circ}$ \\
\hline$<$ A7.01.A8 & $121^{\circ}$ \\
\hline
\end{tabular}

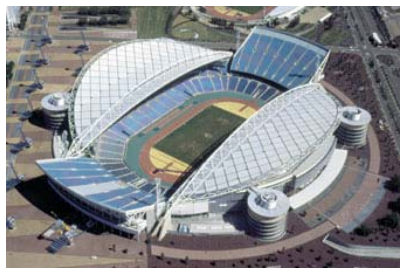

superfiecie de graderios: $49.536 \mathrm{~m} 2$

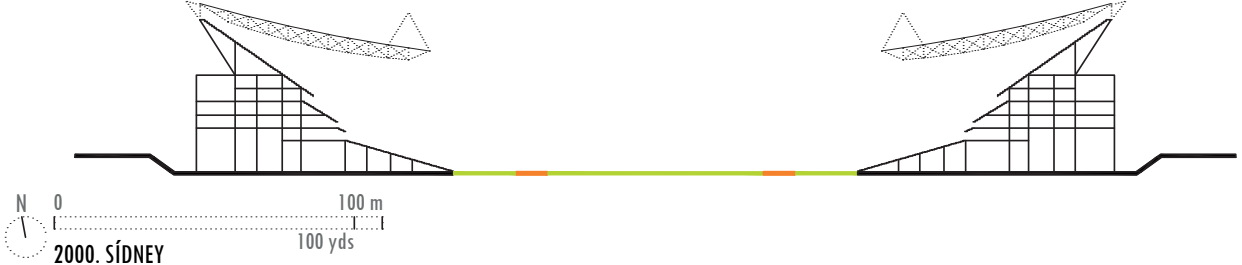

2000.4. Relación con la ciudad. Posición respecto al centro urbano

A 17 km al Este del centro de Sidney, y a 8km está Parramatta. Alrededor del Sidney Olimpic 
Park está el Bicentennial Park.. La estación de metro más cercana es Olímpica que está a 400 metros y comunica directamente con el centro de Sydney.

\subsection{Breve relato de la historia del Estadio}

El reto era diseñar el estadio Olímpico de mayor aforo de la historia y una vez terminados los Juegos, se reconfigurará reduciendo su aforo y completando su cubierta. Se destina su uso post olímpico a: rugby league ( 13 jugadores), rugby unión (15 jugadores), fútbol australiano, fútbol y criquet. Para lo cual se quitó la pista de atletismo y la grada inferior con sus dos seminiveles se motorizó permitiendo movimiento para adaptarle a las diferentes formas y dimensiones requeridas por los citados deportes.

\subsection{Descripción del Estadio; Graderío}

Capacidad para 110.000 espectadores en el momento de los Juegos Olímpicos. Con la reforma de 2001 se redujo este número a 83.000 personas. Con tres niveles de tribunas, el primero rodea el $100 \%$ del perímetro del campo, mientras que el segundo y tercero se divide en dos sectores laterales. Para los Juegos en los dos extremos del eje longitudinal se dispuso una grada extra con capacidades de unos 15.000 espectadores cada una. La cubierta del conjunto, que es translucida y de doble curvatura, quedó provisionalmente sin completar por la incidencia de estos graderíos.

\subsection{Descripción del Estadio; Pista}

Cuerda de la pista de 400 metros y nueve calles de 1,22m (4 pies). En el campo se puede marcar un terreno de juego de $105 \times 70$ metros.

Programa Deportivo: Atletismo, Final de fútbol y las Ceremonias de Apertura y Clausura

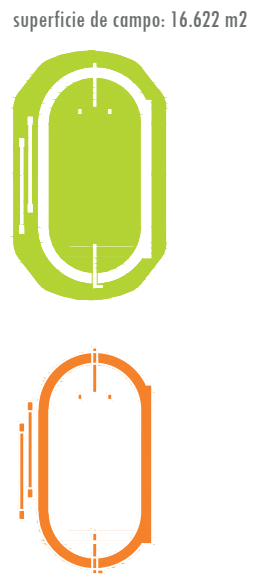

superficie de pista y fosos: $5.340 \mathrm{~m} 2$
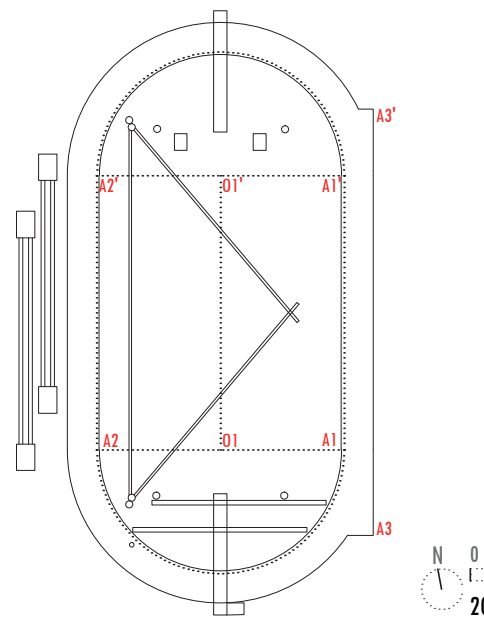

2000. SíDNEY

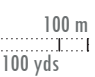

2000.8. Elementos significantes

2000.9. Avances técnicos

El estadio puede transformar su configuración mediante gradas móviles sobre raíles acercando los espectadores al terreno de juego.

\subsection{Autores. Tipo de encargo}

HOK LOBB en colaboración con el estudio local Bligh Soller architects

Originalmente HOK, fundada en 1955 en St Louis, Missouri, por George Hellmuth, Obata Gyo y George Kassabaum. Es en la actualidad el estudio de arquitectura e ingeniería más grande con sede en los Estados Unidos.

En 1983 constituyó "HOK Sports Venue Events", especializada en estadios deportivos y centros de convenciones, en 1999 se fusiona con LOBB Shorts Architecture y en 2009 pasa a ser una firma independiente con el nombre de Populous. Proyectando los estadios de Wembley, el Olímpico de Londres y el de Wimbledon entre otros.

El responsable del proyecto fue Rod Sheard, nacido en Brisbane, Australia (1951). Se inicia en la arquitectura deportiva cuando, en 1975, se traslada a Londres y comienza a trabajar en Howard V. Lobb \& partners, de la que en 1993 es nombrado director y cambia el nombre de la firma por LOBB Sports Architecture. Hasta su fusión con HOK Shorts en 1999, realiza entre otros, el Galpharm Stadium in Huddersfield; la primera construcción deportiva en ganar el galardon "Edificio del Año" del Royal Institute of British Architect's, el Reebok Stadium en Bolton, el Millennium Stadium en Cardiff (el primer estadio europeo con el techo practicable),

Sheard es el único arquitecto que ha desarrollado dos estadios Olímpicos.

Tipo de encargo. Concurso de proyecto y obra convocado por el gobierno de Nueva Gales
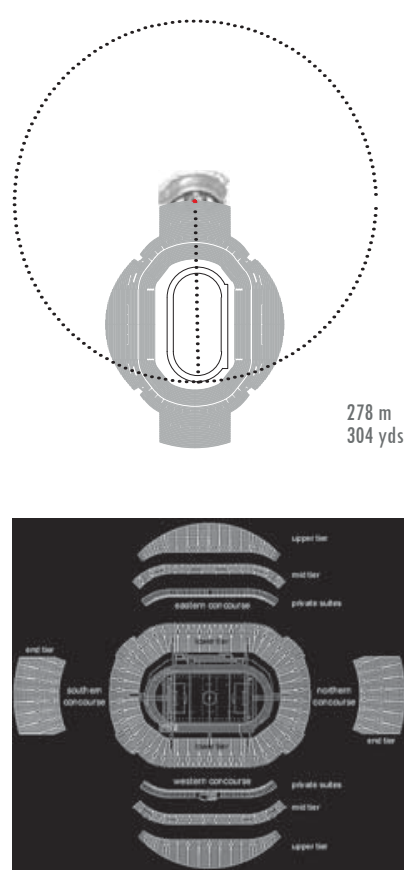

dimensiones $y$ superficies aproximadas pista

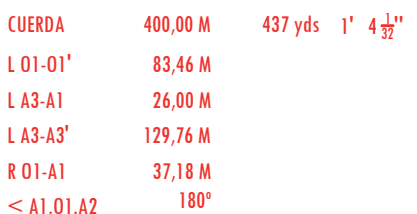

$<$ Al.01.A2

marca del ganador

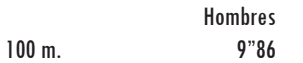

$200 \mathrm{~m}$

$400 \mathrm{~m}$.

$800 \mathrm{~m}$.

$1500 \mathrm{~m}$.

$5000 \mathrm{~m}$

$10000 \mathrm{~m}$.

$110 / 100 \mathrm{mv}$

$400 \mathrm{mv}$

3000 obst

Altura

Pértiga

Longitud

Triple

Peso

Disco

Martillo

Jabalina

$4 \times 100$

$4 \times 400$

Decathlón

Heptalon

$20 \mathrm{~km}$ marcha

$50 \mathrm{~km}$ marcha

Marathón

$20 " 09$
$43 " 84$

l'45"08

3'32"07

13'3"49

27'18"20

$13 " 00$

$47 " 5$

$8,21 " 43$

$2,40 \mathrm{~m}$

$5,90 \mathrm{~m}$

$8,65 \mathrm{~m}$

$17,71 \mathrm{~m}$

$21,29 \mathrm{~m}$

$69,30 \mathrm{~m}$

$80,02 \mathrm{~m}$

$90,17 \mathrm{~m}$

$37 " 61$

2'56"35

8641 ptos

1h19,03

$3: 42,22$

2h:10'1

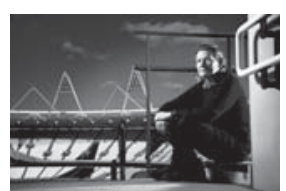

Mujeres

$10 " 7$

$21 " 84$

49"11

$1,56 " 15$

4,05"10

$14,40 " 79$

$30: 17,49$

$12 " 65$

53,02

2,01

4,60

6,99

15,2

20,56

68,40

71,16

68,91

41,95

$3: 22.62$

3909ptos

lh:29,05

$2: 23,14$ 
del Sur

Las constructoras fueron Multiplex Constructions y Ambros Australia Ltd

2000.1 1. Edificios coetáneos

Tate Gallery, en Londres. Obra de los arquitectos Herzog y de Meuron.

Second Stage Theatre de Nueva York de Rem Koolhas.

En 1997 se inauguró en Bilbao el Museo Guggenheim de Bilbao de Frank Gehry.

\subsection{Hechos históricos relevantes}

1998 se pone en orbita el primer modulo de la Estación Espacial Internacional

11 de septiembre de 2001 atentado terrorista contra las Torres Gemelas de Nueva York. 2001 , se publica el desciframiento del genoma humano

2002, el Euro comienza a circular por doce países de la Unión Europea

Bibliografía Sydney 2000:

Official Report of the XXVII Olympiad. Sydney 2000 Olympic Games. (2001). Ed. Sydney Organising Committee for the Olympic Games. ISBN 0-9579616-1-8

SHEARD, Rod (2001). Sports Architecture. Ed. Spon Press, Londres. ISBN 0-419-21 220-5 


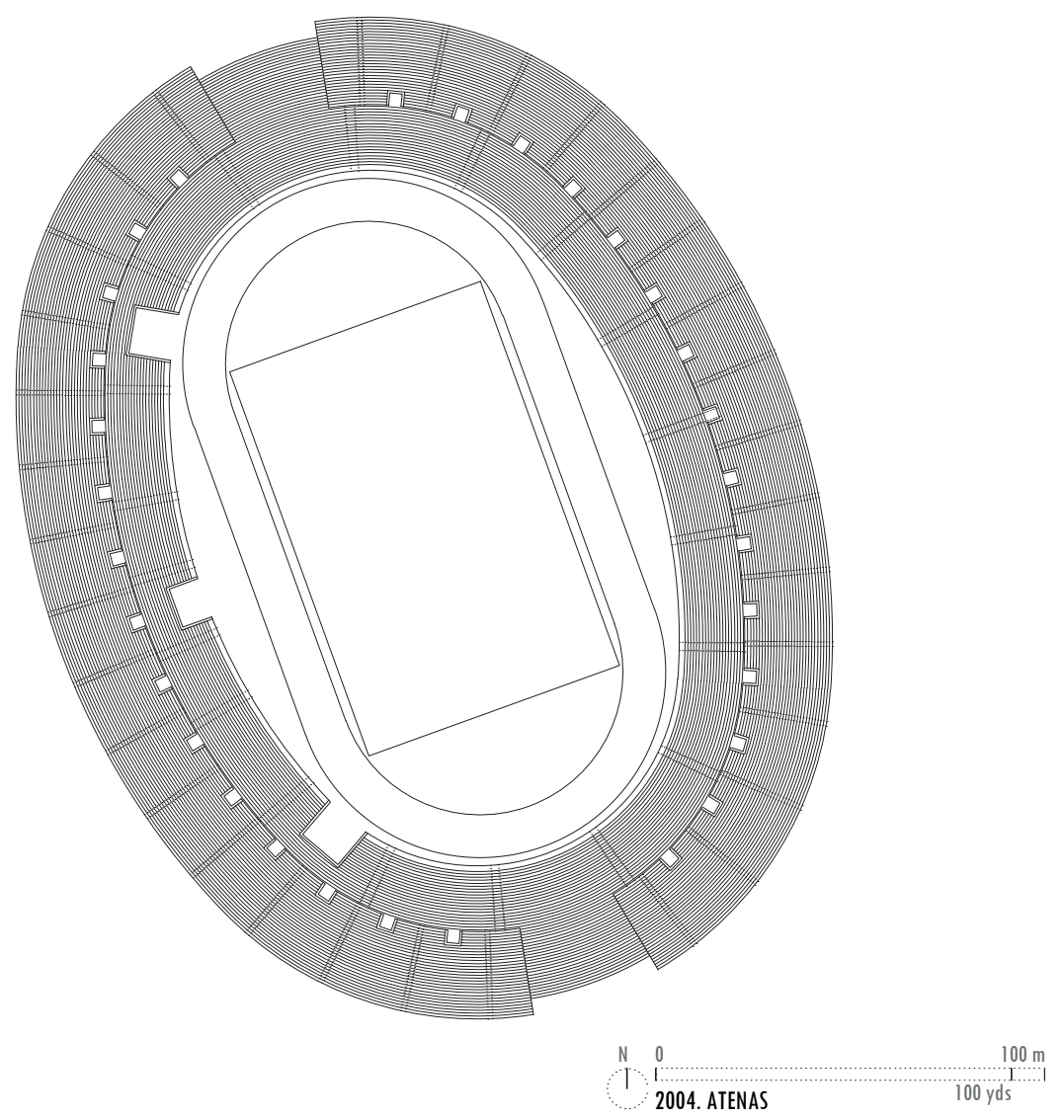

2004.0. Nombre del Estadio

Olympiako Stadio Athinas "Spyros Louis"

Estadio Olímpico de Atenas "Spyros Lovis", llamado así en honor al corredor griego ganador del oro olímpico en la maratón de las primeras Olimpiadas de la Era Moderna, en 1896.

2004.1. Situación

Leoforos Olimpionikou Spirou Loui, Marousi 151 23, Athinas, Grecia.

2004.2. Fechas

1979. Se inicia el proyecto para la construcción del Estadio Olímpico de Atenas. A cargo está el arquitecto Rudolf Moser en colaboración con la firma Weidleplan Consulting, H. Stalhout, F. Herre y D. Andrikopoulos.

1980. 7 de enero. Se coloca la primera piedra del Estadio "Spyros Louis"

1982. 6 al 9 de septiembre. Inauguración del Estadio con motivo del Campeonato Europeo de Atletismo.

1986. 14 de abril. El parlamento heleno decide presentar candidatura para los Juegos Olímpicos de 1996, la llamada "Olimpiada del Centenario", aunque finalmente la elegida es Atlanta.

1988. 29 de junio. Inauguración del complejo OAKA para las Instalaciones Olímpicas.

1991. 28 de junio al 12 de julio. Se celebran los Juegos Mediterráneos de 1991.

1996. 5 de enero. Es aceptada en Lausana la candidatura de Atenas como ciudad candidata para los Juegos de 2004. Las otras candidatas son Buenos Aires, Ciudad del Cabo, Estambul, Lille, Río de Janeiro, San Petesburgo, San Juan, Sevilla y Estocolmo.

1997. 1 de agosto al 10 de agosto. Campeonato mundial de Atletismo 1997. Último evento importante antes de la renovación del Estadio Olímpico.

1997. 5 de septiembre. Los miembros del $\mathrm{ClO}$ eligen a Atenas como ciudad anfitriona de los Juegos Olímpicos de 2004.

2002. Verano. Empiezan los trabajos de remodelación del Estadio. Fue un proceso de renovación global del ámbito confiado al arquitecto S. Calatrava.
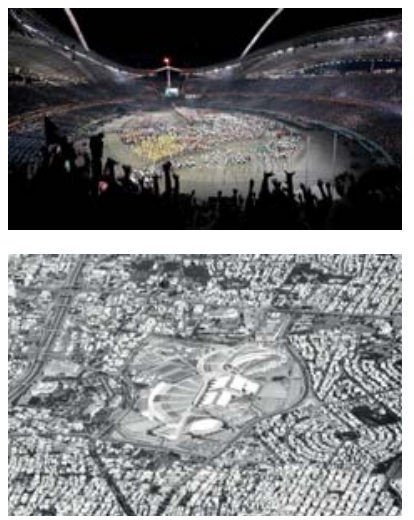

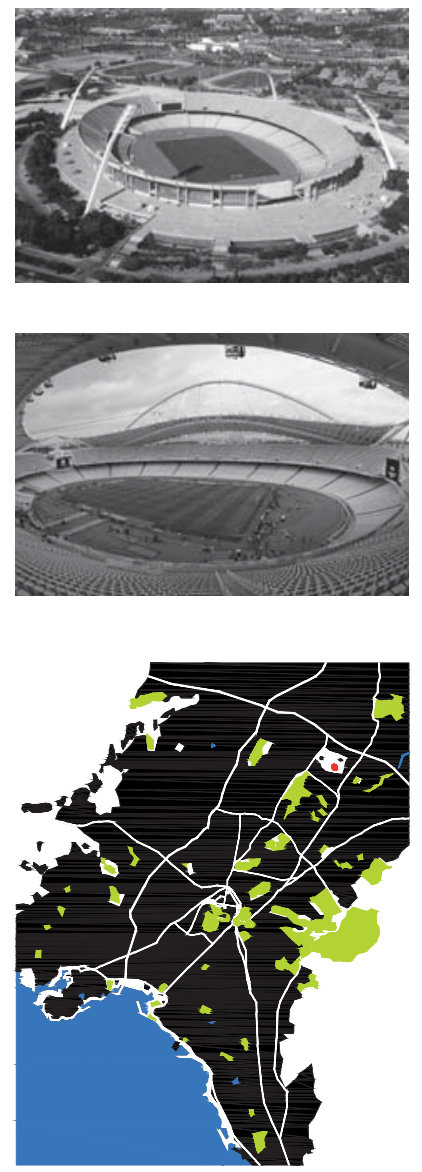

dimensiones y superficies aproximadas graderío

L $01-01 ' \quad 80,45 \mathrm{M}$

L $01-02 \quad 99,44 \mathrm{M}$

L 02-03 181,88 M

R 01-Al $\quad 51,58 \mathrm{M}$

R 02-A2 151,01 M

$<$ A1.01.A2 $\quad 132^{\circ}$

$<$ A2.02.A2 $^{\prime} \quad 48^{\circ}$
2004. 30 de julio. Fin de los trabajos de construcción del Estadio Olímpico e inauguración del mismo.

2004. Del 13 al 29 de agosto. Se celebran los Juegos Olímpicos de Atenas.

2004. 17 de septiembre al 28 de septiembre. Se celebran los Juegos Paralímpicos de Atenas 2004.

2007. Final de la Liga de Campeones de fútbol.

2004.3. Preexistencias en el lugar:

El lugar sobre el que se erige el Estadio Olímpico fue una vez parte de la antigua demo de Athmonon. Hacia el 576 a.c. tuvo lugar una reorganización política y Atenas fue dividida en diez partes, cada una correspondía a una tribu y abarcaba varios demos. El centro administrativo, religioso y residencial de la demo de Athmonon estaba en Pelikas, en una prominencia del terreno que actualmente se conoce como Maroussi. Los hallazgos arqueologicos demuestran que el lugar estuvo habitado desde la antigüedad hasta la era bizantina

En el momento de los primeros Juegos Olímpicos modernos (1896), Maroussi tenía una población de apenas 1.800 habitantes, pero el rendimiento individual de los competidores del distrito era verdaderamente asombroso: Spyros Louis ganó el maratón, seguido (en sexto y octavo lugar, respectivamente) por dos de sus paisanos, Papsymeon y Masouris. Inmediatamente después de los Juegos, se abrió en Maroussi uno de los centros de atletismo más antiguos del país.

2004.4. Relación con la ciudad. Posición respecto al centro urbano

La distancia entre el Estadio Olímpico de Atenas y el centro de la ciudad es aproximadamente de $11 \mathrm{~km}$ y hasta la Acrópolis, de $13 \mathrm{~km}$.

Las instalaciones deportivas están rodeadas principalmente por zonas residenciales con algún centro comercial. La distancia que las separa del estadio no es muy grande y por eso, en días de eventos musicales el nivel sonoro puede llegar a ser muy molesto.

Estación de metro "lrene» de la línea 1 está situada a menos de $800 \mathrm{~m}$. En autobús, la línea X 14 lleva al estadio desde la Plaza de Syntagma, en el centro de Atenas.
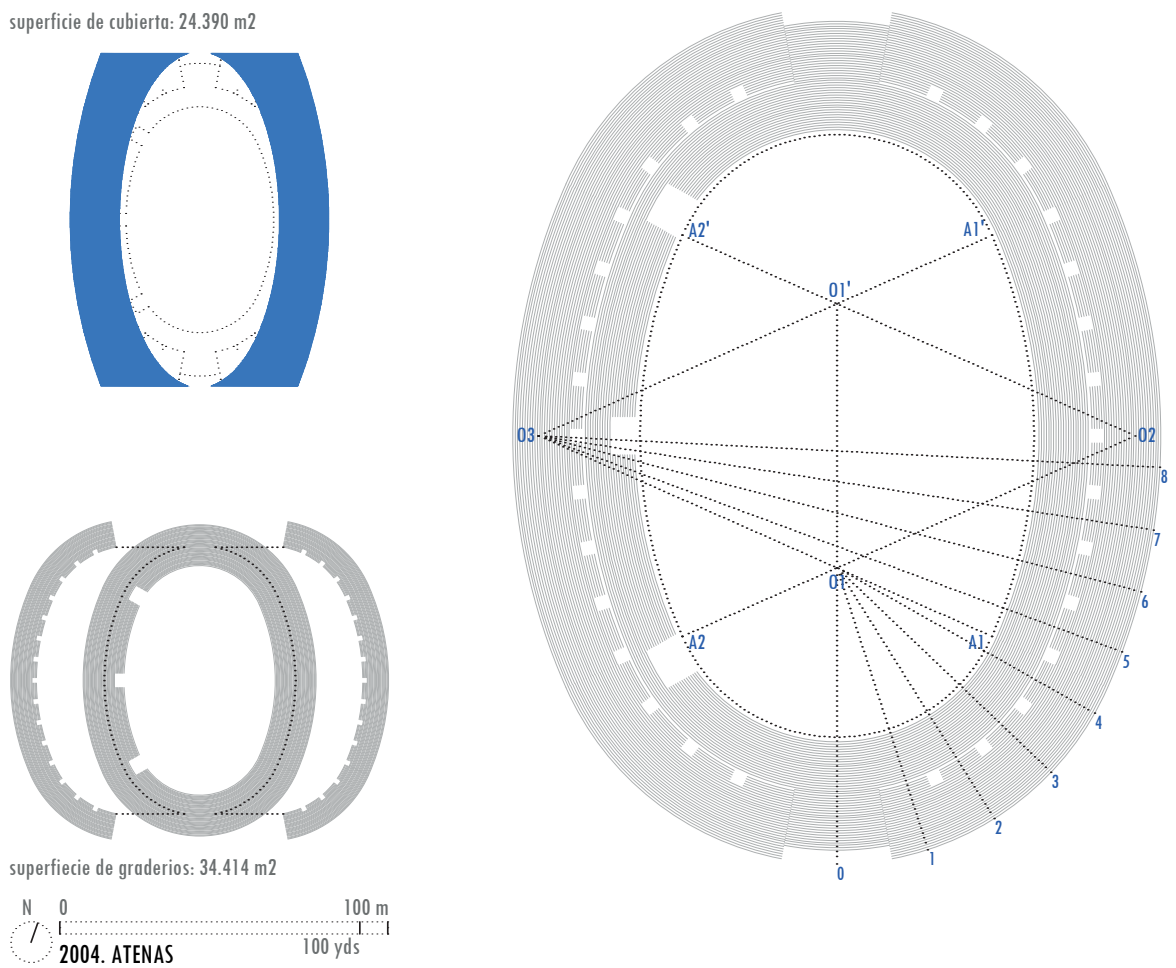

2004.5. Breve relato de la historia del Estadio:

El estadio había sido construido para los campeonatos de Europa de Atletismo del año 1982. Pero el sueño de que los Juegos Olímpicos volvieran al país y a la ciudad en que nacieron comenzó incluso antes de los años 80 . En 1976, y debido a los incidentes que habían venido sucediéndose (boicots, atentados, corrupción) Grecia se ofrece para organizar de forma permanente los Juegos, idea que no prosperó.

Cuando Atenas es designada para organizar los Juegos de la XXVIII Olimpiada el día 5 de septiembre de 1997, el estadio lleva ya construido 15 años, la decisión de reformar y 
mejorar el estadio se demora, finalmente el arquitecto Santiago Calatrava se ofrece y es designado para realizarlo, las obras comienzan a contrareloj en 2002

El elemento clave de la transformación consistió en la instalación de una cubierta formada por dos piezas simétricas.

\subsection{Descripción del Estadio; Graderío}

De geometría ovalada con dos niveles de graderías, aunque parecen casi continuos. Construido de forma modular mediante grandes prefabricados de hormigón.

El estadio tiene una capacidad máxima de 75.000 espectadores. Sin embargo, para las ceremonias olímpicas este número se redujo a 72.000 , y para las competiciones de atletismo bajó a los 56.700 espectadores.

Inicialmente sin ninguna cubierta, pero para los Juegos, además de las adaptaciones funcionales exigidas por el $\mathrm{ClO}$, Santiago Calatrava proyectó una cubierta de grandes dimensiones construida con vigas tubulares de acero pintado en blanco y paneles de policarbonato, formando dos semicubiertas simétricas suspendidas por sendos arcos paralelos, que siguen la forma en planta de las gradas superiores y un subsistema de costillas paralelas.

\subsection{Descripción del Estadio; Pista}

La pista de atletismo, ovalada, tiene una cuerda de 400 metros, con ocho calles de cuatro pies $(1,22 \mathrm{~m})$, cada una y un noveno carril en la recta de llegadas. Está realizada en una superficie sintética llamada Sportflex Super X Performance, de un rojo más oscuro que los habituales y con distinta formulación.

En el centro, se encuentra una gran área de césped natural, compuesto por especies de gramíneas en un substrato de arena, con hormigón en la base para drenar el agua de lluvia a través de dos canales laterales. En el momento de celebración de los Juegos, el campo estaba diseñado en módulos extraíbles separadamente, de manera que pudieran modificarse y reemplazarse por partes. No obstante, en 2010, se decidió cambiar este sistema modular por uno permanente, puesto que resultó muy complicado en varios conciertos. Se puede marcar en su interior un campo de fútbol de $105 \times 68 \mathrm{~m}$.

Cuenta con 4 fosos para el salto con pértiga, 4 círculos para lanzamiento de peso, 2 carriles para lanzamiento de jabalina, 2 círculos con redes de seguridad para lanzamientos de disco y martillo, 6 fosos para salto de longitud y triple salto, 2 colchones para salto de altura y 2 tableros electrónicos.
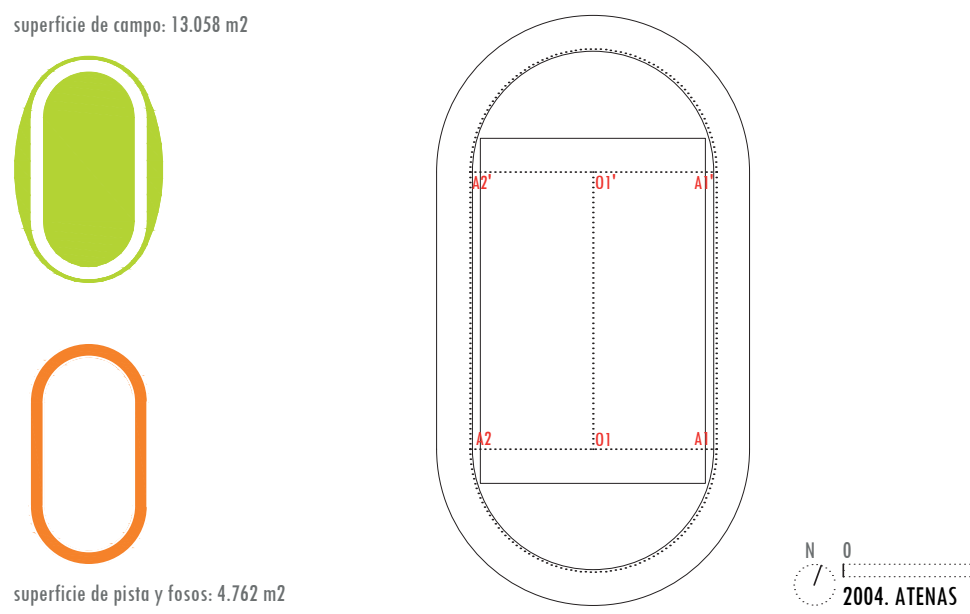

Programa Deportivo:

Atletismo, final de Fútbol y las Ceremonias de Apertura y Clausura de los Juegos.

\subsection{Elementos significantes}

El pebetero, que es una aguja situada en el eje longitudinal del estadio en la proximidad de la confluencia de las dos semicubiertas, inicialmente se planteo con una altura descomunal de 110 metros, aunque finalmente se realizó con una dimensión más modesta.

\subsection{Avances técnicos}

A partir de estos Juegos, el cronometraje oficial se encargaría de toda la información que se emitiera dentro de los estadios, de las sobreimpresiones de TV y de la transmisión de resultados al sistema de información a comentaristas (CIS).

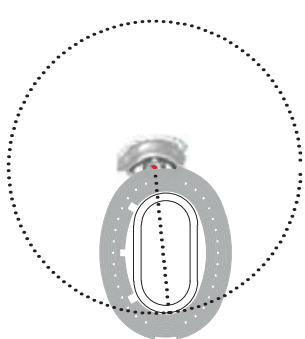

$219 \mathrm{~m}$

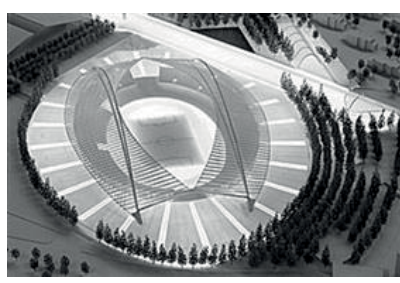

marca del ganador

Hombres Mujeres

$200 \mathrm{~m}$

$400 \mathrm{~m}$.

$800 \mathrm{~m}$.

$1500 \mathrm{~m}$.

$5.000 \mathrm{~m}$

$10.000 \mathrm{~m}$.

$110 / 100$ m.v.

400 m.v.

$3.000 \mathrm{~m}$ obst

Altura

Pértiga

Longitud

Triple

Peso

Disco

Martillo

Jabalina

$4 \times 100 \mathrm{~m}$

$4 \times 400 \mathrm{~m}$

9"85

9785
$19 " 79$

$44 " 00$

l'44"45

3'34"18

13'14"39

$27 \times 05 " 10$

$12 " 91$

$47 " 63$

8'05"81

2,36 m

$5,95 \mathrm{~m}$

$8,59 \mathrm{~m}$

$17,79 \mathrm{~m}$

$21,16 \mathrm{~m}$

$69,89 \mathrm{~m}$

$82,91 \mathrm{~m}$

$86,50 \mathrm{~m}$

38 "07

2'55"91

$20 \mathrm{~km}$ marcha

$10 \mathrm{~km}$ marcha

$50 \mathrm{~km}$ marcha

Ih 19' 40

Maratón

3h $38^{\prime} 46$

2h10' 55

$2 \mathrm{~h} 26^{\prime} 20 "$

dimensiones y superficies aproximadas pista

CUERDA I $400,00 \mathrm{M} \quad 437 \mathrm{yds} \quad \mathrm{I}^{\prime} 4 \frac{1}{32} "$

L $01-01^{\prime} \quad 84,31 \mathrm{M}$

ROI-Al 37,53 M

$<$ A1.01.A2 $\quad 180^{\circ}$

$2,06 \mathrm{~m}$

$4,91 \mathrm{~m}$

$17,33 \mathrm{~m}$

$19,59 \mathrm{~m}$

$67,02 \mathrm{~m}$

$75,02 \mathrm{~m}$

$71,53 \mathrm{~m}$

$41 " 73$

3'19"01

Ih 29'12"

$49 " 41$

$57 " 90$

$24 " 36$

$2 " 37$

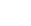

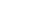




\subsection{Autores. Tipo de encargo}

Weidleplan Consulting Arquitectura. Los arquitectos que figuran como responsables del proyecto dentro de la empresa son R. Moser, H. Stalhout, F. Herre y D. Andrikopoulos. Weidleplan Consulting es una empresa internacional de arquitectura y Project Management con sede en Stuttgart (Alemania), proyecto suyo es el estadio Jaber Al-Ahmad en Kuwait.

Santiago Calatrava (1951), arquitecto español especializado en grandes infraestructuras, entre sus numerosos proyectos destacan: la Estación de Stadelhofen (en 1983, su primera obra importante), el puente Lusitania de Mérida (1991), el Auditorio de Tenerife (2003) o la Ciudad de las Artes y las Ciencias de Valencia (2005).

\section{Tipo de encargo}

En 1979 se encargó a la firma Weidleplan Consulting la construcción del denominado Estadio Olímpico que serviría para acoger el Campeonato Europeo de Atletismo del año 1982 En 2002 el comité Organizador de los Juegos Olímpicos de Atenas y el Ministerio de Cultura encargaron a Santiago Calatrava su renovación

\subsection{Edificios coetáneos}

El edificio Fórum, en Barcelona. Jacques Herzog y Pierre de Meuron.

Edificio del Parlamento de Escocia. Enric Miralles.

Teatro de la Ópera de Copenhague. Henning Larsen.

\subsection{Hechos históricos relevantes}

El 3 de febrero, en Nueva York, la ONU anuncia la urgente necesidad de regular la explotación comercial de la Antártida.

El 4 de febrero, en la Universidad de Harvard, Mark Zuckerberg funda Facebook, por aquel entonces llamado Thefacebook, como un proyecto universitario.

Bibliografía Atenas 2004:

SKARVELI, E y ZERVOS, I.- Official Report of the XXVIII Olympiad. Volume I (2005) ISBN: 960-88101-7-5 SKARVELI, E y ZERVOS, I.- Official Report of the XXVIII Olympiad. Volume II (2005) ISBN:960-88101-8-3 PEDERSEN, P.M. y THIBAULT, L.- Contemporary Sport Management. 2014. ISBN: 978-1-4504-6965-4 DARLING, J.K.- Architecture of Greece. 2004. ISBN: 0-313-32152-3

KISER, K.- Santiago Calatrava: The Architect Studio. Arvinius Forlag, 2014.

http://www.atenas.net

http://e-ache.com

http://www.stadia.gr/OAKA 


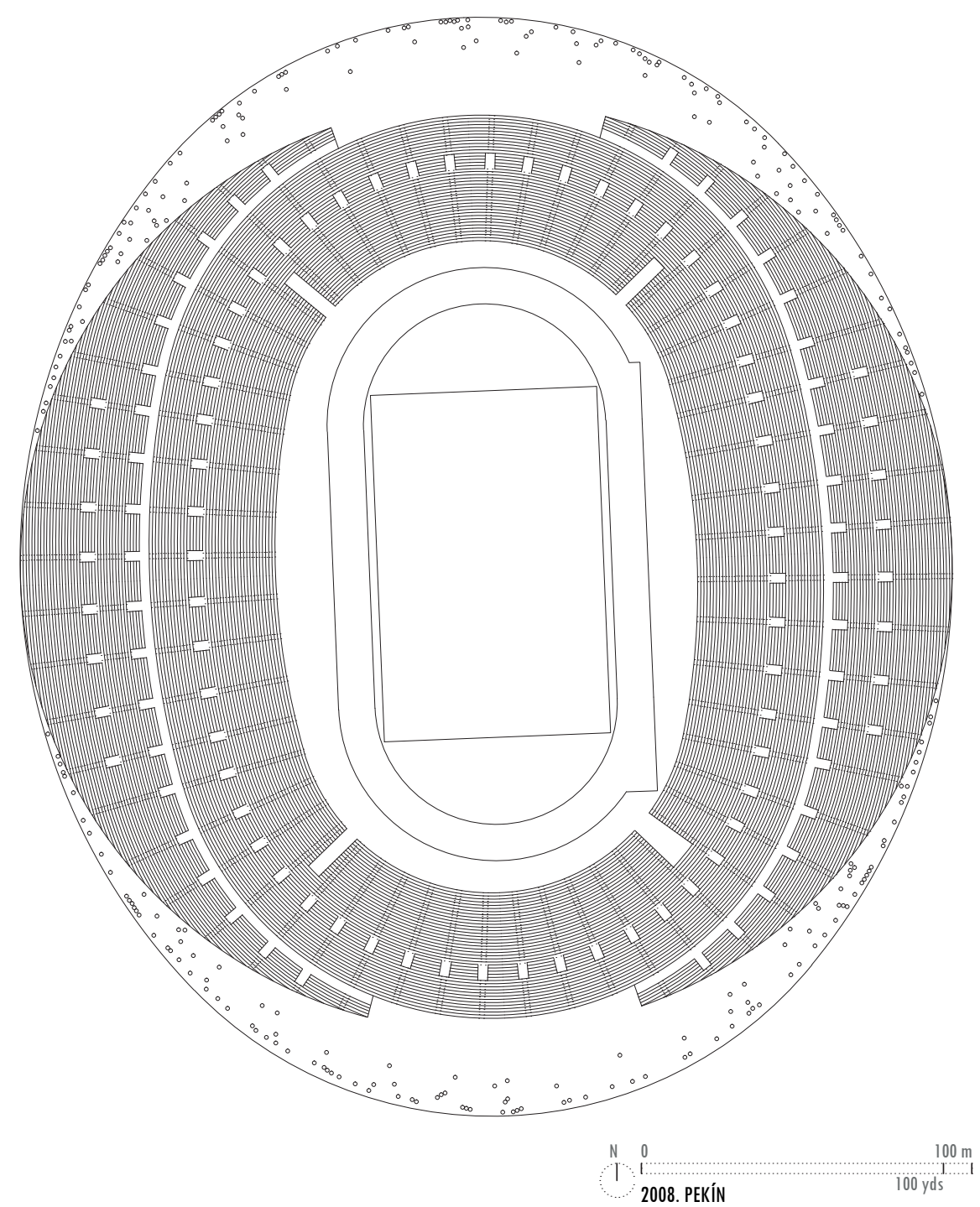

2008.0. Nombre del Estadio

Estadio Nacional de Pekín

2008.1. Situación

1 National Stadium S Rd, Chaoyang, Pekín, China

2008.2. Fechas

2000. El 28 de agosto, Pekín presenta su candidatura a la celebración de los Juegos Olímpicos de 2008.

2001. El 13 de julio, en Moscú, la ciudad de Pekín resulta elegida para la celebración de las XXIX Juegos Olímpicos.

2003. El 24 de diciembre, comienza la construcción del Estadio.

2004. En julio, el proyecto es detenido temporalmente para realizar unas modificaciones.

2004. El 27 de diciembre, se retoma la construcción del estadio.

2008. 18 de abril. Inauguración del Estadio.

2008. El 8 de agosto, se celebra la ceremonia de inauguración de los Juegos.

2008. El 24 de agosto, se celebra la ceremonia de clausura de los Juegos.

2009. El 8 de agosto, fecha del primer aniversario de la inauguración de los juegos, se represente la ópera Turandot, de Puccini.

2009. En agosto se juega la supercopa de la liga italiana. También nl el mismo mes del 2011 y 2012.

2015. Del 22 al 30 de agosto. Campeonatos Mundiales de Atletismo. 

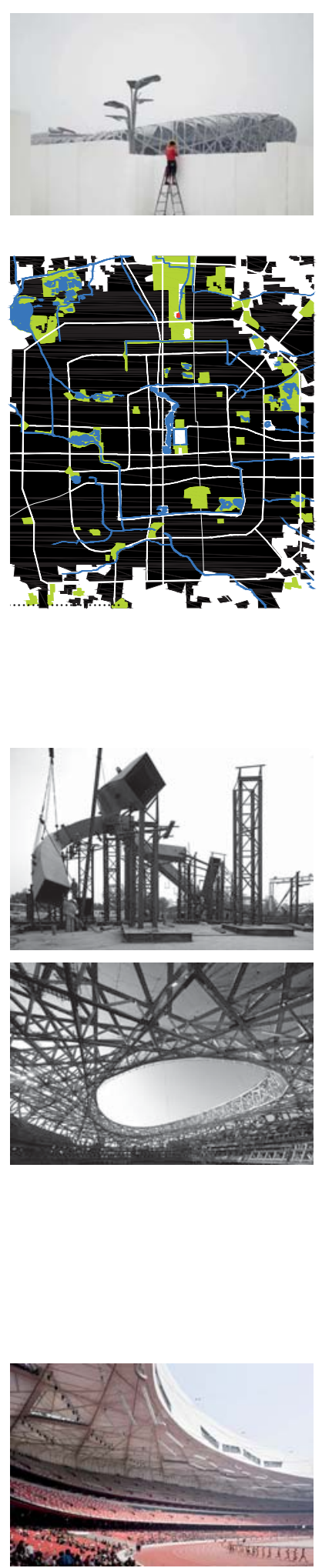

2008.3. Preexistencias en el lugar

Terreno prácticamente plano de uso agrícola, con alguna vivienda dispersa y que colindaba con un parque público.

Usualmente un edificio se construye de modo que intervenga y se relacione con un contexto preexistente, en el caso del Estadio Nacional de Pekín sucedió totalmente al contrario, en este caso se diseñó y construyó el contexto para que sirviera de apoyo urbanístico a la construcción.

Requirió el desarrollo completo de las infraestructuras urbanas necesarias, tres amplias carreteras nuevas y una enorme estación de metro, así como todas las conexiones necesarias para vincular las anteriores con las infraestructuras preexistentes y, a través de ellas, con la propia ciudad. En las zonas colindantes al parque Olímpico se construyeron grandes edificios comerciales.

\subsection{Relación con la ciudad. Posición respecto al centro urbano}

El Estadio está situado a $9 \mathrm{~km}$. al norte del centro de la ciudad y a $20 \mathrm{~km}$. del aeropuerto de Pekín.

Existen numerosas líneas de autobús que lo unen con el centro de la ciudad y la línea 8 del metro (estación Centro Olímpico).

\subsection{Breve relato de la historia del Estadio:}

El acelerado desarrollo económico de la República Popular China desde fines del siglo XX fue uno de los principales factores que decidieron la elección de Pekín como sede de los Juegos Olímpicos. Pekín se postuló por primera vez en 1993, con el fin de celebrar los Juegos Olímpicos de 2000. Resultando derrotado por Sydney por tan solo dos votos de diferencia. Volviendo a presentar candidatura para los Juegos del 2008, siendo designada en 2001. Pekín no contaba con el estadio capaz para celebrar los Juegos Olímpicos, el llamado "Estadio de los Trabajadores"l era una instalación obsoleta, por ello, en ese mismo año se realizó el concurso internacional para el diseño del futuro Estadio Nacional. El concurso fue ganado por los arquitectos suizos Jacques Herzog y Pierre de Meuron.

En abril del 2003 el Comité Olímpico Chino acepto el proyecto y el 24 de diciembre de ese mismo año se iniciaron los trabajos de construcción del nuevo estadio con la adaptación del terreno y la instalación de los cimientos, aunque los principales trabajos de construcción no comenzaron hasta el mes de marzo de 2004.

Las obras de construcción se detuvieron en agosto de ese año a causa de la percepción del alto coste de la edificación. Se sugirió a los arquitectos e ingenieros que quizá se pudiera cambiar el diseño para ahorrar costos y poder finalizar la construcción a tiempo. En el nuevo diseño fundamentalmente se prescindió de la cubierta practicable.

Se reanudaron las obras a principios de 2005. El estadio fue inaugurado el 18 de abril de 2008. La inversión en el estadio fue de 4 mil millones de yuans (USD $\$ 500$ millones) (338 millones de euros)

El estadio se inspira en un cuenco de la dinastía china Shang, se concibe como un objeto de arte, un recipiente de hormigón de forma casi circular en torno al que se alza un complejo entramado de perfiles estructurales.

La imagen del estadio es puramente estructural, fachada y estructura son una misma cosa.

\subsection{Descripción del Estadio; Graderío}

El estadio está constituido por un "cuenco" de hormigón armado, en cuya pared interna se sitúan las gradas y desde cuyo borde superior, hacia el exterior, se despliega un trenzado de elementos longitudinales de acero que sirve de fachada y de estructura para la cubierta, siendo independientes de la estructura del graderío.

El graderío esta dividido en tres niveles el inferior encajado en el terreno, por su borde superior se produce el acceso y los dos superiores son de carácter tectónico, estos cuentan con ocho niveles de accesos.

El tamaño de la planta elíptica viene dictado por la necesidad de alojar a 100.000 espectadores alrededor de la pista de atletismo y el campo de juego. De la misma forma, la diferencia de altura de las gradas situadas en los ejes principales de la elipse, permite, mayor proximidad del público al espectáculo.

El sólido capaz que abarca el Estadio tiene unas dimensiones aproximadas de $333 \mathrm{~m}$. de largo por $284 \mathrm{~m}$. de ancho por $69 \mathrm{~m}$. de altura. El Estadio ocupa en planta una superficie de 21,4 has. y tiene una superficie construida de $258.000 \mathrm{~m} 2$. y se le prevé una vida útil de unos 100 años.

El proyecto original contemplaba una capacidad de 100.000 espectadores. Esta capacidad 
se redujo a 91.000 al simplificar el diseño y al término de los Juegos se redujo aún más al retirarse, de forma reversible, 11.000 butacas, por lo que la cifra actual de espectadores es de 80.000 .
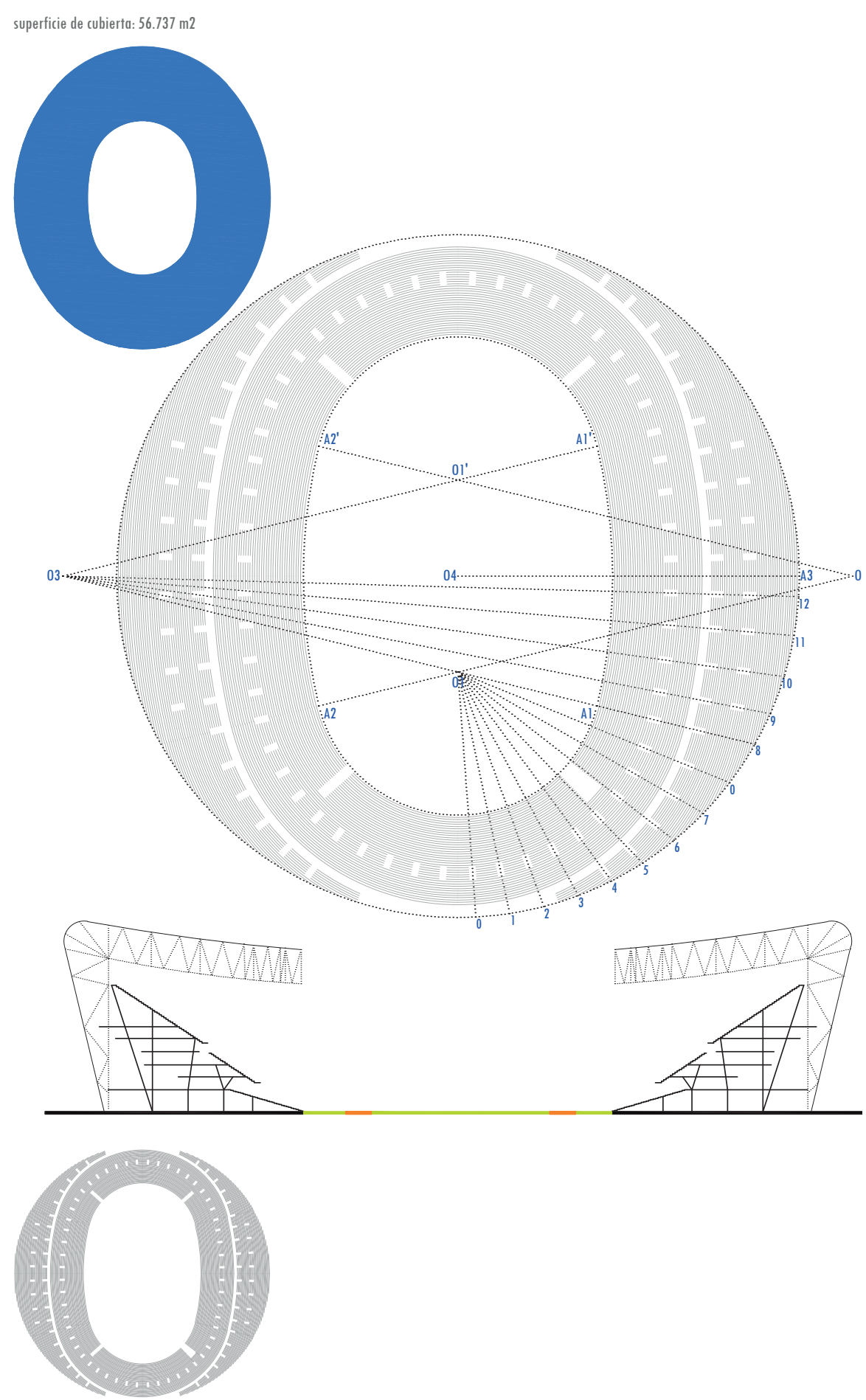

superfiecie de graderios: $40.325 \mathrm{~m} 2$

$$
\begin{array}{lll}
N & 0 & 100 \mathrm{~m} \\
1 & 100 \mathrm{yds}
\end{array}
$$

La geometría de los elementos de fachada, aparentemente colocados al azar, viene definida por las limitaciones geométricas dictadas por la capacidad portante de la propia estructura. La cubierta está formada por una membrana de doble capa, una en la parte superior de la estructura compuesta por un ETFE (etileno tetrafluoroetileno) transparente y otra en su parte inferior cubierta por PTFE (politetrafluoroetileno) translúcido, membrana acústica que refleja

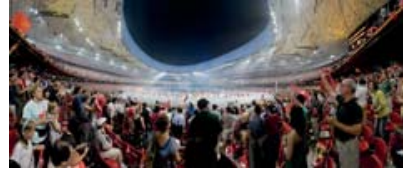

dimensiones y superficies aproximadas graderío

$\begin{array}{lr}\text { L 01-01' } & 79,30 \mathrm{M} \\ \text { L 01-02 } & 167,84 \mathrm{M} \\ \text { L 01-04 } & 39,65 \mathrm{M} \\ \text { L 02-04 } & 163,09 \mathrm{M} \\ \text { R 01-A1 } & 59,12 \mathrm{M} \\ \text { R 02-A2 } & 226,96 \mathrm{M} \\ \text { R 04-A3 } & 141,72 \mathrm{M} \\ \text { < A1.01.A2 } & 153^{\circ} \\ \text { < A2.02.A2 } & 27^{\circ}\end{array}$

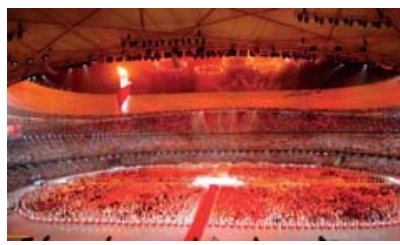




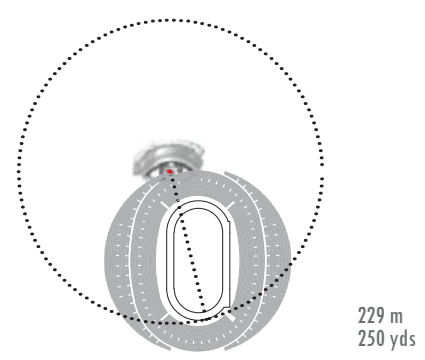

marca del ganador

$\begin{array}{lrr} & \text { Hombres } & \text { Mujeres } \\ 100 \mathrm{~m} . & 9 " 69 & 10 " 78 \\ 200 \mathrm{~m} & 19 " 30 & 21 " 74 \\ 400 \mathrm{~m} . & 43 " 75 & 49 " 62 \\ 800 \mathrm{~m} . & 1,44 " 65 & 1,54 " 87 \\ 1.500 \mathrm{~m} . & 3,33 " 11 & 4,00 " 23 \\ 5.000 \mathrm{~m} & 12,57 " 82 & 15,41 " 40 \\ 10.000 \mathrm{~m} . & 27,01 " 17 & 29,54 " 66 \\ 110 / 100 \mathrm{mv} & 12 " 93 & 12 " 54 \\ 400 \mathrm{mv} & 47 " 25 & 52 " 64 \\ 3.000 \mathrm{obst} & 8,10 " 34 & 8,58 " 81 \\ \text { Altura } & 2,36 \mathrm{~m} & 2,05 \mathrm{~m} \\ \text { Pértiga } & 5,96 \mathrm{~m} & 5,05 \mathrm{~m} \\ \text { Longitud } & 8,34 \mathrm{~m} & 7,04 \mathrm{~m} \\ \text { Triple } & 17,67 \mathrm{~m} & 15,39 \mathrm{~m} \\ \text { Peso } & 21,51 \mathrm{~m} & 20,56 \mathrm{~m} \\ \text { Disco } & 68,82 \mathrm{~m} & 64,74 \mathrm{~m} \\ \text { Martillo } & 82,02 \mathrm{~m} & 76,34 \mathrm{~m} \\ \text { Jabalina } & 90,57 \mathrm{~m} & 71,42 \mathrm{~m} \\ \text { 4 X 100 } & 37 " 10 & 42 " 31 \\ \text { 4 X 400 } & 2,55 " 39 & 3,18 " 54 \\ \text { 20km marcha } & 1 \mathrm{~h} 19: 01 & 1 \mathrm{~h} .26: 31 \\ \text { 50km marcha } & 3 \mathrm{~h} 37: 09 & \\ \text { Decathlón } & 8.527 \mathrm{ptos} & \\ \text { Heptathlón } & & 6.733 \mathrm{ptos} \\ \text { Marathón } & 2 \mathrm{~h} .06: 32 & 2 \mathrm{~h} .26: 44\end{array}$

dimensiones y superficies aproximadas pista

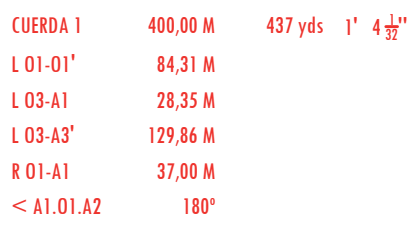

el sonido, colaborando a mantener la atmósfera entusiasta del estadio, a la vez que oculta la estructura, evitando que robe protagonismo al espectáculo.

Debido a su irregular envolvente que deja huecos a lo largo de todo el perímetro, no existen accesos definidos al edificio, permitiendo al usuario entrar por donde más le convenga. Las circulaciones están organizadas de tal manera que no se tenga que recorrer grandes distancias para ir a los servicios públicos o los puestos de comida, desde los asientos. La circulación es perimetral, siguiendo la forma del estadio mismo. Podemos localizar pasillos, escaleras, rampas y ascensores en todo su perímetro interior para facilitar el acceso a las localidades desde cualquier lugar. En el interior del estadio, los peatones transitaran en un entramado de sendas, de textura lisa, entre la fachada exterior trenzada y el trasdós de las gradas permitiendo la observación del entorno. Ahí se encuentran restaurantes, bares, tiendas, etc.

Por el subsuelo se producen las circulaciones de carácter restringido.

\subsection{Descripción del Estadio; Pista:}

Dimensiones: Cuerda de la pista de 400 metros y nueve calles de 4 pies de ancho $(1,22 \mathrm{~m}$.) y un ancho total de 36 pies $(10,98 \mathrm{~m}$.). Orientación norte-sur. La recta este se alarga 169 pies $(51,51 \mathrm{~m}$.) para alcanzar una longitud total de 142 yardas $(129,85 \mathrm{~m}$.). Espacio libre interior de 115 yardas $(105,16 \mathrm{~m}$.) de largo por 76 yardas $(69,49 \mathrm{~m}$.) de ancho en el que se puede marcar un campo de fútbol.

La pista de atletismo, homologada como clase 1 IAAF, esta realizada en un pavimento sintético prefabricado de última generación, calandrado y vulcanizado de espesor constante compuesto de goma polisoprénica estabilizada, cargas minerales, vulcanizantes, estabilizantes y pigmentos colorantes. Conformado por dos estratos con diferentes características biomecánicas vulcanizadas entre si en caliente constituyendo un solo pavimento homogéneo. La superficie tiene una impresión pigmentada específica, antideslizante, que se realiza en el propio proceso de producción, confiriendo mayor superficie de apoyo al atleta y por lo tanto estabilidad y seguridad en la pisada. Facilita su limpieza, evacuación de aguas y adherencia del calzado deportivo.

El estrato inferior dispone de una estructura de celdas hexagonales inclinadas que le confieren una especial elasticidad que facilita y acelera el gesto atlético, especialmente el movimiento de rotación entre el quinto y primer metatarso del apoyo del pie, así como aumentando la reacción (devolución de energía) y elasticidad (comodidad) logrando minorizar el tiempo de apoyo del pie del atleta sobre la superficie en cada zancada.

En cuanto al tipo de césped empleado se sabe que fue producido en China por la empresa Baremburg y que es una mezcla de varios tipos de césped pero la composición exacta se mantiene en secreto. Es desmontable, forma un mosaico de más de 6.000 módulos cuadrados de polietileno de $4 \times 4$ pies y 1 pie de espesor. compuestos de gravas y arenas para el drenaje y sobre ellas una capa de mantillo. Un módulo completo, incluyendo la hierba, pesa más de media tonelada. Permitió su cultivo fuera del estadio y su montaje después de la ceremonia de apertura en tan solo 24 horas, quedando listo para las competiciones
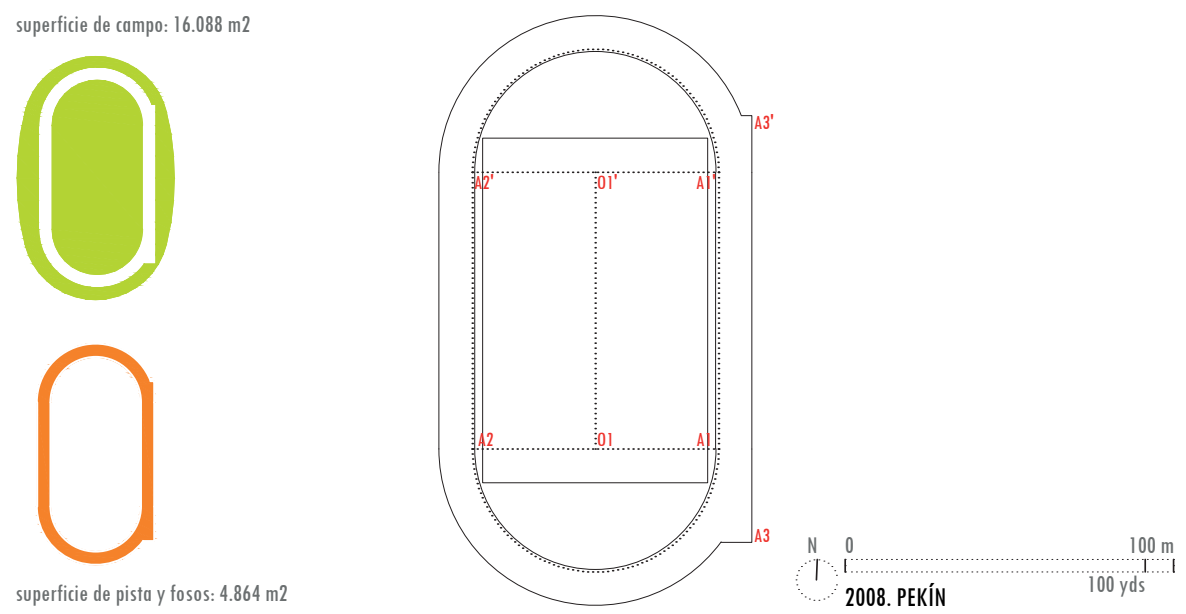

Programa Deportivo: Atletismo, la final del torneo de Fútbol y las Ceremonias de Apertura y Clausura de los Juegos.

2008.8. Elementos significantes 


\subsection{Autores. Tipo de encargo}

Jacques Herzog y Pierre de Meuron, arquitectos. Colaborador artístico Ai Weiwei. Jacques Herzog (1950) y Pierre de Meuron (1950) nacieron los dos en Basilea, Suiza. Arquitectos por el Politécnico de Zurich, en 1975. En sus primeros trabajos, tales como la Casa Azul, la Casa de Piedra o el Almacén Ricola, tomaron como punto de partida la construcción tradicional y los materiales cotidianos pero reinterpretándolos para que adquiriesen un nuevo significado. El resultado fueron unos edificios formalmente severos y de aspecto minimalista en los que el elemento más innovador se manifestaba sobre todo en el exterior, en la "piel" del edificio. A fines de los años ochenta, gracias al favorable eco que habían tenido los primeros proyectos, el estudio empezó a recibir encargos de mayor envergadura. Entre éstos cabría destacar la construcción de un parque de locomotoras y una torre de control (Basilea, 1989-1994) para la compañía suiza del ferrocarril, o el nuevo centro de producción y almacenamiento de la empresa Ricola en Mulhouse (Alsacia, 19931994).

Este último proyecto supuso una síntesis de las experiencias formales y materiales acaparadas hasta la fecha. Aunque por su volumen dicho edificio se asemejaba al Almacén Ricola de Laufen, formalmente se distinguía de éste al presentar sendos voladizos en dos de sus fachadas además del recubrimiento de las mismas con paneles de policarbonato serigrafiado con motivos vegetales.

Una solución parecida, aunque mucho más audaz, se aplicaría en la Biblioteca de la Escuela Técnica de Eberswalde (Alemania, 1994-1999), donde se revistieron por entero los cuatro costados del edificio con placas de hormigón estampadas con técnicas de impresión fotográfica. Los motivos para las serigrafías fueron encargados al conocido artista alemán Thomas Ruff, quien los escogió de entre su colección de revistas ilustradas.

Continuaron con la ambiciosa propuesta para la Tate Modern (Londres, 19942000). Interviniendo en la antigua central eléctrica levantada por Giles Gilbert Scott.

En mayo de 2001, reciben el Premio Pritzker de Arquitectura.

En los últimos años, el estudio Herzog \& De Meuron ha realizado proyectos en los principales países del mundo, entre ellos España, donde en Santa Cruz de Tenerife ha diseñado el muelle del puerto y la Fundación Óscar Domínguez. En Barcelona ha levantado el emblemático Edificio Forum, un enorme triángulo equilátero de 160 metros de lado por sólo 25 de altura y recubierto de material translúcido, de color azul añil que dispone de un gran auditorio subterráneo y de una amplia sala de exposiciones. En Madrid la nueva sede de exposiciones de la Fundación La Caixa. . Ai Weiwei, (1957), nacido en Beijing, es un activista y artista contemporáneo. El arte visual de Ai Weiwei incluye instalaciones escultóricas, carpintería, vídeo y fotografía. Su uúltima gran retrospectiva de 2013 "Ai Weiwei: According to What" es una adaptación y ampliación del Museo Hirshhorn de Washington a partir de una exposición de 2009 en el Museo de Arte de Tokio Mori. Posteriormente viajó a Brooklyn Museum, Nueva York y otros lugares.

Trabajos más recientes abordan su investigación sobre las secuelas del terremoto de Sichuan y las respuestas a su detención por parte del gobierno chino.

Como activista, ha criticado constantemente al gobierno chino por su postura respecto a la democracia y los derechos humanos. También ha investigado corrupción gubernamental y encubrimientos en China, particularmente el caso del derrumbe de escuelas en Sichuan tras el terremoto de 2008. El 3 de abril de 2011 fue detenido en el aeropuerto internacional de Pekín, estuvo bajo arresto durante 81 días sin cargos oficiales.

Tipo de encargo.

En 2002, la Comisión para la Planificación Municipal de Pekín celebró un concurso internacional del que formaron parte del jurado Koolhaas, Nouvel y Perrault, entre otros.

\subsection{Edificios coetáneos}

Se termina la construcción de la Torre Porta Fira, obra del arquitecto japonés Toyo Ito, en Barcelona.

En Madrid, la Caja Mágica de Dominique Perrault y los Teatros del Canal de Juan Navarro Baldeweg.

Se concede a Jean Nouvel el Premio Pritzker del 2008.

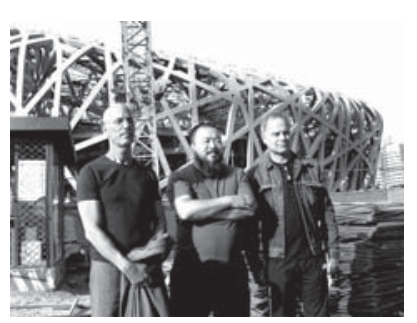


2008.12. Hechos históricos relevantes

El 10 de septiembre, en el Laboratorio Europeo de Física de Partículas del CERN (Suiza) se lleva a cabo uno de los mayores experimentos hasta el momento cuando el acelerador de partículas entra en funcionamiento y el primer haz de protones recorre 27 kilómetros para tratar de simular el "big bang" a muy pequeña escala.

El 4 de noviembre se elige en Estados Unidos a Barack Obama como presidente, convirtiéndose en el primer ciudadano afroamericano que ocupa la Casa Blanca.

Bibliografía Pekín 2008:

Official Report of the Beijing 2008 Olympic Games. 2008. ISBN 978-7-5644-0263-1

Arquitectura Viva. $n^{\circ} 118-119$. Pekín Olímpico. pág. 82/101 


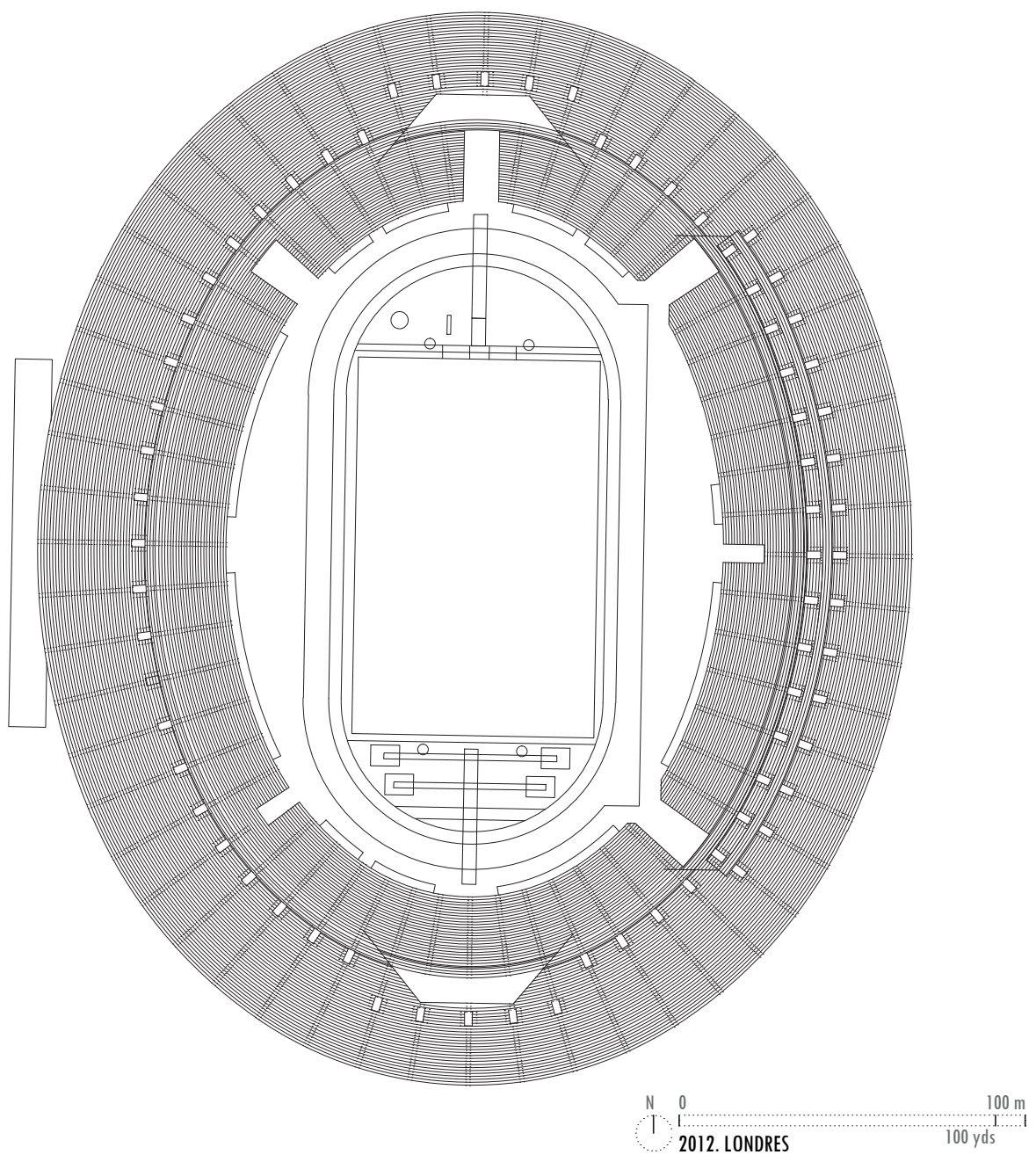

2012.0. Nombre del Estadio

London Olympic Stadium

2012.1. Situación

Elizabeth Olympic Park, London E20 2ST, Reino Unido

\subsection{Fechas}

2004. Se define la extensión, forma y localización (siempre en las cercanías de la ciudad de Stratford, lugar en que se construirá el estadio) del futuro Parque Olímpico de Londres.

2005. El 6 de julio, en la reunión celebrada por el Comité Olímpico Internacional en Singapur, Londres es designada ciudad sede de los Juegos Olímpicos y Paralímpicos de 2012. Casi inmediatamente comienzan los primeros trámites de compra del terreno, expropiaciones, negociaciones...

2008. En febrero se reúne la junta olímpica para dar solución al problema del "doble uso" previsto para el estadio, por el cual sería necesario reducir su capacidad de 80.000 a 25.000 espectadores después de los Juegos.

2008. En mayo, se inicia la construcción del estadio.

2010. Se crea la Olympic Park Legacy Company para el control del desarrollo que tendrá el lugar después de los Juegos.

2012. El 2 de abril la London Legacy Development Corporation para asumir las responsabilidades de la Olympic Park Legacy Company .

2012. Entre el 27 de julio y el 12 de agosto se celebran los oficialmente conocidos como Juegos de la XXX Olimpiada, los cuales son seguidos por cuatro mil millones de espectadores en todo el mundo. 


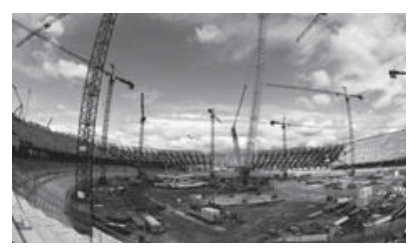

2013. El 29 de mayo el London Legacy Development Corporation da luz verde a los planes de transformación del estadio.

2013. El 24 de abril la National Lottery Anniversary Run se convirtió en el primer acto público celebrado en el estadio después de los Juegos.

2013. El 23 de julio se firma un acuerdo a cincuenta años entre el Estadio Olímpico y el UK Athletics (órgano de gobierno para el deporte del atletismo en el Reino Unido) para uso del estadio en las competiciones de atletismo.

2013. El 25 de julio se adjudica el contrato a Balfour Beatty Group Limited para llevar a cabo los trabajos de la cubierta.

2013. El 13 de agosto comienzan las primeras obras de remodelación del estadio.

2014. El 6 de enero Balfour Beatty Group Limited es designado como principal contratista para llevar a cabo las obras de remodelación del estadio.

2014. En junio el Lee Valley Hockey and Tennis Centre abre sus puertas al público.

2014. El 18 de septiembre se instalan las primeras cámaras tipo timelapse en el estadio.

2014. A finales de año abre el nuevo canal del Parque Olímpico.

2015. En febrero se nombra a la compañía francesa VINCl operadora del estadio.

2015. El 17 de febrero se instala la primera de las catorce nuevas torres de iluminación.

2015. Para el 19 de junio el coste total de la transformación del estadio ascenderá a doscientos setenta y dos millones de libras.

2015. En verano el estadio se reabre para una serie de eventos incluyendo competiciones de atletismo y deportes de motor, los partidos de la quinta Rugby World Cup antes de cerrar por última vez para la fase final de su transformación.

2016. En agosto el estadio reabrirá sus puerta definitivamente como el nuevo centro nacional de atletismo del Reino Unido y hogar del West Ham United Football Club.

\subsection{Preexistencias en el lugar}

La construcción del estadio Olímpico de Londres ha supuesto una de las mayores regeneraciones urbanas que la capital inglesa ha sufrido en los últimos años. Tanto esta megaconstrucción como el Parque Olímpico en el que se inserta, han transformado completamente el barrio de Stratford, cuya actual fisonomía poco tiene que ver con la del suburbio industrial que empezó a crecer en la segunda mitad del siglo XIX (gracias a la llegada del ferrocarril en 1839) y que hasta entonces había estado ocupado por grandes extensiones agrarias pertenecientes al condado de Essex. La ciudad fue aumentando su población y expandiéndose significativamente, llegando a convertirse en 1886 en el centro de la administración del distrito de West Ham y formando parte del Gran Londres desde 1965 (tras incorporarse al distrito de Newham). Pero en la actualidad, el barrio caracterizado por una amalgama de polígonos herrumbrosos y bañado por el río Lea (uno de los más contaminados de Inglaterra), a dado paso a una nueva remesa de viviendas, espacios verdes (con más de 4.000 árboles y 300.000 plantas), amplias avenidas e interminables carriles bici, alcanzando en 2011 una población de 98.812 .

En 2005, cuando Londres se hizo con la candidatura, el actual Parque Olímpico era todavía un erial de desechos industriales, un vertedero de neumáticos y un cementerio de tendido eléctrico. Pero con el inicio de la construcción de la Villa Olímpica se demolieron más de 200 edificios, los canales y arroyos del East London se limpiaron y se realizó un rastreo en busca de bombas sin detonar (ya que este referente en la arquitectura deportiva se levanta sobre el que fue uno de los barrios más castigados por la II Guerra Mundial), renovando así una superficie de casi $950.000 \mathrm{~m}^{2}$.

Por otra parte, en los inicios de la construcción hubo importantes problemas de toxicidad puesto que muchos de los edificios demolidos eran fábricas que producían residuos tóxicos y fue necesario descontaminar el área mediante la instalación de una central de "biorremediación del suelo" antes de continuar con las obras de desarrollo del Parque Olímpico. Se realizó una exhaustiva labor de limpieza del terreno que supuso la retirada de más de dos millones de toneladas de tierra contaminada

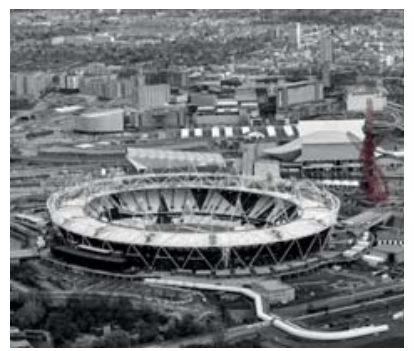

2012.4. Relación con la ciudad. Posición respecto al centro urbano

El London Olympic Stadium está situado en la ciudad de Stratford, que pertenece al municipio de Newham y se localiza dentro del área conocida como Londres exterior. Este término hace referencia a la zona del Gran Londres (subdivisión administrativa de alto nivel que cubre la totalidad la ciudad) desarrollada después de la definición del condado de Londres en 1889. El estadio se sitúa al este del casco histórico, en lo que originalmente fue conocido como el East End londinense, a varios kilómetros de algunos de los edificios más emblemáticos de Londres como el Big Ben $(8,62 \mathrm{Km}$.), el London Eye $(8,19 \mathrm{Km}$.), la Abadía de Westminster $(8,90 \mathrm{Km}$.) y el Palacio de Buckingham $(9,70 \mathrm{Km}$.). En las inmediaciones encontramos algunas áreas importantes como el Victoria Park o las Harckney Marsh. 
La comunicación con el centro de la ciudad es excelente tanto por carretera, donde encontramos varias autovías recorren este tramo, como en transporte público, ya que en las cercanias del Queen Elizabeth Olympic Park encontramos estaciones de tren, tranvía y metro, así como varias paradas de autobús.

\subsection{Breve relato de la historia del Estadio}

El 6 de julio del 2005, en la reunión que el COI mantuvo en Singapur, se anunció a Londres como la ciudad ganadora del honor de celebrar la XXX Olimpiada.

Normalmente, cuando se trata de la construcción de estadios olímpicos, la mayoría de los arquitectos $y$, por supuesto de las naciones anfitrionas, prefieren hacer gala de sus capacidades y levantar grandes estructuras. Sin embargo, la lógica dice que reflexionar sobre lo que se desea obtener cuando concluya un proceso, ayuda a que los primeros pasos sean más sólidos. Así comenzó Londres su proyecto para organizar los Juegos Olímpicos 2012: decidiendo primero cómo quedará la ciudad cuando todos los atletas hubieran regresado a sus casas. Tratando de evitar un legado envenenado. El trabajo no fue fácil. La pérdida de patrocinadores del proyecto a consecuencia de la crisis económica o la falta de tiempo fueron algunos de los principales contratiempos a los que se tuvieron que enfrentar los responsables de la construcción.

Londres se dispuso a realizar unos juegos olímpicos más verdes, ecológicos y sostenibles. El grupo de arquitectos, ingenieros, constructores y urbanistas encargados del proyecto, se dieron a la tarea de diseñar un estadio que cumpliera con la promesa ambientalista hecha por Londres; fue así como, luego de varios análisis y con la premisa: «No cambiemos el deporte, cambiemos el edificioll, el equipo definió la idea de crear un estadio desmontable, un recinto deportivo flexible, capaz de cambiar y adaptarse a las verdaderas necesidades de la ciudad y sus espectáculos. La propuesta se basaba en construir una estructura que durante los juegos olímpicos pudiera albergar 80.000 espectadores; pero, que pasados los mismos, pudiera desmontarse y convertirse en un escenario para tan sólo 25.000 , un volumen de espectadores mucho más real para los eventos regulares que se puedan realizar en el futuro.

Para llevar a cabo la obra, se diseñó un estadio con dos estructuras, una interna y permanente, conformada por un tazón de hormigón y 25.000 asientos y otra desmontable o temporal con 55.000 localidades, que se construyó utilizando 112 piezas prefabricadas de acero, cada una de $90 \mathrm{Tm}$. que se encajaron unas con otras como si de un mecano se tratase, hasta formar el elemento completo. La estructura temporal, se preveía que al finalizar los juegos se desmontará y se enviará a Río de Janeiro para su utilización en los Juegos Olímpicos del 2016. Las obras se iniciaron en mayo del 2008 y concluyeron en el 2011.

\subsection{Descripción del Estadio; Graderío}

Aunque está preparado para poder albergar un total de 80.000 espectadores durante el desarrollo de los Juegos, el estadio permite que, una vez estos hayan finalizado, su capacidad se reduzca más de dos tercios; lo que se consigue gracias a un diseño claramente dividido en tres partes:

La primera, constituida por los dos niveles inferiores, es permanente. Fabricada en hormigón armado bajo en dióxido de carbono ( $40 \%$ menos carbono que el regular) procedente del reciclaje de residuos industriales, con un aforo de 25.000 asistentes.

La segunda, el nivel superior y es una construcción de carácter efímero. Se realizó con una estructura metálica (compuesta por 112 cerchas de acero, las cuales se fabricaron con tuberías de gas obtenidas de excedentes industriales), que sostiene una losa escalonada de hormigón ligero en el que se distribuyen 55.000 asientos desmontables. Por último se colocó la cubierta, que abarca dos tercios del graderio, hecha de cloruro de polivinilo rígido (PVC), sostenida por medio de tensores de acero (lo que permite un rápido desmontaje) y diseñada para evitar que la velocidad del viento en el interior del recinto supere los $2 \mathrm{~m}$./seg. durante las competiciones atléticas (lo cual invalidaría las marcas).

Posteriormente se colocaría la envolvente, de 20 metros de altura y 900 metros en su circunferencia, también fabricada con un material plástico, en esta ocasión a base de poliéster y polietileno, con una impresión de tinta resistente a los rayos UV.

Graderío de planta elíptica y sección dividida en las dos partes ya mencionadas, la inferior excavada en el terreno, con una profundidad de 19 pies $(5,79 \mathrm{~m}$.) y la superior, una construcción aérea, de 75 pies $(22,86 \mathrm{~m}$.) de altura. La primera fila de asientos se encuentra a nivel de la pista. En alzado se observa que la altura de las torres de focos es prácticamente la misma que el vuelo de la cubierta.

El Estadio Olímpico, al estar situado dentro de una isla (con forma de diamante) dibujada por dos cursos de agua ya existentes, establece su relación con el Queen Elizabeth Olympic Park a través de cinco puentes. Una vez dentro del recinto, el se posibilita el acceso al graderío mediante un total de 71 vomitorios, que vierten a la intersección de un pasillo oval con cada

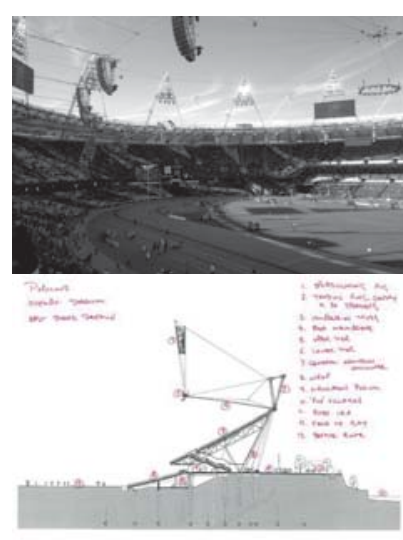




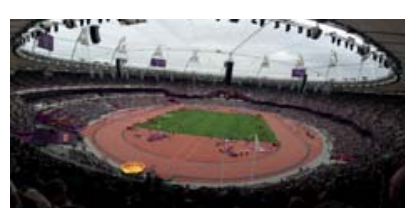

dimensiones y superficies aproximadas graderío

L $01-01$ ' $\quad 91,03 \mathrm{M}$

L 02-02' $\quad 47,75 \mathrm{M}$

L $01-02 \quad 25,99 \mathrm{M}$

L 02-04 57,88 M

L 04-05 134,41 M

R OI-Al $55,14 \mathrm{M}$

R 02-A2 81,19 M

R 04-A4 139,08 M

$<$ Al.01.A2 $\quad 67^{\circ}$

$<$ A2.02.A4 $32^{\circ}$

$<$ A4.04.A4' $49^{\circ}$ uno de los pasillos radiales, lo que asegura un acceso y evacuación muy fluido. Existen además tres entradas a nivel de subsuelo para autoridades, jueces y atletas, que ofrecen acceso directo al campo.

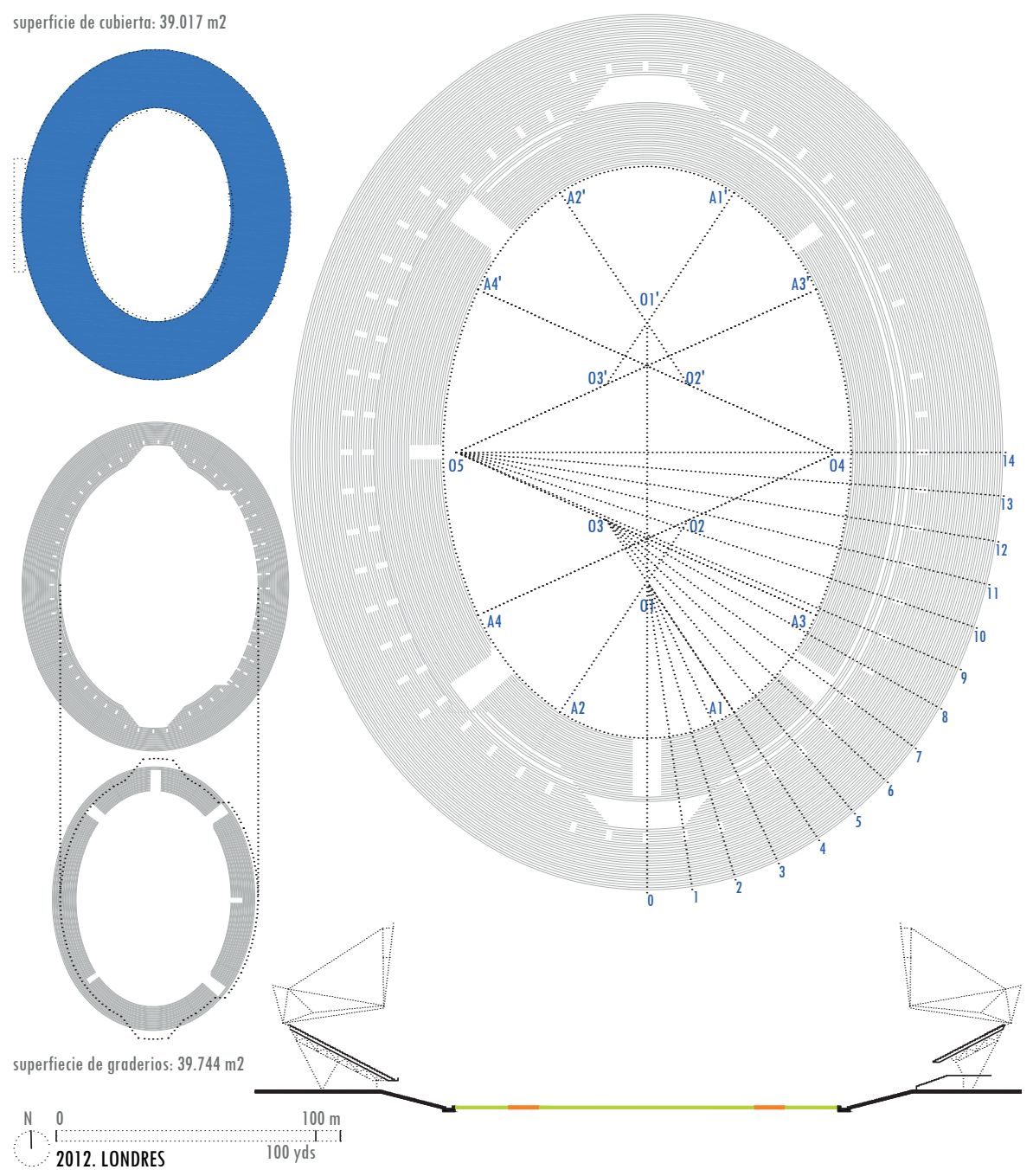

\subsection{Descripción del Estadio; Pista}

Dimensiones: Cuerda de la pista de 400 metros y nueve calles de 4 pies de ancho $(1,22 \mathrm{~m}$.) y un ancho total de 36 pies (10,98 m.). Inclinación hacia el interior de 0,5\%. Orientación norte-sur. La recta este se alarga 169 pies $(51,51 \mathrm{~m}$.) para alcanzar una longitud total de 152 yardas $(139 \mathrm{~m}$.). Fosos de saltos en el exterior de ambas rectas. Espacio libre interior de 118 yardas $(107,90 \mathrm{~m}$.) de largo por 76 yardas $(69,49 \mathrm{~m}$.) de ancho en el que se puede marcar un campo de fútbol. La pista está excavada en la arcilla blanda que conforma el terreno del lugar y aprovecha la pendiente natural del mismo.

La pista y la grada están separadas por un foso.

Material:

Pista. Fue prefabricada e instalada por Mondo y su composición es la siguiente:

Una capa superior resistente a la luz ultravioleta e impermeable que optimiza la durabilidad y la tracción de la misma.

Una lámina inferior que cumple la función de amortiguamiento o absorción del impacto y de retorno de la energía, basada en una estructura de celdas en forma de diamantes, diseñadas para ser flexibles en todas direcciones (no sólo en la del corredor), lo que la convierte en un colchón ideal y un material de rápida reacción.

Ambas capas están hechas de goma vulcanizada, un proceso que intercala la estructura molecular de diferentes materiales y mejora las condiciones de la superficie haciéndola más uniforme, fuerte y elástica

Cesped. En el campo se utiliza una Hierba híbrida DESSO GrassMaster, caracterizada por su composición mezcla de cesped natural y artificial: las fibras de hierba artificial se 
insertan a $20 \mathrm{~cm}$. (7,9 pulgadas) de profundidad, cubriendo aproximadamente el $3 \%$ de la superficie total, de manera que, a medida que la hierba natural va creciendo, sus raíces se van entrelazando con ellas para crear un campo sólido, con un buen drenaje y buenas características de juego.

Programa Deportivo: Atletismo y las Ceremonias de Apertura y Clausura

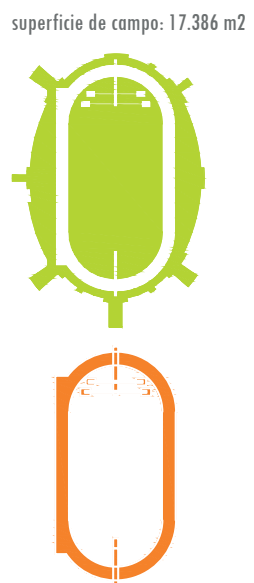

superficie de pista y fosos: $5.614 \mathrm{~m} 2$
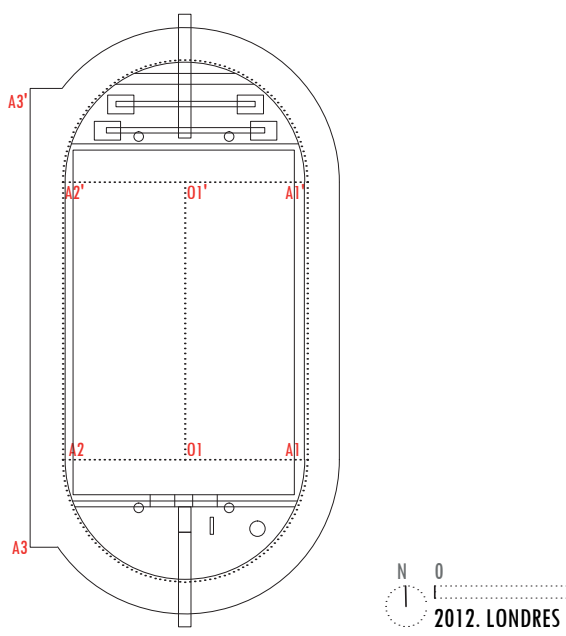

2012. LONDRES

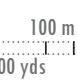

2012.8. Elementos significantes:

La descontaminación de los terrenos y la utilización de materiales reciclados

\subsection{Avances técnicos:}

La retransmisión en 3D: los Juegos Olímpicos de Londres 2012 son los primeros en retransmitir imágenes de televisión en vivo en formato de visión estereoscópica, gracias a 33 cámaras 3D que graban más de 230 horas de cobertura en este sistema.

Seguridad informática: el "laboratorio tecnológico" de Atos, equipado con cientos de ordenadores, realizó 200.000 horas de pruebas desde comienzos de 2011 para tratar de prevenir cualquier incidente informático que pudiera perturbar el desarrollo de los Juegos. Además, durante el evento, un "centro de control" con 9.500 ordenadores y 900 servidores vigila ininterrumpidamente el desarrollo de las operaciones para garantizar que el sistema informático puede transmitir sin incidentes datos no alterados por un acto delictivo $\circ$ un problema técnico.

Retransmisión televisiva en súper Hi-Vision: más de seis kilómetros de cables de fibra óptica fueron necesarios para conectar el Parque Olímpico con el centro televisivo principal de la BBC, para retransmitir los Juegos Olímpicos con una calidad y definición sin precedentes en la historia del certamen. Se obtienen imágenes de definición ultra-avanzada (súper Hi-Vision), con una resolución de $7680 \times 4320$ píxeles (una calidad de imagen 16 veces mayor que el $H D)$.

Retransmisión por internet: para una correcta retransmisión por internet de los Juegos Olímpicos, que permita imágenes en alta definición y versiones adaptadas para todo tipo de receptores (PCs, tablets, móviles...) se ha desarrollado una nueva tecnología para video llamada "chunked streaming" (video online en fragmentos). Este sistema estará habilitado en el llamado Live Interactive Video Player (Reproductor interactivo de video en vivo), desarrollado específicamente para cubrir los Olímpicos en la página web del medio. Además de este tipo de cobertura, la organización promovió una información constante de los juegos mediante cuentas oficiales en algunas de las redes sociales y sitios más relevantes de internet como Twitter, Google+, Facebook y YouTube.

Cámaras robóticas: Getty Images instaló en algunos puntos concretos del estadio (focos, vigas, andamios...) cámaras robóticas controladas remotamente y capaces de girar 360 grados, que proporcionan imágenes de lugares inaccesibles para los fotógrafos humanos.

Cronometraje: el nuevo sistema de cronometraje denominado Quantum Timer ofrece una resolución de un microsegundo (cien veces más que los dispositivos existentes hasta el momento), con él, la información recogida por un hardware especial compuesto por 16 relojes independientes, se retransmite instantáneamente a las pantallas para mostrar los tiempos con una precisión casi absoluta. Además los tacos de salida en la pista serán completamente electrónicos por primera vez, ya que hasta ahora se requería que los deportistas empujaran los bloques cinco milímetros para registrarla.

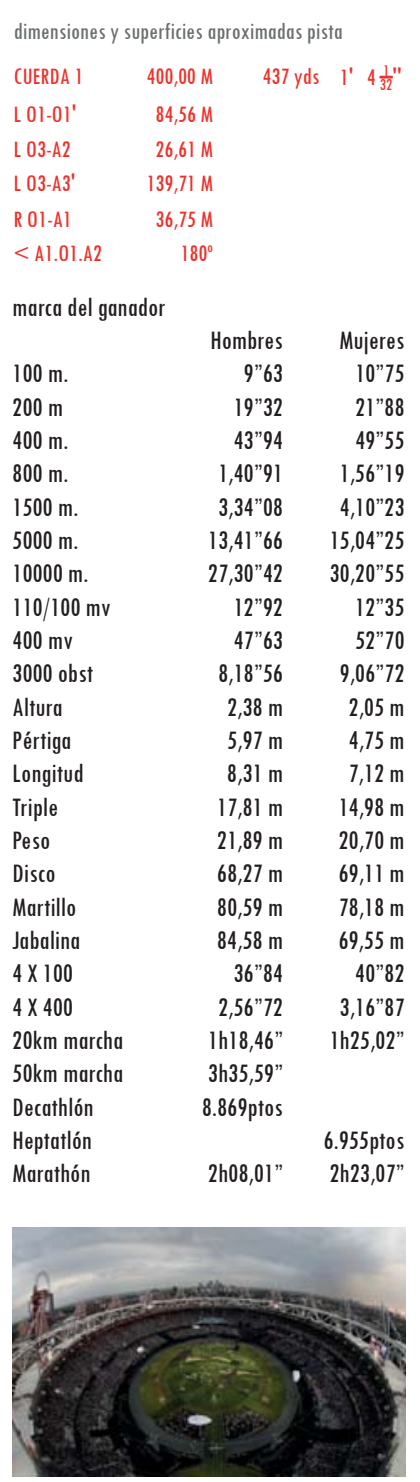


2012.10. Autores. Tipo de encargo:

Arquitectos:

HOK fundada en 1955 en St Louis, Missouri, por George Hellmuth, Obata Gyo y George Kassabaum. Es en la actualidad el estudio de arquitectura e ingeniería más grande con sede en los Estados Unidos.

En 1983 constituyó "HOK Sports Venue Events", especializada en estadios deportivos y centros de convenciones, en 1999 se fusiona con LOBB Shorts Architecture y en 2009 pasa a ser una firma independiente con el nombre de Populous. Proyectando los estadios de Wembley, el Olímpico de Sydney y el de Wimbledon entre otros.

El responsable del proyecto fue Rod Sheard, nacido en Brisbane, Australia (1951). Se inicia en la arquitectura deportiva cuando, en 1975, se traslada a Londres y comienza a trabajar en Howard V. Lobb \& partners, de la que en 1993 es nombrado director y cambia el nombre de la firma por LOBB Sports Architecture. Hasta su fusión con HOK Shorts en 1999, realiza entre otros, el Galpharm Stadium in Huddersfield; la primera construcción deportiva en ganar el galardon "Edificio del Año" del Royal Institute of British Architect's, el Reebok Stadium en Bolton, el Millennium Stadium en Cardiff (el primer estadio europeo con el techo practicable), ..., Sheard es el único arquitecto que ha desarrollado dos estadios Olímpicos.

Es importante destacar que Peter Cook fue consultor del proyecto.

Peter Cook (22 de octubre de 1936, Southend, Essex), estudió arquitectura en la Bounemouth College of Art entre 1953 y 1958 y más tarde en la Architectural Association School of Architecture de Londres, donde se graduaría en 1960 y a la que más tarde regresaría como profesor. Posteriormente, al mismo tiempo que trabajaba en la oficina de James Cubitt \& Partners, Cook fue uno de los miembros fundadores del grupo Archigram, una asociación de arquitectos londinense muy influyente en los sesenta. Fue director del Institute of Contemporary Arts en Londres entre 1970 y 1972; en 1984, fue nombrado profesor vitalicio en la Staedelschule de Frankfut, lo que terminó de establecer su reputación de docente en las escuelas de arquitectura alemanas; en 1990, comenzó a trabajar como profesor de arquitectura en The Bartlett Scool of Architecture, en la Universidad de Londres, retirándose en 2005 .

Entre sus últimas obras encontramos la nueva Facultad de Derecho de la Universidad de Negocios y Economía de Viena, realizada con su estudio CRAB, en 2013 y más recientemente, la Escuela Abedian de Arquitectura de la Universidad de Bond en la Gold Coast, Australia. Dentro de sus muchos premios y condecoraciones destacan: la medalla Jean Tschumi, a la crítica arquitectónica o docencia arquitectónica, otorgado por la Unión Internacional de Arquitectos; la Medalla de Oro del RIBA, otorgada al grupo Archigram en 2002 y el Premio Stirling (con que fue galardonado junto a Colin Fournier) por la Kunsthaus de Graz en 2004. Todos estos logros fueron determinantes para que Populous (que en Reino Unido todavía se desarrolla como "HOK Sports Venue Events") fuese seleccionado para la participar en el desarrollo del proyecto del Parque Olímpico de Londres y el posterior diseño del London Olympic Stadium, el cual colaboraría con Sir. Peter Cook a la cabeza y el arquitecto Rod Sheard (que ya había trabajado en el estadio olímpico de Sydney 2.000) como encargado de la ejecución.

Tipo de encargo. Directo en función de los meritos ostentados.

\subsection{Edificios coetáneos}

Pabellón de la Serpentine Gellery de Herzog y de Mearon en colaboración con Ai Weiwei. En diciembre se inaugura el Museo del Louvre en Lens de Sanaa. Se terminan las obras del CCTV de Beijing de Rem Koolhaas

\subsection{Hechos históricos relevantes}

El 4 de julio se presentan en el CERN (Laboratorio Europeo de Física de Partículas) los resultados preliminares de los análisis conjuntos de los datos tomados por el LHC y se anuncia el hallazgo del bosón de Higgs.

El 25 de agosto fallece en Columbus, Estados Unidos, el astronauta Neil Armstrong, primer hombre en pisar la luna.

El 5 de diciembre fallece en Río de Janeiro el arquitecto Óscar Niemeyer. 
Bibliografía Londres 2012 :

KNIGHT, Tom; RUSCOE, Sybil. London 2012 Olympic and Paralympic Games. The Official Commemorative Book. The London Organising Committee of the Olympic Games and Paralympic Games Ltd 2012. ISBN 978-1-1 19-97314-0

DYCKHOFF, Tom; BARRETT, Claire. The Architecture of London 2012. Vision Design. Lagacy. The London Organising Committee of the Olympic Games and Paralympic Games Ltd 2012. ISBN 978-1-1 19-99386-5 

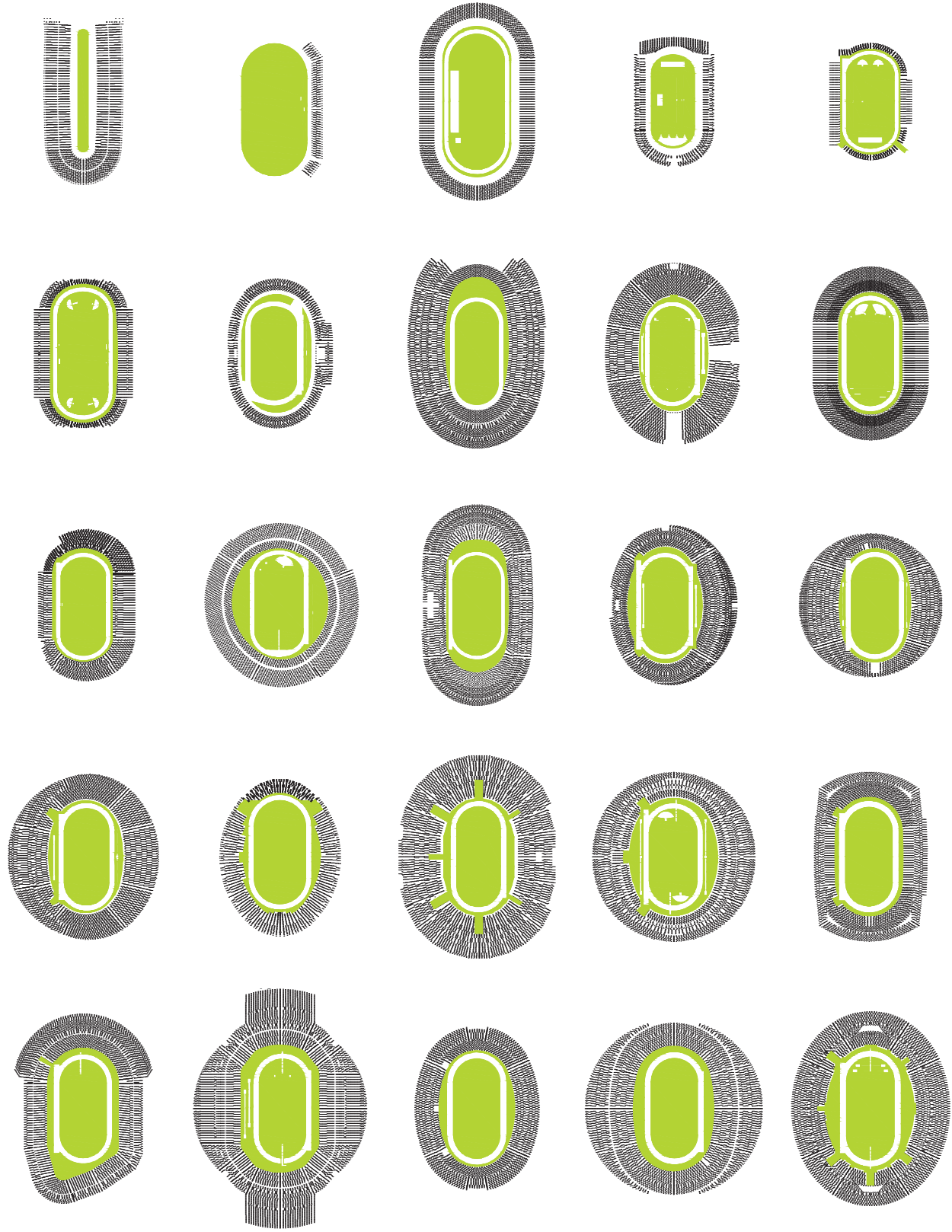

B- Tesis

El estadio Olímpico. Sus fundamentos arquitectónicos 
B. Tesis

B.1 El Estadio espacio de especial significación.

La compleja relación entre lo visible y lo evocativo

B.1.1 Espíritu agonal

B.1.2 El "intangible aglutinante"

B.1.3 El origen mítico

B.1.3.1 Origen mítico de los JJ.OO.

B.1.3.1.1 Origen mítico de los Juegos de la Antigüedad

B.1.3.1.2 Origen mítico de los Juegos Modernos

B.1.3.2 Destrucción y olvido

B.1.3.2.1 Destrucción y olvido previos a los Juegos de la antigüedad

B.1.3.2.2 Destrucción y olvido previos a los Juegos modernos

B.1.3.3 Reinstauración

B.1.3.3.1 Reinstauración de los Juegos Olímpicos de la antigüedad

B.1.3.3.2 Reinstauración de los Juegos Olímpicos modernos

B.2 Origen del Estadio Moderno

B.2.1 El colector social

B.2.2 Los modelos clásicos. El estadio, el circo y el anfiteatro.

B.2.2.1 El estadio

B.2.2.1.1 Olimpia

B.2.2.1.2 Atenas

B.2.2.2 El circo romano

B.2.2.3 El anfiteatro

B.3 Búsqueda del modelo. Establecimiento del "tipo"

B.3.1.1 Decantación del contenido programático

B.3.1.2 Homogeneización y Homologación

B.3.1.2.1 La cuerda y geometría de la pista

B.3.1.2.2 La orientación

B-52

B-53

B-58

B.3.1.3 Seguridad. Y las consecuencias de la violencia

B.3.1.3.1 Seguridad relativa al flujo de las masas

B.3.1.3.2 Consecuencias derivadas de la violencia

B.3.1.4 Multifunción

B.3.1.5 Nuevas tendencias

B.3.2.1 Clasificación de los estadios por su traza

B.3.2.1.2 Óvalo

B.3.2.1.3 Elipsoide

\section{B.3.2.1.4 Extraños}

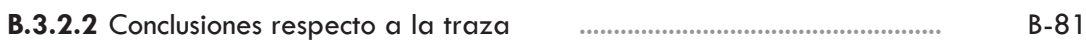

B.3.3 Significación

B.3.4 Técnica. Mass Media 
B.5.1 Momentos de cambio en el entendimiento geométrico de los estadios

B.5.2 El caso de Pekín

B-102

B.5.3 Isópticas. El panóptico inverso

B.6 Morfología

B.6.1 Escala. Proporción y Tamaño. "Lo grande"

y su riguroso requerimiento estructura

B.6.2 La configuración del espacio mediante la estructura.

Los estadios de Kenzo Tange

B- 114

B.6.3 Composición. Entre lo tectónico y lo topográfico

B- 119

\section{Conclusiones}

D. Bibliografía 
B.1 El Estadio, espacio de especial significación.

La compleja relación entre lo visible y lo evocativo

Supremo bien, el agua; el oro, como
de noche el fuego ardiente, resplandece
sobre cualquier otra riqueza altiva.
Si exaltar unos Juegos
deseas, alma mía,
no verás nunca en pleno día un astro
más brillante y ardiente
que el Sol en medio del desierto cielo.
No cantemos tampoco
más excelso certamen que el de Olimpia;
...Pídaro'.

La relación entre el estadio y su usuario, es la historia acerca de la compleja relación entre lo visible y lo evocativo; lo físico y lo emocional.

En la introducción del catalogo de la exposición celebrada en Instituto Holandes de Arquitectura, NAi, en 1995, los comisarios de la misma, Matthijs Bouw y Michelle Provoost, escribían una frase que sirve como punto de partida a nuestra reflexión:

El estadio no es un objeto de ingeniería, sino una expresión de la cultura popular y deportiva, con un significado simbólico y social.

Los estadios no son solo edificaciones de carácter funcional, son, también, espacios de especial significación. Son lugares de emoción compartida, de mitos y leyendas.

¿Pero, cómo es esto posible?, ¿̇cómo un lugar donde se desarrolla un simple juego puede producir estos grandilocuentes efectos?

Primero nos aproximaremos a como el espíritu agonal que caracteriza el deporte, y que es directo heredero de los ritos de iniciación, es capaz de crear en los estadios un halo cuasi mitológico alrededor de los competidores, que transciende y, que es capaz de emocionar a los espectadores, provocándoles un profundo sentimiento de participación iniciática.

Después rastrearemos como un "intangible aglutinante" ha acompañado al hombre desde tiempo inmemorial y es algo consustancial de las sociedades desarrolladas. Y como estas, sus masas, encuentran en el estadio su más perfecto acomodo arquitectónico, como espacio de reunión y autoafirmación.

$Y$ en una tercera parte, analizaremos como el origen mítico de los juegos antiguos tiene su eco en los juegos modernos, proporcionándoles un regusto de origen mitológico que forma parte de la liturgia olímpica que se desarrolla en los estadios.

1. Odas triunfales. Olímpica Primera. Estrofa 1 


\section{B.1.1 Espíritu agonal}

Ya a principios del siglo V a.C. en la primera estrofa, de la ya citada Oda Triunfal Olímpica Primera, el poeta Píndaro equipara la relevancia de los Juegos Olímpicos con la del agua, el oro, el fuego y el sol.

Los Juegos fueron capaces de provocar el magnífico episodio poético de las Odas Triunfales, que ha sido calificado como uno de los más hermosos de la literatura universal.

El catedrático de filología griega de la Universidad de Barcelona, José Alsina (1926/1993) en introducción a las Odas triunfales de Píndaro', publicadas por Planeta, nos aclara

Puede parecernos, hoy en día, extraño que unos acontecimientos atléticos fueran la génesis de tan altas manifestaciones poéticas. Pero no hay que olvidar que en el fondo de los Juegos griegos había toda una concepción religiosa y política del mundo.

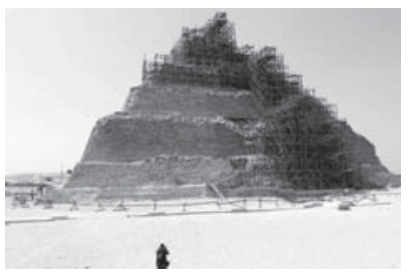

Y no solo en la cultura griega se entremezcla el deporte con la religión y las manifestaciones del poder. También del Antiguo Egipto nos queda constancia de la Ceremonia del Heb Sed, una de sus ceremonias más antiguas. En ella el Faraón debía mostrar ante sus súbditos y ante los dioses que estaba capacitado para gobernar el país. Y al mismo tiempo, ser garante del orden cósmico al ser capaz de mantener el equilibrio entre las fuerzas del caos y la armonía cósmica (maat).

Gracias a los estudios y minuciosa labor de restauración del arquitecto y arqueólogo francés Jean Philippe Laver (1902-2001)2 podemos observar en Saqqara, en el complejo funerario del faraón Dyoser (2686-2667), la representación eterna de la Heb Sed. Es la perpetuación en piedra de las cabañas rituales de madera que se construían con motivo del jubileo del rey. Este se celebraba cuando cumplía los treinta años de gobierno y a partir de ahí, cada tres años. En esta ceremonia el faraón tenía que visitar y recibir el beneplácito de las representaciones de cada uno de los principales dioses que se instalaban en capillas construidas con cañas y maderas, recorrer una serie de circuitos procesionales, realizar una carrera ritual en torno a dos edículos en forma de $D$, como los que hoy todavía se pueden apreciar en el patio sur de la pirámide de Dyoser, y lanzar una flecha a cada uno de los puntos cardinales. El arquitecto Imhotep, en el complejo funerario de Dyoser (2686-2667), además de inmortalizar el Heb Sed, construyó la primera pirámide de la que nos ha llegado conocimiento.

Este ritual, de gran importancia para la monarquía egipcia, tiene orígenes prehistóricos y continuó realizándose hasta la Baja Época. Resulta interesante contrastar que, dada la escasa esperanza de vida de los hombres de entonces, fueron pocos los faraones que vivieron lo suficiente como para poder organizar su Heb Sed.

Como podemos observar en el Heb Sed, se realiza una carrera ritual, como demostración del vigor y de la juventud del faraón. Y se señalaba cada uno de los puntos cardinales con el vuelo de una flecha como demostración de su capacidad de control del orden cósmico y el equilibrio entre el caos y la armonía. Toda una amalgama de deporte, religión y poder.

También, en las culturas precolombinas de Mesoamérica, en los complejos ceremoniales encontramos canchas de Juego de Pelota (tlatchtli en náhuatl).

Volviendo a Grecia, tomamos prestada una frase del texto de introducción de Alsina, antes citado, para referirnos al espítitu agonal:

acaso la más notable manifestación de la sociedad griega arcaica fuese lo que se ha

1. PÍNDARO (s. V aC.) Odas Triunfales. Introducción, traducción y notas de José Alsina. Ed. Planeta 1990. ISBN 84320-4877-1

2. Cuando, con veintitrés años, comenzó a trabajar en Saqqara como asistente del jefe de las excavaciones solo se adivinaba la gran mole de la pirámide escalonada. La labor incansable de una vida cargada de ilusión y esfuerzo ha tenido la recompensa de sacar a la luz todo un amplio complejo funerario 
convenido en llamar espíritu agonal. Se trata de una concepción de la vida en la que lo que importa sobre todo es la lucha, el certamen, el concurso, en el que el mejor exhibe sus cualidades y excelencias.

A través de la competencia se revelaba la luz de la excelencia (aretá), y era convicción de la sociedad griega y de Píndaro, el poeta que la canta, que sólo lograba florecer por la gracia divina. La victoria de los Juegos era, pues, una armónica combinación de la excelencia y el favor de los dioses. La misión del poeta era, a su vez, muy importante; las gestas para acceder a la inmortalidad debían ser glosadas y cantadas, aceptando para la poesía una misión trascendente.

El mundo no sería bello si la poesía no pregonara su belleza. ${ }^{1}$

El profesor de filosofía y autor de; Le sportif, le philosophe, le dirigeant y del Analyse du sport, Bernard Jeu $(1929 / 1991)^{2}$, sostiene la hipótesis de que fueron los ritos de paso, propios de la adolescencia, los que desencadenaron los grandes Juegos Olímpicos. Este autor participaparticipando de la línea de pensamiento que sitúa a la competición iniciática como origen del deporte.

La iniciación no es sólo un mecanismo de cohesión social sino también un banco de pruebas donde el joven debe demostrar su valía personal mediante la superación de una serie de obstáculos que requieren una meritoria preparación física.

El mismo procedimiento de expresar la excelencia individual mediante la competición se hace patente en los ritos de acceso al matrimonio, como queda reflejado, entre otros muchos ejemplos, en el siguiente fragmento del Canto XXI de La Odisea de Homero:

Penélope. - Oídme, orgullosos pretendientes que día tras día venís a este palacio para comer y beber las provisiones de un héroe ausente hace mucho tiempo, sin más excusa que vuestra ambición de tomarme por esposa. Voy a someteros a una prueba. Éste que veis aquí es el arco del divino Ulises: si hay alguno de vosotros capaz de tenderlo sin esfuerzo y lanzar una flecha a través de las doce hachas, a ése será al que siga, abandonando para siempre esta casa tan hermosa y tan bien abastecida, en la que entré virgen y de la cual no podré olvidar ni aun en el sueño.

José Ortega y Gasset, utilizó el mítico rapto de las sabinas ${ }^{3}$, para ilustrar su magnífico ensayo sobre El Origen deportivo del estado. Subraya la importancia del Juego en las tribus primitivas. Según el pensador y filósofo español, estas tribus se dividían en tres clases sociales: la de los viejos, los hombres maduros y la de los jóvenes. Los jóvenes de dos o tres hordas próximas deciden, impulsados por un instinto de sociabilidad, juntarse y vivir en común. Para Ortega en esas asociaciones juveniles, de carácter hermético, se cultivaban las destrezas vitales de la caza y la guerra con un severo entrenamiento, generando todo ello agrupaciones que introducirán en la marcha de la historia fenómenos tales como la exogamia, la guerra, la disciplina de entrenamiento o los festivales de danzas.

Ortega enaltece el dinamismo de esta sociedad juvenil que danza y combate, que lucha, ama y guerrea, y que, a fin de cuentas, está integrada por deportistas. De esta manera explica el origen de la fratría, anterior a la misma polis griega, y que no es más que la clase de edad de los jóvenes orquestada en asociación de fiesta y guerra. En Atenas la fratría desaparecería rápidamente, circunstancia que no se dio en una Esparta anclada en la estricta observancia de la tradición, y que instrumentaría una vida militar alrededor de las fratrías. La misma efebía practicada en Atenas, tal como lo describe Aristóteles en su obra sobre la constitución de Atenas, vendría a significar, en cierto modo, la pervivencia de esas sociedades juveniles $y$, muy especialmente, la reminiscencia de los antiguos ritos de iniciación, que han perdurado, de una u otra forma, en nuestra cultura y que pueden considerarse como el origen del deporte.

El Estadio se ve revestido de la trascendencia que los ritos de iniciación aportaron al deporte, que puede considerarse directo heredero de los mismos. Tal vez un cierto halo mágico y ceremonial se puede percibir, por este motivo, en los Estadios.

1. José Alsina, Introducción. Odas triunfales. Citado en la pagina precedente. .

2. Deportista y profesor de filosofía en la Universidad de Lille 3. Autor también de "Le sport, la mort et la violence". 3. Ante la escasez de mujeres, el fundador de Roma, Rómulo, organizó unas pruebas deportivas en honor al dios Neptuno, a las que invitó a los pueblos vecinos. Acudieron varios de ellos, pero los de una población, La Sabinia, eran especialmente voluntariosos y fueron a Roma con sus mujeres e hijos y precedidos por su rey. Comenzó el espectáculo de los juegos $y$, a una señal, cada romano raptó a una mujer, y luego echaron a los hombres. 


\section{B.1.2 El "intangible aglutinante"}

¿Cuál es la naturaleza del vínculo que reúne a los individuos, para formar una masa de gente con ilusiones y emociones compartidas?

¿De dónde viene la capacidad de aglutinar a una gran cantidad de diferentes individuos alrededor de un sentimiento en común?

¿Cómo se anuda ese lazo misterioso?

Es interesante la reflexión que sobre este asunto realiza el filosofo y catedrático en la Escuela de Arte y Diseño de Karlsruhe, Peter Sloterdijk (1947) en su ensayo Espumas, Esferorogía plural, de 2004, que supone la tercera entrega de la trilogía Esferas.

Si tomamos como ejemplo las sociedades antiguas, es claro que podemos aceptar la evidencia que la coexistencia de los seres humanos en la polis griega significa algo diferente que...

una reunión muda de ganado que pasta en el mismo prado. Ética Nicomaquea. Aristóteles

íbasta realmente con aducir, siguiendo a Aristóteles, una "comunidad de habla y pensamiento" como motivo de la convivencia entre muchos no emparentados? ¿Se comprende adecuadamente la coexistencia, entendiéndola, con el autor de Ética Nicomaquea, como una sinergia de política y amistad?

La nueva filosofía, en tiempos de Platón, interpretó la cohabitación de seres humanos con sus iguales, así como con animales, plantas, piedras, maquinas, dioses y planetas, como

... un todo ordenado al modo matemático, eutónicamente proporcionado, bajo el prometedor titulo de cosmos. Pocas veces trataba de esto sin abrirse desde las condiciones impresionantes de orden en lo grande al poder-sentirse-en-orden-yen-su-sitio de las almas individuales y de sus cooperaciones en la polis reformada imaginariamente.

... los antiguos apenas hablaban alguna vez sobre el universo sin tratar al mismo tiempo de la ciudad, y prócticamente nunca discutían sobre la ciudad sin lanzar su mirada el universo a través de las lentes de la analogía.

El tercer libro de las Leyes de Platón, que alude a un posible surgimiento del Estado por la agrupación de los pocos supervivientes tras la última gran inundación.

El atractivo de la hipótesis platónica del diluvio universal consiste en que los individuos comparten haber sido señalados por el azar, o por la decisión de un ser superior, al convertirlos en únicos supervivientes de un mismo hecho catastrófico. La predestinación o un acto de voluntad propia, libremente elegido.

... no pocas entre las ciudades áticas más importantes parece que surgieron de un synoikismós, de la decisión de comunas regidas por la nobleza, antes autónomas, de colaborar dentro de muros comunes.

Quizás la explicación venga del lado de que el hombre es un ser individualista y a la vez gregario. Necesita el apoyo y la protección del grupo.

Sloterdijk reflexiona sobre naturaleza del vínculo que reúne a los individuos formando lo que la tradición sociológica llama "sociedad".

Cuando uno se ha convencido que el modus vivendi, es decir, el ritmo de desarrollo, de la sociedad moderna se basa en un acto doble -la descomposición de los conglomerados sociales en unidades complejas individuadas y su recombinación en 
conjuntos cooperativos-, salta a los ojos hasta qué punto en la formula "entrada de las masas en la historia" se articula también una problemática arquitectónica.

Los colectivos modernos han de plantearse la tarea de producir las condiciones espaciales que apoyen el aislamientos de los individuos, aquí, y su reunión en conjuntos de cooperación y contemplación multicefalos, allí. Esto exige nuevos planteamientos en arquitectura. Peter Sloterdiik. Pag. 462

Surgen nuevos planteamientos en la manera de habitar, de planificar la vivienda, y en la manera de reunirse, con el estadio como pieza de mayor dimensión y significado. Esta tesis trata, fundamentalmente, de analizar el desarrollo y evolución de una de esas dos importantes tipologías arquitectónicas: el estadio.

El "intangible aglutinante" que ha acompañado al hombre desde sus orígenes, y que sigue siendo algo consustancial con las sociedades desarrolladas, encuentra en el estadio el más perfecto acomodo arquitectónico para la reunión y autoafirmación de las masas, estableciéndose un lazo de carácter emocional con el espectador, un sentimiento de comunión y pertenencia. 


\section{B.1.3 El origen mítico}

La vida no es la que uno vivió, sino la que uno recuerda y cómo la recuerda para contarla. Gabriel García Márquez.

Nadie me verá del todo

ni es nadie como lo miro.

Nadie nos ha visto. A nadie

ciegos de ver, hemos visto.

Miguel Hernández,

Cuanto se muestra es una visión de lo invisible.

Anaxágoras de Clazomene (500-428 a C.)

La materia de conocimiento de la Historia no es el pasado como tal, sino aquel pasado del que nos ha quedado alguna prueba o evidencia. R.G. Collingwood.

Esta aseveración recogida en Idea de la Historia', obra póstuma (1947) del filosofo de la historia, historiador y arqueólogo ingles Robin George Collingwood (1889/1943), nos habla de la perdida de un campo de datos, entre lo realmente sucedido y aquello que nos transmite la historia. Este campo de datos ocultos son un terreno abonado, en el que florecen las leyendas y en el que se asientan las razones mitológicas.

Los historiadores no han sido capaces de reconstruir la historia completa de los Juegos (no conocemos sus orígenes) como tampoco la conocían los griegos antiguos; así se impuso la redacción de un o, mejor dicho, varios relatos fantásticos y aleccionadores que explicarán esos orígenes. $Y$, seguramente, la fabulación es más sugerente que la realidad. En palabras de Píndaro, en su Olímpica Primera Epodo 1 Maravillas, hay muchas, y a menudo

las leyendas humanas

rebasan la verdad; bien adornadas

con dispares ficciones

las fábulas engañan.

El origen, tanto de los Juegos de la antigüedad clásica como los Juegos modernos, no supusieron un origen desde la nada sino, y con toda claridad, una recuperación de un pasado esplendoroso, después de muchos años de olvido y abandono.

La idea de un pasado, seguida de su olvido, etapa oscura en la que florecen los mitos, y luego su recuperación son dos partes enlazadas con razones mitológicas. Es curioso que este mismo esquema coincide con la estructura de las odas de Píndaro, según el ya citado catedrático José Alsina en la introducción a las Odas Triunfales

En general, se observa que la estructura de sus odas tiende a constituirse a base de una tripartición: actualidad-mito-actualidad. En general también, la relación entre el mito y la actualidad suele comportar ciertas relaciones.

En el siguiente cuadro expresamos las relaciones y coincidencias que se pueden establecer entre los orígenes de los Juegos de la antigüedad clásica y de los modernos, siempre, con el eslabón de enganche de un "olvido" previo.

1. COLLINGWOOD, Robin George (1946). Idea de la Historia. Titulo original The Idea of History. Ed. Fondo de Cultura Económica,Segunda edición 1996. ISBN 9681601963,9789681601966 


\begin{tabular}{|c|c|c|c|}
\hline & B.1.3.1 & B.1.3.2 & B 1.3.3 \\
\hline & Origen mítico & Destrucción & Reinstauración \\
\hline & & y olvido & \\
\hline & B.1.3.1.1 & B.1.3.2.1 & B.1.3.3.1 \\
\hline Juegos clásicos & Dioses, héroes & Decadencia & Rey Ifito \\
\hline & y hombres & Invasiones & \\
\hline & Pélope y Enómao & Terremotos & \\
\hline & Heracles & & \\
\hline & Heracles cretense & & \\
\hline & B.1.3.1.2 & B.1.3.2.2 & B.1.3.3.2 \\
\hline Juegos modernos & Olimpiadas clásicas: & Decadencia & Coubertin \\
\hline & Cultura, deporte, & Prohibición & \\
\hline & Fair play, & Terremotos & \\
\hline & Tregua sagrada & & \\
\hline
\end{tabular}

El hombre crea los mitos y los olvida, para luego sorprenderse cuando los encuentra.

El mito se justifica y alimenta con el descubrimiento de algo perdido y olvidado. Y vemos como en ambos casos existió un pasado esplendoroso que acaba trágicamente y cae en el olvido. Posteriormente se "descubre", y este redescubrimiento produce admiración y nostalgia de un pasado mejor, lo que empuja a su reinstauración.

\section{B.1.3.1 Origen mítico de los JJ.OO.}

Podemos calificar como mítico tanto el origen de los Juegos Olímpicos de la Antigüedad como el de los Juegos Olímpicos Modernos, aunque con cierto matiz diferencial en el significado de mítico.

Si recurrimos al diccionario de la Real Academia Española comprobaremos que mítico (del latín mythǐcus, y este del griego $\mu$ Uı ı́ós) es el adjetivo que significa "perteneciente o relativo al mito". Y en mito (del griego $\mu$ Ũ 0 ○) encontramos cuatro matices en su acepción

1. Narración maravillosa situada fuera del tiempo histórico y protagonizada por personajes de carácter divino o heroico. Con frecuencia interpreta el origen del mundo $\circ$ grandes acontecimientos de la humanidad.

2. Historia ficticia o personaje literario o artístico que condensa alguna realidad humana de significación universal.

3. Persona o cosa rodeada de extraordinaria estima.

4. Persona o cosa a las que se atribuyen cualidades o excelencias que no tienen, 0 bien una realidad de la que carecen.

Podemos identificar el "mito" de los orígenes de los Juegos de la Antigüedad con la primera definición, ya que en sus antecedentes, hechos maravillosos anteriores a la época histórica, son protagonizados por personajes de carácter heroico y con la intervención de los propios dioses.

Y el "mito" del orígen de los Juegos Modernos podemos identificarlos con la tercera acepción; cosa rodeada de extraordinaria estima.

\section{B.1.3.1.1 Origen mítico de los Juegos de la Antigüedad}

Los remotos orígenes del santuario de Olimpia aparecen envueltos en la bruma de innumerables leyendas que reflejan una doble estratificación, una pregreco-micénica y otra greco-histórica. Las tres leyendas más significativas sobre la institución de los Juegos Olímpicos son, la de Pélope y Enómao, la del héroe Heracles, el de los doce trabajos y la del otro Heracles, este último de origen cretense. 
Empecemos por la última. Según Hesíodo' al nacer Zeus, su madre, la diosa Madre o diosa Tierra, Gea, Rea o Meter, según las versiones, lo escondió de la insaciable voracidad de su padre Cronos, "en su seno", en una gruta, situada en la región cretense de Dicte. Aqui, se produce todo un cruce de claves relacionadas con las creencias e historia de la Grecia de la antigüedad. Por un lado el desplazamiento de los dioses ancestrales, tierra y tiempo, Gea y Cronos, por otros nuevos dioses. El monte que preside Olimpia es el Kronion, en honor de Cronos y a sus pies se situaba la gruta dedicada a Res, cuyo primitivo altar fue descubierto por Ernst Curtius (1886/1956). Y, según su ayudante, el arquitecto y arqueologo Wilhelm Dörpfeld ${ }^{2}$, corresponde con la denominada gruta del Ida cantada por Píndaro en la Olímpica $\mathrm{V}$, estrofa 3

Tú que allende las nubes, Zeus Salvador, te encuentras,

Tú que habitas el monte a quien Crono da el [nombre],

Tú que la ancha corriente del Alfeo enalteces

Al igual que la gruta venerable del lda,

Supicante a Ti acudo, al son de la lidia flauta

Recordemos que el monte Ida es un monte cretense, al igual que la región de Dicte, y que la cultura Minoica Cretense es considerada como el umbral de la Hélade, como así lo expresa, el profesor de filología clásica y catedratico de Deusto, Santiago Segura Munguía en su publicación de 1992, Los Juegos Olímpicos. Educación, deporte, mitología y fiestas en la antigua Grecia.

Como decíamos, se produce un desplazamiento de los dioses antiguos hacia el nuevo olímpo presidido por Zeus, un dios traído por el pueblo invasor de los dorios, que se mezclará e integrará con las culturas ancestrales.

Santiago Segura, en la pagina 148 del citado libro nos proporciona un relato de la primea leyenda, relativa Zeus, sobre el origen de Olimpia

Cronos había conquistado el poder que antes ostentaba Urano. Rea iba dandole hijos a Cronos, pero éste sabedor que uno de ellos lo destruiría, los devoraba a medida que iban viniendo al mundo.

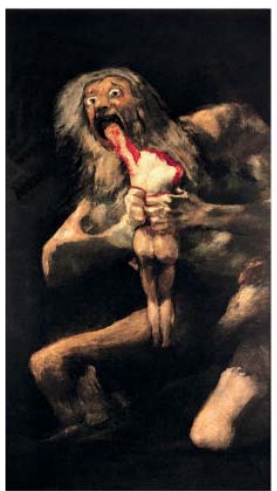

Hecho representado por Goya en el cuadro Saturno devorando a un hijo. Saturno es el equivalente romano a Cronos. Pero sigamos con el relato de Segura

Harta de producir hijos inutilmente, Rea, al nacer Zeus, le entregó a su marido, en lugar del niño, una piedra envuelta en pañales. Cronos se la tragó, mientras Rea confiaba el recien nacido a los Curetes, los cuales ayudados por las ninfas Ida y Adrastea, hijas del rey cretense Meliseo, lo criaron con leche de la cabra Amaltea.

Un mito local de Olimpia asegura que los Curetes que llegaron hasta allí procedentes de Creta eran cinco hemanos. El mayor de ellos Heracles (en versión Cretense), organizó una competición deportiva entre los mismos y coronó al vencedor con una corona de olivo.

Siendo esta competición el origen de los Juegos y como eran cuatro los hermanos de Heracles el cretense, los Juegos se conmemorarían cada cuatro años. Finalmente Zeus derrotó a su padre Cronos y asumió los poderes de soberano del universo.

Como hecho contrastado, sabemos por las construcciones absidales y las cerámicas protohelénicas encontradas en las excavaciones arqueologicas de Olimpia, que el lugar estuvo habitado en el tercer milenio aC.. La llegada de los aqueos, es fijada por los historiadores a comienzos del segundo milenio. Y a principios del siglo XII aC. se produce la invasión de los poderosos dorios.

Pero no podemos presentar ningún dato histórico que avale un origen cierto de los Juegos. Los historiadores con un conocimiento más próximo a las fuentes, como Pausanias, no son capaces de aportar ningún indicio fiable de cuándo se producen.

Pausanias, viajero, geógrafo e historiador griego del siglo II dC., en su obra Descripción de Grecia, en el Libro V: Élide y Olimpia, en varios, y algo farragosos, fragmentos del relato, cuenta como se mezclan hombres, reyes, héroes, dioses y alguna competición deportiva.

Y en alguno de estos relatos, aparece el rapto de Hipodamia, por Pélope como motivo del inicio de los Juegos.

1. Poeta griego del siglo VIII o VII aC., autor de las obras Teogonía, Eeas, El escudo de Heracles, Trabajos y días, entre otras.

2. Wilhelm Dörpfeld (1853/1940) fue un arquitecto y arqueólogo alemán que particpó en las excavaciones llevadas a cabo entre 1877 y 1881 en Olimpia, y posteriormente, junto a Heinrich Schliemann, en Orcómenos y en Troya. 
Según su version de la leyenda, el rey de Pisa, Enómao, prevenido por el oraculo de que el pretendiente que se casara con su hija Hipodamia lo iba a destronar, impuso la condición de que el que quisiera desposarse con su hija, debería previamente vencerle a él en una carrera de carros, reservándose el derecho de dar muerte a los retadores derrotados. Enomao confiaba, para su victoria, en su "carro tirado por yeguas aladas más rápidas que el viento".

Pausanias (VI. 21, 7, 9 10) afirma que el número de pretendientes fracasados y muertos se elavaba a dieciocho y, que incluso, Enómao tambien había degollado a las yeguas de uno de los pretendientes.

Hasta que un día Pélope, hijo de Tántalo, rey de Frigia, y este a su vez hijo de Zeus y de la oceánida Pluto, pretende a Hipodamia y reta a Enómao.

En versión del historiador y gramatico griego, Apolodoro (siglo II a.C) en su compendio de mitología denominado Biblioteca de Apolodoro

Pélope, [...] como sobresalía por su belleza, llegó a ser amado por Poseidón, quien le regaló un carro alado, que incluso cuando atravesaba el mar no se mojaba los ejes. El rey de Pisa Enómao, que tenía una hija, Hipodamía, y bien porque él estuviese enamorado de ella, como dicen algunos, bien porque según un oráculo hubiera de morir a manos de su yerno, nadie la tomaba por esposa, pues el padre, al no haber podido convencerla para que se uniese a él, mataba a los pretendientes. Enómao, que tenía armas y caballos recibidos de Ares, ofrece su hija como premio a cada pretendiente; éste debía huir con su carro con Hipodamía hasta el istmo de Corintio. Enómao, armado, al punto lo perseguía y, si lo alcanzaba, le daba muerte; quien consiguiera escapar le daba a Hipodamía como esposa. De este modo había matado a muchos candidatos [...]

También Pélope acudió a pretenderla; Hipodamía [...] se enamoró de él, y persuadió a Mírtilo [...] para que le ayudase. Mírtilo era el auriga de Enómao, y como amaba a Hipodamía, deseoso de complacerla, no puso pernos en los ejes de las ruedas e hizo así perder la carrera a Enómao, que enredado en las riendas fue arrastrado y murió; otros dicen que lo mató Pélope. Enómao moribundo, enterado de la maquinación de Mírtilo, lo maldijo rogando que pereciera a manos de Pélope

El frontón oriental del templo de Zeus en Olimpia inmortiliza los momentos previos a la fatal carrera. Según recoge Conrado Durantez en su publicación de 1977, Las Olimpiadas Griegas, Pausanias describe quien es quien en el magestuoso grupo escultorico:

En los frontones, figura en el de delante la carrera de carros que iba a celebrarse entre Pélopoe y Enómao y la preparación de ambos para ella. Una imagen de Zeus esta en el centro del frontón y a la derecha está Enómao con casco a la cabeza, y junto a él su mujer Estérope, una de las hijas de Atlas. Mírtilo el auriga de Enómao, está sentado delante de los caballos, los cuales son cuatro. Despues vienen dos hombres que no tienen nombre, encargado por Enómao de cuidar sus caballos. De este lado figura en el extremo el Cladeo, despues del Alfeo es el río más venerado por los eleos. A la derecha de Zeus están Pélope e Hipodamía, el auriga de Pélope y los caballos, dos hombres, lacayos tambien de Pélope, y donde otra vez se estrecha el frontón está el Alfeo

Tambien Píndaro en la Olímpica l, a partir del verso 65 nos canta una parte de los hechos

$Y$ así, los Inmortales

a su hijo remitieron a la raza

efimera del hombre. $Y$ cuando, luego,

en la flor de su edad, ennegrecía el bozo de su mentón, al matrimonio aspiró que ofrecía el soberano

Antistrofa 3

de Pisa, y se propuso

obtener la mano de su padre

a la noble Hipodamia. En plena noche

y solo dirigióse

a la orilla del mar de blanca espuma,

e invoca al dios, que altisonante, empuña

el tridente. $Y$ el Numen se le muestra.

$Y$ a él entonces: "si los dulces dones

-dice- de Cipris, Poseidón, merecen

una compensación, ataja ahora

la broncínea alabarda de Enomao

y condúceme a Élide en tu carro

más rápido, y acércame al Triunfo.

Que trece procos ya entregó a la muerte,

$Y$ asi va dilatando el matrimonio

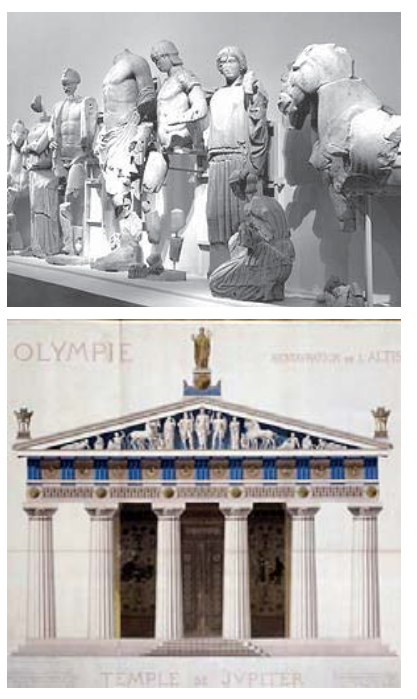


Epodo 3

de su hija. Un riesgo ingente

a un cobarde no acepta. Y si la muerte

es lo que nos espera,

¿a qué vivir sentado en la tiniebla

$y$ consumir en vano

una vejez sin nombre

ajeno a todo bien? Jamás. Yo quiero

afrontar esa prueba,

y tú otórgame el éxito en la empresa."

Así dijo apoyándose

en palabras que hallaron cumplimiento.

Y para honrarle concedióle el Numen

áureo Carro y unos alados potros

Que nunca se fatigan.

Estrofa 4

Y sometió la Fuerza de Enomao,

$y$, a su lecho, a la virgen.

Seis hijos engendró, seis capitanes

de esforzado valor. Y hoy él preside

llustres sacrificios,

y reposa a la orilla del Alfeo,

en una tumba cabe

un altar que visian peregrinos

sin cuento. Resplandece allá a lo lejos

de Pélope la gloria

en gracia a los certamenes de Olimpia,

en donde se compite a la carrera

y en la lucha tenaz. $Y$ aquel que vence

goza ya para el resto de sus días

una dulce bonanza,

Y, ciertamente, en Olimpia, en el centro del Altis estaba situado el Pelopion, recinto sagrado dedicado Pélope. Su estructura inicial era un túmulo de tierra que se remontaba a la época micénica.

Según ésta segunda leyenda Pélope, nuevo señor de la Élide, instituyó los Juegos para conmemorar su victoria sobre Enómao, añade Conrado Durantez.

Pausanias en otros fragmentos, se refiere al mítico héroe Heracles como organizador de los Juegos, cuando conquistó Elis, capital de la región de Elida. El motivo que el mismo Pausanias atribuye a la feroz invasión, es el siguiente: Augias, rey de Elida, tenía tanto ganado que la mayor parte de sus tierras no eran aptas para el cultivo y la tarea de limpiarlas era de tal magnitud que se veía impotente para ello. Siguiendo, una vez más, el relato de Conrado Durantez:

Augias convino con Heracles que si él era capaz de realizar tamaño trabajo, le entregaría una zona de Elida o bien la décima parte del numero de cabezas de ganado de sus rebaños. El astuto Heracles realizó rápidamente su labor desviando para ello las aguas de los ríos Alfeo y Peneo haciendolos pasar por las tierras de Augias, que en breve plazo quedaron libres del cúmulo de excrementos que la esterilizaban. Pero cuando Heracles fue a reclamar al rey la recompensa del pacto, Augias se negó a entregarsela por considerar que el exito obtenido por el heroe en su empresa, habia sido debido más a la habilidad que al trabajo.

Y Píndaro también le adjudica la instauración de los Juegos en su Oda Triunfal Olimpica X, Epodo 3

el Tiempo. Él en su curso ha revelado

a la posteridad de qué manera

repartió Heracles el botín de guerra,

ofreció las primicias,

y cómo organizó los festivales

cuatrienales, fundando

la primera Olimpíada y los premios.

¿Quién fue el que conquistó el trofeo alado

con sus manos, sus piernas o su carro,

aspirando a la gloria de los Juegos

y lograndolo al fin con sus acciones? 
Pausanias, relata que el propio Heracles, una vez instaurados los Juegos, consiguió las victorias en la lucha y en el pancracio y sus yeguas alcanzaron la victoria en la carrera de carros conducidas por lolao, su sobrino e hijo de Ificles y Automedusa, que era uno de sus más fieles compañeros y auriga de su carro.

Por eso, tal vez, las metopas dorias del templo de Zeus en Olimpia ilustran los doce trabajos míticos de Heracles. Son doce relieves casi cuadrados de 160 de altura, con figuras casi a escala natural, realizados hacia el 546 a. C.

Hemos podido comprobar, basándonos en los textos citados de referencia, que los dioses, los héroes y los hombres, en una época protohistórica, entremezclaron sus destinos para el establecimiento "mitico" de los Juegos de la atigüedad clásica. Y que esta acepción de "mito" corresponde inequivocamente con la primera entrada del diccionario de la RAE, "narración maravillosa situada fuera del tiempo histórico y protagonizada por personajes de carácter divino o heroico. Con frecuencia interpreta el origen del mundo o grandes acontecimientos de la humanidad".

\section{B.1.3.1.2 Origen mítico de los Juegos Modernos}

En 1894 Pierre de Fredy, barón de Coubertin, iniciaba la singladura del Movimiento Olímpico Moderno en las aulas de la parisina Universidad de la Sorbona. Habían pasado mil quinientos y un año desde que el emperador romano Flavio Teodosio I el Grande prohibiera en el año 393 los Juegos Olímpicos por considerarlos paganos' . Es importante destacar que el Movimiento Olímpico Moderno geminó en un sustrato de cultura y conocimiento, en el que se propugnaba que la educación física y el deporte formaran parte de los conceptos fundamentales de una educación integral.

El interés por los Juegos de la antigüedad se despertó con la exhumación de los restos arqueologicos del santuario de Olímpia.

Como base, nos apoyaremos otra vez, en el experto y entusiasta relato del Presidente de la Academia Olímpica Española, el magistrado Conrado Durantez, esta vez, sobre la investigación arqueologica de Olímpia.

El primer viajero del que tenemos conocimiento que busco la desaparecida Olimpia, fue el intelectual, diplomatico y militar sueco de origen alemán Matthias Palbitzki (1623/1677), que en 1647, en su largo viaje por Europa, visitó el valle en el que estuvo el antiguo y desaparecido santuario.

Casí un siglo después, en 1723 está fechada la infuctuosa carta escrita por el monje benedictino, además de historiador, traductor, bibliógrafo, paleógrafo y editor, Bernard de Montfaucon (1655/1741) al obispo de Corfú, tambien aficionado a las excavaciones arqueologicas en su diocesis:

ipero que representan todos juntos en comparación de lo que se podría hallar sobre la costa de Morea opuesta a estas islas?. Se trata de la antigua Elis en donde se celebraban los Juegos Olimpicos y en donde se erigían una infinidad de monumentos a los vencedores con estatuas, bajos relieves e inscripciones. Es preciso que la tierra sea allí removida, ya que como creo, aún nadie ha buscado en el lugar.

El merito de descubrir el lugar exacto del enclave se lo debemos a estudioso de la antigüedad, el inglés, Richard Chandler (1737/1810), que en 1766 observó como humildes casas de campesinos contenian materiales de inusitada nobleza, sin duda pertenecientes a la antigüedad clásica. De su olfato no podemos dudar, ya en Atenas él mismo confiesa, en su publicación de 1769, titulada lonian Antiquities Hemos comprado dos finos fragmentos del friso que encontramos insertos en unos portones de la ciudad, y los vendedores se presentaron con un hermoso fragmento perteneciente a las metopas, y que yacía olvidado en el jardín de un turco

Las piezas a las que se refiere, eran restos del Partenón.

Volviendo a su descubrimiento en Olimpia, siguiendo las descripciones de Pausanias, Chandler, localizó el templo de Zeus, descubriendo fragmentos del muro de la cella y de un capitel.

La primera planificación cientifica para la excavación de Olímpia, corresponde a 1767, con los estudios de campo del padre de la arqueologia moderna, el alemán Johann Joachim Winchelmann (1717/1768). Su asesinato un año despues, en 1768 , impidió su puesta en marcha.

Pasados veinte años, en 1787, el francés Fauvel levanta el primer plano topografíco preciso del lugar.

A principios del siglo XIX se inicia una etapa en la que los arqueologos ingleses realizan una importante
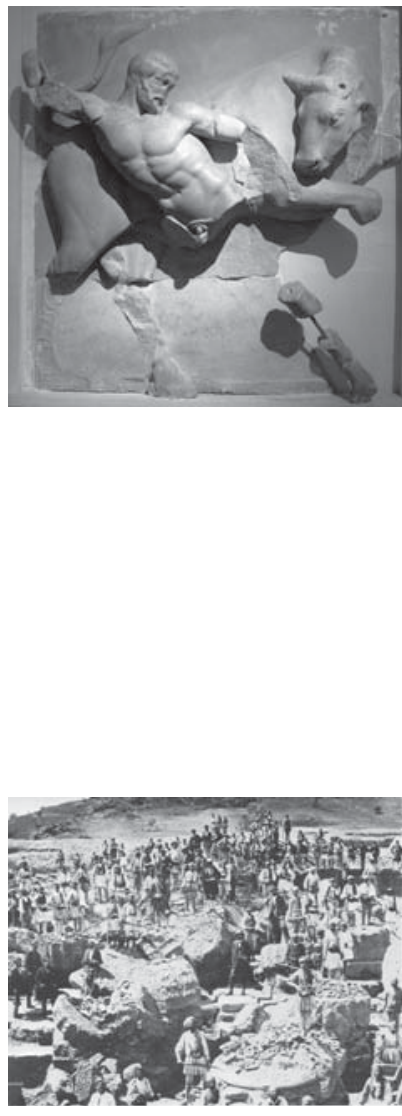

1. Dato histórico que se ha venido dando por cierto pero que el investigador Conrado Durantez está en la actualidad preparando un documentado estudiocon la pretensión de rebatirlo 
actividad, según relato de Conrado Durantez:

El 25 de febrero de 1805 llega el capitan (William Martin) Leake a la región y despues de examinar detenidamente lo conseguido en las anteriores investigaciones declara: "hay razones para creer que están todavía por realizarse los descubrimientos más importantes de Olímpia". Durante tres días enteros (Edward) Dodwell y (William) Gell, ayudados por un grupo de turcos contratados, excavaron en las inmediaciones del emplazamiento del Templo de Zeus, encontrando trozos de columnas y fragmentos de capiteles. En 1807, Wilkins, en su obra Antigüedades de la Magna Grecia, publica un plano de la planta del gran Templo de Zeus en la que da ya la distribución correcta de las columnas de $6 \times 13$ que componian el peristilo, y poco despues en 1813 , el celebre arqueologo Cockerell, visita tambien Olimpia, levantando Lord Spencer Stanhope un plano detallado del lugar basado en las primeras medidas que le falicitó el arquitecto Allason.
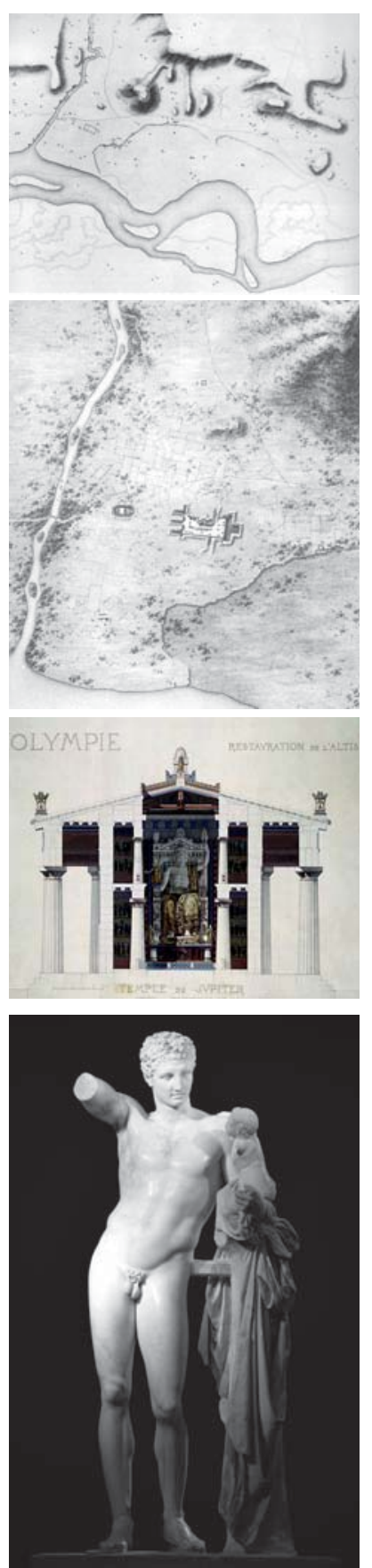

En la lucha de independencia de Grecia contra el Imperio Otomano, un grupo del ejercito francés, en auxilio de los rebeldes, desembarca en las costas de Morea. Una vez consolidada la posición, una segunda oleada de expertos del museo del Louvre, inician las excavaciones en Olimpia, centrándose en el Templo de Zeus y sacando a la luz buena parte de las metopas que representaban los trabajos de Heracles. Finalmente el nuevo gobierno griego prohibe las excavaciones pero permite que lo exhumado quede en poder de los franceses que se lo llevaron al Museo del Louvre, donde hoy se encuentran. En 1831 se publicaron los resultados de las excavaciones en dos volumenes titulados Expedición Científica de Morea. Los expedicionarios pasaron seis semanas, a partir del 10 de mayo de 1829, en Olimpia. Siguiendo las instrucciones marcadas por el arquitecto y arqueologo Jean-Nicolas Huyot (1780/1840) y bajo la dirección del arquitecto Guillaume-Abel Blouet (1795/1853) y el arqueologo J.J. Dubois se realizaron las excavaciones. En la expedición participaron tambien los pintores Poirot, Trézel y Duval. A esta expedición debemos los magnificos grabados y dibujos que nos han legado.

Con la coronación de Otón I, hijo de Luis de Babiera, como rey de Grecia, en 1833, y el nombramiento del arqueologo alemán Ludwig Ross (1806/1859) como Conservador de las Antigüedades de Grecia, la influencia alemana se hace notar. En 1852, Ernst Curtius pronuncia un apasionado discurso, ante la sociedad cientifica, sobre Olimpia, su significado y la necesidad de abordar de forma metolologica su excavación. Despues de muchos abatares, en 1874, se firma el contrato que permitía la concesión de las excavaciones al gobierno alemán. En 1875 se inicia una serie de seis campañas que finalizan en 1881 . En ellas se sacó a la luz la mayor parte de lo que ahora conocemos de Olimpia. La direccín de estas excavaciones se llevaba desde Berlin con la dirección de Ernst Curtius (1814/1896) y de Friedrich Adler (1827/1908). Repartiendose los trabajos de campo los doctores Gustav Hirschfeld, R. Weil, Greorg Treu, Adolf Furtwängler y Karl Purgold, los arquitectos Richard Bohn, Wilhem Dörpfeld y Paul Graet, y los maestros de obras Adolf Boetticher, Streichert, Steinbrecht y Bormann. Las conclusiones de sus trabajos se publicaron con los titulos Olympia. Resultados de la Excavacion. Tomos I-V (1890/1897) y Olimpia y sus alrededores, que incluia plano dibujados por Wilhelm Dörpfeld y Jahann August Kaupert, 1882.

Por la fechas anteriores podemos comprobar que el punto algido del conocimiento e interés por el pasado explendoroso de Olimpia coincide con la del momento historico del discurso de Coubertin en la Sorbona.

Y podemos entender la fascinación que producia la exhumación de una gran cultura, capaz de tan altos logros artisticos. El Hermes de Praxíteles había sido encontrado el 8 de mayo de 1877, al lado del Templo de Hera, en el mismo lugar donde Pausanias lo habia descrito (V.-17,3).

Pero lo importante era que en el fondo de los Juegos había toda una concepción armonica, religiosa y politica del mundo. Un mundo que se caracterizaba por el espiritu agonal, propio de la sociedad arcaica, en la que lo que importa sobre todo es la lucha, el certamen, el concurso, en el que el mejor exhibe sus cualidades y excelencias. Los Juegos eran en honor de los dioses y a ellos se dedicaban sus victorias. Los participantes eran hombres libres, que lo hacian por el honor y la gloria, en representación de sus ciudades. Obteniendo como único premio una rama del olivo sagrado. Y según el anteriormente citado José Alsina

Lo importante es vencer, porque con la victoria el atleta tiene la posibilidad de encargar a un gran poeta la oda triunfal, que ensalzará su persona y su familia hasta extremos inauditos, si bien el mismo poeta no dejará de recordarle que nuestra condición es mortal y que resulta altamente peligroso el elogio excesivo y la ambición de convertirse en dios. Las columnas de Hércules marcan el fin del mundo, suele decir Píndaro, con lo que se quiere recordar al vencedor las limitaciones de la existencia humana. Querer superar estos limites es hybris, insolencia, y los dioses suelen castigarla duramente. 
conoce como "fair play".

Y se decretaba una tregua sagrada, ekekheria, que era pregonada por los espondoforos (mensajeros de la paz), y aquél que la quebraba quedaba excluído de los Juegos.

Este espiritú de paz inspira la actúal Carta Olímpica, cuando, en los principios fundamentales 3, 6 , manifiesta

el olimpismo aspira al establecimiento de una sociedad pacifica y comprometida con el mantenimiento de la dignidad humana... Ilevando a cabo... acciones a favor de la paz... a fin de tender a construir un mundo mejor y más pacifico

La Carta Olimpica, es la codificación de los principios fundamentales del Olimpismo y establece las reglas que lo rigen. Su primera publicación fue en 1908, bajo el titulo Annuaire du Comité International Olympique, y algunos de sus puntos habian sido escritos por Pierre de Coubertin alrededor de 1898. En sus principios fundamentales, que figuran a continuación, se recoge con claridad el transfondo del "mito" de los Juegos de la antigüedad; recordemos la tercera acepcion de mito del diccionario de la RAE, "cosa rodeada de extraordinaria estima"

1 El Olimpismo es una filosofía de la vida, que exalta y combina en un conjunto armónico las cualidades del cuerpo, la voluntad y el espíritu.

Al asociar el deporte con la cultura y la formación, el Olimpismo se propone crear un estilo de vida basado en la alegría del esfuerzo, el valor educativo del buen ejemplo y el respeto por los principios éticos fundamentales universales.

2 El objetivo del Olimpismo es poner siempre el deporte al servicio del desarrollo armónico del hombre, con el fin de favorecer el establecimiento de una sociedad pacífica y comprometida con el mantenimiento de la dignidad humana.

4 La práctica deportiva es un derecho humano. Toda persona debe tener la posibilidad de practicar deporte sin discriminación de ningún tipo y dentro del espíritu olímpico, que exige comprensión mutua, solidaridad y espíritu de amistad y de fair play.

5 Cualquier forma de discriminación contra un país o una persona basada en consideraciones de raza, religión, política, sexo o de otro tipo es incompatible con la pertenencia al Movimiento Olímpico.

\section{B.1.3.2 Destrucción y olvido.}

Para la creación y consolidación de las leyendas y de los mitos es conveniente establecer una cierta distancia entre los mismos y el observador.

Pío Baroja en su narración, publicada en 1934, Las Noches del Buen Retiro, en un fragmento ambientado en una tertulia en la Nochebuena, un personaje refiere el cuento, donde se insertan los siguientes versos: En mi huerta te criaste,

tu fruta nunca la vi:

los milagros que tú hagas

que me los claven aquí.

Se refiere a un hecho ampliamente recogido por el folklore popular, en cancioncillas, versos, copla y refranes. Como este cuento popular, recogido en la revista de Folklore, numero 317, de 2007

Un hortelano que tenía un naranjo, un naranjo, un naranjo agrio, pero no había echado nunca naranjas y se secó. El naranjo estaba seco. Pero iban a hacer un santo. Le decían san Nicolás. Y era un santo imuy grande! Entonces los de la Hermandad dicen:

-iOye! ¿̇Pues tú no sabes dónde hay un árbol muy bueno para hacer ese santo? Ése lo tiene Fulano en la huerta.

-Vamos a ir por él.

Dice:

—Bueno, a ver si nos lo quiere vender —dice-. Está seco, pero sí ahora mismo...

$Y$ le dijeron:

- ¿Nos va usted a vender el naranjo este, que vamos a hacer un santo, san Nicolás, que se ha averiado?

Dice:

1. BAROJA, Pío. (1934). Las Noches del Buen Retiro. Ed. Tusquets. ISBN: 978-84-8310-635-8 
—iHuy! Sí, sí.

-Pues venga.

-Y no lo voy a vender: lo voy a dar - dice-; pero os voy a decir una cosa. De los lados me tenéis que dejar para hacerme un pesebre a la burra.

Dice:

—Bueno, pues entonces... ivale, vale! Yo lo..., lo dejamos.

- Pero cuando el santo esté hecho, me tenéis que llamar para verlo yo, porque yo tengo que decirle una cosa.

Y cuando ya el santo lo tenía hecho, le llamaron. Él ya, él ya había hecho el pesebre para la burra y todo.

Cuando el santo estaba hecho y todo, le llamaron, y le dijo..., se puso debajo del santo y le dijo:

-Del pesebre de mi burra,

eres hermano carnal.

En mi huerto te crié y fruto no comí.

Los milagros que tú hagas,

que me los cuenten a mí.

Otra versión popular dice

¿Cómo en tus milagros creo, si te conocí ciruelo?

Esta claro que hace falta establecer una distancia temporal, una capacidad de olvidar.

Como habíamos dicho anteriormente, el hombre crea los mitos y los olvida, para luego, sorprenderse cuando los encuentra.

El mito se justifica y alimenta con el descubrimiento de algo perdido y olvidado. Necesita el asombro y el enigma. Según Aristóteles la filosofía surge de la admiración que los hombres sienten ante el mundo. Es el asombro que experimentamos ante el espectáculo enigmático que despliega el universo lo que nos mueve a filosofar. Pero como el propio Aristóteles se encargó de indicar, ése es el mismo fondo del que surgen los mitos, y también ellos, al igual que la filosofía, pretenden proporcionar una interpretación coherente de la realidad que otorgue un sentido al mundo.

Mito, originariamente en griego significaba "palabra verdadera", ha acabado siendo sinónimo de algo así como relato inventado o cuento. Según el sociólogo alemán Max Weber (1864/1920), el proceso de desencantamiento del mundo es consustancial al desarrollo de las sociedades modernas.

Vamos a comprobar como en ambos casos, en los Juegos de la antigüedad y en los modernos, existió un pasado esplendoroso, que acaba trágicamente y que cae en el olvido. Que posteriormente se "descubre", y este descubrimiento produce admiración y nostalgia de un pasado mejor. Pero, antes vamos a conocer esos dos finales trágicos y esos dos olvidos paralelos.

\section{B.1.3.2.1 Destrucción y olvido previos a los Juegos de la antigüedad.}

Pausanias nos introduce en el asunto del olvido, en su ya citado, repetidamente relato, recogido por Conrado Durantez

El viaje mítico de Oxilo que llega a las comarcas peloponésicas acompañado de los heraclidas y de los pueblos dorios, no es más que otra versión de la invasión nórdica...

Los heraclidas eran los descendientes de Heracles. Hasta en la época helenística muchos linajes nobles se decían heraclidas.

Centrémonos cuando Oxilo al mando de sus etolios, llegó hasta Elida para su conquista

...Como las fuerzas atacantes y defensoras estaban equilibradas en poder, Oxilo convino con el rey Eleo que la victoria se dilucidase por un duelo singular entre dos representantes de ambas bandos. Por los Eleos fue elegido Degmeno arquero de gran habilidad y por los etolios el hondero Pirecnes. Venció éste y consecuentemente Oxilo recuperó el reino de sus antepasados. Después de su victoria, el nuevo rey permitió a los antiguos habitantes que siguieran en sus tierras en las que también instaló colonos etolios que se mezclaron con los eleos. Concedió honores al rey depuesto y embelleció notablemente la ciudad de Elis, haciéndola populosa y rica cuando convenció a los que habitaban las aldeas próximas a sus murallas para que se trasladasen a vivir dentro del mejorado recinto urbano. ...

Este fragmento nos habla del cambio de una cultura rural y aristocrática a otra basada en las polis y 
la cooperación.

... Protegió a los primeros pobladores aqueos maltratados por los invasores dorios y restableció los Juegos Olímpicos con tanta magnificencia, que algunos lo han considerado como su verdadero fundador, ya que desde los tiempos de Heracles, aquellos habían caído en desuso.

En los relatos de Pausanias sobre la instauración de los Juegos por Heracles, o Pélope, la relación entre hombres, héroes y dioses era distinta que en los tiempos del anterior relato. El profesor de filosofía Pedro González Calero, hablando de la datación de Troya, también nos describe el pasado como bello y lejano

Cuando, varios cientos de años después de la época de Homero, los griegos llegaron a ser filólogos e historiadores, entraron a discutir la fecha de la caída de Troya. La datación más generalmente aceptada fue la del año 1184 antes de Cristo. Para el poeta, los acontecimientos que narra se sitúan en un pasado bello y lejano, cuando los hombres eran más altos y más fuertes de lo que ahora son, y los dioses iban y venían entre aquéllos. No nos dice cuánto tiempo hace de esto, ni por qué no había héroes nacidos de dioses en los días del poeta... Las hazañas de los poemas de Homero se sitúan, tímidamente, en la Edad de Bronce, cuando Micenas era rica en oro.'

Pero ¿̇qué ocurrió entre medias?, sabemos que el aristocrático mundo micénico entró en una época de decadencia y oscuridad. Su cultura estaba fuertemente influenciada por la minoica; habían desarrollado la escritura, se expresaban en griego e invocaban ya a los mismos dioses que presidieron, desde el Olimpo, la historia de la Grecia clásica. En las tablillas micénicas redactadas en la escritura denominada lineal B, figuran los nombres de Zeus, Hera, Atenea, Poseidón...

Varias teorías explican, sin las suficientes pruebas documentales el ocaso de esta cultura. Manuel Bendala, catedrático de arqueología de la Universidad Autónoma de Madrid, en su publicación de 1994, titulada Los Albores de Grecia, nos aporta una primera visión

Pese a que la reciedumbre de sus ciudadelas pudiera presagiar una resistencia casi indefinida ante cualquier contingencia, la civilización micénica se derrumbó, como un castillo de naipes, apenas sus gentes se habían enjugado el sudor que derramaron con la construcción de sus murallas sobrehumanas. Un grave acontecimiento, o una cadena de ellos, dio al traste con los reinos micénicos, y de la brillantez de sus tiempos de gloria, se pasó a un período oscuro, hundido en una profunda depresión, y poco accesible al investigador, que se enfrenta con él al más vidrioso problema de la historia de la arqueología griegas. No es nada fácil saber que es lo ocurrió exactamente, pero el hecho es que la investigación presenta un panorama repleto de ciudades destruidas y abandonadas, de gentes que huyen acá y allá, como cierre de la floreciente etapa arqueológicamente clasificada como del Heládico Reciente III B.

Destrucciones y abandonos dan paso, pues, al periodo de profunda decadencia que Gilbert Murray calificó como Dark Age (época oscura), en su libro The Rise of the Greek Epic, publicado en $1907^{2}$.

Denominación que cuajó con éxito, ya que expresa fielmente la situación del mundo griego en ese periodo y la extrema dificultad de los investigadores para arrojar alguna luz sobre lo sucedido. Solamente un hecho casual se alía con los investigadores. En el siglo XIII aC., en el palacio de Pilos, la oficina de administración y el archivo sufren un voraz incendio y las tablillas con los asientos y contabilidad apuntados sobre tablillas de arcilla cruda, se cuecen convirtiéndose en ladrillos con capacidad de soportar el paso del tiempo y revelarnos su contenido. Significan una excepcional mirilla sobre lo que sucedía antes de la destrucción total del palacio.

Estas tablillas demuestran una gran actividad antes de la destrucción del palacio con importantes acopios de viveres, recuento de armas, instrucciones de vigilancia. Todo fue inútil, al final, el palacio y la ciudad fueron destruidos. Y lo sucedido en Pilos no fue un caso aislado. Derrumbándose, en todo el ámbito micénico, el orden presidido por las poderosas monarquías, con él desaparecería la burocracia palaciega organizadora de los intercambios, tributos y todo lo que regulaba la intensa actividad económica basada en el comercio internacional. Y con los burócratas, también, desaparece la escritura. ¿Pero quines fueron los causantes de tales desastres? Retomamos el relato del profesor Bendala

La historia tradicional, a partir de las noticias transmitidas por Tucídides y otros historiadores antiguos, del estudio de los dialectos griegos y de otros indicios, explicaba

1. González Calero, Pedro (2012). Filosofía para bufones. Ed. Planta. Col Ariel. ISBN: 9788408005223

2. Gilbert Murray (1866/1957) Helenista britanico, professor de la Universidad de Oxford. Editado por Clarendon Press 
el final de la civilización micénica de forma sencilla o, mejor, muy simple: la penetración en Grecia de una estirpe de griegos, los dorios, que desde las regiones del norte invadieron el territorio dominado por los micénicos; la violencia de la invasión y la rudeza cultural de estos griegos dóricos sumieron a Grecia en la decadencia...

Esta penetración dórica se relacionaba o asimilaba con el relato mítico del Retorno de los Heráclidas.

Esta explicación era comúnmente admitida, pero no ha podido corroborarse con los hallazgos arqueológicos, es más, estos la han puesto en entredicho.

El gran micénico ingles, John Chadwick (1920/1998), en 1975 en una conferencia en Roma, titulada Chi erano i dori?, propone una nueva y sugestiva hipótesis: en el mundo micénico convivían dos estratos lingüísticos, ambos dialectos del mismo idioma griego. Uno muy dinámico y con grandes influencias minoicas, denominado standard, que era usado por la aristocracia y los burócratas. El otro el substandard, hablado por las amplias clases inferiores.

La lengua substandard seria en protodorico y los dórios no serian sino la masa de la población de los reinos micénicos; estaban pues en el ámbito micénico y no tuvieron que venir de parte alguna. La imposición del dialecto substandard fue una más de las consecuencias del colapso de la civilización micénica, con una inversión violenta de la estructura social.

El doctor Klaus Kilian (1939/1992) del Instituto Arqueológico Alemán, que excavó en Tirinto en los años ochenta, defiende que la ruina de las ciudades micénicas se debe fundamentalmente a desastres naturales. La destrucción de Pilos la atribuye a un terremoto y las huellas de esos temblores telúricos las encontró Kilian en la mayoría de las ciudades: Micenas, Tirinto, Midea, Atenas, Tebas, Lefkandí y otras incluida Troya.

Seguramente el colapso de la cultura micénica produjo el "desvanecimiento" de los Juegos y su olvido. Los motivos del ocaso, las invasiones, la decadencia, los terremotos... tal vez, algún día lo podamos afirmar con seguridad.

\section{B.1.3.2.2 Destrucción y olvido previos a los Juegos modernos.}

Sobre las teorías e hipótesis del origen de los Juegos hay una muy amplia bibliografía.' El interés de su estudio, propiciado por el misterio e incertidumbres que las envuelve, han eclipsado el relato de su declive y ocaso.

Según recoge el profesor de Historia de la Antigüedad de la Universidad de Graz, Ignomar Weiler (1938), en su estudio "Problems in the Discussion of the Reason for the Decline of the Ancient Olympic Games" ${ }^{2}$, de 1984, solamente y en esa fecha, existía un análisis que se ocupaba exclusivamente de esta cuestión; "Las razones de la decadencia de los antiguos Juegos Olímpicos", por Kleanthis Palaeologos. ${ }^{3}$ Esto no significa, evidentemente, que se haya obviado el tema, porque existen muchos intentos de explicación en la literatura Olímpica.

Pero hay que destacar que ninguno de los autores que se han estudiado, ofrecen una única explicación. El estudioso berlines de la Antigüedad Clásica, Alexander Demandt ${ }^{4}$, lo achaca a un "cúmulo de factores". E indica que "la elección de una sola causa, algo que es popular entre los polemistas, sin embargo es inservible como un método de interpretación, ya que se muestra en contra de cuestiones concretas del relato histórico".

Un breve repaso de algunos de los libros canónicos, más conocidos, sobre la historia de la Antigua Olimpia nos debe proporcionar las condiciones en las que basarnos para construir un catálogo de hipótesis, argumentos y factores que subyacen a las explicaciones del declive de los Juegos.

Johann Heinrich Krause (1802-1882) realizó uno de los primeros estudios de la historia de Olimpia basado en un análisis exhaustivo de las fuentes. El Profesor Weiler le atribuye haber elaborado el

1. Por ejemplo:

ULF, Christoph y. WEILER, Ingomar (1981): Der Ursprung der antiken Olympischen Spiele in der Forschung. Versuch eines kritischen Kommentars, en: Stadion 6 p. 1-38.

Y tambien:

MARÓTI, Egon. Bibliographie zum antiken Sport und Agonistik (Acta Antiqua et Archaeologica 22, Budapest 1980) Nr. 307.

2. WEILER, Ingomar (1984) Problems in the Discussion of the Reason for the Decline of the Ancient Olympic Games. Ed. OARe 1984. Sesión 24, Academia Olímpica Internacional. Olimpia, pp 121-136

3. En: The International Olympic Academy. Undecima sesión (1971) p. 54-70.

4. DEMANDT, Alexander. (1984) Der Fall Roms. Munich, p. 541 y siguientes 
"primer estudio sistemático, con un gran nivel académico," dedicado a la agonística y gimnástica griega. El profesor Krause en su publicación sobre Olimpia de 1838, deduce que el apogeo de los Juegos se produjo en los ciento veinte años que separa la sexagésima y la nonagésima Olimpiada (540-420 aC). Según Krause, el "entusiasmo agonístico" por parte de los antiguos griegos en realidad no mueren en los últimos siglos de la era antigua, sino más bien se desplaza su centro de gravedad a la periferia del mundo griego. El poder y la influencia de Roma acentuaron esa tendencia, que en el fondo significó un cambio del modelo. Krause ve dos razones para esto; en primer lugar, la "mente romana", con su "fría seriedad cívica" tuvieron un efecto desfavorable sobre la agonística y en segundo lugar, los romanos desconfiaban de las grandes concentraciones en sus estados sometidos, de esa manera no mostraron ningún empeño en su promoción.

Krause nos dice muy poco acerca de la historia de los Juegos Olímpicos durante el período de la Roma Imperial, aparte de vagas indicaciones a medidas de apoyo de los emperadores Augusto, Trajano, Adriano, Séptimo, Severo, Didio Juliano y Flavio Julio Valente, y quedando solo claro que Teodosio I suspendió los juegos "para siempre", apenas una generación después de haber sido descritos, en tiempos Juliano, como un "importante y celebrado evento".

Poco después, el prestigioso arqueólogo que exhumó las ruinas de Olimpia, Ernst Curtius (1814/1896) ofrece otra versión. Según él, el período "cuando Píndaro cantaba y Fidias enseñaba", es decir, después de la gran victoria sobre los persas, fue la "edad de oro" de Olimpia ${ }^{3}$. Dos factores habían sentado las bases para ello, a saber, "el sentimiento de identidad nacional" y el "vigor y espíritu juvenil del pueblo". Pero cuando el vínculo Panhelénico se rompió con la guerra del Peloponeso, tan solo 50 años después de la batalla de las Termópilas, el declive de Olimpia se hizo evidente. Por lo tanto, la decadencia interna procedió de una cadena causal de acontecimientos. A pesar de las hostilidades en la guerra del Peloponeso, la "estatua de bronce de la paz de Dios" seguía en pie "en su antiguo lugar en el salón del templo", no concordando con la realidad del momento. Según Curtius, esta hipocresía llevó "con una velocidad aterradora a un proceso de secularización, junto con una pérdida de respeto por los dioses y por las leyes de sus antepasados". Todo esto da testimonio del "declive de una nación", donde la fe menguante era "incapaz producir el resurgimiento de un espíritu nacional, que se encontraba en crisis".

Además, otro importante componente del éxito de los Juegos también se tambaleaba, la alegría del festival, como punto de encuentro y celebración. El ardiente sol de julio y la humedad producida por las áreas pantanosas del curso del río Alpheios comenzaron a ser considerados negativamente y poco agradables. También la disminución de la prosperidad significaba un retraimiento a la asistencia a Olimpia.

Según Curtius estas son las razones internas del declive, que contrastan con cuestiones externas que apuntalan su supervivencia, como: el favor de los macedonios y sobre todo el impulso de algunos emperadores romanos. Olimpia alcanzó la respetable cifra de "casi trescientas Olimpiadas" y sus instalaciones "incluso sobrevivieron a la llegada del Cristianismo". Fueron únicamente las "grandes catástrofes las que destruyeron el Mundo Antiguo". Aquí Curtius se refiere tanto a las invasiones de los Bárbaros, como a los desastres naturales, inundaciones y terremotos.

Por su parte, el profesor de Columbia y experto en la historia de la Europa Oriental, Clarence Augustus Manning (1893/1972) data la "edad de oro de los grandes festivales" hasta el final del siglo VI aC. ${ }^{4} \mathrm{El}$ autor distingue dos períodos en la historia de los agones Panhelénicos, el primero el que va desde su inicio hasta la Guerra del Peloponeso ( $480 \mathrm{aC}$ ), "la edad del amateur", y el segundo hasta el $400 \mathrm{dC}$, "la edad del profesional". Este cambio se debió principalmente a la "influencia de los sofistas y al nuevo sistema de la educación". En primer lugar, la practica deportiva ya no era, como había sido hasta ese momento, "parte de la educación de todos los jóvenes" y, en segundo lugar, la popularidad de la gimnasia griega había sido socavada considerablemente por las "termas, desde en el siglo $V$ aC". El resultado fue, según Manning, que "los competidores, que originalmente eran miembros de las familias más importantes de Grecia ... pasaron a ser, finalmente, hombres con cerebros infrautilizados y organismos anormalmente desarrollados, a semejanza de los gladiadores romanos". El deporte fue profesionalizado, "convirtiéndose en comercio". Estas cuestiones constituyen, según Manning, las principales razones del declive de los ideales deportivos griegos y con ellos el de los propios Juegos.

Según, el historiador deportivo inglés, E. Norman Gardiner, las 25 Olimpiadas desde 576 a 476 aC constituyen el período más importante en el atletismo griego 5 : "Nunca tuvo un nivel más alto", porque "aún no existían los males de la especialización y profesionalidad".

Según Gardiner, "en el siglo III aC todo cambió". Olimpia, que había encarnado desde los tiempos

1. KRAUSE, Johann Heinrich. (1971). Gymnastik und Agonistik der Hellenen. Leipzig 1840. Ed. Hildesheim. Nueva York. Introducción.

2. KRAUSE, Johann Heinrich. (1972). Olympia. Viena 1838. Ed. Hildesheim. Nueva York. p. 45 y siguientes

3. CURTIUS, Ernst. Olympia. 1852-1879. (1935) Ed. Berlin. p. 64 y siguientes

4. MANNING, Clarence Augustus. (1917) Professionalism in Greek Athletics. Ed. Classical Weekly 11. p. 74-78.

5. GARDINER, E. Norman. (1925) Olympia. Its History and Remains. Oxford 1925. p. 96, 120, 150, 165 y siguientes. 
remotos de la colonización griega todos esos ideales religiosos, políticos y sociales, que los distinguían de la barbarie, a partir del siglo III aC perdió esa visibilidad y dejó de ser un factor de integración Panhelenico. Y aunque tanto los Juegos y el culto continuaron existiendo, Olimpia ahora sólo representaba "un ideal del pasado".

En la época romana, según Gardiner, el impulso de algunos emperadores propició nuevas etapas de esplendor. Pero a diferencia de épocas anteriores, la competencia estaba cada vez más monopolizada por los atletas profesionales, luchado por "su propia gloria y el beneficio" y no por el honor del Estado. Esto derivaba en una creciente brutalidad de los juegos.

También, el filohelenismo de Adriano y de sus sucesores trajo consigo "una nueva ola de brillantez al atletismo" y una nueva edad de oro a Olimpia, que duró hasta la mitad del siglo III dC. Sólo con el colapso de la pax Romana, provocada por la presión de los Bárbaros y sobre todo con el "poder que todo lo conquista del cristianismo" provoco el ocaso de Olimpia. En conclusión, podemos decir que Gardiner distingue dos factores de declive: la crisis de las ciudades-estado, en primera instancia y el ascenso del cristianismo para que Olimpia y los Juegos Olímpicos, se hundan en la insignificancia.

De acuerdo con la historia del deporte del arqueólogo Bruno Schroder (1878/1934), de gran influencia en el mundo de habla alemana, los Juegos Olímpicos disfrutaron de su apogeo en el siglo $\mathrm{V} \mathrm{aC}{ }^{6}$. Para Schroder las claves del ocaso de Olimpia consisten, por una parte, en que los atletas griegos pierden terreno frente a los de las colonias y por otra al emergente profesionalismo que "resta gran parte de su valor como ideal". Y sobre su final, dice; "sin duda también influenciado por el cristianismo", pero no añade más referencias.

En contraste, el estudio de Ferenc Mezö, Historia de los Juegos Olímpicos ${ }^{7}$, ganador del premio literario de los Juegos de Ámsterdam, es mucho más prolijo dedicándole un capitulo completo. Data el cenit de los Juegos para el período comprendido entre la 78 y 95 Olimpiada (468 a 400 aC). El final de este período coincidió con el auge del sofisma, que tenía un "efecto desmoralizador sobre la moral y la religión griega y, por tanto, también para los Juegos". La creciente preeminencia de la educación intelectual era, naturalmente, a expensas de la educación física. Además, según Mezo, ya no era el deporte en sí o el disfrute y el placer que se deriva del ejercicio físico lo que atrajo a los jóvenes a participar en los Juegos, sino más bien las "ventajas derivadas de beneficio económico y el anhelo por una vida desahogada". La agonística, que significaba una "forma noble y desinteresada de competencia", había sido reemplazada por el profesionalismo". Esta fue la razón para el aumento de los casos de corrupción y violencia en los Juegos.

Para Mezö, en la época imperial, se impone un predominio de las actividades intelectuales y una perdida de valoración de la actividad física. Además, en algunos casos, desde la literatura cristiana se refuerza es tendencia. Veamos por ejemplo el texto de Cipriano de Cartago, San Cipriano (200/258), en el que hablando de una competición deportiva dice: "Que vacíos son esos juegos con sus carreras... el pueblo se alegra cuando un caballo es más rápido que otros y se apena cuando es más lento... que deprimente, repugnante y deshonroso es ese afán."

Aunque también podríamos citar otros autores cristianos, como Eusebio, Metodio y Juan Crisostomo, que en sus alegorías de los atletas que luchan para llegar al cielo, se presenta una visión positiva de los juegos.

Para Mezö, la verdadera razón del declinar de los Juegos es más profunda y está íntimamente relacionada con el ocaso del mundo griego, "el mundo griego llevaba en sí el germen de su propia destrucción. Estaba maduro para su decadencia y su ocaso fue acompañado por el marchitamiento de la mejor flor del mundo antiguo, el festival de Olimpia".

Julius Jothner, uno de los mayores expertos en agonística y gimnasia antigua, estableció una síntesis entre los textos clásicos y sus consecuencias materiales para el deporte y entre la filología clásica, arqueología e historia antigua ${ }^{8}$. Concluye su primer volumen de la "Historia del Deporte de la Antigüedad" con un capítulo sobre la "Degeneración", en el que enumera los siguientes fenómenos característicos: la transición de la vieja conciencia nacional Helénica a un cosmopolitismo, por el cual incluso esclavos y extranjeros podían participar en los Juegos. Aún más, los atletas ya no competían por el honor de su ciudad natal, sino que también por las potencias extranjeras y por la ganancia material. $Y$ por último, que el gusto de los griegos derivó hacia los modelos de competición romanos, con sus juegos de gladiadores. Estas fueron las principales razones para el ocaso del deporte griego. Por lo tanto Jothner considera que las influencias extranjeras echaron a perder la fina sensibilidad deportiva de los helenos. Además alude a factores externos que aceleraron este ocaso. La falsa independencia de Grecia dentro del Imperio Romano y la oposición del cristianismo a todas las instituciones del paganismo, incluidos los juegos Panhelénicos.

6. SCHRÖDER, Bruno. (1927). Der Sport im Altertum. Berlin. p. 27

7. MEZÖ, Ferenc. (1930) History of the Olympic Games. Munich. p. 202-218

8. JOTHNER, J. (1945). Die athletischen Leibesobungen der Griechen. Ed. F. Brein, vol. 1, Vienna. p. 144-154 
Según el libro de Heinz Schobel (1913/1980) sobre Olimpia, que apareció en 1964, los Juegos Olímpicos llegaron a su apogeo "coincidiendo con las guerras persas, entre, aproximadamente, 500 y 450 a.C., a lomos por el fervor patriótico"'.

Schobel se refiere a la afirmación de Karl Marx de que el "siglo de Pericles" fue un "período de gran prosperidad interior", y hace coincidir el apogeo con ese mismo periodo. Luego, cita el "tiempo de entre 440 y 338 aC" como el "período de inicio de la decadencia", argumentándolo principalmente con criterios socio-económicos; Schobel habla ... de la "primera crisis griega de larga duración en la trata de esclavos", del "estancamiento de la polis", de las "diferencias de clase en las ciudades" y de la competencia entre los "pequeños fabricantes, sobre todo entre los agricultores y artesanos", como resultado de la mano de obra barata de los esclavos. Supone que las consecuencias de este proceso fueron el desarrollo del profesionalismo en el deporte y una gran brecha social entre los competidores. Para Schobel La Guerra del Peloponeso, con su consecuente crisis económica y política de la polis tuvo consecuencias particularmente graves para los Juegos Olímpicos.

Así, Schobel se opone a los historiadores que intentan explicar el declive por razones morales y espirituales. E insiste que las causas reales se asientan en las "transformaciones socio-económicas y políticas relativas a la trata de esclavos". La influencia de Roma sobre los Juegos Olímpicos también tuvo consecuencias negativas: "los romanos no veían ninguna utilidad práctica en la gimnástica griega". Y solo permitían los Juegos Olímpicos como parte de la compensación Imperial hacia los pueblos y provincias anexadas.

Olimpia, se había convertido "en un parque de atracciones deportivas", donde los juegos se habían contaminado con las "características del circo". La "decadencia final de agonísmo en Olimpia y en última instancia, el final de los Juegos Olímpicos" se produjo con la proclamación del cristianismo como religión de Estado en el año 393 dC. Aunque, Schobel continua insistiendo que la "grave crisis en el comercio de esclavos de la antigüedad impidió la supervivencia de la agón Panhelénico más significativo." Lo que quedaba de Olimpia fue destruido por los "poderosos" terremotos de 522 y 551 dC, con los cuales el célebre lugar desapareció de la vista antes de que pudiera renacer bajo unas "totalmente nuevas circunstancias sociales".

Carl Diem considera que la "edad de oro" de los Juegos Olímpicos debió haber sido de entre los años 468 y 337 aC. ${ }^{2}$ Después de estas fechas se produce el "inicio inconfundible de la declive" de los juegos. Acentuado con el proceso de conversión de Grecia en una provincia de Roma. Con esto Olimpia alcanzó su punto más bajo, antes de su última floración, en tiempos de la pax Augusta. Para Diem, el "festival de culto" se había transformado, en un "espectáculo sin sentido". Mientras en épocas anteriores, la competencia habían significado el jubilo de servir a Dios (Diem considera todo el ejercicio físico tiene sus orígenes en un culto), había pasado a ser un negocio. También hace una breve mención de la invasión de los Bárbaros y al papel del cristianismo y al edicto de Teodosio I. Diem sostiene que los griegos ya habían perdido su fuerza moral y que el espíritu olímpico se había "refugiado en Rodas, Bizancio y Alejandría", para "acabar muriendo en estos últimos santuarios de la libertad". Diem se refiere al factor dominante en el ocaso de los Juegos Olímpicos como la secularización pagana del deporte y la perdida de un "liderazgo de clase intelectual" entre los griegos.

El historiador deportivo y profesor alemán, Gerhard Lukas, relaciona el declive de Olympia con el de la misma polis griega ${ }^{3}$. Considera que el apogeo de los Juegos "había coincidido con el punto álgido del poder de las polis". "La estima por la agonística y la búsqueda de kalokagathía como expresión de una educación armónica" caracterizan el espíritu de la polis. Pero la Guerra del Peloponeso produjo una gran transformación. El debilitamiento económico redujo la capacidad de dedicar tiempo al cultivo del cuerpo. Además, después de Sócrates una división se había producido en el sistema educativo griego entre lo "intelectual y físico". De acuerdo con lo expresado por Lukas, resultó que las aulas de los sofistas se llenaran de estudiantes delgados y pálidos y que las arenas deportivas quedarán vacías. Pese a que el helenismo significaba una nueva consideración de los valores en los que habían florecido los Juegos, pero, definitivamente, el incremento de la influencia del cristianismo les había condenado, por su paganismo, y se fueron hundiendo en la insignificancia. Lukas concede especial importancia a la decadencia moral de la época imperial que hizo cada vez más evidente después de la segunda mitad del siglo II dC y llegó a su punto más bajo en el momento de Filostrato. Los "tejemanejes decadentes" en los gimnasios y en las termas y los "profesionalizados y decadentes atletas" testificaban una "decadencia moral".

Fijemos ahora nuestra atención en la investigación, antes citada, de Kleanthis Palaeologos, publicada

1. SCHÖBEL, Heinz . (1964) Olympia und seine Speile. Leipzig, 2nd ed. 1967 p. 32-45

2. DIEM, Carl. (1960) Weltgeschichte des Sports. 3rd ed. 1971. Stuttgart vol. 1, p. 232-238.

3. LUKAS, Gerhard. (1969). Die Korperkultur in frohen Epochen der Menschheitsentwicklung. Berlin. p. 107, 118,

145 y siguientes 
en The International Olympic Academy. Sesión Undécima (1971) p. 54-70', para seguir analizando la cuestión del declinar y ocaso de los Juegos. El autor entre una serie de factores destaca, como el "cambio de las creencias sociales, evolución de las instituciones, abandono de las tradiciones y de los dioses olímpicos". Palaeologos se refiere, además, a "un declive intelectual y físico en la gente del mundo antiguo".

Las conclusiones de los expertos nos permite establecer una horquilla o rango, tanto para las fechas como para las causas del ocaso de los Juegos. Procedemos a agruparlas en conjuntos con caracteres semejantes:

1. El declinar del entusiasmo agonístico en Grecia (J.H. Krause), perdida del sentimiento de identidad nacional (E. Curtius), declive intelectual y físico de la población (K. Palaeologos) y la perdida del liderazgo de clase intelectual entre los griegos. (C. Diem)

2. Desplazamiento del centro de gravedad de la cultura griega a las colonias, junto con la perdida de autonomía de las polis. (J.H. Krause, E.S. Gardiner, B. Schroder, F. Mezo, G. Lukas)

3. Perdida de la independencia del mundo Panhelenico, junto con la aparición del cosmopolitismo. (E. Curtius, E.S. Gardiner, J. Jothner)

4. Macedonios y romanos aportan una diferente sensibilidad, con un enfoque mas utilitario, derivado de su acusada formación militar. (K. Palaeologos, J.H. Krause, H. Schobel)

5. Avance de las tribus germánicas (hérulos). Final de la Pax Augusta. (E. Curtius, C. Diem, E.S. Gardiner)

6. La influencia de los sofistas en el ideario educativo griego, en particular sobre la kalokagathía (C.A. Manning, F. Mezo, C. Diem, K. Palaeologos)

7. Factores naturales, como terremotos e inundaciones (E. Curtius, H. Schobel)

8. Falta de independencia y protagonismo de Grecia bajo el dominio romano. J. Jothner, C. Diem)

9. La influencia del cristianismo (ES Gardiner, B. Schroder, J. Jothner, G. Lukas, H.-V. Herrmann); casi todos los autores se refieren al decreto de Teodosio I.

10. Profesionalización, a menudo asociada con el aumento de la corrupción y brutalidad (CA Manning, Th. Woody, B. Schroder, F. Mezo, J. Jothner, H. Schobel, K. Palaeologos)

11. El predominio de los intereses intelectuales de la época imperial (F. Mezo, G. Lukas, K. Palaeologos)

12. Las condiciones socio-económicas (H. Schobel, G. Lukas, K. Palaeologos)

13. Tendencia a la secularización (E. Curtius, C. Diem, H. Bengtson)

14. Crisis moral (G. Lukas, K. Palaeologos)

Después de todo este análisis podemos aventurarnos a establecer el siguiente resumen sobre el declive: Llegar a la conclusión de que el rechazo de una teoría con una sola causa parece tan trivial como la aceptación de un sistema que combina diferentes perspectivas.

En un intento de establecer "el cúmulo de factores" que explican el declinar y el ocaso de los Juegos Olímpicos de la Antigüedad Clásica y sí su inicio lo podemos hacer coincidir con la guerra del Peloponeso (431 al $404 \mathrm{aC}$ ) y el proceso de cambio que se producen en las condiciones socioculturales.

Pérdida de la autonomía de las polis y del desplazamiento del centro de gravedad de la cultura griega hacia las colonias periféricas.

Un cambio de mentalidad, que tiende a dar prioridad a las consideraciones intelectuales y emocionales, tendencia que se acrecienta durante el periodo imperial, con la influencia de las religiones mistéricas orientales y fundamentalmente del cristianismo y también de los pensamientos filosóficos como el neoplatonismo y neopitagorismo. Por otra parte los atletas defienden su estatus asociándose y profesionalizándose.

La presión por el avance de las tribus germánicas, la invasión de los hérulos en el año 267 dC y el decreto de Teodosio I en el 393 dC, sólo fueron el golpe final definitivo.

Los violentos terremotos que se producen entre los años 522 y 551 dC, junto con las inundaciones y desprendimientos de monte Cronos acaban por ocultar cualquier vestigio, cayendo la ubicación de Olimpia en el olvido.

En cuanto a la arquitectura del Santuario de Olimpia, el final lo podríamos resumir, siguiendo el relato de Conrado Durantez ${ }^{2}$, en su publicación Las Olimpiadas Griegas de 1977.

1. En: The International Olympic Academy. Undecima sesión (1971) p. 54-70.

2. Conrado Durántez Corral (1935) Magistrado, Presidente de la Academia Olímpica Española y Presidente de la 
A principios del siglo III dC todos los elementos arquitectónicos ya estaban trazados y se encontraban en perfectas condiciones de uso. Las últimas grandes obras habían sido un acueducto y su cisterna, denominada Exedra de Herodes Ático, en honor a su filántropo benefactor.

El principio del fin material comienza con la invasión de la tribu germánica de los hérulos, a principios del año $267 \mathrm{dC}$. Ante la gravedad de la situación el Senado Olímpico decide defender el templo de Zeus y su mayor valor la colosal imagen del dios, de marfil y oro, obra de Fidias. Para ello no dudan en desmontar otras construcciones para poder levantar una potente muralla, de mas de tres metros de grosor y cuatro de altura, alrededor del templo de Zeus. No sabemos los detalles del episodio, pero si que lograron el objetivo de defender la colosal estatua. Sabemos que en 395, dos años después del edicto de Teodosio I, la estatua de Zeus es transladada a Constantinopla y colocada en el palacio de Lausus, donde quedó destruida en un pavoroso incendio en el año $476 \mathrm{dC}$.

En ese mismo año los visigodos, comandados por Alarico l, que habían invadido Tracia y Grecia, saquean Olimpia. En el 408 dC los emperadores Teodosio II de Oriente y Honorio de Occidente dictan sendos decretos ordenando que todos los lugares y templo que sigan tributando culto a los dioses paganos sean destruidos. En el $426 \mathrm{dC}$ los grandes templos de Olimpia son incendiados. Los terremotos entre los años 522 y 551 dC acaban por dislocar y diseminar los grandes bloques de piedra de las antiguas construcciones.

Otra vez, el final es semejante, decadencia, invasiones, terremotos... y olvido.

Enterrados los gloriosos restos, el paraje hasta perdió el nombre. En un mapa veneciano de 1516, en el que aparece grafiada la confluencia de los ríos Alfeo y Cladeo, se denomina a la zona, Andilalo. En otra referencias la llaman Serviana.

\section{B.1.3.3 Reinstauración}

Después del olvido y su posterior redescubrimiento, la gran carga de significado que esto arrastra, es tierra fértil para un nuevo florecimiento. Y así se produce, otra vez y por dos veces.

\section{B.1 3.3.1 Reinstauración de los Juegos Olímpicos de la antigüedad}

Su restauración se produce en una época anterior a la histórica. Sus orígenes vuelven a estar envueltos en tinieblas, ¿̇cómo volvieron a reunirse los atletas para competir por la gloria en Olimpia?, con seguridad no lo sabemos, ni quien lo impulsó o favoreció.

Según Pausanias, la restauración se debe a Ífito, rey de los eleos. Descripción de Grecia, libro V, capítulo IV $(5$ y 6$)$

En el siguiente Ífito, un descendiente de Óxilo, y contemporáneo de Licurgo que dio las leyes a los Lacedemonios, restaura los Juegos Olímpicos, y dijo los días de reunión con una especie de tregua franca para la celebración de estos juegos, porque se habían interrumpido: la razón, la voy a decir en detalle en relación con Olimpia.

[6] Grecia gemía entonces desgarrada por las guerras internas, y desolado, al mismo tiempo por la plaga. ífito fue a Delfos para consultar al oráculo acerca de los males. Él fue respondido por la Pitia que restaurase los Juegos Olímpicos y sería la salvación de Grecia, por tanto esto se encargó a los Eleos. Ífito Inmediatamente ordenó un sacrificio a Hércules, para apaciguar al Dios que Eleos creían que les era contrario. Hay una inscripción en la entrada de Olimpia, que dice que Ífito era hijo de Hemon, pero la mayoría de los griegos creían hijo de Praxónidas, por los monumentos antiguos de los Eleos se demuestra que su padre llevaba el mismo nombre que él.

El relato de Pausanias, al entrar en escena el rey eleo Ifito comienza a tener un mayor grado de precisión histórica. $Y$ existen elementos de referencia o restos arqueológicos que avalan la narración. La existencia de Ífito, los historiadores la sitúan a comienzos del siglo IX aC. En esa época las tensiones migratorias se habían relajado, la organización social alrededor de las polis se estaba consolidando. Solo la conflictividad bélica significa un grave riesgo para los Juegos y su santuario.

De ahí, el gran éxito de rey Ífito, que logra firmar un pacto o acuerdo de paz entre los tres pueblos que se consideraban con derecho sobre el santuario. Por un lado los etolios o eleos de Elide, por otro

Asociación de Academias Olímpicas Ibereroamericanas.

DURANTEZ CORRAL, Conrado. (1977). Las Olimpiadas Griegas. Ed Delegación Nacional de Deportes. ISBN 84400-2621-8 
los aqueos o pisatios, de Pisa y por último los más poderosos y también los más alejados, los aguerridos espartanos de Laconia.

En el año 884 aC. firman la Tregua Sagrada (ekecheiria), los reyes Ífito por los eleos y Cleostenes por los pisatios. Y por los espartanos, el famoso legislador Licurgo. Por el tratado el territorio de Olimpia se declara inviolable, lo mismo que los atletas y peregrinos que se dirijan hacia allí, una vez proclamada la Tregua por los espondroforos o mensajeros de la paz.

Pausanias en su Descripción de Grecia, en el libro V capitulo XX (1), lo describe, quedando acreditada su existencia

En el templo de Hera hay muchas otras ofrendas hechas a la diosa, y dignas de curiosidad. Que vea, entre otras cosas, una cama forrada con marfil, el disco de ĺfito, y una mesa en la que está reservada la corona para los ganadores. Se afirma que la cama era un juguete de Hipodamia. El disco de Ífito contiene la tregua que los Eleos usan para indicar los Juegos Olímpicos con el tiempo de tregua y las franquicias que están siempre acompañados. Estas leyes están escritas en el disco, no en línea recta como usualmente ocurre, pero en toda su superficie y en círculos

También en el capitulo XVI (2) se deja claro el protagonismo que daban los antiguos a ífito con respecto a la Tregua

Al atravesar el bosque sagrado, me encontré regalos de Micito dispersos en todas direcciones, pero después de la estatua de ífito y Ecequiria (la tregua) que con sus manos está coronando al héroe

La definitiva entrada de los Juegos en la historia se produce en el año 776 aC., cuando se comienza a apuntar el nombre del vencedor en las tablas sagradas de Olimpia. El primero en tener ese honor fue Corebo de Elida, ganador de la carrera de un estadio (medida de longitud equivalente a seiscientos pies). Este hecho tiene una gran importancia en el mundo griego, porque sirve como punto inicial del computo del tiempo en Olimpiadas, espacio de tiempo fijado en cuatro años que separa la celebración de los sucesivos Juegos.

Pausanias, en el capítulo VIII (5 y 6), nos habla primero de olvido y recuperación de la memoria, muy en línea con la tesis aquí defendida y luego se refiere a la primera Olimpiada ganada por Corebo, es importante no confundir primera Olimpiada, con los primeros Juegos. Ya que, los Juegos se venían celebrando previamente a la instauración del computo del tiempo en Olimpiadas.

[5] Desde Óxilo, que no descuidó ninguno de estos espectáculos, los Juegos Olímpicos fueron interrumpidos hasta que los restaura Ífito. Habíamos casi olvidado, poco a poco lo van recordando, y al recordar a alguien en estos juegos, se añadirán a las que ya habíamos encontrado.

[6] Este es claramente el resultado de los Juegos Olímpicos que tuvieron cuidado de preservar la memoria, porque desde la primera Olimpiada (776 aC.) se ofrece un premio en las carreras, y fue Corebo de los Eleos quien ganó. No está su retrato en Olimpia, pero si su tumba en el borde de la Elide. En la decimocuarta Olimpiada (724 aC.) se añadió la doble carrera. el Pisano Hipeno fue el ganador de una corona de olivo, y en la siguiente Olimpiada el Lacedemonio Acanto fue coronado.

\section{B.1.3.3.2 Reinstauración de los Juegos Olímpicos modernos}

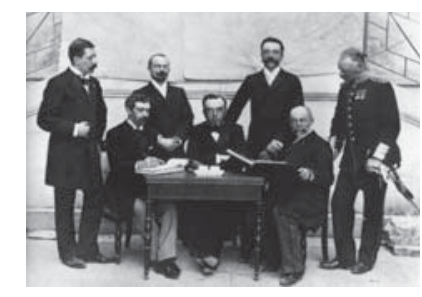

Coubertin habló, por primera vez, de su idea de unos Juegos Olímpicos en un discurso pronunciado en la Universidad de la Sorbona en 1892, pero su restauración no se haría realidad hasta dos años después en una conferencia internacional en el mismo lugar. Allí se declararon "restablecidos" los Juegos Olímpicos con la siguiente frase solemne: "Hemos votado unánimemente por la restauración de una idea con dos mil años de antigüedad, el Olimpismo de la antigua Hélade emerge después de muchos siglos" (Actas del Congreso de París de 1894).

El gran éxito de Coubertin, fue la combinación de dos binomios fundamentales, como son educación y deporte y por otro lado internacionalización y paz.

Antes de Coubertin había habido otros intentos de recuperación de los Juegos. En la propia Grecia bajo el impulso personal de Evangelos Zappas (1800/1865) se celebraron los primeros festivales olímpicos en Atenas. Y luego después de su muerte, según su mandato, los festivales olímpicos de los años 1870 
y 1875 , para lo cual, y también a su costa, había exhumado y acondicionado el estadio Panathinaikó.

Remontandonos en el tiempo otros muchos intentos, incluso en España y en la Edad Media. Es la referencia mas antigua que tenemos sobre la celebración de algo parecido a unos Juegos Olímpicos desde el colapso de los de la antigüedad clásica. Nos la proporciona el novelista murciano del siglo de oro español Ginés Pérez de Hita (1544/1619), que recoge en su "2 $2^{a}$ parte de las Guerras Civiles de Granada", publicada el año de su muerte en 1619, que en la ciudad almeriense de Purchena, en 1569, cuando los moriscos la convirtieron en cabeza del Valle del Almanzora, Abén Humeya, rey de los moriscos sublevados contra Felipe II, reviviendo tradiciones que su pueblo musulmán asimilara de los pueblos conquistados, convocó unos juegos deportivos y culturales, en los que se llevaron a cabo varias pruebas semejantes a las celebradas en de Olimpia (velocidad, triple salto y lucha), junto a música, baile y otra serie de competencias. Además los ganadores eran coronados con laurel y podían participar atletas de ambos lados del Mediterráneo.

...pues es de saber que Abenhumeya, después del cerco de Vera, tan vano a su pretensión, se retiró a Pucherna con todo su campo, determinando aguardar allí a Murcia y su reino, si acaso si fuera le querían seguir, y visto que Lorca y Murcia no le seguían, determinó hacer unas solemnes fiestas de esta forma:

Al que en travada lucha mejor lo hiziese, le daría cien escudos de oro y le coronaría de hojas de laurel.

Más aquel que se mostrase más suelto y corriese más ligero y llegase al puesto disputado, otros cien escudos de oro.

Más al que de tres saltos alcanzase más tierra por medio le daría otros cien ducados de oro.

Tiempo después, durante la Revolución francesa se coqueteó con la idea de reavivar los Juegos. En el calendario republicano, que fue diseñado en 1792 por Gilbert Romme (1750/1795) matemático y miembro de la Convención, se señalaba en los años bisiestos la celebración de olimpíadas francesas, francíadas, incluyéndolas en el calendario como unidades de tiempo. Un año después, el orador de la revolución, Georges-Jacques Danton (1759/1794), alentó la organización de Juegos Olímpicos en el Campo de Marte. Como instrumento ligado a un plan global de pedagogía nacional.

En Inglaterra, desde principios del siglo XVII, exactamente desde 1612, hasta 1852, se celebraban los Cotswold Olimpick Games, cerca de Chipping Campden en Gloucestershire. Solo dejándose de celebrarse en tiempos de la guerra civil, entre 1642 y 1660 . Fueron iniciativa del abogado local Robert Dover, con la aprobación del rey Jaime. Eran un evento festivo en el que participaban todas las clases sociales, solo tuvo la oposición de los sectores mas puritanos. En su última etapa sufrieron un proceso de degeneración chabacana y acabó con la venta de los terrenos en los que se celebraba.

También en Inglaterra, impulsado por William Penny Brookes (1809/1895), cirujano, magistrado, botánico y pedagogo, se creo la Wenlock Agricultural Reading Society (WARS) en 1841, con el fin de cooperar al desarrollo integral de una clase trabajadora de los suburbios de Wenlock y los adyacentes. En 1850, añadieron al programa de actividades las relacionadas con la cultura física, denominándola Olympian Class y establecieron los juegos-festivales al final de cada temporada. En 1860 la Olympian Class pasa a depender, de la recién creada, Wenlock Olympian Society. En 1861 organizaron los juegos olímpicos de Shropshire. Y en 1866 se celebraron en Londres los primeros Juegos Olímpicos Nacionales, bajo el auspicio de la National Olympic Association, que había sido co-fundada por Brookes en 1865. El barón Pierre de Coubertin visitó dicha Sociedad en 1890, e invitó a Brookes, como delegado honorario al congreso de la Sorbona, en 1894, en el que se fundó el Comité Olímpico Internacional, aunque no pudo asistir por motivos de salud.

Coubertin valoraba mucho la labor de Brookes, así en un artículo publicado en la revista "La Revue Athlétique", en 1890, con el título "Los Juegos Olímpicos de Much Wenlock: una página de la historia del atletismo" escribía

¿Pero dónde está Much Wenlock? Puedo imaginar la confusión del lector al encontrar unidos un nombre bárbaro con la memoria de la antigüedad. Much Wenlock es una pequeña ciudad en Shropshire, un paraje en la frontera de Gales y si los Juegos Olímpicos... sobreviven hoy en día, es debido... al Dr. P. Brookes. El fue quien los inauguró hace cuarenta años, y todavía es él, ahora a la edad de 82 aunque se mantiene alerta y vigoroso, quien los continua organizando e inspirando.

$Y$ en un segundo artículo siete años después apostillaba

Es seguro decir que solo la gente de Wenlock ha seguido y preservado las verdaderas tradiciones Olímpicas.

Publicado, en 1892, en la revista "Review of Reviews de Nueva York, bajo el titulo "A typical english- 
man: Dr. W. P. Brookes of Wenlock".

Otro importante antecedente del Movimiento Olímpico, que es el sustrato en el que se asientan los Juegos, es la interesantísima labor del pastor anglicano Thomas Arnold (1795/1842) después de nueve años formando a alumnos para ingresar en la Universidad, fue invitado a enseñar, en 1828, en el colegio privado de Rugby, Rugby Public School, (Public School en el Reino Unido equivale a colegio privado, normalmente en régimen de internado, frente al State School, que es un colegio público), que por entonces no tenía el mismo status que los de Eton o Winchester. Pero su particular fuerza del carácter y celo religioso le hicieron transformar por completo la pedagogía de la institución y construirse él mismo un modelo diferente al de los demás colegios privados, en el que sin arrinconar las lenguas clásicas, subrayó la práctica de la educación física y el deporte; introdujo el estudio de las matemáticas, la historia, las lenguas modernas y estableció un perfecto sistema para mantener la disciplina basado en tutores y preceptores nombrados entre los alumnos más antiguos, que debía supervisar la educación de los más jóvenes. Esta reforma de la enseñanza alcanzó tanto prestigio que el estado la adoptó y a partir de ahí muchos otros países. Aparece un retrato de este modelo de enseñanza en una famosa novela biográfica, Tom Brown's Schooldays, escrita por su pupilo Thomas Hughes.

La figura de Arnold, es especialmente importante por significar un cambio radical en el modelo educativo, en el que la educación física y el deporte forman parte del núcleo fundamental de la formación de los individuos. Binomio educación y deporte.

Y Coubertin encuentra esta armonía en los Juegos de la antigüedad, teniendo muy presente en su ideario restaurador los patrones clásicos de Olimpia, como podemos deducir de esta mezcla de textos seleccionada por el estudioso de los temas Olímpicos Conrado Durantez, los primeros son del barón, los segundos de la Carta Olímpica

En los tiempos del esplendor de Olimpia las letras y las artes armoniosamente combinadas con el deporte, aseguraban la grandeza de los Juegos Olímpicos...ya que la educación atlética ejerce por lo menos idéntica acción sobre la moral que sobre lo físico....y si por un lado desarrolla los músculos, también forma el carácter y la voluntad: en una palabra produce hombres. La indispensable necesidad de la cultura física y la cultura del carácter, no excluye la formación de la inteligencia ni de la sensibilidad. Se trata de un todo armónico.

Los principios olímpicos antiguos y coubertinianos hallan su acomodo normativo en la Carta Olímpica cuando precisan que "el objetivo del olimpismo es poner siempre el deporte al servicio del desarrollo armónico del hombre con el fin de favorecer el establecimiento de una sociedad pacífica y comprometida con el mantenimiento de la dignidad humana.....apoyando y fomentando la formación de la ética deportiva...velando por el mantenimiento del espíritu del fair play en el deporte y por la erradicación de la violencia"

Como elemento probatorio de este espíritu que acompaña al deporte traemos la frase de Nelson Mandela (1918/2013) que utiliza la Organización de Naciones Unidas como uno de los lemas del Día Internacional, por la Paz, la Democracia y la Libertad

El deporte tiene el poder de cambiar al mundo; tiene el poder de inspirar; tiene el poder de unir a las personas de una manera que pocas cosas pueden lograr y añade

Le habla a la juventud en un lenguaje que comprende. El deporte puede crear esperanza donde antes solo había desesperación.

...Es más poderoso que el gobierno para romper barreras raciales.

Conclusión, creemos que ha quedado suficientemente acreditado, que los Juegos modernos tienen un punto coincidente con los de la antigüedad, en que ambos provienen de un esplendoroso pasado, que podemos considerar como mítico.

Y que el origen mítico de los juegos antiguos tiene su eco, también, en los modernos, proporcionándoles un regusto de origen mitológico que pasa a formar parte de la liturgia olímpica que tiene lugar en los estadios.

Aunque esto pueda considerarse, sólo, como una interpretación de los hechos, pero nos ha permitido el placer de sobrevolar momentos de gran interés de la historia. Y como decía Derrida

Nada amo más que recordar y la memoria misma. Nunca he sabido contar una historia. Se pierde la narración para conservar el recuerdo. Al incorporar el recuerdo a una historia se impone una interpretación. 
BIBLIOGRAFÍA. El estadio espacio de especial significación.

BAROJA, Pío. (1934). Las Noches del Buen Retiro. Ed. Tusquets. ISBN: 978-84-8310-635-8

BENDALA, Manuel. (1994). Los albores de Grecia. Ed. Historia 16. ISBN: 84-7679-100-3

COLLINGWOOD, Robin George (1946). Idea de la Historia. Titular original: The Idea of History. Ed. Fondo de Cultura Económica, Segunda edición 1996. ISBN: 9681601963,9789681601966

DURANTEZ, Conrado. (1977). Las Olimpiadas Griegas. Ed. Delegación Nacional de Educación Física y Deportes. Comité Olímpico Español. ISBN 84-400-2621-8

DURANTEZ, Conrado. (2001). Pierre de Coubertin y su ideario. Ed. Comunidad de Madrid, Dirección General de Deportes. ISBN 8445119737,9788445119730

GARCÍA MÁRQUEZ, Gabriel (2002). Vivir para contarla. Contemporánea Debolsillo. Ed. Random House Mondadori, sa. Tercera edición, 2010. ISBN: 978-84-8346-205-8

GONZÁLEZ CALERO, Pedro (2012). Filosofía para bufones. Ed. Planeta. Col Ariel. ISBN 9788408005223

GRIFFIN, Jasper. (1980). Homero. Título original: Homer. Ed. Alianza Editorial. Clásicos de Grecia y Roma. Primera edición 2008. ISBN: 978-84-206-6560-3

HERNÁNDEZ, Miguel (1958). Cancionero y Romancero de Ausencias. Paperback. Ed. El Pais, 2004. ISBN-10: 8498150396 ISBN-13: 978-8498150391

HOMERO. La Odisea. Ed. EDAF. ISBN 84-7166-394-5. Primera edición 1981. Introducción Alberto Bernabé, Traducción Felipe Ximénez de Sandoval. B. ACP

HUGHES, Thomas (18579. Tom Brown's Schooldays. Ed. Pelangi ePublishing Sdn Bhd, 2012. ISBN 9670351715 , 9789670351711

JEU, Bernard. Análisis del deporte. Ed. Bellaterra. Barcelona. ISBN: 84-7290-056-8. Primera edición 1988

LÓPEZ ESTÉVEZ, Roberto. (2012). Pierre de Coubertin: Olimpismo Moderno y Movimiento Olímpico. Ed. EFDeportes. com. Revista Digital. Buenos Aires. Año 17. N170. www.efdeportes.com

ORTEGA Y GASSET, José. El Origen Deportivo del Estado. Obras Completas, Madrid, Alianza Editorial, Revista de Occidente. 1983. Tomo II, pp. 607 - 623

PAUSANIAS (s. II dC.) Descripcion de Grecia: Atica y Elide. Ed. Alianza Editorial, 2000. ISBN 9788420636870 PÉREZ DE HITA, Ginés. (1619). Guerras Civiles de Granada. Ed. Maxtor, 2010. Facsímil. ISBN 9788497616799

PÍNDARO. (s. $\vee$ aC.) Odas Triunfales. Introducción, traducción y notas de José Alsina. Ed. Planeta 1990. ISBN 84320-4877-1

SEGURA MUNGUÍA, Santiago. (1992). Los Juegos Olímpicos. Educación, deporte, mitología y fiestas en la antigua Grecia. Ed. Grupo Anaya. ISBN 84-207-4369-0

SLOTERDIJK, Peter (2004). Esferas III. Espumas. Esferorogía plural. Biblioteca de Ensayo. Ediciones Siruela. ISBN 978-84-7844-951-4. Segunda edición febrero 2009. Titulo original: Sphären III (Plurale Sphärologie). Schäume. Suhrkamp Verlag, Frankfurt am Main, 2004. Tracción Isidoro Reguera. B. ACP

STRATHERN, Paul (2000). Derrida, en 90 minutos. Ed. Siglo XXI de España editores. Madrid (2002). ISBN 84-323. $1112-X$

WEILER, Ingomar. (1984). Problems in the Discussion of the Reason for the Decline of the Ancient Olympic Games. Ed. OARe 1984. Sesión 24, Academia Olímpica Internacional. Olimpia, pp. 121-136

Charte Olympique '91. (1991). Ed. Comité International Olympique

El Olimpismo (2004). Dirigido por Rafael Ansón. Cap. 4. El Santuario de Olimpia. Conrado Durántez Corral. Ed. Universidad Camilo José Cela. ISBN: 84-95891-12-3

Revista de Folklore. $\mathrm{n}^{\circ} 317$ (2007). Ed. Fundación Joaquin Díaz

The Stadium and the City. Editado por John Bale y Olof Moen. Keele University Press. ISBN 1853311103. Primera edición 1995. B. ACP 
B-26 


\section{B.2 Origen del Estadio Moderno}

Antes de estudiar el desarrollo del estadio moderno, concretado en los estadios olímpicos, vamos a establecer cuáles son sus antecedentes y dónde están las fuentes de su origen.

Hay un modelo arquitectónico deportivo que precede en el tiempo al estadio en diferentes ubicaciones olímpicas, el hipódromo. Esto sucede en Amberes 1920, cuando el acaudalado aficionado al deporte Ernest Grisar adquiere el hipódromo situado en Kiel, al sur de Amberes. El terreno tenía una superficie de $19 \mathrm{Ha}$. En los suspendidos Juegos de Berlín que se debían celebrar en 1916 la organizadora de carreras de caballos Union Klub, en febrero de 1907, se hace con el arrendamiento por 30 años de unos terrenos situados al norte de Grunewald, en el denominado Parque del Pueblo, espacio público cedido por el emperador Guillermo II en 1868; el lugar era una meseta rodeada de densos bosques de pinos. El 23 de mayo de 1909 se inaugura el hipódromo de Grunewald, proyectado por el arquitecto Otto March (1845/1913). Tenía una capacidad de 40.000 espectadores y su superficie interior superaba los 85.000 m2. En Colombes, Paris 1924, a la orilla del Sena y adecuando una llanura inundable, en 1883 se construye un hipódromo, que es comprado por el periódico "Le Matin", en 1907, para transformarlo en estadio para acoger competiciones de atletismo, rugby y fútbol. En Los Angeles, en 1870 se instaló en el área del futuro estadio una feria de estable de productos agrícolas y ganaderos, llamado Agricultural Park. En la cual se trazó una pista para carreras de galgos, caballos y trotones, que se disputaban los días festivos.

Si bien por el modelo hipódromo se interesaron arquitectos tan importantes como Friedrich Schinkel que hacia 1834 proyectó un Palacio Real en la Acrópolis, integrado con el Partenón, los Propileos, el Erecteion, jardines. Incorporaba, en su zona central, un hipódromo del tipo de los de la Grecia antigua. También dibuja un hipódromo en el Palacio Charlottenhof de Potsdam en su proyecto de jardines de 1836.

En las ciudades importantes había un gran interés por los hipódromos, por ejemplo, en Paris en el año 1845 se inauguran dos, uno, el Circo de los Campos Elíseos, inicialmente llamado de la Emperatriz y posteriormente como Circo Olímpico, en el que Beriloz dirigió cuatro conciertos memorables. Fue proyectado en piedra por el importante arquitecto Jacques Hittorfs (1792/1867). A él también se deben la plaza de la Concordia, los Campos Elíseos y la Gare de Paris-Nord. Fue demolido alrededor de 1899-1900. Era de forma circular y pequeña dimensión, contaba con un interesante espacio interior.

El otro hipódromo inaugurado en Paris en 1845 era el de l'Etoile. Estaba construido en madera y justo un año después un incendio lo destruyó parcialmente y tuvo que ser reconstruido, funcionando hasta 1855 en que fue demolido para poder trazar la plaza de l'Etoile. En Paris había varios hipódromos más en esos tiempos.

También en Londres fue construido un hipódromo en 1851 frente al amplio paseo de los jardines de Kensington. Era un anfiteatro de enormes dimensiones, con el graderio continuo y enteramente cubierto. Entre los espectáculos programados los había con un fuerte regusto clásico; carreras de carros, ióvenes de Troya y corceles de Tesalia, por ejemplo.

Pero por muy importantes que fueran los hipódromos en el siglo XIX y aunque es un tipo edificatorio muy semejante al estadio, por algún motivo los estadios iniciales no lo tuvieron como clara referencia. Tal vez la cuestión escalar los diferencia seriamente, al aumentar el tamaño en planta aunque no en sección, la proporción del espacio es radicalmente distinta y la excesiva lejanía entre los espectadores produce una relación entre los mismos absolutamente diferente.

Por lo cual, dejando a un lado el hipódromo, establecemos tres antecedentes históricos básicos, para desarrollo del estadio Olímpico moderno.
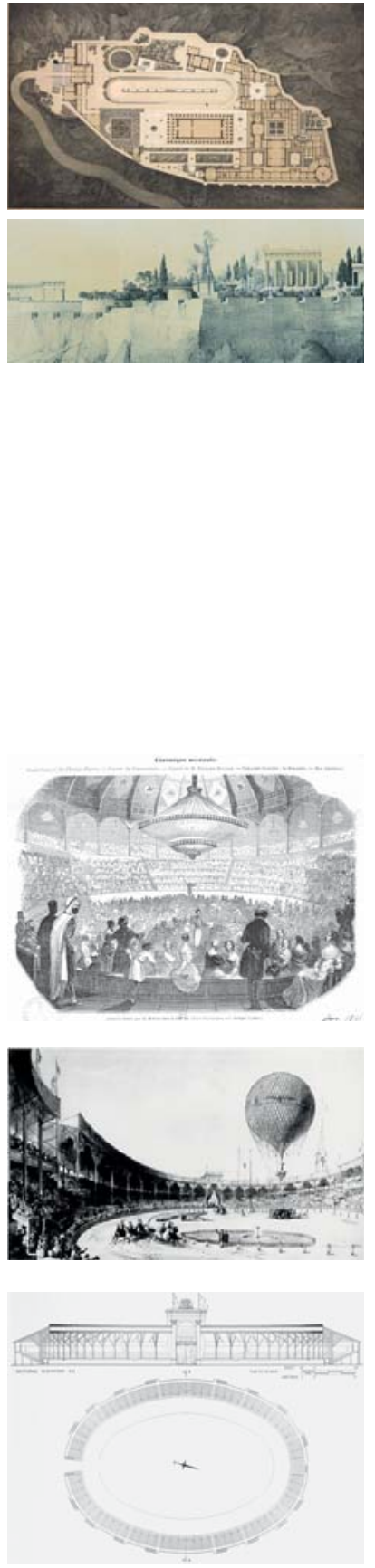

Friedrich Schinkel. Hacia 1834 Palacio Real en la Acrópolis.

Circo de los Campos Elíseos, 1845

Hipódromo l'Etoile, 1845 


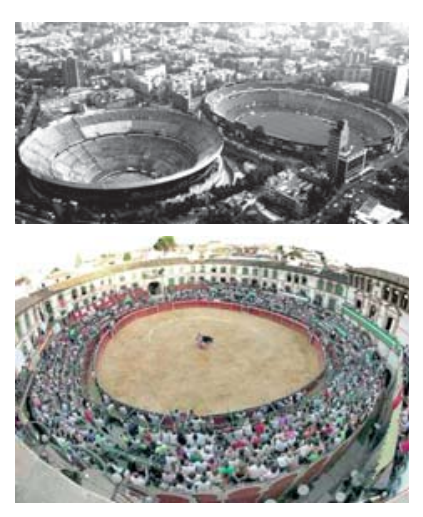

Plaza Monumental y Estadio Azul. México. Corrida goyesca en la plaza de un pueblo.
El colector social. (B.2.1)

La entrada de las masas en la historia, a finales del siglo XVIII, con su entusiasmo asambleario, plantea un problema arquitectónico. Se ha de estudiar la tarea de producir las condiciones espaciales que apoyen la reunión de individuos en conjuntos de cooperación y contemplación multicéfalos. Esto exige nuevos planteamientos en arquitectura.

Los modelos clásicos. El estadio, el circo y el anfiteatro. (B.2.2)

El estadio griego, el circo y sobre todo el anfiteatro romano suponen acreditados modelos para grandes concentraciones, cuya perfección formal permitía recuperarlos incluso después de una interrupción de más de 1500 años.

Las plazas de toros, que supusieron un hilo de continuidad histórica desde la antigüedad clásica hasta nuestros días, por la condición periférica e insustancial de España en el desarrollo de los estadios, han quedado apartadas de los impulsos de desarrollo, sin aportar nada al proceso ni beneficiarse del mismo.

Es curiosa la inversión producida, imponiéndose, en el estadio, el modelo arquitectónico del anfiteatro. Cuestión derivada, tal vez, de la preponderancia del espectáculo sobre la competencia ritual o quizás, simplemente, por las ventajas propias del modelo arquitectónico de anfiteatro sobre el del estadio clásico.

El estadio industrial. Inglaterra. (B.2.3)

En la Inglaterra del siglo XIX se produce el desarrollo del deporte, primero, como parte integral de la educación más elitista $y$, posteriormente, mediante su popularización. Paralelamente aparecen nuevos materiales de construcción y nuevas técnicas constructivas, nuevas funciones,... nuevos tipos arquitectónicos. El Cristal Palace de Joseph Paxton es un paradigma de la arquitectura "industrial", que tiene su adaptación y desarrollo en los estadios ingleses del siglo XIX. 


\section{B.2.1 El colector social}

La entrada de las masas en la historia, a finales del siglo XVIII, con su entusiasmo asambleario, plantea un problema arquitectónico. Se ha de implementar la tarea de producir las condiciones espaciales que resuelvan las condiciones de reunión de individuos en conjuntos de cooperación y contemplación multicéfalos. Esto exige nuevos planteamientos en arquitectura.

Peter Sloterdijk en el ya mencionado ensayo titulado Espumas. Esferorogía plural', en la pagina 462 afirmaba:

Los colectivos modernos han de plantearse la tarea de producir las condiciones espaciales que apoyen el aislamientos de los individuos, aquí, y su reunión en conjuntos de cooperación y contemplación multicefalos, allí. Esto exige nuevos planteamientos en arquitectura.

Se refiere a nuevos entendimientos en cuanto a la manera de habitar, en relación con la vivienda, y en la manera de reunirse, refiriéndose principalmente al estadio, como la pieza de mayor dimensión y significado, entre los elementos arquitectónicos cuyo fin ultimo es la de dar cabida a la reunión y, sobre todo, a la expresión de las masas.

Para el filosofo alemán, son los dos temas que le suscitan mayor interés de entre todos los de la arquitectura moderna. El del desarrollo y evolución de esas dos importantes tipologías arquitectónicas. Sobre una de ellas, la del estadio, trata esta tesis.

El Estadio, por su dimensión y significado, se destaca como el elemento principal entre los espacios de reunión y comunión de grandes masas

Se constata, en esos momentos de ebullición que preceden a la revolución francesa en los convulsos finales del siglo de las luces, la no existencia de los lugares adecuados para este fin.

Ya durante la revolución francesa se puso de manifiesto que los activistas de la revuelta solo podían recurrir para sus reuniones a los edificios del Ancien Régimen. Es más lo que un día pasó a llamarse arquitectura de la revolución ya había sido proyectada antes de 1789 en sus partes más sugestivas: piénsese en la controvertida Casa de los Guardas Agrícolas de Claude Nicolas Ledoux, fechada en 1768 y 1773, en el Cenotafio de Newton de Étienne-Lovis Boullée, del año 1784, o la Casa de un cosmopolita de Vaudoyer, de 1785. Que estos proyectos sin excepción, quedaran en el papel no fue achacable tanto a las circunstancias adversas como a su propia lógica especulativa; todavía no estaban maduros los tiempos para la emancipación de la concepción escultural del espacio y los formalismos geométricos.

Es destacable que entre los lugares en los que tuvieron lugar los procesos revolucionarios de los Grandes Días estuvieran dos edificios de carácter deportivo.

El primero de ellos; el Jeu de Paume donde se reunió el Tercer Estamento, autodenominado Asamblea Nacional, el 23 de junio. Allí, los reunidos, hicieron el famoso juramento de no dispersarse antes de que la constitución del reino estuviera elaborada y descansará sobre fundamentos firmes.

Este juramento es muy expresivo de lo que significa una masiva reunión de individuos que conforman un ideario compartido y una voluntad común. Esta es, quizás, la característica principal que posteriormente convertirá al estadio en un espacio único de gran carga emocional, un colector social, en palabras de

1. SLOTERDIJK, Peter (2004). Esferas III. Espumas. Esferorogía plural. Biblioteca de Ensayo. Ediciones Siruela. ISBN 978-84-7844-951-4. Segunda edición febrero 2009. Titulo original: Sphären III (Plurale Sphärologie). Schäume. Suhrkamp Verlag, Frankfurt am Main, 2004. Traducción Isidoro Reguera. B. ACP 
Peter Sloterdijk.

En otoño de 1789, la Asamblea Nacional, se reunió en la Escuela de Equitación de las Tullerias, en la Salle du Manège, y para ello tuvo que ser arreglada, aunque precipitadamente, para satisfacer las necesidades de los constituyentes.

En mayo de 1793 la Asamblea, ya como Convención Nacional, se trasladó al Palacio de las Tullerias, donde, según los planos del artista Gisors, se había acondicionado una sala de plenarios en forma de un anfiteatro semielíptico con 700 asientos para los diputados y 1.400 plazas para los espectadores.

La fantasía planificadora de los arquitectos no permaneció inactiva: desde 1789 se elaboraron numerosos proyectos para edificios de reunión dignos de la Asamblea Nacional, por regla general con motivo de concursos académicos, la mayoría en estilo heroico-clasicista, no pocos ya en dimensiones monumentales, como si la republica solo pudiera manifestarse en el decorado de un Imperio Romano: la línea que va de Ėienne-Louis Boullée hasta Albert Speer, dicho sea de paso, no deja nada que desear en cuanto a claridad, ...
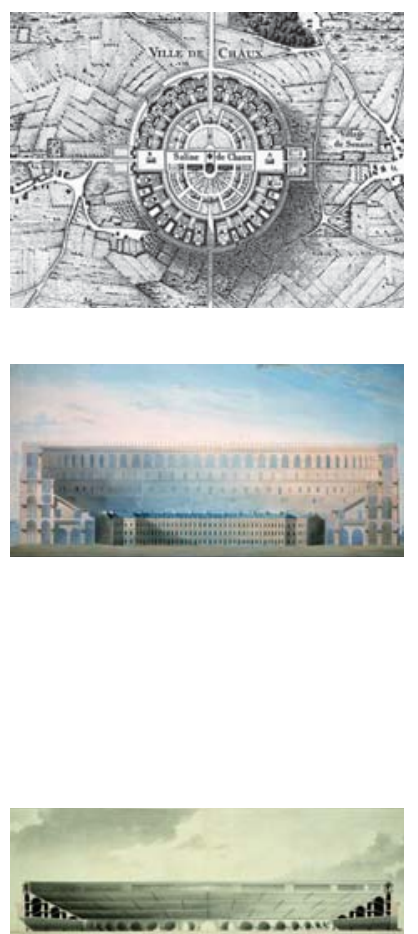

¿A que referencia o que modelo podían recurrir?

Bajo el efecto del entusiasmo asambleario los antiguos modelos de edificios para grandes concentraciones volvieron inmediatamente, digamos que inevitablemente, a plantearse: con el anfiteatro de los griegos como con el circo o la arena de los romanos la Antigüedad europea ponía a disposición dos acreditados modelos para grandes concentraciones, cuya perfección formal permitía recuperarlos incluso después de una interrupción de más de 1500 años

Es curioso que en el proyecto de Claude Nicolas Ledoux (1736/1806), Salinas Reales de Arc-etSenans, de alrededor de 1775, en uno de los planos de conjunto, las trazas de la actuación propuesta mantiene una relación muy significativa con la planta del arranque de la estructura del coliseo de Roma. Demuestra que los modelos de la antigüedad, aunque sin la aplicación práctica directa, eran manejados y valorados en las épocas prerrevolucionarias.

También en Inglaterra tenemos constancia de este mismo interés. Según se puede observarse en el catálogo de la exposición Stadia: Sport and Vision in Architecture, celebrada en la Casa Museo de Sir John Soane, en Lincoln's Inn Field en Londres, de 2012 y recogido en el catalogo editado por el doctor Jerzy Kierkuc-Bielinski y el profesor Geraint John'.

Sir John Soane visitó Roma por primera vez en 1778, estudió y dibujó los restos arquitectónicos de la antigüedad clásica. Más tarde, siendo profesor de arquitectura en la Royal Academy, en sus conferencias presentaba un bellísimo dibujo en color hecho por él mismo del Coliseo de Roma, seccionado, y en su interior el Circus Royal Crescent, de John Wood, construido entre 1767 y 1774 en Bath. Con ello quería mostrar la enorme escala de anfiteatro romano. El inmenso conjunto de viviendas, trazado sobre un urbanismo que recreaba un circo romano, cabía perfectamente en su interior.

En esta misma exposición, además de interesantes dibujos de Giovanni Battista Piranesi (1720/1778), se exponía un facsímile del alzado del utópico circo proyectado por Étienne Louis Boullée (1728/1799), de unas proporciones gigantescas. Estas mismas imágenes las cataloga Franz-Joachim Verspohl ${ }^{2}$ como Coliseo con capacidad para 300.000 espectadores. Se confunde el modelo de origen, o es que la ampliación de escala y tamaño del anfiteatro nos remite a las dimensiones del circo. Y pudo inducir al error.

Es curioso que, adelantándose a los acontecimientos, tal vez, los acontecimientos referidos son la conclusión del estado de animo que se venía forjando en la sociedad desde hacía algún tiempo.

... el Ancien régime había coqueteado con la idea de la antigua arena como escenario festivo absolutista: en 1769, con la ocasión de la boda del Delfín con Maria Antonieta, fue construido en el Rond Point de los Campos Elíseos un edificio gigantesco al estilo del Coliseo, que sirvió como lugar de diversión popular durante un decenio, antes de que hubiera de ser demolido a causa de su estado ruinoso.

Pues bien, a comienzos de los años ochenta la Academia de Paris comenzó a convocar una serie de concursos para edificios públicos de celebración: en 1781, para una Fête publique; en 1782, para un circo; en 1783, para una ménagerie en una arena. Eran proyectos con un cierto carácter utópico y no referidos a una realización concreta.

1. KIERKUC-BIELINSKI, Jerzy; GERAINT, John. (2012). Stadia: Sport and Vision in Architecture. Ed. Sir John Soane's Museum. Londres. ISBN: 9780955876288

2. VERSPOHL, Franz-Joaquim. (1976). Stadionbauten von der Antike bis zur Gegenwart. Regie und Selbsterfahrung der Massen. Ed. Anabas. ISBN 3-87038-043-8. 
Los concursos académicos todavía se movían plenamente dentro de la fascinación por los fantasmas tardo-absolutistas del gobierno del pueblo. Gozaban de licencia para soñar, mas o menos sin consecuencias, en grandes receptáculos para la aglomeración pasivamente-jubilosa de los súbditos ante las espectaculares representaciones de poder y arte del reino.

Por otra parte, según nos relata el Historiador Alec Forssmann, en Historia National Geographic n ${ }^{\circ} 120^{1}$ : el lunes 1 de diciembre de 1783 se congregó en torno al jardín de las Tullerías una de las mayores aglomeraciones humanas de la historia de París; según algunas fuentes, la multitud allí reunida llegó a 400.000 personas. Todas querían asistir a un espectáculo que nadie habría imaginado pocos años antes: el de dos hombres que se disponían a elevarse hasta los cielos a bordo de un enorme globo de aire. Desde hacía días, en la ciudad no se hablaba de otra cosa y la prensa se había hecho amplio eco del acontecimiento. Los espectadores ocupaban los muelles y los puentes, las ventanas y los tejados de las casas, los campos y hasta las poblaciones aledañas. La simple vista del globo antes de su despegue causaba asombro. De color rosa y amarillo, medía más de nueve metros de altura y estaba envuelto completamente por una red de malla cuadrada. En el extremo inferior se había colocado una barquilla de mimbre donde irían los "pilotos»: el profesor Jacques Charles y su ayudante Nicolas-Louis Robert.

Pero el festivo espectáculo no requería ninguna adecuación arquitectónica precisa.

Sólo después del estallido de la Revolución pudo ser ocasionalmente realizable y políticamente virulento un modelo de arena y anfiteatro para la generalidad de las "masas"; como se percibe, sobre todo, en la gran fiesta de la Federación- de las confederaciones de patriotas que se habían unido para la defensa frente a intrigas contrarrevolucionarias-, celebrada el día del primer aniversario de la toma de la Bastilla, el 14 de julio de 1790, en el Campo de Marte de París.

Imitando a las federaciones regionales de guardias nacionales que habían empezado a celebrar su fiesta en el Midi, a partir de agosto de 1789 y se extendían por toda Francia, el Marqués de Lafayette, que era el comandante de la Guardia Nacional de París, decidió organizar, para conmemorar el aniversario de la toma de la Bastilla, la fiesta nacional de la Federación, en París.

Un año después, en 1791, la Asamblea Nacional francesa decidió que esta primera conmemoración del 14 de julio de 1791 fuese la fiesta de la reconciliación y la unidad de todos los franceses.

Desde el 1 de julio de 1790, 1.200 obreros dieron inicio a los trabajos de excavación en el lugar elegido para la escenificación de la ceremonia. Se trataba de transformar el Campo de Marte en un vasto espacio, semejante a un circo romano, para acoger a una gran multitud, en el centro del cual se elevaría el altar de la Patria.

Los trabajadores estaban bien alimentados pero mal pagados, así que cuando se les reprochó la lentitud con que avanzaban los trabajos, amenazaron con paralizar las obras. Ante el lento ritmo de los trabajos, se decidió apelar a la buena voluntad de los parisinos, quienes respondieron en masa. El propio rey Luis XVI vino desde Saint-Cloud y dio un golpe con un pico, a la vez que Lafayette, en mangas de camisa, trabajaba como un obrero más. Enseguida se formó un hormiguero humano en el que los obreros de los arrabales se mezclaban con los nobles, los monjes con los burgueses, y las prostitutas iban de la mano con las damas de los barrios altos. Los carboneros, los carniceros, los impresores, acudían con sus banderas tricolores.

Con esta manifestación de masas, la más grande de la historia europea desde los días del Circus maximus romano, se llevó a cabo la aproximación más cercana de la Revolución Francesa a la idea entusiastita de una asamblea popular real e integral.

Los federados desfilaron con sus tambores y sus banderas, en número total de 100.000 incluidos los de París. Los parisinos, entorno a los 400.000 , se situaron sobre los taludes que se habían levantado alrededor de la explanada. Luis XVI se sentó en el pabellón que se había erigido delante de la Escuela Militar. La participación de la gente fue multitudinaria y entusiasta. La misa, de carácter patriótica, fue celebrada en el "altar de la patria" por Charles-Maurice de Talleyrand-Périgord, que por entonces era el obispo de Autun. Lafayette, con uniforme de gala, llegó montado en un caballo blanco y subió al estrado pronunciando un juramento en nombre de los federados de todos los Départements. Gesto que reforzaba la unión de todos los franceses y de estos con el

1. http://www.nationalgeographic.com.es/articulo/historia/secciones/8848/globo_aerostatico_conquista_los_ cielos.html 
rey. Luis XVI prestó, también, juramento a la Nación y a la ley, la multitud enardecida entonó un Te Deum, y el rey se marchó mientras la multitud se abrazaba entre sí y lanzaba vivas, algunas de ellas dirigidas al propio monarca.

El punto de atracción de la mirada de los montajes festivos en el Campo de Marte consistía en un arco de triunfo colosal, hecho de cartón madera y yeso, con cuya erección la militante república de patriotas anunciaba inequívocamente su interés por el simbolismo victorioso de la época de los emperadores romanos.

Casi un siglo después, el 14 de julio de 1880 se declaró oficialmente día de la fiesta nacional francesa, a petición del diputado Benjamin Raspail. Esta festividad no sólo se celebra en conmemoración del 14 de julio de 1789 (toma de la Bastilla), sino también en memoria de la Fiesta de la Federación. La primera recuerda una jornada sangrienta, la segunda a una jornada festiva sin que disminuya, no obstante, la importancia de la primera. El 14 de julio es, por tanto, la conmemoración de la toma de la Bastilla y de la Fiesta de la Federación.

La modernidad del espectáculo de culto patriótico en el Campo de Marte de París (que fue imitado en todas las ciudades importantes de Francia con grandes concentraciones análogas en estadios improvisados y al que hasta el año VIII del calendario de la Revolución, es decir 1799, siguieron numerosas celebraciones semejantes, añadiendo ya, ocasionalmente, momentos agonales y deportivos) consiste en que, con él, la configuración de la multitud capitalina multicéfala en una "masa" presente, como tarea arquitectónica, organizatoria y técnico-ritual (después jurídico Asamblearia también), pasa al estadío de desarrollo explicito. La preparación y realización de la fiesta de la Federación de 1790 y de sus acontecimientos subsiguientes puso en evidencia que la "masa", la "nación" o el "pueblo" sólo puede darse como sujeto colectivo en la medida en que la reunión física de esas magnitudes se convierte en objeto de una escenificación metódica, que abarca desde la movilización a participar, pasando por la dirección escénica de afectos en el estadio y por la fijación de la atención de la "masa" mediante un espectáculo fascinógeno, hasta acabar, al final, en una disolución de la multitud controlada por guardias ciudadanos. No hay pasta sin recipiente en el que se dé forma; no hay "masa" sin una mano que sepa para que la amasa.

La fiesta de la Federación del 74 de julio de 1790, de la que tanto de facto como de iure proviene la moderna cultura de "masas" como escenificación de acontecimientos, es informativa porque en ella se presentó ya en formas ejemplares y definitivas la relación entre público, espectáculo y lugar de reunión.

Con esto parece que para Peter Sloterdijk el contenido que le es propio al estadio, en su función de contenedor de masas, quedaba prefijado ya en la celebración de la fiesta de la Federación. Se necesita que la presencia de público sea avasalladora, cuanto más mejor. Se necesita que el espectáculo sea entendible, de una evidencia elemental, absolutamente visual, completamente pautado y codificado para que su entendimiento sea total, para que se pueda producir una síntesis afectiva, de entusiasmo colectivo entre espectáculo y espectadores.

En palabras de Sloterdijk

Quien no entiende el texto ha de entender la acción; a quien le resulta extraña la acción, ha de ser cautivado por el colorismo del espectáculo. La fusión sonosférica se encarga del resto.

De aquí se derivan tres cuestiones fundamentales, respecto al lugar de reunión, żcuál es el tamaño máximo posible de un estadio? źqué morfología debe adoptar para que el conglomerado de espectadores se comporte como una masa unitaria? ¿Y cuál debe ser la relación formal entre público y espectáculo?. Es entonces cuando se produce una inevitable mirada retrospectiva a los modelos de éxito de la antigüedad, el circo y el anfiteatro.

Y para Sloterdijk

...dado que apenas es posible reactivar una forma sin volver a poner en juego también, al menos mediante, los contenidos unidos a ella originariamente, el moderno interés por los antiguos "containers" de "masas", el anfiteatro, arena, circo, se amplía en un renacimiento popular, en el que, junto con las formas arquitectónicas de los tipos de acontecimiento correspondientes, vuelven las luchas, las competiciones, el drama de diferenciación, que discrimina entre vencedor y perdedor; solo la muerte no puede ser ya bienvenida en el estadio moderno, como era en la antigua arena.

Pero pese al vigoroso impulso inicial, la concreción del modelo arquitectónico sufre un largo letargo, hasta el final del siglo XIX cuando se retoma la tarea de la formalización del estadio. Y tal vez, la razón de esa paralización, es que una vez asentados los principios de la revolución, los pensadores de la Constitución y los juristas del Tercer Estamento se dieron cuenta, o fueron temerosos, de los riegos 
de descontrol y violencia a los que podía conducir una toma de soberanía del pueblo emanada de grandes concentraciones y de la función cefálica de un pleno popular asumiendo la soberanía. $Y$ es que, realmente ya lo habían comprobado en los tumultuosos alzamientos populares del 14 de julio de 1789, o los del 10 de agosto de 1792, con el asalto al palacio de las Tullerias y el final de la monarquía constitucional. $O$ en las masacres de septiembre de ese mismo año.

Así que sólo, mediante la limitación de los derechos sobre la libertad de reunión, pudo frenarse esa espiral de violencia. Con la constitución de 1791 se emprendió el camino para diferenciar a la multitud presente y vociferante con la soberanía popular. La Constitución del Directorio fue más allá, prohibiendo de hecho las reuniones al aire libre, al considerarlos como amotinamientos. $Y$ esa prohibición se mantuvo durante todo el siglo XIX.

Pero, éste parón en el desarrollo del estadio era coyuntural, la necesidad estaba clara, solo faltaba por articular sus usos y su contenedor arquitectónico. Porque el estadio surge como condensador social y es previo a la necesidad deportiva del mismo.

Aunque hay algunos ejemplos, bien fundamentados, de propuestas de estadios llevadas a cabo, como, por ejemplo, la Arena Cívica de Milán que fue inaugurada, en 1807, con una Naumaquia en presencia de Napoleón Bonaparte. Habían pasado sólo doce años desde la aprobación de la Constitución del Directorio. Y es reseñable, que esta gran experiencia se desarrollara bajo control y auspicio francés, pero fuera de sus fronteras.

Fue proyectado, en 1805, por el arquitecto y urbanista, de origen suizo, Luigi Canonica (1764/1844). Formaba parte del ambicioso proyecto de transformación del área del Casillo Sforzesco, junto con el Arco della Pace, de los Caselli Daziari y del Foro Bonaparte. Ocupa el lugar liberado al desmontar los restos del castillo de Trezzo sull'Adda y las fortificaciones españolas (1522/1706) que rodeaban el Castillo Sforzesco. Las piedras de las fortificaciones españolas se reutilizaron para la construcción del estadio.

Canonica realizó un interesante ejercicio de mirada retrospectiva a la antigüedad clásica de la Roma Imperial. En cuanto al trazado en planta, adopta el ovoide elíptico de los anfiteatros, dilatando un poco en su eje longitudinal. Y, por otra parte, el carácter recio y más masivo de los circos, como atestiguan, tanto su imagen, como las secciones y alzados. En clara referencia en la traza, al Coliseo y, en el desarrollo, al circo de Majencio de la Vía Appia Antica de Roma.

Tenía una capacidad para 30.000 espectadores, una cuarta parte de la población de Milán en ese momento. Era un recinto multiusos utilizado para fiestas, espectáculos y celebraciones'. Durante el siglo XIX es utilizado como teatro, circo, para carreras de caballos y de coches de caballos, vuelo de globo, etc. En 1895 se celebra el campeonato de Italia de Ciclismo y en 1909 la etapa final del primer Giro de Italia. En 1910, se celebra el Italia Francia de Fútbol. También se utiliza para Boxeo, Automovilismo, Rugby, ...

El origen del estadio, tal como se ha presentado en este capítulo, está relatado con el objetivo principal de dar acomodo a las grandes multitudes celebrantes y un poco desligado de la utilidad deportiva, aspecto que será tratado en otros capítulos de este trabajo.
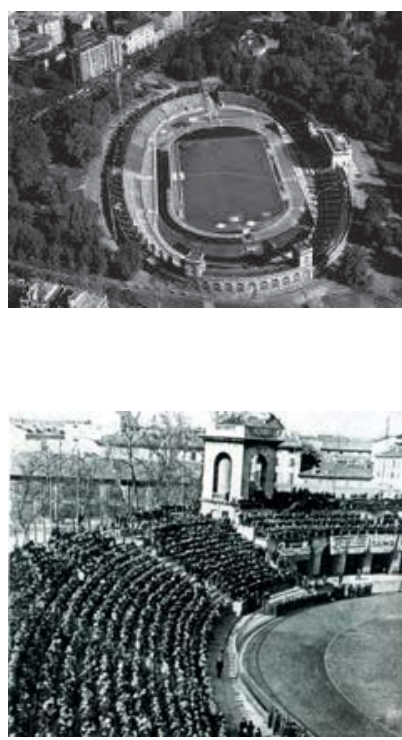

1. En cuanto al atletismo, inicialmente la pista tenia un desarrollo de $500 \mathrm{~m}$ y era de tierra batida negra, en 1963 se reconvierte a $400 \mathrm{~m}$ adaptándose al reglamento internacional, pasando a ser de tierra batida roja (polvo de ladrillo) y en los años 70 se cambió a material sintético. En este estadio se han batido 12 records del mundo. Desde Luigi Beccali, oro olímpico en LA 32 en 1.500 m, que el 17 de septiembre de 1933 corrió esta misma distancia en 3'49"O que suponía una nueva mejor marca mundial. Hasta 1980 en que el 11 de mayo Wladislaw Kozakiewicz batía el record del mundo de salto con pértiga con una marca de 5,72 m. Y el 3 de julio, Edwin Moses también batía el record del mundo de $400 \mathrm{~m}$ vallas con un tiempo de $47 " 13$. 


\section{B.2.2 Los modelos clásicos. El estadio, el circo y el anfiteatro}

El estadio griego, el circo y sobre todo el anfiteatro romano suponen acreditados modelos para grandes concentraciones. Su perfección formal ha permitido recuperarlos incluso después de una interrupción de más de 1500 años.

Es curiosa la inversión producida al imponerse en el estadio el modelo arquitectónico del anfiteatro. Es cuestión derivada, tal vez, de la preponderancia del espectáculo sobre la competencia ritual o, simplemente, por las ventajas propias del modelo arquitectónico de anfiteatro sobre el del estadio clásico.

\section{B.2.2.1 El estadio}

La palabra estadio tiene tres significados, primero, la distancia de 600 pies, en segundo lugar la carrera disputada sobre esa distancia y por ultimo, la pista de carreras, que media un estadio (600 pies).

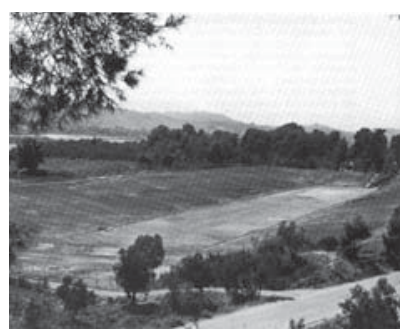

Es una más de las interesantes contribuciones arquitectónicas a la cultura universal de la antigua Grecia. Inicialmente fueron espacios llanos en la proximidad de taludes naturales $y$, con el tiempo, fueron evolucionando hacia estructuras más sofisticadas con graderíos de piedra o incluso mármol, conductos de drenaje alrededor de la pista y, en tiempos helenísticos, entrada espectacular para atletas y jueces por pasillos abovedados (criptón) desde el recinto del santuario. Llegaron a tener grandes capacidades de aforo; por ejemplo en Nemea aproximadamente treinta mil y en Olimpia cuarenta o cuarenta y cinco mil.

La pista se preparaba generalmente con arcilla apisonada, regada y rulada, para crear una costra dura. Detrás de la línea de salida, que era inicialmente una simple línea dibujada en la superficie de la pista, había espacio para el juez de partida, y después de la línea de meta un espacio para frenado de los atletas, por lo general de unos $15 \mathrm{~m}$ de longitud (curiosamente, también es la longitud regulada para las pistas de atletismo modernas).

Con el tiempo, el proceso de salidas para las carreras se hizo más sofisticado. En el siglo $\mathrm{V} a \mathrm{C}$., se marcaron salida y llegada con losas de piedra (Balbis) que tenían sendas acanaladuras para disponer los pies y coger impulso en la salida, un antecedente de los actuales "tacos de salida". Los "balbis", en Olimpia, estaban divididos en 20 sectores de un ancho de 4 pies olímpicos cada uno, en Nemea en 22 y en Epidauro en 11. Las separaciones eran unas estacas de madera; aún se pueden distinguir sus bases de anclaje. A partir del siglo IV aC. mejoraron el procedimiento con un curioso sistema (hysplex) compuesto por postes y travesaños de madera y cuerdas, por medio del cual un juez de partida podía liberar a todos los atletas de forma simultánea, un concepto semejante al de los boxes de los hipódromos actuales. La línea de meta es coincidente con la salida de la carrera del doble estadio (diaulo). En las carreras más largas que un estadio, en el centro del balbis se situaba un elemento (kampter) para marcar el giro y cambio de sentido.

Al principio el publico se situaba en los taludes naturales próximos a la pista, pero a partir de principios del siglo $\mathrm{V}$ aC. se convirtió en característica común que alrededor de la pista se levantan terraplenes artificiales, muchas veces complementando a los naturales, para asegurar una clara visión de la pruebas por parte de los espectadores. Y para evitar la aparición de cárcavas producidas por la lluvia, se dotó de conductos de drenaje alrededor de la pista y se daba una pequeña inclinación a la pista.

Más tarde, ya en época romana, se construyeron, en bastantes estadios, graderíos de piedra; por ejemplo en Delfos, Delos y Rodas, o de mármol en Atenas e Isthmia. Para asegurar el flujo ordenado del publico, los graderíos estaban divididos en sectores mediante las escaleras. Era característica común la existencia de algunos asientos, en una plataforma elevada, en las posiciones reservadas para los jueces especialmente capacitados (Hellanodikai) y en Olimpia, existía una especial reservada para la sacerdotisa de Deméter Chamyne, según se cree, única mujer autorizada para asistir a los Juegos. También en la época romana, las entradas a los estadios se hicieron más monumentales y, a menudo, se añadió en el lado de meta un graderío semicircular (sfendóne). En el caso del recientemente 
descubierto de Aphrodisias en sus dos extremos. Durante la etapa griega solo era utilizado para las competencias atléticas y festivo-culturales. En algunos y destacados casos en relación los grandes santuarios panhelénicos (Olimpia, Delfos, Delos, Epidauro). En tiempo de los romanos, sobre todo en las ciudades de Asia Menor, también sirvieron para espectáculos de gladiadores y audiciones musicales. Entre los ejemplos más famosos, además de los mencionados anteriormente, deben mencionarse los estadios en Atenas, Mileto, Rodas, Pérgamo, Priene, Magnesia del Meandro y, en Roma, el estadio de Domiciano, hoy Piazza Navona.

En el estadio griego podemos distinguir dos tipos claramente diferenciados, el inicial, que representa a la perfección, el de Olimpia y un segundo tipo caracterizado por el de Atenas.

\section{B.2.2.1.1 Olimpia}

El estadio más antiguo del que tenemos referencia histórica y física es el de Olimpia. Además es el de más renombre y relevancia. Las excavaciones arqueológicas han llegado a establecer que por lo menos existieron tres estadios sucesivos en el tiempo, al pie del monte Kronion. El que podemos visitar hoy en día es un rectángulo plano de aproximadamente $211 \mathrm{~m}$ de largo por $32 \mathrm{~m}$ de ancho. La pista tienen una longitud de 192,28 m. Dice la leyenda que fue el propio héroe Heracles el que estableció la distancia, contando 600 pies. Fue uno de los más largos de Grecia. La dimensión exacta de los pies era diferente en las distintas ciudades de la Hélade por lo cual da lugar a dispares longitudes totales de cada uno de los estadios; el de Delfos es 15 metros mas corto y el de Epidauro 11 metros. La pista esta rodeada por un sistema de canales de piedra por donde, según los arqueólogos, corría agua para refrescarse público y atletas. El estadio de Olimpia no tenía gradas. Los espectadores se sentaban sobre la hierba en una serie de taludes laterales. Había sólo una tribuna, en el lado sur, y se supone que estaba reservada a las personalidades que presidían los juegos y a los jueces. Se llegaron a celebrar 293 juegos: 194 antes de nuestra era y 99 posteriores. Esto demuestra el arraigo que tenía en la cultura griega el sentimiento de colectividad y el valor que se le otorgaba a la tradición deportiva. La localización actual, lógicamente, corresponde con la última versión del estadio, los anteriores, de mayor antigüedad, disfrutaban de una relación mas intensa con el santuario. En el siguiente relato, del admirado Conrado Durantez, podemos entender las claves del por qué de las sucesivas transformaciones del estadio.

Para el caminante que procedente de la ruta de Arcadia se aproxime al santuario en una de las frecuentes y luminosas noches de Olimpia, se quedará impresionado ante la majestuosa vista del Estadio, tanto más conmovedor en su evocador recuerdo cuanto más se admire dentro de la esquemática y austera dimensión física que siempre tuvo, pese a ser las victorias conseguidas sobre las pistas de su blanca arena, las más codiciadas del agonimo heleno. Nada resaltará de su conjunto a la mirada del viajero, que sólo podrá admirar el gran rectángulo blanquecino central de sus pistas enmarcado, como en los mejores tiempos, por graderíos naturales de suave pendiente. Sólo el denso silencio hará recapacitar sobre la gloriosa y azarosa milenaria andadura de su existencia. Por otra parte, su avanzada ubicación, previa al emplazamiento del sagrado recinto y apartada de él, podrá explicar mejor que ningún otro dato al visitante avisado, de la lenta y progresiva secularización de unos Juegos religiosos, que al profanizarse, despejaron del sagrado recinto del dios el originario y rituario lugar de competición en el que los atletas y sus triunfos al mismo dios le eran ofrecidos, a través del puro y sencillo culto del agonismo litúrgico'.

Las características anteriores descritas corresponden al estadio construido durante el período clásico tardío. Desde mediados del siglo IV aC., la pista de Olimpia ya no sufrió modificaciones reseñables. Pero anteriormente tuvo un largo y legendario proceso de transformación que tiene su origen en los tiempos de la instauración de los Juegos Olímpicos. La primera pista requeriría simplemente un espacio libre y suficientemente nivelado en relación directa con los elementos primigenios del santuario. Evidentemente no queda ningún vestigio. El primero de los estadios conocidos se construyó hacia el 550 aC. y el lugar de emplazamiento no está claro. -

Sabemos que aquellos eran originalmente Juegos rituales de los cuales lógicamente se deduce que estas antiquísimas y primeras competiciones debieron de tener lugar dentro del Altis. El olivo sagrado, de cuyas ramas eran cortadas las coronas de los vencedores, estaba en el interior del Santuario y mientras la carrera permaneció integrada en el antiguo culto de la fertilidad y representaba una carrera ritual de pretendientes, el olivo sagrado marcaría la meta. Cuando el Rey Ifito cambió la prueba de su contexto
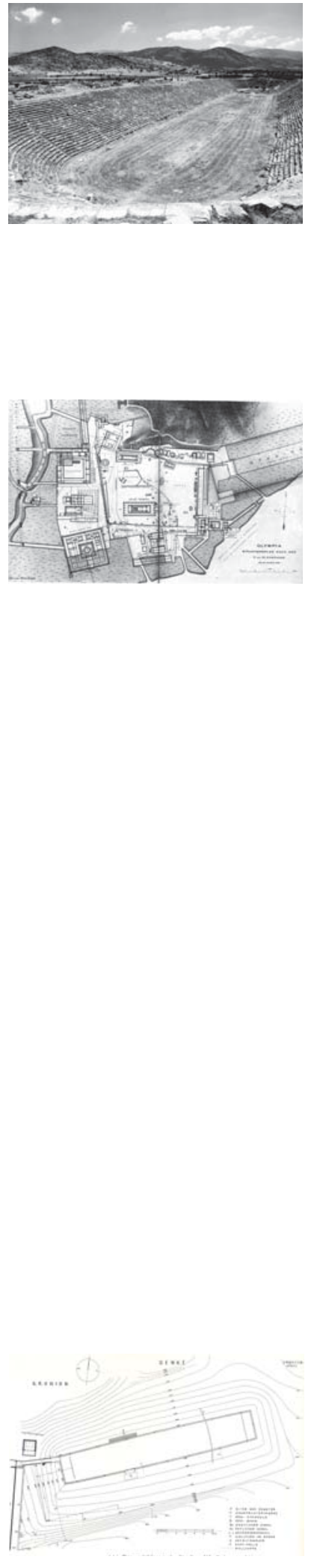

1. DURANTEZ, Conrado. (1977). Las Olimpiadas Griegas. Ed. Delegación Nacional de Educación Fisica y Deportes. Comité Olímpico Español. ISBN 84-400-2621-8 


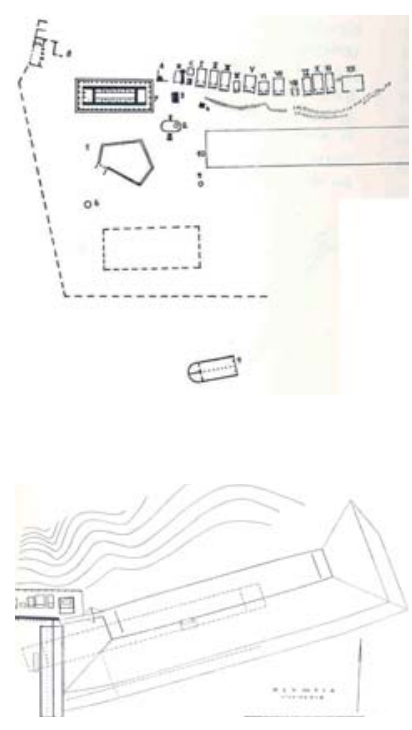

original y la programó en honor al Zeus Olímpico, escogería posiblemente un punto diferente de meta - puede ser que el altar de Zeus- y establecería una longitud permanente para la carrera. De todos modos podemos asegurar que la más antigua carrera en Olimpia tenía lugar en el corazón del sagrado bosque, donde el templo de Zeus fue construido más adelante. Drees'

Por lo que relatan los arqueólogos modernos de Olimpia, Emil Kunze (1901/1994) y el también arquitecto Alfred Mallwitz (1919/1986) en sus publicaciones acerca de los avances de las excavaciones ${ }^{2}$, se sabe muy poco del primitivo estadio. Se puede deducir que tenía la misma orientación que los posteriores y que desapareció totalmente debido a su cota tpopografica más elevada. Debió poseer en la zona sur una protección o talud artificial. En la zona norte, la pista debió de lindar con la falda de la colina natural, todavia sin regularizar en ese momento.

El segundo Estadio, para facilitar la formación de taludes, se replanteó a un nivel más bajo que su predecesor. Las pistas tenían una anchura de $26 \mathrm{~m}$ y siempre la longitud de $192 \mathrm{~m}$. Su estructura estaba todavía incrustada dentro del Santuario, como una pieza más del gran culto a Zeus, de ahí que en su lado oeste la pista estuviese abierta, y se supone que prolongando el eje longitudinal se encontraría el gran altar de Zeus, siempre a la vista de los corredores.

El segundo estadio supuso un notorio adelanto técnico respecto al anterior al haber planificado su trazado encuadrando sus extremos entre losas y orientarlo para que quedara rodeado en sus lados norte y sur por colinas de suave pendiente para cómodo lugar de asiento de los espectadores. Dice Emil Kunze:

Su configuración se encuentra notoriamente proyectada ya hacia el futuro, siendo la primera vez que el lugar adjudicado a los espectadores se configura con la instalación de las pistas en una sola pieza

La construcción de un sumidero en la esquina sudoeste que canalizaba las aguas que podrían verterse sobre la pista o gradas circundantes y las conducia hacia el Alfeo, supuso un avance técnico más a añadir a la nueva y mejorada instalación.

El estadio resultó de nuevo insuficiente ante las crecientes necesidades de espacio. Entonces se construyó un tercer y último estadio, que pese a los pequeños aditamentos y reformas de período romano, ha llegado casi completo hasta nuestros días.

Esta instalación era moderna y espaciosa. Los motivos para reformar el antiguo estadio fueron, por una parte, su adecuación arquitectónicas al gusto de la época que se distinguia por la preferencia de los espacios cerrados. La pista fue trasladada hacia el este y norte, en una zona próxima pero fuera de los límites del Altis, cuyo recinto sagrado y rodeado de edificios se veía hasta ese momento interrumpido por la pista de carreras. Esto descomponía el homogéneo conjunto de los templos. El Altis fue cerrado por el lado del estadio con la construcción de la Galería del Eco y el Edificio Sureste.

La nueva pista conservó el sentido tradicional y la dirección de la carrera ya habitual, el decir la meta seguía estando situada al oeste puesta la mira y dirección de los estadiodromos en el sagrado recinto. Se trasladó $75 \mathrm{~m}$ hacia el este y 7,5 y 9,5 hacia el norte. Al realizar esta traslación el talud norte se acercó a la pendiente ladera del Cronos, proporcionando un inclinado y espaciosos graderío natural. [...] La pista central fue elevada unos treinta centímetros quizá para proveerla de un mejor drenaje. Todo el vasto rectángulo fue enmarcado por una hilera de bloques de piedra porosa que los separaban y delimitaban de los taludes circundantes y a los límites de la pista se la dotó de una perfecta canalización para conducción de agua que se depositaba en diversas fuentes distribuidas para que los espectadores pudieran refrescarse. El trazado de la pista era oval, el ancho en el centro era de 34,33 m, mientras que 30,7 en el oeste y 31,87 en el este. Esta anomalía respondía a motivos de percepción óptica ${ }^{3}$.

También existían motivaciones deportivas para la construcción de un nuevo Estadio. El número de espectadores había aumentado, lo que hacía insuficiente la capacidad de los taludes. Estos se ampliaron y se habilitaron los de los extremos este y oeste. Además se procedió a la construcción de un sitial o tribuna prominente donde acomodar a los jueces o personajes distinguidos. Por último, también se pueden encontrar motivaciones religiosas. El profesionalismo de los atletas y la secularización total de las competiciones habían apartado a los juegos de su sentido religioso original, de ahí la necesidad de sacarlos del recinto sagrado

Este modelo de estadio cumplió su función durante trescientos años.

1. DREES, Ludwig (1968). Olympia. God, Artits and Athletes. Ed. Pall Mall Press. ISBN-10: 0269670157

2. KUNZE, Emil. (1972). 100 Jahre deutsche Ausgrabung in Olimpia. Ed. Prestel. Munich

MALLWITZ, Alfred. (1972). Olimpia und seine Bauten. Ed. Wissenschaftliche Buchgesellschaft Darmstadt

3. DURANTEZ, Conrado. (1977). Las Olimpiadas Griegas. pg.65/66 
En época romana, siglo I aC., se amplió el talud sur, elevando su altura cerca de un metro y se realizaron trabajos de mejora en el norte. A mediados del siglo II dC. se efectuó la última y definitiva modificación del estadio. Se elevó el nivel de las pistas centrales veinte centímetros para mejorar las condiciones del drenaje, y se elevó mas el terraplén sur para posibilitar mayor acomodo de los espectadores. En el terraplén norte se trazaron profundas zanjas longitudinales para prevenir la avalanchas de lluvia procedentes del Kronion y el altar originario de la sacerdotisa de la diosa Deméter Chamyne fue sustituido por otro más importante. Con la construcción del talud oeste había quedado, en el ángulo noroeste, un pasadizo o entrada a las pistas desde el Altis. En esta época se cubrió el pasadizo mediante una bóveda.

\section{B.2.2.1.2 Atenas}

El estadio de Atenas, tuvo mucha menos tradición que el de Olimpia, pero, siendo más moderno ha supuesto una influencia mayor en el desarrollo del estadio actual. El estadio de Olimpia es el origen, pero su influencia es solo de carácter evocativo.

En la Atenas clásica, los juegos y las carreras de carros significaban el punto culminante de las Panateneas, que era el más importante de todos los festivales de la región Ática. Y esto se venía produciendo desde los tiempos mas remotos, cuando el Ática estaba gobernada por reyes y su población eminentemente agrícola honraba en los festivales a la diosa tutelar y pedía su favor para obtener una abundante cosecha, como demuestran la representaciones en algunas vasijas arcaicas encontradas en la necrópolis cercana a la puerta Dipylon. Pero ¿̇dónde se celebraban estos festivales? Antes del siglo IV a. de C. debió haber existido un hipódromo, donde se desarrollaban no sólo las carreras de carros sino también los juegos deportivos. Esto parece evidente, pero no podemos determinar con certeza su localización. Existen varias opiniones. Algunos arqueólogos creen que el lugar más probable debió de ser una planicie triangular cerca de Nuevo Phaleron, lugar donde la topografía favorable de las tres colinas de Munychia forma un recinto de unas grandes dimensiones, capaz de albergar a miles de espectadores. Se cree que allí se celebraron los primeros Juegos Panatenaicos. En las excavaciones arqueológicas, no se han encontrado en ese lugar rastros de construcciones en piedra, lo cual indica que no debía existir una instalación permanente, como en el caso de Olimpia; solamente unas gradas de madera para los notables de la ciudad, los Arcontes (Magistrados) y Athlothetes (organizadores de las Panateneas). No parece que se dispusiera lugar alguno reservado para el público general, que muy probablemente tenia que permanecer de pie y con dificultades para la visión del desarrollo de las pruebas.

El público, al no tener un espacio asignado y diferenciado del propio de la competición, y llevado por la emoción y el ansia de ver, muchas veces dificultaría el propio desarrollo de la competición al invadir su espacio. Esta relación no acotada entre publico y competición, queda reflejada en el tratado sobre la caballería de Jenofonte (431/354 aC.), títulado Hipárquico, en el que indica como situar a los jinetes delante de la multitud en las paradas y las carreras, dejando suficiente espacio para su libre circulación y así evitar posibles incidencias con el público. Instrucciones innecesarias si los espectadores tuvieran acotado un espacio o estuvieran sentados.

En el siglo IV Pericles promovió la construcción del Odeón para los concursos musicales. Al mismo tiempo se levantaban, en otros lugares de Grecia, edificaciones especificas para las competiciones atléticas y ecuestres. Mientras tanto, en Atenas se continuaron desarrollando las competiciones con la mayor sencillez, en un espacio abierto y con una topografía favorable. Hasta que un siglo después, Licurgo (396/323 aC.) el famoso orador, propuso e impulsó la idea de construir un Estadio, donde dar un mejor acomodo a espectadores y competidores.

Una vez seleccionado un cerrado valle, la obra ejecutada bajo la dirección del propio Licurgo, consistió fundamentalmente en la adecuación del terreno, rellenando su lado sur hasta el nivel de las dos laderas, cerrando así el barranco por tres lados. El terreno interior, destinado a la competición se hizo horizontal. Las laderas fueron perfiladas para conseguir una pendiente uniforme en forma de herradura. Además, se separó la arena de competición con respecto al público por medio de un parapeto y se marcó las líneas de salida y llegada con una hilera de piedras. Significó un considerable esfuerzo en tiempo y dinero, como demuestra el decreto, datado en el tercer año de CXII (329 aC.), en el que Eudemos (originario de Platea con ciudadanía ateniense) es mencionado con honores por aportar 1.000 yuntas de bueyes para la construcción del Estadio y del Teatro Panatinaico. Detrás del parapeto había un deambulatorio que recorría todo el perímetro de la pista y bajo su pavimento corría un conducto abovedado, que recogía el agua de lluvia. Algunos restos de este conducto siguen existiendo. En ese periodo las laderas no estaban cubiertas de gradas de mármol y los espectadores se sentaban en el suelo, como muy probablemente se hacia en Olimpia en la antigüedad. Sólo los sacerdotes, arcontes, generales, embajadores y representantes de ciudades extranjeras, así como los que presidían los juegos y los huérfanos cuyos padres habían muerto luchando por Atenas, tenían reservados bancos de madera. En el siglo III a. C. se realizaron algunas reparaciones en el Estadio, como muestra la inscripción que dice "el estadio fue reparado por Heracleitos en una "forma acorde")".
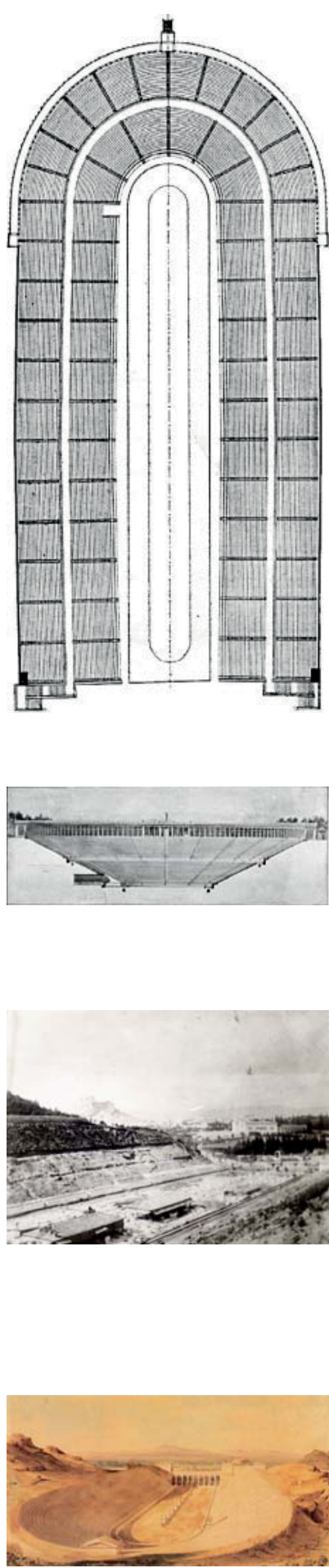

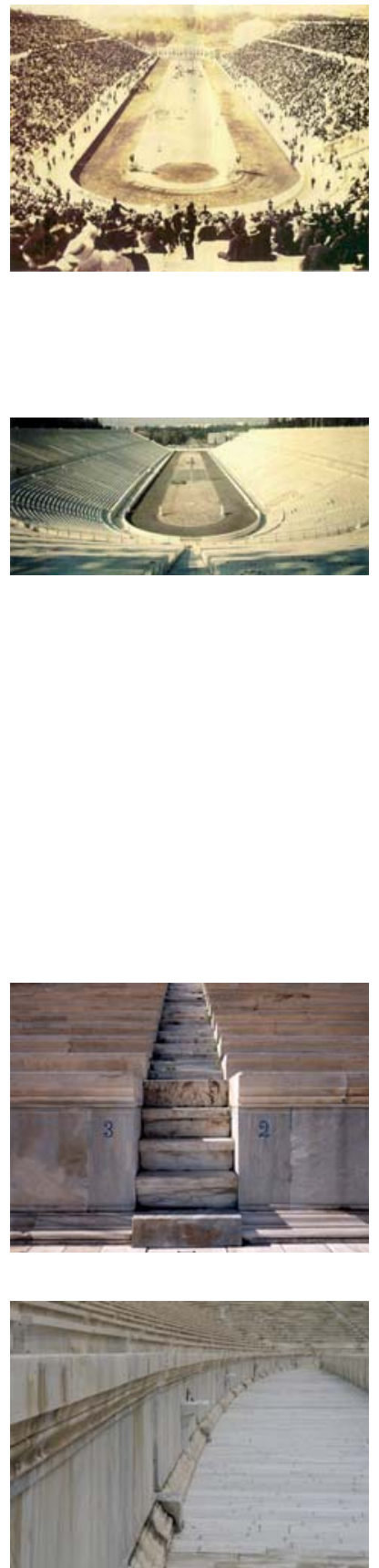

En tiempos del emperador Adriano, en el siglo II dC. el estadio fue completamente restaurado y suntuosamente decorado por Herodes Ático. El sofista ateniense, que destinó su inmensa fortuna para el embellecimiento de espléndidos edificios y estructuras de uso público, no sólo repartió su generosidad en Atenas y en varias ciudades de Grecia, sino también de Italia y Asia.

En el 139 dC. Herodes Ático fue elegido athlothete, organizador de las Panateneas, y en el periodo de su mandato las fiestas llegaron a su mayor esplendor y magnificencia. Sirva como ejemplo el detalle de la participación en las fiestas de un barco sobre ruedas, con toda su arboladura, arrastrado por bestias de tiro y dotado de un mecanismo oculto que simulaba los movimientos de la navegación. Cuando, Herodes Ático agradeció a sus conciudadanos el honor conferido, terminó diciendo:

Será en un Estadio de mármol en el que espero recibiros, oh atenienses, a vosotros, así como a los Atletas y a los extranjeros, que luego serán nuestros invitados.

El retórico Filostrato, biógrafo de Herodes nos dice:

no hay otro teatro que pueda ser comparado con el estadio

Pausanias nos asegura que su visión era magnifica, indescriptible, y en su admiración fue hasta el punto de añadir que esta obra casi había agotado las canteras de mármol del monte Pentélico'.

La actuación de Herodes Ático sobre el Estadio supone, además, una transformación del mismo, por razón del cambio de su función. En tiempo de los romanos, además de los Juegos Atléticos, en el Estadio se llevaban a cabo espectáculos de gladiadores y caza de animales salvajes, como atestigua el historiador Spartianos, cuando relata que el emperador Adriano donó en una ocasión 1.000 animales salvajes, para ser cazados en el Estadio. Estas razones funcionales, llevaron a la modificación de la barrera entre la pista y los espectadores $y$, también, a la relación entre la primera fila y la pista. En el Estadio de Licurgo la primera fila de asientos estaba más cerca de la barrera que en el de Herodes. La distancia hasta el corredor que discurre alrededor de la pista era muy parecida a la del espectador y los actores del teatro de Epidauro, es decir, un poco más de 2 metros. Esta distancia es también semejante en el punto de los puestos de honor a la del teatro de Dionisio, aunque en el resto de la alineación va variando. Esta variación también debió de existir en el Estadio de Licurgo, siguiendo una ley óptica, con el fin de que los espectadores de las gradas largas tuvieran una mejor visibilidad. La alineación de la primera fila de asientos no discurría paralela al eje de la pista, sino que debió tener forma curva. El radio de esa curvatura debió ser de aproximadamente 2.000 metros.

Cuando Herodes renovó el estadio, el corredor perimetral se amplió mediante la demolición de las filas inferiores de las gradas de la construcción antigua, quedando elevada, la primera fila de asientos a una altura de 1,66 metros, apoyándose sobre un muro de mármol, con basa y cornisa. El pasillo, el corredor que rodeaba la pista no tenía en todas partes la misma anchura. En su parte semicircular y en los extremos, era de 2,82 metros, y en la mitad de las dos partes largas de 5,00 metros.

La zona del público, que se llamaba theatron (lugar desde el que se contempla), estaba dividido en graderíos de 23 filas cada uno, separados por la diazoma, un pasillo longitudinal de 3,04 metros de ancho. La primera fila del graderío superior estaba levantada respecto a la diazoma 2,03 metros. La diazoma tenia acceso directo desde los extremos, por medio de dos escaleras. En la primera fila se disponían asientos con respaldo, llamados tronos, que ocupaban el espacio de dos filas normales.

Cada grada tiene una profundidad de $73 \mathrm{~cm}$ y un alto de $36 \mathrm{~cm}$, que es $4 \mathrm{~cm}$ mas que las del teatro de Dionisio. El espacio para cada espectador no esta marcado. Si suponemos igual al señalado en el teatro de Dionisio, $33 \mathrm{~cm}$, supondría un aforo total de 69.000 espectadores y si tomáramos un valor de 45 $\mathrm{cm}$ el aforo sería de 47.000. La parte superior de graderío estaba rematado por un estrecho pasillo. El graderío estaba dividido en 30 sectores, llamados kerkides, por medio de 31 escaleras de 1,07 m de anchura. La parte semicircular (sphendone) estaba dividida en 6 sectores en la grada baja y 12 en la alta. Los primeros peldaños de cada escalera se proyectaban sobre el pasillo. El primer asiento de cada fila desde la escalera estaba ornamentado con el relieve de una cabeza de búho.

En la ladera izquierda, en el punto de encuentro entre el tramo recto y el semicírculo, se abría un vomitorio que cortaba las ocho primeras filas. Sus dimensiones eran 7 metros de profundidad y 4,75 metros de anchura; en sus restos se puede apreciar los espacios necesarios para alojar los elementos de fijación y giro de unas puertas. El vomitorio daba acceso a una galería abovedada de 3,96 metros de alto y 3,69 metros de ancho, revestida de piedra del Pireo. Penetraba considerablemente en la colina y después de una pronunciada curva salía detrás de ella. Existen dos teorías sobre la razón de este pasadizo. La primera lo relaciona con la entrada secreta de los Estadios de Olimpia y de Epidauro. Pausanias nos dice que los atletas de Olimpia y los árbitros eran llevados al Estadio por un pasaje secreto; también podemos suponer que la bóveda a la entrada del Estadio Panatenaico hubiera servido para el mismo propósito. La segunda, tal vez más plausible, dice que fue construido por Herodes Ático, para permitir la introducción de animales salvajes en la arena. Esto nos lo relaciona con las entradas abovedadas a los teatros romanos, "ábsides" y nos lleva a pensar que la entrada al Estadio de Olimpia al principio estaba descubierta "hypaethral" y que en tiempo de los romanos se cubrió con una bóveda 
El graderío, koilon', esta apoyado en los dos extremos del lado Norte sobre grandes hastiales de piedra que contienen el terreno. En estos hastiales se apoyan las escaleras que rematan la diazoma. El graderío estaba rematado en la parte semicircular, Sphendone, por una Stoa, un gran pórtico dórico de 32 metros de longitud y 10 metros de ancho.

Además se supone, por los restos encontrados, que el lado Norte del Estadio estaría cerrado por unos Propileos.

En lo alto de la colina occidental que rodea el Estadio, Herodes Ático erigió un templo a la Fortuna de la ciudad. $Y$ en la cima de la colina oriental los ateniense erigieron más tarde, sobre su tumba, un monumento de agradecimiento a su memoria, y en él grabaron la siguiente inscripción, muy elocuente en su concisión: "Aquí yace Herodes Ático de Marathón, digno de toda alabanza. Que todo lo que le rodea, es su propia obra".

En cuanto a las dimensiones, el Estadio tenía un ancho de 33,55 metros, su suelo estaba 30 centímetros por encima del corredor perimetral, el radio del Sphendone era de 16,76 metros. Hay que destacar que tanto el Estadio de Olimpia cómo el de Epidauro no contaban con sphendone, sino que estaban rematados en dos lados rectos cortos.

En lo que era la salida, "aphesis" debió de haber habido cuatro o más grandes estelas verticales de mármol Pentélico, de 2,58 metros de altura coronados por dos cabezas de 43 centímetros de altura mirando, cada una, en sentido contrario. Una de ellas representa al dios Hermes, con barba. El himno homérico invoca a Hermes como el ude multiforme ingenio (polytropos), de astutos pensamientos, ladrón, cuatrero de bueyes, jefe de los sueños, espía nocturno, guardián de las puertas, que muy pronto habría de hacer alarde de gloriosas hazañas ante los inmortales diosesll. La otra representa a un juvenil Apolo, severo y majestuoso al mismo tiempo. Las cuatro estelas encontradas son muy parecidas, prácticamente iguales, la primera apareció en 1870 , las otras a finales del s. XIX. El trabajo del artista deja visibles deliberadamente las marcas de cincel. Es evidente que fueron hechas en un período en el que a los artistas les gustaba imitar el arte arcaico, y esto coincide, precisamente, con los tiempos en que Herodes restaura el Estadio. $\mathrm{Y}$ es probable que sea una copia de una escultura del siglo $\mathrm{V}$ aC. Estas estelas seguramente formarían parte del mecanismo de salidas, como parecen indicar los taladros y acalanaduras que muestran. Aunque no se han encontrado los limites del Estadio en su lado Norte, donde queda abierto, podemos pensar que su longitud sería la habitual en los Estadios Griegos, 600 pies griegos, lo que significa 177,6 metros, puesto que el pie griego es 0,296 metros.

\section{B.2.2.2 El circo romano}

Desde el punto de vista arquitectónico, el circo es una construcción mucho mas simple que la del anfiteatro y no puede provocar las fértiles soluciones arquitectónicas a que dan lugar otros programas más complejos. Sin embargo, desde el punto de vista histórico, el circo acaso sea el primero entre los que acogen las diversiones de los romanos, más que las otras dos grandes estructuras lúdicas, el teatro y el anfiteatro.

El modelo del circo romano proviene del estadio griego pero asumiendo la función del hipódromo, lo que exige unas dimensiones mucho mayores, pues si el estadio sirve para las carreras pedestres y los juegos atléticos, el circo está destinado para las carreras de carros y otros espectáculos y representaciones que conmemoraban los acontecimientos del Imperio.

El circo romano es, en general, un recinto muy alargado con remates circulares en uno o los dos de sus extremos, teniendo globalmente una forma oval. En el centro, rodeada de gradas generalmente de piedra, estaba la arena (en latín hārēna) una pista rectangular muy alargada dividida en dos por la spina en torno a la cual giraban las cuadrigas un determinado números de veces. La spina se decoraba con una serie de trofeos, estatuas, obeliscos y memoriales diversos. En cada uno de sus extremos había un pilar cónico denominado meta. En uno de los extremos del Circo estaban las Carceres, de donde salían los carros, y en el otro solía haber una entrada monumental o arco del triunfo.

En el Circo Máximo de Roma podían correr doce carros, medía aprox. 600 metros de largo, 225 metros de ancho y podía albergar a unos 150.000 espectadores sentados. Sus graderíos, para poder

1. El koilon era el conjunto de gradas donde se asentaban los espectadores. Ocupaba la ladera de la montaña, y recibió también el nombre de theatron, cuyo significado es "lugar desde el que se mira", que más tarde pasó a referirse a todo la construcción. Tenía forma semicircular y los asientos estaban situados en gradas. Estaba dividido en sectores (kerkís): de forma vertical, por escaleras y en horizontal, por pasillos (diazoma).

En el Teatro Dionisio al principio los asientos de las primeras filas estaban hechos de madera, y el resto de la gente se sentaba directamente sobre la tierra; pero alrededor de 499 a. C. se comenzaron a construir líneas de bloques de piedra en la ladera de la colina para crear asientos permanentes y estables, que se fueron haciendo cada vez más comunes; los de la primera fila fueron llamados prohedria, eran de mejor calidad y estaban reservados para los sacerdotes y para los ciudadanos más respetados. Entre el koilon y la orchesta había un murete llamado balteus
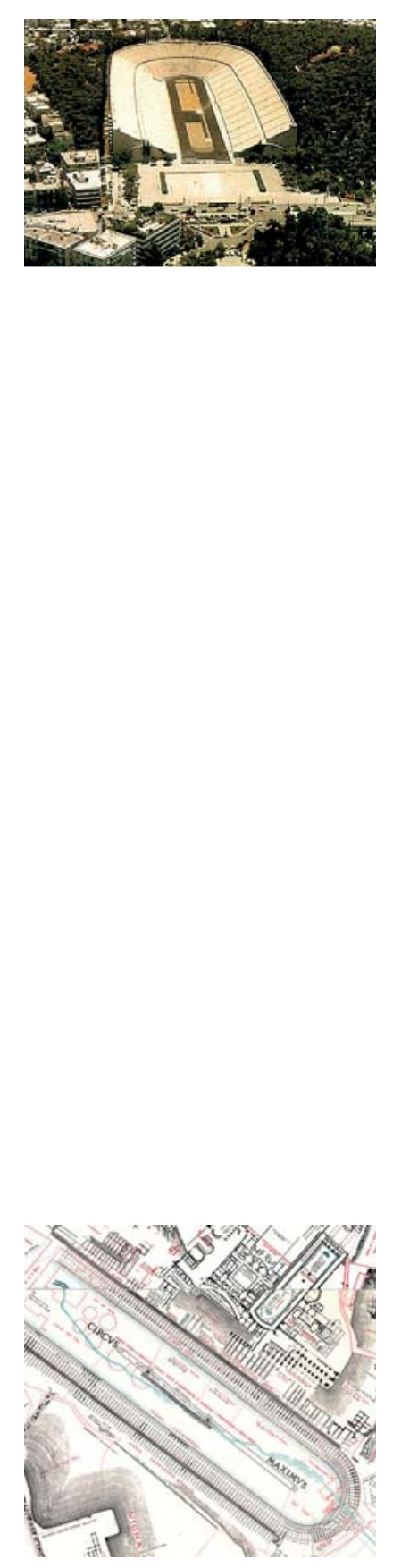
acomodar a tal multitud de espectadores, debieron de ser estructuras importantes y no diferentes de las del Coliseo, pero desarrolladas en longitud. Las dimensiones de los circos variaban mucho, por ejemplo en de Tarraco, construido a finales del siglo I dC., tenía un aforo para 25.000 personas y medía 340 m. de largo por 117 m. de ancho. En España hubo también circos en Mérida, ltálica, Toledo y Segóbriga.

\section{B.2.2.3 El anfiteatro}

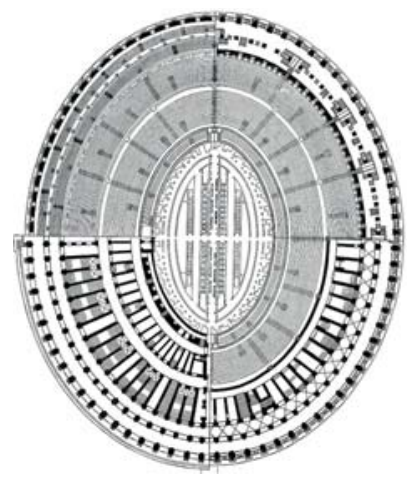

Si los teatros, circos y estadios respondían en Roma a las mismas necesidades del mundo griego, y por lo tanto los romanos se limitaron a transformar a su modo las estructuras helenísticas, los anfiteatros eran algo enteramente nuevo y sin precedentes, consecuencia de una afición enteramente propia, los combates de gladiadores.

En un principio, estos combates, que se introdujeron en Roma en 264 a. de J.C., tenían lugar en las plazas públicas, en los foros, como el foro Boario, donde eran frecuentes. Luego se utilizaron graderíos provisionales de madera.

El primer anfiteatro de piedra fue, según el historiador francés León Homo (1872/1957), el de Statilius Taurus' ${ }^{1}$ construido en época de Augusto en el Campo de Marte. Años mas tarde, Vespasiano empezó en mucho más gran escala el enorme anfiteatro que continuó Tito y termino Domiciano y que en honor de estos emperadores lleva el título de anfiteatro Flavio (70-82), conocido vulgarmente con el nombre de Coliseo. Es sin duda uno de los monumentos más insignes que nos ha dejado la civilización romana.

La planta del Coliseo la forma una falsa elipse, es decir, un óvalo compuesto por cuatro semicírculos, cuyo eje mayor mide 188 metros y 156 metros el menor. Un anfiteatro es como la unión de las cáveas de los teatros y de esta similitud procede su nombre. Los teatros griegos y también su versión evolucionada del teatro romano, son un gran ejemplo de cómo por aplicación y mejora de un tipo edificatorio, destilando sus condiciones constructivas y de uso, se consigue alcanzar un grado de precisión y belleza impresionantes. El anfiteatro aprovecha y saca partido de esa fecunda experiencia.

El graderío estaba dividido en el podium, donde se colocaba el emperador y su corte, senadores, magistrados y grandes cuerpos del Estado; y en tres partes superiores, llamadas maeniana, se situaba la masa de espectadores. Esto equivale bastante aproximadamente a la distribución de la cávea de los teatros en ima, media y summa cávea. Separaban estas diversas partes unos pasillos anulares llamados praecinctiones y luego el graderío se dividía a su vez en sectores (cunei) separados por escaleras. Para sostener el inmenso graderío, que podía alojar a más de 50.000 espectadores, se organizó toda una estructura de muros radiales unidos entre si por bóvedas y que servía de pasajes de acceso $\circ$ de emplazamiento para las escaleras.

El público accedía desde el exterior a través de los 80 arcos que circundaban la fachada. Cada arco tenía un número y el espectador sabía cual era el arco que le correspondía para alcanzar su localidad directa y rápidamente. Luego, por los corredores interiores y escaleras llagaba a su recinto y desde allí a su sector (cunei) y localidad.

Por debajo del plano de la arena, una complicadísima infraestructura servía a la complicada tramoya de estos juegos. Verdaderos chiqueros subterráneos se utilizaban para conducir a las fieras, que luego se elevaban a la superficie por ascensores mecánicos. Con un verdadero alarde técnico para la época, esta arena podía transformarse en lago o piscina para naumachias.

La fachada o expresión externa de este inmenso óvalo es una de las más hermosas creaciones de la arquitectura romana. Su enorme altura de 50 metros está dividida en cuatro ordenaciones: mixta arcodintel las tres primeras y mural la cuarta. Los tres órdenes inferiores son de columnas adosadas, dóricas, jónicas y corintias. El cuarto orden mural es de pilastras corintias. Sobre la triple y robusta arquería abierta, la coronación mural, más alta que las ordenaciones inferiores, da un peso de gravedad a toda la composición. En este ático todavía se ven las ménsulas que sostenían los mástiles que servían para mantener el velarium, que manejados por marineros de Misena, para proteger a los espectadores del sol y la intemperie.

Los constructores romanos utilizaron en esta obra toda su ciencia y sabiduría técnica. En el Coliseo encontramos fábricas de sillería, hormigones revestidos de piedra o ladrillo, bóvedas de diversos materiales y composiciones geométricas, de cañón, rampantes, de arista, etc. Cada material y cada 
procedimiento están utilizados en perfecta adecuación de las necesidades de cada caso a los esfuerzos y cargas que habían de resistir. El anillo exterior y estructura de fachada está noblemente aparejado por sillares de travertino, con lo que se logra a la vez solidez y magnificencia.

Descrito el anfiteatro Flavio, constituido en "modelo" se puede decir que quedan descritos todos los anfiteatros romanos, versiones mas simplificadas del monumento tipo.

Aunque Vitruvio en los Los Diez Libros de Arquitectura ${ }^{1}$ no se refiere directamente al anfiteatro, lo que trata del teatro es, prácticamente en su totalidad, de aplicación. En el Libro V, Capitulo III, Ubicación del teatro, se refiere a la elección del lugar para edificarlo. Habla de la salubridad del aire, de la orientación de los vientos, ...

Durante la representación de los juegos, los ciudadanos permanecen sentados mucho tiempo junto con sus mujeres y con sus hijos, se entretienen divertidos con el espectáculo y sus cuerpos, al mantenerse quietos por el placer de presenciar las representaciones, dejan los poros abiertos por donde va penetrando el aire, que, sí procede de lugares pantanosos o insalubres, introduce dentro de los cuerpos corrientes nocivas. Por tanto, se elegirá con todo cuidado el lugar destinado para el teatro y se evitarán así tales inconvenientes e incomodidades. También debe ponerse especial cuidado en su orientación, de modo que no se vea castigado por el viento que procede desde el mediodía, pues a pleno sol sus rayos llenan por completo el perímetro del teatro y el aire encerrado $u$ ocluido en la curvatura, al no poder expandirse libremente, se recalienta como consecuencia de su movimiento, se vuelve muy candente, llegando a quemar abrasadoramente, por lo que reduce la humedad de los cuerpos.

...también se refiere a las cimentaciones, a sus graderías y a los corredores de distribución, importando mucho las proporciones para que el funcionamiento acústico sea correcto...

Sobre los cimientos se fijarán las gradas de piedra o de mármol. Los corredores de separación deben guardar proporción respecto a la altura del teatro y su altura no debe ser mayor que su propia anchura. Si tuvieran una mayor altura, rechazarían las voces y las elevarían hasta las partes más altas del centro del teatro, no permitiendo que llegue con nitidez el sentido de las palabras al oído de quienes están sentados en la parte superior de los corredores

...y prosigue con los flujos de gente, atendiendo a su comodidad y seguridad...

Es muy conveniente distribuir unos accesos anchos y espaciosos; los accesos o entradas hacia las gradas más altas estarán separados de los que están situados más abajo, y todos deben ser seguidos, rectos y sin curvas para que, cuando el público salga del espectáculo, no sufra apreturas, sino que desde cualquier parte acceda a las salidas, convenientemente separadas, sin ningún obstáculo y sin problemas.

...y vuelve a insistir en el sonido, en el manejo de la arquitectura a favor de su fin utilitario; un teatro funciona como una maquina, como un instrumento perfectamente afinado...

Precisamente por esto, los antiguos arquitectos, siguiendo los rastros de la naturaleza en sus investigaciones sobre la expansión de la voz, que se eleva de modo natural, hicieron a la perfección las gradas de los teatros y buscaron, a través de cálculos matemáticos y de proporciones musicales, que toda palabra pronunciada en el escenario llegara a los espectadores de la manera más clara y más agradable. Como los instrumentos de aire, sean de bronce o de cuerno, logran una gran sonoridad acompañando a los instrumentos de cuerda si están perfectamente afinados, así también los antiguos fijaron la estructura de los teatros, por medio de las normas de la armonía y con el objetivo de potenciar el volumen de la voz

Continua dedicando un capítulo a la armonía y otro a los vasos del teatro, resonadores de bronce para potenciar el sonido. En el capitulo $\mathrm{VI}$ explica con toda precisión el trazado de los teatros y en el siguiente el trazado especifico de los teatros griegos, para rematar el tema con el capitulo IX dedicado a la acústica.

Estas cuestiones esenciales, que recorre el maestro para el trazado de los teatros, bien pueden aplicarse directamente al proyecto del estadio Olímpico, la elección del lugar, la proporción en su trazado, los flujos, la armonía, el sonido...
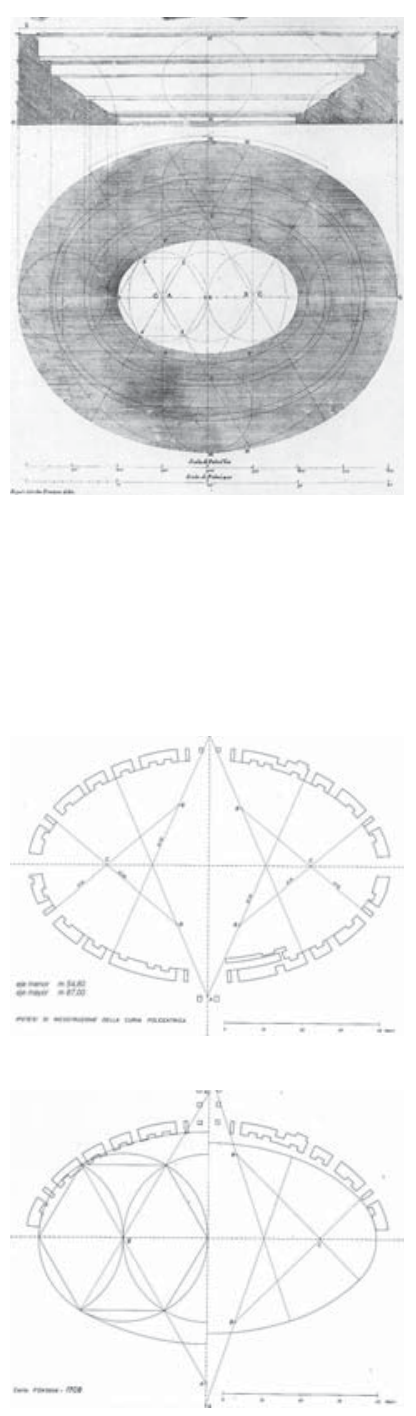


\section{B.2.3 El estadio industrial. Inglaterra}

En la Inglaterra del siglo XIX se produce el desarrollo del deporte, primero, como parte integral de la educación más elitista y, posteriormente, mediante su popularización. Paralelamente aparecen nuevos materiales de construcción y nuevas técnicas constructivas, nuevas funciones... nuevos tipos arquitectónicos. Un interesante ejemplo es el del Cristal Palace de Joseph Paxton que su esfuerzo por agrandar las luces estructurales. Su sistema constructivo industrializado supone un paradigma de la arquitectura industrial de la que derivan los estadios ingleses del siglo XIX.
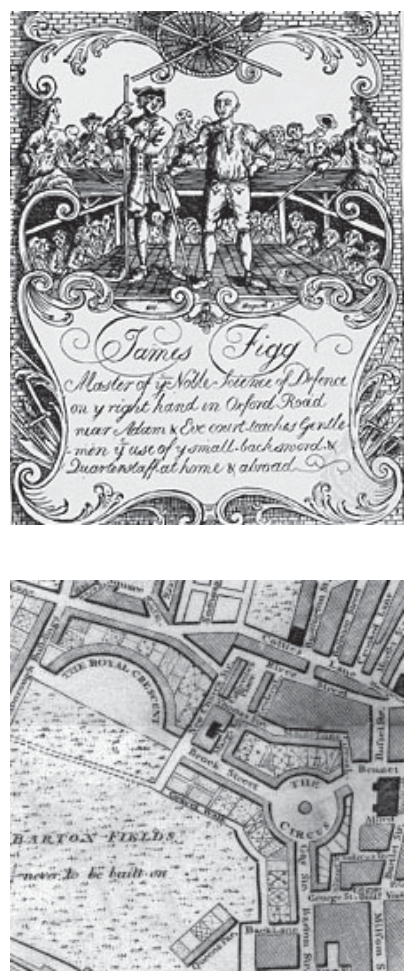

Previamente a la revolución industrial de dieron iniciativas para la construcción de arquitecturas deportivas; en 1720, James Figg (1659-1734), reconocido como primer campeón ingles de boxeo (en esos tiempos se boxeaba sin guantes), construyó en Londres un anfiteatro, llamado Boarded House en Marybone Fields, dedicado a diferentes formas de espectáculos deportivos. Figg que en un principio destacó como tirador de esgrima, cambió, guiado por intereses económicos, ell noble arte de la espada, florete y sable por el vulgar del boxeo, como espectáculo. Deporte como negocio, en el que la brutalidad y la violencia se convierten en protagonistas, produciéndose una relación con espectáculos marginales, como la pelea de gallos o de algunos otros animales, más circo romano que deporte. Boarded House, no fue la única en su tiempo, pero sí la mas conocida y documentada; hasta nosotros han llegado los carteles que anunciaban sus espectáculos. Estas edificaciones de carácter supuestamente "deportivo", consideramos que no suponen el origen del desarrollo del estadio moderno, el cual se asienta en ideales mucho más nobles y profundos, además de las diferencias meramente escalares.

En el otro extremo del espectro, desde la prospección y especulación cultural, nos encontramos como John Wood (1704-1754) introduce en su propuesta para el plan urbanístico de Bath, de 1724, una instalación Ilamada Grand Circus, para la celebración de espectáculos deportivos. Como podemos observar, la denominación nos retrotrae a la herencia romana, que la alta sociedad y burguesía de la Inglaterra Imperial y relacionaba con el desarrollo una nueva cultura social del ocio. También, hay que destacar que en la parte existente de la ciudad aparecen grafíados algunos lugares para tomar el aire y hacer ejercicio en carrozas, o a caballo y una pista para carreras de caballos.

Con la revolución industrial, que suponía la afluencia masiva de población a las ciudades y provocaba disfunciones en la organización social con problemas de marginación y exclusión, apareció la necesidad imperiosa de la reforma de los sistemas educativos. Las personas que habían cambiado un modo de vida rural en contacto con los espacios abiertos por los arrabales fuertemente densificados de las ciudades industriales, encontraron en la asistencia a las competiciones deportivas una válvula de escape. Además del bálsamo terapéutico que supone el sentido de pertenencia a un equipo de una masa de gente desubicada.

Además, iba aumentando el interés por las prácticas deportivas

a medida que se acercaba el final de siglo, los hombre corrían, nadaban, boxeaban, etc se publicaron libros sobre los deportes y se crearon asociaciones de carácter privado que impulsaban la práctica de nuevas disciplinas deportivas. Sin embargo, no existía ni un solo estadio de atletismo, ni reglas o condiciones universales para las competiciones.'

Los primeros estadios eran campos deportivos acompañados de graderíos muy básicos en los que se hacinaban los espectadores.

Tal vez el primer estadio de la sociedad industrial fue el de Lansdowne Road, en Dublín. Impulsado por el organizador de los primeros All Ireland Athletics Championships, Henry Wallace Doveton Dunlop (1844/1930). Era un marchador laureado e ingeniero graduado del Trinity College de Dublín que fundó el Irish Champion Athletic Club en 1871. Después de unos primeros campeonatos celebrados en el Trinity College, el rector de la universidad prohibió cualquier otra competición en el campus. Dunlop en 1921, escribiría:

Por lo tanto, me vi obligado a buscar otro terreno, y después de una cuidadosa consideración elegí el actual Lansdowne Road Con el fallecido Edward Dillon (mi entrenador), tomé un contrato de arrendamiento de 69 años al Pembroke. Estate, con el pago de una renta de $£ 60$ al año por solamente una porción del terreno que se extienden desde el ferrocarril hasta unas 60 yardas del Dodder. Tendimos una pista de arcilla de un cuarto de milla, ubique con mi teodolito el actual Lansdowne Tennis Club, fundé el Lansdowne club de tiro con arco, el de cricket y por último, pero no menos importante, el Football Club Lansdowne de Rugby -colores rojo, negro y amarillo- en

1. MORAGAS, Miquel (1996). Las Claves del éxito: Impactos sociales, deportivos, económicos y comunicativos de Barcelona'92. Ed. Bellaterra: Centre d'Estudis Olímpics, UAB. Miquel de Moragas i Spa (1943) es Catedrático de Teoría de la Comunicación 
El Lansdowne Road era un recinto polideportivo, con pista de atletismo, campo de cricket, croquet, tres campos de fútbol (rugby), tiro con arco y tenis. Lansdowne Road fue el escenario de la primera competición internacional de atletismo entre Irlanda e Inglaterra en 1875. El primer partido de rugby se celebró en 1876, Leinster contra Ulster. En marzo de 1878 el Lansdowne fue testigo del primer partido internacional de Rugby disputado en la historia, entre Irlanda e Inglaterra.

Otros estadios precursores de esta época en el Reino Unido fueron los relacionados con el club pionero en atletismo, el London Athletic Club, fundado en 1863, aunque inicialmente su nombre era Mincing Lane Athletic Club. Inició sus competiciones en 1863, en el recién inaugurado West London Cricket and Running Grounds de Brompton. En 1866 el club cambio de nombre porque entre sus miembros había "señores" de todas las partes de Londres. En 1869 se traslada a los recién abiertos Lillie Bridge Grounds. En 1877 adquieren seis acres y medio en Stamford Bridge y ahí trasladan sus instalaciones. En 1904 en la propiedad de los terrenos pasa a manos de Gus Mears, gran aficionado al fútbol, que compra terrenos aledaños y encarga al mas afamado ingeniero/arquitecto deportivo Archibald Leitch la construcción de un gran estadio. Proyecta en el lado este una tribuna cubierta para 5.000 espectadores sentados y los otros tres lados están formados por un potente graderío para publico de pie, construido con las tierras provenientes de la excavación de la línea de metro Piccadilly. La capacidad prevista era de 100.000 espectadores

En Stamford bridge participan dos personajes decisivos en la configuración del estadio moderno, Archibald Leitch y Charles Perry.

Archie $(1865 / 1939)$ se inició en la practica de la arquitectura construyendo edificios industriales, aportando su experiencia al nuevo modelo edificatorio del estadio. En 1899 le fue encargado su primer estadio, el de los Glasgow Rangers, el lbrox Park. Ahí se inicia una larga y fructífera carrera de cuarenta años, que extrañamente no se vio empañada por el desastre de 1902, en el que la parte trasera de la tribuna oeste del recién construido lbrox Park cedió durante la celebración de un partido entre Escocia e Inglaterra. Cientos de espectadores cayeron desde 12 metros de altura, muriendo 25 personas y resultando heridas 517. Desde ese momento las gradas de madera sobre estructura metálica quedaron prácticamente proscritas, siendo mayoritariamente sustituidas por gradas hormigón o graderíos sobre el terreno. Entre los muchos estadios construidos por Leitch podemos destacar: Anfield, Arsenal Stadium, Celtic Park, Old Trafford, Villa Park, West Ham, White Hart Lane. El historiador británico del deporte y su arquitectura, Simon Inglis en su publicación de 2005, Engineering Archie: Archibald Leitch - Football Ground Designer, atribuye a este renombrado especialista escocés en estadios de fútbol algún tipo de participación en el estadio Olímpico de Amberes, ya que parece que están documentados varios viajes suyos a la ciudad flamenca durante el periodo de construcción del estadio.

En cuanto a Charles Perry, Martin Polley en su libro The British Olympics: Britain's Olympic Heritage 1612-2012, dice en su pagina 97 que Perry preparó la pista de Amberes, además de las de Atenas, Londres y Estocolmo. De Perry sabemos muy poco, solo que pertenecía al London Atheletic Club que tenia sus instalaciones en Stamford Brigde; seguramente fuera entrenador y además hacia las veces de cronometrador.

1. El Fitzwilliam Lawn Tennis Club de Dublin fue fundado en 1877 
BIBLIOGRAFÍA. Origen del estadio moderno.

BAKER, William Joseph. (1982) Sports in the Western World. Ed. Illini Books editions. 1988. ISBN 0-252-06042-3

DREES, Ludwig. Olympia: gods, artists, and athletes. Ed. Praeger, 1968

HOMO, Léon. (1951) Rome impériale et l'urbanisme dans l'Antiquité. Ed. Albin Michel. 1971. ISBN: 978-2-226-29642-

INGLIS, Simon (2005). Engineering Archie: Archibald Leitch - Football Ground Designer. English Heritage. ISBN 1-85074-918-3

KIERKUC-BIELINSKI, Jerzy; GERAINT, John. (2012). Stadia: Sport and Vision in Architecture. Ed. Sir John Soane's Museum. Londres. ISBN: 9780955876288

KUNZE, Emil. (1972). 100 Jahre deutsche Ausgrabung in Olimpia. Ed. Prestel. Munich

LUCIANI, Roberto. (1993). El Coliseo. Ed. Anaya. ISBN: 84-207-5275-4

MALLWITZ, Alfred. (1972). Olimpia und seine Bauten. Ed. Wissenschaftliche Buchgesellschaft Darmstadt

NEPPI MODONA, Aldo. (1963) Todo sobre Roma Antigua. (Espectáculos, Actore y público). Ed. Grijalbo. 1969.

Barcelona. Depósito Legal: S,S.-77-69

PHILIPP, Klaus Jan. (2000). Karl Friedrich Schinkel: v. 1 \& 2: Spate Projekte/Late Projects. Ed. Axel Menges. ISBN $978-$ 3930698110

POLLEY, Martin (2011). The British Olympics: Britain's Olympic Heritage 1612-2012. Ed. English Heritage. ISBN 978 1848020580

SLOTERDIJK, Peter. (2004). Esferas III. Espumas. Esferorogía plural. Ed. Siruela, Biblioteca de Ensayo. $2^{a}$ edición. 2009 Titulo original: Sphären III (Plurale Sphärologie). Schäume. Suhrkamp Verlag, Frankfurt am Main, 2004. Traducción Isidoro Reguera. ISBN 978-84-7844-951-4

VITRUBIO POLLIÓN, Marco (s. I dC.) Los Diez Libros de Arquitectura. Título original: De Architectura. Traducción; OLIVER DOMINGO, José Luis. Ed. Alianza Forma 1995. Madrid. ISBN 84-206-7133-9

VERSPOHL, Franz-Joaquim. (1976). Stadionbauten von der Antike bis zur Gegenwart. Regie und Selbsterfahrung der Massen. Ed. Anabas. ISBN 3-87038-043-8.

WARD-PERKINS, John B. (1972) Arquitectura Romana. Ed. Aguilar. 1989. Madrid. ISBN: 84-03-33107-X

The Stadium and the City. Editado por John Bale y Olof Moen. Keele University Press. ISBN 1853311103 . Primera edición 1995. B. ACP

http://www.nationalgeographic.com.es/articulo/historia/secciones/8848/globo_aerostatico_conquista_los_cielos. html 
A continuación analizaremos el Estadio y su evolución hasta el establecimiento de lo que podemos considerar su "arquetipo".

...es obvio que (el tipo) nunca está formulado a priori, sino deducido siempre de una serie de ejemplos. Antoine-Chrysostome Quatremère de Quincy. (1755/1849)

Para definir "tipo" Giulio Carlo Argan utilizó la antigua definición de Quatremère de Quincy. Y es que "el tipo implica la presencia de elementos con una cierta continuidad entre sí que forman la serie tipológicas". La palabra tipo no representa tanto la imagen de algo a copiar o imitar perfectamente, como la idea de un elemento cuya condición es servir de regla al modelo. El modelo, para la ejecución práctica del arte, es un objeto que ha de repetirse tal cual es. El tipo, en cambio, es un objeto según el cual cada uno puede concebir obras que no se asemejen entre sí.

En el modelo odo esta precisado y determinado, mientras que en el tipo todo es más o menos vago. Por eso advertimos que en la imitación de los tipos no hay nada que el sentimiento y el espíritu no puedan reconocer... Para Rafael Moneo,

el tipo, tal vez pueda ser definido como aquel concepto que describe un grupo de objetos caracterizados por tener la misma estructura formal.'

Y el profesor Vittorio Gregotti, define el concepto genérico de tipo en su ensayo titulado "Territorio de la Arquitectura"

1. Como modelo de donde extraer copias y esquemas de comportamiento (en cuanto resume los rasgos característicos de un grupo de fenómenos).

2. Como conjunto de rasgos característicos cuya inserción en un fenómeno determinado nos permite su clasificación.

Es a partir del positivismo, la corriente filosófica que afirma que el único conocimiento auténtico es el conocimiento científico, y que tal conocimiento solamente puede surgir de la afirmación de las teorías a través del método científico, cuando todas las disciplinas plantean la necesidad de sistematizar el objeto del conocimiento a través de líneas tipológicas. La arquitectura también se ve imbuida por ese pensamiento lógico.

La necesidad de explicar y sistematizar una realidad programática conocida hace que aparezca una clasificación de arquitectura por géneros: religiosa, civil, o militar; o de arquitectura pública o privada.

Se establece otro concepto interesante como es el de control tipológico de la arquitectura a través de las relaciones entre tipo y programa.

La variedad y clasificación de los edificios y los nuevos programas derivados de la Revolución Industrial (mercados, teatros, bibliotecas, hospitales, cárceles, etcétera...) condujeron al arqueólogo, filósofo, crítico de arte y político francés Quatremère de Quincy a enunciar las ideas diferenciales sobre tipo y modelo; en definitiva, a establecer el sistema tipológico. Se pueden así establecer diferentes tipologías para su posterior estudio.

El estadio es, quizás, la tipología arquitectónica que menos cambios ha sufrido a lo largo del tiempo, manteniendo el modelo invariable desde la antigüedad clásica, ejemplarizado por el coliseo romano.

En este punto, es necesario hacer una serie de aclaraciones o precisiones léxicas y de concepto.

En Olimpia las competiciones se realizaban en el estadio. El Estadio era un tipo arquitectónico
B.3 Búsqueda del modelo. Establecimiento del "tipo"

B.3.1 Función

B.3.1.1 Decantación del contenido pro gramático

B.3.1.2Homogeneización y Homologación

B.3.1.3Seguridad. Y las consecuencias derivadas de la violencia

B.3.1.4 Multifunción

B.3.1.5 Nuevas tendencias.

B.3.2 Forma.

B.3.3 Significación

B.3.4 Técnica. Masmedia 
caracterizado por su disposición lineal, un punto de partida y una meta y la máxima proximidad de los espectadores. En el antiguo santuario los tres estadios superpuestos en el tiempo de los que tenemos noticia tenían forma de artesa. Los cuatro graderíos consistían en un terraplenado del terreno. El de Delfos, consistía en un graderio continuo que daba continuidad a los dos lados largos mediante una exedra en solo uno de sus extremos, el coincidente con la línea de meta, foco de máxima atención, de iguales características era el de Atenas, de Herodes Ático. Otra variante se produce en el estadio de Aphrodisias, recientemente descubierto en la actual Turquía, en el que el graderío era continuo en todo su perímetro, conectado con dos exedras. No tenemos el conocimiento sí así era en tiempo de los griegos o, casi con seguridad, fue completado en época romana, para convertirlo en un singular anfiteatro.

Como ya se a dicho anteriormente la palabra estadio es de origen griego (stádion), y era en aquella lengua una medida de longitud equivalente a 600 pies griegos, lo que significa 625 pies romanos, entre unos 192 y 174 metros según los autores y en función de los lugares. Aparte de ello, era, claro, el lugar donde se realizaban carreras, e incluso designaba a las mismas carreras.

Si consultamos el diccionario de la RAE, estadio. (Del lat. stadľum, y este del gr. orádıov).

1. m. Recinto con graderías para los espectadores, destinado a competiciones deportivas.

2. m. Lugar público de 125 pasos geométricos, que servía para ejercitar los caballos en la carrera. También sirvió antiguamente para ejercitarse los hombres en la carrera y en la lucha.

3. $m$. Distancia o longitud de 125 pasos geométricos.

La formulación arquitectónica del estadio griego con el paso del tiempo se ha perdido, y los estadios modernos, formalmente, han derivado desde el anfiteatro romano, aunque hayan conservado en algunos casos elementos típicos de los estadios griegos.

El tipo, anfiteatro, permite una visión mas homogénea a todos los espectadores, no penaliza a las carreras de media y larga distancia, y permite en su interior la inclusión de campos de juego para deportes de equipos.

Volviendo la definición de la RAE para centrarnos en la etimología deanfiteatro.

(Del lat. amphitheātrum, y este del gr. á $\mu \varphi ı \theta \varepsilon ́ \alpha т \rho O V)$.

1. $m$. Edificio de forma redonda $u$ oval con gradas alrededor, y en el cual se celebraban varios espectáculos, como los combates de gladiadores o de fieras.

La superficie interior del anfiteatro se denominaba 'arena'. Que, por otra parte, resulta ser otra manera con la que actualmente designamos a los estadios. Es un termino introducido por los ingleses y que a través de ahí se ha ido extendiendo a otras lenguas. Asumido del latín, se le postula un origen etrusco, y su más antigua grafía era con hache y ese, 'hasena'. La palabra que designaba la misma realidad que en español, se especializó en el lenguaje del circo (recinto en el que se hacían las carreras de cuadrigas), en que designaba a la pista, que era de arena. También se conoció en ocasiones a los gladiadores (que luchaban en el anfiteatro) como 'arenarius', que sería nuestro 'arenero'. En francés actual, donde a la arena la llaman 'sable' (del latín 'sabulum', "grava”), toma otros significados, y llaman así 'arène' a la palestra y al desierto, y 'arène taurom' a nuestros ruedos taurinos.

arena. (Del lat. arēna).

1. f. Conjunto de partículas desagregadas de las rocas, sobre todo si son silíceas, y acumuladas, ya en las orillas del mar o de los ríos, ya en capas de los terrenos de acarreo.

2. f. Metal o mineral reducido por la naturaleza o el arte a partes muy pequeñas.

3. f. Sitio o lugar del combate o la lucha.

4. f. Ruedo de la plaza de toros.

Por otra parte, el hipódromo griego se transformo en el circo romano, con unas características semejantes, aunque diferenciadas. Mientras que el hipódromo actual difiere de esos modelos.

Y aunque suponga una pequeña disgresión del tema, añadimos como recordatorio lo siguiente. Hace unos años se acostumbraba a llamar campo de fútbol a aquél, sin importar si tuviera graderio o no, en el que exclusivamente se jugaba a este deporte. $Y$ estadio al que contaba con pista de atletismo, sin intervenir, tampoco en esta denominación la existencia del graderío.

Ahora quizá sorprenda la distinción entre campos y estadios.

El español 'campo' procede del latín 'campus', que parece ser palabra de origen rural, quizá pre latina, cuyo significado original era el de "llanura", y que pronto pasó a designar al campo de batalla. De 
hecho en español tenemos algunas palabras derivadas de 'campo' propias del lenguaje militar, como 'campear', que significa, según la $R A E$, en sus quinta, sexta y séptima acepción

5. intr. Mil. estar en campaña.

6. intr. Mil. Dicho de un ejército: Salir a combatir en campo raso.

7. intr. Mil. Correr o reconocer con tropas el campo para ver si hay en él enemigos

En castellano antiguo, al Cid que destacaba en la batalla, se apodó Campeador. El germánico, por su lado, dio un paso más, y en el alemán actual 'Kampf' significa "lucha". También tiene que ver, campo, con campeones, palabra que del latín pasó al germánico, de éste al longobardo (lengua germánica hablada por las tribus que invadieron el norte de Italia en el siglo VI), y posteriormente al italiano, lengua de la que la tomó el castellano a principios del siglo XIV.

El acto de nominación (dar nombre a las cosas) no es inocuo y a veces prevalece sobre la realidad, como nos alecciona Peter Sloterdijk en su ya mencionado ensayo Esferas III

Marcel Duchamp pasó los días de Navidad de 1919 con su familia en Rouen. La tarde del 27 de diciembre partía de Le Havre rumbo a Nueva York a bordo del SS Touraine, poco antes de la salida fue a una farmacia de la rue Blomet, donde compro un preparado contenido en una ampolla de tamaño medio, lo abrió y vació y pidió al farmacéutico que volviera a cerrar y sellar el recipiente abombado de forma caprichosa. Una vez en Nueva York, Duchamp entregó la ampolla vacía, que había llevado en su equipaje, al matrimonio de coleccionistas Walter y Lovise Arensberg como regalo de visita, con la argumentación de que los acomodados amigos poseían de todo, a él se le ocurrió traerles 50 centímetros cúbicos de aire de Paris. Así es como sucedió que un volumen de aire costero francés entrara en la lista de los primeros ready mades. Parece que a Duchamp no le preocupaba que su objeto de aire preparado representara una falsificación desde el principio, puesto que no había sido llenado con aire de Paris, sino con el de una farmacia de Le Havre. El acto de nominación prevaleció sobre su procedencia real.

Así, el estadio de los Juegos de la antigüedad y el estadio actual son dos elementos arquitectónicos claramente distintos, pero el acto de nominación, nos permite establecer una continuidad, aunque pudiera ser ficticia, a través de los tiempos.

Ahora, pretendemos establecer, mediante un análisis sistemático desde diferentes puntos de vista, que los estadios, y especialmente los olímpicos, comparten unas características que los hacen más homogéneos, conforman una clara y diferencia tipología arquitectónica. Y no con el fin banal de facilitar su estudio, como se puede desprender del juicio de Oriol Bohigas:

(el análisis tipológico es propio para el) uso y consumo de las universidades norteamericanas provincianas, donde la historia se enseña en paquetes aislados, como una historia de la vivienda, una historia de los hospitales, una historia de los edificios gubernamentales o una historia de los monumentos

sino, con el fin de comprobar que es un elemento arquitectónico claro y diferenciado que merece la máxima atención.

En opinión de Sloterdijk, los episodios que han significado importantes puntos de inflexión en la conformación de lo que denomina colectores, han sido los Juegos Olímpicos, la Revolución Rusa y el Fascismo

Lo que une a esa trinidad heterogénea es el reto común de desarrollar grandes interiores para multitudes presentes y movilizadas, con el fin de administrar su capacidad de reacción mediante ilusiones-punto-central escenificadas.

La reintroducción, bendecida por el éxito, de los Juegos supuso un gran impulso para la definición formal, de este increíble colector de masas que es el estadio

La "idea olímpica" no sólo deparó a la ideología deportiva moderna su instancia suprema y el ritual que la motiva al máximo; reforzó, también, la fuerza de atracción de la concentración física de masas, por muy despolitizada, internacionalizada y centralistamente fracturada que fuera.

Con la presente tesis, pretendemos aportar los datos necesarios, junto a los análisis críticos que puedan permitir considerar a los estadios Olímpicos como una tipología con una serie de caracteres que le son consustanciales.

Se estudia, a continuación, de una manera metódica el desarrollo de las características comunes para poder establecer la serie tipológica desde varios aspectos, como son; Función, Forma, Significación y Técnica-MassMedia. 


\section{B.3.1 Función}

El gran interior de los estadios, donde se celebra su ceremonial, se ha considerado la parte nuclear en cuánto a la definición de su tipo edificatorio, puesto que su principal característica es la relación que establecen el binomio formado por la propia competición y sus espectadores.

Para facilitar el análisis se divide su estudio en:

Decantación del contenido programático

Homogeneización y Homologación

Seguridad. Y las consecuencias derivadas de la violencia

Multifunción

Nuevas tendencias

\section{B.3.1.1 Decantación del contenido programático}

Se plantea la cuestión desde la intención inicial de proponer espacios útiles para el desarrollo de múltiples especialidades deportivas y acoger el mayor numero posible de espectadores. El proceso ha ido decantando el contenido programático hacia la especialización en razón a las compatibilidades de uso y condiciones de visibilidad, observación y participación de los espectadores.

Cuando comienza la andadura de los Juegos Olímpicos modernos todavía no estaban precisadas las dimensiones adecuadas de la pista de atletismo ni cuál debía ser el espacio necesario en su interior, ni tampoco a que deportes debía acoger. En definitiva no estaba definido el contenido funcional.

Ya desde los primeros Juegos, la variedad de deportes programados y sus necesidades especificas, en cuanto a dimensiones y condiciones particulares, imposibilitan su convivencia en una sola instalación. En los Juegos de la "reincorporación", como le gustaba decir a Coubertin, en Atenas 1896, de todos los deportes programados, atletismo, ciclismo en ruta, ciclismo en pista, esgrima, gimnasia artística, tiro, natación, tenis, halterofilia, lucha greco-romana, solo tuvieron su desarrollo en el estadio, los señalados en el cuadro adjunto.

Pero la intención de convertir al estadio en escenario unificador y vertebrador de los Juegos queda manifestada por la iniciativa de realizar un acto conjunto de entrega de premios de la totalidad de los deportes, con el posterior desfile de todos los medallistas, lo cual constituyó la primera ceremonia de clausura de unos Juegos.

Por otra parte, en los propios deportes no estaban definidas de forma definitiva sus reglas y contenidos, que se han ido estableciendo con el paso del tiempo y la experiencia adquirida por el ejercicio de prueba y error.

Así, en atletismo, el numero de pruebas inicialmente programadas es reducido y con el tiempo, en sucesivas ediciones de los Juegos, se irán sumando especialidades, que muchas de ellas se consolidarán en el programa definitivo y otras volverán a desaparecer del escenario.

En Paris, los Juegos se diluyen entre todas las actividades de la Exposición Universal de 1900. Las competiciones de Atletismo se celebraron en las instalaciones del Racing Club de Francia de manera aislada y sin la existencia, propiamente dicha, de un estadio. Situadas en el Boix de Boulogne. La pista para las carreras era en forma de ovalo de aproximadamente $500 \mathrm{~m}$ de cuerda. La recta de $100 \mathrm{~m}$ tenia una pequeña inclinación y su firme era irregular. Los lanzamientos de disco y jabalina se realizaron en una pradera con árboles, que aunque fueron podados, los artefactos en alguna ocasión incidieron con ellos; además impedían la vista completa de los concursos.

En St Louis, 1904, se incorporan al estadio los deportes de equipo, el fútbol y el exótico lacrosse, deporte originario de los indios norteamericanos, además de tiro con arco y tira de cuerda o soga. 
En Londres 1908, se produce un salto cualitativo. Es el primer estadio construido ex profeso para los Juegos y en él, de manera ambiciosa, se quiere albergar el mayor número de deportes posibles, además de las ceremonias de inauguración y clausura. Para tal motivo el estadio contiene, además de la pista de atletismo, un amplio campo interior, piscina y velódromo, rodeado de graderío a lo largo de todo su desarrollo.

La excesiva distancia de los espectadores a los focos de atención del espectáculo no permiten la consolidación del modelo. En la siguiente edición de los Juegos, en Estocolmo 1912, se proyecta un estadio de pequeña dimensión, el péndulo pasa al otro extremo.

Esta reducción implicaba que tanto el velódromo, como la piscina o el campo de rugby, en menor medida, salieran del estadio y requirieran una edificación propia y diferenciada.

El programa definitivo de los Juegos que aparece en el Official Report, además de las competiciones deportivas, se refiere a varias actividades paralelas realizadas en el estadio de un carácter cultural - divulgativo como un concierto militar de música sueca y 300 intérpretes, demostración de deportes populares de Gotland, concierto inespecificado, gala de los boy scouts suecos con demostraciones, conciertos, desfiles, etc, gran coral, fuegos artificiales, etc.

Para los Juegos de Berlín 1916, no celebrados por motivo de la Primera Guerra Mundial, el estadio GrunewaldStadion o Deutsches stadion, proyectado por Otto March, retoma los principios del White Stadium de Londres 1908. Volvía a proponer un estadio multideporte que inclúa velódromo y piscina, aunque esta ya no estaba en la pista, sino q integrada en el graderío.

En Amberes, 1920, se opta, otra vez como en Estocolmo, por un estadio de pequeñas dimensiones. En este caso no sabemos si como consecuencia de la ley del péndulo o motivado por la necesaria austeridad que acompañaron los Juegos. Bélgica era un país arrasado después de haber sido su territorio escenario destacado de la Primera Guerra Mundial. Aunque el estadio era de reducidas dimensiones en él su disputaron un buen número de deportes.

Es de señalar que en un espacio interior reducido se hayan dado las condiciones necesarias para la practica del rugby. Demuestra que en estos primeros años las normas de cada deporte no estaban absolutamente fijadas o podían adaptarse a las necesidades del lugar.

Cuatro años después, en Paris 1924, el estadio vuelve a ser de mayor dimensión, aunque se destina a un número menor de deportes. Es el primer caso en el que se construye un parque olímpico, en una misma localización. Se construyen para los Juegos instalaciones especificas para cada deporte. Además del estadio de atletismo y una pista aledaña auxiliar de entrenamiento, piscinas para natación, saltos y waterpolo, un estadio de esgrima de carácter provisional, un estadio de tenis, acompañado de seis pistas, un espacio amplio para entrenamientos y también la primera villa Olímpica.

La mayor dimensión de la cuerda del estadio, tal vez podríamos explicarla, por la voluntad de los organizadores de que el rugby pudiera disputarse en unas condiciones adecuadas. Hay que recordar que Louis Faure-Dujarric, el arquitecto del estadio y gran impulsor de los Juegos, fue capitán del equipo de rugby del Racing Club de Francia en los años 90 del siglo XIX.

En Ámsterdam, 1928, el estadio vuelve a incluir un velódromo y se desarrollan un buen número de deportes. Constituye lo que podiamos denominar el primer estadio moderno y sus intenciones proyectuales abarcan la globalidad del objeto. Suponiendo un ejemplo arquitectónico de altísimo valor, obra del arquitecto Jan Wils. A partir de esta edición de los Juegos, se establece, como medida estándar, la cuerda de 400 metros para la pista de atletismo.

En Los Angeles, 1932, se aprovecha el estadio construido en 1923. Su pista, que correspondía con el sistema imperial de medidas, medía un tercio de milla y hubo ser reducida para los Juegos a los 400 metros establecidos desde Ámsterdam 1928 como de cuerda obligatoria. Se produce así un desajuste entre pista y graderío.

En Estados Unidos ya se había experimentado en la construcción de grandes estadios, el Franklin Field de la Universidad de Pennsyilvania en Filadelfia, construido a principios del siglo XX, según el proyecto de la firma de arquitectura Frank Miles Day \& Brotherand, es un excelente ejemplo.

En Los Angeles se afianza el camino, sin retorno, de que cada deporte necesita su instalación adecuada para satisfacer sus cada vez más detalladas y singulares exigencias. Por ello el estadio queda para el atletismo, las ceremonias que aglutinan todo el entramado olímpico, en este caso y reforzando esta idea, la entrega de las medallas de todos los deportes se realizó en el estadio. Tal como ya se había hecho en la primera edición, en Atenas 1896. También queda fijada de manera definitiva la celebración de la competición ecuestre, el Premio de las Naciones, con toda su carga simbólica de enfrentamiento entre caballeros defendiendo el honor patrio. La gimnasia, por su parte, todavía no ha encontrado su propio acomodo y sigue celebrándose en el estadio, aunque de una forma precaria, exponiéndose a los cambios climáticos, viento, lluvia, y con una visibilidad escasa, por la gran la lejanía de los espectadores a los aparatos. En el estadio también se disputan las finales de los deportes de equipo, aunque para las

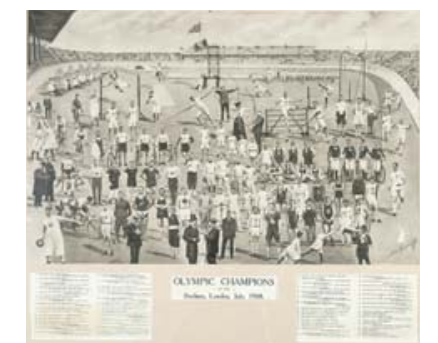

Orla de campeones Olímpicos en Londres 1908 Se dibujan todas las especialidades deportivas realizandose dentro del estadio.
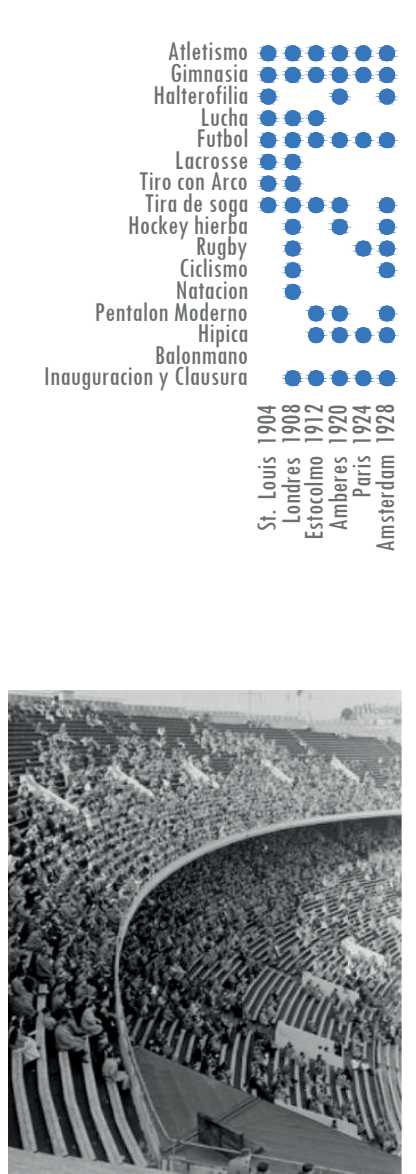

Grada del Franklin Field Stadium. Filadelfia 
fases previas y para poder concentrar los Juegos en pocos días, se lleven a cabo en otras instalaciones. En Los Angeles fue la primera vez que se concentraron todas la finales en dos semanas. En los iniciales Juegos de Atenas tuvieron una duración de 10 días, pero en el resto de las ediciones anteriores los Juegos se habían repartido a lo largo de tres y hasta seis meses, reazón que los condenaba a una baja intensidad mediática con una escasa repercusión entre el gran público.

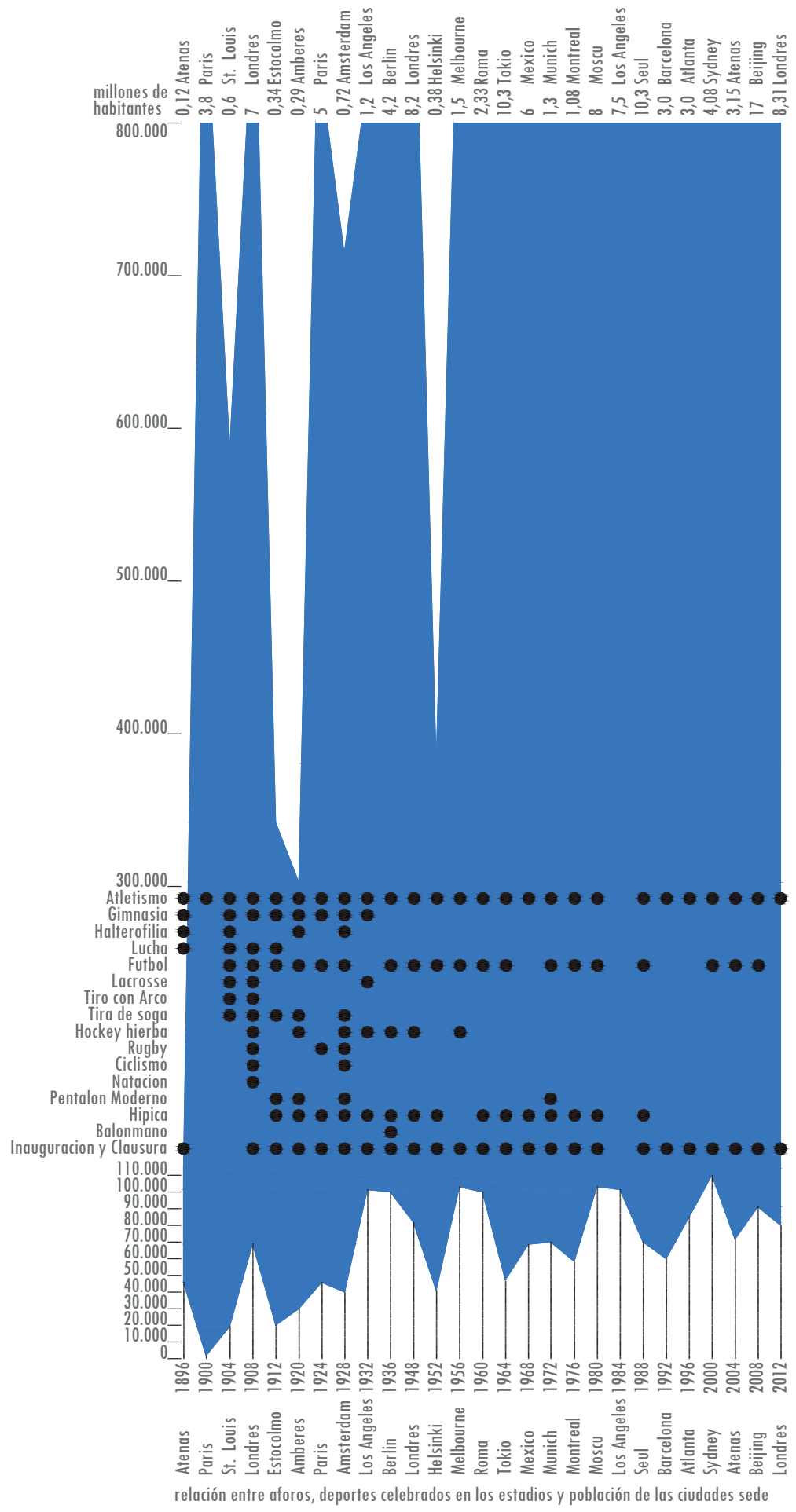

Con Los Angeles 1932 y ya, definitivamente, con Berlín 1936, podemos considerar fijado el contenido programático de los estadios Olímpicos. Casi todos los deportes han adquirido en ese momento una suficiente madurez y sus reglas ya están claramente definidas, así como las instalaciones que le son necesarias.

En Berlín, un incipiente balonmano representa una anomalía al jugarse sobre hierba y disputarse en el estadio. La gimnasia, por primera vez y de forma definitiva, sale del estadio, buscando una mayor 
proximidad del espectador al gimnasta. Las competencias se celebran en el teatro al aire libre Dietrich Eckart, con capacidad para 20.000 espectadores.

La dimensión y superficie de hierba del espacio central, en el interior de la pista de 400 metros de cuerda, permiten la disputa de partidos de fútbol y de jockey hierba, hasta la fecha en que este deporte cambia la superficie de juego reglamentaria por la hierba artificial, siendo los primeros Juegos celebrados sobre la nueva superficie los de Montreal 1976.

La competición hípica del Gran Premio de las Naciones, de manera obligatoria, se celebra al final de los Juegos, ya que los cascos de los caballos dejan impracticable la hierba para otros deportes.

Después de la Segunda Guerra Mundial, en Londres 1948, se inicia una serie que se ha mantenido, prácticamente sin alteración, hasta nuestros días.

Así pues el contenido programático "tipo" del estadio podemos decir que queda establecido con los siguientes deportes:

Altletismo

Fútbol, final

Hockey Hierba, solo hasta Montreal

Hípica, Premio de las Naciones, aunque la tendencia es a dejar de celebrarse en el estadio

Ceremonias de Apertura y Clausura

Además de algún deporte, esporádico y compatible, casi siempre de demostración como por ejemplo el fútbol australiano en los Juegos de Melbourne 1956. En esta edición las competiciones de Hípica se disputaron en Estocolmo, por razón de la normativa australiana para el control de enfermedades de los animales.

La complejidad creciente de las Ceremonias de Apertura y Clausura dificulta que puedan realizarse en los estadios mayor numero de competiciones, por motivo del tiempo necesario para el desmontaje $y$ montaje de escenarios.

En cuanto al aforo, se ha comparado, en el cuadro adjunto, el contenido programático de los estadios con su aforo y estos dos datos con la población de las ciudades sede en el momento de los Juegos. No pudiéndose llegar a establecer ninguna conclusión lógica.

Habría que hacer unas precisiones respecto a los aforos. Los datos proporcionados por los organizadores son aproximados, siempre con un redondeo al alza. Los estándares de confort han evolucionado a lo largo del tiempo, ampliándose el espacio asignado para cada uno de los espectadores en el graderío. Así pues, los estadios antiguos contaban con una mayor densidad de ocupación. Además disponían de áreas para espectadores de pie, que permitían un aumento muy considerable en cuanto al aforo.

En cuanto a las poblaciones de las ciudades, sus cómputos dependen de la inclusión o no de sus áreas metropolitanas, extremo que en algunos casos no se ha podido acreditar con seguridad.

Es comprobable que el aforo de los estadios no esta relacionado con su contenido programático deportivo. Si repasamos los dos estadios con velódromo, Londres 1908 y Ámsterdam 1928, sus aforos son respectivamente de 68.000 y 40.000 espectadores. De los veintiséis estadios, el de Londres 1908 es el número quince en cuanto a aforo, y el de Ámsterdam el veintidós.

El aforo tampoco está en relación con la población de las ciudades sede. Por ejemplo, México con una gran población, la octava mayor, su estadio es, sin embargo, el decimotercero en cuanto a aforo. Beijing, la más poblada, con 17 millones de habitantes en el momento de la celebración de los Juegos, su estadio ocupa el lugar séptimo.

Podemos deducir que las dimensiones de los estadios y sus aforos, dependen más de cuestiones de oportunidad que de datos deducibles, comparables y claramente establecidos, como son los que se han manejado, es decir, población de la ciudad y número de deportes celebrados en el estadio. Entendemos por cuestiones de oportunidad a preexistencias, reutilización de estadios, dimensiones de los solares disponibles, capacidad económica, tiempo de preparación, propiedad, utilización futura del estadio, etc.

En cualquier caso, la media de los aforos de los estadios han ido aumentando con el paso del tiempo, pudiéndose establecer la gráfica adjunta en la página siguiente.

Por otra parte, en cuánto a la cubierta de la grada, se puede comprobar que se produce una evolución. Los primeros estadios son descubiertos. Luego se alternan los descubiertos con los que cuentan con cubierta sobre la tribuna. Munich es el primer caso en el que la cubierta tiene una dimensión y un protagonismo mayor. En Montreal se cubre absolutamente todo el graderío. De los sigientes estadios 
los de Moscú, Barcelona y Atlanta están algo fuera del proceso evolutivo. Puesto que Moscú está construido en 1956, Barcelona supone la reelaboración del estadio de 1929 y Atlanta era un estadio semi-temporal. La tendencia de las últimas cuatro ediciones ha sido la de estadios con los graderíos a cubierto, si no completamente sí en su mayor parte.

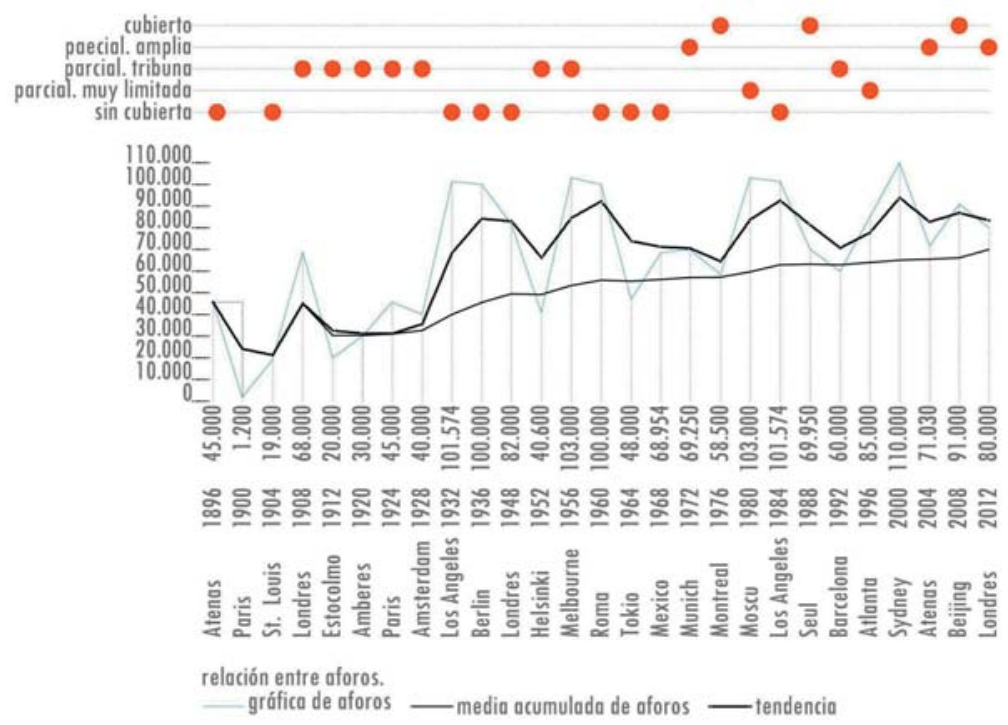

Es de destacar que los dos estadios que, probablemente, construyen un interior mas monumental, Los Ángeles y Berlín, son estadios descubiertos.

\section{B.3.1.2 Homogeneización y Homologación}

Todo se organiza en torno a dos polos ideológicos que controlan la actividad que se desarrolla en él -el de la justicia y el de la igualdad-, lo que exige al espacio deportivo unas condiciones totalmente rigurosas en sus características físicas'

Asegurar la igualdad de condiciones de competición de los atletas y la capacidad para la comparación de los resultados obtenidos, ha llevado a un largo proceso de homogenización de las instalaciones. Ello ha permitido la homologación, para medir y comparar las marcas de manera homogénea.

También los reglamentos deben ser iguales para mayor coherencia y evitar situaciones injustas. Para ilustrar este razonamiento, veremos lo sucedido en la prueba de los 400 metros lisos en los Juegos de Londres 1908. En la final competían tres atletas norteamericanos y uno británico; uno de los norteamericanos iba en cabeza y otro, a juicio de los árbitros, obstruyó al británico no dejándole progresar. Los jueces pararon la carrera y decretaron su repetición otro día, siguiendo las normas del reglamento de la Amateur Athletic Asociation del Reino Unido. Pero según las reglas de la Union, por la que se regía el atletismo americano, no había motivo de penalización y, en cualquier caso, si la hubiere el castigo sería la descalificación del infractor una vez terminada la carrera. El día de la nueva carrera no se presentaron los norteamericanos en señal de protesta, por lo cual corrió solo y fue proclamado campeón olímpico el británico Halswelle con un tiempo de 50"0 segundos, siendo el peor tiempo registrado de todos los vencedores en los Juegos pasados y futuros, si exceptuamos el pésimo resultado de la carrera en la pista de Atenas, en la que en cada giro los atletas tenían que desacelerar.

En esa misma prueba ocurrió otro hecho, aparentemente insignificante, pero que ponía de manifiesto todo un problema. Las primeras series se corrieron sobre una distancia de 400 metros, mientras que para las semifinales y la final se retrasó la línea de meta 2, 4/5 yardas para que la distancia completara el cuarto de milla.

Y es que otro elemento de distorsión se produce al sumar en el movimiento olímpico culturas que basan su sistema de medidas en el métrico decimal y otras en el imperial. $Y$ aunque el deporte estaba más desarrollado en la parte anglófona, como el impulso de los Juegos gravita sobre Francia, desde el principio las distancias de las carreras se referencian al sistema métrico decimal, con la pequeña excepción de Londres 1908 en donde se programaron de manera complementaria las pruebas de 10 millas para marchadores y la carrera de 5 millas.

1. Juan Miguel Hernández de León. El espacio de la excepción. Sobre el carácter de la arquitectura deportiva. AV: Monografía 1992. №33, pág. 4/7 


\section{B.3.1.2.1 La cuerda y geometría de la pista}

Le Corbusier, en 1926, dibuja para el proyecto del Garaje de la rue Cardinet en su azotea un club social, con terrazas, jardines, un pabellón con el bar y a su espalda una amplia zona deportiva. En los croquis originales adjuntos podemos observar, al menos dos pistas de baloncesto y una pista de atletismo, compuesta por un óvalo, de 200 metros y la recta de velocidad; la forma de la pista se adapta a la geometría de la cubierta y sus curvas son extraordinariamente cerradas. Evidentemente no es una instalación destinada a la competición, pero vemos que en ella no subyace ningún tipo claro y definido. En ese momento todavía no se habían fijado las dimensiones básicas de las pistas de atletismo para los estadios Olímpicos, que se haría tan solo dos años más tarde. A partir de los Juegos de Amsterdam 1928.

Se plantea una cuestión crucial; cuál debe ser la cuerda y los radios de giro de la pista de un estadio $y$, en menor medida, su ancho.

Evidentemente tiene alguna ventaja el que entrena en instalaciones con características semejantes a las de la competición. De igual manera el valor de las marcas está en función de las bondades de la pista en las que están realizadas. Por lo cuál cuando los registros son ciertamente exigentes, se necesita que las condiciones de competición sean las mismas.

Repasaremos cuál ha sido la evolución de las cuerdas y su geometría en los estadios Olímpicos: En Atenas 1896, al reaprovecharse el estadio de la antigüedad, la pista tiene la cuerda resultante de sumar dos longitudes de un estadio (600 pies atenienses) y dos curvas muy cerradas. La mejor descripción del efecto de las mismas sobre el corredor la podemos obtener de las memorias publicadas por George Robertson, atleta de Oxford que compitió en tenis y en los lanzamientos de disco y peso: “ el brusco giro al final de cada recta, hace imposible tiempos rápidos... los corredores parecían literalmente pararse al llegar a la curva, en comparación con el ritmo anterior.

Paris 1900, la pista para las carreras era en forma de óvalo, de aproximadamente $500 \mathrm{~m}$ de cuerda. La recta de $100 \mathrm{~m}$ tenía una pequeña inclinación y su firme era irregular. Los lanzamientos de disco y jabalina se realizaron en una pradera con árboles.

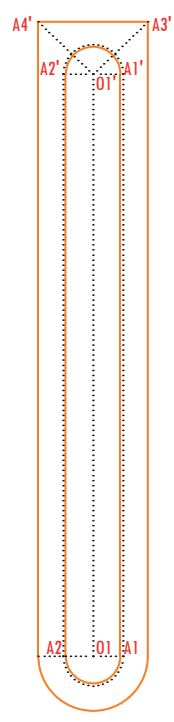

1896. ATENAS

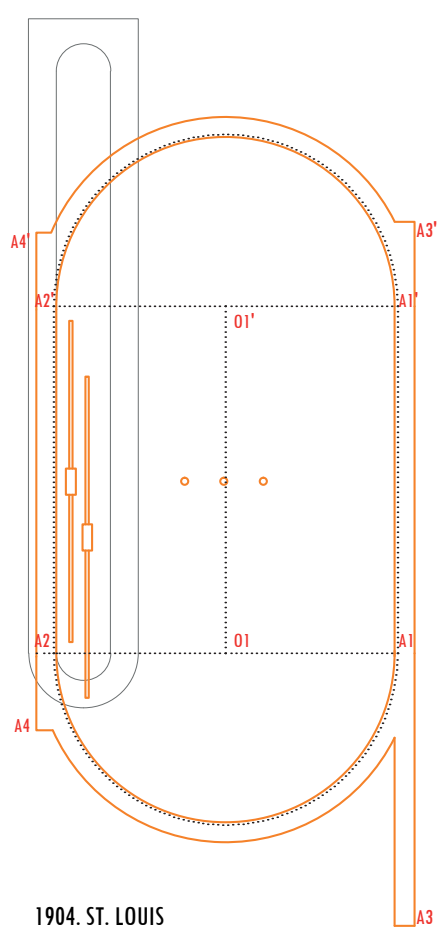

1904. ST. LOUIS

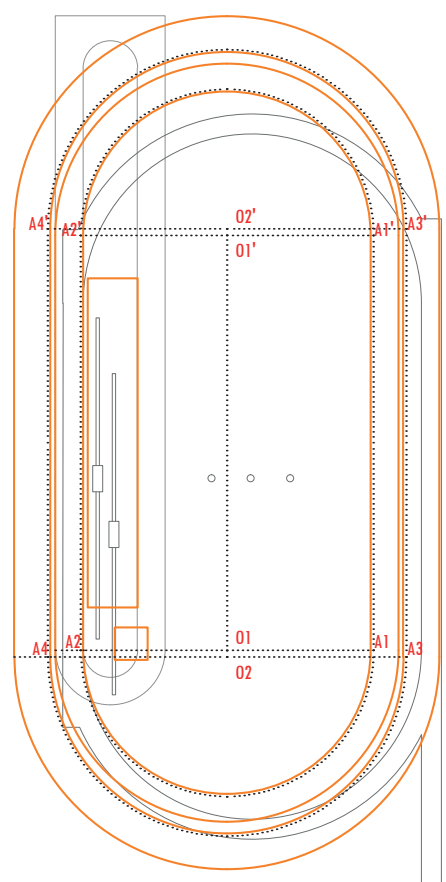

1908. LONDRES
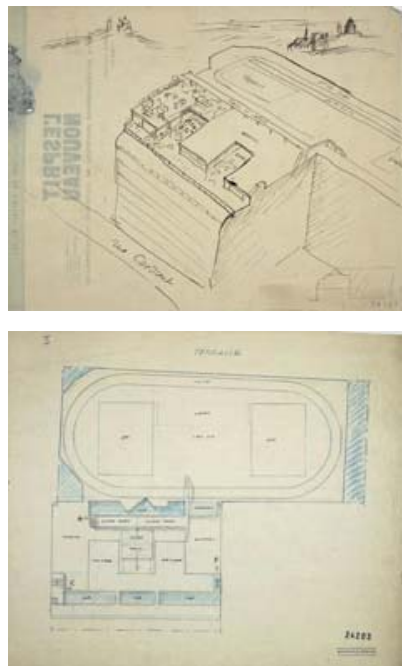

Atenas 1896

dimensiones y superficies aproximadas pisto

L O1-Al

$$
409,23 \text { M } \quad 447 y d s \quad l^{\prime} \quad 7 \frac{2711}{64}
$$

$\begin{array}{rr}\text { L A3-A4 } & 33,52 \mathrm{M} \\ \text { R 01-Al } & 8,60 \mathrm{M}\end{array}$

R OI'-A3' 23,17 M

$<$ Al.01.A2 $180^{\circ}$

$<A 3^{\prime} .01^{\prime} .4^{\prime} \quad 93^{\circ}$

St Louis 1904

dimensiones y superficies aproximadas pista

\begin{tabular}{|c|c|c|}
\hline CUERDA & $536,44 \mathrm{M}$ & 586 yds $1^{\prime} 11 \frac{111 "}{16}$ \\
\hline L $01-01 '$ & $105,85 \mathrm{M}$ & \\
\hline LA3-Al & $22,51 \mathrm{M}$ & \\
\hline L A3-A3' & $151,95 \mathrm{M}$ & \\
\hline L A4-A2 & $25,84 \mathrm{M}$ & \\
\hline L A4-A4' & $214,97 \mathrm{M}$ & \\
\hline R 01-Al & $51,98 \mathrm{M}$ & \\
\hline$<$ Al.01.A2 & $180^{\circ}$ & \\
\hline \multicolumn{3}{|c|}{ Londres 1908} \\
\hline \multicolumn{3}{|c|}{ dimensiones y superficies aproximadas pista } \\
\hline CUERDA I & $602,01 \mathrm{M}$ & 658 yds $\quad l^{\prime} 1 \frac{3}{16}$ \\
\hline CUERDA 2 & $530,78 \mathrm{M}$ & 580 yds l' $4 \frac{27 " \prime}{32}$ \\
\hline L $01-011^{\prime}$ & $126,55 \mathrm{M}$ & \\
\hline L 02-02' & $130,75 \mathrm{M}$ & \\
\hline L $01-02$ & $2,10 \mathrm{M}$ & \\
\hline R OI-Al & $44,19 \mathrm{M}$ & \\
\hline R 02-A3 & $54,19 \mathrm{M}$ & \\
\hline$<$ Al.01.A2 & $180^{\circ}$ & \\
\hline$<\mathrm{A} 3.02 . \mathrm{A} 4$ & $180^{\circ}$ & \\
\hline$<$ A3.01.A4 & $176^{\circ}$ & \\
\hline
\end{tabular}
y buena planimetría. Un su recta de tribuna se podían correr los 100 y 110 metros ya que tenía una longitud de 500 pies (152,4 metros, 166,6 yardas). Y la recta opuesta se prolongaba más allá del ovalo para permitir las carreras de 200 metros, en recta, su longitud era de 750 pies (228,6 metros, 234,9 yardas). Estaba marcadas las calles para que cada atleta corriera sin riesgo de interferencia con los otros participantes (en Atenas ya fue así, no sabemos en Paris). El ancho de la pista era de 20

Le Corbusier, proyecto Garaje rue Cardinet, 1926 
pies $(609,6 \mathrm{~cm})$, lo que permitió que las carreras de 800 y 400 metros se realizarán a una sola manga, aunque con unos estándares de comodidad y no interferencia entre corredores muy alejado de los actuales. Los concursos estaban organizados de tal manera que permitieran la mayor simultaneidad posible.

Londres 1908, pista de atletismo de un tercio de milla de cuerda $(536,45 \mathrm{~m}$.) y 24 pies $(7,32 \mathrm{~m}$.) de anchura. Terreno central de hierba, de forma ovalada, de 700 pies (213,36 metros) de largo por 300 pies (91,44 m.) de ancho, en donde se realizaría la mayor parte del programa olímpico. Rodeando exteriormente a la pista de atletismo se situaba la pista para el ciclismo, con firme de hormigón y curvas peraltadas, de 35 pies (10,67 m.) de ancho y una cuerda de tres octavos de milla, 660 yardas, (603,50 $\mathrm{m}$.). La gran novedad es que en el interior de la pista de atletismo se situaba una enorme piscina de 100 metros de largo por 50 pies (15,24 m.) de ancho, con una profundidad de 1,20 m. en los extremos y $3,70 \mathrm{~m}$. en el centro. La piscina contaba con una torre, que era abatible, para los concursos de saltos de trampolín y palanca.

Estocolmo 1912, pista con una cuerda de 385 metros.

Berlín 1916, la pista prevista para los Juegos no celebrados por motivos bélicos, tenía 600 metros de cuerda. Dimensión muy grande y extraña, solo igualada por la del Budapest.

Amberes 1920, cuerda de la pista de 389,8 metros y seis calles.

\begin{tabular}{|c|c|c|}
\hline \multicolumn{3}{|c|}{ Estocolmo 1912} \\
\hline \multicolumn{3}{|c|}{ dimensiones y superficies aproximadas pista } \\
\hline CUERDA & $384,10 \mathrm{M}$ & $420 y d s \quad 0^{\prime} \quad 2 \frac{3}{64} "$ \\
\hline L 01-01' & $71,37 \mathrm{M}$ & \\
\hline L 02-02' & $44,46 \mathrm{M}$ & \\
\hline R OI-Al & $38,65 \mathrm{M}$ & \\
\hline R $02-A 3$ & $27,49 \mathrm{M}$ & \\
\hline$<$ Al.01.A2 & $80^{\circ}$ & \\
\hline$<$ A3.02.Al & $50^{\circ}$ & \\
\hline \multicolumn{3}{|l|}{ París 1924} \\
\hline \multicolumn{3}{|c|}{ dimensiones y superficies aproximadas pista } \\
\hline CUERDA & $500,00 \mathrm{M}$ & $546 y d s \quad 2^{\prime} 5 \frac{3}{64} "$ \\
\hline L $01-01^{\prime}$ & $103,36 \mathrm{M}$ & \\
\hline R 01-Al & $45,94 \mathrm{M}$ & \\
\hline R 02-A3 & $35,18 \mathrm{M}$ & \\
\hline R 03-A4 & $37,14 \mathrm{M}$ & \\
\hline$<$ Al.01.A2 & $43^{\circ}$ & \\
\hline$<$ A3.02.Al & $65^{\circ}$ & \\
\hline$<$ A2.03.A4 & $72^{\circ}$ & \\
\hline
\end{tabular}

\section{Estocolmo 1912}
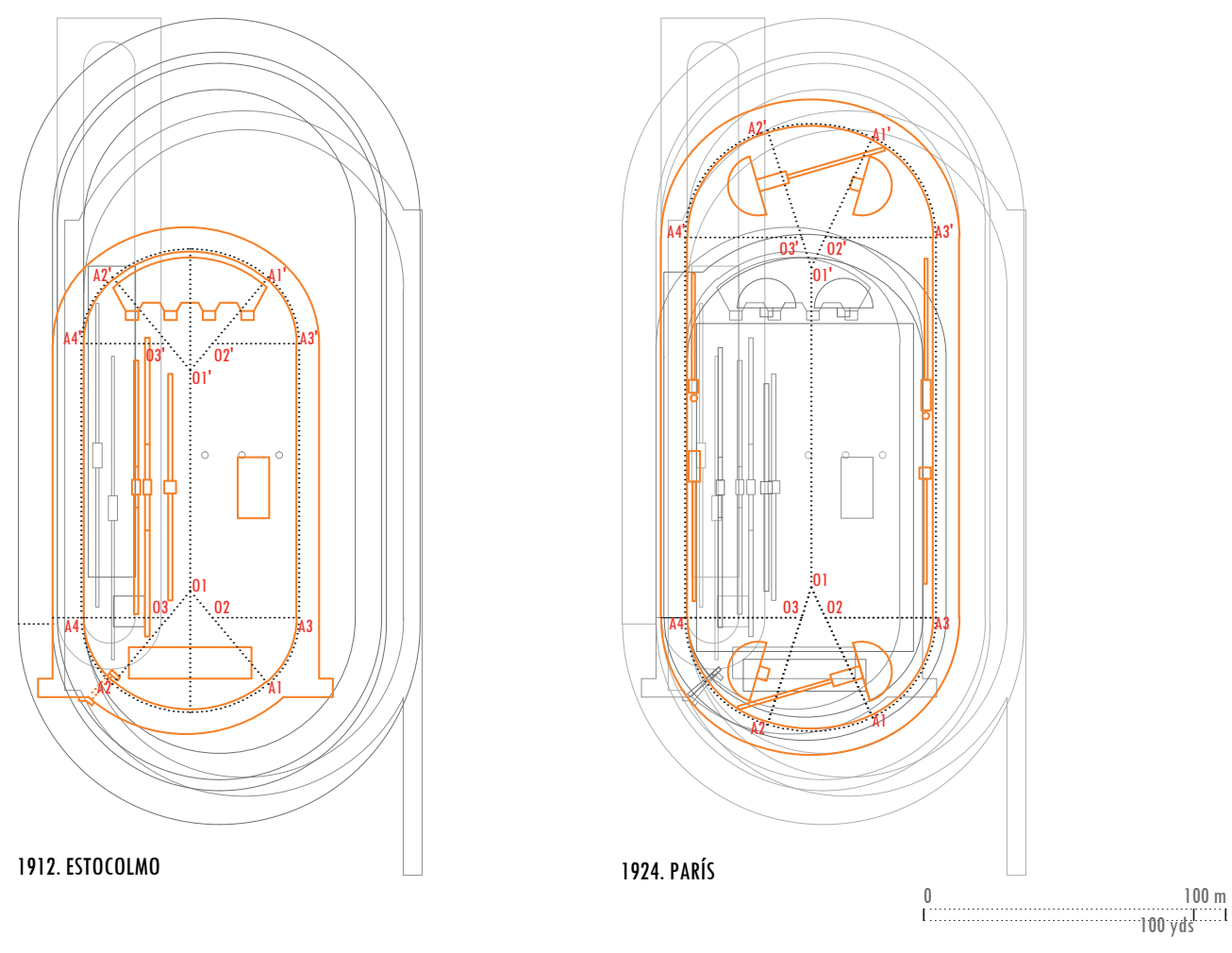

Paris 1924, Cuerda de la pista de 500 metros y seis calles de 8,50 metros de ancho y curvas trazadas con tres centros. Espacio libre interior en el que se puede marcar un campo de rugby de $140 \times 70$ o de fútbol de $103 \mathrm{~m}$. x 73,20 m.

Medio kilómetro es un medida muy lógica en el mundo regido por el sistema métrico decimal. Hubo infinidad de pistas de esta dimensión, entre ellas la célebre Arena de Milán y la del viejo estadio de Montjüc, en Barcelona.

Amsterdam 1928, cuerda de la pista de 400 metros y seis calles de 8 metros de ancho total. velódromo de 500 metros y un ancho de 9 metros más un metro de respeto. Espacio libre para campo de juego interior de 120 x 80 yardas (109,73 x 73,15 metros).

Fue la primera con una cuerda de 400 metros y a partir de esta edición se establece como dimensión obligatoria. 


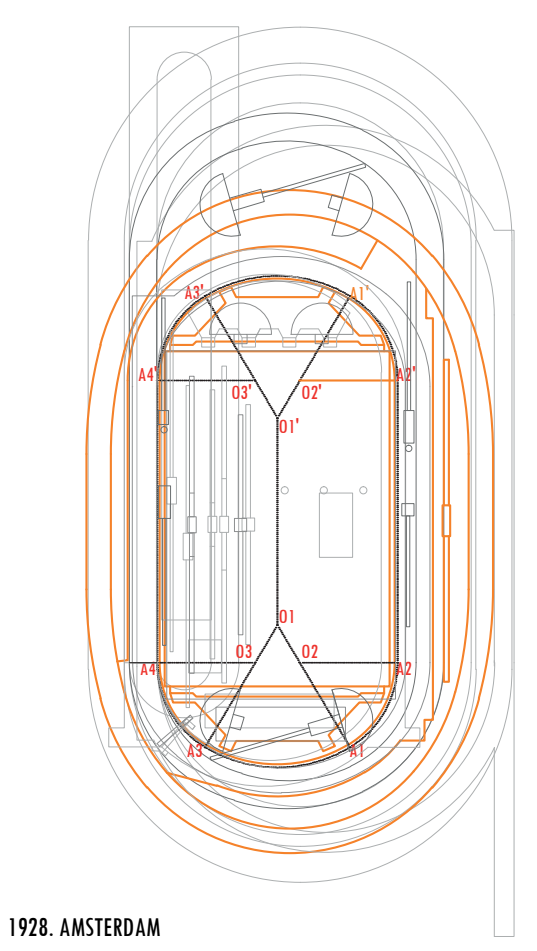

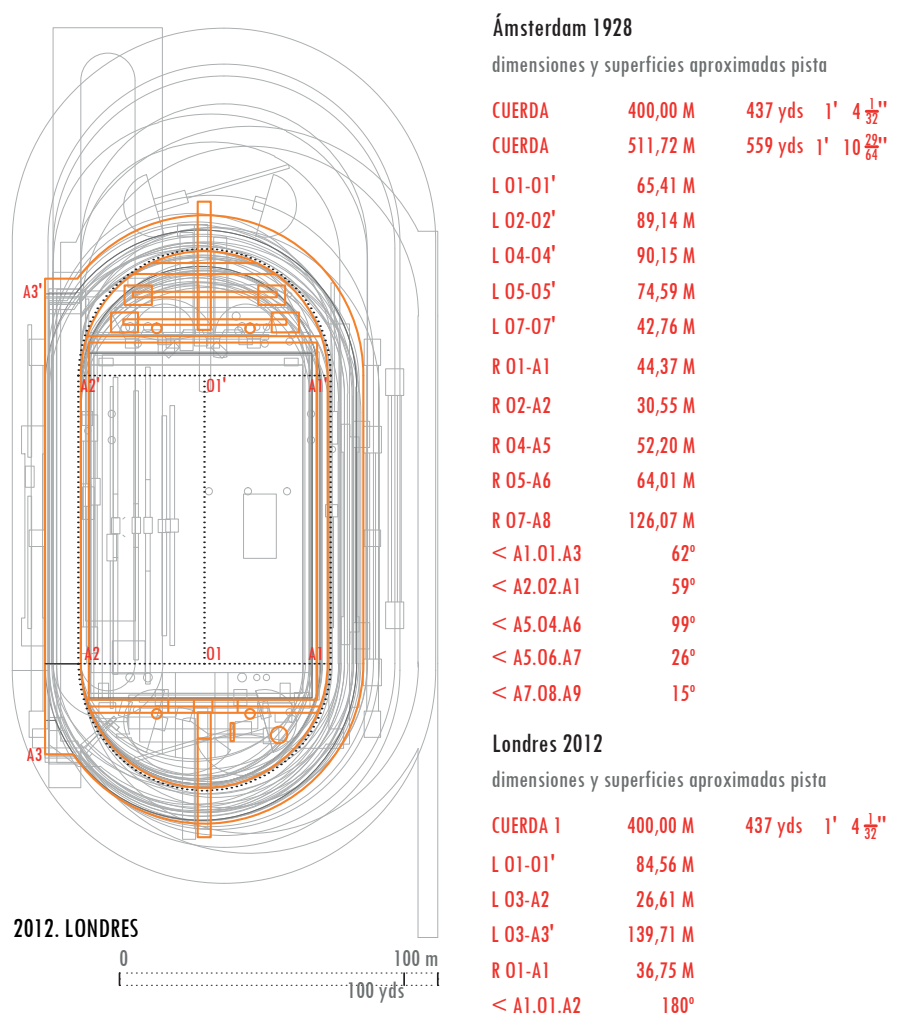

En Los Angeles como el estadio estaba construido con anterioridad y contaba con pista de $1 / 3$ de milla, esta tuvo que reducirse produciéndose un desajuste entre pista y graderío.

A partir de aquí todos los estadios han contado con una pista de 400 metros de cuerda. La razón de esta dimensión creemos que es por tres motivos;

1. Es una cifra exacta del sistema métrico decimal.

2. Acercar al espectador al espectáculo

3. En su interior cabe un campo de fútbol

En las pistas más grandes las ventajas cronométricas eran evidentes. Como señalaba Miguel Ángel Villaseñor, miembro de la Asociación Española de Estadísticos del Atletismo, en el articulo Hubo un tiempo en el que no todas las pistas medían 400 metros publicado en la revista Atletismo Español de julio de 2014, en igualdad de condiciones la velocidad en recta es siempre superior a la velocidad en curva. Cuanto más grande es la pista la curva es más abierta y mejora la velocidad. En la prueba de 400 metros, en una pista de 500, se recorrían dos rectas, una curva completa y, quizá, un pequeño trozo de la curva inicial. Y decimos quizá porque no en todas las pistas era así, pues ello depende de la longitud de las rectas y el radio de las curvas. En el parisino Colombes, por ejemplo, en un 400 se recorrían 277 metros de recta y 123 de curva. El estadístico vitoriano José María García ha calculado que en la prueba de 400 metros, en una pista de 500, la ventaja era de aproximadamente 3 décimas de segundo. En la prueba de 800 metros, en una pista de 500 metros, se hacen tres virajes en lugar de cuatro, la ventaja se calcula en 2 décimas, porque la velocidad es menor.

En las pistas menores ocurre lo contrario. Hay que dar más vueltas para completar la distancia y por lo tanto hay un mayor número de curvas y son más cerradas, la fuerza centrífuga tiende a sacar al atleta de su calle y le obliga a correr en una posición inclinada y altamente asimétrica, por lo cual las marcas salen claramente desfavorecidas. En largas distancias que el problema relacionado con las leyes físicas es menor tiene el efecto negativo de orden psicológico al ser mayor numero de vueltas para la misma distancia. Se demuestra con las marcas de pista cubierta, pistas de 200 metros, cuando las comparamos con las de aire libre, de 400 metros.

A partir de la estandarización obligatoria de la cuerda de la pista para los futuros Juegos, buena parte de los estadios ya construidos modificaron y unificaron sus dimensiones, por ejemplo Colombes en 1938 para el Campeonato de Europa de Atletismo, el Olímpico de Estocolmo con el mismo motivo en 1958, el estadio White City de Londres en 1931. Quizás el último gran campeonato celebrado en una pista no homogeneizada fueron los Juegos del Mediterráneo en el estadio de Montjuic en Barcelona en 1955, con su pista de 500 metros, que con la profunda remodelación para los Juegos de 1992, paso a tener 


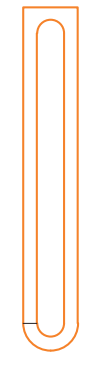

ATENAS 1896

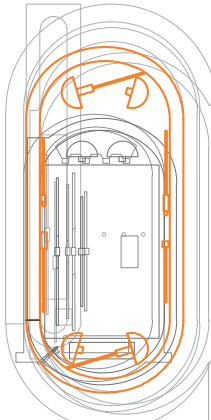

PARÍs 1924

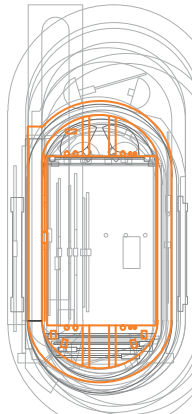

HELSINKI 1952

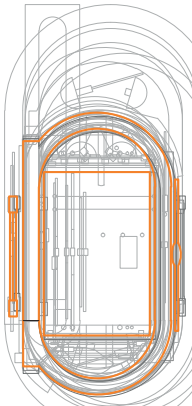

MUNICH 1972

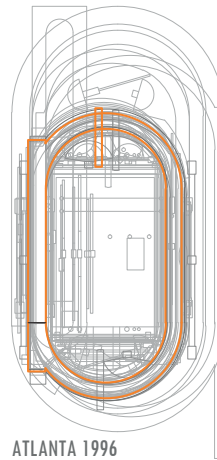

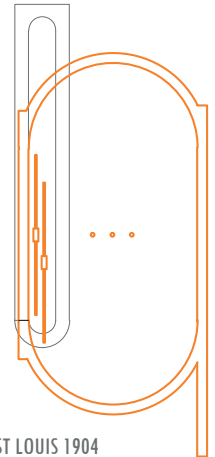

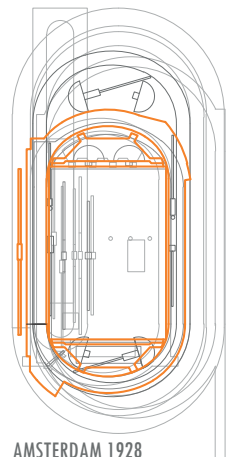

AMSTERDAM 1928
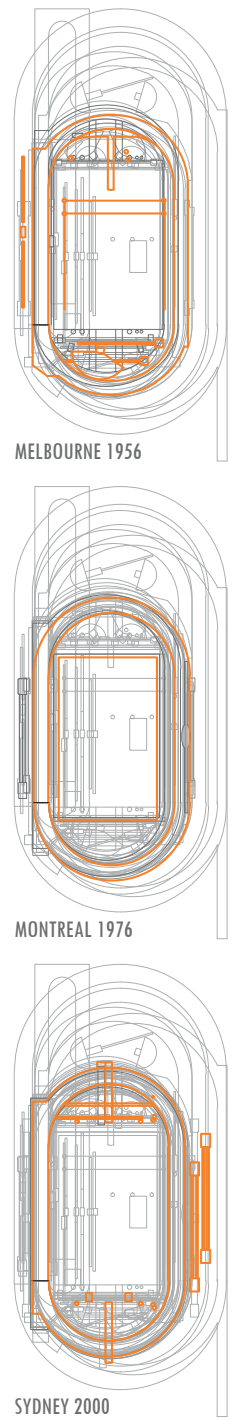
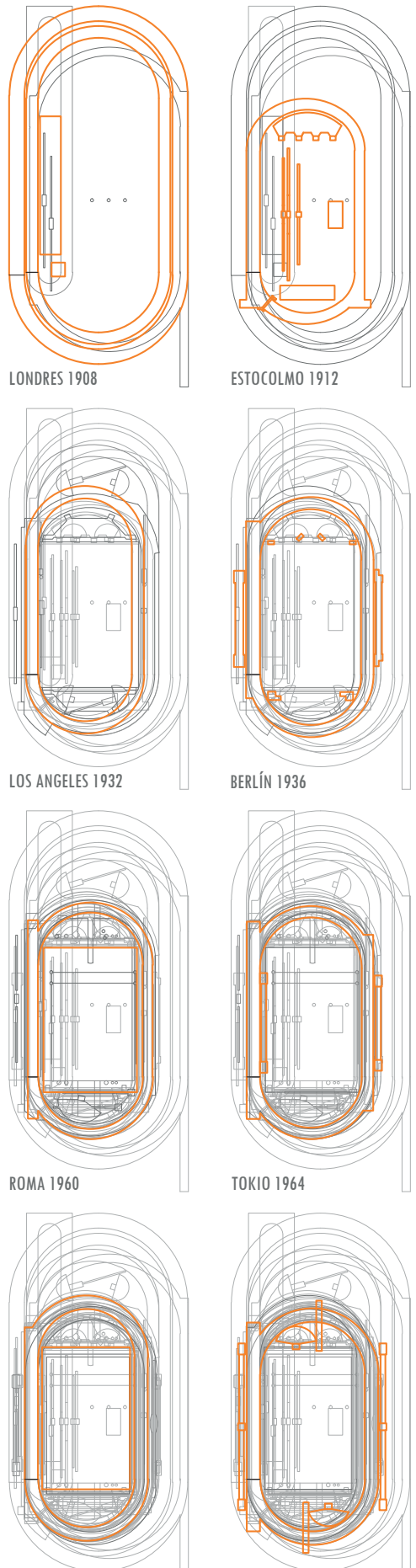

MOSCÚ 1980
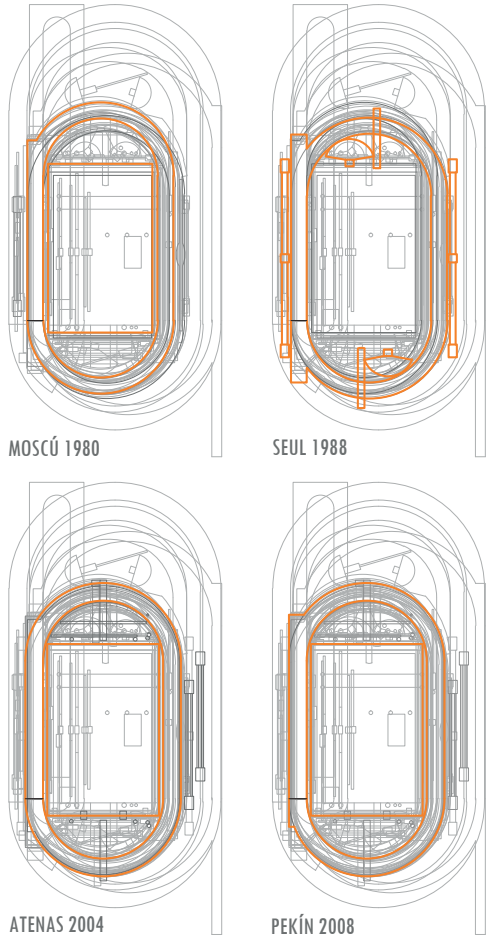
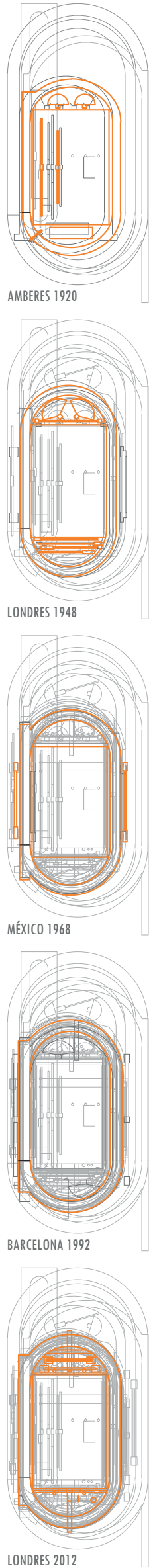
la dimensión obligada.

Desde Ámsterdam 1928 casi todos los estadios que se construyen en el mundo corresponde con la dimensión oficial de los 400 metros, con la variante anglosajona de las 440 yardas, que equivalen a 402,336 metros.

Por otro lado están los radios de curvatura, con los que se trazan las pistas. Cuando las pistas eran mayores de 400 metros, la recta de 100 y 110 metros se alojaba sin dificultad en el ovalo, en los trazados menores y siempre a partir de la estandarización de la cuerda después de Ámsterdam 1928, la compatibilidad de las rectas con el trazado global es más problemático. Para solucionarlo surgen las pistas con varios radios de curvatura. La cuestión es conseguir que la diferencia entre las fuerzas centrifugas que afectan al corredor sean las mínimas, por lo cual no debe existir gran variación entre los distintos radios. El caso más acusado desfavorablemente es el de Helsinki 1952, con su radio más reducido de 22,30 metros a lo largo de $35^{\circ}$ de desarrollo por dos veces en cada una de las curvas. A partir de Roma 1960 todas las pistas cuentan con un solo radio de curvatura.
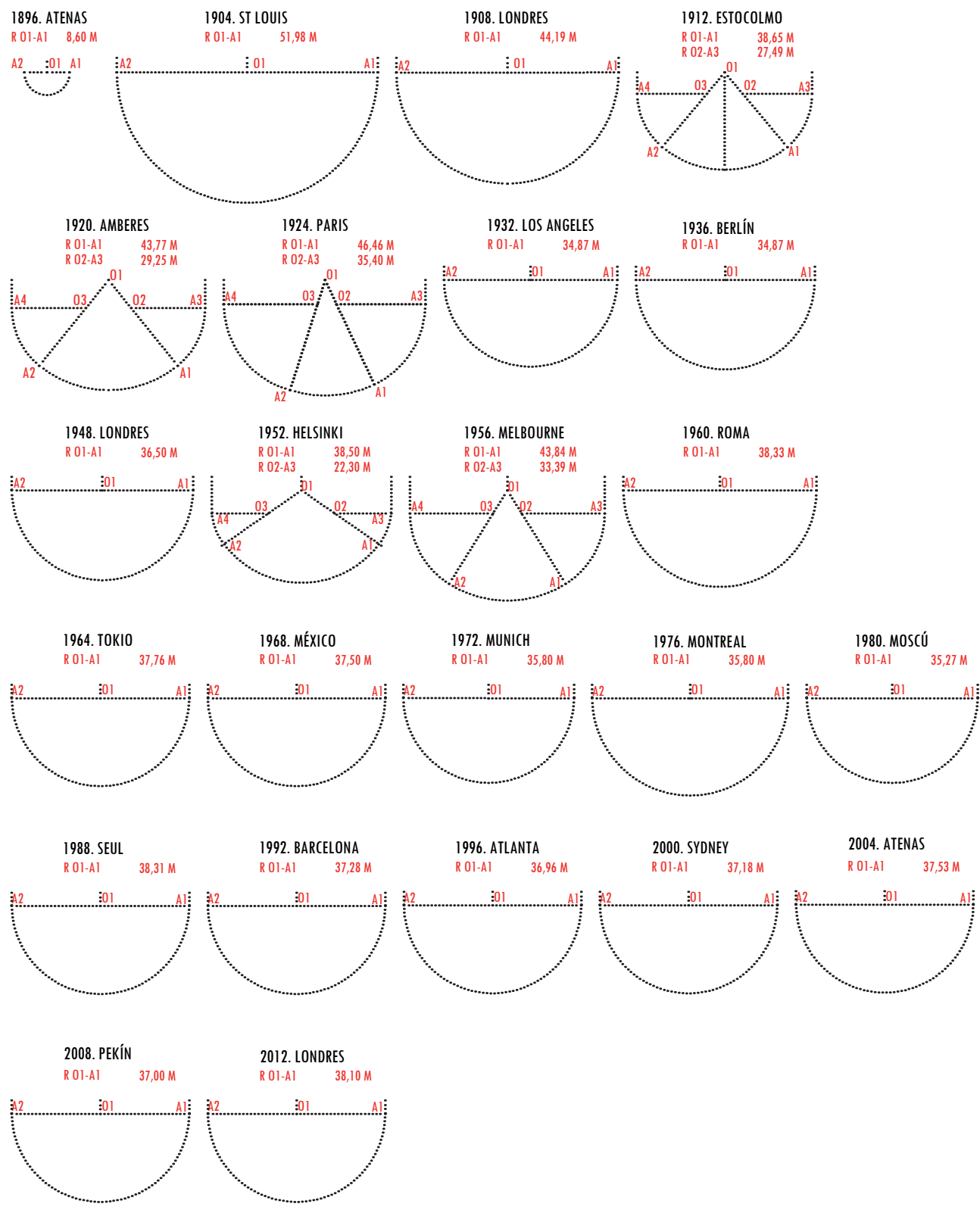

Si atendemos a los cálculos, anteriormente reseñados, del estadístico José María García, la unificación de la cuerda de los estadios a 400 metros es de absoluta justicia para que las marcas de todos los atletas del mundo y los records puedan ser comparables en igualdad de condiciones. 


\section{B.3.1.2.2 La orientación}

Implica como inciden los rayos del sol sobre el graderio y la pista, y cómo varía la percepción del espacio en función de las cambiantes luces y sombras. El interior del estadio esta expuesto a la incidencia directa del sol que, además de moldear el espacio, puede provocar efectos de intenso contraste y afectar negativamente a la practica deportiva y a la capacidad de visión de los espectadores y a su confort'.

Los Juegos Olímpicos como acontecimiento global, se han celebrado en casi todas las latitudes, aunque solo una edición en el área comprendida entre los trópicos, la de México'68 y dos ediciones en el hemisferio austral, Melbourne'56 y Sydney'2000. No se han celebrado en África y en Sudamérica se celebrará la próxima edición en Río de Janeiro'2016. Los más septentrionales han sido los de Helsinki'52, latitud $60^{\circ} 10^{\prime} \mathrm{N}$ y los más próximos al ecuador los de México, latitud $19^{\circ} 24^{\prime} \mathrm{N}$.

Se ha dispuesto sobre el mapamundi la localización de todos los Juegos disputados, más la del estadio de Olimpia y el Coliseo, estos últimos en color naranja. Y se han grafiado la dirección de los ejes longitudinales de cada estadio.

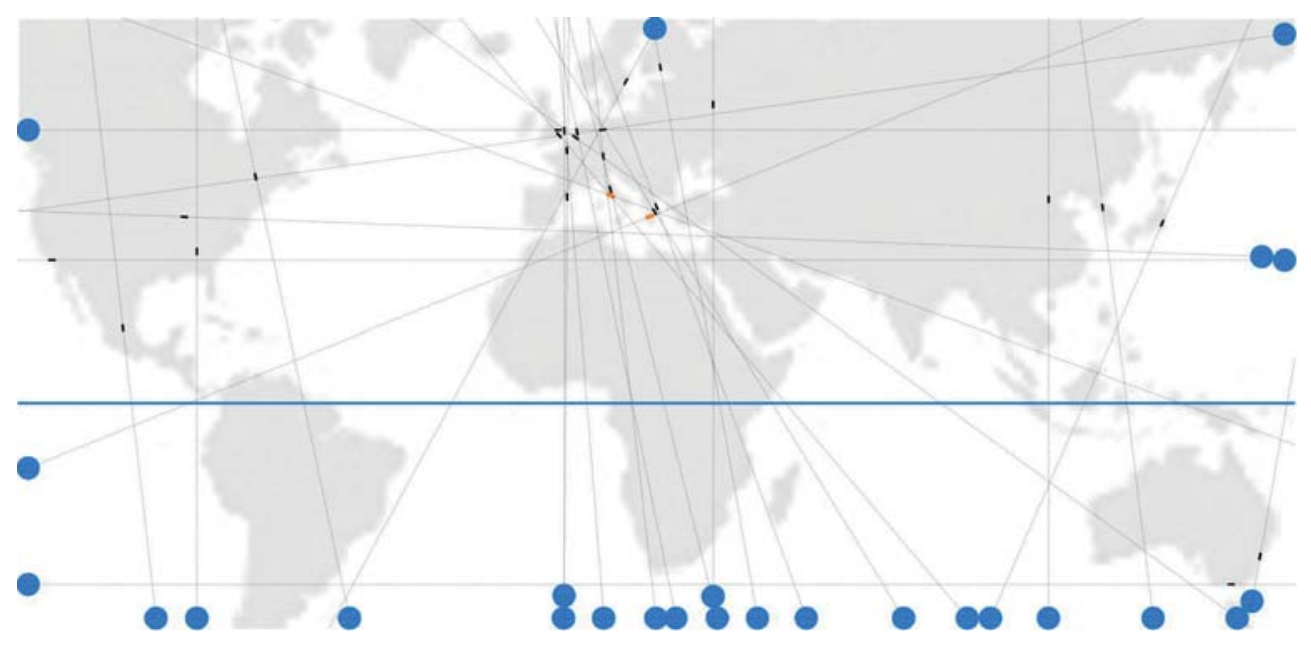

Para una comparación adecuada se ha abatido el hemisferio sur sobre el norte para poder posicionar las dos ediciones oceánicas en igualdad de condiciones que el resto del hemisferio septentrional. La latitud de Sydney $34^{\circ} 0^{\prime} \mathrm{S}$ coincide exactamente con la de Los Angeles $34^{\circ} 0^{\prime} \mathrm{N}$ y la de Melbourne $37^{\circ} 47^{\prime} \mathrm{S}$ esta entre las de Tokio $35^{\circ} 42^{\prime} \mathrm{N}$ y Atenas $37^{\circ} 70^{\prime} \mathrm{N}$

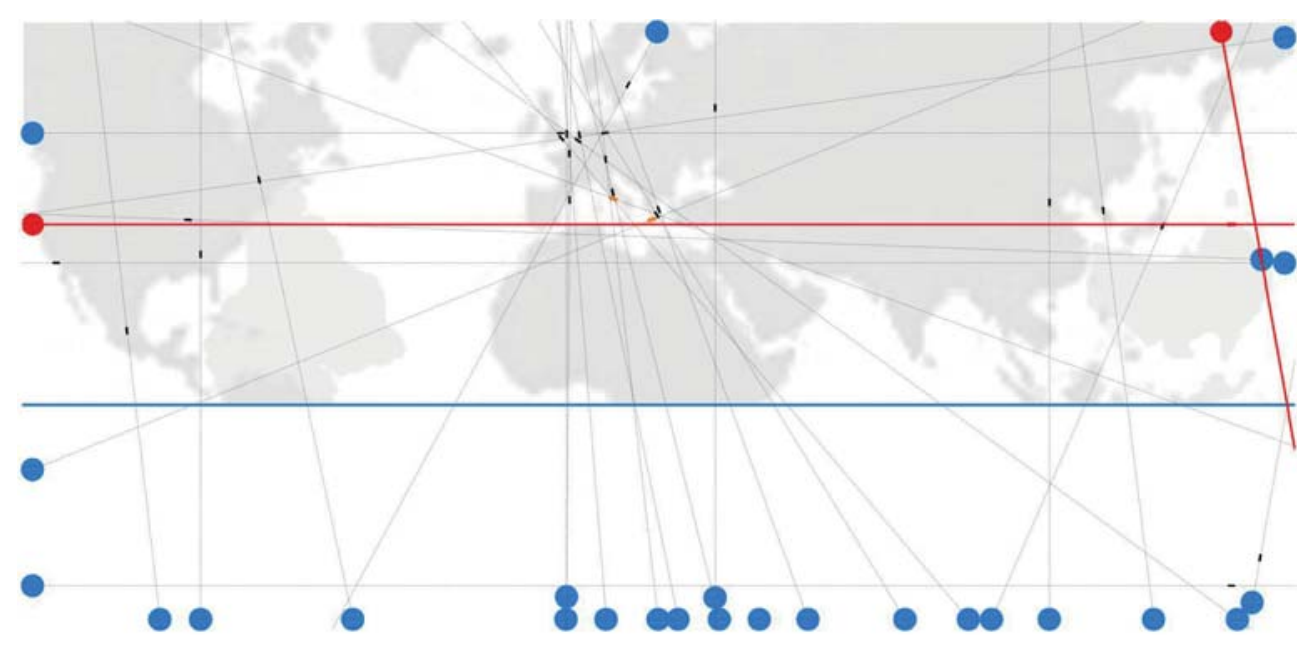

1. En el Official Report de los Juegos de la IX Olímpiada de Amsterdam, en su pagina 181 se justifica la orientación del estadio, como sigue

El eje del Estadio se dispone en dirección Norte-Sur, y no como la del viejo Estadio que era Este-Oeste. Esta orientación se considera mejor, en primer lugar, porque por la tarde, cuando se celebran la mayoria de los acontecimientos, el sol baña con luz de poniente la arena, y, en segundo lugar, las gradas altas de los laterales protegen la pista de los vientos dominantes. En tercer lugar, la Tribuna Principal en el lado oeste, proporciona a los espectadores una mejor protección de los vientos fríos. 
Existe una cierta disparidad en cuanto a los resultados, aunque abunda la dirección norte-sur. Las direcciones de los de Olimpia y el primero de Atenas (I) las podemos justificarla por la oportunidad que ofrecía la topografía favorable. en el caso del santuario la proximidad del monte Kronion para asentar en sus laderas el graderío y el de Atenas es un estadio de origen absolutamente topográfico. Los dos primeros estadios Norteamericanos, st. Louis (III) y Los Angeles (X), junto con Wembley (XIV) y Berlín (XI) casi coinciden en la orientación este-oeste, son de los años 1904, 1923, 1923 y 1936. Luego hay una serie de estadios en los que parece que su dirección, un tanto aleatoria, depende de condiciones de las preexistencias o de la propia forma de terreno disponible; Londres (IV) 1908, Estocolmo (V) 1912, Amberes (VII) 1920. El caso de Tokio (XVIII) 1964, no encontramos explicación plausible a su inclinación hacia el oeste. A partir de esta edición las once últimas, excluyendo Los Angeles (XXIII) 1984 por ser el mismo estadio que el utilizado en 1932, la orientación es claramente norte-sur.

A parte de la dirección la pista de atletismo tiene un claro sentido marcado por la recta de meta, como es sabido siempre se corre en sentido antihorario, por lo cual la recta de meta, que está ligada con la tribuna principal tiene el sentido definido. El siguiente cuadro aparecen sucesivamente todas las ediciones disputadas, volvemos a excluir solamente a la segunda edición de Los Angeles (XXIII), no solo la dirección sino que también el sentido. La dirección dominante como ya habíamos dicho es la nortesur y claramente en sentido sur. En los estadios con dirección este-oeste el sentido es mayoritariamente hacia el este.
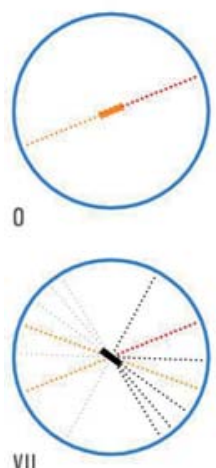

VII

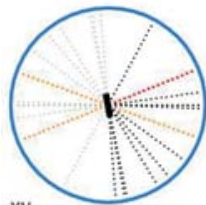

XV

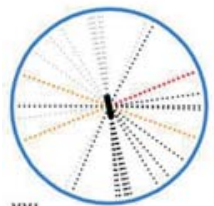

$x \times 1$

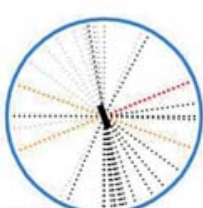

XXYIII

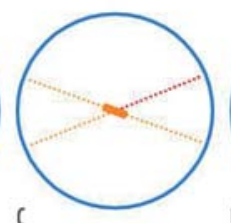

c

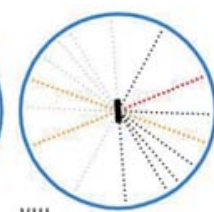

VIII

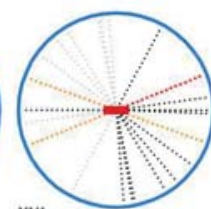

XVI

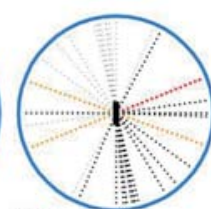

XXII

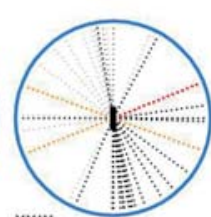

$x x \mid x$
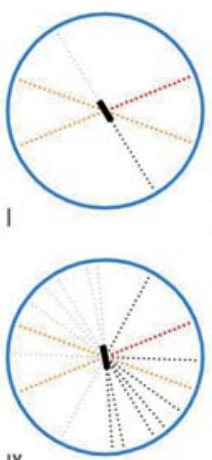

IX

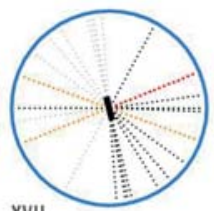

XVII

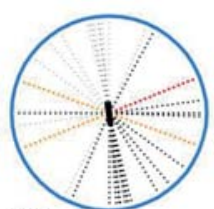

XXIV

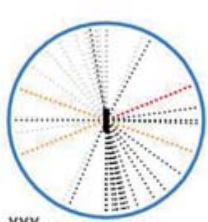

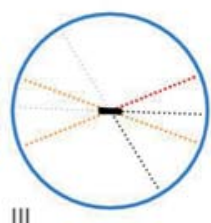

III

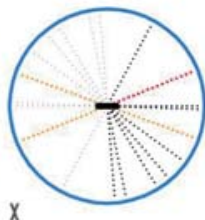

$x$

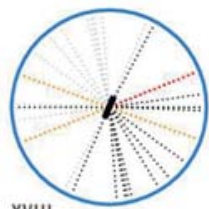

XVIII

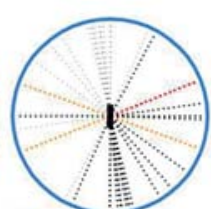

$X X Y$

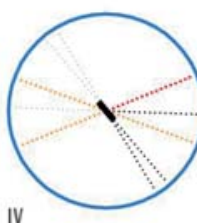

IV

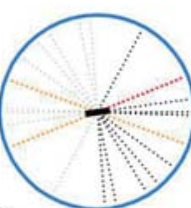

XI

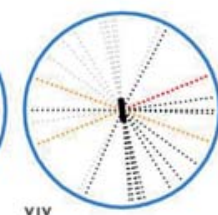

XIX

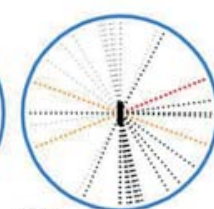

XXYI

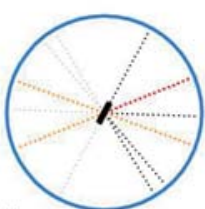

v

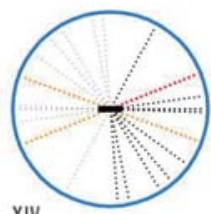

XIV

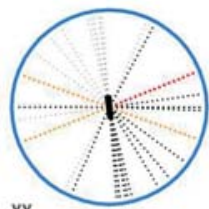

XX

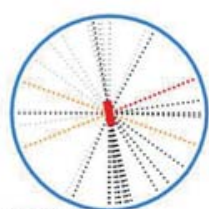

XXVII
Olimpia

C Coliseo de Roma

Atenas 1896

St Louis 1904

Londres 1908

Estocolmo 1912

Amberes 1920

VIII París 1924

IX Amsterdam 1928

Los Angeles 1932

Berlín 1936

XIV Londres

XV Helsinki

XVI Melbourne

XVII Roma

XVIII Tokio

XIX México

XX Munich

XXI Montreal

XXII Moscú

XXIV Seul

XXV Barcelono

XXVI Atlanta

XXVII Sydney

XXVIII Atenas

XXIX Pekín

XXX Londres

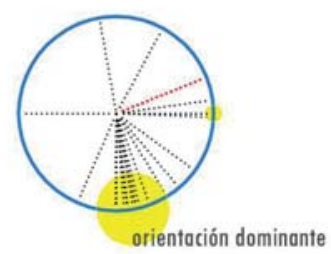

Encontramos algunas singularidades. En Estocolmo (V) los corredores llegan a meta corriendo hacia el norte, podemos encontrar algún tipo de explicación, aunque no deja de ser una especulación; la alta latitud de la ciudad 59.19' $\mathrm{N}$ supone que la luz no es muy intensa, por lo cual no hay excesivo problema de que por contraste la parte delantera de los atletas quede en fuerte sombra, muy oscura, y los rayos 
del sol son bastante horizontales, correr hacia el sur puede suponer algún riesgo de deslumbramiento. Pero Helsinki XV) esta aun mas al norte y el sentido de la recta de meta es sur. Melbourne (XVI) orientada este-oeste y la recta de llegada sentido oeste, llama la atención este extremo por el posible problema de deslumbramiento de los atletas si las pruebas se programan por la tarde, que es lo mas normal. La única explicación que podemos aventurar es que al ser el hemisferio austral a medio día en la tribuna principal el sol incidiría desde atrás. Y por último el caso de Sydney (XXVII), la dirección de la pista es norte sur y el sentido sur, los cual es lo habitual en el hemisferio septentrional, en el sur, el sentido debía ser inverso, hacia el norte, el caso de Sydney (XXVII) es semejante al de Estocolmo (V), pero con una diferencia de latitud de $25^{\circ}$.

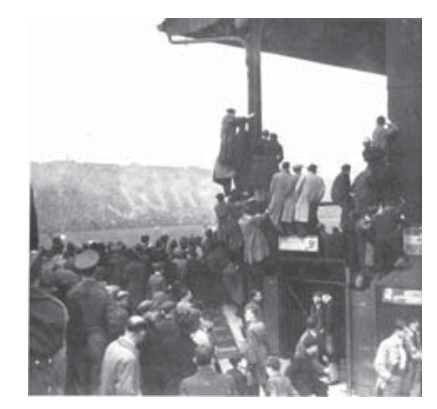

\section{B.3.1.3 Seguridad. Y las consecuencias de la violencia}

En el proceso de desarrollo del estadio moderno, las cuestiones relacionadas con la seguridad en la utilización, fundamentalmente acceso y evacuación, y las consecuencias derivadas de la violencia, han supuesto modificaciones sobre el modelo que se han ido incorporando paulatinamente. Vamos a hacer una breve incursión sobre los dos elementos de carácter general mas determinantes; la seguridad relativa al flujo de las masas y las consecuencias derivadas de la violencia.

B.3.1.3.1 Seguridad relativa al flujo de las masas.

Una condición absolutamente necesaria que debe cumplir un estadio es la de dar cabida a un gran masa de espectadores. Los estadios de la primera generación eran grandes contenedores de espectadores y cualquier espacio útil era ocupado por el publico. Una vez colmatadas las gradas se ocupaban los lugares mas insospechados.

El día 5 de abril de 1902 en el minuto 51 del partido de fútbol que enfrentaban a las selecciones de Escocia e Inglaterra, la parte trasera de la tribuna oeste del recién construido lbrox Park, cedió y decenas de espectadores cayeron desde 12 metros de altura y esto unido a las avalanchas posteriores dio como resultado; 25 personas muertas y 517 heridas. Por motivos de seguridad se decidió finalizar el encuentro, temiendo que las masas de espectadores saliendo del estadio interfirieran con las labores de rescate. El nuevo estadio de los Glasgow Rangers, inaugurado en 1900 era el mas avanzado de su tiempo y con capacidad para 80.000 espectadores. Era la primera gran obra Archibald Leitch, que con el tiempo se convertiría en el mayor constructor de estadios de todos los tiempos. Un mes antes de la tragedia Leitch había escrito al supervisor municipal Frederick Holmes

No tengo dudas que todo esta en orden, pero es mejor que los dos vayamos a revisar la estructura con el fin de tener en cuenta todas las precauciones posibles para la seguridad de los espectadores

Holmes a su vez escribe al secretario general de los Rangers, diciendo que ha inspeccionado la estructura durante la construcción y también el día anterior a la misiva, confirmando que estaba en perfectas condiciones y que si bien hasta el momento el estadio no había alcanzado el aforo de los 80.000 espectadores, si se habían llenado partes completas del graderío sin presentar la mas mínima duda. El día de la catástrofe el estadio no llego a llenarse, la entra fue de 68.114 espectadores, pero el público se concentró cerca de la entrada en la grada oeste, que parecía una masa compacta de gente, antes del accidente comenzó a caer un fuerte chaparrón, que provoco un intenso flujo de gente hacia la grada cubierta, cuando colapso una pequeña zona de graderío por la que cayeron alrededor de 80 o 100 personas, el publico de alrededor intentó escapar, arrollando y aplastando a los de la parte baja de la grada, al ceder las vallas para la contención de las avalanchas. Los muertos no solo se debieron al fallo de la estructura sino también al efecto perverso del movimiento incontrolado de las masas.

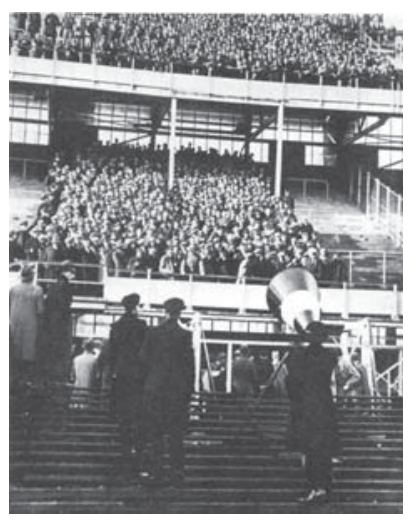

La concentración de un gran numero gente supone un problema de estabilidad. Prestemos la atención a la siguiente fotografía del magnifico y ligero estadio proyectado por Brinkmann y van der Vlugt,

El 15 de Octubre de 1936, 3 meses antes del final de las obras y 5 meses antes de su inauguración, el Estadio Feyenoord de Rotterdam fue sometido a una "prueba de carga". 1.500 soldados y desempleados fueron conducidos a una zona de la grada. Cuando se dio la orden, todos al unísono comenzaron a saltar arriba y abajo. Los ingenieros midieron entonces la deformación del acero traccionado y de la estructura de hormigón donde se encontraban. Después de la prueba, los "voluntarios" fueron invitados a un trago y un cigarro.

La fotografía tomada durante esta prueba, con el director, en primer plano, dirigiendo a las masas con un megáfono, sirve para avalar el argumento de que los estadios, más que cualquier otro tipo de construcción del siglo $\mathrm{XX}$, han sido el escenario de la confrontación física entre muchedumbre y arquitectura. Cuando se diseña un estadio, 
Pero la multitud no es una masa estática, como hemos visto la prueba de carga era dinámica, pero tampoco nos referimos a eso ya que el problema del calculo estructural dinámico es una cuestión técnica ya resuelta en los grandes puentes. Nos referimos a la muchedumbre como "masa viva", como un organismo en movimiento que obedece a ciertas pautas, pero es ciertamente imprevisible ante factores como la densidad, la impaciencia, el movimiento desordenado, el ansia o el pánico.

La multitud en el estadio se somete pacientemente a las fórmulas y estructuras para el alojamiento de masas. Aunque una repentina "erupción" / una transición deliberada de una condición cerrada a abierta) siempre es posible, la lista de desastres ocurridos en el S.XX demuestra lo pasivamente que actúa la multitud cerrada en "recipientes preexistentes". ${ }^{2}$

Camiel van Winkel con la expresión "multitud cerrada" se refiere a los conceptos que maneja el premio Nobel de literatura, Elias Cannetti (1905/1994) en su ensayo de 1960 titulado Masa y poder, en el diferencia entre "masa abierta y cerrada". Dice que el estado natural de la masa es abierta, sin limites prefijados, con voluntad de expandirse y con la misma rapidez que se forma se deshace, siempre permanece en ella vivo el presentimiento de su desintegración y ante ello responde con un crecimiento acelerado mediante la asimilación de nuevos elementos individuales. Por otra parte la masa cerrada, esta acotada, ha renunciado a su crecimiento y necesita un espacio seguro y protegido.

En los estadios las masas se encuentran acotadas en un espacio arquitectónico especialmente diseñado al efecto. Su situación debe ser estable, en equilibrio, y los flujos de acceso y salida perfectamente estudiados, tratados como mecánica de fluidos, ya que su comportamiento a ello es asimilable.

Lo acontecido en el estadio Hillsborough de Sheffield el 15 de Abril de 1989 muestra que incluso a finales del siglo XX la gestión del movimiento de las masas puede fallar. El saldo final de 96 muertos y 170 heridos fue la consecuencia de una serie de defectos en serie, errores en la adjudicación de entradas, coordinación y supervisión de la policía, capacidad de las puertas de acceso, la colocación de los palcos y la valla utilizada para evitar la invasión de los espectadores al campo de juego. El caso es que se produjo una tremenda avalancha de espectadores que aplastó a la gente en las primeras filas contra la valla de protección del campo, ante el caos reinante la policía decidió abrir las puertas del estadio y una gran cantidad de espectadores que habían ido al campo y no tenían entrada aprovecharon la ocasión para entrar. Quedó registrado por las cámaras de televisión. Cientos de hinchas se apretujaban unos contra otros y docenas de ellos eran literalmente aplastados. En estos casos la multitud se comporta como un organismo vivo, un organismo con dinamismo propio e insensible a la influencia individual de cada uno de sus integrantes. Elias Canetti describe el pánico como la desintegración de la multitud dentro de la propia multitud. Un estallido de pánico en una multitud equivale al retorno súbito del miedo individual al contacto que los miembros de la multitud habían olvidado temporalmente. Se trata de la repugnancia fundamental a ser tocados por alguien o algo desconocido y que, según Canetti,

supone la raíz de las distancias y jerarquías que los seres humanos hemos creado a nuestro alrededor. Solo en la multitud es donde el hombre se libera de su miedo a ser tocado. Esta es la única situación en la que el miedo cambia a todo lo contrario. La multitud cuya constitución física es también densa o compacta en la que uno no se percata de quien esta pegado a él. Tan pronto como el hombre se rinde a la multitud, deja de temer su contacto. Todos son iguales, las distinciones no cuentan, ni siquiera cuenta el sexo de las personas. La persona pegada a él es igual que él mismo. Se siente como se siente el otro. Es como si todo sucediera en el mismo y único cuerpo. Esto es quizás una de las razones por la cual una multitud se cierra en sí misma. La gente más miedosa se junta y no se temen los unos a los otros. Esta inversión del miedo a ser tocado forma parte de la naturaleza de las multitudes. ${ }^{3}$

La historia del estadio de Hillsborough revela, sin embargo, que donde hay una creciente densidad y una falta de vías de escape se alcanza tarde o temprano un punto de transición, un punto en el cual ese temor a ser tocado y que había sido olvidado, vuelve con más fuerza. Psicológicamente, la multitud se desintegra en un conjunto de personas individuales y ahí se produce el pánico y la tragedia.

Camiel van Winkel, en su ya citado ensayo nos hace un repaso histórico y aterrador de los desastres por fallos en la seguridad de los estadios, solamente hemos omitido del texto original los ocasionados por la violencia de los propios espectadores y los reservamos para el siguiente capitulo

El desastre de Sheffield, por espantoso que fuera, no ha sido ni único ni excepcional.

La historia del s. XX en lo que se refiere a eventos deportivos de masas, en Europa y

1. Baile, disciplina, densidad, y muerte. La multitud en los estadios. Camiel van Winkel The Stadium. The Architecture of Mass Sport. (2000). Ed. Michelle Provoost. NAI Publishers Rotterdam. ISBN 90-5662-145-9

2. Idem

3. CANETTI; Elias. (1960). Masa y poder. Ed. Alianza Editorial, 2005. ISBN 8420637513 
fuera de ella, está plagada de idénticos o parecidos incidentes. El papel desempeñado por los hooligans en la creación de estas "fosas comunes" es insignificante, Muchos de estos incidentes se produjeron al llevar a una multitud a un estadio, que era demasiado pequeño para acogerla o que no disponía de accesos adecuados a los gradas, lo que provocaba que literalmente en la multitud se pisaran unos a otros. Esto ocurrió en la ciudad escocesa de Sutherland (1964, 2 muertos,) en Kwanglu, corea del Sur (1965, 14 muertos), en Bukaw, Congo (1969, 27 muertos) Cairo (1947, 49 muertos) y tan reciente como 1996 en Guatemala (84 muertos). Igualmente común es el fenómeno inverso: espectadores dentro del estadio desatan el pánico y corren en estampida hacia las salidas. Incidentes de este tipo ocurrieron en Buenos Aires (1944, 8 muertos) Jalapa, México (1964, 24 muertos) y en Glasgow (1971, 66 muertos). El pánico puede desatarse por una falsa alarma (Teresina, Brasil 1973, 4 muertos) - por una repentina lluvia de granizo (Kathmandú, 1988, 80 muertos). El ruido de una máquina de refrescos ocasionó una reacción de pánico en los espectadores en el Roosevelt Racecours de Wesbury, Nueva York en 1971 provocando 37 heridos. La falsa sensación de que es estadio está a punto de derrumbarse (Salvador, Brasil 1971, 3 muertos) puede generar un pánico tan real como si se derrumbara de verdad un muro (Sheffreal, 1914, 75 muertos) o un techo (Lille, 1946, cientos de atrapados). Un gol en los instantes finales de un partido de fútbol puede provocar un choque entre una marea de gente que está ya abandonando el estadio y grupos de hinchas que deciden volver a sus asientos (Moscú 1982, 20 muertos). Según la teoría de Canetti, existe un arraigado antagonismo entre multitud y arquitectura. Este se encuentra en la naturaleza de una multitud que desea crecer, Los edificios son como recipientes que impiden el crecimiento de la multitud. No importa en que lugar aparezca la multitud, las ventanas y las puertas se rompen, el dinamismo de la multitud manifiesta en sí mismo una destrucción dirigida a fronteras y limitaciones. Además existe un deseo de atraer a aquellos que están fuera de la multitud. En la multitud el individuo siente que está traspasando los límites de su propia persona. Tiene un sentimiento de alivio porque se han eliminado las distancias que utilizaba para volver a encerrarse en sí mismo. Al eliminar esta distancia, se siente libre; su libertad representa el cruce de esas fronteras; quiero que lo que le pasa a él, le pase a otros.

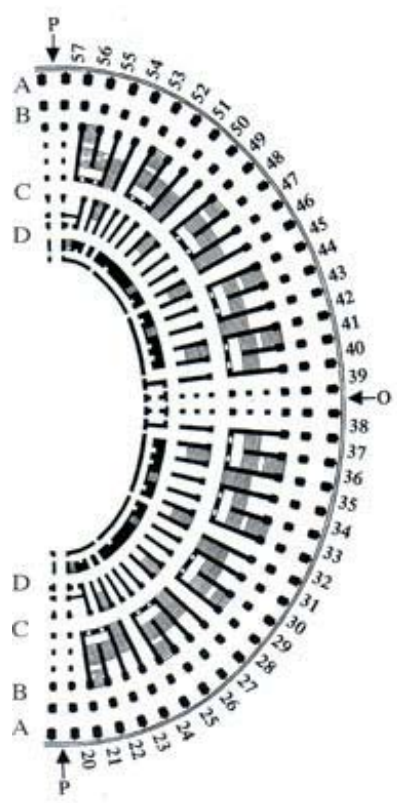

El desarrollo del estadio moderno ha supuesto un inagotable proceso de intentar controlar y ordenar el flujo de las masa. Un indicio claro de esta evolución lo podemos tener estudiando la capacidad de evacuación de los estadios.

El White City Stadium, Londres 1908, contaba con 23 entradas de publico para un aforo de mas de 80.000 personas, parece llamativo su escaso numero si tenemos en cuenta que uno de los problemas del desastre de lbrox Park, fue el reparto poco equilibrado de espectadores por el estadio, concentrándose en la proximidad al acceso. Ibrox Park contaba con 19 accesos siendo 6 de ellos dobles. Si lo comparamos con el Coliseo de Roma del siglo I dC. Que para 50.000 espectadores tenia 80 arcos de entrada que circundaban la fachada, cada arco tenía un número y el espectador sabía cual era el arco que le correspondía para alcanzar su localidad directa y rápidamente, por los corredores interiores y escaleras llegaba hasta su nivel, existían cuatro, el mas bajo llamado podium y los tres superiores maeninana, separados por los pasillos de carácter anular llamados praecinctiones y luego, a su vez, el graderío se dividía en sectores (cunei) separados por escaleras.

El fin ultimo, en cuanto a seguridad, de las entradas es su capacidad de evacuar el recinto en un cierto tiempo determinado, la norma Británica UK Guide to Safety at Sports Grounds lo fija en 8 minutos, manejando las siguientes hipótesis;

Velocidad de 1 persona en llano y rampas: $100 \mathrm{~m} / \mathrm{min}$

Velocidad de 1 persona en escaleras: $30 \mathrm{~m} / \mathrm{min}$

Anchura de una fila de personas: $0,60 \mathrm{~m}$

Flujo de personas por cada fila de personas: 40 pers $/ \mathrm{min}$

Si aplicamos la actual norma española para calcular el ancho de paso de los accesos. Por cada metro lineal de paso en espacios exteriores se fija en 600 personas en liso y 480 en caso de escaleras, si esto lo aplicamos a lbrox Park, White City, Estocolmo y el Coliseo romano, obtenemos los siguientes datos comparados

$\begin{array}{rrrr}\begin{array}{r}\text { Aforo } \\ \mathrm{n}^{\circ} \text { total }\end{array} & \begin{array}{r}\text { Aforo/480 } \\ \text { personas/ } \\ \text { metro lineal }\end{array} & \begin{array}{r}\mathrm{n}^{\circ} \\ \text { accesos }\end{array} & \begin{array}{r}\text { ancho } \\ \text { teórico } \\ \text { acceso }\end{array} \\ 80.000 & 166,6 & 25 & 6,66 \mathrm{~m}\end{array}$

Ibrox Park

80.000

166,6

$6,66 \mathrm{~m}$ 


$\begin{array}{lrrrr}\text { White City } & 88.000 & 183,3 & 24 & 7,63 \mathrm{~m} \\ \text { Estocolmo } & 14.000 & 29,2 & 14 & 2,08 \mathrm{~m} \\ \text { Coliseum } & 50.000 & 104,1 & 56 & 1,86 \mathrm{~m}\end{array}$

Los accesos de lbrox Park tenían alrededor de 3 metros de ancho, los de White City tenían un ancho entre 3,40 (20 uds) y 4,00 (4 uds) metros y los de Estocolmo 2,90 m. Los del coliseo estarían alrededor de la dimensión del cálculo.

Lo que indica que el Coliseo es un edificio mucho mas seguro y avanzado en cuanto a capacidad de evacuación, lo que significa en seguridad, que los estadios iniciales, con excepción del de Estocolmo.

En 1926 el White City Stadium fue sometido a una reforma en profundidad, además de reducirse el aforo, el tamaño de la pista y cubrirse todo su graderío, se procedió a resituar y ampliar los vomitorios, pasando a tener 42 unidades de 3,50 metros de ancho de paso.
White City 1926
70.000
145,8
42
$3,47 \mathrm{~m}$

Pasando a estar dentro de lo que es ahora la norma en España. Y el último de los estadios Olímpicos Londres 2012, vuelve a estar en los números del Coliseo.
Londres 2012
80.000
166,6
104
$1,60 \mathrm{~m}$

En el Official Report de Amsterdam 1928, se relata una justificación de las vías de evacuación De esta manera las escaleras de evacuación se distribuiyen ordenadas en las tribunas y de fácil acceso. La anchura de las escaleras se determinó por la condición de que el Estadio con todo su aforo completo podía ser evacuado en 10-12 minutos. Dos mil quinientos espectadores por cada brazo de la escalera, o lo que es lo mismo, 5000 por escalera tendrían la capacidad de salir de las tribunas. Suponiendo una inclinación de 30 grados y una velocidad de 0,6 metros por segundo, supone una anchura de la escalera de 9,50 metros.

En América en las escaleras de las estaciones, se considera 66 personas por metro y por hora en sentido ascendente y 60 personas por metro y hora en descendente, que son datos semejantes a los utilizados. Las escaleras para la grada descubierta se fija en 7,50 metros, mientras que todas las escaleras restantes son de 5 metros de ancho.'

Pero los estándares de seguridad se alcanzan de manera definitiva en Berlín 1936. En el Informe Oficial, publicado en 1937 bajo el titulo de The XI th Olympic Games Berlín, 1936. Official Report. En su Volume I. justifica con bastante extensión y precisión la medidas adoptadas para la correcta evacuación del estadio. El graderío en sección esta dividido en dos partes, la inferior excavada en el terreno, con una profundidad de 45 pies (13,70 m.) y la superior, una construcción aérea, de 54 pies $(16,46 \mathrm{~m}$.) de altura. Un corredor de distribución central reparte el flujo de espectadores, de una manera diferenciada, mediante 20 vomitorios con escaleras a la parte alta y otros 20 vomitorios a nivel a la grada inferior, permitiendo un acceso y evacuación muy fluido. Se diferencian las circulaciones de público y de autoridades, jueces y atletas, estos últimos cuentan con un acceso diferenciado mediante un túnel subterráneo, que además conecta con las diferentes instalaciones del Reichssportfeld. El acceso directo a la pista, sin interferir al flujo de gente alrededor del estadio, se produce por la puerta y túnel de Marathon. El estadio forma, por primera vez, desde el punto de vista arquitectónico y compositivo parte de un conjunto perfectamente diseñado y organizado.

La principal consideración para la disposición de los diferentes edificios en el Reichssportfeld fue la necesidad de garantizar el libre acceso y la salida de los espectadores, los invitados de honor, los competidores, para todas las personas relacionadas con la organización y para la prensa. El Estadio Olímpico, como eje principal de los Juegos, se encuentra en el medio, y muy cerca de los principales accesos desde el este y el sur, y desde las estaciones de metro y ferrocarril municipal. La Puerta olímpica, la entrada principal del Estadio Olímpico cuenta con 52 tornos para el público de pago y de las dotaciones necesarias para la recepción y la atención de los espectadores. ... Además la entrada sur cuenta con 28 tornos más, por lo que en una hora los 100.000 espectadores pueden comprar sus entradas y acceder al estadio. ${ }^{2}$ Del Report Official.

El espacio alrededor del estadio es dos veces la superficie de sus graderíos, para poder asegurar una fácil evacuación y acceso a los diferentes sistemas de transporte.

El nivel de seguridad de un estadio es inversamente proporcional al tiempo de desalojo del mismo, ante casi cualquier amenaza lo mas seguro es poder sacar a todos los espectadores de una manera ordenada en el menor tiempo posible. Tan importante como que se den las condiciones de seguridad

1. The Ninth Olympiad being the Official Report Of The Olympic Games of 1928 celebrated at Amsterdam. Issued by The Netherlands Olympic Committee. (Committee 1928) Edited By G. Van Rossem. Secretary General. Translated By Sydney W. Fleming. Amsterdam J. H. De Bussy, Ltd. Printers \& Publishers. 60-62 Rokin

2. The XI th Olympic Games Berlin, 1936. Official Report. Volume I. (1937) Ed. Organisationskomitee Für Die Xi. Olympiade Berlin 1936 E. V. Responsable de contenidos Dr. Carl Diem. Editor Dr. Friedrich Richter. Ilustraciones Wilhelm Reetz, Berlin. Copyright 1937 Wilhelm Limpert-Verlag, Berlin Sw 68, Ritterstrasse 75 

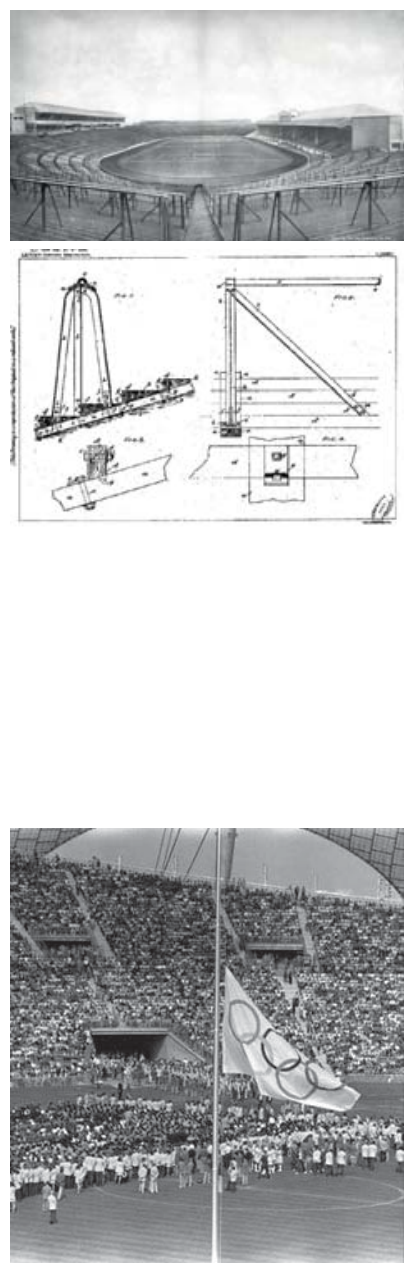

en la evacuación es que el espectador sienta esa seguridad. Para eso los recorridos deben ser claros, lo mas cortos y directos posible Que el espectador este siempre orientado en donde esta y poder ver la salida y que existen también otras alternativas. Una depurada geometría del estadio ayuda a ello, Deben esta bien señalizados y deben estar libres de cualquier elemento que supongan retenciones, que distorsione el fluir natural de las masas.

Aunque respecto a la seguridad de utilización de los estadios hayamos puesto el foco en la cuestión de la evacuación, hay otros muchos aspectos a tener en cuenta, como pueden ser; la pendiente de los graderíos, distancias entre escaleras, numero de gradas consecutivas, separaciones entre sectores, prohibición de espectadores de píe, etc.

En el desarrollo del estado moderno se ha producido un proceso continuo de aportar soluciones como respuesta ante las casuísticas presentadas. Por ejemplo después del desastre de lbrox Park, se dejó casi de utilizar la madera como material para la formación del graderío, sustituyéndose casi de manera universal por las gradas prefabricadas de hormigón armado. En cuanto a las vallas de prevención de avalanchas el propio Archibald Leitch patentó un modelo "seguro".

\section{B.3.1.3.2 Consecuencias derivadas de la violencia}

Si bien en la historia de los Juegos modernos no se han dado episodios de violencia en los estadios, lo ocurrido en el mundo del fútbol han supuesto una serie de medidas correctoras que han sido aplicadas de igualmente a los Olímpicos, para intentar garantizar la seguridad en los estadios.

La violencia que han padecido los Juegos siempre ha sido ajena a los estadios, como el criminal episodio de Munich en el que once deportistas y entrenadores israelitas fueron asesinados por terroristas palestinos, o la matanza de estudiantes en México diez días antes del comienzo de los Juegos.

Casi todas las desgracias en los estadios están relacionadas con el fútbol, para ello existen dos razones. La primera es de carácter estadístico. Es el evento deportivo que más espectadores arrastra, con gran diferencia si exceptuamos el caso particular de los Estados Unidos de América. La segunda está en relación con el gran fanatismo que provoca.

La lista de incidentes es larguísima, en 1946 hubo 44 muertos y 500 heridos en Bolton, por peleas multitudinarias en el Bulden Park, en un encuentro entre el Bolton y el Stoke City. Nueve años más tarde, en 1955, una nueva tragedia dejó 152 muertos en Nápoles, tras unos incidentes provocados por un penalti pitado a favor del Bolonia, en un partido contra el Nápoles. Sin embargo, ninguna de las dos desgracias anteriores tuvo la magnitud de la ocurrida en 1964 en Lima, en un encuentro que enfrentó a Perú y Argentina y en el que se jugaban la clasificación para los Juegos Olímpicos de Tokio. Se disputó en el Estadio Nacional, que se abarrotó para la ocasión. La asistencia oficial fue de 47.197 espectadores. El combinado argentino vencía por un gol a cero a falta de dos minutos del final. En ese instante, Perú anotó el gol que ponía el empate en el marcador, pero el árbitro lo anuló. Ante esta decisión, un aficionado saltó al terreno de juego y agredió al colegiado. La Policía respondió a este ataque soltando a los perros, que se abalanzaron sobre el agresor. Esta situación desató el desconcierto en las gradas y los aficionados de ambos países, que hasta ese momento se habían comportado de forma ejemplar y disfrutaban del partido unos al lado de otros, empezaron a enfrentarse. Desbordada por la batalla campal que se había desatado en las gradas, la Policía intentó parar el conflicto lanzando gases lacrimógenos. El resultado final fue catastrófico: más de 300 muertos. Pocos años después, en 1968, se produjo el mayor desastre del fútbol argentino. El 29 de mayo de 1985, en el estadio de Heysel de Bruselas final de la Copa de Europa entre Juventus y Liverpool disputaban la y miles de aficionados de ambos conjuntos viajaron hasta Bruselas para alentar a los suyos. La Prensa había considerado el partido como uno de los mejores de la época, ya que enfrentaba al fútbol inglés (cuyos equipos habían logrado siete de las últimas ocho Copas de Europa) y al fútbol italiano (en ese momento, Italia era vigente campeona del mundo con seis jugadores de la Juve en sus filas). Los radicales de ambos equipos quisieron ser protagonistas y colarse en lo que iba a ser una fiesta del fútbol. Desde primeras horas de la mañana hubo altercados en Bruselas, pero el momento de mayor dramatismo se vivió dentro del estadio, cuando un grupo de hooligans atacó a otro de tifosis italianos. Los hinchas ingleses derribaron la valla que separaba a ambas aficiones y se desató una batalla campal en la que no faltaron navajazos, botellazos y agresiones de todo tipo. El conflicto dejó como resultado 39 muertos. La imagen del fútbol quedó muy dañada y desde este incidente se redujo la asistencia de aficionados a los estadios por miedo a los violentos.

Con la entrada del siglo XXI, el desarrollo de las nuevas tecnologías y los precedentes anteriores, las medidas de seguridad en los estadios han aumentado de manera muy positiva. De hecho, en lo que llevamos de siglo no se registra ninguna gran tragedia en el fútbol europeo. Sin embargo, en los países menos desarrollados las condiciones siguen siendo aún precarias $y$, desgraciadamente, cada cierto 
tiempo nos encontramos con incidentes en un campo de fútbol. Especialmente trágico fue lo ocurrido en Ghana en 2001. Al menos 130 personas que fueron a presenciar el partido entre el Accra Hearts y el Kumasi Ashanti perdieron la vida. El Accra se proclamó vencedor (2-1) y los hinchas del equipo derrotado no lo aceptaron de buen grado. Comenzaron a destruir los asientos de las gradas, ante lo que la Policía respondió cerrando las puertas del recinto y lanzando contra ellos granadas lacrimógenas. Los cuerpos de seguridad fueron acusados por la opinión pública como los principales culpables, así como la poca seguridad existente en los estadios en el fútbol africano. Sea como fuere, los aficionados volvieron a ser las víctimas de un fallo en la seguridad y más de un centenar de inocentes se dejaron la vida allí. Más reciente es la tragedia ocurrida en Port Said, Egipto, el 1 de febrero de 2012. Se enfrentaban el equipo local, el Al-Masry y el Al-Ahly, cuyas aficiones tienen gran rivalidad por motivos políticos. Los locales se impusieron por 3-1, pero, al finalizar el partidos, los aficionados del Al-Masry invadieron el terreno de juego para perseguir a los hinchas y jugadores del Al-Ahly, lanzándoles piedras y botellas. El resultado, una vez más, fue trágico: 74 muertos y cerca de mil heridos.

Si atendemos a los hechos, es innegable que el aumento de las medidas de seguridad en los campos ha dado sus frutos y cada vez es más complicado que alguien se deje la vida en un estadio, aunque aún queda mucho por mejorar en aquellos países con menos recursos. Sin embargo, no se deben olvidar las tragedias que han ocurrido a lo largo de la historia y es necesario seguir trabajando para mantener la seguridad.

Desde el punto de vista arquitectónico, cuanto mas claro y sencillo es un estadio, si su comprensión y entendimiento se obtiene con un simple vistazo, es mas fácil evitar la aparición de episodios de violencia. Para ello la nitidez y depuración geométrica es un gran aliado. Los sistemas pasivos, fundamentalmente la vigilancia pasiva, mediante cámaras y centros de control tienden hacia un nuevo concepto de seguridad: las personas se sienten seguras, pero no vigiladas o amenazadas.

Como conclusión con respecto a la seguridad en los estadios, con el devenir del tiempo se han tenido que ir adoptando unas medidas de corrección encaminadas a garantizar la seguridad de sus usuarios Durante las circulaciones masivas tanto en caso de entrada como de salida el espectador debe no solo estar a salvo sino también debe sentirse a salvo, no es siempre tarea fácil, son multitudes ruidosas y abstraídas evacuando de gradas escalonadas y desde una altura, a veces, importante. Factores que ayudan a cumplir el objetivo de la seguridad en este sentido son:

La geometría del estadio debe ser precisa. Con una distribución y recorridos claros y despejados para permitir siempre a los espectadores ver a donde van, y las rutas alternativas en caso de bloqueo del camino propio. Tener conocimiento de lo que está por venir es vital para la seguridad de las masas, la experiencia ha demostrado que lo desconocido puede provocar ansiedad e incluso pánico entre un gran número de personas en situación de gran confinamiento. Por tanto se deben evitar circulaciones complejas o laberínticas, aunque son buenas circulaciones en ángulo porque evitan longitudes de gentío excesivamente largas, lo cual produce riesgo de avalanchas, igualmente no son convenientes repentinos cambios de nivel o de anchura y contrastes fuertes en cuanto a la luminosidad. La claridad espacial debería ser reforzada con un sistema de señalización igual de claro y visible. Esta debe ser secuencial, es decir que la información se va proporcionando según se avanza, no toda de golpe. Para reforzar esta claridad, se puede recurrir al color. La falta de claridad en la señalización puede producir dudas y retenciones o vueltas atrás en el sentido contrario a la masa, lo cual desordena absolutamente el flujo, Es conveniente que las rutas de circulación tengan remansos para que las personas puedan esperar, pensar - lo que necesiten sin interferir al flujo principal. Siempre es conveniente la existencia de estos espacios próximos a las zonas donde los espectadores deban tomar decisiones en cuanto a la dirección a tomar. 


\section{B.3.1.4 Multifunción}

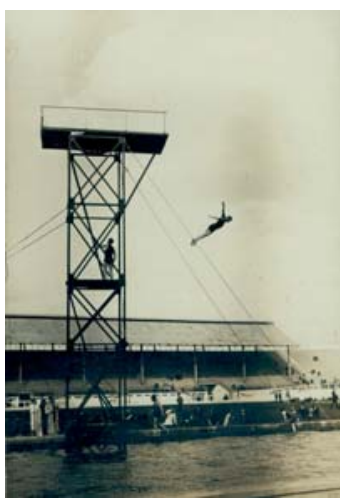

Gimnasia 9 Gimnasia Halterofilia Lucha Futbol Lacrosse Tiro con Arco Tira de soga Hockey hierba Rugby Ciclismo Natacion Pentalon Moderno Hipica Balonmano

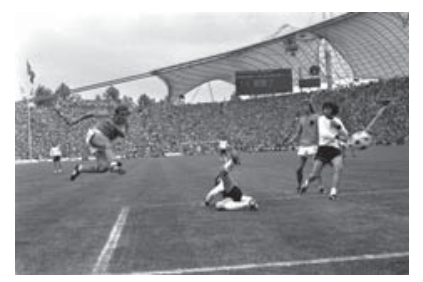

En la Carta Olímpica el punto tercero de los Principios Fundamentales del Olimpismo dice El Movimiento Olímpico ... alcanza su punto culminante en la reunión de los atletas del mundo en el gran festival del deporte que son los Juegos Olímpicos.

El espíritu de los Juegos es mucho más que una serie de pruebas deportivas aisladas. Que fue el problema para el fracaso de los Juegos de Paris 1900 y St. Louis 1904, en las que no existió, en ningún momento, una comunidad de competidores arropada por un público cómplice. Las competiciones se dilataron en el tiempo y se realizaron en el caso de Paris en diferentes localizaciones sin ningún nexo común entre las mismas. En Londres se quiso revertir la situación, el estadio construido para el efecto el White City, fue ciertamente ambicioso en ese sentido. Su enorme graderío oval contenía no solo la pista de atletismo sino también un velódromo y lo que es más extraordinario, una enorme piscina de 100 metros de largo por 25 de ancho con su torreta para trampolines y palancas, que para evitar la interferencia visual que podía suponer la enorme estructura, esta se abatía y sumergia dentro de la piscina. El estadio de Londres fue un intento serio de estadio multifunción, en el se celebraron las competiciones de los siguientes deportes:

Atletismo, Gimnasia, Lucha, Fútbol, Lacrosse, Tiro con arco, Hockey hierba, Rugby, Ciclismo, Natación, Salto de trampolín, Waterpolo y las Ceremonias de Inauguración y Clausura.

Pero la dificultad para seguir adecuadamente las pruebas, unido a la creciente necesidad de instalaciones especificas para cada deporte y la necesidad de concertar todas las competiciones en un corto lapso de tiempo produjo que el modelo no prosperara. El caso de Ámsterdam fue un segundo, auque algo más modesto intento. El caso es que la formulación final de los estadios fue derivando hacía un modelo de función dual, compuesto por un campo de deportes de equipo, fundamentalmente fútbol, cuya superficie de juego fuera la hierba y pista de atletismo alrededor. Como las competiciones de atletismo que atraen un gran numero de espectadores son escasas, una al año a lo sumo, toda la rentabilización de la instalación dependía del fútbol y del rugby en menor medida y solo en los casos de países con gran tradición en este deporte, en Estados Unidos del fútbol americano. La necesidad del fútbol moderno de contar una superficie de juego perfecta, en cuanto a su regularidad y calidad de la hierba hace casi imposible la celebración de espectáculos o cualquier otra actividad, incluso la frecuencia de partidos de fútbol esta limitada. Por lo cual, en los estadios Olímpicos después de los Juegos lo normal era la convivencia del fútbol con el atletismo, siendo el fútbol el uso principal.

El mejor ejemplo para ilustrarlo es el caso del Olímpico de Munich, después de los Juegos ha tenido un intenso y brillante uso como estadio de fútbol, sede del Bayern Munich y del TSV 1860 Munich. Además en él se ha celebrado la copa del Mundo de 1974, la Eurocopa de 1988 y numerosos partidos de la selección alemana.

En el muy detallado estudio realizado en 2008 por Arne Feddersen y Wolfgang Maennig, profesores de económicas y ciencias sociales de la Universidad de Hamburgo, titulado Arenas vs. Multifunctional Stadia - Which Do Spectators Prefer?' en el que se han manejado miles de datos, llegan a la conclusión documentada estadísticamente de que los espectadores prefieren estadios únicamente de fútbol en contra a los estadios en los que se contaba con pista de atletismo. En Alemania era normal y habitual la cohabitación de los dos deportes, pero a partir de 1991 se inició un proceso de exclusividad en los estadios solo para la practica del fútbol

Los espectadores prefieren la atmósfera que se crea en un estadio exclusivo de fútbol. Muchos de los estadios europeos multifuncionales se han reconvertido en estadios durante la última década, en la Bundesliga casi han desaparecido los estadios de atletismo. En el estudio se han procesado la asistencia a todos los estadios desde el inicio de la Bundesliga en 1963/64, contabilizándose 13.100 encuentros hasta el final de la temporada 2005/06. demostrándose que se produce un aumento de asistencia fijado en un $18,7 \%$ cuando se prescinde del atletismo. 
Los autores denominan multifuncionales a los que además de fútbol sirven para atletismo y estadios a los exclusivos de fútbol.

Como parte del proceso, descrito por los dos profesores alemanes, de reconversión de los estadios, en Munich en el año 2001 se realizó un referéndum entre los ciudadanos para saber si preferían la reforma del estadio Olímpico en uno exclusivo de fútbol, perdiéndose el para siempre el lugar donde se celebraron los Juegos de 1972, o la salvaguarda del patrimonio y la construcción un nuevo estadio de fútbol en otra localización, el $65,8 \%$ de los votantes, lo que supuso el $37,5 \%$ de los muniqueses, optaron por esta segunda opción. Desde este momento el viejo estadio es un lugar muy visitado por los turistas y en él se han celebrado grandes conciertos y otros muchos eventos.

En cuanto a los estadios de fútbol el futuro parece claro, estadios muy específicos, cada día mas equipados, y rodeados de múltiples funciones, hoteles, comercios, restaurantes, etc, que permita ayudar a su retorno económico.

Y en cuanto a los de atletismo, ¿̇cuál es su futuro?. En el próximo capitulo, Nuevas tendencias lo intentaremos analizar. ${ }^{\prime}$

1. No se ha contemplado la multifuncionalidad de los estadios de Montreal y Sydney, porque despues de los Juegos, al desmontar su pista de atletismo, han perdido la principal función de un estadio Olímpico,

la celebración de las competiciones atléticas. 


\section{B.3.1.5 Nuevas tendencias}

En vista de la difícil convivencia entre el deporte rey y el rey de los deportes, se necesita una nueva estrategia de cara a los nuevos estadios Olímpicos.

Es primordial que los estadios sean sostenibles y que su uso después de los Juegos esté garantizado. Hemos vivido lamentables ejemplos como el fallido estadio Olímpico de Sevilla, que vivió solamente un efímero momento de gloria con el campeonato del Mundo de Atletismo de 1999 o las abandonadas instalaciones olímpicas de Beijing 2008, como pone de manifiesto una información de Reuters titulada Desiertas Sedes Olímpicas en Beijing'

Cuatro años después de que Beiiing organizara unos espectaculares Juegos Olímpicos de verano, la bulliciosa capital de China ha visto mejorado enormemente su transporte público e infraestructuras, pero muchas de las instalaciones construidas para el evento languidecen sin mantenimiento, infrautilizadas y suponiendo una carga para las finanzas públicas.

La celebración de la Olimpiadas proporciona una oportunidad única a las ciudades para mostrar su personalidad y capacidades. Y no hay mejor manera de potenciar una visión de futuro que mediante la construcción de espacios y estadios de diseño avanzado. Entonces, podemos considerar que el diseño de las instalaciones Olímpicas se ha convertido en una competición en si misma, en la que lo que esta en juego es el prestigio nacional. ¿̇Pero a que precio? Brandon Smith, en su articulo titulado The Future of Olympic Architecture is Portable ${ }^{2}$ pone el dedo en la llaga en lo que puede suponer la mayor de las debilidades del proyecto olímpico de las ciudades sede

Las ciudades candidatas proponen un planteamiento urbano y unas edificaciones, prometiendo su sostenibilidad y su uso continuado después de que la llama olímpica se haya apagado. Pero ciudades como Beijing o Montreal no han sido capaces de cumplir esa promesa. Muchas de las instalaciones están abandonadas o se usan muy ocasionalmente. En ellas todavía cuelgan los carteles y pancartas con el logo Beijing 2008 y van mostrando, día a día, el inexorable paso del tiempo.

[...]

Suponer que el proyectar instalaciones espectaculares va a suponer un impacto positivo y duradero a la ciudad anfitriona, es algo que esta muy lejos de poderse prever y asegurar. Para ser seleccionada como sede de los Juegos, una ciudad debe sugerir planes audaces, pero también debe tener un enfoque equilibrado.
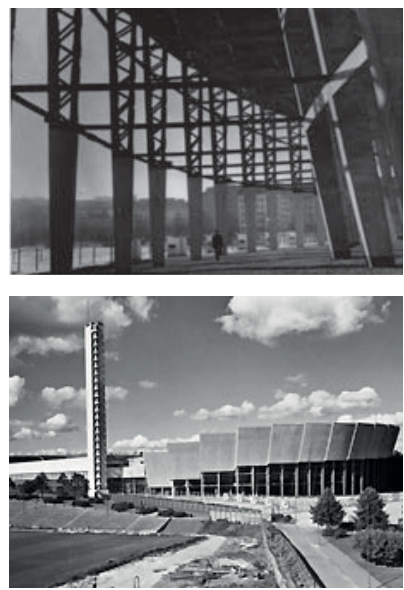

El esfuerzo de organización de unos Juegos es enorme, la ciudad sede debe, además de dar respuesta a todos los requisitos técnicos y organizativos necesarios, proyectar lo mejor de su imagen hacia el exterior. Pero tiene que controlar que el legado que dejen los Juegos no se conviertan en un quebradero de cabeza, y el mayor riesgo para que esto sea así son instalaciones costosas de mantener e hiperdimensionadas para la ciudad, y por tanto infrautilizadas.

En este sentido el estadio Olímpico de Londres 2012 nos parece que abre un camino interesante de cara al futuro. Se proyectó con unas premisas muy claras, sensatas e innovadoras, diríamos incluso que revolucionarias. Durante los Juegos debía acoger con brillantez el espectáculo Olímpico y después suponer un legado ajustado a las necesidades de la ciudad.

Si bien todos los estadios requieren una adaptación especifica para la celebración de los Juegos, pero esa transformación no suele afectar a su "carácter". Ha habido estadios existentes, como el de Los Angeles 1932, ampliados de una manera permanente para los Juegos. El de Helsinki 1952 es un caso especial. Construido entre 1934 y 1938, para los Juegos fue ampliado con una grada provisional de madera que envolvía por su exterior tres cuartas partes del estadio y que junto con la torre se convirtieron en los elementos mas significativos del estadio, por lo cual tras los Juegos se decidió mantenerlos, pasando de efímeros a permanentes. En Sydney el estadio tuvo una configuración con mayor aforo para los Juegos y se dejó sin cubrir completamente el graderio. Al terminar estos se desmontaron las dos extensiones del graderío, diminuyendose el aforo y se procedió a completar la cubierta. Aunque si bien es cierto que en Helsinki y Sydney, en el proyecto Olímpico, se recurrió a instalaciones de carácter efímero, es en Londres donde este concepto adquiere el principal protagonismo. Hasta el momento los estadios Olímpicos se habían construido con la intención de perdurar. Incluso Albert Speer para el de Berlín 1936 había manejado el concepto conocido como la teoría del valor de la ruina de una construcción. Así, al redactar el proyecto se debía tener en cuenta su ocaso y decadencia. Que las construcciones tuvieran la capacidad de acabar siendo una noble ruina, como en el caso de los restos de la antigüedad clásica. Speer estaba apelando aquí, con cierta raigambre romántica e historicista, a una ontología de

1. Reuters.. Lunes, 09 de abril 2012, 11:57 AM EDT

2. SMITH, Brandon. (2012). The Future of Olympic Architecture Is Portable. http://mashable.com/2012/07/31/ olympic-architecture/ 
la decadencia, una ontología al servicio no ya del presente, sino del futuro, pretendiendo acaso ser un Piranesi de lo por venir.

Para ilustrar mis ideas, hice dibujar una imagen romántica del aspecto que tendría la tribuna del Zeppelinfeld después de varias generaciones de descuido: cubierta de hiedra, con los pilares derruidos y los muros rotos [...] pero todavía reconocible. Albert Speer.

Algo semejante de concepto manejó, poco más tarde, María Zambrano en el compendio de textos que, en los años 50, se publicarían con el título de Islas', ahí asevera:

Las ruinas son una categoría de la historia y hacen alusión a algo muy íntimo de nuestra vida. Son el abatimiento de esa acción que define al hombre entre todas: edificar. Edificar, haciendo historia. Es decir, una doble edificación: arquitectónica e histórica. Maria Zambrano.

A lo "duradero" se opone lo efímero. Así al ideólogo, poeta, editor y fundador del movimiento futurista, Filippo Tommaso Marinetti (1876/1944) en su furor en defensa de lo efímero cae en la paradoja de admitir que sin la concepción de lo imperecedero, su arte de lo perecedero no tendría significación ni enemigo alguno.

Lo efímero y lo perecedero eran conceptos sobre los que se había reflexionado en el tiempo de las vanguardias de principios del siglo XX y se continua haciendolo.

Nosotros, que mantenemos que una obra maestra debe ser incinerada con el cadáver de su autor..., [y que estamos] contra la concepción de lo inmortal y lo imperecedero, nosotros afirmamos que el arte ha de devenir de lo perecedero, lo transitorio y lo consumible. Marinetti.

En Londres 2012 se abandona un concepto ampliamente compartido e interiorizado, el que la construcción de un estadio que va a ser testigo y soporte de un hecho con un valor histórico, tiene que perdurar y convertirse en un elemento de referencia y peregrinación en el futuro. Así son actualmente los estadios Olímpicos de Berlín, Helsinki y Munich.

Sucede todo lo contrario. Se proyecta un estadio para dar servicio a las necesidades Olímpicas, con una capacidad de 80.000 espectadores, y que una vez finalizados los Juegos pueda reconvertirse en un estadio adecuado para la demanda real del atletismo londinense, con capacidad para 25.000 personas. Todo esto según las previsiones de Lord Sebastián Coe, doble campeón olímpico en 1500 metros, director de la candidatura olímpica y presidente del comité organizador de Londres 2012 . Pero, ¿cómo hacer posible estas dos condiciones tan divergentes?

Los arquitectos de Populous, como responsables del proyecto, tenían que plantear un nuevo modelo de estadio. Así, según Rod Sheard (1951) su arquitecto jefe

Entendimos lo que se nos estaba pidiendo, lo cual nos permitió pensar de una manera alternativa. $^{2}$

Ya habían proyectado el estadio de Sydney, que como ya hemos dicho se reacondicionó de una manera importante después de los juegos. También habían construido instalaciones efímeras en las que lo ligero y reciclable tenían un valor fundamental. Pero construir un gran estadio que pudiera llegar a reducirse en dos terceras partes, constituía un problema con una escala muy diferente. Entonces buscaron la colaboración, por un lado de una gran ingeniería con un gran bagaje técnico y por otro lado a un gran productor de ideas, que eran el BuroHappold Engineering y Peter Cook (1936), fundador de Archigram, director de la Bartlett y poseedor de un extenso y prestigioso curriculo. En Archigram, en los años sesenta habían soñado con edificios de alta tecnología, con capacidad de mutar en función de las necesidades, con diseños realizados por elementos que se acoplaban unos en otros, casas que se podían trasladar y expandir, incluso ciudades en movimiento compuestas por edificios acoplables, que tenían la capacidad de reajustarse y cambiar. Cincuenta años después las ideas subyacentes en las propuestas del grupo de Cook, se adaptaban con claridad a la manera con la que había que pensar el nuevo estadio Olímpico.

Por una parte el estadio debía cumplir con lo que dice el propio Sheard

un contenedor para el más espectacular acontecimiento de deportes y entretenimiento en el mundo [...] el objetivo no es que sea monumental, ni aplicarle las reglas arquitectónicas o juzgarlo por los mismos valores que se juzgaría a un coliseo. ${ }^{3}$

Y ciertamente, en el estadio proyectado su huella es mucho menor que la del de Wembley. Sheard lo compara con un gigantesco elemento de ensamblaje, un gran mecano, en el que solo es permanente su

1. ZAMBRANO, María. Islas. Ed. Verbum, 2013. ISBN 9788479624170

2. DYCKHOFF, Tom; BARRETT, Claire (2012). The architecture of London 2012. Vision. Design. Legacy. Ed. An official

London 2012 publication. ISBN 978-1 11 19-99386-5

3. Idem 


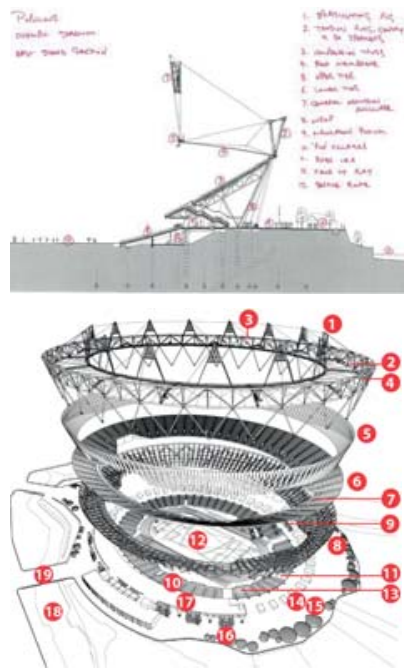

1 Torres de iluminación

2 Acceso a la cubierta

3 Anillo estructural de la cubierta

4 Cubierta. Red de cables y lamina de poliester reforzada con PVC

5336 paneles textiles $25 \times 2,5 \mathrm{~m}$. retorcidos $90^{\circ}$

6 Grada Alta. Capacidad máxima 55.000 esp.

7 Pantalla gigantes de video

8 Estructura metálica soporte grada alta

9 Escaleras de acceso grada alta

10 Grada Baja 25.000 espectadores

11 Tunel acceso atletas

12 Arena

13 Prensa

14 Aseos

15 Bares. cafeterias, tiendas, etc.

16 Nivel de acceso para el público

17 Hospitalidad

18 Río

19 Puentes de acceso

grada inferior, modelada en el terreno, con un marcado carácter topográfico, que se acentua al verse rodeado de agua por tres de sus partes y accesible mediante puentes. El espectador siguiendo un recorrido ascendente, en el que se disponen los puestos temporales para comida, aseos y otros servicios, accede por el borde superior del gigantesco "cuenco", en el que se "dibujan" la extensa serie de líneas concéntricas que forman el graderío para 25.000 espectadores.

Para los Juegos, encima de este elemento telúrico, se despliega una ligera y sofisticada estructura, capaz de albergar a 55.000 espectadores adicionales, formada por zigzagueantes vigas blancas de acero, coronadas por los elementos que soportan los equipos de iluminación que se repiten secuencialmente en la parte superior, conformando una corona, aun más ligera, de brillos y destellos. Todo este sistema aéreo fue inicialmente propuesto, inspirado por el pensamiento de Peter Cook, con la ambiciosa intención de convertirse en un elemento desmontable y reutilizable en las futuras ediciones Olímpicas como complemento a estructuras permanentes. Una arquitectura móvil y adpatable, especifica de los Juegos, que permitiría un uso sostenible de los recursos empleados.

Todos los accesos de público se producen por el plano de encuentro de estas dos actitudes, la reciedumbre de lo definitivo y lo evanescente de lo efímero, distribuyendo el flujo de espectadores con gran fluidez por medio de los 56 puntos de entrada. Circulaciones restringidas y de servicio se producen en el subsuelo.

Las gradas superiores, aunque provisionales, tienen un exigente requerimiento estructural. Para reducir costes y el impacto medioambiental, se dispone una estructura lo más ligera y económica posible. La estructura de acero de forma circular y 800 metros delongitud está arriostrada por las zigzagueantes vigas externas, que fue armada como un mecano y sirve de sujeción de las gradas de hormigón prefabricado. Todo, a su vez, está bajo la cubierta que forma una fina membrana de poliéster revestido de PVC cobijando dos tercios del graderío. Por encima de la cubierta se eleva el ya mencionado anillo de torres de iluminación triangulares (cada una de $28 \mathrm{~m}$ de altura) que, de lejos, da al estadio la apariencia de flor de lirio a punto de abrirse. "La idea es cambiar las reglas de la construcción" añade Sheard.

cada pieza tiene su sitio, su valor estriba en su utilidad y en su contribución a la totalidad. El estadio busca ser elegante, ligero, y producir un impacto mínimo al medio ambiente.

Como conclusión, asumir la incompatibilidad entre fútbol y atletismo, obliga a cambiar de uso de los estadios Olímpicos después de los Juegos, como ha ido sucediendo progresivamente.

Hagamos un pequeño repaso, en Los Angeles después de muchos años de convivencia, en este caso con el fútbol americano, recientemente se ha eliminado, de manera irreversible, la pista de atletismo en la que se habían celebrado dos ediciones Olímpicas. En Sydney se hizo justo después de los Juegos, incluso el estadio de Amberes ha sido demolido para construir un nuevo campo de fútbol.

La nueva opción, la que abre la última experiencia Britanica, era la construcción de un legado permanete en forma de estadio de atletismo ajustado en dimensión a la demanda y un complemento de carácter efimero para los Juegos, que permita su celebración con todo espledor.

Proponiendo un interesante contraste entre lo permanente y duradero y lo efimero y mutable, que nos permite escenificarlo en las ideas contrapuestas del futurista Marinetti y las de Albert Speer con su teoria de la ruina, a las que nos hemos referido anteriomente.

Pero nada acaba siendo lo que parece y el tiempo modifica cualquier previsión y teoria, ahora con la presente tesis a punto de concluir, el futuro del estadio de Londres ha cambiado contradiciendo su propia teoria. El fútbol acaparador ha vuelto a entrar en escena, aunque en esta ocasión alcanzádonse un interesante equilibrio. Será el estadio de fútbol del West Ham, pero desde el último viernes de junio hasta el final de julio, durante los proximos 50 años, pasará a ser otra vez estadio de atletismo para poder celebrar los competiciones de mas alto nivel. Para ello, la corona superior de carácter efimero se convierte en permanente, se reduce el numero de espectadores a 54.000, se proyectan graderios moviles-deslizantes para aproximar el público al terreno de juego del fútbol y la cubierta se amplía y se hace mas pesada.

A esto ha ayudado que el estadio haya sido proyectado para poder ser fácilmente modificado, gracias a que su finalidad a largo plazo no fue claramente prefijada, dejando abierta su evolución futura. Como tantas veces sucede, la arquitectura "temporal" ha acabado convirtiéndose permanente.

1. Traducción literal del inglés bowl 
La evolución del modelo del estadio Olímpico durante ya más de un siglo en desarrollo se percibe formalmente en su interior, a través de su traza en planta, de su sección más representativa y del elemento de cubrición. A partir de la envolvente externa podríamos determinar otra serie tipológica independiente que, a pesar del interés creciente que levanta entre la crítica, se aleja de los supuestos de este estudio.

La forma del estadio depende fundamentalmente del graderío al ser el elemento que tiene volumetría. No debemos olvidar que las gradas, en el fondo, son el público. Con el estadio lleno lo construido tan solo se adivina y lo que se percibe son filas y filas superpuestas de gente. La forma del graderío está en relación con las visuales y con la pista deportiva pero esta, al ser un plano horizontal y prácticamente sin ningún objeto, se comporta, compositivamente, como un elemento de carácter neutro. Son las gradas, dispuestas para garantizar la correcta visión de todos y cada uno de los espectadores, las que confieren al estadio el carácter desde el punto de vista arquitectónico. Su dibujo en planta permite comprender las características esenciales de su traza. Acometeremos este análisis y los de la sección y cubrición se afrontarán en posteriores capítulos.

En 1992 con motivo de los Juegos de Barcelona, la revista catalana Arquitecturas Bis publicaba un numero doble, el 46 y 47 , en el que en su peculiar diseño alargado y como introducción a los proyectos de la Barcelona Olímpica, publicaba un estudio gráfico comparativo, con criterios de dibujo y escalas semejantes, de las plantas de un buen numero de estadios. La sorpresa era mayúscula. Los estadios, que aparentemente son todos muy semejantes entre sí, mostraban una gran disparidad en cuánto a su forma y tamaño. Cierto es que la mayoría eran estadios de las etapas incipientes en el desarrollo de la serie tipológica y mostraban las dudas e incertidumbres que acompañaron sus inicios.

\section{B.3.2.1 Clasificación de los estadios por su traza}

Si iniciamos el recorrido en el estadio griego por antonomasia de la antigüedad, el de Olimpia, veremos que obedece a la necesidad de dar cabida a la prueba principal y originaria de los Juegos la del estadio, y sobre la que se basan el resto de carreras. Por lo cual la instalación deportiva tiene como características principales la longitud de un estadio y los graderíos, de carácter topográfico, lo más cerca posible del espectáculo. Su forma es la de artesa y sus lados largos se curvan para mejorar la visión de los espectadores. Su escala y proporción están en función de la larga y estrecha proporción de la pista. Mientras, en el otro "ancestro" del estadio Olímpico moderno, el anfiteatro romano ejemplarizado en el Coliseo, su escala y proporción nos remite al cumplimiento de las condiciones de visión y confort de los espectadores y está caracterizado por una forma cerrada en sí misma y la verticalidad de sus graderíos. Uno de los modelos es alargado y el otro concéntrico, aunque con una cierta elongación desde el círculo hasta el óvalo, como resultado de enlazar dos teatros romanos. Los cambios producidos en el programa deportivo de unos Juegos y la incesante necesidad de mejorar las condiciones de participantes y espectadores condicionan y justifican las decisiones tomadas por los arquitectos a la hora de proyectar los sucesivos estadios.

En capítulos anteriores se ha analizado el desarrollo tipológico del terreno dispuesto para la competición. Primero atendiendo a cómo se ha ido estableciendo el programa funcional y posteriormente estudiando cómo se han definido y fijado sus características formales básicas de acuerdo a las necesidades funcionales para la celebración del espectáculo. En este apartado, mediante el análisis comparado de las trazas de los diferentes estadios Olímpicos y atendiendo únicamente a sus características esenciales, se establece una clasificación formal de las mismas

1. Herradura (r_c_r)

2. Óvalo (c_r_c_r)

3. Elipsoide' (c_C_c_C)

4. Extraños Sin calificar
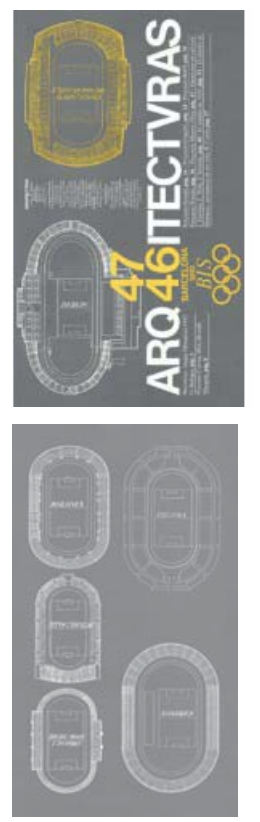

1. No es realmente un elipsoide, es un tipo de óvalo semejante a una elipse pero se utiliza esta denominación para poderlo diferenciar. 
y un catálogo de caracteres diferenciales que les son aplicables

\section{a. descompuestos}

Su generatriz no es continua, está conformado por diferentes secciones.

b. asimétricos

Presentan alguna asimetría.

c. crecimientos irregulares

Estadios que han sufrido alguna ampliación, de una forma irregular por no poder dar continuidad a su trazado regulador.

d. diagrama de Gavin Hadden'

La disposición del público se ordena siguiendo los diagramas propuestos por el "ingeniero de estadios", el estadounidense Gavin Hadden, en su publicación de 1925 Stadium Design². Según Hadden, la forma de los estadios debía responder al acomodamiento natural de los espectadores, analizando cual es el proceso de ocupación en función de las preferencias lógicas de los espectadores. Dicho estudio supone un cambio sustancial en el trazado de los estadios, donde el público, tradicionalmente, se colocaba en igual número de filas concéntricas en torno al óvalo que rodea el campo y las pistas, los proyectos que aplican la teoría de Hadden el numero de filas no es constante a lo largo de todo el desarrollo del estadio, produciendo una cota de coronación variable, que le confiere una imagen de un mayor dinamismo.

e. angulosos

Se modifica su geometría básica introduciendo ángulos y rectas,

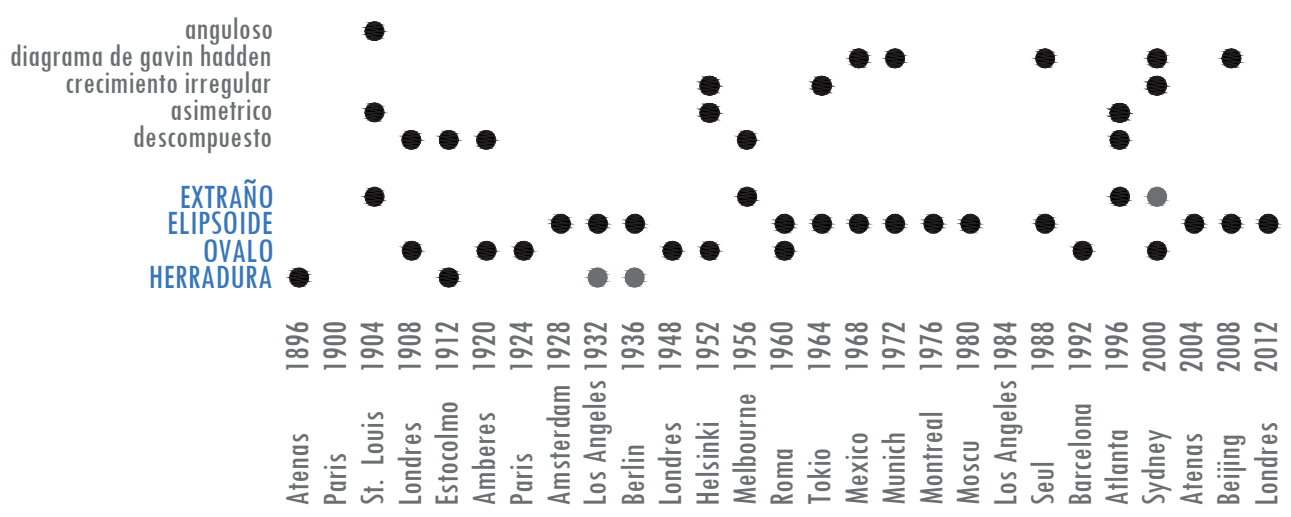

\section{B.3.2.1.1 Herradura}

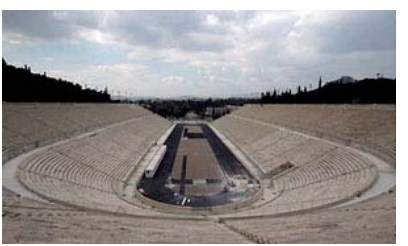

La tipología del estadio inaugural en Atenas es una mezcla del estadio de la Grecia clásica y del teatro, del cual su graderío es directo heredero, mientras que su longitudinalidad está tomada de los antiguos campos de competición. En sección, la grada se construye acomodando el terreno al cumplimiento de las correctas visuales en todos los puntos del estadio.

Su forma de herradura supondrá una fuerte influencia sobre los estadios de las primeras etapas del desarrollo de los Olímpicos de Estocolmo, Los Ángeles y en menor medida del de Berlín.

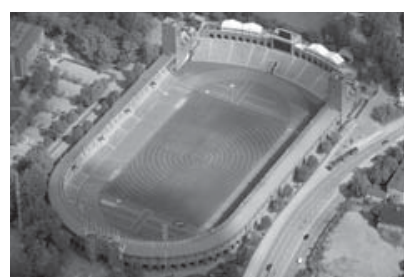

En el de Estocolmo, su arquitecto Torben Grut, propone claramente un estadio en forma de herradura. No importa que su parte abierta que da contra la ladera se cierre con un graderío y una arcada, porque son claramente ajenos a la geometría general de su traza y a su sistema estructural, mientras el graderío de la herradura es de obra; el que hace de cierre a norte esta labrado sobre el terreno y solo la grada de la herradura está cubierta. Todo esto refuerza el entendimiento global de la forma. En una versión previa del proyecto aparece con el graderío cerrado en forma de óvalo y la recta de llegadas en sentido sur, no como la definitiva que mira al norte.

El de Los Ángeles vuelve a contar con arcada, como el de Estocolmo, que cierra la ficticia herradura, de los tres niveles de gradas. La inferior pasa y cierra el ovalo y las dos superiores se interrumpen, quedando el estadio abierto a su orientación este, aunque limitado por un arco central y los peristilos laterales. El graderío inferior esta excavado en el terreno mientras que el intermedio está formado por el relleno de tierras y el superior es de obra. Esta completamente descubierto. El cambio de escala que

1. Gavin Hadden (1888/1956). Ingeniero civil y editor. Participa en la construcción de numerosos estadios, entre ellos, el Bucknell University Stadium de 1923 en Lewisburg/Pennsylvania, el Dyche Stadium 1926 Evanston/Illinois, Brown University Stadium 1935, Calvin Falwell Stadium 1938. Y está en posesión una larga lista publicaciones; Stadium Design, 1925; Mobility Seats, 1927; Airport planning. Sites and Sizes, 1927; Work of the office of Gavin Hadden, civil engineer. 1922-1937. Facilities for recreation, 1937; Manhattan District History, 1944.

2. Editada en Nueva York por la American Society of Civil Engineers 
supone con respecto a los estadios de ediciones anteriores hace que el problema de la cubierta sea completamente de otra dimensión. La estructura para cubrir estos graderíos sería descomunal y requiere nuevos criterios sustentantes.

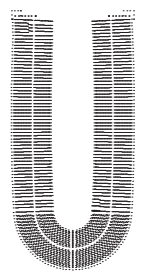

ATENAS 1896

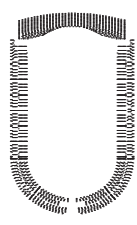

ESTOCOLMO 1912

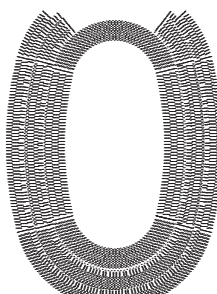

LOS ANGELES 1932

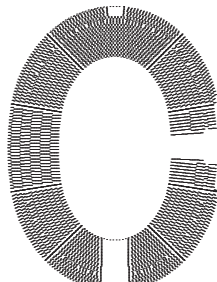

BERLÍN 1936

En el Berlín la traza es claramente un elipsoide aunque ciertos elementos arquitectónicos permiten emparentarlo con los estadios en herradura. Vemos como en el extremo de poniente de su eje longitudinal está situada la puerta y el túnel de Maratón y encima de ellos el graderío se abre al denominado Campo de Mayo, interrumpiéndose la parte superior de la grada para permitir la visión de la torre con la campana Olímpica, enmarcada por las dos torres de Maratón. El graderío inferior se convierte en una escalinata ceremonial coronada por el pebetero en el que arde el Fuego Olímpico. En el lado sur del eje transversal se dispone el palco de honor y encima del mismo la tribuna de prensa para 1.000 plazas, rematada en su parte superior por las 20 cabinas cerradas de radio. El marcador está situado en la parte superior del eje de la curva este. Todas estas posiciones descritas lo que producen es enfatizar sus dos ejes principales. La extensión virtual del estadio entre las dos torres de Maratón a lo largo del Campo de Mayo hasta la torre de la Campana, están tensionando la forma y estableciendo una cierta similitud con el estadio ateniense de forma de herradura muy dilatada.

\section{B.3.2.1.2 Óvalo}

Una vez definida la pista de competición en forma de óvalo, la manera natural de configurar los graderíos es mediante la adicción de un número determinado de filas ciñendo
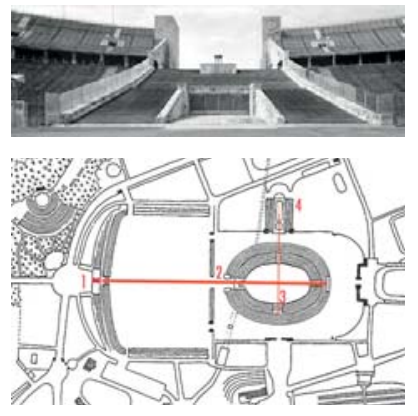

1. Torre de la Campana. 2. Torres de Maratón. 3. Palco de Honor. 4. Estadio de Natación 


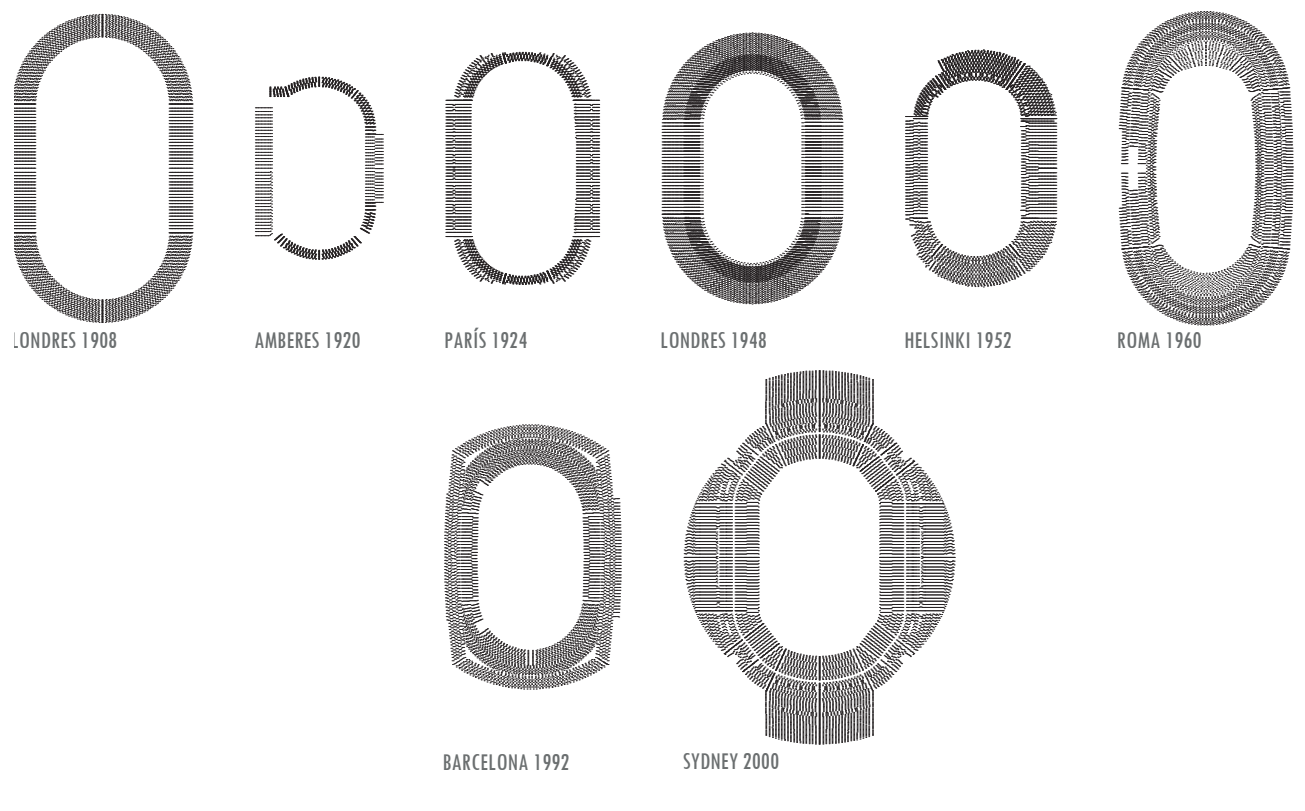

el espacio de competición. La homotecia entre pista y grada fue muy efectiva para cuerdas de un tercio 
de milla o de 500 metros donde las carreras de velocidad en recta de 100 y 110 metros se incluían sin ninguna distorsión de su perímetro. Al reducirse la cuerda a 400 metros las rectas no son suficientes para dar cabida a dichas carreras y deben prolongarse fuera del óvalo. Desde ese momento, la correspondencia homotética no es posible $y$, una vez liberada la relación entre la pista y el graderío se impone la directriz del trazado elipsoide que atiende mejor a las condiciones de visión de los espectadores. Esa condición de curvatura del graderío, acompañando a las rectas de competición ya existía en Olimpia y en el estadio de Licurgo de Atenas, en la Grecia clásica.

El gigantesco estadio de Londres de 1908, es el primero que propone un óvalo perfecto de dos curvas enlazadas por dos rectas, con doble simetría y ejes perpendiculares. Todo ello alrededor del velódromo de tres octavos de milla (660 yardas, $603,50 \mathrm{~m}$.) de cuerda y con un ancho de 35 pies $(10,67 \mathrm{~m}$.), en el que en su interior se dispone una pista de atletismo de un tercio de milla $(536,45 \mathrm{~m})$. La recta de velocidad tiene perfecto acomodo en el óvalo y así el velódromo circunscribe a la pista con precisión y lo mismo le sucede a la grada con respecto a ambos. Sus graderíos se independizan del terreno mediante una estructura metálica sobre la que se apoyan gradas de hormigón. Las dos cubiertas se limitan a las dos rectas aunque sus extremos insinúan timidamente las curvas.

Amberes 1920 y Paris 1924, proponen estadios que con traza oval, pero con caracteres de lo que hemos denominado como descompuestos y la razón para encuadrarlos en esta calificación es que la grada en recta y en curva corresponden a dos tipologías distintas en ambos estadios. Sus geometrías claramente los delatan. El de Amberes es el ejemplo más claro; está compuesto por tres tipos de graderíos además de un pabellón de acceso, que se abre hacía la pista, y la puerta de Maratón, con una configuración semejante a un arco de triunfo. En sus dos rectas contaba con tribuna cubierta, dividida en dos partes diferenciadas cada una de ellas, en las superiores se encontraban los palcos. La de la recta principal era más larga, 105 metros, rematándose en el extremo de llegadas con el pabellón de acceso, formando chafán y en el lado de las salidas con una pequeña torre. El graderío de la recta opuesta tiene una longitud de $\mathbf{7 0}$ metros. En las dos curvas se desarrolla un graderío con pendiente muy tendida para público de pie y el remate superior de dicho graderío, acotando el espacio del estadio, formaba una alineación de columnas dóricas enlazadas por un arquitrabe. Pero no solo la adición de piezas nos remite a su carácter descompuesto, también lo producen los diferentes lenguajes utilizados. Su autor Ferdinand de Montigny de carácter polifacético, campeón de esgrima y hockey, en su desarrollo profesional recurre a un sinfín de estilos arquitectónicos como beaux arts, art decó, neorural, neorococo, en la más pura de la tradición ecléctica. Barclay F. Gordon' califica la arquitectura de este estadio:

en su planificación, una expresión tardía del estilo Beaux Arts. Sus formas son producto de un delirante Eclecticismo, con elementos de estilo y ornato pertenecientes a muchos periodos históricos. Sólo un Henry Higgins² de la arquitectura, podría interpretar todos estos leguajes.

En París, seguramente la premura de tiempo, las limitaciones económicas y la facilidad constructiva están detrás de esta supuesta "descomposición"y nos basamos en que la propuesta ganadora del concurso, del mismo arquitecto Louis Faure-Dujarric, proponía un gran estadio con tratamiento unitario en el que su generatriz era continua y solamente aparecía un elemento compositivo especial, el gran arco de acceso.

En Amberes, además, la pequeña cuerda de la pista provoca que para poder alojar la recta de velocidad se recurre a una llamativa asimetría. Con tan solo 389,8 metros es la segunda pista más pequeña de todas las Olímpicas.

En Londres, 1948, el proyecto del estadio de Wembley Park es de 1921/23, construido con motivo de la Exposición del Imperio Británico, fue reutilizado en los Juegos Olímpicos. Tenía una capacidad para 126.500 personas, de las cuales 25.000 estaban sentadas bajo cubierta, otras 10.000 en asientos de graderío y al menos 91.500 de pie. Todos ellos disfrutaban de una visión homogénea del terreno de juego.

Helsinki, 1952. El Estadio fue edificado por fases, entre 1934 y 1952. En primer lugar se levantaron los graderíos, en 4 etapas diferentes, construidos en hormigón armado conformando el óvalo. La tribuna cubierta de la recta de llegadas tenía un mayor desarrollo. Para los Juegos Olímpicos de 1940 que se celebrarían en Helsinki, se amplió el aforo mediante gradas provisionales de madera hasta los 62.000 espectadores. La Segunda Guerra Mundial retrasó los juegos hasta 1952 y las gradas de madera, que pretendían ser una medida temporal y que serían derribadas una vez terminados los Juegos, se habían mantenido en su posición durante casi una década, pero acabaron pudriéndose.

Dos años antes del inicio de los Juegos, las gradas de madera fueron sustituidas por otras de hormigón armado que permitían alojar a 50.000 espectadores. Como la cubierta de la tribuna principal impedía
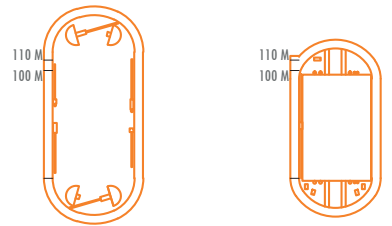

$1 / 3$ MILLA, $500 \mathrm{M}$

400 METROS
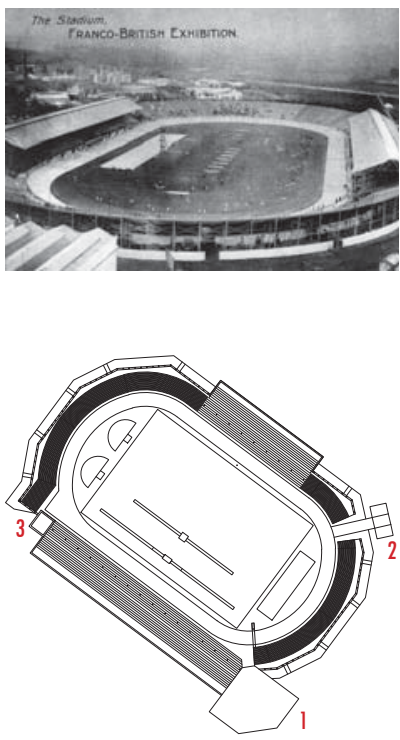

Amberes 1920. 1. Pabellón de acceso

2. Puerta de Maratón. 3. Torre
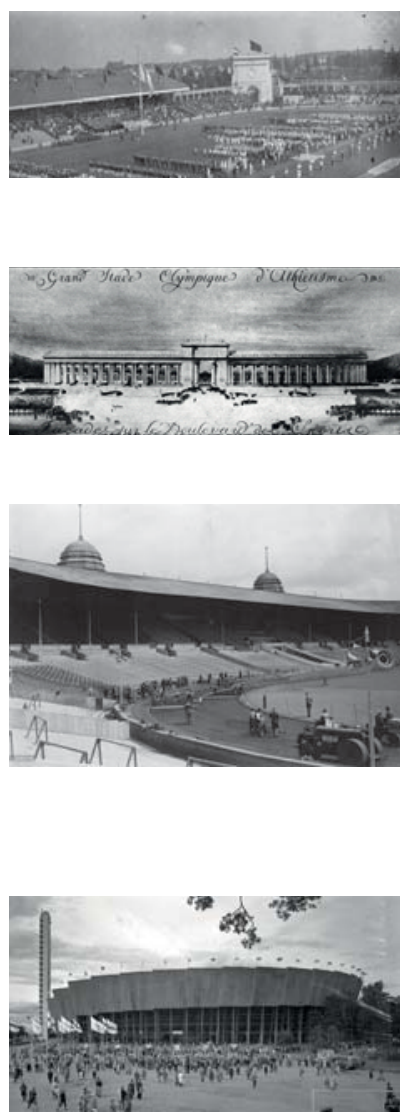

1. GORDON, Barclay F. (1983). Olympic Architecture. Building for the summer games. John Wiley \& Sons. Nueva York. ISBN 0-471-06069-0

2. Personaje principal de la obra de teatro Pigmalión, de George Bernard Shaw. 1913 

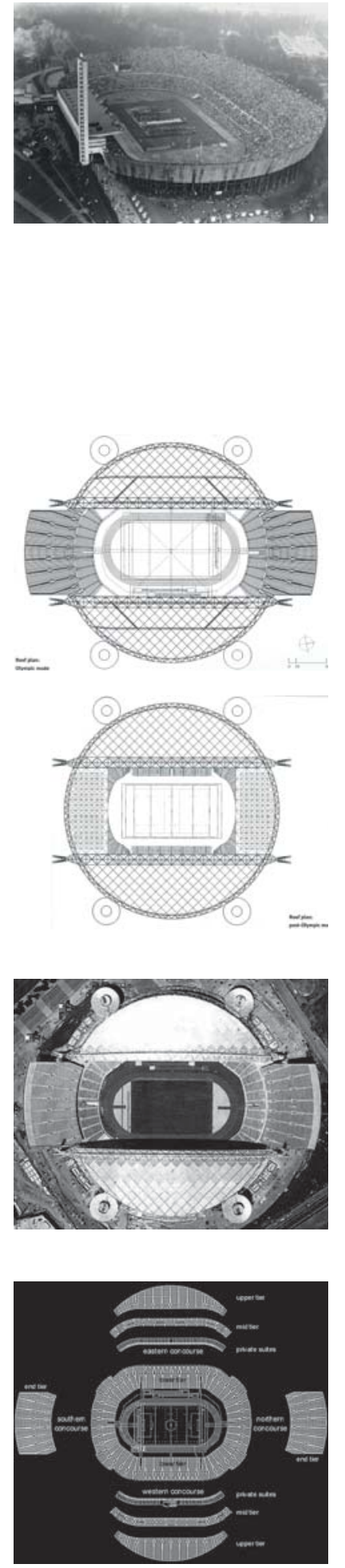

el crecimiento del graderío en esa dirección la ampliación se repartió por el resto de su perímetro, en lo que hemos venido a denominar "crecimiento irregular" y la parte de mayor interés en cuanto al espectáculo, la recta y línea de meta, es la que cuenta con menor densidad de público. El Comité Olímpico estimo insuficiente el aforo, indicando que las localidades deberían superar las 60.000. A tal efecto se construyeron nuevas gradas de madera llegándose a los 70.000 espectadores. Durante los Juegos, en los días secos, para evitar el riesgo de incendio las gradas de madera se rociaban con agua antes del inicio de las actividades deportivas. La ligera, casi imperceptible, asimetría de la directriz del arranque del graderío responde a la necesidad de dar cabida a la recta de velocidad.

En Barcelona 1992 la traza del estadio es el resultado de una intervención nostálgica sobre el estadio de 1929. Dicho estadio estaba levantado alrededor de una pista de 500 metros con la singularidad de que el encuentro entre recta y curva no se producia mediante la tangencia. Para preservar las viejas fachadas el nuevo estadio adopta esa singularidad en su grada alta, mientras que su grada de pista se ciñe a la misma en forma de óvalo.

En Sídney el reto era diseñar el estadio Olímpico de mayor aforo (todos sentados) de la historia y una vez terminados los Juegos que fuera posible su reconfiguración consistente en, reducción del aforo, completar la cubierta y adaptación al uso post olímpico, que se establecía fundamentalmente en los siguientes deportes: rugby league (13 jugadores), rugby unión ( 15 jugadores), fútbol australiano, fútbol y criquet. Para conseguirlo se eliminó la pista de atletismo y la grada inferior con sus dos seminiveles se motorizó permitiendo el movimiento para adaptarse a las diferentes formas y dimensiones requeridas por los citados deportes. El sistema está preparado para que el cambio de configuración se pueda realizar de un día para otro si fuera necesario.

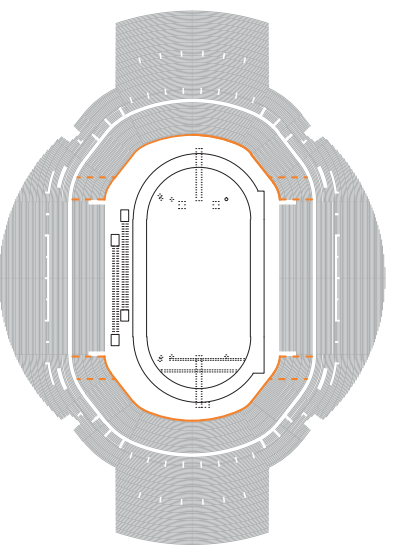

2000. Sidney. Estadio Olímpico, pista de atletismo

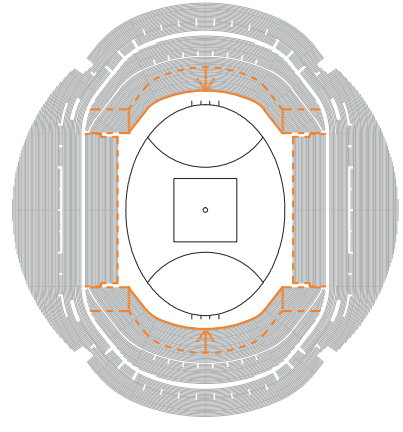

2002. Sidney. Estadio ANZ, fútbol australiano

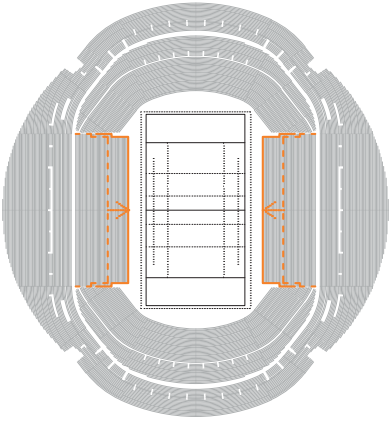

2002. Sidney. Estadio ANZ, rugby y fútbol

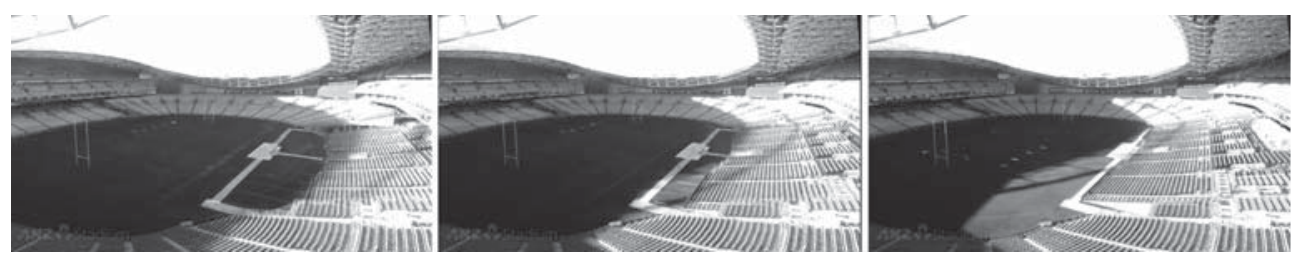

La capacidad en el momento de los Juegos Olímpicos era de 110.000 espectadores. Con la reforma de 2001 se redujo este número a 83.000 personas. El estadio cuenta con tres niveles de tribunas, el primero rodea el $100 \%$ del perímetro del campo con una traza de óvalo anguloso, mientras que el segundo y tercero se divide en dos sectores laterales que concentra a los espectadores en las rectas, siguiendo parcialmente los diagramas de Hadden. Para los Juegos en cada uno de los dos extremos del eje longitudinal se dispuso una grada extra con capacidad de unos 15.000 espectadores, lo que podemos asimilar a lo que hemos denominado como crecimiento irregular.

\section{B.3.2.1.3 Elipsoide}

A este tipo de traza la denominamos elipsoide por diferenciarla de la anterior, aunque su tipo corresponde también con el óvalo, pero para facilitar el entendimiento las hemos separado en dos grupos, en el anterior están encuadrados los óvalos compuestos por dos rectas y dos curvas, mientras que en este grupo se incluyen las figuras formadas por cuatro curvas simétricas respecto a sus ejes perpendiculares, aunque realmente está claro que no es un elipsoide sino que también es un óvalo.

El primer elipsoide, aunque con timidez, es el propuesto en el estadio de Ámsterdam. Su traza se corresponde con cuatro curvas y dos rectas, por lo que podríamos considerarlo un modelo híbrido. 
Por primera vez los criterios de la modernidad están en el trasfondo del diseño de un estadio. Lenguaje moderno, parco en elementos decorativos, adecuado a la función y con ciertos guiños expresionistas. Según afirma Martin Wimmer',

el estadio está considerado como una verdadera pieza maestra de la arquitectura.

La fachada de ladrillo en su composición, la horizontalidad y los elementos decorativos reflejan la influencia que supuso para Jan Wils la obra de Frank Lloyd Wright, pero también de Berlage y de Dudok. Tras la cuidada fachada aparece un estadio completamente funcional. El terreno de juego circundado por la pista de atletismo y en el exterior un velódromo de $500 \mathrm{~m}$. Las gradas se adaptan al ovalo del que conforma del velódromo hasta completar un aforo de 40.000 espectadores. La transición entre tribunas cubiertas en las rectas y curvas en este caso es más "suave", menos discordante que en los estadios previos de París y Amberes, dominando absolutamente la continuidad y dinamismo del graderío.

En los laterales las gradas están cubiertas en una longitud de 60 metros: en el oeste la grada principal, en el este la llamada grada de Marathon con la puerta de acceso para la mítica carrera de gran fondo. Las cubiertas, en fuerte voladizo, están armónicamente integradas en la composición general.

La clara horizontalidad de la composición sólo se ve alterada por el hito vertical de la Torre Marathon. En lo más alto de la misma, a 42 metros de altura, se sitúa el pebetero con la llama olímpica. Es el elemento de carácter más expresionista del conjunto.

La geometría básica de Los Ángeles y Berlín se sustenta en lo que hemos venido a denominar como elipsoide. En Roma el radio de curvatura de las dos curvas que se desarrollan en paralelo a las rectas es tan amplio que puede confundir su traza y parecer un óvalo. Las gradas bajas al llegar a la curva norte se convierten en superficies regladas, como se pone de manifiesto por falta de paralelismo entre sus directrices, la interior y exterior.

En Tokio el estadio construido en 1958 se correspondía con un elipsoide puro, con igual número de filas de gradas en todo su perímetro y una modesta cubierta en la tribuna de meta. La ampliación requerida para los Juegos se veía impedida por la cubierta, lo mismo que había sucedido ya en Helsinki, y la respuesta aquí fue exactamente la misma, un crecimiento irregular partiendo de los dos extremos de la cubierta hasta alcanzar el punto de mayor desarrollo en el eje de la recta del trescientos (la opuesta a la tribuna principal). Es muy interesante la posición en la que se coloca el pebetero del Fuego Olímpico, en la parte más alta del graderío, frente a la tribuna principal en el estreno del eje del anteriormente descrito crecimiento irregular, reforzando la tensión así producida.

La traza del de México 1968 está cargada de fuerte poso que le aporta el cuidadoso estudio y análisis previo realizado por sus arquitectos. En marzo de 1950, una vez designado el equipo que proyectaría el estadio y que estaba formado por Augusto Pérez Palacios, Raúl Salinas Moro y Jorge Bravo Jiménez, Pérez Palacios viaja para visitar algunos estadios, además analiza otros a través de las publicaciones disponibles, especialmente los de; Berlín (1936), proyectado por Werner March; Florencia (1931) de Pier Luigi Nervi, o las propuestas no construidas de Le Corbusier para París (1937) y la de Niemeyer para Maracaná (1941). Pérez Palacios dibujó numerosos croquis analíticos que mostraban su preocupación respecto al funcionamiento, la forma, las isópticas, la iluminación y la configuración de las gradas o de los sistemas estructurales. Le impactaron otro tipo de estadios menos conocidos, como los de las universidades de Yale, Denver, Providence y Cornell, en Estados Unidos, por las soluciones arquitectónicas basadas en el diagrama del estadounidense Gavin Hadden². Que proponía que la forma de los estadios debía responder al acomodamiento natural de los espectadores, analizando cual es el proceso de ocupación en función de las preferencias lógicas de los espectadores. Dicho estudio supone un cambio sustancial en el trazado de los estadios, donde el público, tradicionalmente, se colocaban en igual número de filas concéntricas en torno al óvalo que rodea el campo y las pistas. Después de su análisis comparativo, Pérez Palacios opta por el planteamiento de Hadden, como lo demuestra el croquis inicial que realizó, descrito por él mismo: "...a base de dos grandes valvas desiguales para alojar en una forma natural y espontánea pero eminentemente lógica a los espectadoresl). Este dibujo muestra además una zona de graderías a cubierto bajo un balcón volado II...buscando la yuxtaposición de las gradas en un nivel intermedio entre campo y últimas filas de asientos. Accesos en forma de rampa, eliminando las escaleras, posibilidad de varias rampas y accesos a diferentes niveles... con una disposición de gradas dejando dos espacios, las cabeceras del campo, con menor número de asientos para evitar la sensación de encierroll.

Su traza en planta, contenida dentro de un círculo, está compuesta por un delicado juego de elipses que dibuja de un modo asimétrico el graderío, rompiendo esquemas clásicos y favoreciendo la proximidad de la mayor parte del público al centro de gravedad del espectáculo. Consideramos que es una planta compuesta con gran sensibilidad y finura.

En la traza del de Múnich se siguen los criterios aplicados por primera vez en un estadio Olímpico en

1. WIMMER, Martin. (1976). Olympic Buildings. Ed. Leipzig. Lic 600/34/75. 5938721

2. HADDEN, Gavin (1925). Stadium Design. Ed. American Society of Civil Engineers. Nueva York.
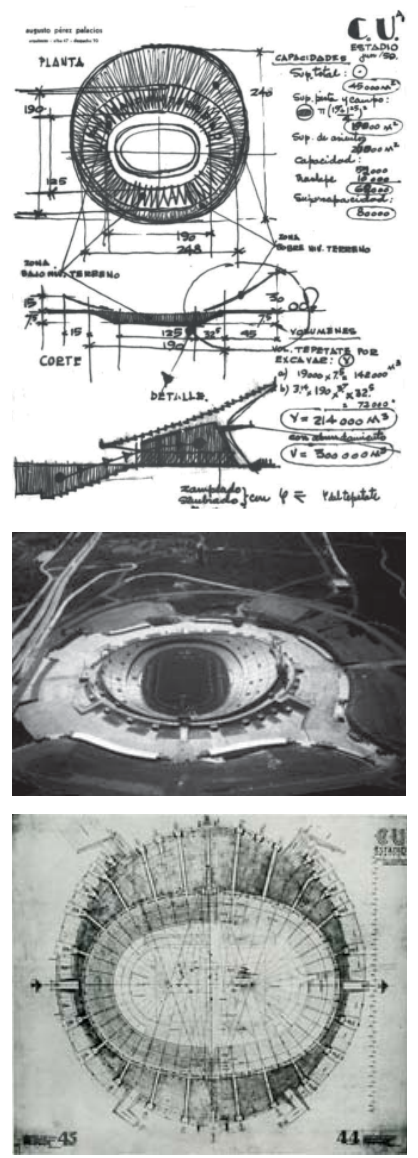

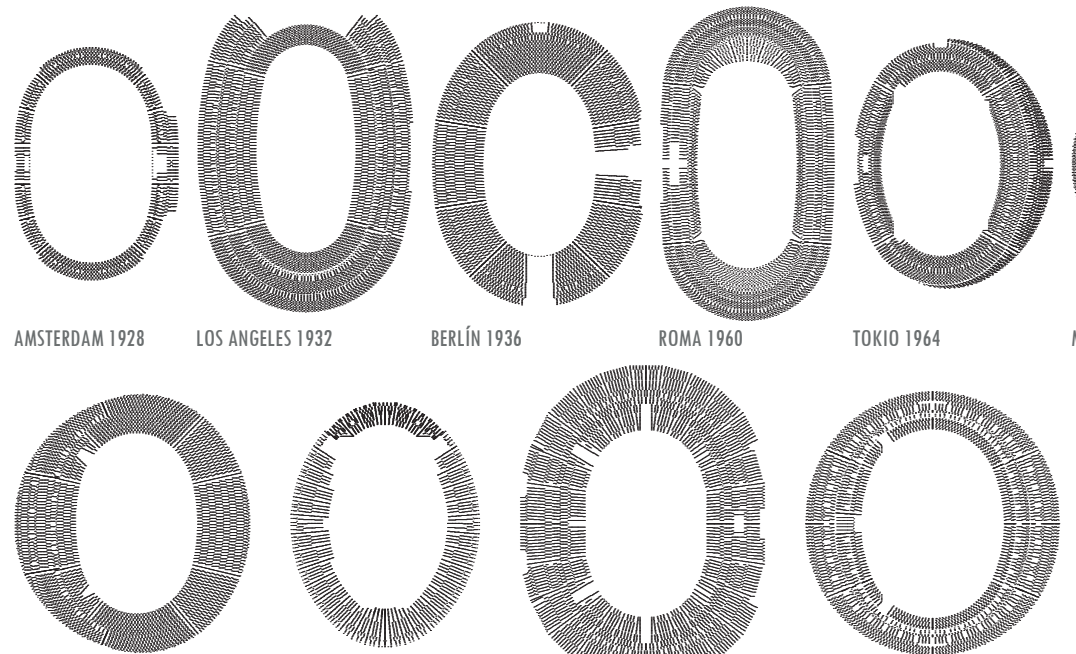

MUNICH 1972

MONTREAL 1976

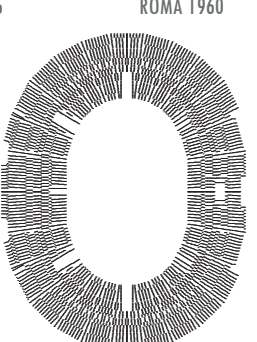

TOKIO 196

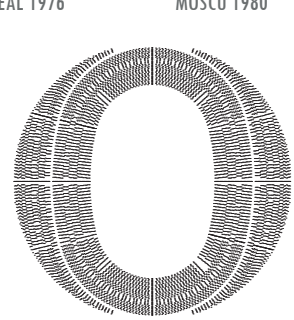

PEKÍN 2008

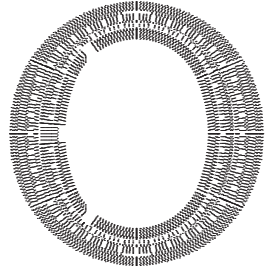

SEUL 1988

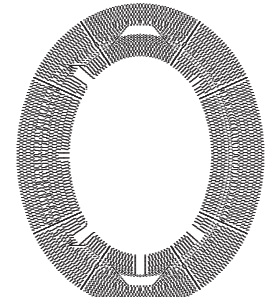

LONDRES 2012
MÉXICO 1968
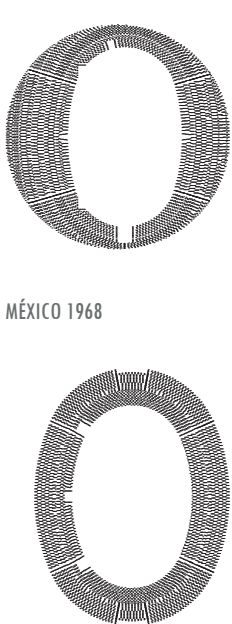

ATENAS 2004 
Montreal es el primer estadio que se plantea un uso post Olímpico diferente al necesario para los Juegos, así su arquitecto Roger Taillibert, disocia el graderío en diferentes estratos superpuestos, asignando al inferior la capacidad de cambiar su configuración. En el catálogo se adjuntan planos originales del arquitecto con los estudios básicos de diferentes composiciones.

Moscú y Atenas 2004 proponen un elipsoide regular con poca capacidad para emocionar y en Seúl se aplican las teorías de Hadden sobre tres anillos de gradas superpuestos en los que se va variando su traza reguladora. El de Pekín, con algunas características semejantes al de Seúl, destaca por la perfección formal de su planta y por la capacidad de construir un magnifico espacio interior, en el que el graderío aunque segmentado en tres niveles, tiene la capacidad de percibirse como una unidad, proporcionando una gran potencia e intensidad al espacio.

El estadio está constituido por un "cuencoll de hormigón armado, en cuya pared interna se sitúan las gradas y desde cuyo borde superior, hacia el exterior, se despliega un trenzado de elementos longitudinales de acero que sirve de fachada y de estructura para la cubierta, siendo independientes de la estructura del graderío.

El tamaño de la planta elíptica viene dictado por la necesidad de alojar a 100.000 espectadores alrededor de la pista de atletismo y el campo de juego. De la misma forma, la diferencia de altura de las gradas situadas en los ejes principales de la elipse, permite mayor proximidad del público al espectáculo. En el proceso del proyecto para simplificar su diseño y reducir la inversión se redujo la capacidad a 91.000 espectadores y al término de los Juegos se redujo aún más al retirarse, de forma reversible, 11.000 butacas, por lo que la cifra actual de espectadores es de 80.000 . El perímetro exterior se corresponde prácticamente con un círculo.

En Londres 2012 su envolvente también tiende al círculo. Siempre que sucedía esto anteriormente, México, Seúl, Pekín, la configuración del graderío se correspondía con la aplicación de las teorías de Hadden, ciñéndose su directriz interior a la pista, pero extrañamente en Londres no sucede esto. Aquí simplemente la grada se separa desmesuradamente de la pista en las dos rectas, en contra de uno de los principios básicos, la cercanía del espectador al espectáculo.

Normalmente, cuando se trata de la construcción de estadios olímpicos, la mayoría de los arquitectos y, por supuesto de las naciones anfitrionas, prefieren hacer gala de sus capacidades y levantar grandes estructuras. Sin embargo, la lógica dice que reflexionar sobre lo que se desea obtener cuando concluya un proceso, ayuda a que los primeros pasos sean más sólidos. Así comenzó Londres su proyecto para organizar los Juegos Olímpicos 2012: decidiendo primero cómo quedará la ciudad cuando todos los atletas hayan regresado a sus casas. Tratando de evitar un legado envenenado. El trabajo no fue fácil. La pérdida de patrocinadores del proyecto a consecuencia de la crisis económica o la falta de tiempo fueron algunos de los principales contratiempos a los que se tuvieron que enfrentar los responsables de la construcción.

Londres se dispuso a realizar unos juegos olímpicos más verdes, ecológicos y sostenibles. El grupo de arquitectos, ingenieros, constructores y urbanistas encargados del proyecto, se dieron a la tarea de diseñar un estadio que cumpliera con la promesa ambientalista hecha por Londres; fue así como, después de varios análisis y con la premisa: "No cambiemos el deporte, cambiemos el edificio», el equipo definió la idea de crear un estadio desmontable, un recinto deportivo flexible, capaz de cambiar y adaptarse a las verdaderas necesidades de la ciudad y sus espectáculos. La propuesta se basaba en construir una estructura que durante los juegos olímpicos pudiera albergar 80.000 espectadores; pero, que pasados los mismos, pudiera desmontarse y convertirse en un escenario para tan sólo 25.000, un volumen de espectadores mucho más real para los eventos regulares que se puedan realizar en el futuro.

Para llevar a cabo la obra, se diseñó un estadio con dos estructuras, una interna y permanente, conformada por un tazón de hormigón y 25.000 asientos y otra desmontable o temporal con 55.000 localidades, que se construyó utilizando 112 piezas prefabricadas de acero, cada una de 90Tm. que se encajaron unas con otras como si de un mecano se tratase, hasta formar el elemento completo. La estructura temporal, se preveía que al finalizar los juegos se desmontaría y se enviaría a Río de Janeiro para su utilización en los Juegos Olímpicos del 2016.

Aunque está preparado para poder albergar un total de 80.000 espectadores durante el desarrollo de los Juegos, el estadio permite que, una vez estos hayan finalizado, su capacidad se reduzca más de dos tercios; lo que se consigue gracias a un diseño claramente dividido en tres partes:

La primera, constituida por los dos niveles inferiores, es permanente. Está fabricada en hormigón armado bajo en dióxido de carbono ( $40 \%$ menos carbono que el regular) procedente del reciclaje de residuos industriales, con un aforo de 25.000 asistentes.

La segunda, el nivel superior, es una construcción de carácter efímero. Se realizó con una estructura metálica (compuesta por 112 cerchas de acero, las cuales se fabricaron con tuberías de gas obtenidas de excedentes industriales), que sostiene una losa escalonada de hormigón ligero en el que se distribuyen 55.000 asientos desmontables.
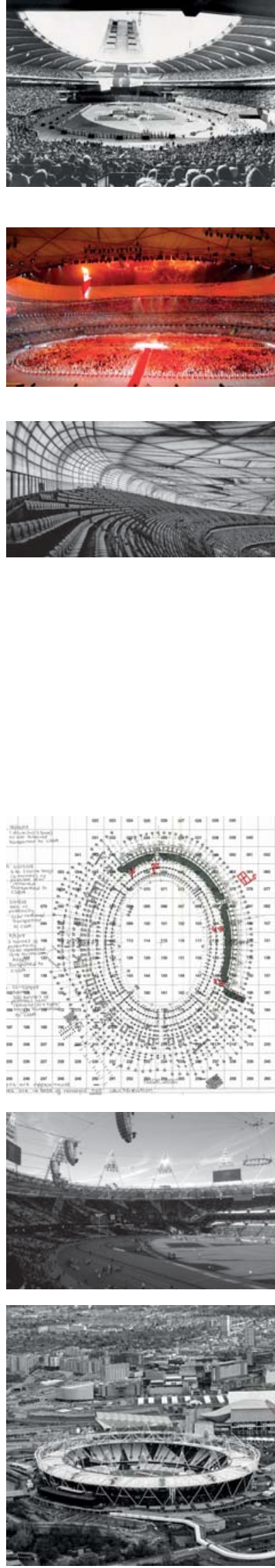


\section{B.3.2.1.4 Extraños}

En este apartado se incluyen, por una parte, los dos de difícil catalogación, Melbourne y Atlanta, .y en los dos casos la razón es semejante. El del hemisferio austral es un estadio de criquet, reconvertido provisionalmente en Olímpico y el americano, uno previsto para baseball, que se adaptó para los Juegos y posteriormente fue demolida la ampliación para devolver su uso al deporte original, de ahí la explicación a la forma casi circular del primero y la incalificable del segundo. En Atlanta necesitaban un nuevo estadio de béisbol puesto que el Atlanta-Fulton County Stadium se había quedado obsoleto. En uno de sus aparcamientos se decidió construir para los Juegos el Centennial Olympic Stadium, con pista de atletismo. Una vez finalizados los Juegos se demuele parcialmente y se

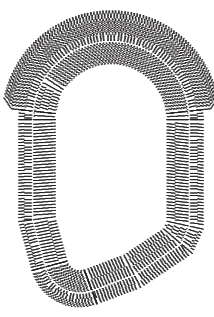

ATLANTA 1996

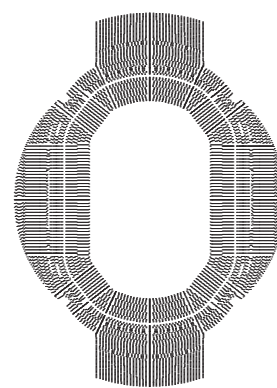

SYDNEY 2000 
completa un estadio apto para el béisbol con capacidad para 45.000 espectadores. Concluida la remodelación y puesto en uso, se procedió a la demolición del antiguo estadio. El aforo para los Juegos fue de 85000 espectadores. El Melbourne Cricket Ground ha sido el principal escenario deportivo de la ciudad durante muchos años. Se usa para la práctica del cricket en verano y para el futbol australiano en invierno.

Las gradas habían sido construidas en varias secciones durante muchos años. Para los Juegos se eliminaron las gradas más antiguas, reemplazándolas por otras de hormigón, de tres niveles, con capacidad para 40.000 espectadores, lo que elevó el total del aforo a 104.000. Por lo cual su traza quedó configurada con la adición de varias actuaciones diferenciadas en el tiempo y casi independientes en su concepción.

Por otra parte, también se puede catalogar como de extraño el ya analizado de Sydney, del cual podríamos decir que es un óvalo extraño y anguloso, en el que se ha aplicado la teoría de Gavin Hadden y de crecimiento irregular y todo esto por decisiones de proyecto para conseguir unos objetivos complejos y ambiciosos, mayor aforo en los Juegos que en su posterior uso, utilización para el atletismo en la cita Olímpica y para los deportes típicamente australianos después, pudiendo cambiar de configuración con agilidad, como ya hemos visto en la pagina 76.

El de St. Louis también lo incluimos en este apartado, sí es que se puede catalogar como estadio.

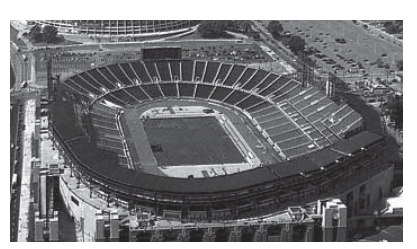

\section{B.3.2.2 Conclusiones respecto a la traza}

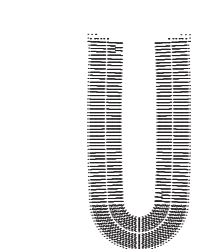

ATENAS 1896

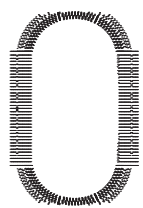

PARÍS 1924

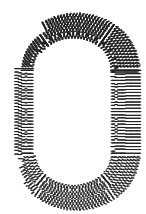

HELSINKI 1952

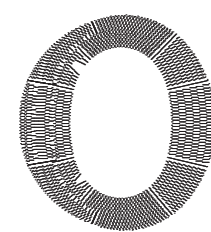

MUNICH 1972

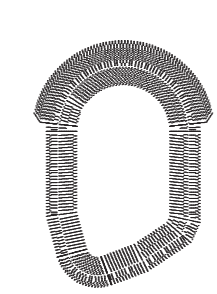

ATLANTA 1996
ST LOUIS 1904

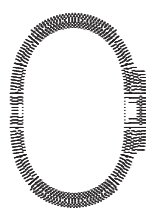

AMSTERDAM 1928

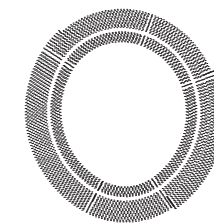

MELBOURNE 1956

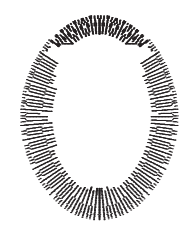

MONTREAL 1976

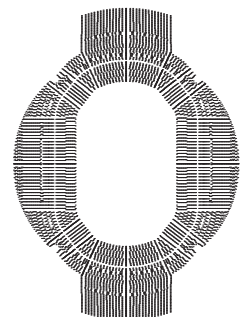

SYDNEY 2000

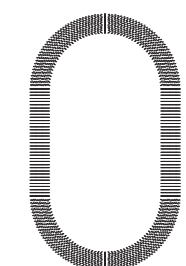

LONDRES 1908

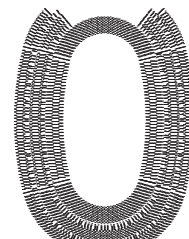

LOS ANGELES 1932

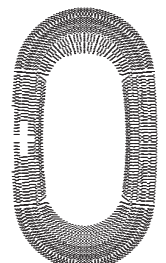

ROMA 1960

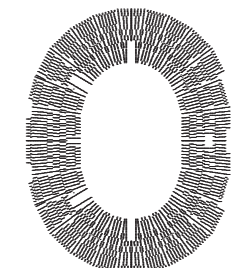

MOSCÚ 1980

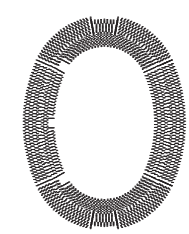

ATENAS 2004
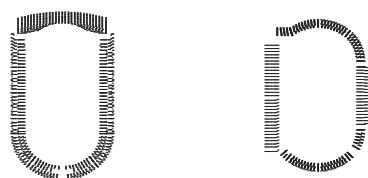

ESTOCOLMO 1912

AMBERES 1920

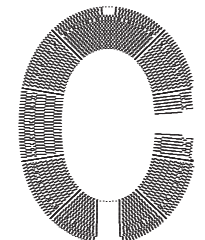

BERLÍN 1936

LONDRES 1948

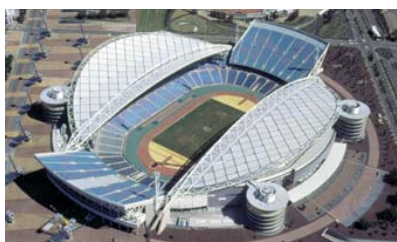

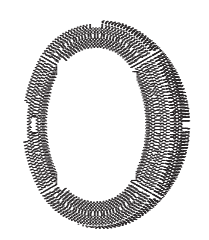

TOKIO 1964

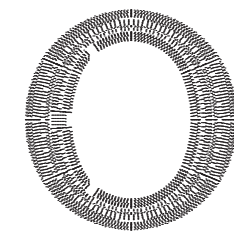

SEUL 1988

BARCELONA 1992

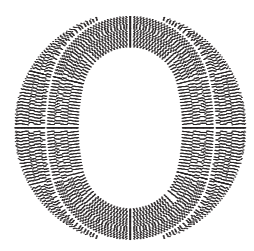

PEKÍN 2008
MÉXICO 1968
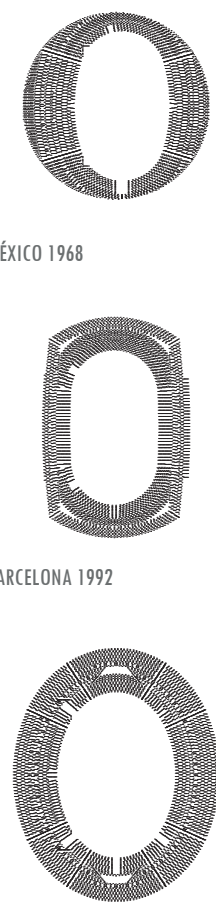

LONDRES 2012 

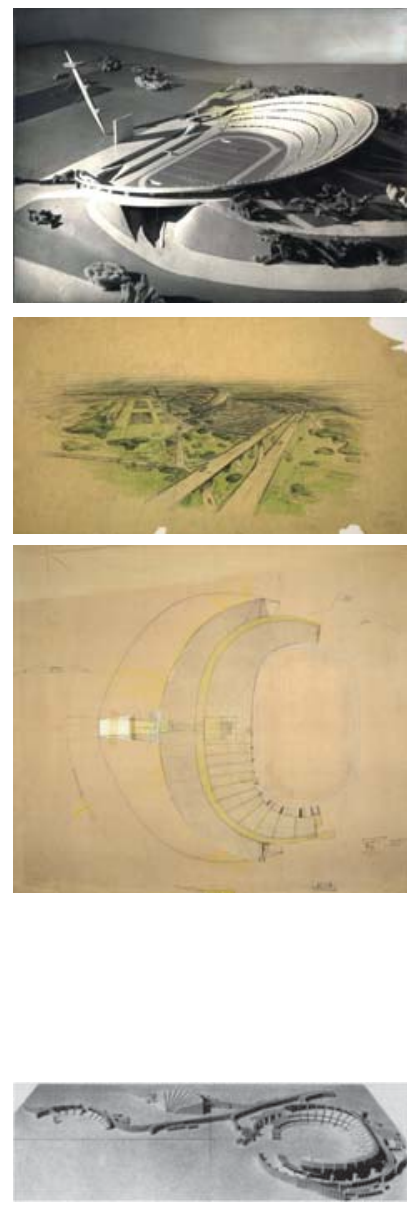

Maqueta y perspectiva estadio 100.000 espectadores. Croquis estadio Chandigarh. Fundación Le Corbusier.

Estadio Jeddah. Jorn Utzon
Según el cuadro adjunto podemos concluir que la tendencia que se confirma es la que proponen los estadios de traza tipo elipsoide y entre ellos los que aplican los diagramas de Hadden y nos distancia de la traza tipo herradura. Tal vez en un futuro podamos volver a encontrar algún guiño melancólico a este histórico modelo, pero en cualquier caso parece que el compromiso entre la proximidad del publico al espectáculo y la necesidad de rodear al mismo con la intensidad emocional que suponen los espectadores es irreversible y ha ido alejando progresivamente a los estadios de soluciones en las que se producen discontinuidades en el graderío.

Podemos referirnos a interesantísimos proyectos de grandes arquitectos con propuestas asimétricas, que concentran los espectadores en uno de los lados del estadio o abren grandes discontinuidades en el mismo, como a la propuesta para un gran estadio Nacional en París de Le Corbusier de 1936, en la que proponía un gran estadio multiusos para 100.000 espectadores, traspasando los límites del deporte:

en respuesta a las nuevas funciones surgidas de la evolución social. Un "Centro" que ofrece a los organizadores culturales unas grandiosas posibilidades de creación hasta ahora desconocidas: discursos, teatro, deporte, música, danza, puesta en escena, la participación de una masa de 100 mil, agrupados y formando una unidad, por la arquitectura.

Dando solución a diferentes aspectos:

a) anfiteatro con condiciones semejantes de todos los espectadores y equipado con las más diversas instalaciones

b) circulación interna, ordenada y capaz de garantizar los movimientos de 100.000 espectadores

c) circulación exterior, perfectamente organizada y separada (metro, autobuses, coches y peatones)

d) conexión de flujo entre los fondos y el anfiteatro, eficaz y flexible

e) propuesta de cubierta para el estadio (una solución flexible, atirantada)

f) diseño basado en el movimiento de tierras, excavación por debajo del nivel natural; terraplén arriba y parte superior de obra en hormigón armado

g) un aspecto del paisaje monumental, pero no árido.

El "Centro" debe tener el carácter de nacional. Ahora es muchas circunstancias en las que un grupo de hombres debe ser capaz de comunicarse en la forma unánime que puede provocar la emoción producida por el arte. Música, letras, teatro, mimo, danza, etc.

Este mismo esquema el arquitecto francosuizo lo repetirá en el estadio de Chandigarh $1950 / 65$ y el estadio Firminy-Vert proyectado en 1954 y construido después de su muerte en 1966/68.

O el maravilloso estadio propuesto por Jorn Utzon para Jeddah, en Arabia en 1967, en el abre el graderío en una de sus rectas y lo justifica por razones climáticas y de confort de los espectadores y participantes.

Pero de las reflexiones de Oscar Niemeyer, en el libro titulado Mi arquitectura, del año 2000, podemos sacar conclusiones y aplicarlas a la forma de los estadios, en la citada publicación repasando sus proyectos llega al de Maracaná,

Me gustaría, por ejemplo, hablar del estadio Nacional de Maracanà (Río de Janeiro), una propuesta que me entusiasmó entonces, pero que el tiempo hizo que la considerara en una manera diferente.

Por entonces, la idea en boga con respecto a los estadios de fútbol era que el área menos soleada se debía agrupar a la mayor parte de los espectadores. Por contrario, en la grada opuesta (la soleada del estadio) se debía poner apenas un pequeño porcentaje de los espectadores. $Y$ éste fue el camino que seguimos, un proyecto que nos llenó de ilusión, con su enorme arco de 300 metros del que colgaba una gran cubierta ligera. $Y$ todo el complejo deprimido siete metros, para evitar agobiar el espacio circundante.

La comisión preseleccionó dos proyectos, entre los que estaba el nuestro, recomendando que nada se debía proyectar por debajo nivel natural de la tierra. Pero, aconsejados por el ingeniero Baumgarten, el más distinguido en ese momento, pedimos un estudio geotécnico y, como encontramos el argyle compacto en la cota - 1 1, decidimos no hacer caso a la comisión. Bajamos cuatro metros y fuimos eliminados, siempre pensamos que nuestro proyecto era el mejor.

El tiempo pasa, y como asiduos espectadores de fútbol, finalmente, nos dimos cuenta de 
nuestra equivocación. Lo importante era, por el contrario, mantener la misma densidad de público a lo largo de todo el estadio, y así, la atmósfera festiva se extiende y multiplica por todo el estadio.

Recuerdo una conferencia en el Instituto de Arquitectos de Brasil y como se sorprendió uno de los autores del proyecto ganador cuando dije que su proyecto era mejor que el nuestro.

¡Que ironía! Muchos años más tarde, una tarde en la residencia de Petropolis de la embajadora Maria Marttins, el amigo de su marido, el depuesto presidente Gentelio Vargas, al que no conocía personalmente, se acercó y me dijo "Dr. Niemeyer, sí hubiera estado en el cargo, su proyecto para el Estadio Nacional se habría construido." Reí, sin decir una palabra, pero queriendo decir: el otro era mejor.

Niemeyer con el conocimiento profundo, como aficionado al deporte, del espacio que se produce en los estadios, se dio cuenta que lo importante era mantener la misma densidad de público a lo largo de todo el estadio, y así, la atmósfera festiva se extiende y multiplica por todo el estadio. Y es que el público es parte integrante y fundamental del espectáculo y se requiere que forme una masa compacta, continua y homogénea alrededor de la competición. En esta dirección es hacía donde ha ido evolucionando en cuanto a su forma el estadio moderno. Para ello se necesita una geometría clara, de transiciones suaves, regular y continua. Buscando la disposición formal que permita la mayor empatía entre los espectadores y los competidores.

Si nos fijamos en la imagen preparada por el estudio de Norman Foster para su proyecto de ampliación de Nou Camp en Barcelona, en ella se confunden el colorido de la cubierta con el de las gradas, dando la sensación de que estas se han doblado hacia dentro, abrazando el espacio casi por completo. 


\section{B.3.3 Significación}
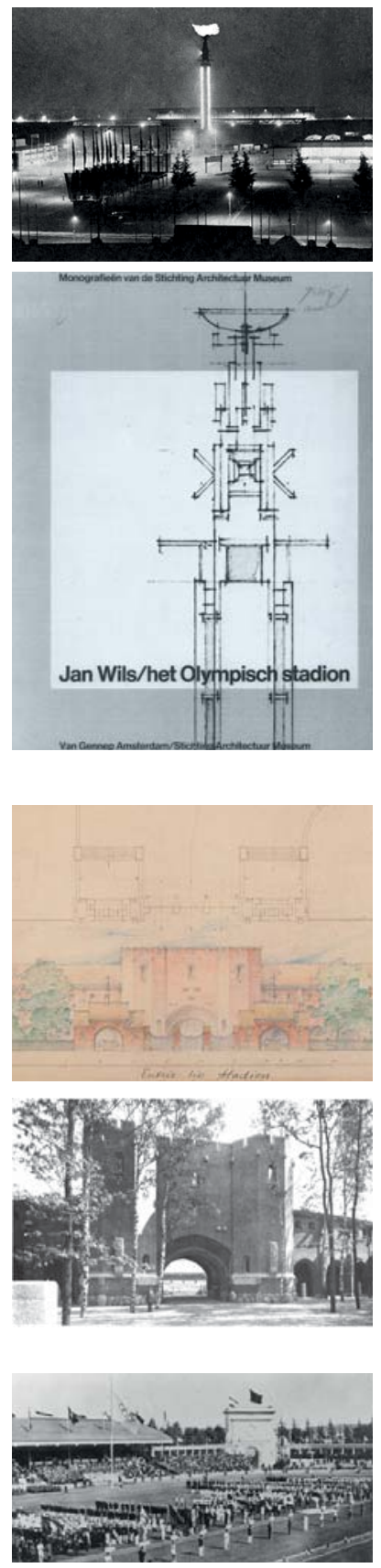

En Amberes 1920, se incorporan símbolos olímpicos que necesitan su acomodo en el estadio. Por primera vez se realiza el izado de la bandera Olímpica. Se sitúa un gran mástil en el eje de la tribuna principal, dentro de la pista de carreras, próximo a la recta de contra meta. También como elemento novedoso se construye un arco de triunfo como entrada ceremonial de atletas y de la carrera de Maratón; es un elemento masivo y exento con una abertura central en forma de arco, o quizás más bien de bóveda,

1. Pero en Londres 1908 para que la carrera pudiera comenzar en el Castillo Windsor (para que la Reina pudiera observa la salida) y terminar en el Estadio Olímpico, los organizadores se vieron obligados a extender la distancia hasta los extraños 42.195 metros (26,2 millas). En 1921 la Asociación Internacional de Federaciones Atléticas fijó en forma definitiva esta distancia para todas las carreras de Maratón.

2. Revista Arkitektur. Número 7. 1912 
dado el espesor del elemento. Recordemos que en el estadio de Olimpia el acceso de atletas se producía desde el Altis a través también de una bóveda por debajo del talud del graderío.

Además, en Amberes, se hace por primera vez el juramento Olímpico y la suelta de palomas con mensajes de paz; el final de la Primera Gran Guerra era muy reciente. En los siguientes Juegos en París se incorporan el logo Olímpico, con los cinco aros y el eslogan "Citius, Altius, Fortius".

En Los Ángeles, el existente peristilo con un arco central de mayor dimensión acompañado por siete vanos menores a cada lado, se remata, para los Juegos de 1932, con un elemento vertical de hormigón de 107 pies de altura, aproximadamente 32,61 metros, coronado por un pebetero de bronce, en el cual ardería de una forma estable y duradera el fuego olímpico. Para los Juegos de 1984 se añadió encima del vano central los aros olímpicos. El graderío, en la zona de la arcada, es un tercio menor que en el resto del estadio, proponiendo un eje longitudinal significante en referencia al estadio clásico de Atenas, en forma de herradura. En la curva contraria se situaba el mástil con la bandera olímpica.

Es la primera vez que se aúna en la composición arco y fuego y se contrapone el mástil con la bandera Olímpica.

En Berlín la relación entre los diferentes elementos simbólicos es mucho más elaborada. En un mismo eje se disponen las dos torres de Maratón, el túnel, la puerta y la escalinata, con el pebetero del fuego Olímpico como foco central de la composición. Siempre el fuego se recorta sobre el horizonte; en el caso de Berlín las gradas se abren y separan para permitir encuadrar la perspectiva que se remata a través del Campo de Mayo.

En Helsinki, como ya había sucedido en Ámsterdam, el fuego Olímpico corona la esbelta torre. Aunque su lenguaje nada monumental no parece ser la mejor base. Un pebetero auxiliar situó en la propia pista procediendose a su encendido con solemnidad pero gran sencillez. La torre es un elemento fundamental de la composición general del estadio.

En Atenas 2004 se volvió sobre la idea de aunar torre y fuego como elementos simbólicos. El pebetero, que es una aguja situada en el eje longitudinal del estadio en la proximidad de la confluencia de las dos semicubiertas, inicialmente se planteo con una altura descomunal de 110 metros, aunque finalmente se realizó con una dimensión más modesta.

En México y Tokio, en consonancia con los criterios de los proyectos de extender el graderío delante de las rectas, aunque en la capital japonesa solo de una de ellas, y englobar su traza en planta dentro de un círculo, el pebetero se sitúa en el extremo de su eje transversal, el de la línea de crecimiento de la grada, en su límite superior. En México la puesta en escena de su encendido con la atleta ascendiendo la larga escalinata elevada por encima del público hasta la parte más alta de la tribuna refuerza la intención del proyecto, manifestando la clara línea de tensión diagramática.

El bello y poderoso pebetero de Tokio fue realizado con las técnicas de la calderería tradicional japonesa de la ciudad de Kawaguchi.

La tendencia de los últimos años es que los elementos simbólicos dejen de pertenecer al mundo de la arquitectura para pasar a ser parte del espectáculo, en el que la tecnología y capacidad de sorprender, más propia de la prestidigitación, lo aleja del necesario reposo que requiere la arquitectura.
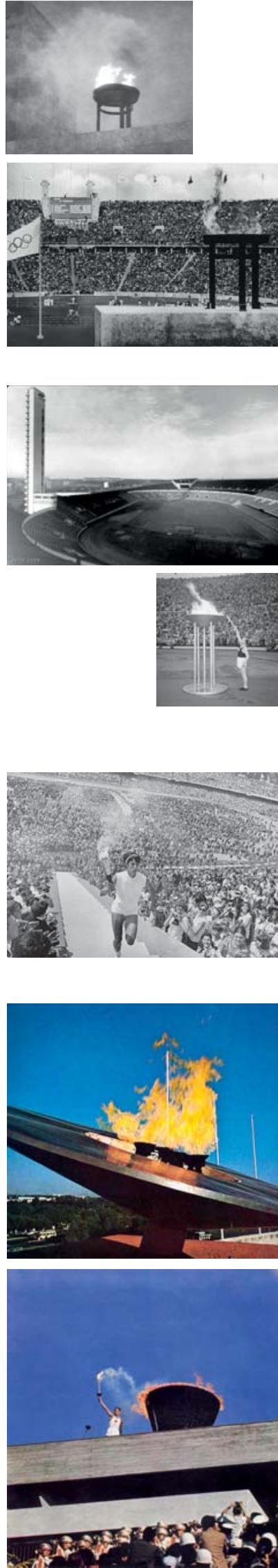

Berlín. Helsinki. Helsinki.México. México. Tokio 


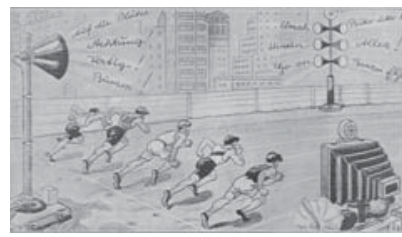

El 14 de julio de 1790, el pueblo de Paris celebró el primer aniversario de la Revolución. Para esta 'Festividad de la Confederación' construyeron colectivamente un enorme estadio en los Campos de Marte que es considerado el primer estadio permanente de la edad moderna. Fue inaugurado con una gran procesión-desfile, ante más de cuatrocientos mil espectadores. El acto continuo con ceremonias políticas y religiosas y luego le siguió algunos juegos competitivos. A partir de esa fecha se repitieron con una periodicidad anual. Progresivamente se convirtieron cada vez en menos políticos y más dirigidos al entretenimiento y al deporte. A partir de 1795 se formó una comisión que analizase las deficiencias funcionales de la instalación. Se observó, que a causa de la gran dimensión de la construcción, que los espectadores más alejados no podían escuchar los discursos, la música, o los resultados de las competiciones. Para solventar estas disfunciones se hubieran requerido medios tecnológicos inimaginables en aquella época.

En 1904 en St. Louis, para facilitar el seguimiento de las competiciones por parte de los espectadores se utilizó por primera vez en unos Juegos la megafonía que anunciaba los resultados de las pruebas. Además de marcadores en todos los concursos para que los espectadores pudieran seguir la marcha de la competición. También se marcaron, por vez primera, para los lanzamientos círculos concéntricos con referencias a las distancias.

En Los Ángeles 1932, en el lugar de máxima visibilidad y significación, encima del arco central del peristilo, se instaló un panel de resultados gigante de 13,40 × 6,70 metros, que fue manejado por marineros de la armada estadounidense. Un potente sistema eléctrico de megafonía permitía anunciar los resultados mediante 23 enormes altavoces que distribuían de una manera equilibrada el sonido a todo el estadio.

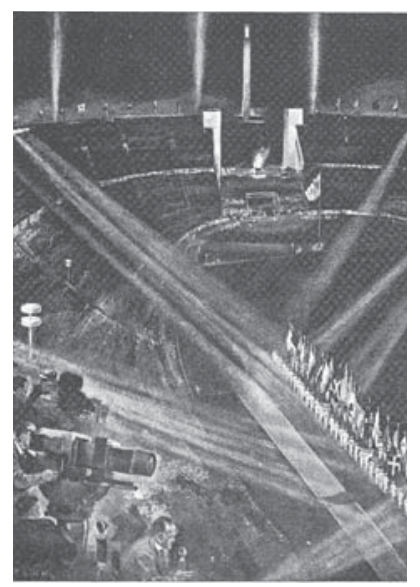

Pero el salto cuantitativo se produce cuando lo que está sucediendo dentro del estadio se puede seguir simultáneamente fuera de él, no importa la distancia a la que puedan estar los «nuevos espectadores». Los juegos de Berlín fueron el primer acontecimiento televisivo a gran escala; emitido en 27 salas de televisión distribuidas por la ciudad donde la gente podía seguir las competiciones.

Una viñeta cómica de la época auguraba un futuro en el que todos los espectadores serían televidentes y los estadios carecerían de público y su papel como animadores quedaría sustituido por la megafonía. Un especie de ironía de mundo ficticio sustituyendo al mundo considerado hasta el momento como normal.

La imagen de una gran cámara de televisión en el estadio de Berlín donde unos potentes rayos de luz focalizan la acción y el graderío queda convertido en una masa negra, densa, continua y silenciosa, solo se destaca la arquitectura del estadio, su pebetero, su apertura al Campo de Mayo, la Torre de la Campana por un lado y por otro la propia cámara y el locutor. Con ésta imagen Henning Eichberg' ilustra su artículo Stadium, Pyramid, Labyrinth: Eye and Body on the Move publicado en The Stadium and the City, editado por John Bale y Olof Moen, en 1995

El libro Olympia, de donde hemos traído la imagen, asimilaba subliminalmente la cámara de la televisión -que por primera vez en la historia mandaba imágenes en directo- con "con el cañón de una inmensa artillería"

La cámara, aquí, se convierte en una poderosa arma que permite establecer lo que Foucault ${ }^{2}$, en su conferencia "Espacios otros; utopías y heterotopías", señala como la diferencia entre los emplazamientos sin lugar real, pero que mantienen una relación real con el espacio real de la sociedad a través de la analogía, y aquellos que tienen una existencia real, pero que

son una especie de contraemplazamientos, de utopías efectivamente realizadas en las

1. Del Institute for Research on Sport, Body and Culture, Gerlev Idraetshojskole, Slagelse, Dinamarca

2. M. Foucault, "Espacios otros", Carrer de la ciutat, $\mathrm{n}^{\circ} 1$, "Utopias y heterotopias", enero 1978 
que los emplazamientos reales que se pueden encontrar en el interior de la cultura están a un mismo tiempo representados, contestados e invertidos.

En la ceremonia inaugural de los Juegos de Pekín la imagen retransmitida a todo el mundo, que fue seguida por más de 900 millones de espectadores, en un momento dado no correspondía exactamente con la realidad de lo que estaba sucediendo en el estadio. Sucedió que mediante tratamiento digital de las imágenes en tiempo real se reforzó y multiplico los efectos de los fuegos de artificio.

"Crean otro espacio; otro espacio real, tan perfecto, tan meticuloso, tan bien dispuesto como desordenado está el nuestro". Foucault

La entrada de la televisión en los estadios se produce de manera paulatina.

En 1960, en Roma, se empleó por primera vez un sistema de grabación magnética de señales de televisión, cuya ventaja principal frente al kinetoscopio empleado hasta entonces (dispositivo que captaba con una cámara cinematográfica las escenas y las presentaba en un monitor de televisión) era, además de la calidad, que las imágenes se podían grabar y reproducir, dando la posibilidad al emisor, pero también al receptor, de revivir las experiencias una y otra vez.

Fueron además los primeros Juegos emitidos en directo por las televisiones de Europa y, gracias al empleo del magnetoscopio, los primeros con retransmisiones internacionales. En total, 18 países europeos recibieron las señales en directo a través de Eurovisión' mientras que para los otros continentes, las retransmisiones se realizaban al día siguiente, en versión diferida, cuando las cintas magnéticas grabadas con los programas de los juegos llegaban por avión a Estados Unidos, Canadá y Japón.

El avance de la nueva tecnología era inexorable. En la siguiente edición, cuatro años después, en Tokio, la retransmisión ya fue en color y en directo vía satélite para América del Norte y Europa. En México fue la primera vez que se utilizó la cámara lenta basada en técnicas de disco magnético.

En los Juegos de Montreal, por primera vez, se retransmitió alcanzado a todos los continentes mediante la utilización de un sistema integrado de satélites (Intelsat).

A partir de los Juegos de Atenas, de 2004, el cronometraje oficial se encarga de toda la información que se emita dentro de los estadios, de las sobreimpresiones de TV y de la transmisión de resultados al sistema de información a comentaristas (CIS).

Los Juegos Olímpicos de Londres 2012 son los primeros en retransmitir imágenes de televisión en vivo en formato de visión estereoscópica, gracias a 33 cámaras 3D que graban más de 230 horas de cobertura en este sistema.

En cuanto a la seguridad informática: el "laboratorio tecnológico" Atos, equipado con cientos de ordenadores, realizó 200.000 horas de pruebas desde comienzos de 2011 para tratar de prevenir cualquier incidente informático que pudiera perturbar el desarrollo de los Juegos. Además, durante el evento, un "centro de control" con 9.500 ordenadores y 900 servidores vigilaba ininterrumpidamente el desarrollo de las operaciones para garantizar que el sistema informático pudiera transmitir sin incidentes los datos. Previniendo cualquier acto delictivo o un problema técnico.

Para la retransmisión televisiva en súper Hi-Vision, más de seis kilómetros de cables de fibra óptica fueron necesarios para conectar el Parque Olímpico con el centro televisivo principal de la BBC, para retransmitir los Juegos Olímpicos con una calidad y definición sin precedentes en la historia del certamen. Se obtienen imágenes de definición ultra-avanzada (súper $\mathrm{Hi}$-Vision), con una resolución de $7680 \times 4320$ píxeles (una calidad de imagen 16 veces mayor que el HD.

Para una correcta retransmisión por internet de los Juegos Olímpicos, que permita imágenes en alta definición y versiones adaptadas para todo tipo de receptores (PCs, tablets, móviles...) se desarrolló una nueva tecnología para video llamada "chunked streaming" (video online en fragmentos). Además de este tipo de cobertura, la organización promovió una información constante de los juegos mediante cuentas oficiales en algunas de las redes sociales y sitios más relevantes de internet.

Otro avance tecnológico son las cámaras robóticas. Se colocaron en algunos puntos estrategicos del estadio (focos, vigas, andamios...) cámaras robóticas controladas remotamente y capaces de girar 360 grados, que proporcionan imágenes de lugares inaccesibles para los fotógrafos humanos.

Lo cierto es que con la retransmisión en tiempo real de las competiciones la función del estadio cambia sustancialmente, de ser un lugar cerrado, opaco para el exterior y en el que solo participan los presentes, auténticos protagonistas de su ritual, pasa a convertirse en un gran plató de televisión y donde los espectadores presenciales pasan formar parte de espectáculo televisivo como fondo necesario y que adoptan la función de representar las emociones de los nuevos y mayoritarios espectadores, que permanecen silenciosos y anónimos.

Ya no es solo importante como se percibe el espacio desde sus tribunas y como la arquitectura potencia la comunión entre deportistas y espectadores, ahora es igual o más importante aún como es captado por las cámaras de televisión.

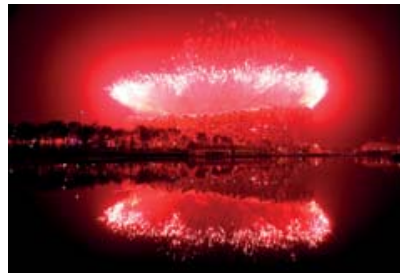


BIBLIOGRAFÍA. Búsqueda del modelo. Estableciomiento del "tipo"

CANETTI; Elias. (1960). Masa y poder. Ed. Alianza Editorial, 2005. ISBN 8420637513

COOK, Peter. (1972). Archigram. Princenton Architectural Press. 1999. ISBN 1-56898-194-5

DYCKHOFF, Tom; BARRETT, Claire (2012). The architecture of London 2012. Vision. Design. Legacy. Ed. An official London 2012 publication. ISBN 978-1 1 19-99386-5

HADDEN, Gavin. (1925). Stadium Design. Ed. American Society of Civil Engineers. Nueva York

HERNÁNDEZ DE LEÓN, Juan Miguel. El espacio de la excepción. Sobre el carácter de la arquitectura deportiva. AV: Monografía 1992. N³3, pág. 4/7

INGLIS, Simon. (2005) Engineering Archie. Archibald Leitch football ground designer. Ed. English Heritage. ISBN: 1850749183

MONEO VALLES, Rafael. Sobre el concepto de Tipo en Arquitectura. Dpto. Publicaciones de Alumnos, ETSAM. 1982. SHEARD, Rod. (2001). Sports architecture. Spon press. ISBN 0-419-21220-5

SLOTERDIJK, Peter (2004). Esferas III. Espumas. Esferorogía plural. Biblioteca de Ensayo. Ediciones Siruela. ISBN 978-84-7844-951-4. Segunda edición febrero 2009. Titulo original: Sphären III (Plurale Sphärologie). Schäume. Suhrkamp Verlag, Frankfurt am Main, 2004. Traducción Isidoro Reguera. B. ACP

VERSPOHL, Franz-Joaquim. (1976). Stadionbauten von der Antike bis zur Gegenwart. Regie und Selbsterfahrung der Massen. Ed. Anabas. ISBN 3-87038-043-8.

VITRUBIO POLLIÓN, Marco (s I d.C.) Los Diez Libros de Arquitectura. Título original: De Architectura. Traducción; Oliver Domingo, José Luis. Ed. Alianza Forma 1995. Madrid. ISBN: 84-206-7133-9

WIMMER, Martin. (1976). Olympic Buildings. Ed. Leipzig. Lic 600/34/75. 5938721

ZAMBRANO, María. Islas. Ed. Verbum, 2013. ISBN 9788479624170

Artículos

FOUCAULT, Michel. Espacios otros. Carrer de la ciutat, $\mathrm{n}^{\circ} 1$, "Utopias y heterotopias", enero 1978

ÖSRBERG, Ragnar; GRUT, Torben. Stockholms Stadion. Arkitektur, 1912, n 7

VILLASEÑOR, Miguel Ángel, Hubo un tiempo en el que no todas las pistas medían 400 metros. Atletismo Español. Julio 2014

WINKEL, Camiel van. Baile, disciplina, densidad, y muerte. La multitud en los estadios. The Stadium. The Architecture of Mass Sport. (2000). Ed. Michelle Provoost. NAI Publishers Rotterdam. ISBN 90-5662-145-9

Informes Oficiales. Official Report.

Tesis Doctoral

FEDDERSEN, Arne; MAENNIG, Wolfgang. (2008). Arenas vs. Multifunctional Stadia - Which Do Spectators Prefer?.

IASE/NAASE Working Paper Series, No. 08-15

VÁSQUEZ ROCCA, Adolfo. Sloterdijk y Canetti: El detonante iconográfico y operístico de la política de masas. Pontificia Universidad Católica de Valparaíso - Universidad Complutense de Madrid

WEB

SMITH, Brandon. (2012). The Future of Olympic Architecture Is Portable. http://mashable.com/2012/07/31/ olympic-architecture/

http://architectureofthegames.net/tag/venues/page/7/

London Olympic Stadium 1908. RIBA. https://www.architecture.com/Explore/Buildings/LondonOlympicStadium 1908. aspx 


\section{B.4 Relación con la Ciudad}

Hacia afuera, contra la ciudad, la Arena ofrece una muralla inanimada. Hacia adentro levanta una muralla de hombres. Todos los presentes dan su espalda a la ciudad. Se han desprendido del orden de la ciudad, de sus paredes, de sus calles. Durante la duración de su estancia en la Arena no les importa lo que sucede en la ciudad.

Dejan allí la vida de sus relaciones, de sus reglas, de sus usos y costumbres.'
Elías Canetti, en su ensayo de 1960, Masa y Poder, aborda en un epígrafe titulado La Masa Como Anillo la relación entre el estadio y la ciudad.

La Arena está bien delimitada hacia afuera. Corrientemente es visible a gran distancia. Su emplazamiento en la ciudad, el espacio que ocupa, es de todos conocido.

Pero los estadios, aún siendo una de las grandes infraestructuras urbanas que destacan por su gran tamaño, mantienen una relación extraña y esquiva con la ciudad.

De toda la serie de estadios Olímpicos, solo el de Amsterdam 1928 corresponde con una situación plenamente urbana. Su situación está prevista en el planeamiento de extensión de la ciudad, en el límite suroeste del Plan Zuid de Berlage de 1914. Las condiciones del solar son claras y precisas, bien comunicado, al lado de uno de los canales, como remate de una gran avenida y su inmediata extensión es un gran parque urbano.

En el cuadro adjunto, se puede comprobar como en el resto de estadios su ubicación rehúye implicarse en la construcción de la ciudad y en muchos casos evita dar respuesta al problema de articulación formal de la gran escala del estadio en la ciudad: la del monumento urbano. Entendemos su arquitectura como una pieza urbana que, por sus dimensiones, no puede nunca ser neutral en la construcción de la ciudad. Se observa como aspecto negativo que en la elección de la ubicación de los estadios Olímpicos, en muy pocos casos se haya contemplado la realidad del proyecto urbano, dejándose los criterios de selección del lugar a los propios de la oportunidad o disponibilidad.

\footnotetext{
solar urbano

exposición universal parque deportivo esp nat intersticio urbano espacio natural

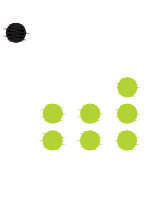

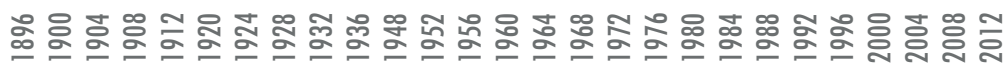

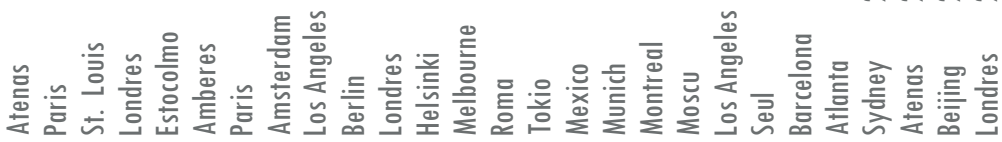

Su ubicación suele ligarse a suelos deportivos disponibles $\circ$ previstos. También encuadrados en actuaciones de otro orden como Exposiciones Universales o diferentes tipos de parques urbanos o suburbanos, espacios naturales e intersticios urbanos.

La localización del estadio de Atenas 1896 , fue decidida en la antigüedad y estaba condicinada por la realidad topografica del emplazamiento que se hallaba fuera del recinto de la ciudad. En París 1900, se desarrollo en las instalaciones del Racing de Francia en el Bois de Boulogne, en St Louis, en el área deportiva que formaba parte del recinto de la Exposición Internacional, lejos del centro de la ciudad. En Londres 1908, se volvian a ligar los Juegos con una Exposición, que se ubicaba en un área de oportunidad al oeste del centro, en un fragmento de campiña atrapada por los nuevos crecimientos urbanos pero muy bien surtida de medios de comunicación.
}

1. CANETTI; Elias. (1960). Masa y poder. Ed. Alianza Editorial, 2005. ISBN 8420637513 


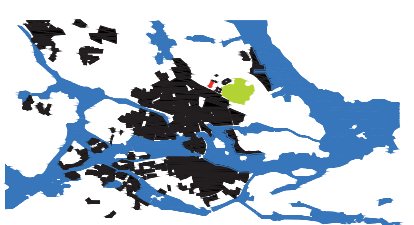

.
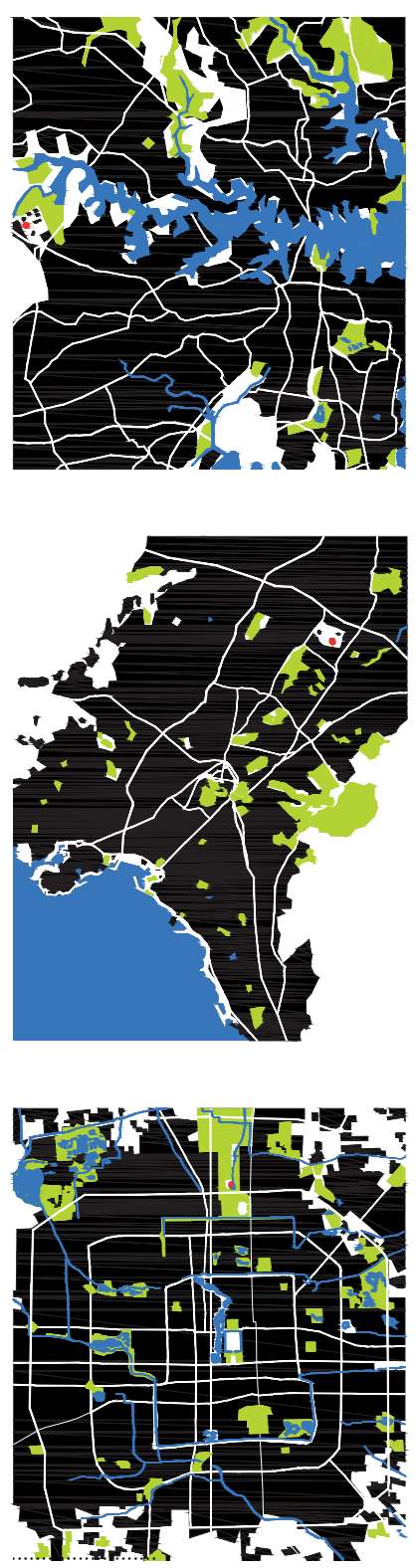

En grande el plano con la ubicación del estadio de Londres 1908, en el margen Estocolmo 1912, Sydney 2000, Atenas 2004 y Pekín 2008

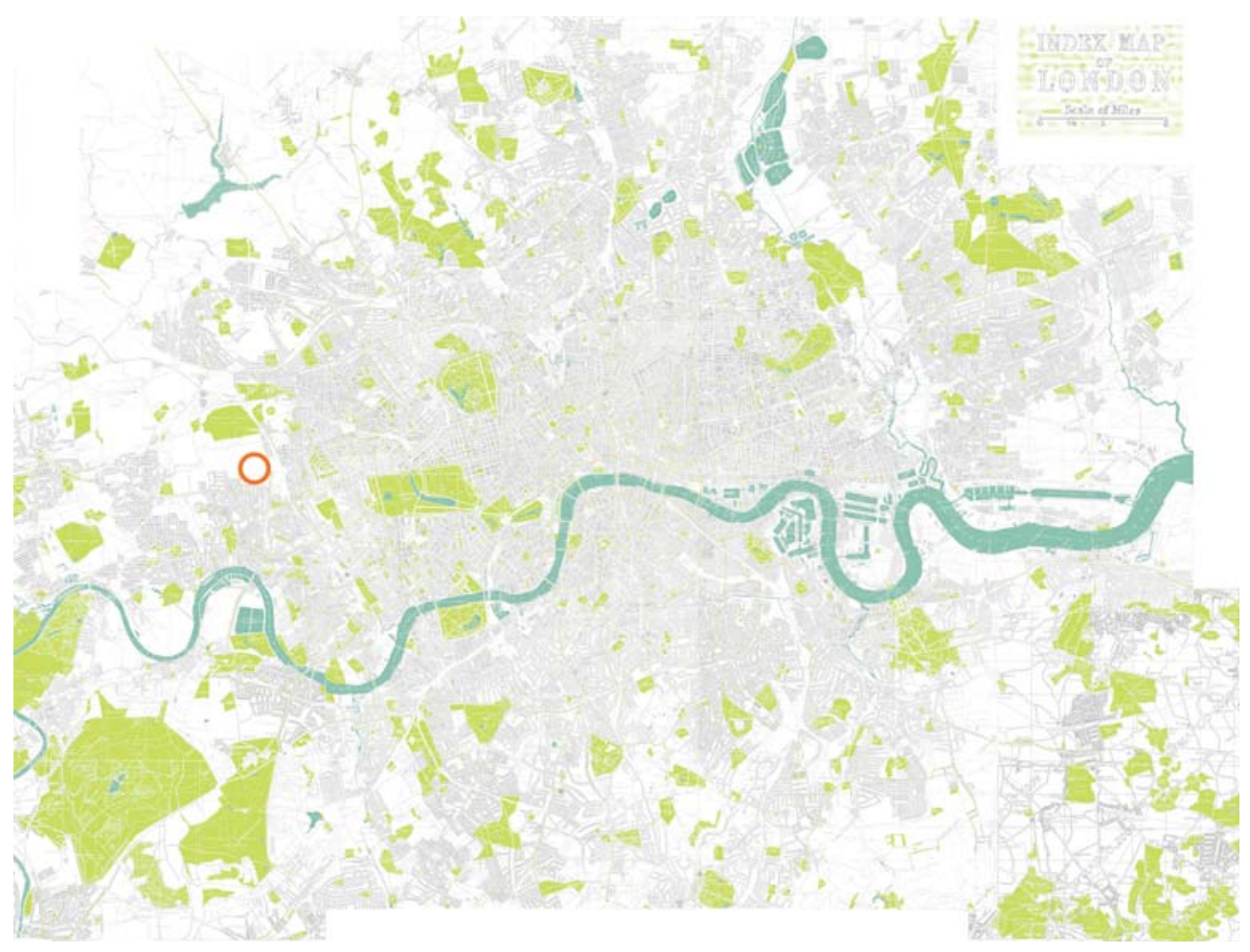

En Estocolmo 1912, se ocupa un suelo deportivo en el borde urbano, en Atenas 2004 es una gran parcela urbana destinada a parque deportivo. En Pekín se establece en un parque deportivo.

Planteamientos urbanos como los de Sydney o Londres 2012, son la excepción. En la ciudad austral se busca la recuperación de un degradado espacio natural de gran valor y su ligazón y enlace con la ciudad. En Londres la recualificación de un paraje post industrial muy contaminado en un nuevo foco de centralidad de la ciudad.

Decía Canetti que

su emplazamiento en la ciudad, el espacio que ocupa, es de todos conocido. Siempre se siente dónde está, incluso cuando no se piensa en ella. Las voces que salen de ella llegan muy lejos. Si no está cubierta, buena parte de la vida que en ella transcurre se comunica a la ciudad circundante.

Pero por muy excitantes que sean estas comunicaciones, no es posible entrar en ella sin dificultades. El número de asientos es limitado. Su densidad tiene fijado el límite...

... Su estar juntos en gran número está garantizado por determinado tiempo, su excitación les ha sido prometida, pero bajo una condición muy especial: la masa debe descargar hacia adentro.

Las filas están escalonadas hacia arriba para que todos vean lo que ocurre abajo.

Pero abajo solo hay un gran vacío, una explanada con un pasto cuidadísimo, rodeado de un anillo de color. Si entrar en el estadio tiene sus dificultades, acceder a la arena es imposible, es un espacio reservado a los elegidos. Juan Miguel Hernández de León en su artículo "El espacio de la excepción. Sobre el carácter de la arquitectura deportiva" proponía una interesante aplicación de los conceptos expuestos por Foucault en su conferencia titulada "Espacios Otros; Utopías y Heterotopías"' en los espacios deportivos,

Foucault establecía la diferencia entre los emplazamientos sin lugar real, pero que mantienen una relación real con el espacio real de la sociedad a través de la analogía, y aquellos que tienen una existencia real, pero que "son una especie de contraemplazamientos, de utopías efectivamente realizadas en las que los emplazamientos reales que se pueden encontrar en el interior de la cultura están a un mismo tiempo representados, contestados e invertidos". Este sistema de lugares plantea un concepto interesante para la definición del espacio deportivo: la heterotopía de compensación: "Crean otro espacio; otro espacio real, tan perfecto, tan meticuloso, tan

1. FOUCAULT, Michel. Espacios otros. "Des espaces autres", Conferencia dictada en el Cercle des études architecturals, 14 de marzo de 1967, publicada en Architecture, Mouvement, Continuité, n 5, octubre de 1984 
bien dispuesto como desordenado está el nuestro".

Compensación, o mejor excepción, como lógica espacial de la arquitectura deportiva. En efecto, ésta responde a una sistemática normalizada donde cada posición y cada zona responde a un código preestablecido.

En los estadios coexisten dos espacios diferenciados, dependientes el uno del otro pero absolutamente separados, no es posible traspasar la frontera que los une.

Los accesos, también, son independientes y diferenciados. Para entrar al espacio protegido hay que atravesar un laberinto de áreas restringidas y finalmente acceder desde los vestuarios donde los "actores" cambian su aspecto mundano por el de los escogidos.

...también supone un sistema selectivo en cuanto a ubicación y acceso, al igual que en la heterotopía funciona de manera específica la dialéctica de apertura y clausura. En general, se distingue un control y separación de circulaciones que hace que, en un mismo lugar, existan dos espacios incompatibles entre sí. La resolución de los accesos en los estadios y salas deportivas no solo se establece por puntos distintos de penetración, sino incluso mediante anillos superpuestos de circulación, con lo que ya se indica la distinta cualidad de los individuos que intervienen en el acontecimiento. Incluso los rituales de purificación se establecen en una forma obligada mediante la circulaciones por las zonas de servicios y vestuarios.

Como consecuencia de lo anterior, tendremos un espacio privilegiado, inmaculado, el espacio de la acción (del espectáculo), al que no se puede accederse desde los otros espacios yuxtapuestos, como si ambos se desenvolvieran en dimensiones distintas aunque cronológicamente simultaneas. Y cuando la convención cultural desaparece, surge el impedimento físico, ya sea en forma de foso o de valla.

Los estadios pese a pertenecer a la ciudad suponen un contraemplazamiento que los remite a otros lugares e incluso, según Foucault, a tiempos paralelos.

Estamos por tanto, ante un espacio ligado a lo que Foucault definía como heterocronía, es decir, "a fisuras del tiempo que se ponen a funcionar de lleno cuando los hombres se encuentran en una especie de ruptura absoluta con su tiempo tradicional". Y la asistencia al acontecimiento deportivo tiene lugar fuera del tiempo de la actividad real, en la suspensión del tiempo productivo.

Canetti se refiere a la condición de la masa en los estadios como doblemente cerrada. Algo semejante sucede con su vacío espacio interior, inaccesible al público y este último aislado y dando la espalda a la ciudad. Es una gran masa verde enclaustrada; un residuo de la naturaleza confinado en medio de la ciudad.

Situaciones semejantes se producen en otros interesantes ejemplos de arquitectura. El editor de la revista de arquitectura $a+t$ Javier Mozas, nos pone en la pista de un interesante concepto japonés, muy en relación y pertinente con lo que sucede en el estadio; comienza con una cita del filosofo Roland Barthes',

La ciudad de la que hablo (Tokio) contiene una paradoja curiosa: posee un centro, pero este centro está vacío. Toda la ciudad gira alrededor de un lugar a la vez prohibido e indiferente. ${ }^{2}$

En Japón, la influencia del pensamiento zen es grande y abarca desde la arquitectura hasta el arte floral, la caligrafía o las artes marciales. La noción de mu, vacio, se desarrolla a través de una manifestación depurada de la religión budista como medio de liberarse de cualquier pensamiento. De esta forma, a través de un camino de meditación se puede llegar a un estado de iluminación que se basa en el autoconocimiento y el autocontrol, en comunión con el universo. En este estado intermedio se renuncia tanto a lo uno como a lo otro para profundizar en lo neutro, que se queda a medio camino entre el ser y el no ser y que se contrapone a la moral occidental con separación entre bien y mal.

En términos espaciales nos enfrentamos a la gran contradicción de que en Tokio, donde la escasez de suelo edificable es conocida, tengamos el núcleo vacío. Son los jardines del Palacio Imperial los que se colocan en posición central y obligan a que el espacio construido se disponga alrededor de un centro de poder desposeído de la concentración que caracteriza las antiguas ciudades europeas.

El Palacio Imperial y sus jardines constituyen el núcleo vacio de edificación pero presente como espacio de poder y veneración.

1. Cherburgo, 12 de noviembre de 1915 - París, 25 de marzo de 1980. Escritor, ensayista y semiólogo, de la escuela estructuralista

2. MOZAS, Javier. a+t n6. Octubre 1995 


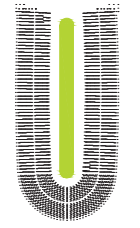

ATENAS 1896

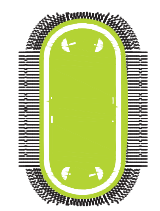

PARÍS 1924

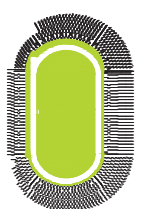

HELSINKI 1952

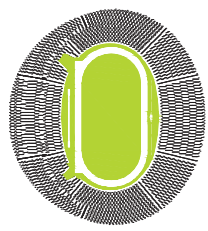

MUNICH 1972

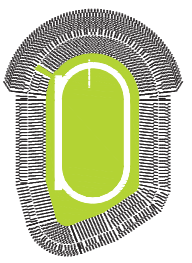

ATLANTA 1996

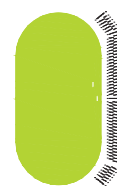

ST LOUIS 1904

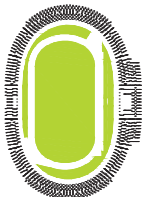

AMSTERDAM 1928

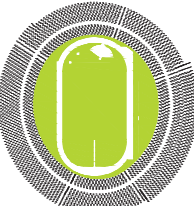

MELBOURNE 1956

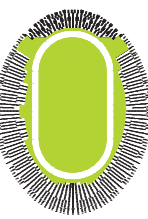

MONTREAL 1976

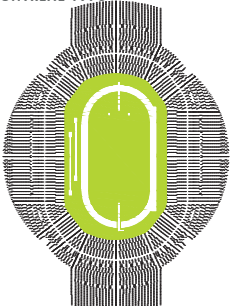

SYDNEY 2000

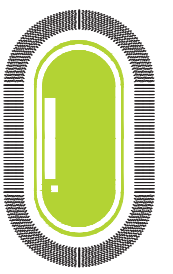

LONDRES 1908

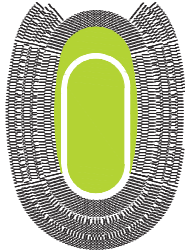

LOS ANGELES 1932

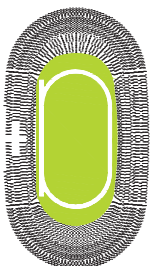

ROMA 1960

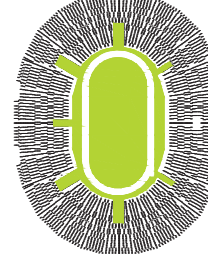

MOSCÚ 1980

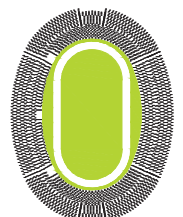

ATENAS 2004
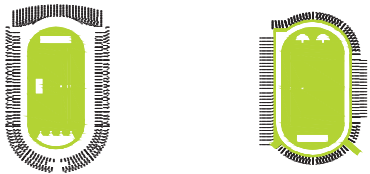

ESTOCOLMO 1912

AMBERES 1920

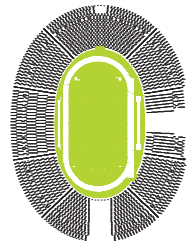

BERLÍN 1936

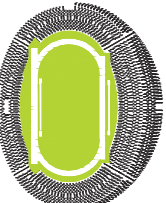

TOKIO 1964

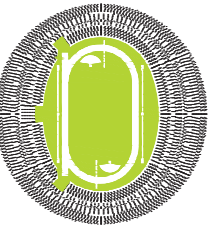

SEUL 1988

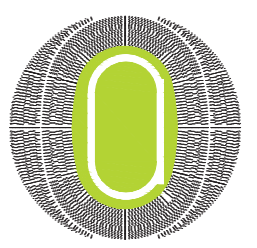

PEKÍN 2008

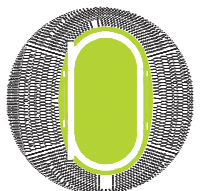

MÉXICO 1968

- I 1992

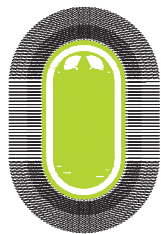

LONDRES 1948
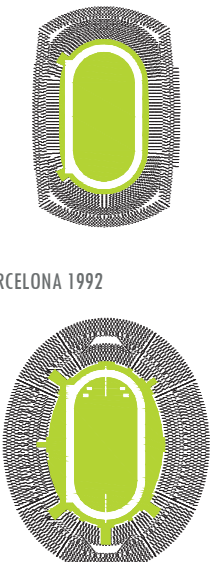

LONDRES 2012

El texto de María Zambrano' sobre las casas patio y la condición del mismo como vacío podría ser aplicable, también, a los estadios, por su condición de espacio acotado y con cualidades que remiten a otros emplazamientos,

En un espacio vacío, pues, y abierto al cielo: a la lluvia, al sol, a la luz, y al patio daban las habitaciones todas de la casa,... Al exterior, calle, plaza o campo la casa apenas ofrecía apertura alguna: algunas pocas y nada amplias ventanas.

La casa fue concebida en los lugares que son la fuente de nuestra civilización como un recinto lo más cerrado posible. Refugio, fortaleza, y que encerraba un espacio libre, vacío... un espacio propio. ... Y lo que es más importante, un recinto que guardaba dentro de sí el ambiente de libertad, el espacio, el aire, la luz.

... Por sus paredes se ve girar la luz del día y entra la noche con su misterio. Es un mirador del cielo, un lugar de contemplación y en este sentido un templo. "Templum" era allá en Babilonia el lugar desde donde se contemplaba el firmamento.

... El patio es también jardín. Famosos son los floridos, encantados patios de Andalucía que yo he visto modulados de ciertas maneras en los maravillosos patios antillanos. De origen árabe, no puede por menos de simbolizar, creo, algo muy islámico pero no

1. Texto conservado en la Fundación María Zambrano con la signatura M-77, 1964. En Aurora. Papeles del "Seminario María Zambrano", n³, Barcelona, 2001, pp. 142-143. 
extraño a la mente cristiana: la rememoración del paraíso terrenal. El patio, el nuestro, el patio hispano es símbolo y recuerdo de ese trocito de paraíso irrenunciable que según padres de la Iglesia como San Agustín, queda intacto en el alma.

\section{B.4.1. Claro en el Bosque}

Con el Jardín del Paraíso, también es con lo que compara los estadios el profesor de literatura, Presidente de Yale University y de la Liga Americana de Baloncesto, A. Barlett Giamatti (1938/1989) en su libro Take Time for Paradise de 1989.

Según la RAE palabra paraíso proviene del avéstico (persa) pairidaēza, que significaba: cercado circular, aplicado a los jardines reales.

El estadio, ciertamente, es un recinto sensiblemente circular con un fragmento de naturaleza en su interior, una abstracción y racionalización del variado paisaje natural que ha derivado en un cuidado monocultivo'.

Un lugar, que comparte características con el Claro del Bosque que nos describe María Zambrano

El claro del bosque es un centro en el que no siempre es posible entrar; desde la linde se le mira [...] Es otro reino que un alma habita y guarda... no se encuentra nada, nada que no sea un lugar intacto que parece haberse abierto en ese solo instante y que nunca más se dará así [...]

[...] la analogía del claro con el templo puede desviar la atención.

Un templo, mas hecho por sí mismo, por "El", por "Ella" o por "Ello", aunque el hombre con su labor y con su simple paso lo haya ido abriendo o ensanchando. La humana acción no cuenta, y cuando cuenta da entonces algo de plaza, no de templo. Un centro en toda su plenitud, por eso mismo, porque el humano esfuerzo queda borrado, tal como desde siempre se ha pretendido que suceda en el templo edificado por los hombres a su divinidad, que parezca hecho por ella misma $[\ldots]^{2}$

La ensayista y pensadora nos relaciona el claro en el bosque con el templo, tal y como lo estaban relacionadas en la antigua Olimpia. Inicialmente el estadio era el claro en el bosque que se extendía al lado del altar del dios protector a los pies del monte Kronion, en el Altis, el bosque sagrado que se halla o se hallaba en la confluencia del Alfeo con el tormentoso Cladeo.

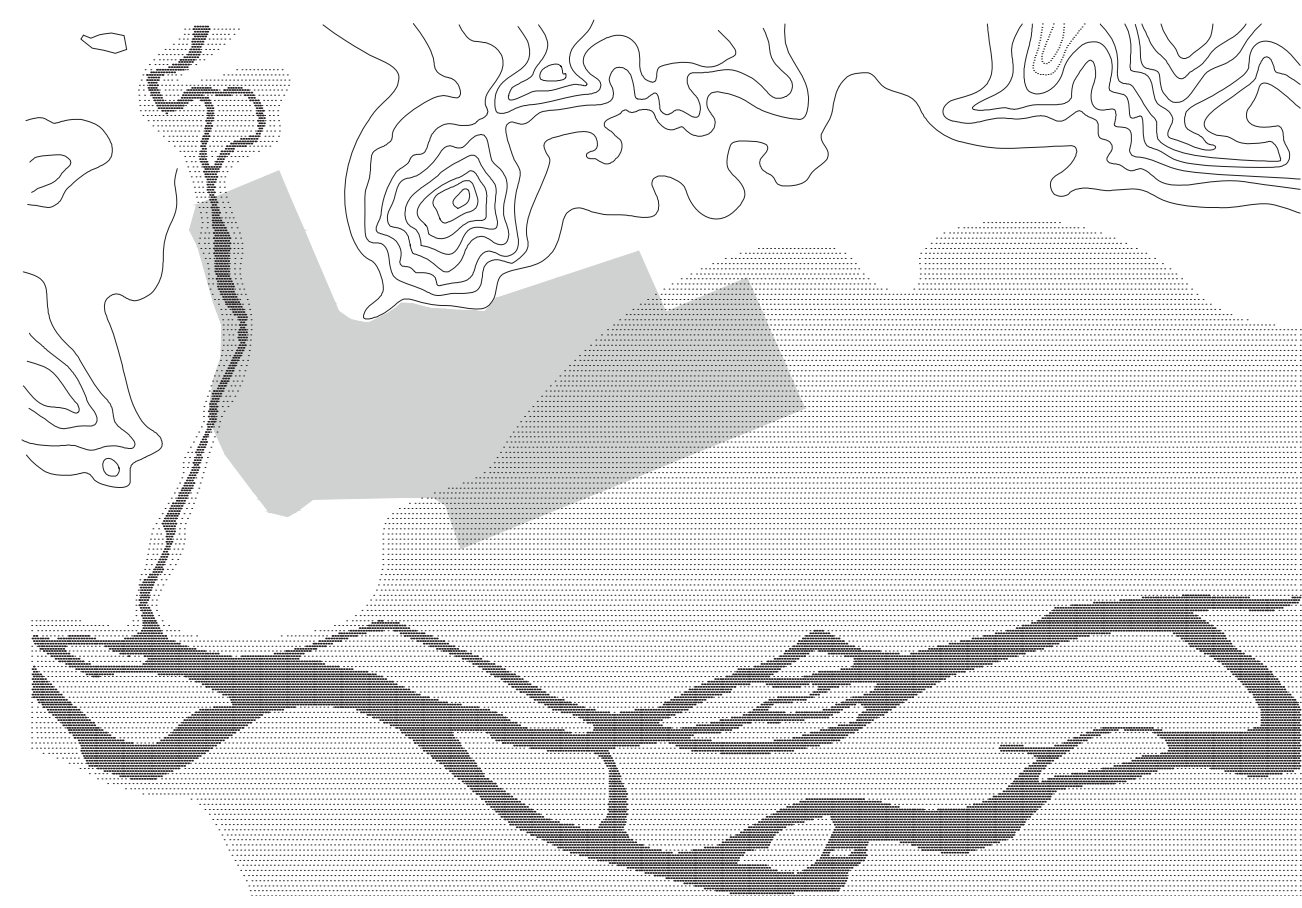

1. Con la excepción de dos casos, en Amberes se conservaron árboles preexistentes que quedaron integrados en el graderío. En el proyecto y construcción frustado estadio Olímpico de Berlín 1916 se conservó un gran roble, en la parte superior del graderío, justo en su eje longitudinal.

2. ZAMBRANO, María. (1973). Claros del bosque. Ed. Biblioteca de Bolsillo, 1993. ISBN 84-322-3039-1
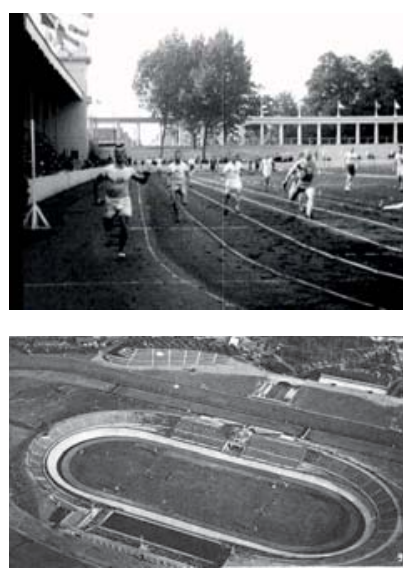
No puedo evitar traer aquí unos fragmentos del precioso Discurso de Ingreso en la Real Academia Española de la Lengua de Ana María Matute, titulado En el bosque, Defensa de la fantasía

[...] el mundo que me ha fascinado desde lo más temprano de la infancia, que desde niña me ha mantenido atrapada en sus redes: el «bosquell que es para mí el mundo de la imaginación, de la fantasía, del ensueño,

[...] Porque los bosques siempre han sido importantísimos para mí. Su mera imagen siempre me ha sugerido toda suerte de historias y leyendas, de recuerdos que ignoraba poseer, pero que estaban ahí, confundidos entre los árboles o escondidos en la espesura de los zarzales.

El estadio de Olimpia formaba parte de un conjunto excepcional, confundido entre los árboles, escondido en la espesura, y para el curioso observador actual un mundo de toda suerte de historias y leyendas.

\section{B.4.2. Oposiciones reconciliadas, el pasado es prólogo}

What's past is prologue.'

Oposiciones reconciliadas.

L'opposition et les cases conjuguées sont reconciliées.'

A pregunta de Pierre Cabanne, Marcel Duchamp explica el por qué de este maravilloso titulo surrealista de la obra que escribió en 1932 sobre el ajedrez

La oposición es un sistema que permite llevar a cabo tal o cual operación. Las casillas conjugadas es lo mismo que la oposición, pero se trata de una invención más reciente a la que se ha dado un nombre distinto. Añadí "reconciliados" debido a que encontré un sistema que suprimía la antítesis. ${ }^{3}$

2000 a.c trazas absidales I Pelopio

XI a.C. I Templo Hera II Pelopio

$X$ a.C Altar de Zeus

IX.VIII a.C Altar de Hestia

VII a.C II Templo Hera I Estadio Terraza de los tesoros

VI a.C III Templo Hera, Buleuterion

V a.C Templo Zeus II Estadio

Heroon

Taller de Fidias Metroon Termas griegas

Teocoleon

III Pelopio

IV a.C Pórtico sur

III Estadio

Muralla griega

Galería del Eco

Filipeion

Leonidaion

III a.C Palestra

Gimnasio

Parecía que, en sus orígenes, los sucesivos estadios de Olimpia en su relación con la ciudad era la antítesis de lo que a partir de 1896 se iba a desarrollar en las Olimpiadas Modernas. Asignamos plenamente a "antítesis" su significado etimológico, de contra posición, según el Diccionario de la Lengua Española. (del latín antithesis, y este del griego antíthesis).

Pero, no sólo se produce una contraposición u oposición, según el término utilizado por Duchamp. En su pasado remoto como organización de carácter rural y su presente como hecho puramente urbano, basta con recordar que la organización de los Juegos Modernos recae en ciudades, y no en territorios o países.

Por otra parte, las Olimpiadas Clásicas, que hunden su origen en la noche de los tiempos llegando a su fin en el siglo IV d.C., han supuesto un largo proceso de desarrollo progresivo en una ubicación estable. Mientras, en las Olimpiadas Modernas su sede es itinerante y la vigencia de cada edición es "fugaz", apenas dura dos semanas.

Pese a todo esto, su relación no podemos reducirla a unas simples operaciones de oposición, pudiendo establecerse una serie de continuidades más complejas, que puedan superar el concepto de antítesis, hacia el concepto acuñado por Duchamp de oposiciones reconciliadas.

Si bien los estadios modernos pertenecen a la ciudad, en su semilla germinal esta el Claro en el Bosque, ese espacio vacío solo accesible a los elegidos. Y la ubicación estable del antiguo santuario, en el que su desarrollo se produce en el tiempo de manera diacrónica desde las primeras construcciones absidales, como vestigio más remoto, en un proceso continuo de perfeccionamiento

Esta labor continua de mejora y perfeccionamiento queda documentada en las descripciones de Pausanias, cuando nos describe que en el templo dedicado a la diosa Era una de sus columnas era de encina, mientras que el resto de la construcción era en piedra. Esta columna vestigio de la continua labor de reconstrucción y actualización constructiva, de la madera a la piedra, que acumula en el templo los conocimientos, esfuerzos y afanes de distintas generaciones nos acerca al termino simbólico japonés de "sengu", proceso de desmantelamiento y reedificación periódica de los santuarios sintoístas. Como proceso que enlaza el pasado con el futuro, actualizando toda la tradición acumulada durante siglos como material genético. Sincronizando presente pasado y futuro.

1. Lo que es pasado es prólogo. SHAKESPEARE, William. La Tempestad, Acto II, escena I. The tempest. Ed. Stanley Thornes. ISBN 0748703799

2. CABANNE, Pierre. (1967). Conversaciones con Marcel Duchamp. Ed. Anagrama. 1984. ISBN 84-339-0406-X

3. Idem 


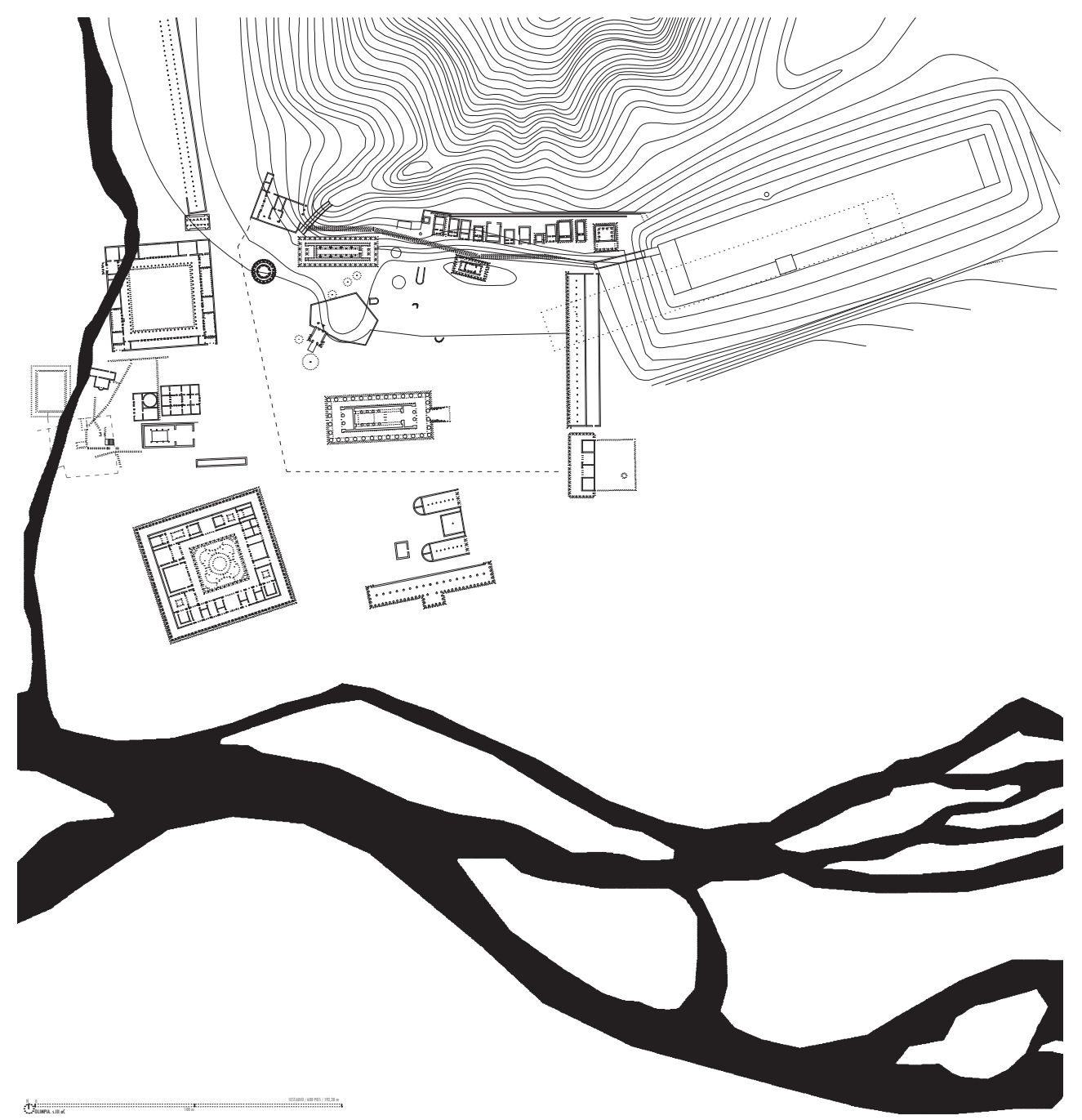

El templo de Ise, en la prefectura de Mie, continua siendo reedificado cada veinte años como se ha venido haciendo desde hace siglos. La primera reedificación tuvo lugar en el año 690 y la última en 2013, con algunas excepciones durante periodos de guerra. Esta idea, contraria a la durabilidad material de los edificios, se basa en los principios sintoístas que concebían los templos asociados a ceremonias puntuales y no como lugares de culto permanente. La reedificación trata de hacerse con métodos tradicionales, pero siempre existen cambios graduales e inevitables tanto en la técnica como en las herramientas que no permiten que apreciemos el nuevo templo como si fuera el original que hubiera permanecido inalterado a lo largo del tiempo. La propuesta de futuro que supone la repetición, hasta en sus más pequeños detalles de este proceso, como un ciclo sin fin, altera la linealidad del tiempo y representa la sincronización en un solo instante del pasado y del futuro, que en veinte años se convertirá inevitablemente en presente.

Este antiguo rito unido a la inestabilidad sísmica del país y al encarecimiento del precio del suelo, como bien escaso, en las principales ciudades -casi el setenta por ciento del territorio japonés está ocupado por montañas y bosques con una pendiente superior al quince por ciento- otorga a las edificaciones japonesas un carácter temporal que se aleja del construir para permanecer que existe en Occidente.

En Occidente la historia se conserva física y materialmente tal y como fue construida; cada legado se pretende que sea el de su tiempo y debe estar fechado y documentado. Cada intervención se marca con una tilde sobre la línea de la historia.

En Oriente el patrimonio histórico puede desaparecer pero los principios estéticos pasan de generación en generación y forman parte de una herencia común o código genético que se actualiza en cada reedificación. Cada instante se encuentra a igual distancia del pasado, del presente y del futuro.
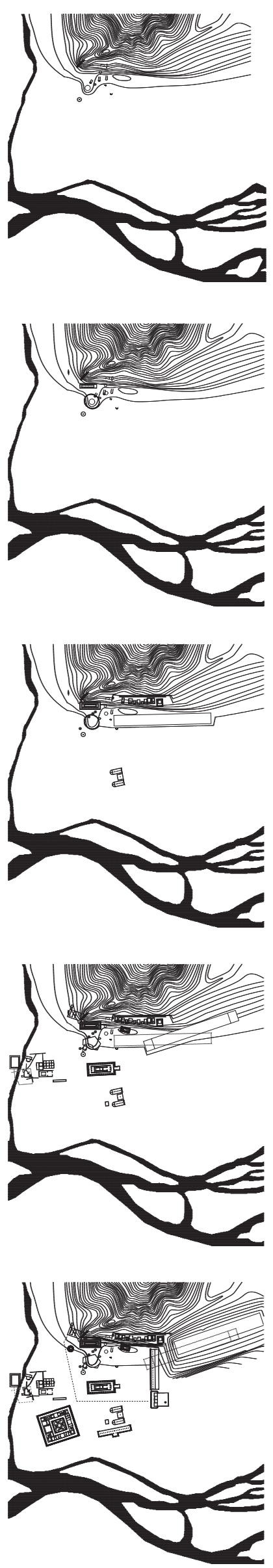
Cada cuatro años se vuelve a representar la liturgia de los juegos, como cada veinte años se reedifica el templo de Ise, siempre el mismo y siempre distinto. No es difícil imaginar que los templos de la antigua Olimpia, cada cuatro años volvían a lucir sus mejores galas, se remozaban, se actualizaban. La columna de encina del templo de Era nos habla de una sustitución incompleta de un antiguo templo de madera por otro construido en duraderas piedras pero formalmente simulando la vieja construcción en madera.

La columna de encina żes el resto de un proceso inacabado de sustitución y actualización? o żun vestigio deliberado, sagrado y venerado, del antiguo templo construido en madera?

Quizás la Grecia prehistórica y aun la histórica preclásica tenga más que ver con el mundo oriental que con el mundo occidental de la cuál es cuna. Un mundo antiguo más cercano a la ambigüedad y la indefinición. En oriente, y nos gustaría decir en la antigüedad, la valoración de espacios intermedios permite la coexistencia de términos contrapuestos. El método dialéctico occidental lo que hace es eliminar la indefinición y la ambigüedad y funde las categorías intermedias y el proceso de síntesis, seña de la cultura occidental, en el que lo que a partir de dos conceptos antitéticos previos se obtiene uno nuevo tras un camino de análisis y fusión que supone la muerte del estado bipolar anterior.

Algo parecido a esta labor de volver a edificar se lleva a cabo cada cuatro años en los Juegos modernos. Cada olimpiada es el antecedente de la siguiente y produce una incesante carrera de relevos que genera una continuidad y ha generado una ya larga serie tipologica.

Y, si como escribió Shakespeare, el pasado es un prólogo, ciertamente en este caso, el pasado remoto puede, en ciertos aspectos, considerarse el prólogo en el que se establecen algunas interesantes continuidades con nuestro pasado más próximo y nuestro presente, objeto de esta tesis.

\section{B.4.3. Reto de Coubertin a los arquitectos}

En 1910 Coubertin convoca un "concurso internacional de arquitectura" y llama a los arquitectos para "levantar los planos para una moderna Olimpia". Especificó las siguientes instalaciones para su construcción:

Edificios, columnatas, estadios, pistas, etc., adecuados para el contexto deportivo y artístico, que son las características del programa de los Juegos Olímpicos Modernos. Gradas para los espectadores.

Estructuras y los indispensables espacios libres para la realización de festividades integradas con los Juegos.

Instalaciones para los directores, deportistas, etc.'

Coubertin, deseaba que estas instalaciones se concibiesen como un complejo urbano, una ciudad de los deportes, algo tan nuevo que "ninguna de nuestras generaciones ni nadie que los preceda haya jamás contemplado nada cercano o remoto a Olimpia".

En su opinión había tres aspectos a tener en cuenta en la Olimpia Moderna:

La ciudad olímpica debería cautivar a los visitantes siendo un complejo de apariencia monumental.

Un mero vistazo en las instalaciones debería transmitir una idea de las funciones respectivas. Su apariencia debería diferenciar claramente su doble carácter, atlético y artístico.

Las construcciones y el paisaje deberían formar una unidad harmoniosa, edificios integrados en el paisaje, interrelación entre el espacio interior y el exterior... ${ }^{2}$

En principio, pensaba que para desarrollar la idea eran apropiadas las dos formas de la ciudad tradicional: la ciudad suburbana con la mezcla de lo urbano y lo rural, o la densa, construida y compacta, con un vacío interior, foco de atención, semejante a una "Meca olímpica". Su preferencia personal era más por los campos abiertos, aunque sin ser excesivamente extensa, algo similar a la "lejanía compacta" de los antiguos Juegos.

Para la ciudad, pensaba una división en dos partes, como sucedía en la Olimpia clásica. En el corazón de la ciudad se encontrarían las instalaciones para deportes, música, teatros y librerías. La "ciudad profana" se situaría en los alrededores, "lejos de la corte de honor" y sin comunicación directa con el centro, allí se encontrarían los restaurantes, alojamientos para atletas y edificios accesorios.

1. Une Olympie Moderne. Revue Olympique. Paris 1910. Archivo ClO Lausana.

2. Idem 
Olimpia era una ciudad para los deportes, el arte y los festivales religiosos. La ciudad de los atletas tenía un carácter temporal, la ciudad del arte y el culto un carácter permanente. Este aspecto también se debía trasladar a la moderna Olimpia.

Para Coubertin no era necesario que todos los deportes se practicasen en recintos cerrados y teniendo en mente el ágora griega, los foros romanos o la plaza española, veía posible la celebración de espectáculos en espacios abiertos cerrados por arcadas.

Para los espectadores, prefería que no existieran gradas. Su recomendación para los arquitectos fue distribuir las 10.000 personas y no apelotonarlas en un "horrible bloque". Se podrían prever terrenos de hierba y bancos de tierra donde las personas podrían moverse libremente, agruparse temporalmente y alternarse reiteradamente. En estas instalaciones la imaginación, la irregularidad y el orden prevalecen al mismo tiempo de modo que el camino de una no excluye o interfiere con las otras. El parque de deporte imaginado siguiendo estas trazas debería parecerse indistintamente a un jardín francés o inglés, o a cualquier tipo de jardín. Debería crear algo nuevo, utilizando los mejores elementos de ambos; reminiscencias de un "casino park", no de un "cementerio".

En definitiva; Coubertin pretendía construir un paisaje, un jardín, tal vez el paraíso.

\section{B.4.4 Homotopía. Independencia de la ubicación}

El proceso de estandarización y homogenización que han sufrido los estadios en su desarrollo para asegurar la igualdad de condiciones entre los competidores sin importar el lugar en el que está situado ni a la cultura a la que pertenece, lleva a plantear la cuestión de la homotopía, es decir si todos los lugares son iguales es porque realmente el tipo estadio es independiente de su ubicación.

Es una cuestión en la que también participan las ciudades; cada día sus arquitecturas son más parecidas, adoptando un concepto de globalidad en el que es difícil distinguir su procedencia geográfica. Las carreteras de acceso a las ciudades, sus aeropuertos internacionales, sus supermecados, estaciones de gasolina, oficinas, etc., cada vez son más difíciles de diferenciar.

Está claro que en los estadios las necesidades para la competición son muy semejantes en todo el mundo, solo varía en cuanto a los deportes de campo más populares que acompañan al agón atlético. El más habitual, a lo largo del mundo, es el fútbol, exceptuando en Estados Unidos, Canadá y Australia. En Los Ángeles es el fútbol americano y el Beisbol en Atlanta. En Montreal el beisbol y en los dos casos oceánicos una combinación entre fútbol australiano con su exótico terreno de juego oval, el rugby y el fútbol.

También las necesidades en cuanto al público son semejantes. Sistemas singulares de control de accesos para procurar la seguridad. Las condiciones de confort, se han igualado en todo el mundo, los requerimientos de visión responden a cuestiones físicas y las amenidades, que es la cuestión con más capacidad de divergencia, tiende a igualarse de manera creciente.

La tendencia de semejanza entre los estadios afecta también a la relación que se establece entre público y competidores que tiende a parecerse.

Con el uso absolutamente adoptado de las superficies sintéticas para el atletismo y su creciente uso en el campo, aunque no ha llegado a los Olímpicos, hace cada vez más independiente del lugar del mundo, con sus diferencias climáticas, en el que se levantan los estadios.

Así pues, podemos considerar al estadio como un tipo edificatorio global, independiente del lugar en el que se asienta. De alguna manera carente de lugar

Este situación actual homotópica ha abierto un nuevo frente de investigación en los estadios, la necesidad de diferenciarse y ser reconocibles, lleva a la cuestión de su imagen a un primer plano de importancia. La imagen externa pasa a ser una prioridad, siendo su vista aérea muy recurrente en las retransmisiones televisivas. Para la sociedad, el estadio, progresivamente está dejando de ser una infraestructura deportiva, de carácter utilitario y funcionalista, para pasar a ser un problema de arquitectura. El caso de Pekín con la propuesta de Herzog y de Meuron escenifica con claridad esta cuestión. Su imagen externa es comúnmente reconocida y es uno de los principales activos de esa edición de los Juegos.

Esta cuestión de imagen entraña un riesgo, y es que, si el proceso de decantación ha ido construyendo edición a edición un tipo edificatorio tremendamente eficaz, que la necesidad de diferenciación y la preponderancia de su imagen puedan producir estadios no ajustados a sus caracteres básicos y trascendentes, que se pueden resumir en la capacidad que tienen los estadios en potenciar la interacción entre competidores y público. El riesgo es que suceda lo mismo que ocurrió, en el Guarnicionero de Adolf Loos, al profesor y sus 44 alumnos con las sillas de montar. $Y$ tengamos que decir como su guarnicionero: 


\section{B.4.5 Topofilia}

Para describir lo contrario al concepto de homotopía, podemos manejar el de topofilia propuesto por Gaston Bachelard en La Poética del Espacio ${ }^{2}$ y que el geógrafo chino-norteamericano Yi-Fu Tuan ${ }^{3}$, ha desarrollado posteriormente. Topofilia es el conjunto de relaciones emotivas y afectivas que unen al hombre con un determinado lugar.

Los paisajes y las arquitecturas, en definitiva los lugares, no son simplemente los fondos visuales de la acción, de los comportamientos y de las emociones.

Las emociones compartidas conforman una huella más indeleble. Construyen un Genius Loci, un espíritu del lugar, que determina su carácter o esencia.

Los estadios establecen unas fuertes relaciones afectivas con sus usuarios, tanto público como competidores. Los momentos de emoción vividos en un lugar nos atan indefectiblemente a él, incluso el conocimiento de lo allí ocurrido tiene también la capacidad de establecer dichos vínculos.

1. LOOS, Adolf. (1908). Ornamento y delito y otros escritos. Ed. Gustavo Gili. Colección arquitectura y critica 1980. ISBN: 842520012 1. Pág. 90

2. BACHELARD, Gaston. (1957). La poética del espacio. Ed. Fondo de Cultura Económica. 2000. ISBN84-375-0368-X

3. Yi Fu Tuan (1930) Geógrafo estadounidense de origen chino. Profesor de las universidades de Nuevo México, Toronto, Minnesota y Wisconsin. Se especializó en el estudio de la experiencia de los hombres en su medio. Destacan las obras Topofilia (1974); Espacio y lugar (1977), y Mundo y ser divididos (1982).

YI-FU TUAN. (1974). Topofilia. Ed. Melusina, 2007. ISBN 9788496614178 


\section{Bibliografía. Relación con la ciudad}

BACHELARD, Gaston. (1957). La poética del espacio. Ed. Fondo de Cultura Económica. 2000. ISBN84-375-0368-X BALE, John. The Stadium and the City. Staffordshire: Keele University Press, 1995. ISBN 1853311103 CANETTI, Elias. (1960). Masa y poder. Ed. Alianza Editorial, 2005. ISBN 8420637513

CABANNE, Pierre. Conversaciones con Marcel Duchamp. Ed. Anagrama. Barcelona. Segunda edición 1984. Titulo original: Entretiens avec Marcel Duchamp. Éditions Pierre Belfond. París 1967.

ISBN: 84-339-0406-X

LOOS, Adolf. Ornamento y delito (1908). Colección Arquitectura y Critica. G. G. Segunda edición. 1980. Barcelona, España. Pág. 90

SHAKESPEARE, William. La Tempestad, Acto II, escena I. The tempest. Ed. Stanley Thornes. ISBN 0748703799

YI-FU TUAN. (1974). Topofilia. Ed. Melusina, 2007. ISBN 9788496614178

ZAMBRANO, María. Claros del bosque. Biblioteca de bolsillo. Ed. Seix Barral. 1977. Cuarta edición octubre 1993. ISBN: 84-322-3039-1

FOUCAULT, Michel. Espacios otros. "Des espaces autres", Conferencia dictada en el Cercle des études architecturals, 14 de marzo de 1967, publicada en Architecture, Mouvement, Continuité, n 5, octubre de 1984 MOZAS, Javier. a+t nº. Octubre 1995

ZAMBRANO, María. Texto conservado en la Fundación María Zambrano con la signatura M-77, 1964. En Aurora. Papeles del "Seminario María Zambrano", n³, Barcelona, 2001, pp. 142-143

Das Deutsche Stadion. Sport und Turnen in Deutschland, 1913. Archivo CIO. id:10021

Une Olympie Moderne. Revue Olympique. Paris 1910. Archivo ClO Lausana. 


\section{B.5. Geometría}

La concepción geometría que subyace y sustenta el carácter de los estadios ha ido variando a lo largo de la secuencia histórica de los mismos, desde los de las etapas inicial y de consolidación, hasta los Juegos de Londres de 1948, en los que domina el equilibrio estático apoyado en la rigurosa aplicación de las simetrías, como mejores garantes de la monumentalidad. Con el estadio de Helsinki se inicia definitivamente el camino de la modernidad, con puntos culminantes en México, Múnich y Pekín. Es destacable que en estos tres casos el encargo del proyecto derive de un concurso de arquitectura. Siempre decía mi padre, Julio Cano Lasso que

en los concursos es donde de una manera más fresca y libre se manifiesta el espíritu del autor y sus ideas sobre Arquitectura

y añadía

a los concursos hay que acudir con estilo deportivo, siempre dispuestos a aceptar el fallo y a ejercitar la virtud de la paciencia y la elegancia del saber perder ${ }^{1}$

\section{B.5.1. Momentos de cambio en el entendimiento geométrico de los estadios}

La recreación del tipo edificatorio estadio se produce a finales del siglo XVIII, cuando el monumentalismo academicista domina el panorama arquitectónico. Así los estadios inician su recorrido de desarrollo imbuidos de una concepción geométrica en la que los preceptos de simetría y equilibrio estático y predecible son la norma, por muy variados y distintos que fueran los lenguajes arquitectónicos aplicados. Los primeros estadios están dominados por estos preceptos aunque se pueda establecer una salvedad con el proyectado por Jan Wils para los Juegos de Amsterdam 1928, en el que la cubierta de la tribuna y el tratamiento y composición de las fachadas anticipan una nueva visión por venir. La influencia del precursor de la arquitectura moderna Frank Lloyd Wright es manifiesta, y pese a que sigue conservando rigurosamente la simetría en su trazado, la torre exterior con la antorcha se sitúa exactamente en el eje de la composición; el tratamiento de sus fachadas abre el camino hacia una nueva concepción de mayor dinamismo.

El de Helsinki de Y. Lindegren y T. Jäntti , resultado de un concurso real de arquitectura, supone la entrada definitiva en la modernidad de los estadios. Su aire sencillo pero emotivo, la dinámica composición con cierto aire de turbina de sus graderíos provisionales de madera, la situación de la torre suponiendo un punto de equilibrio a la composición y su lenguaje, remiten a una arquitectura funcionalista germen del movimiento moderno.

El de la ciudad de México de Raúl Pérez Palacios (ganador del concurso entre profesores y alumnos), propone un entendimiento tridimensional del estadio en relación con el espacio circundante y la topografía. Sus gradas asimétricas y todo el sistema de accesos y rampas lo insertan con naturalidad y potencia en el lugar de actuación. Sí exceptuamos el deslavazado de Melbourne, es el primero en manejar, y con mucho acierto, el deslizamiento de la grada alta sobre la baja construyendo unos potentes voladizos que refuerzan el carácter masivo y telúrico de la actuación.

Munich 1972 supone la fascinación por la entrada en acción de un nuevo concepto geométrico y estructural. Sobre un graderío de carácter topográfico en perfecta armonía con su entorno, se tiende una estructura ligera tensada, que es ajena a cualquier eje de simetría y en la que es imposible establecer direcciones dominantes. Proyecto bajo la responsabilidad de Günter Benisch² y que contó con la inestimable colaboración del arquitecto más señalado en la investigación de este tipo de estructuras ligeras, Frey Otto. La labor de ingeniería la comandó Jörg Schlaich como integrante de la firma Leonhardt + Andrä. El fundamento de la ligereza de la cubierta se asienta en el trabajo a tracción
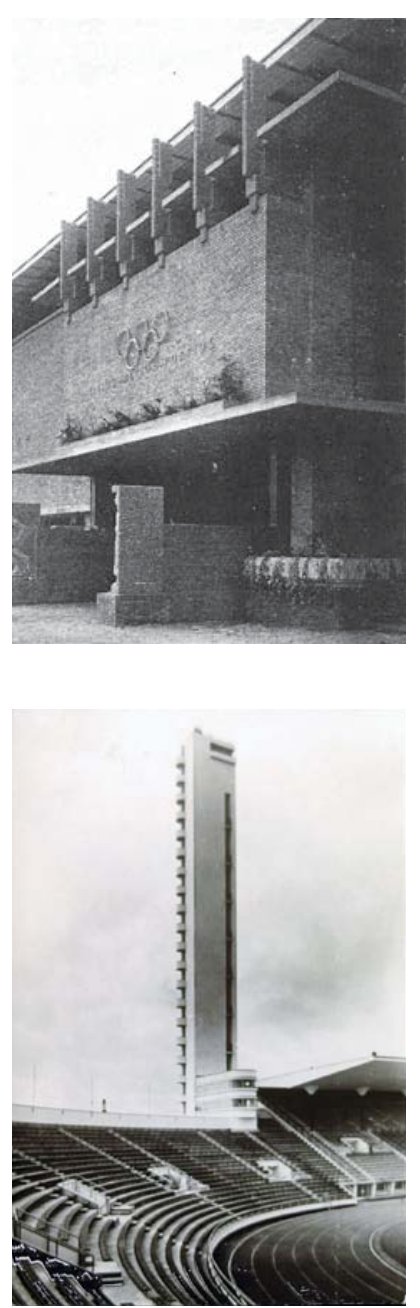

1. CANO LASSO, Julio. (1996). Estudio Cano Lasso. Ed. Electa. ISBN: 88-435-5951-6

2. Ganador del muy bien organizado concurso de arquitectura, del que jurado Egon Eiermann entre otros 

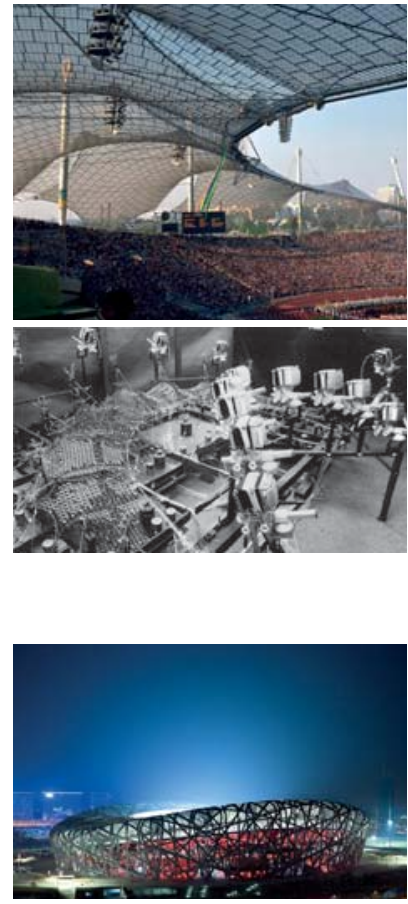

(a)
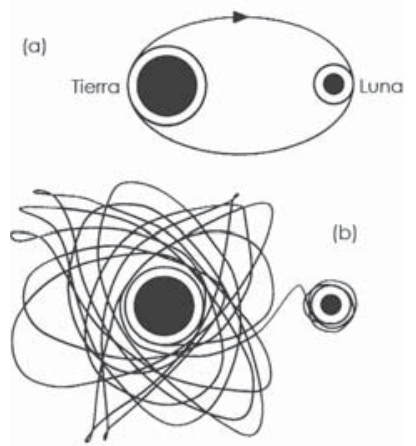

(a). La elipse de Hohmann y (b) la órbita caótica mas eficiente. Dibujo del libro iJuega Dios a los dados?. La nueva matemática del caos de lan Stewart
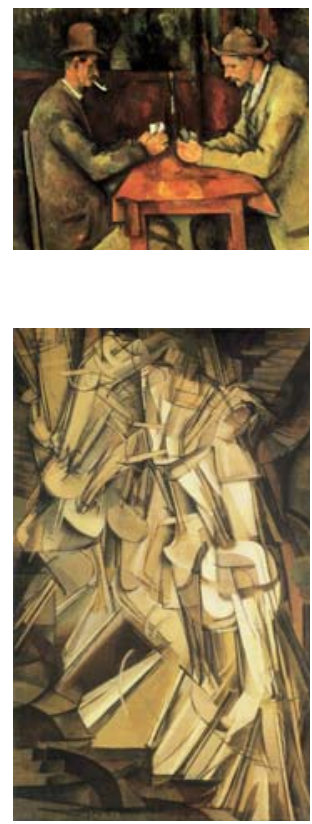

de los cables y a la capacidad resistente de la forma basada en superficies de doble curvatura, que suponen arquitecturas dificilmente representables.

En el fallo del concurso se valoraba muy positivamente el tratamiento paisajístico de la propuesta pero advertía que frente a la simplicidad general del proyecto, las cubiertas planteaban grandes problemas técnicos que deberían ser resueltos.

Un comité de especialistas estudió diferentes soluciones presentadas, seleccionando la elaborada por Frei Otto. Junto con Rolf Gutbrod habían puesto de moda este tipo de estructuras con el pabellón Alemán para la Feria de Montreal de 1967. Varios proyectos presentados al concurso del Parque Olímpico incluían este tipo de estructura.

Para definir las formas de la cubierta utilizaron maquetas realizadas con agua jabonosa; una vez fijados los puntos fijos la película de jabón los enlaza con la minima superficie posible.

Para poder realizar el proyecto de la cubierta del estadio, ante la dificultad de su comprehensión en dibujos planos, se recurrió a un gran número de maquetas. Una primera familia de modelos a escala posibilitó la definición exacta de la geometría por aproximaciones sucesivas, para posteriormente realizar maquetas que permitieran analizar el comportamiento dinámico y estructural del conjunto.

\section{B.5.2. El caso de Pekín}

Una preciosa locura, una tela de araña sin ningún rigor geométrico aparente.

Pero ¿̇Deben ser la arquitectura y su geometría las mismas si han cambiado los sistemas de dibujo y los métodos de cálculo se han hecho infinitamente mas potentes?

El desarrollo de las ciencias físicas a lo largo del siglo XX han modificado el concepto del universo hacía una visión total, desde el átomo a la estrella, demandándonos una intuición del espacio que no es la nuestra, la que hemos recibido casi como herencia biológica

Somos parodiando a Moliere, "euclídeos" sin saberlo, y no podemos intuir, dibujar como querría Eugenio d'Ors- cosas como la curvatura del espacio-tiempo, la infinitud, pero con limites, del universo, la composición del núcleo del átomo, la contradicción lógica entre el corpúsculo y la onda en un mismo ente. ¿Podría existir otra idea del espacio, otra geometría, desde la que pudiéramos intuir y representar estas cosas?

La geometría no es el espacio mismo sino simplemente un sistema para su representación. Ahora nos encontramos, aunque lo arrastremos desde hace más de cien años, en un momento de transición, nuestra concepción espacial del mundo es euclídea, aunque no sabemos si por mucho tiempo.

Cuando Paul Cézanne en algún momento del lustro que va de 1885 a 1890 pinta "Los Jugadores de Cartas", inicia, aunque con timidez, el camino de dislocación de los fundamentos de la representación geométrica del espacio: la perspectiva cónica.

Nuestro espacio euclídeo se representa, racionalmente, por medio de la perspectiva cónica, descubierta por León Bautista Alberti, tan racionalmente que, por ejemplo, en las "Meninas", de Velázquez, podemos determinar con exactitud cualquier medida de profundidad, como la distancia desde el perro hasta la pared del fondo, en función de cualquier medida real que se nos dé: la estatura de uno de los personajes, por ejemplo. Un cuadro en perspectiva cónica es casi una ficha del catastro en las tres dimensiones del espacio euclídeo. ${ }^{2}$

No podemos pensar en la ignorancia o desgana de Cézanne hacia los principios de la perspectiva, ni tan siquiera la voluntad de marcar distancias con la fotografía, representación perfecta del espacio euclídeo, sino la intención de superar un sistema de representación que no cubría todas las expectativas de los más inquietos creadores.

En el Nu descendant un escalier he querido crear una imagen estática del movimiento: el movimiento es una abstracción, una deducción articulada en el interior del cuadro sin que se tenga que saber si un personaje real desciende o no una escalera igualmente real. En el fondo el movimiento es la mirada del espectador que la incorpora al cuadro. Marcel Duchamp ${ }^{3}$ )

1. MOYA BLANCO, Luis. La geometría de los arquitectos griegos pre-euclidiano. Discurso leído el día 15 nov 1953 con motivo de su Ingreso en la Real Academia de Bellas Artes de San Fernando

2. Idem

3. CABANNE, Pierre. (1967). Conversaciones con Marcel Duchamp. Ed. Anagrama. 1984. ISBN 84-339-0406-X 
De esta manera Duchamp nos justifica en la búsqueda de nuevos "medios", la renuncia a la concepción clásica de la perspectiva. En conversación con Pierre Cabanne en 1966 desarrolla estos extremos, y nos los relaciona con las matemáticas y con la geometría

Marcel Duchamp. - yo explicaba que cuando se quiere mostrar un avión en vuelo no se pinta una naturaleza muerta. El movimiento de la forma en un tiempo dado nos hace entrar fatalmente en la geometría y las matemáticas; igual ocurre cuando se construye una maquina...'

Una búsqueda de una nueva manera de representar, a veces desde la intuición, como demuestra lo publicado en 1947 por Leo Stein (hermano de Gertrude, pintado por Picasso; Retrato de Leo Stein, 1906, Museo de Arte de Baltimore) relativo a un hecho acontecido cuatro décadas antes.

Tuvo lugar un momento revolucionario. Picasso empezó a tener ideas. La evolución creativa de Bergson estaba en el aire con su seductor lema del "élan vital". Había un amigo de la pandilla de Montmartre, interesado por las matemáticas, que hablaba de infinitos y cuartas dimensiones. Picasso empezó a tener opiniones sobre lo que era y no era real, aunque como no entendía nada de estas materias, sus opiniones eran infantilmente tontas. Se detenía ante un cuadro de Cézanne o Renoir y decía despreciativamente, "¿Es esto una nariz? No, esto es una nariz", y entonces dibujaba un diagrama piramidal. "¿Es esto un vaso?", decía, dibujando un vaso en perspectiva. "No, esto es un vaso", y dibujaba un diagrama con dos círculos unidos por líneas cruzadas. Yo le explicaba que lo que Platón y otros filósofos entendían por "cosa real" no eran diagramas, que los diagramas eran simplificaciones abstractas y ni un ápice más reales que las cosas con todas sus complejidades, que las ideas platónicas estaban a distancias inmensas de las abstracciones, y que no podían pintarse, pero él estaba inclinado haciendo algo importante; la realidad era importante pasara lo que pasase, y así continuaba Picasso. Leo Stein ${ }^{2}$

Dejando aparte el tono del relato, lo importante es la insatisfacción del artista con los métodos tradicionales de representación y la preocupación por la representación de lo "real" más allá de la percepción.

Los "nuevos medios" a los que se refería Duchamp o la preocupación de Picasso por la representación de lo "real" han supuesto, entre otras muchas investigaciones, un siglo de búsqueda de nuevas formas de representación del espacio que han convivido con la concepción euclídea.

Pero ¿̇desde cuándo la concepción euclídea había sido la única representación del espacio? La respuesta es sorprendente, según apunta Luis Moya; sólo desde el Renacimiento se ha intuido este espacio de un modo lógico y coherente. Desde luego hubo otros conceptos del espacio distintos del nuestro, y, por tanto, hubo cambios y etapas de experimentación como la actual, con la emergencia de los sistemas de diseño paramétricos.

Repasando con atención "De Architectura"3 de Vitrubio, podemos encontrar una contradicción en dos fragmentos no muy alejados.

Primero establece un sistema de proporciones deducido del canon para el cuerpo humano. Sistema absoluto, en el que el Templo queda definido como un ente ideal, completo y perfecto en sí mismo, e independiente de su tamaño, situación, materiales que lo componen, puntos de vista y cualquier otro dato exógeno o particular. En el segundo fragmento, contradice las normas del primero estableciendo la disminución del fuste de las columnas en relación a su altura real y la inclinación que deben darse en función de su altura. Siendo el motivo en ambos casos la apariencia del edificio, o sea tomando en cuenta de manera explicita al espectador.

El conflicto se produce entre realidad y apariencia.

¿Es creíble pensar que las composiciones irregulares de los santuarios de la Antigua Grecia, como la Acrópolis de Atenas, el Santuario de Olimpia o Delfos, carecían de sistema o normas de composición?

Conocemos el sistema de Vitrubio, que éste lo recibe de Hermógenes y éste de otro gran jonio, Hipodamo de Mileto, contemporáneo de Pericles y al cual se refiere Aristóteles aprobando "la nueva manera" como "forma" ideal de la Ciudad y esta forma es la cuadrícula. Es un sistema tremendamente eficiente,

1. Idem. Marcel Duchamp

2. Appreciation, Painting, Poetry and Prose. Ed. Random House. Nueva York

3. VITRUBIO POLLIÓN, Marco (s I d.C.) Los Diez Libros de Arquitectura. Título original: De Architectura. Traducción;

OLIVER DOMINGO, José Luis. Ed. Alianza Forma 1995. Madrid. ISBN: 84-206-7133-9 

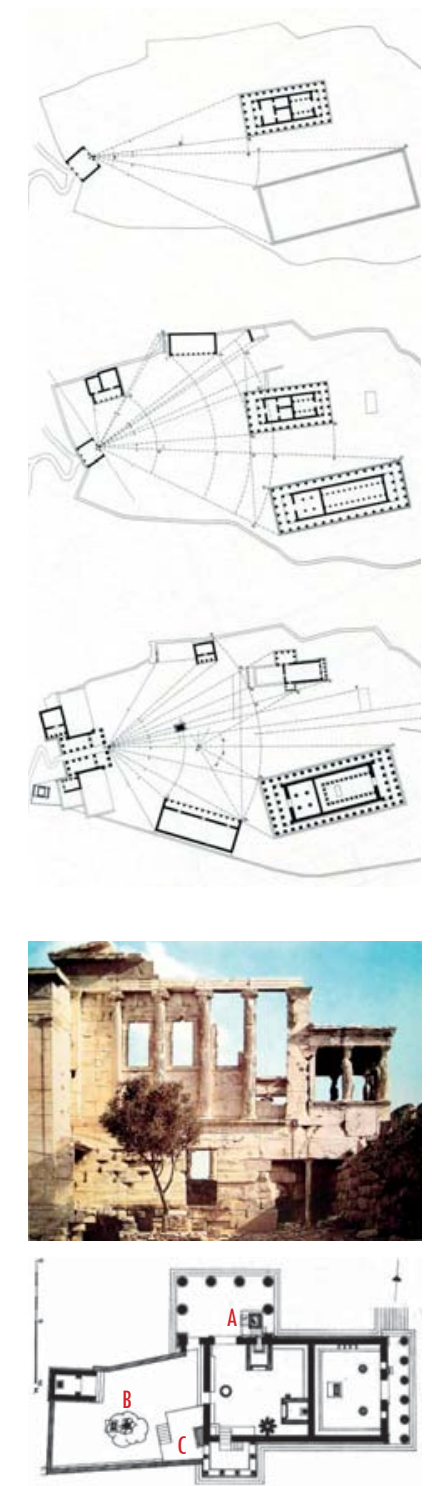

A. Huella del tridente de Poseidón B. Olivo de Minerva

C. Tumba de Cecrops sencillo, rápido y muy versátil.

Pero en el siglo $\vee$ ocurre un hecho destacable, la reconstrucción de dos santuarios; la Acrópolis de Atenas y el Santuario de Aphaia en Egina, el primero según el irregular sistema antiguo y el segundo con el sistema rectangular Hipodámico. $Y$ coincide que son dos obras contemporáneas y en lugares próximos y en ambas con preexistencias que seguían el sistema antiguo.

¿Por qué el mas importante y representativo de los dos carece, según nuestro entendimiento, de un orden lógico? ¿Cuáles son las razones del trazado irregular de la Acrópolis?

Se podría pensar en alguna razón litúrgica de respetar los lugares sagrados antiguos, además de la razón practica de aprovechar las cimentaciones de los templos destruidos. Pero ya Luis Moya en su citado Discurso lo invalida basándose en los estudios derivados de la excavación sistemática realizada por la Escuela Americana de Estudios Clásicos en Atenas, argumentado:

En efecto: los cimientos antiguos no se han aprovechado en los Propíleos, ni en el Erecteo, ni en el Partenón. Respecto al último, caso importante por sus grandes dimensiones y por ser el Templo principal, se empezó por abandonar el emplazamiento del Hecatompedón, el viejo Templo, en época algo anterior a Pericles, el año 480 aproximadamente, y se empezó a construir la base del nuevo. Con Pericles, y hacia el año 450, se modifica esta base y se completa para el futuro Partenón, que en definitiva queda separado del templo antiguo por una calle de veinte a veinticinco metros de anchura. Los restos de éste se arrasaron por completo y sobre ellos se hizo la plaza que precede al Erecteo, y con los tambores de columnas y otros sillares obtenidos de la demolición se hicieron cimientos, muros de contención y relleno de terraplenes en varios sitios de la Acrópolis.'

Pero si no hay razones de tipo litúrgico o constructivo, ¿̇qué otro tipo de razones podemos buscar?

El Partenón está situado en el punto más elevado de la Acrópolis, pero no gracias a la topografía natural, sino de forma artificial y con gran esfuerzo, ya que en algunas partes se necesitaron rellenos de hasta trece metros de altura.

En cuanto a la orientación coinciden el Partenón iniciado antes de Pericles y el definitivo (477-432), que es treinta años posterior. Pero esta coincidente orientación no es paralela a la del templo antiguo. De la posición del Erecteo (terminado el año 407) tampoco podemos obtener ninguna clave. Su caso es más complejo, ya que debía conservarse la situación de varios lugares sagrados: la huella del tridente de Poseidón en la roca viva, el olivo de Minerva, la tumba de Cecrops y otros. Pero ni su posición ni su traza responden a la integración o valoración de las preexistencias, puesto que, la huella del tridente ha quedado en el pórtico norte, pero fuera de su eje. El olivo de Minerva en un patinillo irregular delante de la fachada oeste. Y la tumba de Cecrops quedaba, de manera absurda, debajo del gran pilar de ángulo del cuerpo principal de la fachada oeste, apeándose el peso mediante un potente dintel de mármol.

Tenemos tres grandes edificios casi contemporáneos: el Partenón (447-432), los Propíleos (437-432) y el Erecteo (420-407), dispuestos con absoluta libertad, sin atender a preexistencias, ni a razones constructivas, litúrgicas o topográficas.

Después de lo expuesto anteriormente ¿̇podemos pensar que su composición es arbitrarią ¿Qué razón habría llevado a que el Santuario de Aphaia en Egina respondiera a una traza geométrica y la intervención en la Acrópolis no. No sería más lógico pensar que el criterio geométrico de la Acrópolis es distinto que el criterio geométrico del Santuario de Aphaia, que es el que utilizamos hoy?

¿Pero como no iba a ser distinto si nuestra geometría es Euclídea y la fecha de aparición de los "Elementos" de Euclídes es alrededor del 300, es decir, más de un siglo después de terminarse la Acrópolis?

La organización de los tres edificios principales de la Acrópolis la consideramos "irregular" porque sus ejes no son paralelos, con la irritante circunstancia de que le faltan muy poco para serlo. $Y$ que no es fácil encontrar una relación estética que justifique los agudísimos ángulos que forman, y por la misma pequeñez de éstos podían haberse evitado haciendo paralelos los tres edificios sin alterar prácticamente su organización.

Esto parece hablarnos de un sistema que no tiene en cuenta las paralelas, ni tampoco las niega, sino que simplemente no las necesita. Y con esto volvemos al inicio, a la estructura del estadio Olímpico

1. Idem. Luis Moya Blanco 
de Herzog y de Meuron, en Pekín. Pero también nos podría remitir a los estadios de Tange para Tokio 1964, que para poder definir las formas y su análisis estructural recurre a un gran numero de maquetas, algunas de gran tamaño a escala 1/10 y ante la complejidad de los cálculos se recurrió a una protocalculadora de tipo mecánico.' Para la definición y cálculo del Conjunto Olímpico de Munich, en 1972, además del tradicional método de trabajo con maquetas a escala, se recurre por primera vez a una aplicación sustancial de ordenador. Pero por muy potente que pudiera ser el ordenador la capacidad gráfica y por tanto de representar sus resultados era muy limitada.

Los medios actuales de trabajo, potentes ordenadores personales con pantallas de muy alta calidad gráfica y programas accesibles a cualquier aficionado, están provocando un cambio importante en cuanto a los fundamentos geométricos de la arquitectura.

Las posibilidades que ofrecen los nuevos materiales $y$, lo que es más importante, la conquista del espacio a través del ordenador han producido una revolución de imprevisibles consecuencias ${ }^{2}$

Tal vez los nuevos sistemas de trabajo, con herramientas más potentes de dibujo, análisis y cálculo, dando un tremendo bucle a la historia, permitan despegarnos de las rigideces y simplificaciones, que nos han ayudado a entender las cosas sobre todo desde el siglo XVIII cuando Newton buscaba, ni mas ni menos, el sistema del mundo, La Teoría del Todo, y volvamos a manejar sistemas compositivos más eficaces, intuitivos y próximos a la naturaleza.

\section{B.5.3. Isopticas. El panóptico inverso}

Aunque la arquitectura del estadio está en intima relación con la competición deportiva que en él se desarrolla, incluso, su propio nombre se confunde con el de la primera y principal prueba disputada en el claro del bosque de Olimpia, la clave del espacio que construye es el público y la manera que éste se ordena y dispone.

Cuando Goethe visita el anfiteatro de Verona en 1786, inmediatamente se da cuenta de que el fin último del estadio es contener gente.

me pareció raro contemplar algo tan grande y al mismo tiempo tan vacío. Ciertamente se trata de un monumento que merece visitarse repleto de gente, tal como se llenó en tiempos recientes en honor a José Il y a Pío VI. El emperador, pese a estar acostumbrado a la contemplación de grandes masas de gente, debió quedar asombrado ante semejante espectáculo. No obstante, sólo en tiempos pretéritos, cuando el pueblo era más pueblo que ahora, producía el anfiteatro todo su efecto. Puesto que un anfiteatro se construye para que el pueblo se impresione de sí mismo y se ría de sí mismo. ${ }^{3}$

y nos relata cuál es el proceso que lleva a su configuración formal, basado en la necesidad de visión del espectáculo

Siempre que se celebra algo digno de atención en un lugar llano y todo el mundo acude allí, los que están detrás intentan por todos los medios elevarse por encima de los que están delante: se suben a los bancos, traen toneles, vienen en coche, colocan tablas en diversos sentidos, ocupan un cerro próximo, y rápidamente se forma una especie de cráter.

Si el espectáculo se repite con frecuencia en el mismo sitio, se construyen pequeñas tribunas para los que puedan pagarlas, y el resto de la gente se las arregla lo mejor posible. Satisfacer la necesidad general es tarea del arquitecto, que crea una construcción de planta elíptica, con gradas alrededor, lo más sencilla posible, con objeto de que el mismo pueblo constituya el ornamento. ${ }^{4}$

Planta elíptica y escalonamiento son características básicas de los estadios, que como bien cuenta Goethe están motivadas por la necesidad de ver; la capacidad de visión de todos los espectadores es el arma principal del arquitecto del estadio, como sucede en la siguiente historia extraída del cuento romántico de Ernst T.A Hoffmann titulado Meister Floh (Master Flea) publicado en 1822. Cuenta la lucha llevada a cabo entre los dos ópticos, pero en el fondo nos habla sobre lo visual como arma:

Tan pronto como Leuwenhoek había divisado a su enemigo Swammerdamm intentó bloquear la puerta con su espalda. Cuando Swammerdamm percibió esto sacó un pequeño catalejo de su bolsillo, lo abrió y se acercó al enemigo gritando con fuerza: “ déjame entrar malnacido si tienes agallas!". Rápidamente Leuwenhoek sujetando

1. LLamada "tiger calculator". Recordemos que la primera calculadora electronica, la Sharp Compet CS10A, es de diciemmbre de 1964.

2. PÉREZ ARROYO, Salvador. Sobre formas no convecionales. RC. Resúmenes de Construcción. n³. 1999.

3. GOETHE, Johann Wolfgang von. Viaje a Italia. Ed. Zeta, 2009. ISBN: 8498722632,9788498722635

4. Idem
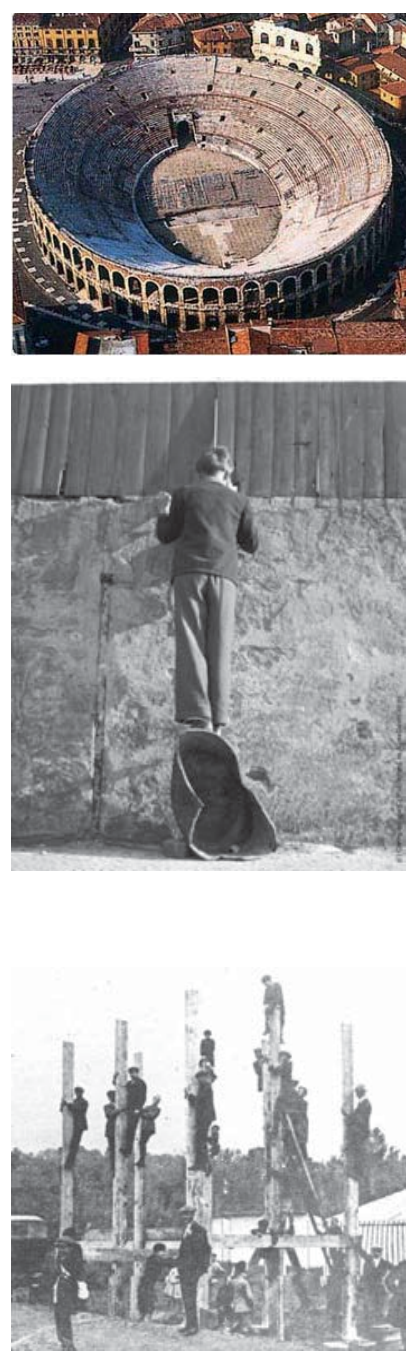


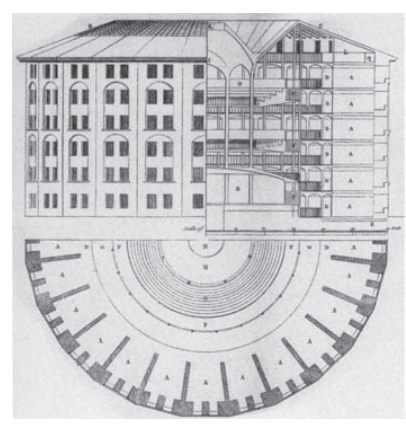

un instrumento similar en su mano gritó: "ven, resistiré y dentro de poco sentirás mi fuerza!".

Los dos prepararon sus catalejos y se abalanzaron el uno contra el otro con furia, golpes mortales con sus catalejos que se alargaban y se acortaban cada vez. Sus mentes se calentaron más y más. Cuando uno de ellos fue alcanzado, gritó fuertemente, saltó alto en el aire, hizo extrañas cabriolas y piruetas como el mejor bailarín del ballet de Paris, hasta que el otro le fijó firmemente a través del catalejo acortado. Cuando el otro recibía los golpes, actuaba de la misma manera. Estaban cargando el uno contra el otro con los saltos más extravagantes, con los gestos más locos y con los gritos más fieros. Sudor caía de sus frentes, ojos ensangrentados en sus caras y tan solo se podía verlos mirando a través de sus catalejos. Habían perdido la razón y por sus bailes de San Vito, podía considerarseles como locos escapados del manicomio. Lo acontecido era bonito de ver.

Lo acontecido era bonito de ver... con esta frase está convirtiendo la desordenada competencia de los dos estrafalarios personajes en espectáculo... saltó alto en el aire, hizo extrañas cabriolas y piruetas como el mejor bailarín del ballet de Paris.

Todos los lectores del cuento nos sentamos alrededor y somos espectadores mudos e invisibles de ésta disputa, convertidos, todos y cada uno, en el guardián de la prisión ideal propuesta por el filósofo Jeremy Bentham en 1791. El concepto de este diseño permite a un vigilante observar (-opticón) a todos (pan-) los prisioneros sin que éstos puedan saber si están siendo observados o no.

La estructura de la prisión incorpora una torre de vigilancia en el centro de un edificio anular que está dividido en celdas. Cada una de estas celdas tiene dos ventanas, una exterior para que entre la luz y otra interior dirigida hacia la torre de vigilancia. Los ocupantes de las celdas se encontrarían aislados unos de otros y sujetos al escrutinio colectivo e individual de un vigilante en la torre que permanecería oculto. Para ello, Bentham no sólo imaginó persianas vecinas en las ventanas de la torre de observación, sino también disposiciones laberínticas en la torre para evitar destellos de luz o ruido que pudieran delatar la presencia de un observador.

Los estadios constituyen la inversión funcional y simbólica del Panóptico. Ya no es una sola persona que observa desde el centro los movimientos de otras situadas a su alrededor sino muchas que, habiendo perdido la centralidad, observan el desenvolverse de los protagonistas que ahora ocupan el centro.

Ésta condición periférica, homogénea y, sobretodo, multitudinaria de los espectadores alrededor del espectáculo, requiere una sistematización y un orden muy preciso que permita el mayor aforo, siempre limitado por la distancia máxima de observación. Ya en la gigantesca construcción realizada en París para la celebración de la Festividad de la Confederación en 1790 se puso de manifiesto la dificultad que tuvieron los asistentes para seguir adecuadamente los acontecimientos,

A causa de la gran dimensión de la construcción, los espectadores más alejados no podían escuchar los discursos, la música, o los resultados de las competiciones'

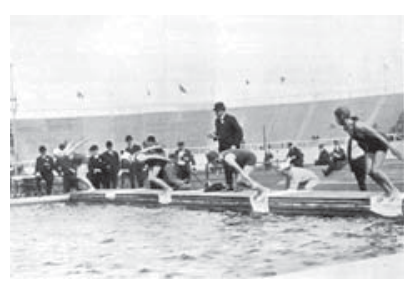

Para los grandes estadios las coreografías de los espectáculos debían ser multitudinarias, para que el ojo humano tuviera la capacidad de seguir los acontecimientos. En el caso de Londres 1908, el seguimiento a gran distancia de una competición de natación se antoja absurdo.

La longitud máxima de cualquiera de los espectadores al espectáculo ha ido fluctuando en la serie histórica de los estadios Olímpicos según datos reflejados en el cuadro adjunto.

Según Rod Shearde, arquitecto de Populus, lo optimo sería no superar los 150 metros y el límite máximo 190 metros. $^{2}$

En toda la seríe Olímpica, solo dos estadios ha estado por debajo de esos guarismos; el de Amberes 1920 con el exiguo aforo de 30.000 espectadores, de los cuales 20.000 permanecían de píe y Estocolmo con 20.000. Está claro que rodear pistas de atletimo y conseguir grandes aforos obligan a que las distancias de observación superen los máximos recomendables.

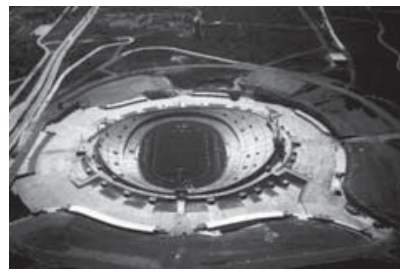

Es estadio de México que fue diseñado atendiendo meticulosamente a las condiciones de visión de los espectadores llega hasta un aforo de casi 70.000 espectadores con una distacia máxima de 201 metros

1. EICHBERG, Henning, Stadium, Pyramid, Labyrinth: Eye and Body on the Move. The Stadium and the City. Ed. Keele University Press. 2005. ISBN 1853311103

2. SHEARD, Rod. Sports Architecture. Ed. Spon Press. 2001. ISBN 0-419-21220-5. Populus es la mayor ingeniería mundial especializada en instalaciones deportivas. Sheard ha sido el responsable de los estadios Olímpicos de Sydney 2000 y Londres 2012 . Único arquitecto en la historia con dos estadios Olímpicos a su cargo. 

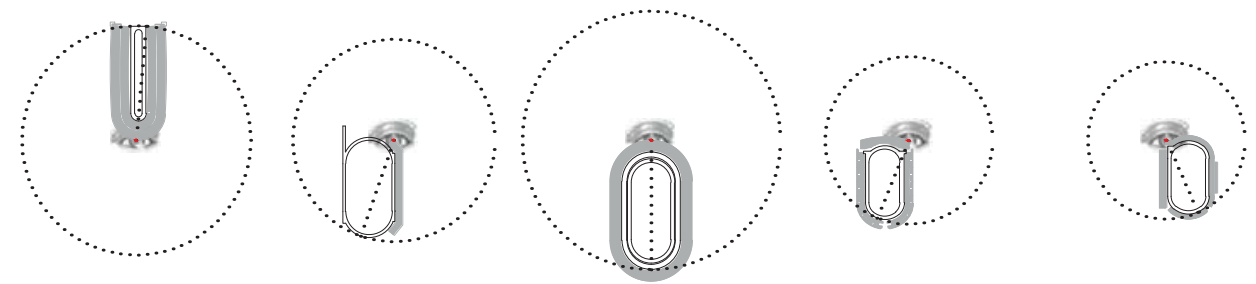

ATENAS $1896(254 \mathrm{~m}$.

ST LOUIS 1904 (225m.)

LONDRES 1908 (287m.)

ESTOCOLMO 1912 (186m.)

AMBERES 1920 (175m.)
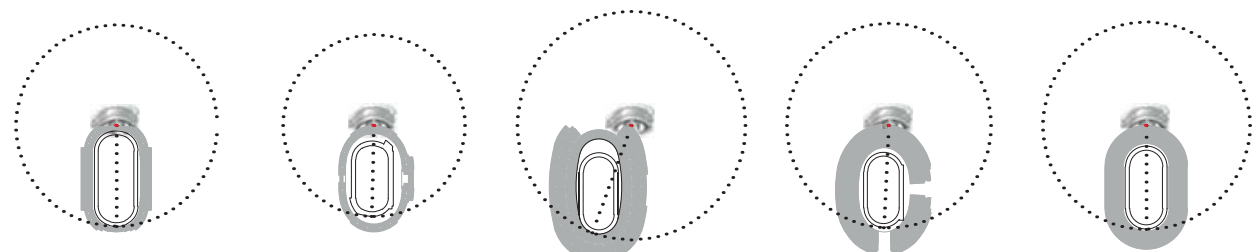

PARís 1924 (224m.)

AMSTERDAM 1928 (202m.)

LOS ANGELES 1932 (253m.)

BERLÍN 1936 (227m.)

LONDRES 1948 (230m.)
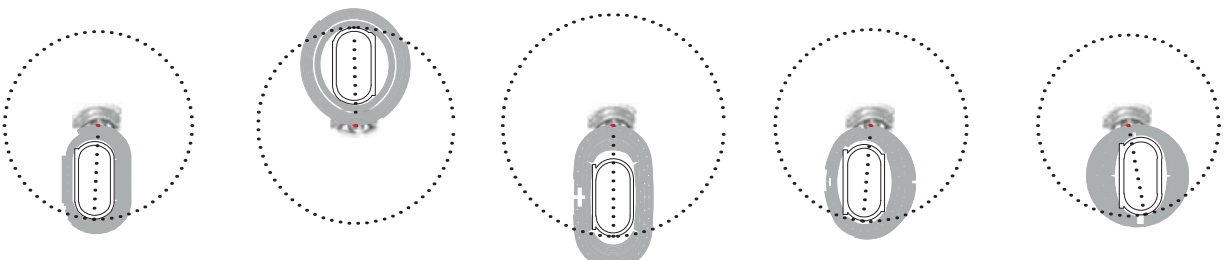

HELSINKI 1952 (209m.)

MELBOURNE 1956 (218m.)

ROMA 1960 (246m.)

TOKIO 1964 (213m.)

MÉXICO 1968 (201m.)
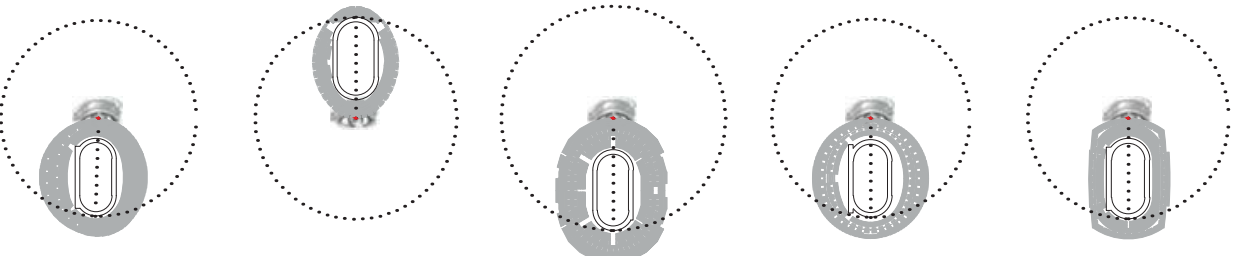

MUNICH 1972 (218m.)

MONTREAL 1976 (224m.)

MOScÚ 1980 (249m.)

SEUL 1988 (220m.)

BARCELONA 1992 (224m.)
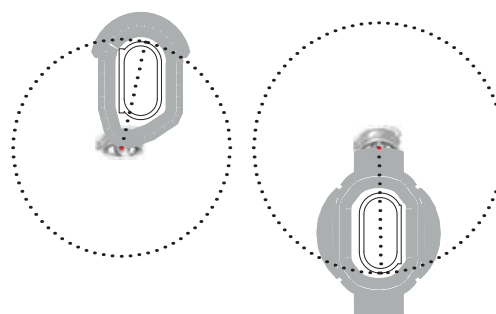

ATLANTA 1996 (241m.)

SYDNEY 2000 (278m.)

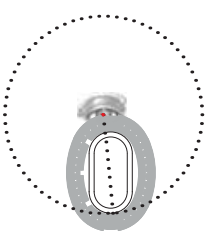

ATENAS 2004 (219m.)

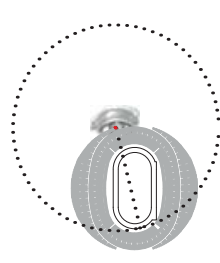

PEKÍN 2008 (229m.)

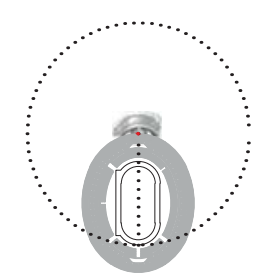

LONDRES 2012 (247m.)

Elias Canetti nos explica cómo debe ordenarse las masas en los estadios

El número de asientos es limitado. Su densidad tiene fijado el límite. Los asientos están dispuestos de tal manera que uno no se aprieta demasiado. Los hombres han de estar cómodos. Tienen que ver bien, cada uno desde su puesto, y no deben molestarse entre sí.

Las filas están escalonadas hacia arriba para que todos vean lo que ocurre abajo. Pero eso tiene por consecuencia que la masa está sentada frente a sí misma. Cada uno tiene mil cuerpos y mil cabezas delante de sí. Mientras él esté, todos están. Lo que le excita, también les excita a ellos, y él lo ve. Los demás están sentados a alguna distancia de él; los detalles, que en otras ocasiones les distinguen y les individualizan, se borran. Todos se hacen muy semejantes, se comportan de modo semejante. Él sólo advierte en ellos lo que le llena a él mismo en este ahora. La visible excitación de los demás aumenta la suya.

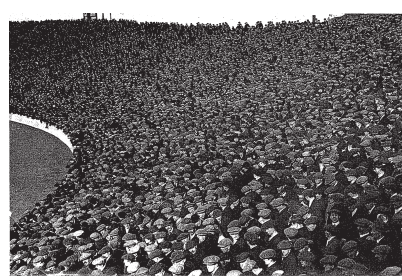

Peter Sloterdijk añade la condición sonosférica del estadio

Quien no entiende el texto ha de entender la acción; a quien le resulte extraña la

1. CANETTI, Elias. (1960). Masa y poder. Ed. Alianza Editorial, 2005. ISBN 8420637513 
acción, ha de ser cautivado por el colorismo del espectáculo. La fusión sonosférica se encarga del resto.'

Continúa Canetti

La masa que así se exhibe ante sí misma no se halla interrumpida en parte alguna. El anillo que constituye es cerrado. Nada se le escapa. El anillo de rostros fascinados superpuestos tiene algo de curiosamente homogéneo.
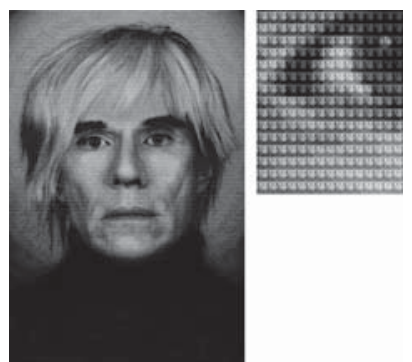

Estudio luminotécnico de Henningsen. Sistema Multishade. Casa Tugendhat

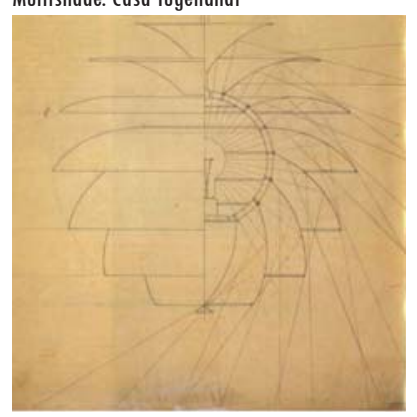

Algo así como los retratos del artista Alex Guofeng Cao, que por medio de pequeñas fotografías de un personaje conocido construye otro. Y también sucede lo mismo con la obra expuesta en el aeropuerto de Gatwick en Londres, que representa la reina Isabel II con motivo de sus cincuenta años de reinado y está constituida por pequeños retratos de personajes anónimos.

El estadio está compuesto por miles de caras ordenadas de una cierta manera, lo que nos hace volver a Goethe

Satisfacer la necesidad general es tarea del arquitecto, que crea una construcción de planta elíptica, con gradas alrededor, lo más sencilla posible, con objeto de que el mismo pueblo constituya el ornamento. ${ }^{2}$

El sistema para la organización y disposición del público es directo heredero de la experiencia acumulada en los teatros de la antigüedad clásica, que han configurado una máquina perfecta desde el punto de vista funcional. Artificio que, al aumentar la escala, precisa del perfeccionamiento de la configuración de las visuales introduciendo la parábola en su generatriz.

Y aquí la palabra clave isóptica, surge desenmascarada de su origen técnico convirtiendose en principio determinante del diseño y trazado de los graderíos que procura la visión igualitaria y completa del espectáculo. Todo un problema de orden geométrico.

1. SLOTERDIJK, Peter (2004). Esferas III. Espumas. Esferorogía plural. Biblioteca de Ensayo. Ediciones Siruela. ISBN 978-84-7844-951-4. Segunda edición febrero 2009. Pág. 471

2. GOETHE, Johann Wolfgang von. Viaje a ltalia. Ed. Zeta, 2009. ISBN: 8498722632,9788498722635 


\section{Bibiografía. Geometría}

CABANNE, Pierre. (1967). Conversaciones con Marcel Duchamp. Ed. Anagrama. Barcelona. ISBN: 84-339-0406-X. Segunda edición 1984. Titulo original: Entretiens avec Marcel Duchamp. Éditions Pierre Belfond. París

CANETTI, Elias. (1960). Masa y Poder. Ed. Muchnik

CANO LASSO, Julio. (1996). Estudio Cano Lasso. Ed. Electa. ISBN: 88-435-5951-6

CANO LASSO, Julio (1988). Cano Lasso. Arquitecto. Ed Fandación Camuñas. Madrid. ISBN: 84-404-2524-4 DOXIADIS, C.A. (1937). Architectural Space in Ancient Greece. The MIT Press. Cambridge, Massachussets, and London, England. 1972. ISBN: 026204021 2. Titulo original: Raumordnung im griechischen Städtebau. Alemania FOUCAULT, Michel. (1975). Vigilar y Castigar. Ed. Siglo XXI. 2004. ISBN 987-98701-4-X

GOETHE, Johann W. Viaje a Italia. Ed. Zeta. ISBN 978-84-9872-263-5

GOMBRICH. Ernest H. (1991). Temas de nuestro tiempo. Propuestas del siglo XX acerca del saber y del arte. Ed. Debate s.a. ISBN: 84-8306-957-1. Segunda edición diciembre 2002. Titulo original: Topics of our Time. Phaidon Press Limited

LE CORBUSIER. (1923). Hacia una arquitectura. Ed. Ediciones Apóstrofe, s.l. ISBN: 84-455-0277-8. Segunda edición 1978. Primera reimpresión sept 1998. Titulo original: Vers une architecture. Paris, 1923, 1928 y 1958 MEREWETHER, Charles. (2008). Ai Weiwei, Herzog \& de Mearon. Ed. Albion. ISBN 1900829282

MOYA BLANCO, Luis. (1953). La geometría de los arquitectos griegos pre-euclidianos. Discurso leído el día 15 nov 1953 con motivo de su Ingreso en la Real Academia de Bellas Artes de San Fernando. Ed. RABBAASF. Madrid MULLER, Joseph-Emile. Impressionism. Ed. Fernand Hazan éditeur. París 1983

PÉREZ ARROYO, Salvador. Sobre formas no convecionales. RC. Resúmenes de Construcción. n³. 1999.

SLOTERDIJK, Peter. (2004). Esferas III. Espumas. Esferorogía plural. Biblioteca de Ensayo. Ediciones Siruela. ISBN 978-84-7844-951-4. $2^{a}$ edición. Febrero, 2009. Titulo original: Sphären III (Plurale Sphärologie). Schäume. Suhrkamp Verlag, Frankfurt am Main, 2004. Tracción Isidoro Reguera

STEIN Leo. Appreciation, Painting, Poetry and Prose. Ed. Random House. Nueva York

STEWART, lan. ¿̇Juega Dios a los dados?. La nueva matemática del caos. Ed. Drakontos bolsillo. Crítica, s.l. ISBN: 978-84-8432-881-0. Segunda edición: octubre 2007. Titulo original: Does God play dice? The new mathematics of chaos .Penguin Books Ltd. Harmondsworth

SHEARD, Rod. Sports Architecture. Ed. Spon Press. 2001. ISBN 0-419-21 220-5

VITRUBIO POLLIÓN, Marco (s. I dC.) Los Diez Libros de Arquitectura. Título original: De Architectura. Traducción; OLIVER DOMINGO, José Luis. Ed. Alianza Forma 1995. Madrid. ISBN: 84-206-7133-9

David-Henry Kahnweiler, marchand, èditeur, ècrivain. Ed. Dominique Bozo. Centre Georges Pompidou, 22 nov 1984 a 28 ene 1985

The Stadium and the City. Ed. Keele University Press. 2005. ISBN 1853311103

AV. $n^{\circ}$ 33. 1992. Juan Miguel Hernández de León El espacio de la excepción. sobre el carácter de la arquitectura deportiva. 
B-110 
B.6.

Hay cuestiones importantes que determinan la configuración arquitectónica de los estadios, como son su estilo, lenguaje, material, color, etc., pero hay otras que por su carácter conceptual son fundamentales en la definición de este tipo arquitectónico. Nos referimos, por un lado a la escala, proporción y tamaño, y por otro a la composición, atendiendo a los conceptos de ligereza o masividad y equilibrio, y, además, a la condición topográfica y/o tectónica

\section{B.6.1. Escala, Proporción y Tamaño. "Lo grande" y su riguroso requerimiento estructural}

Una grieta en la pared, cuando es contemplada en términos de escala, no de tamaño, podría considerarse el Gran Cañón. Una sala podría hacerse de forma que adquiriera la inmensidad del sistema solar

La escala depende de nuestra capacidad para ser conscientes de las realidades de la percepción. Cuando uno se niega a liberar la escala del tamaño, le queda a uno un objeto o un lenguaje que parece certero. Para mí [afirma Robert Smithson] la escala funciona a través de la incertidumbre. ${ }^{2}$

Hablar de la escala es algo complejo; por ejemplo si nos referimos a la basílica de San Pedro en Roma, la relación de cada una de las partes entre sí y con el conjunto parece absolutamente normal. Lo que no es normal es el tamaño de cada una de estas piezas en relación con su tamaño habitual. Cada elemento es más de dos veces mayor y la relación con nosotros, cuando nos acercamos, descubrimos que es disparatadamente grande. En este caso dos tipos de escala [escala entre componentes, escala componente-totalidad] entran en colisión con otros dos tipos [escala habitual, escala del observador).

Los edificios tienen unas medidas constantes y precisas, pero su escala dependerá de la elección de un sistema de proporciones y percepciones.

La simplicidad de la forma ovalada es percibida de manera muy agradable por el oio, y cada cabeza sirve de medida para hacerse cargo de lo descomunal que es el conjunto. Ahora, al contemplarlo vacío, no disponemos de referencias para determinar si la construcción es grande o pequeña. ${ }^{3}$

Goethe pretende evaluar la dimensión del estadio, por medio de la comparación, con un elemento de dimensión conocida, la cabeza humana. La rotundidad formal del interior de los estadios dificulta la percepción de su dimensión. Decía Chillida que las formas puras carecen de escala; en una pirámide hasta que te acercas no eres capaz de discernir su dimensión.

Otro elemento característico del espacio interior de los estadios es la textura; absolutamente dominada por la repetición incesante de las líneas que dibujan sus incontables gradas, vuelve a ser un elemento de gran abstracción. Es cierto que sus dimensiones están en relación directa con las del cuerpo humano, pero su condición seriada dificulta esa lectura.

En el estadio conviven dos escalas, una la magnífica de su vacio interior y otra más menuda de su piel rayada, que funciona como un pentagrama según el cual se colocan y ordenan los espectadores, cediendo parte de su individualidad, para formar parte de un ente mayor, el público.

Al verse así congregado, el pueblo, acostumbrado a una imagen desordenada

1. ELIASSON, Olafur. Weather Project de en la Sala de Turbinas de la Nueva Tate de Londres, abierta al público entre octubre de 2003 y Marzo de 2004)

2. SMITHSON, Robert. "The Spiral Jetty", 1972, recopilado en Stiles, Kristine; Selz, Peter Howard, Theories and documents of contemporary art: a sourcebook of artist' writings, University of California Press, Berkeley, Los Ángeles, 1996, p.533

3. GOETHE, Johann W. Viaje a Italia. Ed. Zeta. ISBN 978-84-9872-263-5 
de sí mismo, andando de acá para allá, habituado a la sensación de que en una multitud no hay ni orden ni concierto, por fuerza sentiría admiración ante este cuadro. En el anfiteatro, en cambio, este animal de múltiples cabezas y sentidos que se mueve desorientado de un lado a otro percibe por primera vez que está reunido en un cuerpo noble, destinado a una unidad, agrupado y afianzado en una masa, como una sola figura, animada de un único espíritu.'

El gran número de espectadores que congregan los estadios Olímpicos, significan una incontable cantidad de gradas y unas dimensiones globales magnificas. Son construcciones muy grandes y "lo grande" supone un salto cualitativo en cuanto a los criterios constructivos y estructurales.

La implicación habitual del problema estructural de las edificaciones en los estadios se desproporciona tremendamente. "Lo grande" supone un riguroso requerimiento estructural.

Antes de Galileo, el instrumento principal del constructor (ya sea del arquitecto que edifica una casa o del ingeniero que construye un barco) es el modelo. El modelo a escala es lo que permite prever el producto final, al evaluar, a priori, las características estructurales, estéticas y económicas; lo que sirve después de guía para la construcción efectiva. Una vez construido y aceptado el modelo, sólo se trataba después de imitar cuidadosamente su forma respetando las debidas proporciones.

Este antiquísimo método de construcción había funcionado durante siglos y se seguía considerando el más fiable y seguro.

Sin embargo, no carecía de inconvenientes ya que, al aumentar las dimensiones de la construcción, más de una vez había sucedido que edificios y máquinas perfectamente sólidos en el modelo se revelaban después, una vez construidos a gran escala, débiles e inseguros, si es que no se derrumbaban antes incluso de estar terminados.

Para explicar esta paradoja Galileo establece la teoría de las proporciones, con la que unifica toda la estructura matemática ${ }^{2}$. Aunque dominaba por completo las sutilezas de la teoría eudoxiana (Eudoxo de Cnido 408/355 a. C.) contenida en los Elementos de Euclides (hacia el 300 a.C.), la consideraba demasiado compleja y no suficientemente eficaz para sus proyectos, y se propone sustituirla con una nueva sistematización.

Las Consideraciones se hacen eco de la paradoja expuesta anteriormente y los técnicos del arsenal veneciano, lo conocían muy bien:

que en estas y otras máquinas semejantes no conviene aplicarles a las grandes los argumentos obtenidos de las pequeñas, ya que muchos diseños de máquinas funcionan a pequeña escala, y después a gran escala no se sostienen. ${ }^{3}$

Efecto que a primera vista parece imposible de explicar, ya que,

siendo así que todas las razones de la mecánica tienen sus fundamentos en la geometría, en la cual no veo que la grandeza o la pequeñez hagan que los círculos, los triángulos, los cilindros, los conos y cualesquiera otras figuras sólidas estén sujetos a distintos condicionantes en uno y otro caso. Cuando la máquina grande se ha fabricado en todos sus componentes conforme a las proporciones de la menor, la cual es válida y resistente para el ejercicio al que está destinada, no alcanzo a ver por qué ella ahora no es invulnerable a los accidentes, siniestros y destructivos, que le pueden sobrevenir. ${ }^{4}$

La contraposición entre mecánica y geometría chirriaba tan fuerte, que, en general, se prefería evitar toda explicación del fenómeno, atribuyéndolo habitualmente a las imperfecciones de la materia; efecto que se habría dejado sentir de manera cada vez más pronunciada al aumentar las dimensiones de la fabricación.

La teoría que Galileo desarrolla en la segunda jornada de su libro hace justicia a este extremo:

No son las imperfecciones de la materia las que producen el fenómeno, sino el mero hecho de que ella tiene una resistencia finita. Incluso suponiendo una materia libre de imperfecciones, sólo es posible ampliar la escala hasta un cierto punto, más allá del cual la fabricación, aun siendo completamente conforme al modelo, termina

1. Idem

2. GALILEO, Galilei. (1638). Consideraciones y demostraciones matemáticas sobre dos nuevas ciencias. Ed. Planeta De Agostini, 1996. ISBN 8439544979, 9788439544975

3. Idem

4. Idem 
Además de las demostraciones matemáticas, desarrolladas todas de manera impecable bajo la guía de la teoría de las proporciones, Galileo

detectó y destacó hábilmente las relaciones que hay entre el tamaño y proporción de las piezas. Mostrando una ilustración de dos huesos de distintos tamaños. Uno de ellos, tres veces más largo que el otro, no mantiene las mismas proporciones en volumen para ser igualmente eficaz. Lo que muestra Galileo se puede entender observando una fruta colgando de un árbol. Si una cereza se hiciera el doble de grande, su peso aumentaría en relación directa al volumen, es decir, crecería con el cubo de su dimensión, mientras que el tallo que la sostiene solo aumenta su resistencia con relación directa a su área, es decir con el cuadrado de su dimensión. Esto hace que una cereza que crezca linealmente acabará en el suelo, pues su tallo será incapaz de soportar un peso que ha crecido más que su capacidad para resistirlo. Con los huesos ocurre lo mismo, basta con observar la proporción relativa de la sección de hueso que tienen animales con tamaños muy diferentes. Esta simple observación limita por si solo el crecimiento de los miembros estructurales. $^{2}$

Cuando se trata con elementos constructivos de gran dimensión, como sucede en los estadios, el trabajo "por forma" de la estructura adquiere gran relevancia; la forma del estadio debe adecuarse para facilitar su eficiencia resistente.

Sí bien el graderío puede descansar sin dificultad sobre el terreno o apearse sobre él, la cubierta se enfrenta con el problema de "lo grande" en toda su magnitud.

No todos los estadios Olímpicos cuentan con cubrición; Atenas o St. Louis, carecen completamente de ella. Los Ángeles, Berlín y México cuentan con una pequeña cubierta para las cabinas de prensa y en México supone un bello gesto estructural pero su dimensión no es muy considerable.

En los estadios de las primeras etapas del desarrollo de la serie histórica, la cubierta se trataba de una manera posibilista, sin recurrir a sistemas estructurales excesivamente ambiciosos y sin que la presencia de pilares en medio del graderío supusiera un grave inconveniente. A este grupo pertenecen:

Londres 1908, Estocolmo, que es el único caso en que la cubierta recorre toda la longitud de la grada, Amberes, París, Ámsterdam, Londres 1948, Helsinki y Melbourne.

En los dos de Londres y en el de Amberes las cerchas de la estructura de la cubierta se plantean como biapoyadas. En el resto de los casos, los apoyos se retrasan lo máximo posible proponiendo cubiertas en ménsula; de ésta manera comienza el esfuerzo por vencer el desequilibrio mediante finos voladizos, inclinaciones y contrapesos.

Posteriormente, en otro grupo de estadios, Roma, Tokio y Barcelona, los apoyos de la cubierta abandonan definitivamente su posición de interferencia en la zona de público del graderío, evitando puntos muertos en la visión del espectáculo, pero sus criterios estructurales siguen siendo muy modestos y la cubierta simplemente se deposita encima de la grada, sin establecer ninguna interacción interesante ni de carácter formal ni estructural.

Montreal supone una revolución. Graderío y estructura forman un mismo mecanismo resistente y, además, está construido con grandes piezas prefabricadas. El proyecto incluía una cubierta textil que podía desplegarse o recogerse a voluntad y para su sujeción se levantaba al lado del estadio una torre inclinada con parte del programa deportivo. Todo era una novedad en la carrera del olímpismo. En Sydney y Londres 2012 también se establece una relación directa entre el trabajo estructural del graderío y la cubierta. Son estructuras en que "la forma" es su principal argumento sustentante.

En un último grupo de estadios las estructuras de la cubierta y del graderío son independientes. En Múnich la interesante y ligera cubierta está traccionada, desarrollada por Frei Otto y Jörg Schlaich, según el proyecto de Günther Behnisch. Y en Pekín la estructura es fachada y cubierta y configura el espacio. Se define mediante 24 pilas desde las que se tiende la estructura primaria de la cubierta y posteriormente una estructura secundaria va entrelazando las pilas e incrementando la rigidez y densidad de la estructura, hasta proporcionarle ese interesante aspecto caótico.

Su concepto estructral supera un entendimiento tradicional y racional de descomposición de las cargas y esfuerzos de una manera lineal, para concebir la estructura como un elemento de carácter natural,

1. Idem

2. CHURTICHAGA; José María. La estructura Veloz. Trayectorias estructurales a propósito de la obra de Emilio Pérez Piñero y Félix Candela.

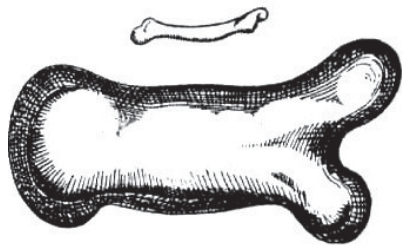

ATENAS 1896

ST LOUIS $\widehat{1904}$
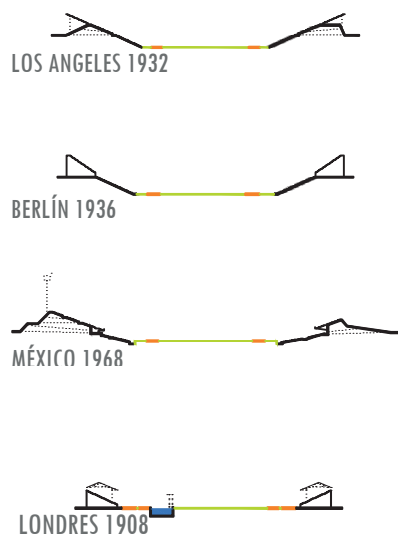

ESTOCOLMO $\frac{\mathbb{1}}{1912}$ 入
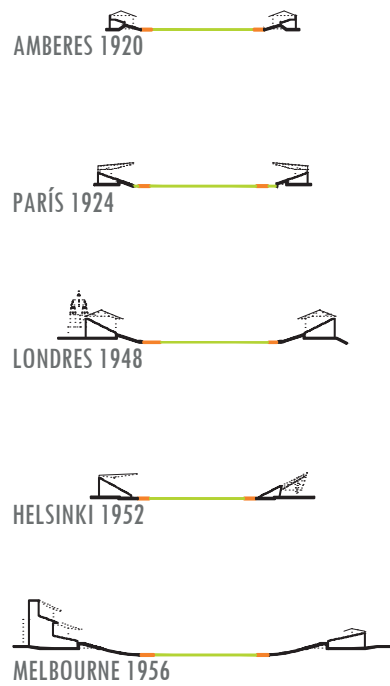


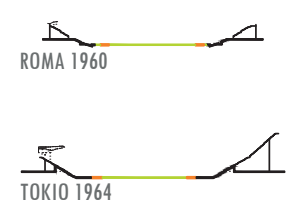

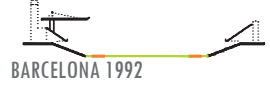
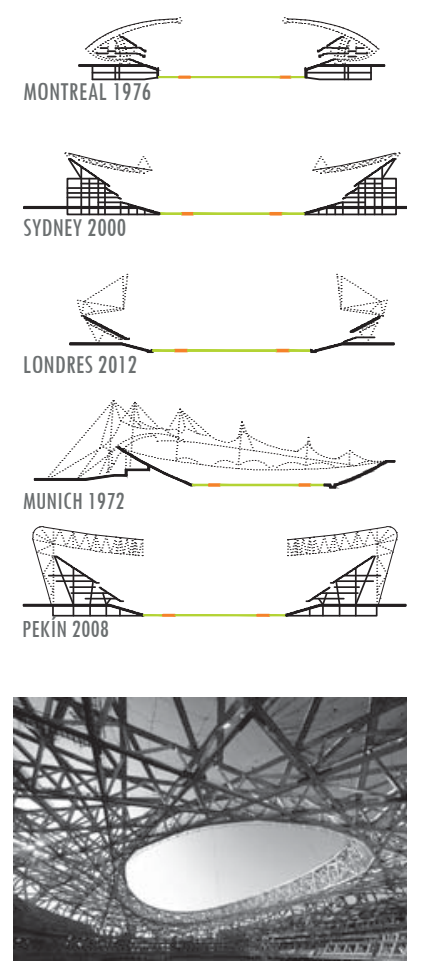

con un comportamiento global, en el que la rigidez que aporta el entrelazado de barras permite respuestas muy variadas en función de las cargas variables.

La imagen del estadio depende y se confia a la estructura.
ATENAS 1896

ST LOUIS 1904

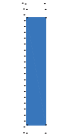

LONDRES 1908

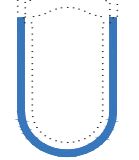

ESTOCOLMO 1912

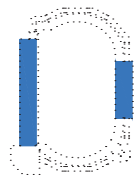

AMBERES 1920

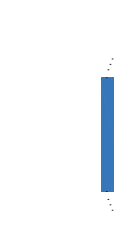

PARÍS 1924

HELSINKI 1952

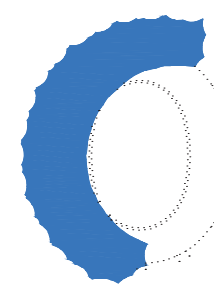

MUNICH 1972

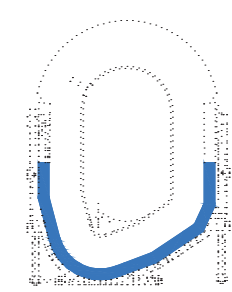

ATLANTA 1996

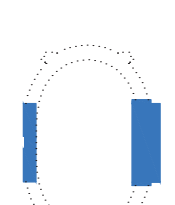

AMSTERDAM 1928

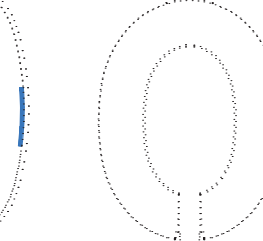

BERLÍN 1936

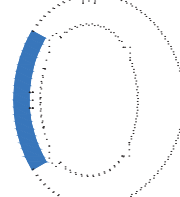

TOKIO 1964

ROMA 1960

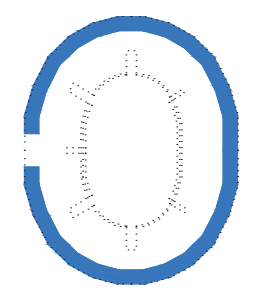

MOSCÚ 1980

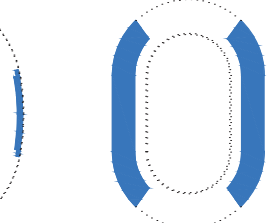

LONDRES 1948

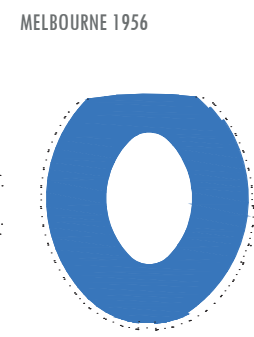

MONTREAL 1976

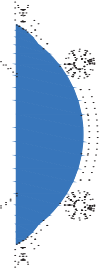

SYDNEY 2000

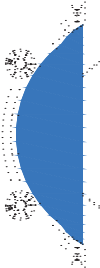

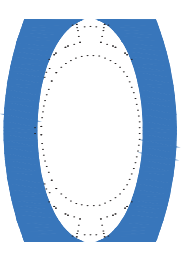

ATENAS 2004

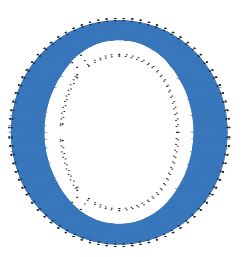

SEUL 1988

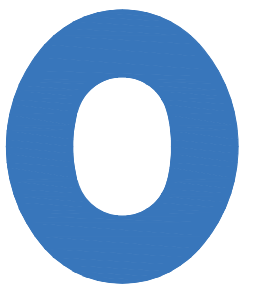

PEKÍN 2008

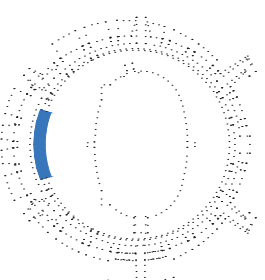

MÉXICO 1968

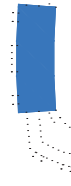

BARCELONA 1992

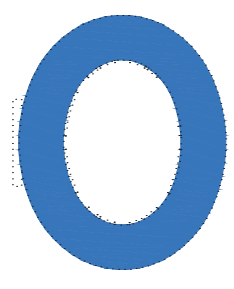

LONDRES 2012

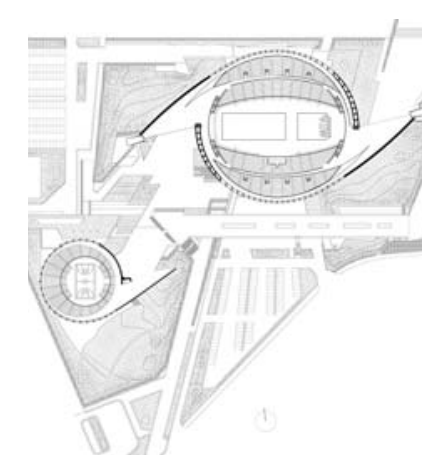

B.6.2 La configuración del espacio mediante la estructura. Los estadios de Kenzo Tange

En los estadios, la relación entre público y espectáculo, con su marcado carácter emocional y bajo unas condiciones técnicas muy precisas y prefijadas, contiene la tensión y la fuerza necesaria para producir elementos arquitectónicos que, además de ser eficaces y depurados, propongan una interesante espacialidad. Su gran dimensión y el contraste de escala entre las menudas filas de gradas y su gran vacío interior, o entre la pequeña dimensión de la cabeza humana, de cada uno de los espectadores, y la gran masa multicéfala de la multitud, suponen todo un reto arquitectónico.

En el complejo de Yoyogi en Tokio, el genio del estructuralismo japonés Kenzo Tange y su equipo de colaboradores ${ }^{1}$, siguiendo lo anteriormente dicho llega a un alto grado de maestría y belleza en el

1. Koji Kamiya, arq. Yoshikatu Tsuboi, ing. estructura y Uichi Ichikawa, ing. Instalaciones, como responsables de un 
Con motivo de los Juegos Olímpicos de Tokio, en 1964, se encarga a Tange el complejo compuesto por los estadios de natación, con aforo de 15.000 espectadores, el de baloncesto, para 4.000 espectadores y un edificio administrativo y de servicios.

El maestro japonés resuelve el proyecto bajo un concepto unitario; espacio, forma, función y estructura son una misma cosa. La estructura, apareciendo en todo su esplendor, es la principal generadora del espacio. Según manifiesta Tange, su máxima preocupación era cómo manejar el gran espacio de las piscinas y qué estructura usar para su cobertura ${ }^{1}$. La gran dimensión del espacio interior multiplica el problema de las luces estructurales. El aumento del tamaño cambia definitivamente la magnitud del problema. Todos sabemos, después de lo publicado por Galileo en 1638'2, que la hormiga del tamaño de un elefante colapsaría; sus patas no podrían aguantar su peso. Al aumentar de dimensión, el peso crece según el incremento del volumen, mientras la capacidad resistente de las patas depende de la sección de las mismas y su aumento esta en función del área. Con el aumento de dimensión, la divergencia entre ambas magnitudes es tan acusada que el colapso es seguro.

En arquitectura, el proyecto y realización de grandes espacios constituye una categoría diferenciada de edificaciones que históricamente se han caracterizado por una gran intensidad emocional. La lucha por agrandar las luces estructurales ha producido ejemplos de una gran belleza y significación. Pensemos por un instante en el Panteón de Roma (125 d.C.), en Santa Sofía de Constantinopla de Isidoro de Mileto y Antemio de Tralles (360 d.C.), en la catedral de León (1301), en el Crystal Palace de Joseph Paxton en Londres (1851), en el hangar de ensamblaje de la fabrica de aviones Glenn Martin en Baltimore de Albert Kahn (1937), o en el lamentablemente desaparecido frontón Recoletos de Madrid de Eduardo Torroja y Secundino Zuazo (1935). Todos son ejemplos que corresponden a épocas distintas, a sistemas estructurales diferentes y están construidos con materiales dispares, pero en todos y cada uno de ellos la estructura, la construcción y el espacio resultante están en una intima relación. No podemos saber hasta qué punto ha podido ser el exigente requerimiento estructural el que ha obligado a ello, pero el caso es que todos los ejemplos referidos muestran su propia realidad sin artificios. Tal vez, en esta sinceridad está su virtud. Podríamos aplicar la famosa frase de Platón y San Agustín:

la belleza es el resplandor de la verdad ${ }^{3}$,

que tanto le gustaba a Mies van der Rohe. Parece como si las fuerzas fueran el mejor aliado del proyectista. Reflexionemos un segundo sobre los antifuniculares y antipolifuniculares de Gaudí ${ }^{4}$, maquetas que construyó en un cobertizo junto a las propias obras de la lglesia de la Colonia Güel, de cuatro metros de altura (a escala 1/10). En un tablero de madera fijado en el techo dibujó la planta de la iglesia, y de los puntos sustentantes del edificio colgó cordeles (para los funiculares) con sacos de perdigones (para las cargas), que así suspendidos daban la curva catenaria resultante, tanto en arcos como en bóvedas. La maqueta, junto a otros numerosos documentos originales de Gaudí, se perdió en el asalto e incendio de la Cripta en 1936. Se realizó una réplica en Stuttgart ${ }^{5}$ en 1982, bajo la dirección de Frei Otto y Jan Molema. Semejante estrategia pudo seguir el propio Otto ${ }^{6}$ para su Multihalle en Mannheim de 1971, en donde podríamos arriesgarnos a decir que la forma final del espacio construido se deja a la libre voluntad de las cargas gravitatorias.

De aquí se deduce una cuestión fundamental; cuando aumenta la dimensión de la estructura, la forma de la misma debe ser el principal fundamento de su sustentación. Debe "resistir por forma". Así ocurre en la cúpula del Panteón, en el sistema de cúpulas de Santa Sofía, en los arcos, bóvedas y contrafuertes de la Catedral de León o en las finísimas laminas cilíndricas de hormigón del Frontón Recoletos. El espacio y la forma de estos edificios son la que corresponde con sus necesidades resistentes. Todos estos ejemplos, además, buscan la ligereza, pues el peso penaliza mucho 7 . La preocupación por la búsqueda de la ligereza queda expresada en la famosa frase de Buckminster Fuller ${ }^{8}$

amplio equipo. Como reconoce el propio Tange, gracias a la unidad y cohesión del equipo se consiguió completar e trabajo en un corto espacio de tiempo. El sistema de trabajo consistía en croquis, confrontar opiniones y maquetas. 1. DOMUS 424/Marzo 1965. Publicación del conjunto de Yoyogui, con entrevista a Kenzo Tange.

2. Consideraciones y demostración matemática, en torno a dos nuevas ciencias (el título original en italiano es Discorsi e dimostrazioni matematiche, intorno à due nuove scienze). 1638.

3. La frase es del Banquete, también conocido como el Simposio, de Plantón escrita hacía el 380 a.C., y dada a conocer en occidente por San Agustín en Las confesiones, libro X, capítulo XVII, del 398 d.C.

4. Una de sus muchas innovaciones en el terreno técnico fue la utilización de una maqueta para el cálculo de estructuras.

5. Universidad de Stuttgart, Instituto de Estructuras Ligeras

6. Multihalle de Mannheim. 1971. Proyecto ocho años posterior al complejo de Yoyogi.

7. Por ejemplo en el Panteón, hormigones y rellenos realizados con piedra volcánica porosa, que aumenta su proporción según ascienden las fabricas.

8. Frase que acostumbraba usar Buckminter Fuller para retar a los arquitectos a cerca de cuan eficientes eran sus edificios en el uso de material, en una ocasión se la planteo a Norman Foster, hecho que le hizo replantearse su posición respecto a la arquitectura.

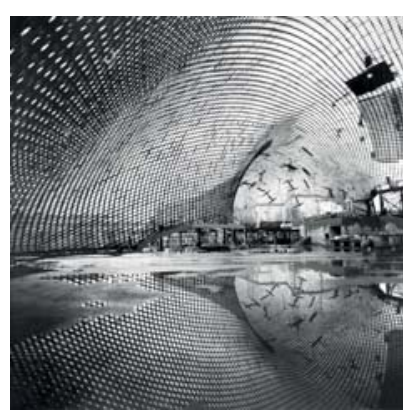


cuánto pesa su edificio.

También buscan la optimización de la capacidad resistente de los materiales utilizados, tratando de llevarlos al limite de sus posibilidades, aunque siempre bajo la lógica de un criterio de economía de medios y eficiencia estructural.

En cualquier caso, parece claro que la gran dimensión del espacio interior lleva inevitablemente a plantearse, con especial relevancia, el problema de sustentación de los elementos constructivos que envuelven dicho espacio.

"La dimensión, nos dice Tange, sugiere estructura: empezando por la jácena, pasando al arco, a la bóveda, a la cúpula y a la estructura suspendida, dependiendo de la superficie que hay que salvar, como en los puentes".'

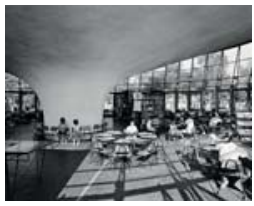

Como Tange pone de manifiesto, en el origen generador del proyecto de una edificación con un gran espacio libre interior está su concepto estructural. Para analizar las posibles soluciones, según sus propias palabras, se apoya en su colega Yoshikatu Tsuboi ${ }^{2}$, prestigioso profesor de ingeniería de la Universidad de Tokio, que anteriormente ya había colaborado con Tange en la realización de la deliciosa biblioteca infantil de Hiroshima en $1951^{3}$.

Pero claro, Tange no se plantea simplemente un problema mecánico, si no más bien una cuestión espacial y una consideración de escala. Según el arquitecto:

"el mayor problema, con respecto al espacio interior, fue garantizar que no adquiriera dimensiones inhumanas cuando estuviera vacío o con poco público".

Por otra parte, no quería ni plantearse soluciones que pudieran fragmentar el espacio y apostaba fuertemente por

"crear y mantener un espacio único donde atletas y espectadores compartieran y se contagiaran de una misma emoción".
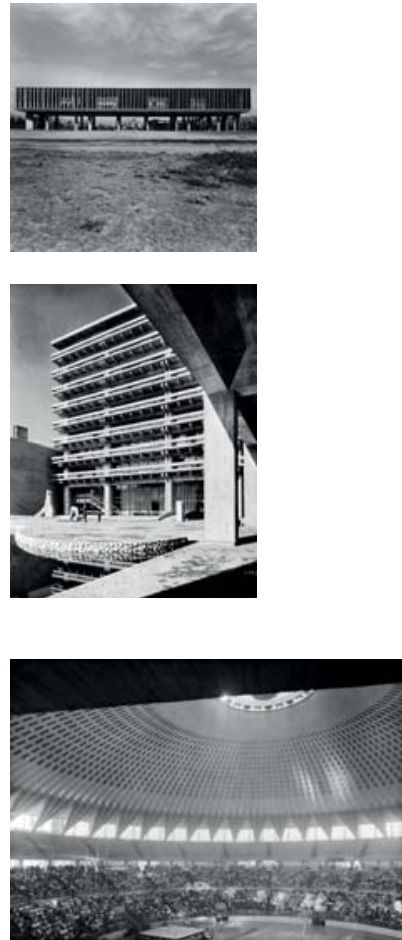

En otro sentido, esgrimía consideraciones de carácter práctico que justificaran su decisión espacial de proyecto,

"en comparación con el espacio convexo de la cúpula, el espacio cóncavo de una estructura suspendida engloba un volumen mucho menor, y esto también simplifica el problema de calefacción, aire acondicionado, acústica".

Kenzo Tange había manejado el hormigón visto con maestría y potencia en el Museo de la Paz de Hiroshima de 1956 y en las oficinas de la Prefectura de Kagawa de 1958, en ambas mostrando con claridad los elementos y ordenes estructurales. La tradicional construcción japonesa en madera, al escalarla y aumentarla de tamaño, necesitaba de un nuevo material capaz de adaptarse a los nuevos requerimientos resistentes y lo encuentra en el hormigón armado. Lo mismo que en la construcción tradicional existe una unidad de material para todos los elementos constructivos, la madera, ahora es el hormigón el material principal y casi exclusivo en las citadas construcciones de Tange.

En el Complejo de Yoyogi, las capacidades de trabajo a flexotracción del hormigón armado quedan superadas por los requerimientos estructurales derivados de las grandes luces a cubrir. Tange, descartando las soluciones espaciales de orden convexo, como la cúpula que utilizaron Annibale Vitellozzi y Pier Luigi Nervi en el Palazzetto dello Sport ${ }^{4}$, en la anterior edición de los Juegos Olímpicos de Roma en 1960, llega a la solución finalmente ejecutada. En palabras de Tange:

"Consideramos varias opciones para la estructura. Con mi colega Tsuboi y otros colaboradores, llegamos bastante rápido a elegir una estructura suspendida- una estructura metálica tensada".

La estructura suspendida metálica sirve al arquitecto para resolver los problemas sustentantes de la cubierta y forma parte de un sistema mecánico complejo, en el que el hormigón armado, trabajando a compresión o por peso propio, compensa los fortísimos esfuerzos de tensado de la ligera red de cables. De forma más escueta lo expresa Tange

"pero para una estructura colgada, se necesita una estructura base de compresión en hormigón".

1. DOMUS 424/Marzo 1965. Publicación del conjunto de Yoyogui, con entrevista a Kenzo Tange. Todas las frases entrecomilladas y en cursiva del articulo son fragmentos de dicha entrevista

2. En algunas publicaciones la trascripción del nombre al alfabeto latino es Yoshikatu y en otros casos Yoshitatsu.

3. En 1957, también habían colaborado en el auditorio Sunpu Kankan, en Shizuoka City

4. Annibale Vitellozzi, arquitecto y Pier Luigi Nervi ingeniero, proyecto de 1956/7. Cúpula nervada de 69,20 metros de diámetro y cascarón de doce centímetros de espesor de hormigón armado. 
Los sistemas estructurales, en los que los esfuerzos a tracción del acero se complementan con los esfuerzos de compresión del hormigón, estaban en plena ebullición en el momento en que se estaba proyectando el complejo de Yoyogi. En 1953 se había terminado el Paraboleum' en Raleigh, Carolina del Norte, del arquitecto Maciej Nowicki y del ingeniero Fred N. Severud, compuesto por dos arcos de casi 100 metros de luz, tumbados y entrecruzados, en el que, de arco a arco, una red principal de cables equilibra el sistema $y$, perpendiculares a estos, otra red de cables secundarios pretensados con curvatura opuesta, lo estabiliza. Entre 1957 y 1960 se había construido el Utica Memorial Auditórium², de planta circular, siendo la primera estructura de doble red de cables construida hasta el momento. Los cables pretensados quedan separados por montantes comprimidos tipo tensegrity; en el interior un doble anillo fuertemente traccionado y en el exterior otro anillo muy comprimido. Gracias a su forma circular es un sistema autoestable. Este pionero proyecto de los arquitectos Gehron \& Seltzer y Frank Delle Cese y del ingeniero Lev Zetlin es el que más se asemeja al comportamiento mécanico de la rueda de bicicleta. El más conocido y mayor de todos, el Madison Square Garden ${ }^{3}$ de Nueva York, con un diámetro de 127 metros es un poco posterior, de 1967.

En Yoyogi, los dos pabellones, el de las piscinas y el de baloncesto, corresponden a soluciones estructurales semejantes entre si, pero diferentes $y$, por otra parte, francamente más complejas que los ejemplos anteriormente citados. Entre las muchas estructuras posibles, la ideada por Tange y sus colaboradores les permite alcanzar los objetivos espaciales y funcionales buscados dentro de una aparente naturalidad. La casi desaparición de la estructura sustentante vertical, que queda reducida a las pilonas que se integran visualmente en el cerramiento exterior y desde el interior no es posible su lectura clara como tal, más el interesante manejo de las entradas de luz natural, producen una extraña sensación de flotabilidad y ligereza, asemejándose casi a un ejercicio de prestidigitación. Junya Ishigami ${ }^{4}$ en su conferencia en la Kenzo Tange Lecture de 2014 en Harvard, al referirse a su proyecto Magic Table (2005), explicaba

en el diseño de estas mesas he querido que su estructura fuera un misterio. Cuanto menos explicito, mejor. Su resultado será mucho mas interesante si el observador no participa del conocimiento de los principios estructurales subyacentes y solo perciba el efecto resultante con naturalidad.

Y ello estaba en relación con los principios sustentantes de una edificación para producir un efecto sublime, tal y como hacía Tange. En las mesas de Ishigami, una lamina finísima de $3 \mathrm{~mm}$, "como un papel", en unas dimensiones de mesas desescaladas, 9,5 m de largo, 2,6 de ancho y 1,1 de alto, ante la mas mínima acción exterior, se producen unas ondulaciones semejantes a las producidas en la superficie del agua. Algo misterioso. Más que arquitectura parece ilusionismo. Pero en definitiva, lo que nos interesa es como, mediante el conocimiento, manejo, incluso diríamos manipulación de las leyes resistentes, se consiguen soluciones arquitectónicas de fuerte componente espacial y del mas alto interés.

En los estadios de Tange, el magnifico "espacio" resultante es consecuencia del hábil manejo de la estructura y aunque su "misterio" es suficientemente conocido, nos hemos permitido hacer unos dibujos explicativos de su funcionamiento, en los cuales destacamos las asimetrías como elementos fundamentales para conseguir los objetivos de fluidez y dinamismo buscados por el autor.

En las piscinas, el sistema estructural esta compuesto por los siguientes tres subsistemas, cubriendo una superficie semejante a un circulo de 120 metros de diámetro5:

a. Estructura central, semejante a un puente en suspensión, compuesta por dos grandes pilonas ( $p$ ), no alineadas, de hormigón de 40 metros de altura, dos cables principales (c) con vano central de 126 metros en catenaria y anclaje (a) al suelo en sus dos extremos. Riostra ( $r$ ) de atado entre los dos anclajes, pasando por las dos pilonas.

b. Graderio de hormigón en voladizo (v). La forma semicircular de los dos graderíos les permite trabajar como arcos de descarga, solicitados a compresión. Su inclinación supone un peso muerto que compensa las fuertes tensiones a las que están sometidos los cables de acero del tercer subsistema.

1. Ahora conocido como J. S. Dorton Arena. El arquitecto murió antes de iniciarse la construcción y los trabajos de supervisión los llevó acabo William H. Dietrick. Dimensión de los ejes principales $92 \times 97$ metros

2. Conocido como AUD, su estructura tiene 72 metros de diámetro.

3. Arquitecto Charles Luckman e ingeniero Fred N. Severud, el mismo que el del Paraboleum. Anillos exterior e interior conectados por 48 cables de 10 centímetros de diámetro. Sistema estabilizado por carga muerta en la cubierta.

4. (1974) arquitecto emergente japonés, invitado en febrero de 2014 al ciclo de conferencias Kenzo Tange Lecture de la Graduate School of design de la Harvard University. Su obra mas conocida es KAIT Studio del Kanagawa Institute of Technology, 2008. Ha sido galardonado con el León de Oro en la Vienal de Venecia de 2010.

5. Datos y descripción de sistemas sacados del informe del ingeniero Mamoru Kawaguchi de 2012 con motivo de la presentación del Estadio Nacional de Yoyogi a los premios del centenario de la Internacional Federation of Consulting Engineers presentado por la Association of Japanese Consulting Engineers
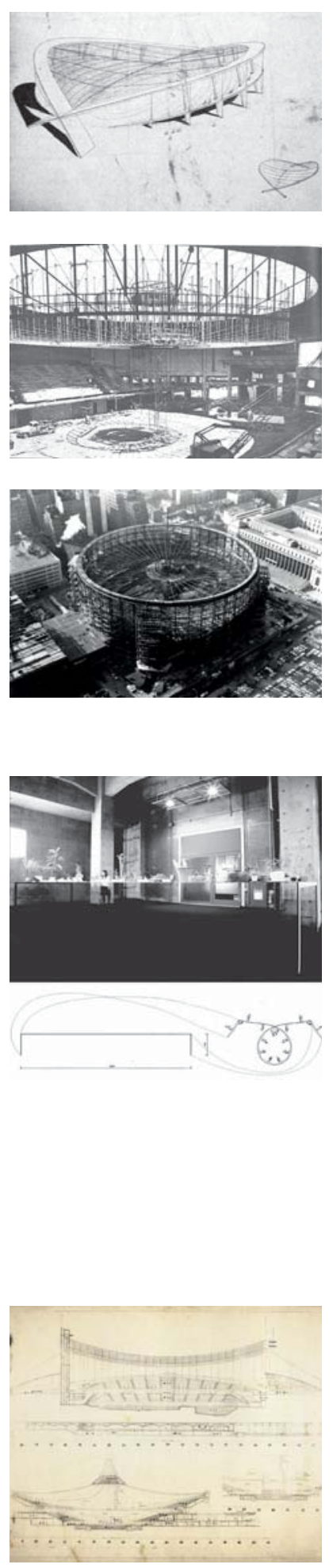


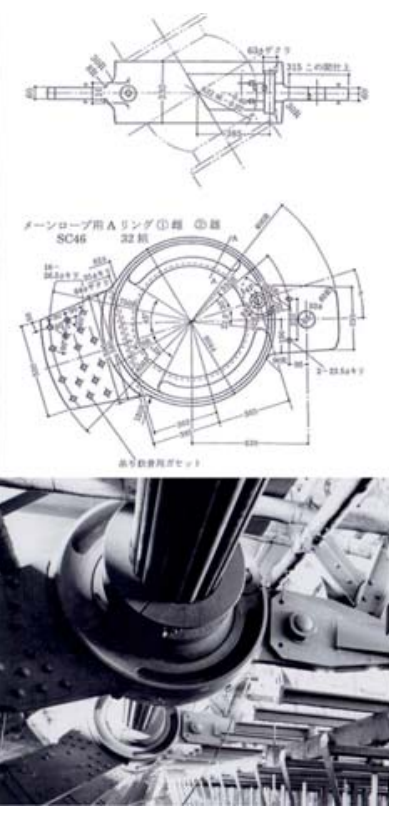

c. Cubierta suspendida. Compuesta por dos familias de cables, la primera, los tirantes de cuelgue en catenaria que discurren desde los principales de la estructura central hasta el borde del voladizo de las gradas de hormigón armado, con un intervalo de 4,5 metros. Perpendicular a esta primera familia discurre la segunda. Su curvatura será inversa y su intervalo varia entre los 1,5 a los 3 metros. Todo este subsistema esta sometido a un fuerte pretensado.

En reacción a la tensión interna del sistema, los dos cables principales adquieren una deformación lateral, abriéndose en el centro hasta 16 metros, facilitando así la entrada de luz natural.

El sistema no es absolutamente simétrico, los cables al pasar por las pilonas sufren una apreciable desviación. Los graderíos y cubiertas se prolongan en los extremos opuestos, con objeto de compensar las tensiones.

El estadio de baloncesto, también está compuesto por tres subsistemas. Se corresponde con una planta de 65 metros de diámetro. A diferencia del de natación, la cubierta no esta conformada por una red de cables.

a. Estructura central, una única pilona en ménsula de hormigón, cable principal en espiral, empezado en la parte superior de la pilona y acabando en el anclaje al terreno. Riostra de atado entre pilona y anclaje.

b. Graderio de hormigón en voladizo. La forma circular del graderío le permite trabajar como arco de descarga solicitado a compresión. Su inclinación supone un peso muerto que compensa las fuertes tensiones a las que están sometidos las cerchas de acero del tercer subsistema.

c. Cubierta suspendida. Compuesto por una familia de cerchas metálicas. Discurren desde el cable principal de la estructura central hasta el borde del voladizo de las gradas de hormigón armado.

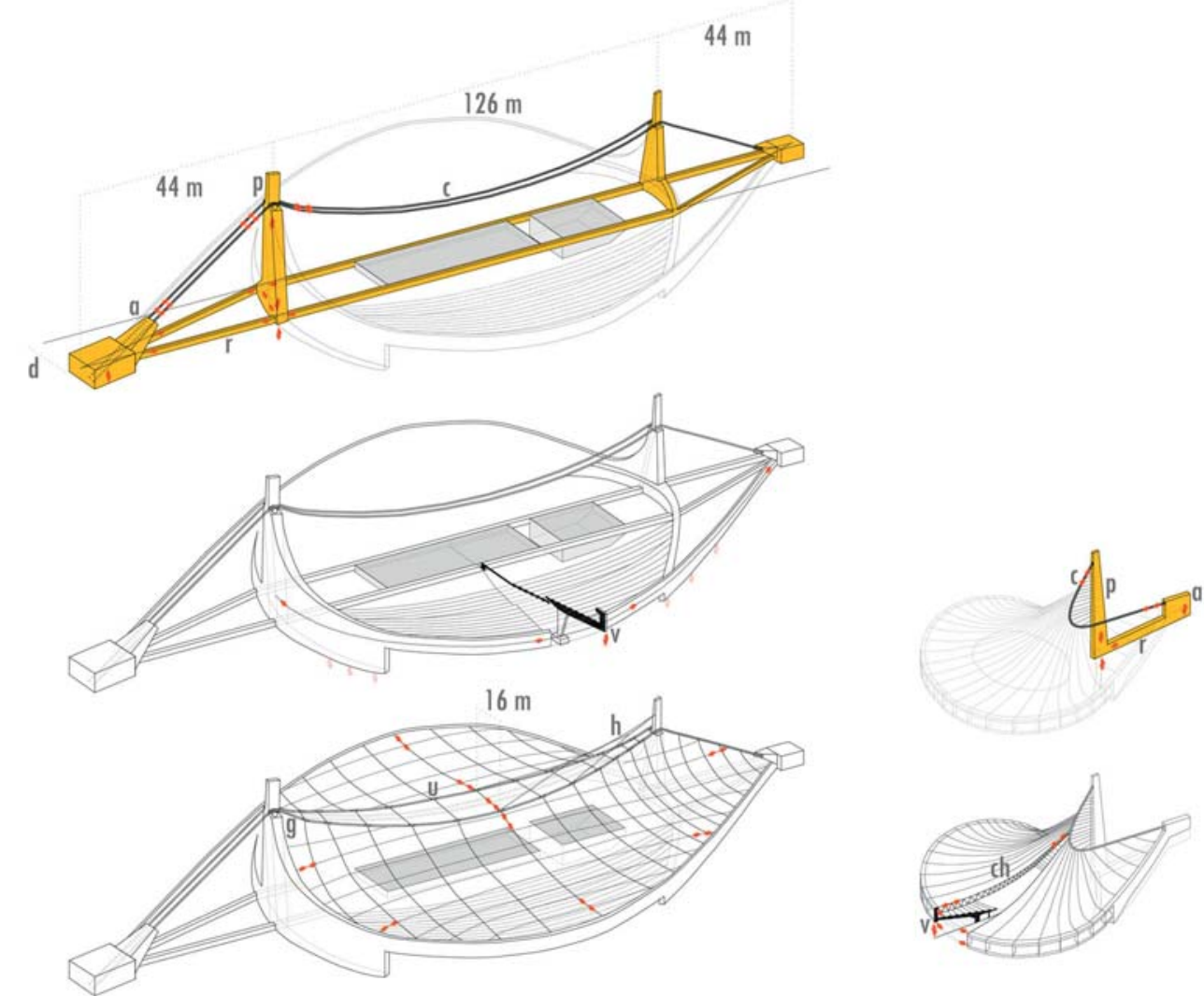

Para poder verificar y validar los cálculos se realizaron más de 10 maquetas a grandes escalas. Algunas de ellas a escala $1 / 30$ (dimensión aproximada 4 × 4 metros'.

Las singularidades del sistema requirieron para su puesta en obra, elementos constructivos novedosos. Citemos los tres más destacados:

a. Amortiguadores hidráulicos (h). Situados en la parte alta de las pilonas para controlar posibles vibraciones en los cables principales.

b. Abrazadera de Unión Universal (u). Conector entre cables que permiten enlaces según los

1. Es curioso que coincide mas o menos con el tamaño de la maqueta de antipolifuniculares de Gaudí para la Capilla de la Colonia Güel. 
diferentes ángulos de encuentro y que también permiten la regulación en tres dimensiones para su montaje. Además son capaces de absorber movimientos incluso después de su puesta en uso.

c. Desviador de cable cónico giratorio (g). Al entrar a trabajar el cable principal, tiene un movimiento en su apoyo en la pilona de carácter rotatorio y para evitar que el cable se dañe se introduce este mecanismo.

La complejidad producida por las asimetrías y al no ser sistemas autoestables, convierte el cálculo y análisis estructural en muy complejo. Como curiosidad decir que los cálculos fueron realizados por una calculadora de tipo mecánico, llamada tigre calculador ${ }^{1}$.

La complejidad que producen las asimetrías, con seguridad, son derivadas de la intención deliberada del arquitecto, lo cual corrobora el insigne ingeniero japonés Mamoru Kawaguchi²:

el objetivo del proyecto era lograr un espacio dinámico, orgánico y funcional,

y para ese fin, tanto la falta de simetría como el tratamiento que hace de la iluminación natural, es muy útil. Los largos y pesados graderíos de hormigón armado visto se despegan del suelo con unos voladizos en un equilibrio aparentemente imposible y producen un efecto de gran dinamismo. Aunque el sistema está equilibrado, sus partes se muestran con un inquietante desequilibrio, como exhibe el croquis de Tange, que es puro dinamismo en su trazo y en sus intenciones, como ponen de manifiesto el giro dramático que obliga a la cubierta, y el fuerte voladizo de los graderíos. Ambos gestos los acentúa con trazo firme. Solo la pilona vertical, centrada en la composición y la simetría contrapuesta del graderio a sus dos lados, aunque en distinto plano, tratan de recuperar el equilibrio, proponiendo una composición de equilibrio inestable de gran dinamismo.

Estructura, espacio, forma y función coinciden en un mismo carácter, que podríamos aventurarnos a resumir como de fluidez y dinamismo, con una aparente naturalidad.

Está claro que Tange buscaba un espacio dinámico,

"no cerrado y opresivo, si no abierto y libre, en el que los quince mil espectadores pudieran desenvolverse y fluir fácilmente, en términos funcionales y psicológicos. $Y$ no solo dentro del estadio, si no también de un estadio al otro".

Objetivo que parece cumplido, si hacemos caso de la impresión que produce al propio arquitecto cuando visita la instalación durante el desarrollo de los Juegos Olímpicos de 1964

"yo, también, por primera vez, disfruté paseando a lo largo de él. (se refiere a la "calle" peatonal en la cubierta del edificio de servicios ${ }^{3}$ ) Y vi que los movimientos de entrada y salida de los dos estadios eran mas fluidos de lo que había pensado. En cuanto entré en el Estadio de Natación, vi como el espacio cambiaba dinámicamente dependiendo de mis movimientos, y me pareció que el movimiento de la gente daba al espacio su propio dinamismo"4.

\section{B.6.3. Composición. Entre lo tectónico y lo topográfico}

El principal criterio para la clasificación y análisis de la composición de los estadios Olímpicos, es la relación entre su carácter topográfico y tectónico.

Los estadios griegos solían estar asentados en una topografía favorable, que posteriormente se manipulaba y modificaba para el aumento del aforo y para mejorar las condiciones de los espectadores. Los estadios estaban fuera de los limites de las ciudades, en entornos naturales. Cuando con los romanos se lleva el espectáculo a los ciudadanos, el recinto necesario ocupa inicialmente de manera temporal sus plazas y las construcciones son ligeras y desmontables, construidas en madera y cuando posteriormente se hacen estables, participan del mismo criterio constructivo.

La serie de estadios Olímpicos devanea y fluctúa entre los dos modelos, el tectónico y el topográfico o una mezcla de ambos

El término tectónico se utiliza en arquitectura como concepto que permite definir o agrupar las decisiones que hacen referencia a su materialidad, o en el conjunto de variables inevitables que permiten que la arquitectura trascienda del mundo de las ideas al mundo real o material. Para comprender la importancia de este concepto, debemos entender el significado en arquitectura de esta palabra,

1. La primera calculadora electrónica, la Sharp Compet CS10A, es de diciembre de 1964.

2. Mamoru Kawaguchi es uno de los más afamados ingenieros en Japón. Proyectó con Arata Isozaki del Pabellón Sant Jordi de Barcelona.

3. El conjunto está compuesto por el estadio de las piscinas, el estadio de baloncesto y un edificio de administración y servicios, que por encima de él discurre un paseo peatonal que conecta los dos estadios.

4. DOMUS 424/Marzo 1965. Publicación del conjunto de Yoyogui, con entrevista a Kenzo Tange. Todas las frases entrecomilladas y en cursiva del articulo son fragmentos de dicha entrevista.
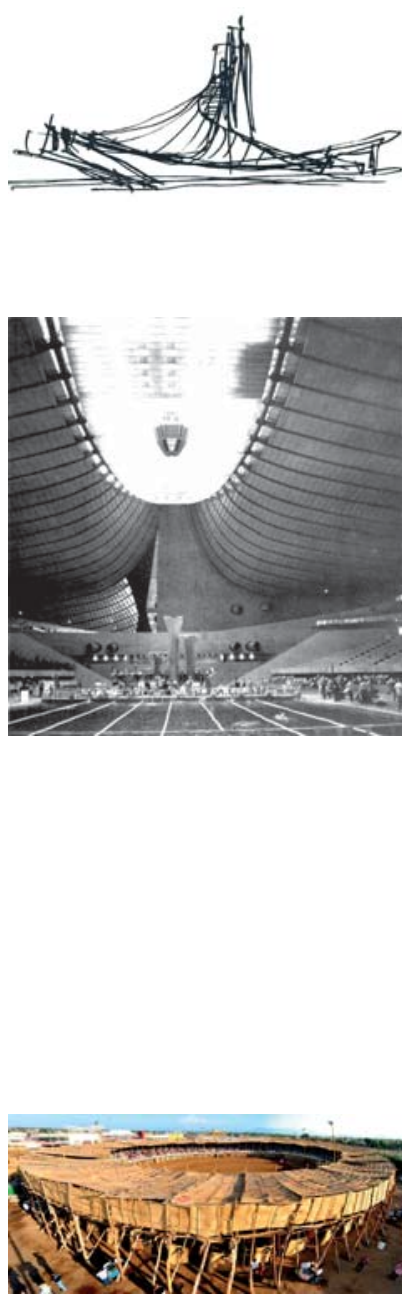

Plaza de toros La Petatera, Ciudad Álvarez, Colima México.

Esta plaza es construida y reconstruida año con año en el mes de febrero a partir de materiales como maderas, petate e ixtle y procesos regionales que tienen más de ciento cincuento años de tradición en Colima.Sus antecedentes constructivos tienen su origen en una profunda tradición religiosa, cuando en el siglo XVII a partir de 1658, el pueblo de Colima arruinado por los temblores decide ponerse bajo la protección de San Felipe de Jesús como santo patrón, quien a partir de entonces, consagran cada año a principios de febrero las fiestas religiosas y paganas entre las que se encuentran las corridas de toros. 


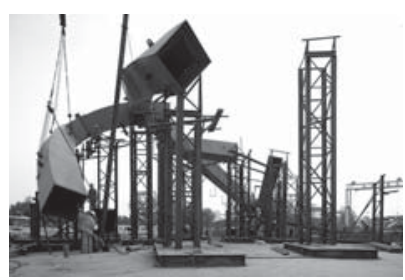

Ligereza, equilibrio, gravedad características fundamentales de la fotografía de Jacques Henri Lartigue (1894/1986)
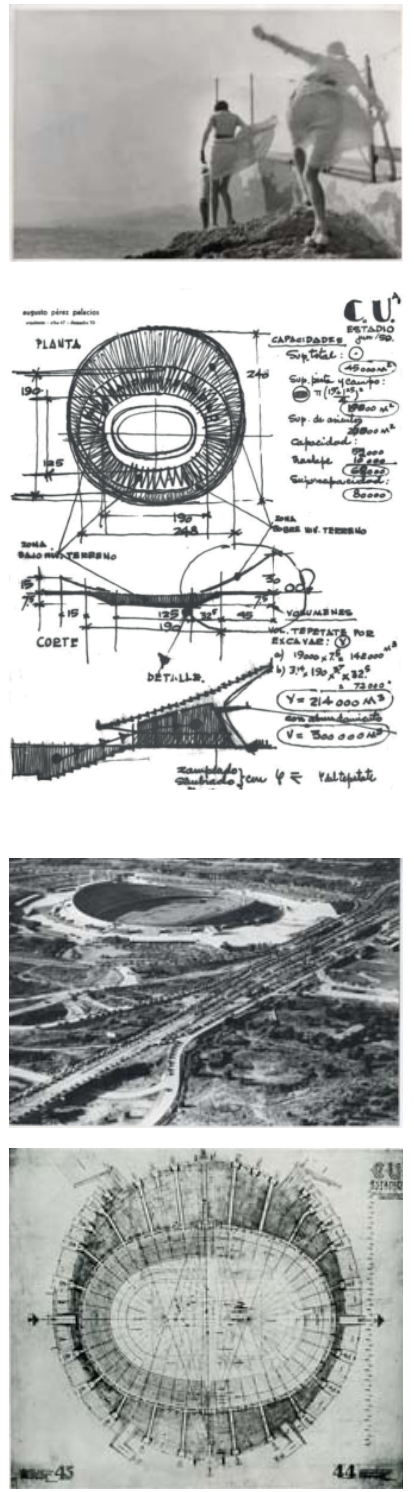

aclarando su relación con técnica, construcción, estructura y estética.

Tectónica tiene diferentes significados. El diccionario lo define como el arte de la construcción, o el arte de la carpintería, y según su origen griego aparece como Tekton (carpintero, cantero o arquitecto) y Tektonikos (arte del carpintero o el constructor). Son varios los autores que han advertido la importancia de este concepto en la arquitectura desde diversas aseveraciones. Por ejemplo, en Structure construction and tectonics, Eduard Sekler (1963), recurre a la definición primaria de la palabra, que comparte la misma raíz griega tec que aparece en arquitectura y tecnología. Según anota Sekler, hace referencia a:

$$
\text { ... aquella actividad humana de dar forma visible a algo nuevo.' }
$$

Igualmentse, recuerda el concepto de Einfühlung, o empatía, que en una definición elemental se refiere a ese proceso de transmisión de sentimientos que los objetos creados por el hombre generan en el espectador. A partir de estos dos conceptos, finalmente, anota que es mediante la tectónica que el arquitecto puede hacer visible aquella clase de experiencias de la realidad que son dominio o campo del arte. En la arquitectura, se hace perceptible el grupo de experiencias, de fuerzas y variables relacionadas entre sí, que definen la forma final de un edificio. En Estudios sobre cultura tectónica, se sofistica y resume lo expuesto por Sekler en el sentido de proponer que:

... la tectónica adquiere el carácter de verdadero arte en la medida en que equivale a una poética de la construcción ... ${ }^{2}$

Para comprender el concepto de tectónica, inicialmente diríamos que la arquitectura trasciende del mundo de las ideas al mundo real y útil mediante la manera en que el arquitecto arregla o dispone sus partes. Y la manera como se "disponen e interrelacionan" sus elementos mediante construcción y estructura es lo que podríamos definir como tectónica.

El filosofo norteamericano, John Dewey (1859/1952), , se refiere a lo que caracteriza la arquitectura y sus resultados (edificios) respecto a otras artes. Afirma que:

... ningún otro elemento muestra pesos y fuerzas, empujes y contraempujes, gravedad, ligereza, cohesión, en una escala comparable a lo arquitectónico, y toma estas fuerzas más directamente y menos en compensación, que cualquiera otro arte. ${ }^{3}$

Por su parte lo topográfico se refiere a lo masivo, que pertenece a la tierra, funciona por peso y por cantidad, frente a lo ligero, elaborado y eficiente de lo tectónico.

Para el proyecto del estadio de México se barajaron simultáneamente dos opciones, cada una con un sesgo diferente.

El croquis inicial se acompaña de dos secciones que representan dos soluciones para los graderíos superiores: estadio sobre terraplén o estadio con estructura de hormigón armado. Las dos propuestas comparten la grada baja excavada en el terreno. Para fundamentar la elección fue solicitado a los arquitectos un estudio comparativo. El sistema en talud aprovecha el perfil resultante de la excavación para levantar las gradas superiores, mientras que la grada construida en hormigón armado permite una gran penetrabilidad entre los dos graderíos, resultando más flexible en su funcionamiento al poderse conformar una galería de distribución debajo de la misma; pero ello suponía un gran consumo de materiales caros y escasos, el acero y el hormigón.

Finalmente se impuso el aspecto económico, Carlos Lazo gerente de la Entidad Ciudad Universitaria decidió que se utilizaría el terraplenado como sistema básico arquitectónico. Entre los argumentos que esgrimió en su respuesta se decía:

los primeros planos del proyecto para el gigantesco Estadio Olímpico especificaban hormigón y otros conocidos materiales usados en estadios de los Estados Unidos, pero México es un país pobre. Tenemos pocas plantas productoras de cemento, sin embargo, tenemos una técnica para construir presas empleando arcilla, que es famosa en el mundo de la ingeniería. Nuestras presas pueden ser comparadas favorablemente con las presas de hormigón siendo mucho más económicas. ${ }^{4}$

Los arquitectos aprovecharon las técnicas de construcción de presas. Empleando arcilla como materia prima y la maquinaria utilizada en esas construcciones. El resultado ha sido una verdadera y original aportación a la arquitectura. Su arquitecto escribiría después:

Creo que la solución a la que llegamos es la mejor demostración de que procedimos de

1. Sekler, Eduard. "Structure Construction and Tectonics". En: Structure in Art and in Science. Ed. Gyorgy Kepes, 89 a 95. Nueva York: George Brazilier Inc. , 1963-1965

2. Frampton, Kenneth. Estudios sobre cultura tectónica. Madrid: Akal, 1997) de Kenneth Frampton (1995)

3. Dewey, John. El arte como experiencia. México: Fondo de Cultura Económica, 1949.

4. Archivo de Arquitectos Mexicanos de la Facultad de Arquitectura de la UNAM: retrospectiva y compromiso.

CRUZ GONZÁLEZ FRANCO, Lourdes. El Estadio Olímpico Universitario del Pedregal. Permanencia y vigencia 
forma lógica, porque el Estadio Olímpico es una de las estructuras más hermosas de Ciudad Universitaria. Para la economía en construcción, una de las reglas principales es tener el material lo más cerca posible. En la construcción del estadio Olímpico empleamos el magnífico material que teníamos a la mano, la misma tierra en donde iba a ser levantado.

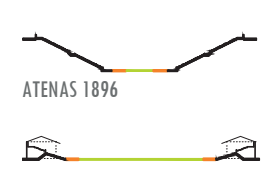

AMBERES 1920

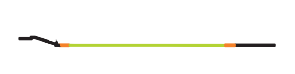

ST LOUIS 1904

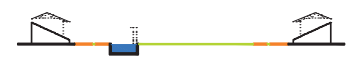

LONDRES 1908

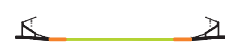

ESTOCOLMO 1912

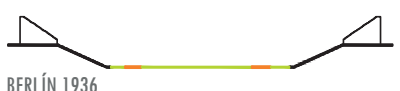

BERLÍN 1936

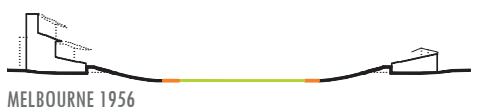

MELBOURNE 1956

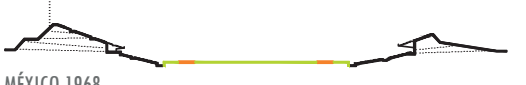

MÉXICO 1968

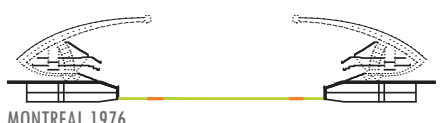

MONTREAL 1976

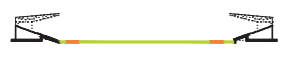

PARÍS 1924

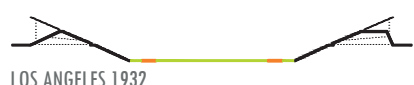

LOS ANGELES 1932

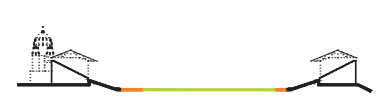

LONDRES 1948

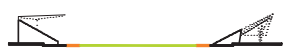

HELSINKI 1952
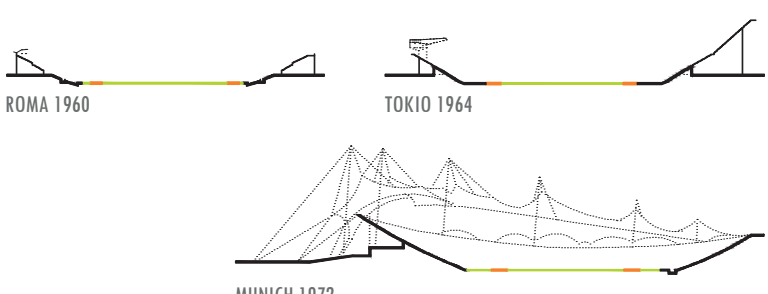

MUNICH 1972
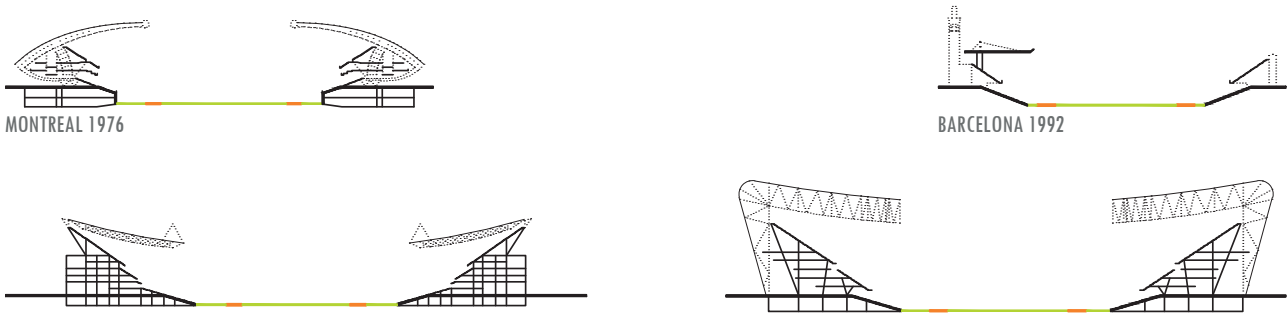

SYDNEY 2000
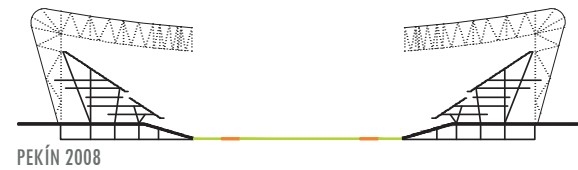

Lo habitual en los estadios Olímpicos es la convivencia ente los dos criterios, aunque hay algunos que son absolutamente topográficos, como los de Atenas 1896, St Louis y México y otros absolutamente tectónicos, en los que en su composición el terreno se ha considerado como un plano horizontal y ajeno a la solución propuesta, como los de Londres 1908 y Helsinki, el resto maneja en mayor o menor medida los dos criterios. El primero en propones con claridad la división más o menos equitativa entre ambos es el de Berlín, en el que su grada baja es topográfica y la alta tectónica, manteniendo la continuidad entre ambas. Si exceptuamos el "extraño" estadio de Melbourne, en México se produce el primer caso en el que se independiza el graderío superior de inferior, aunque de manera muy sutíl.

Una vez independizados los distintos niveles del graderío se puede proponer el vuelo o desplazamiento entre ellos, permitiendo una mayor proximidad del publico al espectáculo. Esta utíl estrategia, produce un efecto adverso ya que secciona y divide a la multitud dificultando la creación de un ambiente emotivo. Por esta última razón se tiende a que la percepción de la grada sea unitaria y completa, por muy dividida que pueda estar por razones de seguridad y acceso.

En el estadio de Pekín, Herzog y de Meruron resuelve la disyuntiva con gran maestría.

La tendencia es que la grada baja reducida a menos de un tercio del total, tenga una constitución "aparentemente" topográfica y tectónica la superior o superiores. Decimos aparentemente, porque realmente su subsuelo suele estar horadado para permitir los accesos de carácter restringido.

La condición topográfica ha tenido desde siempre un fundamento de racionalidad constructiva. Ya los antiguos persas utilizaban rellenos de tierra como cimbra para sus estructuras. ¿̇qué mejor soporte para disponer al público que modelar el terreno de la manera que pueda tener visibilidad sobre el campo de competición? Siempre ha sido una opción económica; antiguamente cuando la mano de obra era barata y los materiales costosos, y hoy en día en que las grandes maquinas de obras públicas son capaces de mover una gran cantidad de metros cubicos de terreno en poco tiempo necesitandose muy poco personal.
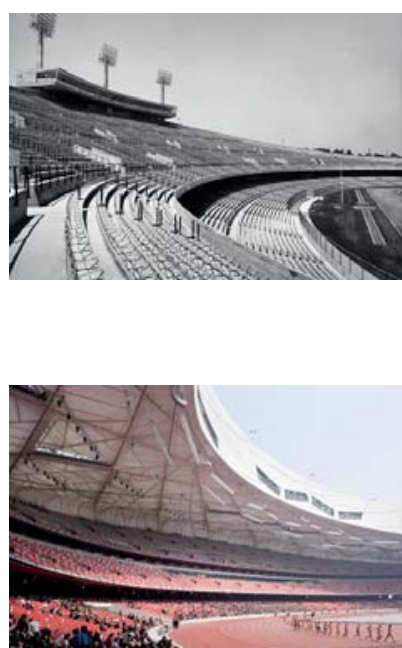

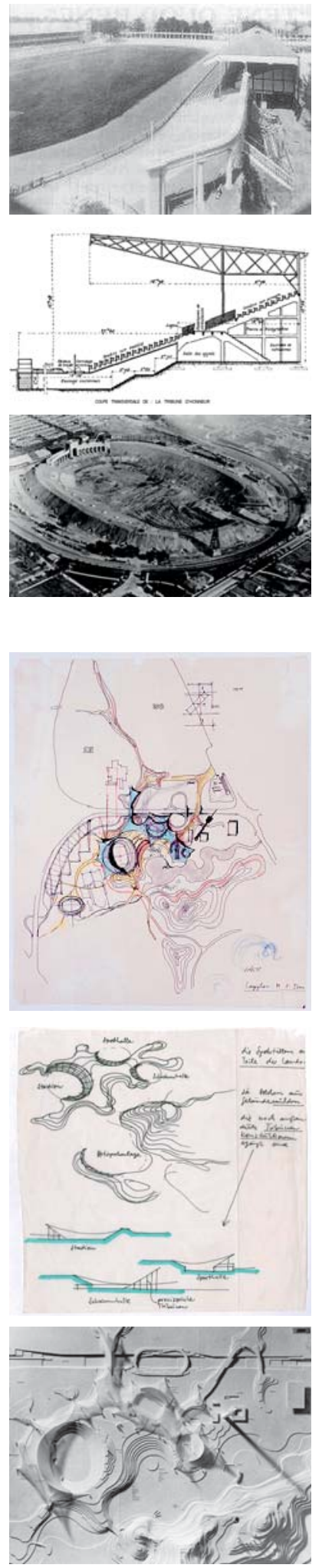

En el estadio de Amberes las tribunas principales son edificaciones sobre el terreno natural, horizontal, y la pista está aproxímadamente a la misma cota que el terreno circundante; pero las gradas para público de píe en las dos curvas del estadio estan construidas mediante aportación de tierras levantando un terraplen artificial. No hacen falta estructuras intermedias para la transmision de las cargas, que se produce directamente al terreno. El trasdos del graderío se dejó en talud en el que se apoyan las escaleras de acceso.

En París, 1924, una ligera excavacion de la superficie del campo de competición para la búsqueda del firme y su nivelado, proporciona un no desdeñable volumen de tierras que permite apoyar la grada baja sin necesidad alguna de estructura aérea. En este caso las tierras se confinan con un muro de contención perimetral. La sección adjunta esta dada por el punto singular en el que por medio de un tunel, los deportistas acceden al terreno central sin interferir al anillo de las carreras. Una sección tipo mostraría la pista y grada baja apoyadas en el terrreno y la grada principal y la alta sobre estructura de hormigón armado.

En el estadio de Los Ángeles, originalmente, todo su graderío estaba apoyado sobre el terreno que previamente había sido modelado. Se levanta en el lugar de una antigua gravera que ya contaba con un cierto volumen excavado. Para la edificación del estadio se ahonda aún más y las tierras obtenidas se disponen alrededor del espacio destinado a la competición. Para los Juegos se amplió un tercio más la altura de la grada mediante una estructura de grandes pilonas y gradas de hormigón armado.

En estos casos, y otros más, el movimiento de tierras se realiza únicamente por razones constructivas para facilitar y abaratar el proyecto. Ya hemos visto como en México se había estudiado la construcción del estadio en dos versiones, una con estructura de hormigón y la realmente realizada mediante movimiento de tierras con la tecnologia de las presas y carreteras. Y que los criterios de sección fueron principalmente económicos.

En el Parque Olímpico de Múnich, el tratamiento topográfico va mucho más allá de las razones utilitarias, es el principio generador del proyecto, supone el principal vehículo para la expresión del carácter del proyecto. Se proponen unos Juegos "verdes", integrados en el paisaje. No importa que este fuera absolutamente de nueva creación aprovechando un gigantesco vertedero generado por los escombros de la ciudad destruida durante la guerra. La colina olímpica, Olympiaberg, contenía más de 10.000 .000 de metros cúbicos de escombros y una altura 60 metros, constituyendo una de las elevaciones más altas de Múnich.

El jurado del concurso valoró muy favorablemente este aspecto de la propuesta presentada por el equipo dirigido por Günter Behnish

Los esfuerzos realizados por los autores para obtener la solución del problema a través de la alteración artificial del terreno.

[...]la inclusión, en la configuración del complejo olímpico, de la colina formada por el antiguo vertedero de escombros. El modelado del terreno, como se propone en el proyecto, es la base para resolver el problema de acomodar el complejo olímpico en un sitio que no está dotado de características naturales adecuadas es encomiable, no sólo desde el punto de vista económico, sino también urbanístico.'

En línea con el espíritu de los años 60 la propuesta se desliga de cualquier rigidez, produciendose una suave integración con la abrupta topográfia, convirtiendo al estadio en un elemento cuasi natural, en el que es dificil definir sus límites y que cuenta con un alto valor paisajistico. Establece unas claras continuidades con el resto de las instalaciones y con la topografía circundante, produciendo unos accesos y circulaciones del publico en el que su comportamiento se puede asimilar al de los fluidos.

Las cubiertas son el complemento perfecto, reforzando estos principios basicos que subyacen en el proyecto.

Despues de más de cuarenta años desde su construcción sigue significandose por su modernidad. 


\section{Bibliografía. Morfología}

ARAUJO, Ramón. La arquitectura como técnica (1), Superficies. ATC Ediciones. Madrid, 2007. ISBN 978-84-920517. O-O

BALE, John. The Stadium and the City. Staffordshire: Keele University Press, 1995. 347 p. ISBN 1853311103

CHURTICHAGA; José María. La estructura Veloz. Trayectorias estructurales a propósito de la obra de Emilio Pérez Piñero y Félix Candela.

ENGEL, Heino. Sistemas de estructuras. Sistemas estruturais. Ed. Gustavo Gili. 2001. ISBN: 9788425218002

GALILEO, Galilei. (1638). Consideraciones y demostraciones matemáticas sobre dos nuevas ciencias. Ed. Planeta De Agostini, 1996. ISBN 8439544979, 9788439544975

GOETHE, Johann W. Viaje a Italia. Ed. Zeta. ISBN 978-84-9872-263-5

SLOTERDIJK, Peter. Esferas III. Espumas. Esferorogía plural. Reguera, Isidoro (trad). Biblioteca de Ensayo. Ediciones Sirvela. Segunda edición febrero 2009. ISBN 978-84-7844-951-4. Titulo original: Sphären III (Plurale Sphärologie). Schäume Suhrkamp Verlag, Frankfurt am Main, 2004

SMITHSON, Robert. "The Spiral Jetty", 1972, recopilado en Stiles, Kristine; Selz, Peter Howard, Theories and documents of contemporary art: a sourcebook of artist' writings, University of California Press, Berkeley, Los Ángeles, 1996, p.533

DOMUS 424/Marzo 1965. Publicación del conjunto de Yoyogui, con entrevista a Kenzo Tange

The Official Report of the Organizing Committee for the Games of the XX Olympiad. Munich 1972. Ed. The Organising Committee for the XX Olympiad.1972. 


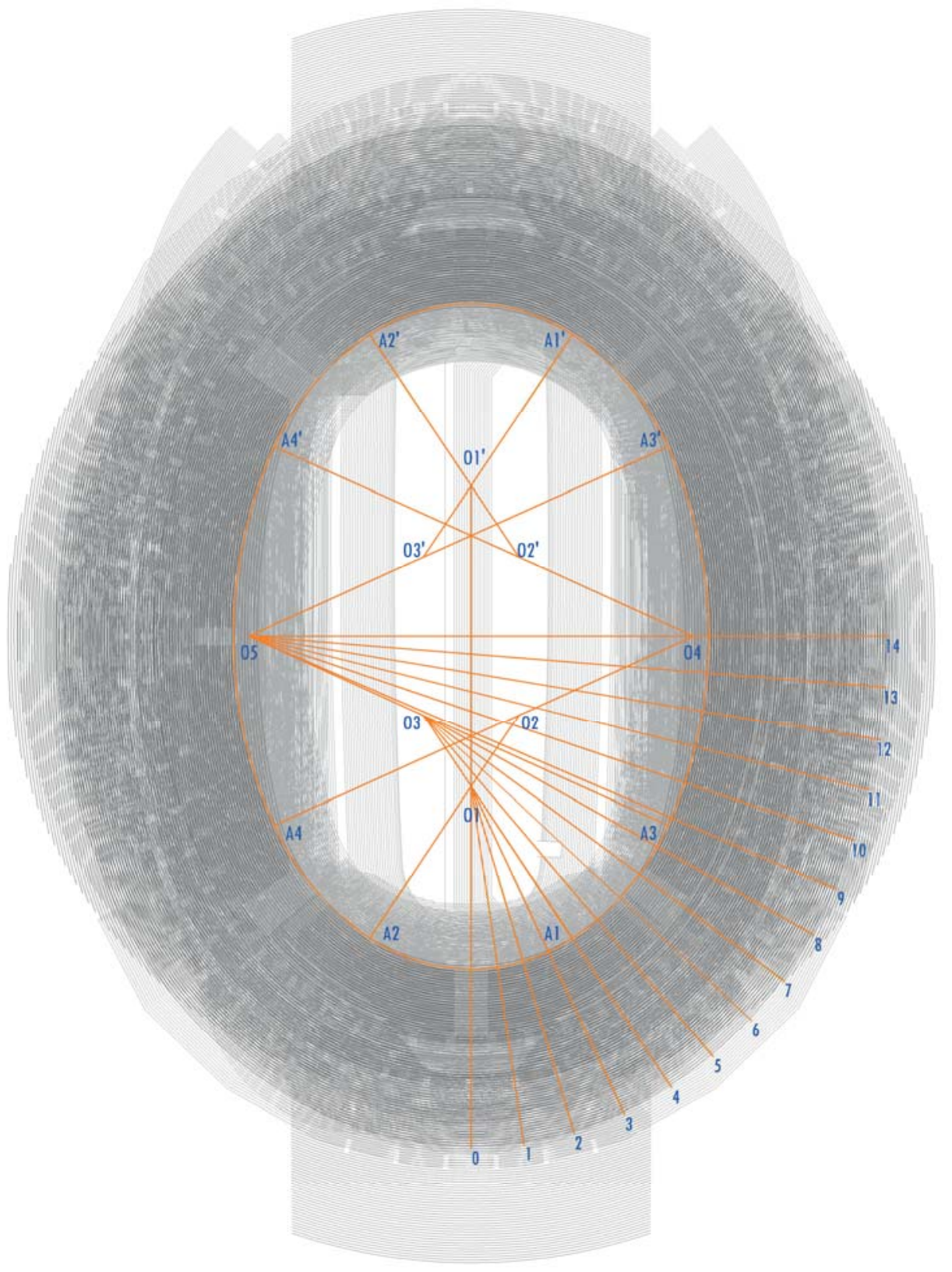

C- Conclusiones

El estadio Olímpico. Sus fundamentos arquitectónicos 


\section{El estadio Olímpico. Sus fundamentos arquitectónicos}

\section{Conclusiones}

El cuerpo de esta tesis se ha elaborado metódica y sistemáticamente después de comprobar la escasa atención dispensada a los estadios por parte de los críticos y analistas de la arquitectura, en particular a los Olímpicos en su globalidad como serie tipológica. Su elaboración incluye una detallada catalogación que recoge los datos más representativos de los veintiséis estadios que han sido sede de los Juegos, lo que ha permitido relacionarlos y establecer comparaciones entre ellos.

Finalmente, el trabajo ha permitido llegar a las siguientes conclusiones:

El estadio Olímpico moderno tiene sus orígenes en los modelos de estadio griego y anfiteatro romano de la antigüedad, así como en los antecedentes de los estadios de la Inglaterra industrial de finales del siglo XIX. Este origen y desarrollo contó con el impulso fundamental de la nueva necesidad de reunión y participación nacida al calor de la entrada de las masas en la historia a partir de la revolución francesa. El ofrecer acomodo a las grandes multitudes celebrantes supone un reto para los arquitectos, incluso aún antes de que se desarrollara el deporte moderno.

Los estadios actuales comparten características derivadas tanto del modelo griego como del anfiteatro romano. La arquitectura del estadio clásico está en íntima relación con la competición deportiva que en él se desarrolla, constituyendo un espacio organizado en torno a dos polos ideológicos que controlan la actividad; el de la justicia y el de la igualdad. El anfiteatro es un mecanismo arquitectónico deudor del entretenimiento y del espectáculo en el que lo fundamental es el espectador y su capacidad para seguir adecuadamente la acción. Aunque inicialmente el carácter de las actividades desarrolladas en el estadio y en el anfiteatro era esencialmente distinto, ambos tipos arquitectónicos convergen y dan como resultado el Estadio Olímpico Moderno.

Se ha comprobado como el espacio contenido en el interior de los estadios olímpicos tiene una fuerte carga evocativa y emocional.

De una parte, por lo que le confiere el deporte y la competición con su espíritu agonal, el estadio se ve revestido de la trascendencia que los ritos de iniciación aportaron al deporte, de los que es heredero directo. De otra parte, por su origen mítico, los Juegos modernos y los de la antigüedad clásica tienen un pasado que se puede considerar mágico y ceremonial. Por último, el potente significado de una gran concentración de gente que, pese a estar colocados de una manera pautada y organizada, forma 
una masa homogénea, continua e indiferenciada. La ligazón que los une, ese "intangible aglutinante", ha acompañado al hombre desde sus orígenes, y sigue siendo algo consustancial con las sociedades desarrolladas. Las masas encuentran en el estadio el más perfecto acomodo arquitectónico para la reunión y autoafirmación, estableciéndose un lazo de carácter emocional con el espectador, un sentimiento de comunión y pertenencia.

Los estadios Olímpicos conforman una serie tipológica clara y definida en la que su espacio interno, por razones principalmente de su gran escala, clara geometría, intensidad emocional y tradición histórica, contiene los fundamentos necesarios para poder producir elementos arquitectónicos de un altísimo interés.

En el transcurso de más de un siglo se ha ido configurando el tipo arquitectónico del estadio Olímpico para dar respuesta a los requerimientos técnicos y a la satisfacción de sus necesidades funcionales, es decir, la adecuación a la creciente especialización de los deportes, las cuestiones derivadas de la seguridad y de la violencia, las distancias máximas de observación en contraposición con el aumento de aforos, la sostenibilidad económica y de uso, etc.

En el cuadro adjunto se ponen en relación los principales parámetros cuantitativos:

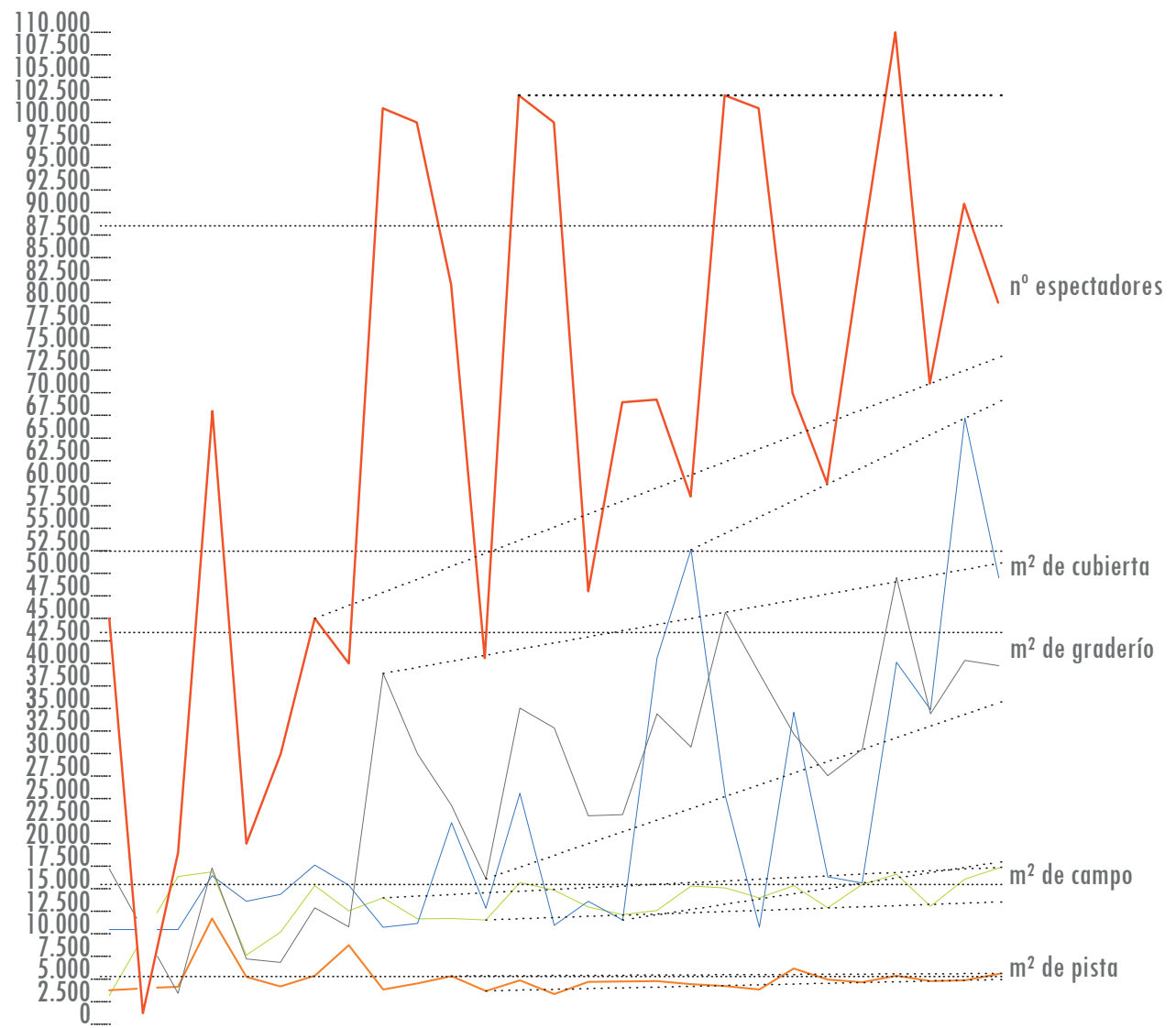

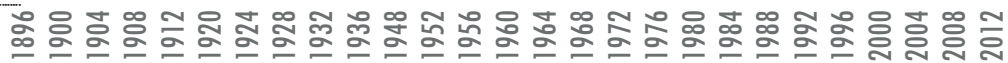

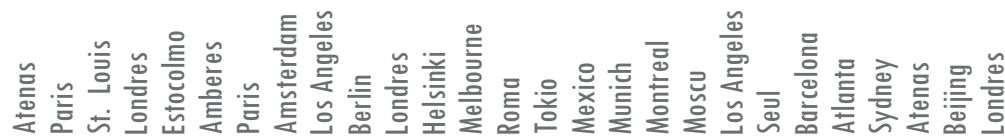

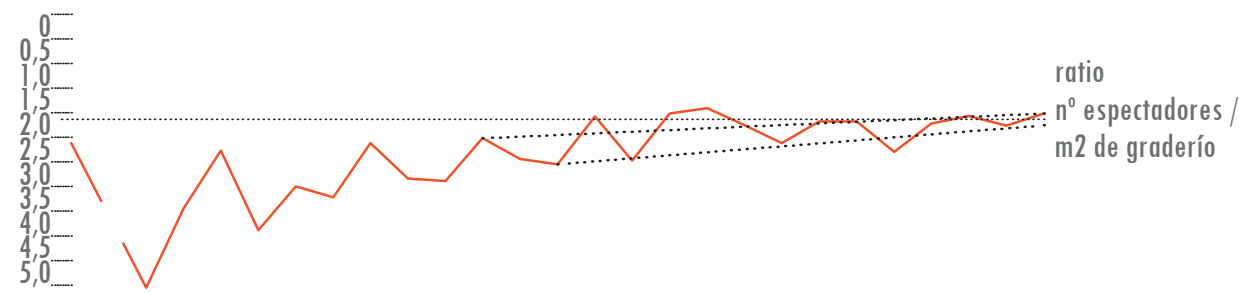


Del cual se puede concluir que, por una parte, en los espacios destinados a la competición se han mantenido unas ciertas constantes: las pistas se han ido ajustando y perfeccionando para que, desde unos principios dubitativos y fluctuantes, se han configurado, finalmente, como un elemento semejante $y$ homogéneo en todas las citas Olímpicas, lo que termina constituyendo un modelo global que asegura la igualdad de condiciones de todos los participantes.

El espacio que rodea la pista, antes de iniciarse el graderío, muestra una ligera tendencia al alza. Este espacio, no apto para la competición, es el utilizado por periodistas y cámaras de televisión.

Por otra parte, la gráfica muestra un incesante aumento en el número de espectadores y de todos los elementos destinados para su confort y seguridad. Los sistemas y controles impuestos para intentar garantizar la seguridad han ido confluyendo hasta constituir un modelo global. Históricamente se ha producido un proceso continuo de soluciones como respuesta ante las distintas casuísticas presentadas destilándose como respuesta, que la geometría del estadio debe ser precisa y con una distribución de recorridos claros.

En cuanto a la forma de los estadios, se ha comprobado que la tendencia apunta hacia los que proponen la traza que hemos denominado como elíptica, aunque realmente sea un óvalo formado por cuatro arcos de circunferencia y entre ellos destacan los que aplican los diagramas de Hadden. Se produce un distanciamiento paulatino y de una manera definitiva del modelo ateniense en forma de herradura. El compromiso entre la proximidad del publico al espectáculo y la necesidad de rodear al mismo con la intensidad emocional que suponen los espectadores es irreversible. Hay un alejamiento progresivo de las soluciones en las que se producen discontinuidades en el graderío.

Los aforos han fluctuado, sin que se pueda establecer de manera concluyente sus causas. Se ha comprobado que no están en relación directa con la población de las ciudades sede, ni con el número de deportes que en él se disputen.

Se puede deducir que las dimensiones de los estadios y sus aforos, dependen más de cuestiones de oportunidad, entendiendo estas como preexistencias, reutilización de estadios, dimensiones de los solares disponibles, capacidad económica, tiempo de preparación, propiedad, utilización futura del recinto, etc. Se comprueba que la media de los aforos de los estadios ha ido aumentando con el paso del tiempo, pudiendo establecerse una convergencia que ronda los 80.000 espectadores.

El número máximo de espectadores tiene una limitación clara, la distancia del espectador a la competición. Si se sobrepasan los doscientos metros, hay una gran dificultad para seguir la acción.

Otra cuestión importante es la cubierta. Los estadios tienden a que la mayor parte de su graderío sea cubierto, protegiendo a los espectadores de los rigores del clima, lluvia y exceso de sol. Es una clara tendencia que se puede deducir de la serie histórica. Ésta se ve favorecida por los avances constructivos y de cálculo, así como por los nuevos materiales que aportan ligereza a la vez que resistencia.

Los elementos significantes de la liturgia olímpica han ido cediendo paulatinamente su impronta arquitectónica para pasar a ser parte del espectáculo, en el que la tecnología y capacidad de sorprender, más propia de la prestidigitación, lo aleja del necesario reposo que requiere la arquitectura.

Con la irrupción de la retransmisión de las competiciones en tiempo real, la función del estadio cambia sustancialmente convirtiéndose en un gran plató. Los espectadores presenciales pasan a formar parte del espectáculo televisivo como fondo necesario y adoptan la función de representar las emociones de los nuevos y mayoritarios espectadores, que permanecen silenciosos y anónimos.

Ya no es sólo importante como se percibe el espacio desde sus tribunas y cómo la arquitectura potencia la comunión entre deportistas y espectadores. Ahora es igual o más importante la manera de como es captado por las cámaras de televisión y transmitido a la mayoría de espectadores ausentes. Llegando a constituir lo que Foucault denomina como "contraemplazamiento"

La relación del estadio con la ciudad es esquiva. Pese a ser una gran infraestructura urbana, rara vez su posición responde a la voluntad de organizar y jerarquizar el organismo urbano. La vocación del estadio es la de claro en el bosque, construyendo un vacío interior de naturaleza domesticada.

Tradicionalmente los estadios han dado la espalda a la ciudad, aunque las nuevas tendencias parecen corregir esa situación y su imagen exterior comienza a ser tenida en cuenta y valorada, con una vinculación más activa con respecto a la ciudad. Pese a constituir una tipología global, que adquiere una gran independencia con respecto al lugar en el que su ubica, es capaz de establecer unas fuertes relaciones afectivas con sus usuarios. Los momentos de emoción allí vividos tienen la capacidad de crear fuertes vínculos con el lugar dónde están ubicados.

En los estadios también se experimenta el cambio en cuanto al entendimiento espacial que nos ha acompañado a lo largo de estos casi ciento veinte años. Los medios actuales de trabajo están provocando un variación importante en cuanto a los fundamentos geométricos de la arquitectura. Desde 
configuraciones iniciales en las que domina el equilibrio estático apoyado en la rigurosa aplicación de las simetrías como mejor garantía de la monumentalidad, hasta el estadio de Helsinki que inicia el camino de la modernidad, con puntos culminantes en México, Múnich y Pekín.

El sistema para la organización y disposición del público es herencia directa de la experiencia acumulada en los teatros de la antigüedad clásica, que han dado lugar una máquina perfecta desde el punto de vista funcional. Artificio que, al aumentar la escala, precisa del perfeccionamiento de la configuración de las visuales introduciendo la parábola en su generatriz. Aquí la palabra clave, isóptica, surge desenmascarada de su origen técnico convirtiéndose en principio determinante del diseño y trazado de los graderíos, procurando la visión igualitaria y completa del espectáculo. Todo un sistema de orden geométrico.

En el estadio conviven dos escalas, una la magnífica de su vacio interior y otra más menuda, la que constituye cada uno de los espectadores ocupando su plaza sobre el graderío. En razón de sus grandes dimensiones, las necesidades de sustentación dan lugar a espacios muy interesantes en los que la forma está íntimamente relacionada con la solución estructural.

En función de su relación con el terreno, se clasifican los estadios con carácter tectónico o topográfico. En la antigüedad los estadios estables fueron topográficos, es decir, adaptados a la topografía, y las instalaciones efímeras lo eran tectónicas y desmontables. La influencia de los estadios de la Inglaterra industrial de finales del siglo XIX induce a la duda de cuál de los modelos aplicar, o estadios en los que su graderío se apoyaba en una modelada topografía o construcciones de tipo aéreo. La elección del modelo topográfico hasta el estadio de Múnich se corresponde con cuestiones económicas o facilidad constructiva, pero en el proyecto de Behnish para el estadio olímpico, se convierte el modelo topográfico en el elemento más característico, produciendo una arquitectura fluida, de continuidades, límites difusos y una íntima relación con el paisaje.

El estadio Olímpico actual se ha convertido, después del largo proceso de prueba y error, en un modelo tipológico de gran eficacia para dar respuesta a sus necesidades programáticas, llegando a constituir un elemento arquitectónico muy depurado geométrica y espacialmente, con lo que la hipótesis de la tesis, consistente en la evaluación el perfeccionamiento del tipo, ha quedado suficientemente argumentada y acreditada.

En la analogía estudiada entre el Coliseo romano y el estadio Olímpico, aún cuandosus funciones sean distintas,

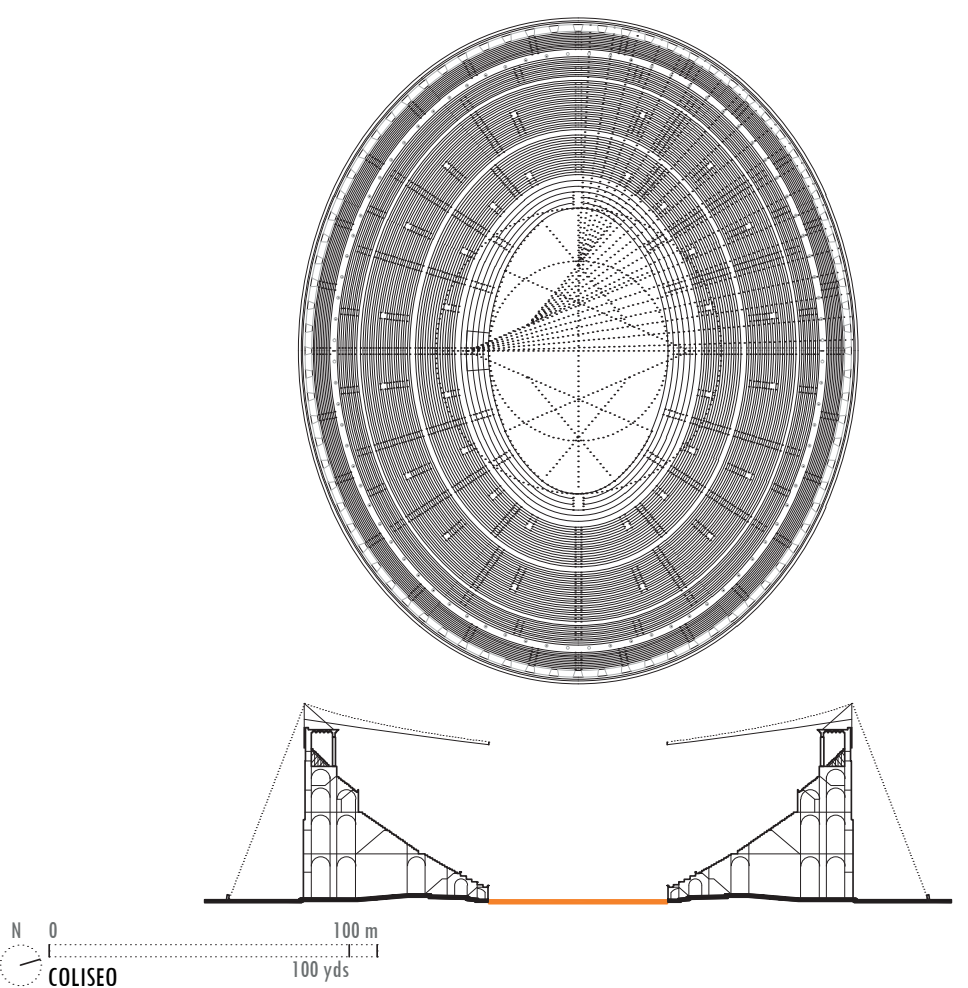


al poner en relación la función decantada y definida del estadio, se comprueba que la dimensión de la pista es mucho mayor que la arena del Coliseo.
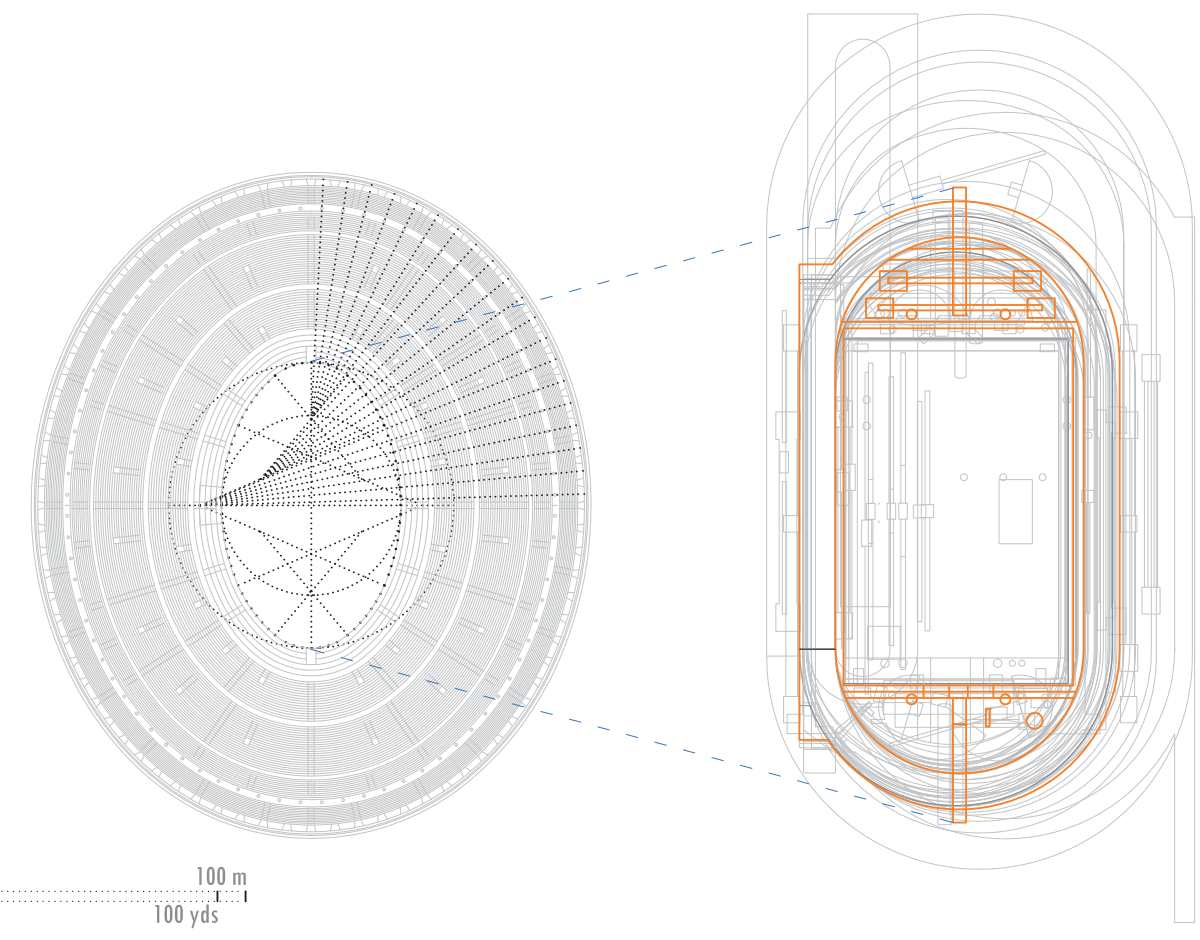

Se procede al cambio de escala del trazado regulador del modelo romano, hasta alcanzar la suficiente dimensión para poder alojar en el interior de su arena una pista de atletismo.

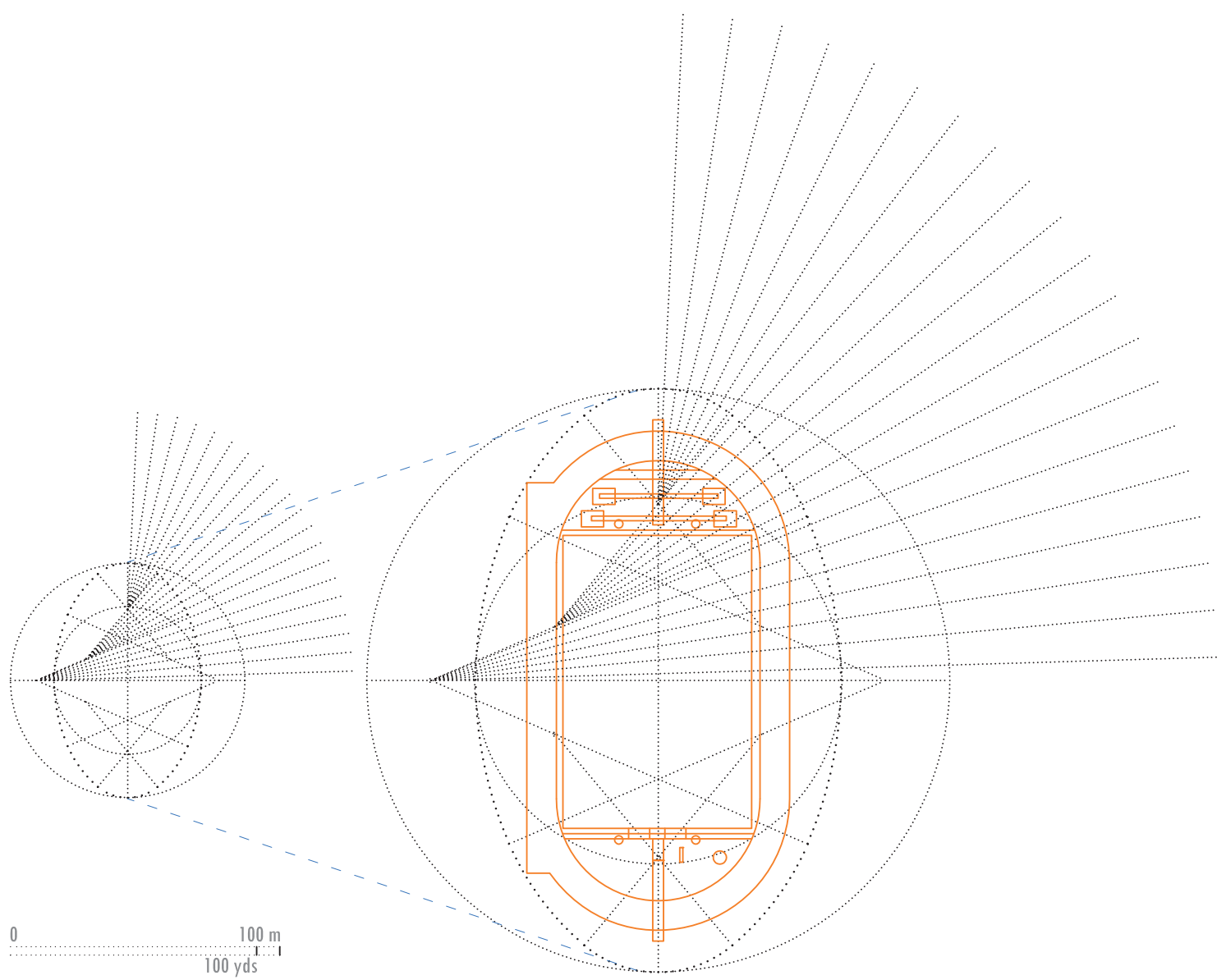




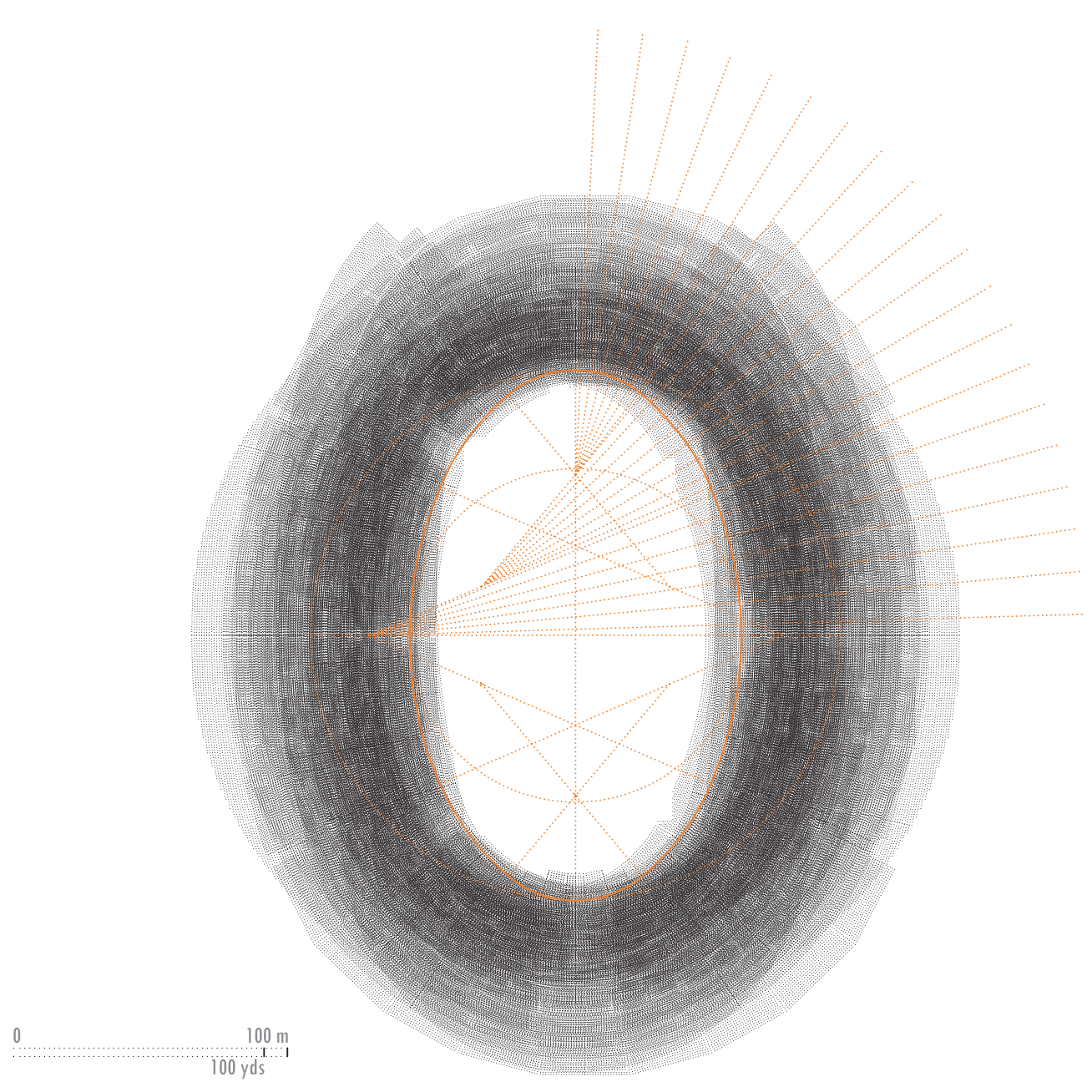

Superponiendolo sobre el dibujo obtenido con la suma de graderíos de los estadios con directriz elíptica, se puede constatar que la traza del Coliseo es semejante a la serie de estadios Olímpicos.

El mecanismo de escalar la planta no es apropiado para la sección pues el graderío del Coliseo es casi coincidente con el de los estadios en cuanto a su altura, sección, inclinación e incluso también la cubierta.

\section{Coliseo vs Olímpico de Pekín}
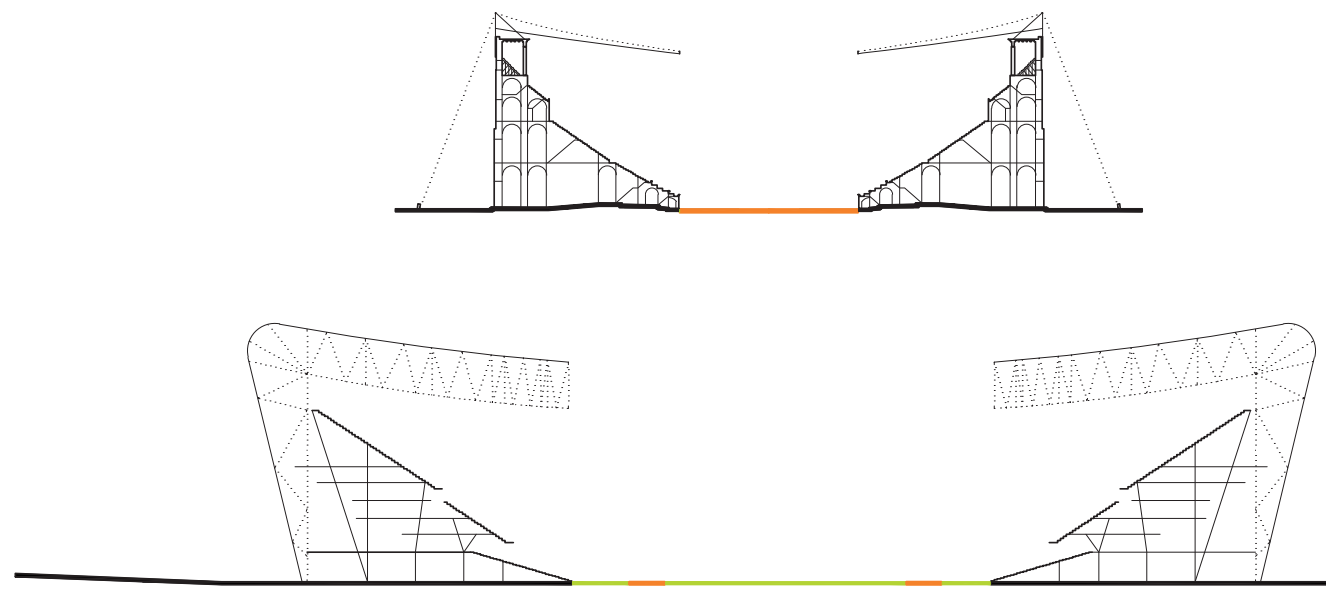


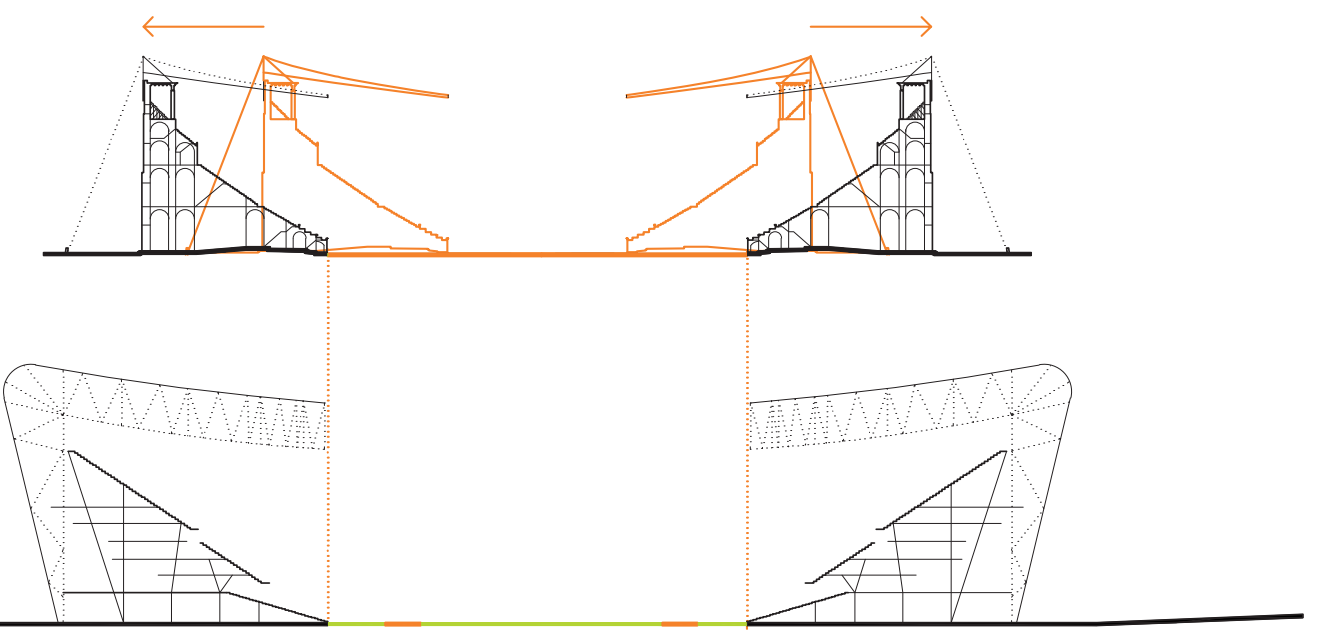

La verificación de una relación directa de carácter formal del estadio Olímpico con el modelo de anfiteatro romano se hace evidente, a pesar de las diferencias en cuanto a uso y dimensión, época y lugar, clima y cultura, y sobre todo a los avances técnicos y de irrupción de retransmisión universal del acontecimiento .

Únicamente se ha introducido una variante reseñable, la aparición de graderío en voladizo que permite fragmentar la cávea en dos o más estratos superpuestos, permitiendo una mayor aproximación del público al espectáculo.

CODA

Se termina este capítulo de conclusiones con una serie de reflexiones y esquemas flexibles y dinámicos de cara a nuevas propuestas de estadios Olímpicos, señalando esbozos para futuras líneas de investigación.

Las principales consideraciones a tener en cuenta son la sostenibilidad de estas infraestructuras, la posibilidad de evolución y adaptabilidad sin contradicciones a usos alternativos post olímpicos y el planteamiento de la vinculación activa con la ciudad a través de su capacidad como motor de revitalización del entorno urbano.

Los futuros estadios Olímpicos necesitan plantear nuevas alternativas. Es primordial que los estadios sean sostenibles y que su uso después de los Juegos esté garantizado y que supongan un legado ajustado a las necesidades de la ciudad.

En el devenir histórico de los estadios el programa deportivo se ha ido decantando desde unos planteamientos iniciales muy amplios e integradores, que incluían el mayor numero de deportes, hacía la monofunción, o a funciones con alternancia en el tiempo. La creciente especialización de los deportes con requerimientos cada vez más específicos dificulta la compatibilidad. La tradicional convivencia entre deportes de campo y atletismo cada día es más complicada.

Los estadios Olímpicos, es decir con pista de atletismo, necesitan ofrecer nuevas alternativas. Es primordial que sean sostenibles y que se asegure su uso post-Olímpico. En este sentido el estadio de Londres 2012 nos parece que abre un camino interesante de cara al futuro. Se proyectó con unas premisas muy claras, sensatas e innovadoras, diríamos incluso que revolucionarias. Durante los Juegos debía acoger con brillantez el espectáculo Olímpico y después suponer un legado coherente a las necesidades de la ciudad, abandonando un concepto ampliamente compartido e interiorizado, que la construcción de un estadio que va a ser testigo y soporte de un hecho con un valor histórico, tiene que perdurar y convertirse en un elemento de referencia y peregrinación en el futuro. La opción, que abre la última experiencia Británica, es la construcción de un legado permanente en forma de estadio de atletismo ajustado en dimensión a su demanda y un complemento de carácter efimero para los Juegos, que permita celebrar el festival Olímpico con todo su esplendor. Se establece así un interesante contraste entre lo permanente y duradero con lo efímero y mutable. 


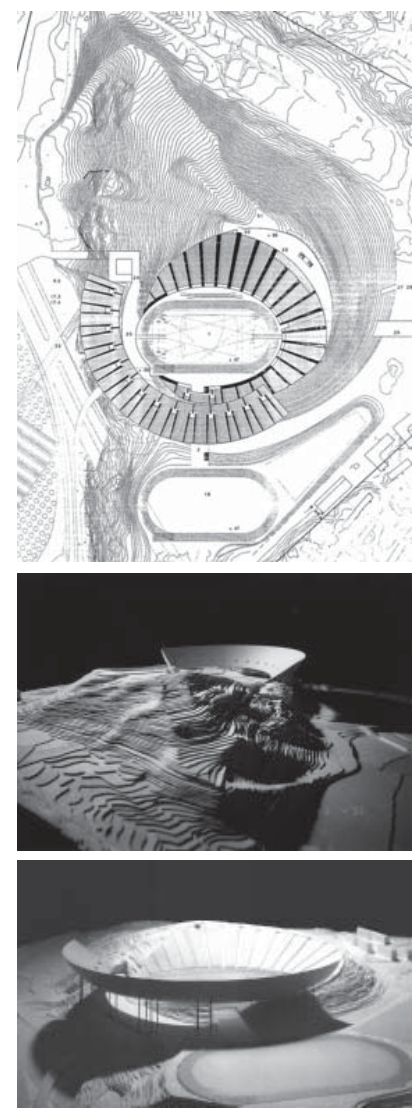

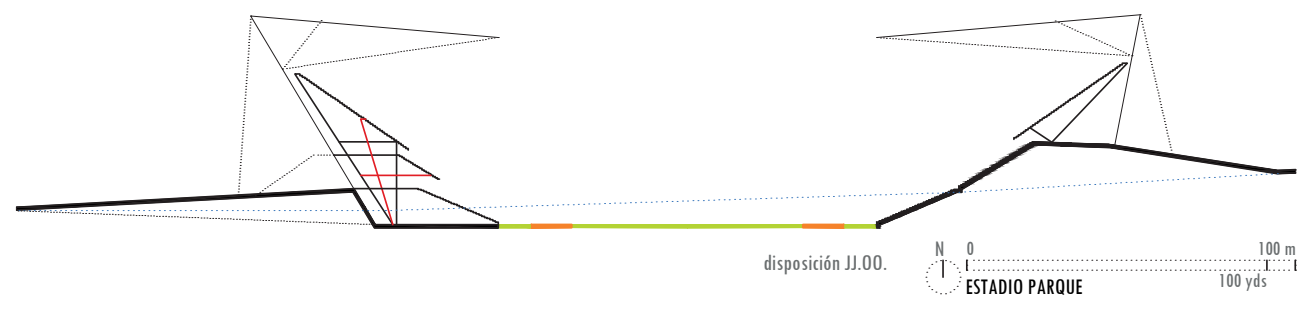

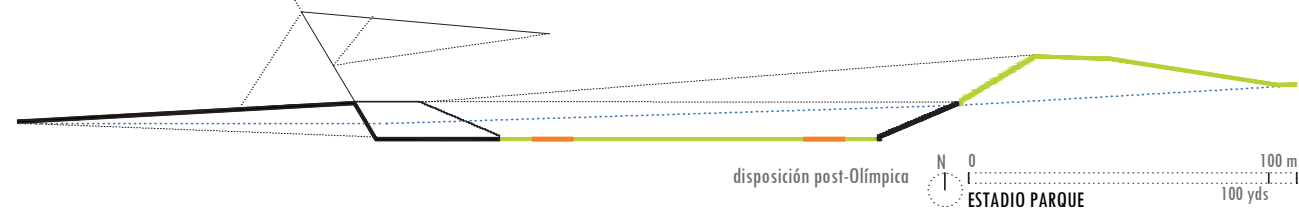

Como ejercicio, sevpropone un modelo de estadio Olímpico-Parque, con la capacidad de asumir el reto Olímpico y que a su vez establezca una relación amable con la ciudad, por su escala y sostenibilidad. Al modelar el terreno se construye un paisaje, que es soporte de un parque en el que el estadio constituye el claro en el bosque. Arquitecturas en las que su materialidad es la propia tierra del lugar, como sucedía en los estadios de la Grecia antigua, pero con la capacidad de crecer y aumentar su dimensión y servicios para la cita Olímpica, mediante arquitectura efímera. Existe una gran tradición de este tipo de actuaciones destinadas a las grandes celebraciones urbanas.

Sobre una topografía favorable, se conforma la traza del estadio mediante la adaptación del terreno, excavando y formando taludes para los graderíos de manera semejante al estadio de Olimpia. Se propone un tratamiento asimétrico en el que el talud de la recta de llegadas es más reducido, permitiendo la instalación de los servicios del estadio, mientras que el opuesto se destina solo al acomodo del público. Para los Juegos se completaría la actuación con un graderío de carácter aéreo sobrepuesto a la topografía, de manera análoga al propuesto por Rem Koolhaas en el concurso para el estadio Olímpico de Estocolmo, en 1996. También se contempla la total cubrición del graderío. El aforo se adecuaría a lo requerido por las autoridades Olímpicas. Una vez terminados los Juegos, se desmontarían las estructuras aéreas, exceptuando la cubierta de la tribuna principal que se descendería para adaptarse a la cota y escala de la tribuna definitiva. En la grada opuesta se podrían desmontar las bancadas de asientos de la parte superior para ajustar el aforo al adecuado para dar servicio a las principales competiciones de atletismo de la ciudad y el país. Esta actuación deberá ser reversible en el eventual caso de celebración de grandes competiciones, Campeonato Continental o Mundial. Al retirar los asientos de la parte alta del talud y sustituirlos por vegetación, compuesta por pequeños arbustos seleccionados en función de su fecha de floración, el estadio queda rodeado de una corona de frescor y color.

Otro futuro posible para los estadios Olímpicos es el tecnológico, que por medio de medios mecánicos se pueda cambiar la configuración para permitir que su uso sea continuado y sostenible.

La solución es compatibilizar el deporte de campo de mayor popularidad con la permanencia del estadio Olímpico, con el atletismo como uso característico, mediante la alternancia en el tiempo.

Para esto se requiere un estadio transformable en el que la grada baja se acomode modificando su posición para que la relación entre público y competición sea la adecuada en cada uno de los dos usos alternativos. Esto supone un gran reto de ingeniería, necesitándose una mega estructura formada por infinidad de elementos mecánicos articulados. De lo cual existen antecedentes Olímpicos, algunos con ya bastante antigüedad, como es el caso del estadio de Montreal o el más contemporáneo de Sydney, pero en ambos casos la pista de atletismo, característica principal de la instalación, ha sido eliminada. En el caso propuesto el alto coste de la instalación y de las labores de desplazamiento y mantenimiento plantean dudas sobre su adecuación. 


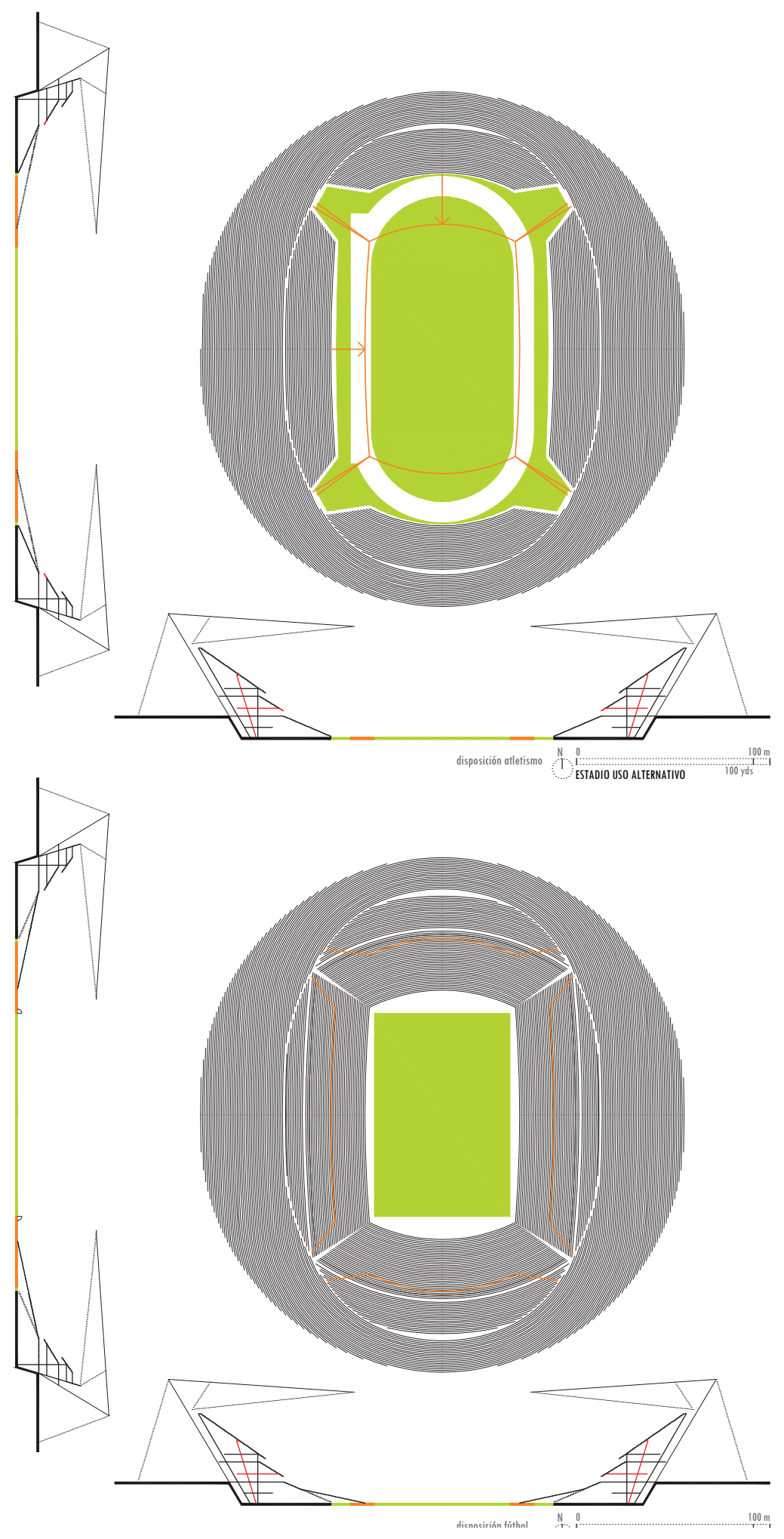

La primera opción parece más congruente con lo que significa el espíritu Olímpico en sus tres vertientes, Educación, Deporte y Cultura. Bien es cierto que los festivales Olímpicos ofrecen el mayor espectáculo deportivo del mundo, pero ese no es su fin último, sino la promoción de la Hermandad, Solidaridad y la Paz.

Un Estadio que, retomando lo que imaginó Coubertin y plasmó en su reto a los arquitectos en 1910, construya un jardín, un paisaje y... tal vez el paraíso. 


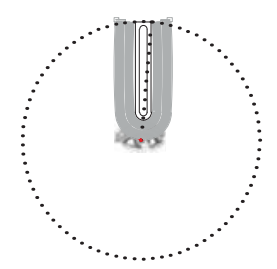

ATENAS 1896 (254m.)

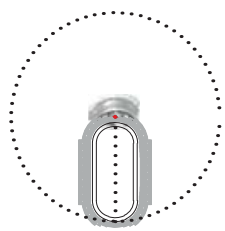

PARÍS 1924 (224m.)

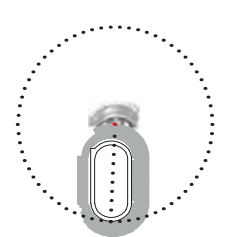

HELSINKI 1952 (209m.)

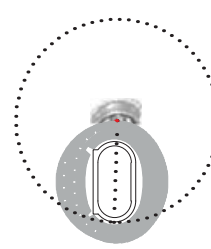

MUNICH 1972 (218m.)

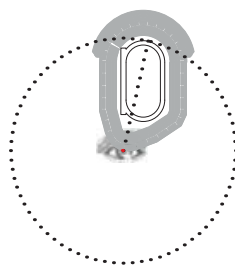

ATLANTA 1996 (241m.)

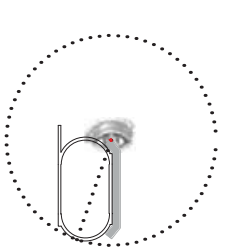

ST LOUIS $1904(225 \mathrm{~m}$.

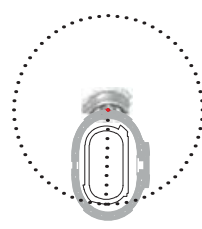

AMSTERDAM $1928(202 \mathrm{~m})$

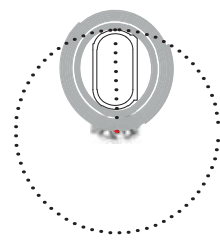

MELBOURNE 1956 (218m.)

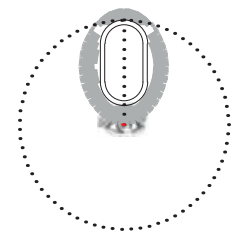

MONTREAL 1976 (224m.)

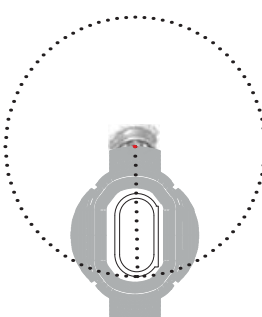

SYDNEY $2000(278 \mathrm{~m}$.)

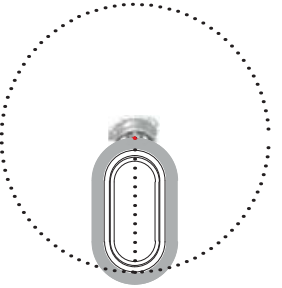

LONDRES $1908(287 \mathrm{~m}$.)

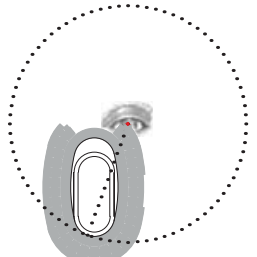

LOS ANGELES 1932 (253m.)

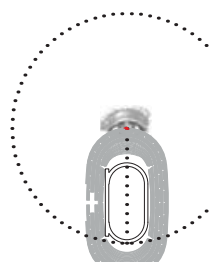

ROMA 1960 (246m.)

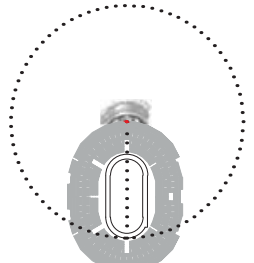

MOSCÚ 1980 (249m.)

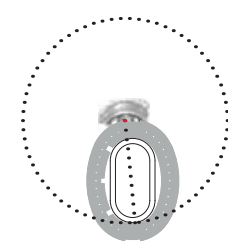

ATENAS 2004 (219m.)

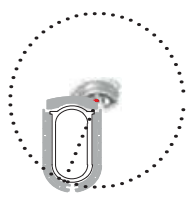

ESTOCOLMO 1912 (186m.)

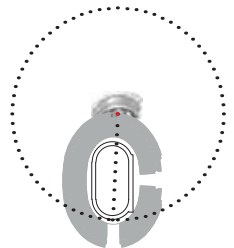

BERLÍN $1936(227 \mathrm{~m}$.)

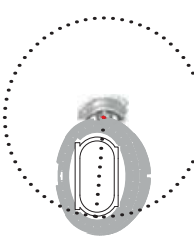

TOKIO 1964 (213m.

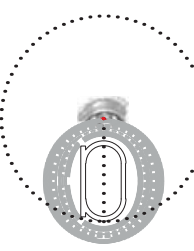

SEUL 1988 (220m.)

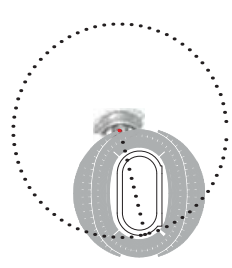

PEKÍN 2008 (229m.)

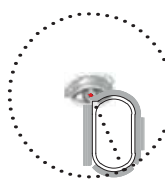

AMBERES 1920 (175m.)

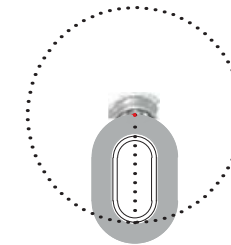

LONDRES 1948 (230m.)

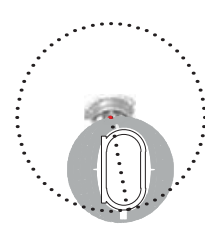

MÉXICO 1968 (201m.

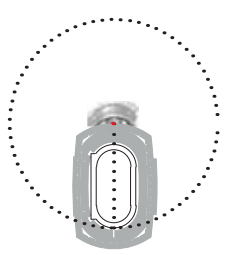

BARCELONA 1992 (224m.)

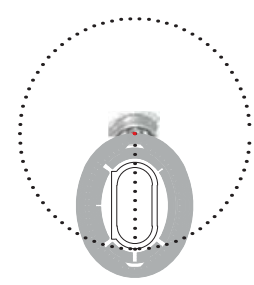

LONDRES 2012 (247m.)

D- Bibliografía

El estadio Olímpico. Sus fundamentos arquitectónicos 


\section{El estadio Olímpico. Sus fundamentos arquitectónicos}

\section{Bibliografía}

ARHEM, Barbro. (1979). Stockholms Stadion. Ed. Estocolmo: Byggnadsminne i stockholms län. ISBN 91-87088-04-5 BACHELARD, Gaston. (1957). La poética del espacio. Ed. Fondo de Cultura Económica. 2000. ISBN84-375-0368-X BAKER, William Joseph. (1982). Sports in the Western World. Ed. Illini Books editions. 1988. ISBN 0-252-06042-3 BAROJA, Pío. (1934). Las Noches del Buen Retiro. Ed. Tusquets. ISBN: 978-84-8310-635-8 BENDALA, Manuel. (1994). Los albores de Grecia. Ed. Historia 16. ISBN: 84-7679-100-3

CABANNE, Pierre. (1967). Conversaciones con Marcel Duchamp. Ed. Anagrama. 1984. ISBN 84-339-0406-X

CANETTI, Elias. (1960). Masa y poder. Ed. Alianza Editorial, 2005. ISBN 8420637513

CANO LASSO, Julio. (1996). Estudio Cano Lasso. Ed. Electa. ISBN: 88-435-5951-6

COLLINGWOOD, Robin George (1946). Idea de la Historia. Titulo original: The Idea of History. Ed. Fondo de Cultura Económica, Segunda edición 1996. ISBN: 9681601963,9789681601966

COOK, Peter. (1972). Archigram. Princenton Architectural Press. 1999. ISBN 1-56898-194-5

DARCY, Simon; TAYLOR, Tracy. (2013). Managing the Olympics. Editado por Stephen Frawley y Daryl Adair.

DAVIS, David. (2012). Showdown at Shepherd's Bush. The 1908 Olympic Marathon and the three runners who launched a sporting craze. Ed. Thomas Dunne Books. NY. 2012. Primera edición Junio 2012 ISBN 978-0-31 2-64100-9

DOXIADIS, Constantinos A. (1937). Architectural Space in Ancient Greece. Traducción Jaqueline Tyrwhitt. Ed. The MIT Press. 1972. ISBN 0262040212

DREES, Ludwig. Olympia: gods, artists, and athletes. Ed. Praeger, 1968 
DREES, Ludwig (1968). Olympia. God, Artits and Athletes. Ed. Pall Mall Press. ISBN-10: 0269670157 ISBN-13: 978-0269670152

DURANTEZ, Conrado. (1977). Las Olimpiadas Griegas. Ed. Delegación Nacional de Educación Fisica y Deportes. Comité Olímpico Español. ISBN 84-400-2621-8

DURANTEZ, Conrado. (2001). Pierre de Coubertin y su ideario. Ed. Comunidad de Madrid, Dirección General de Deportes. ISBN 8445119737,9788445119730

DYCKHOFF, Tom; BARRETT, Claire. (2012). The architecture of London 2012. Vision. Design. Legacy. Ed. An official London 2012 publication. ISBN 978-1 1 19-99386-5

FAURE-DUJARRIC, Louis. Architecte. L'œuvre. Préface de Jacques Lacretelle. S.I., l'Auteur, 1933, in-folio. 60 planches FINDLING, John E., editor. (1990). Historical Dictionary of World's Fairs and Expositions, 1851 -1988. Ed. Greenwood Press. New York. p. 203-205.

FRAMPTON, Kenneth. Historia crítica de la arquitectura moderna. Ed. Gustavo Gili, Barcelona. ISBN 9788425222740 FUSCO, Renato de. Historia de la arquitectura contemporánea. Ed. Celeste, 1994. ISBN 9788487553189

GARCÍA MÁRQUEZ, Gabriel. (2002). Vivir para contarla. Contemporanea Debolsillo. Ed. Random House Mondadori, sa. Tercera edición, 2010. ISBN: 978-84-8346-205-8

GEE, Stephen. (2013). Iconic Vision. John Parkinson Architect of Los Angeles. Ed Angel City Press. Santa Monica, CA. ISBN 9781626400085

GIRARDI, Wolfgang. (1971). Las Olimpiadas. Titulo Original Olympia Ruft!. Ed. Noguer Barcelona. Deposito Legal B-5.160-72

GOETHE, Johann Wolfgang von. Viaje a Italia. Ed. Zeta, 2009. ISBN: 8498722632, 9788498722635

GONZÁLEZ CALERO, Pedro. (2012). Filosofía para bufones. Ed. Planeta. Col Ariel. ISBN 9788408005223

GORDON, Barclay F. (1983). Olympic Architecture. Building for the Summer Games. John Wiley \& Sons. Nueva York. ISBN 0-471-06069-0

GRIFFIN, Jasper. (1980). Homero. Titulo original: Homer. Ed. Alianza Editorial. Clásicos de Grecia y Roma. Primera edición 2008. ISBN: 978-84-206-6560-3

HADDEN, Gavin. (1925). Stadium Design. Ed. American Society of Civil Engineers. Nueva York.

HERNÁNDEZ, Miguel. (1958). Cancionero y Romancero de Ausencias. Paperback. Edi. El Pais, 2004. ISBN-10: 8498150396 ISBN-13: 978-8498150391

HOMERO. La Odisea. Ed. EDAF. ISBN 84-7166-394-5. Primera edición 1981. Introducción Alberto Bernabé, Traducción Felipe Ximénez de Sandoval. B. ACP

HOMO, Léon. (1951). Rome impériale et l'urbanisme dans l'Antiquité. Ed. Albin Michel. 1971. ISBN: 978-2-22629642-9

HUGHES, Thomas (18579. Tom Brown's Schooldays. Ed. Pelangi ePublishing Sdn Bhd, 2012. ISBN 9670351715 , 9789670351711

INGLIS, Simon (2005). Engineering Archie: Archibald Leitch - Football Ground Designer. English Heritage. ISBN $1-85074-918-3$

JEU, Bernard. Análisis del deporte. Ed. Bellaterra. Barcelona. ISBN: 84-7290-056-8. Primera edición 1988

JÖNSSON, Ake. (2012). Solskens olympiaden, vägledning till. Ed: Klocktornet Media AB. ISBN 978-91-637-0085-9

KIERKUC-BIELINSKI, Jerzy; GERAINT, John. (2012). Stadia: Sport and Vision in Architecture. Ed. Sir John Soane's Museum. Londres. ISBN: 9780955876288.

KLUGE, Volker. ZIMMERMANN, Harf, fotografias. (1999) Olympiastadion Berlin. Steine beginnen zu reden. Olympia Stadium : stones are beginning to talk. Ed. Parthas. Berlin. ISBN 103932529286

KRÄMER, Karl (1972). Architekturwettbewerbe. Olympische Bauten München 1972. Ed. Taschenbuch. ISBN-10: 3782802098 
KRAUSE, Gerhard (1936). Das Reichssportfeld. Ilustrado por STRACHE, Wolf. Ed. Reichssportverl. Berlin.

KUNZE, Emil. (1972). 100 Jahre deutsche Ausgrabung in Olimpia. Ed. Prestel. Munich

LANGMEAD, Donald. JOHNSON, Donald Leslie (2000). Architectural excursions: Frank Lloyd Wright, Holland and Europe. Ed. Greenwood Press. USA. ISBN 0-313-30567-6

LE CORBUSIER. (1923). Hacia una arquitectura. Ed. Poseidon. Segunda edición 1978. ISBN 84-85083-05-9

LOOS, Adolf. (1908). Ornamento y delito y otros escritos. Ed. Gustavo Gili. Colección arquitectura y critica 1972. ISBN: 8425200121

LLORELLA, Anja. (2006). Stadium Design. Ed. Daab. Colonia, Londres, Nueva York. ISBN 3-93 7718-38-9

LÓPEZ ESTÉVEZ, Roberto. (2012). Pierre de Coubertin: Olímpismo Moderno y Movimiento Olímpico. Ed. EFDeportes. com. Revista Digital. Buenos Aires. Año 17. N170. www.efdeportes.com

LUCIANI, Roberto. (1993). El Coliseo. Ed. Anaya. ISBN: 84-207-5275-4

MALLWITZ, Alfred. (1972). Olimpia und seine Bauten. Ed. Wissenschaftliche Buchgesellschaft Darmstadt

MALLWITZ, Artur (1909). Das deutsche Stadion im Grunewald. Verlag f. Volkshygiene und Medizin.

MARCH, Werner. ROHRBACH, Charlotte (Fotografias) (1936). Bauwerk Reichssportfeld. Ed. Deutscher Kunstverlag, Berlin. Biblioteca CIO. MA 3465

MATTHEWS, George. MARSHALL, Sandra. (2003). St. Lovis Olympics 1904. Images of American Series. Ed. Arcadia Publisher SC. ISBN-13: 9780738523293

MONEO VALLES, Rafael. Sobre el concepto de Tipo en Arquitectura. Dpto. Publicaciones de Alumnos, ETSAM. 1982.

MOYA BLANCO, Luis. La Geometría de los Arquitectos Griegos pre-euclidianos. Real Academia de Bellas Artes de San Fernando. Madrid, 1953

NYGRÉN, Helge. Helsinki Olimpia Stadion. Ed. Mainosrengas Oy/offsetpaino, 1978. Helsinki

ORTEGA Y GASSET, José. El Origen Deportivo del Estado. Obras Completas, Madrid, Alianza Editorial, Revista de Occidente. 1983. Tomo II, pp. 607 - 623

PAUSANIAS (s. II dC.) Descripcion de Grecia: Atica y Elide. Ed. Alianza Editorial, 2000. ISBN 9788420636870

PÉREZ DE HITA, Ginés. (1619). Guerras Civiles de Granada. Ed. Maxtor, 2010. Facsimil. ISBN 9788497616799

PÍNDARO. (s. $\vee$ aC.) Odas Triunfales. Introducción, traducción y notas de José Alsina. Ed. Planeta 1990. ISBN 84320-4877-1

PIZZORNI ITIÉ, Florence. (1993). Les Yeux du Stade. Colombes, temple du Sport. Ed. L'Albaron. ISBN 2908528452

PHILIPP, Klaus Jan. (2000). Karl Friedrich Schinkel: v. 1 \& 2: Spate Projekte/Late Projects. Ed. Axel Menges. ISBN $978-$ 3930698110

POLLEY, Martin (2011). The British Olympics: Britain's Olympic Heritage 1612-2012. Ed. English Heritage. ISBN 978 1848020580

RANDALL, David (2012). 1896 The first modern Olympics. Libro electronico

RENSON, Roland (1996). The Games Reborn. The VIlth Olympiad Antwerp 1920. Antwerp. Ed. Pandora. ISBN 90 5325-051-4

ROSSI, Aldo. La Arquitectura de la Ciudad. Colección Punto y Línea. Gustavo Gili. 1 986. ISBN 84-252-0615-4

SEGURA MUNGUÍA, Santiago. (1992). Los Juegos Olimpicos. Educación, deporte, mitologia y fiestas en la antigua Grecia. Ed. Grupo Anaya. ISBN 84-207-4369-0

SHAKESPEARE, William. The tempest. Ed. Stanley Thornes. ISBN 0748703799

SHEARD, Rod. (2001). Sports architecture. Ed. Spon Press. Londres, Nueva York. ISBN 0-419-21 220-5

SLOTERDIJK, Peter (2004). Esferas III. Espumas. Esferorogía plural. Biblioteca de Ensayo. Ediciones Siruela. ISBN 978-84-7844-951-4. Segunda edición febrero 2009. Titulo original: Sphären III (Plurale Sphärologie). Schäume. Suhrkamp Verlag, Frankfurt am Main, 2004. Traducción Isidoro Reguera. B. ACP 
STRATHERN, Paul (2000). Derrida, en 90 minutos. Ed. Siglo XXI de España editores. Madrid (2002). ISBN 84-323$1112-\mathrm{X}$

VERSPOHL, Franz-Joaquim. (1976). Stadionbauten von der Antike bis zur Gegenwart. Regie und Selbsterfahrung der Massen. Ed. Anabas. ISBN 3-87038-043-8.

VITRUBIO POLLIÓN, Marco (s I d.C.) Los Diez Libros de Arquitectura. Título original: De Architectura. Traducción; OLIVER DOMINGO, José Luis. Ed. Alianza Forma 1995. Madrid. ISBN: 84-206-7133-9

WIMMER, Martin. (1976). Olympic Buildings. Ed. Leipzig. Lic 600/34/75. 5938721

WIMMER, Martin, (2015). Stadium Buildings: Construction and Design Manual. Ed. DOM Publishers. ISBN-10: 3869224150

YI-FU TUAN. (1974). Topofilia. Ed. Melusina, 2007. ISBN 9788496614178

ZAMBRANO, María. (1973). Claros del bosque. Ed. Biblioteca de Bolsillo, 1993. ISBN 84-322-3039-1

ZAMBRANO, María. Islas. Ed. Verbum, 2013. ISBN 9788479624170

ZEVI, Bruno. (1948). Saber ver la arquitectura. Titulo original "Saper vedere l'architettura". Traducido del italiano por Cino Calcaprina y Jesús Bermejo Goday. Ed Poseidon. Barcelona. Cuarta edición 1981. ISBN 84-85083-01-6

ZEVI, Bruno. Espacios de la arquitectura moderna. Ed. Poseidon, 1980. ISBN 978848508317

Charte Olympique '91. (1991). Ed. Comité International Olympique

Das Deutsche Stadion. Sport und Turnen in Deutschland, 1913. August Reher's Verlag Charlottenburg. Archivo ClO. Id 10021.CIO JO1936S_STADE

Das Reichssportfeld. (1937). Ilustraciones, Herbert Leinbaum. Ed. A. Gallus Druckerei, Berlin. Archivo ClO

El Olimpismo (2004). Dirigido por Rafael Ansón. Cap. 4. El Santuario de Olimpia. Conrado Durántez Corral. Ed. Universidad Camilo José Cela. ISBN: 84-95891-12-3

Jan Wils / het Olympisch stadion (1978). Monografieën van de Stichting Architectuur Museum. ISBN 9060123999

Onward to Olympics. Historical perspectives on the Olympics Games. (2007) Ed. SCHAUS, Gerard P. WENN Steven R. Wilfrid Laurier University Press. ISBN 9780 88920-505-5

Plans des Installations Sportives et du Stade Olympique, 1936. Archivo CIO. Id 10427. CIO JO1936S-STADE. SD 1

The Stadium and the City. Editado por John Bale y Olof Moen. Keele University Press. ISBN 1853311103. Primera edición 1995. B. ACP

The Story Behind the Largest and Finest Stadium in America. 1952. Biblioteca ClO. Id: 206777 jo-1932S-Stade.

The 1912 Stockholm Olympics, Essays on the competitions, the people, the city. Ed: Yttergren, Leif; Bolling, Hans, 2012. ISBN 978-0-7864-7131-7

INFORMES OFICIALES DE LOS JUEGOS

LAMBROS Sp. P., POLITES N. G. (1896). The Olympic Games B.C. 776. - A. D. 1896. Official Report of the Games of the I Olympiad, Athens, 1896. Ed. Central Committee in Athens

Concours Internationaux D'exercices Physiques Et De Sports. Rapports. (1901) Edición a cargo de MÉRILLON, M. D.. Paris. Exposition Universelle Internationale de 1900. Ministère du Commerce, de l'Industrie des Postes et des Télégraphes.

LUCAS, Charles. The Olympic Games, 1904. (1905). Ed. Woodard \& Tiernan Co. St Louis Missouri. EE.UU. 
Spalding's Official Athletic Almanac for 1905. Olympic Games Number. Vol. XVIII N² 17 (1905). Ed. James E. Sullivan. American Sports Publishing Co. Nueva York. EE.UU.

COOK, Theodore Andrea. (1908). The Fourth Olympiad. The Official Report. Ed. The British Olympic Association.

The Official Report of the Olympic Games of Stockholm 1912. Ed: The Swedish Olympic Committee, 1913

Rapport Officiel Des Jeux De La VIlème Olymmpiade Anvers 1920. Ed. Alfred Verdyck, 1958

Les Jeux De La VIII Olympiade. Paris 1924. Rapport Officiel. Ed. Comité Olympique Français

The Ninth Olimpiad. Being the Official Report of the Olimpic Games of 1928 celebrated at Amsterdam. Ed. The Netherlands Olympic Committee (Committee 1928) Amsterdam

Xth Olympiad. Los Angeles 1932. Official Report. (1933). Ed.Xth Olympiade Committee of the Games of Los Angeles. U.S.A. 1932 LTD

The XI th Olympic Games Berlin, 1936. Official Report. Volume I. (1937) Ed. Organisationskomitee Für Die Xi. Olympiade Berlin 1936 E. V. Responsable de contenidos Dr. Carl Diem. Editor Dr. Friedrich Richter. llustraciones Wilhelm Reetz, Berlin. Copyright 1937 Wilhelm Limpert-Verlag, Berlin Sw 68, Ritterstrasse 75

Official Report of the Games of the XXIIIrd Olympiad Los Angeles, 1984. (1985). Ed. Los Angeles Olimpic Organizating Committee.

The Official Report of the Organising Committee for the XIV Olympiad. London 1948. Ed. The Organising Committee for the XIV Olympiad.1953

The Official Report of the Organising Committee for the Games of the XV Olympiad. Helsinki 1952. Ed. The Organising Committee for the XV Olympiad.1952

The Official Report of the Organizing Committee for the Games of the XVI Olympiad. Melbourne 1956. Ed. The Organising Committee for the XVI Olympiad.1956

The Games of the XVII Olympiad Rome 1960. The Official Report of the Organizing Committee. Ed. The Organising Committee for the XVII Olympiad.1960

The Games of the XVIII Olympiad Toyo 1964. The Official Report of the Organizing Committee. Ed. The Organising Committee for the XVIII Olympiad.1964

The Official Report 1968. Produced by the Organizing Committee of the Games of the XIX Olympiad. Ed. The Organising Committee for the XIX Olympiad.1968

The Official Report of the Organizing Committee for the Games of the XX Olympiad. Munich 1972. Ed. The Organising Committee for the XX Olympiad.1972

Montrèal 1976 Official Report. Games of the XXI Olympiad Montréal 1976. Ed. COJO 76, Ottawa. 1978

Games of the XXII Olympiad. Official Report of the Organising Committee of the Games of the XXII Olympiad Moscow. Ed. Moscow Olympic Organizing Committee. 1981

Official Report of the Games of the XXIInd Olympiad Los Angeles, 1984. Ed. Los Angeles Olympic Organizing Committee. 1985

Official Report. Published by the Korean Olympic Organizing Committee. Ed. Seoul Olympic Organizing Committee for the Olympic Games. 1988

Official Report of the Games of the XXV Olympiad Barcelona 1992. Ed. COOB'92, S.A. Barcelona. 1992

The Official Report of the Centennial Olympic Games. The Atlanta Committee for the Olympic Games. Ed. The Atlanta Committee for the Olympic Games. 1997

Official Report of the XXVII Olympiad. Sydney 2000 Olympic Games. Ed. Sydney Organising Committee for the Olympic Games. 2001

Official Report of the XXVIII Olympiad. Ed. ATHOC, Athens 2004, Organising Committee for the Games. 2004

The Official report of the Beijing 2008 Olympic Games. Ed. Beijing Organising Committee for the Games of the XXIX Olympiad (BOCOG). 2008

London 2012, Olympic Games Official Report. Ed. London Organising Committee for the Games of the XXX Olympiad (LOCOG) 


\section{CATALOGOS}

The Stadium. The Architecture of Mass Sport. (2000). Ed. Michelle Provoost. NAI Publishers Rotterdam. ISBN 905662-145-9

ARHEM, Barbro. (1989). Stadion, byggnadshistorisk dokumentation inför byggnadsminnesförklaring. Ed Estocolmo: Stockholms Stadsmuseum.

REVISTAS

CARDEN, Robert W. "The Franco-British Exhibition.." Architectural Review. 1908 July, v. 24, p. [32]-37 ; 1908 Sept., p. [108]-1 11

DUMAS, F.G. The Franco-British Exhibition: illustrated review. London: Chatto and Windus, 1908.

GREENHALGH, Paul. Art, politics and society at the Franco-British Exhibition of 1908. Art History. 1985 Dec., v.8, no.4, p.434-452.

HERNÁNDEZ DE LEÓN, Juan Miguel. El espacio de la excepción. Sobre el carácter de la arquitectura deportiva. AV: Monografías, ISSN 0213-487X, N³3, 1992 (Ejemplar dedicado a: Cultura física), p. 4-7

FOUCAULT, Michel. Espacios otros. "Des espaces autres", Conferencia dictada en el Cercle des études architecturals, 14 de marzo de 1967, publicada en Architecture, Mouvement, Continuité, n 5, octubre de 1984

ÖSRBERG, Ragnar; GRUT, Torben. Stockholms Stadion. Arkitektur, 1912, n7

VILLASEÑOR, Miguel Ángel, Hubo un tiempo en el que no todas las pistas medían 400 metros. Atletismo Español. Julio 2014

WEILER, Ingomar. (1984). Problems in the Discussion of the Reason for the Decline of the Ancient Olympic Games. Ed. OARe 1984. Sesión 24, Academia Olimpica Internacional. Olimpia, pp. 121-136

Revista Arquitectura. COAM, nl 247. 1984

Architectural Review, Julio-Diciembre 1908, vol.24, p.32-37. Biblioteca RIBA, Londres

The Builder, 9 Mayo 1908, vol.94, p533. Biblioteca RIBA, Londres

The Builder 18 Julio 1908, vol.95, p.62. Biblioteca RIBA, Londres

The Builders' Journal and Architectural Engineer, 29 Enero 1908, vol.27, p.102 (Copyright: RIBA Library Books and Periodicals Collection)

The Builders' Journal and Architectural Engineer, 22 Julio 1908, vol.28, p.57. (Copyright: RIBA Library Books and Periodicals Collection)

The Building News. 23 agosto de 1907. Vol 93. P.239. (Copyright: RIBA Library Books and Periodicals Collection)

The Building News, 10 Julio 1908, vol.95 (Copyright: RIBA Library Books and Periodicals Collection)

Revista Arquitecturas Bis. $\mathrm{n}^{\circ} 46$ y 47. Barcelona 1992.

Revista de Folklore. $\mathrm{n}^{\circ} 317$ (2007). Ed. Fundación Joaquin Díaz

Paginas WEB

http://architekturmuseum.ub.tu-berlin.de

http://en.nai.nl/collection

http://home.scarlet.be/ fhermans/antwerpen 1920/stadion.html

http://olympichstadion.nl

http://www.nationalgeographic.com.es/articulo/historia/secciones/8848/globo_aerostatico_conquista_los_cielos.

html

http://www.olympiastadion-berlin.de

SMITH, Brandon. (2012). The Future of Olympic Architecture Is Portable. http://mashable.com/2012/07/31/ olympic-architecture/

http://architectureofthegames.net/tag/venues/page/7/ 
London Olympic Stadium 1908. RIBA.

https://www.architecture.com/Explore/Buildings/LondonOlympicStadium 1908.aspx

Otros documentos

British Olympic Association, Council Minutes, December 20, 1906, BOF Archives

National Register of Historic Places. Inventory-Nomination Form. United States Departament of the Interior. National Park Service. (Form No. 10-300<Rıv. 09-77) y (Form No. 10-306<Rıv. 10-74) 11 de mayo de 1984)

Tesis doctorales

FEDDERSEN, Arne; MAENNIG, Wolfgang. (2008). Arenas vs. Multifunctional Stadia - Which Do Spectators Prefer?. IASE/NAASE Working Paper Series, No. 08-15

JAKIMOVSKA, Gordana (2007). Exploring Flexibility in Stadium Design. Massachusetts Institute of Technology. Master of Science in Architecture Studies.

LLEWELLYN, Matthew P. (2010) Rule Britannia: Nationalism, Identity, and The Modern Olympic Games. The Pennsylvania State University. The Graduate School. College of Health and Human Development

VÁSQUEZ ROCCA, Adolfo. Sloterdijk y Canetti: El detonante iconográfico y operístico de la política de masas. Pontificia Universidad Católica de Valparaíso - Universidad Complutense de Madrid

\section{FUENTES}

Arkitekturmuseet. Museo de la Arquitectura y el Diseño. Estocolmo.

Skeppsholmen, 11149 Stockholm.

British Olympic Association en la University of East London.

Docklands Campus. University Way. London E16 2RD. Reino Unido.

www.uel.ac.uk/Ils/search/resources/boa/

Comité Olímpico Francés CNOSF.

1 Avenue Pierre de Coubertin. 75013 Paris. Francia. http://franceolympique.com

LA84 Foundation, Los Ángeles.

2141 W Adams Blvd. Los Angeles, CA, Estados Unidos. www.LA84Foundation.org

Sveriges Centralförening för Idrottens Främjande

Klocktornet, 3 tr. Olympiastadion. 11433 Stockholm. http://www.scif.se/

Universidad Nacional Autónoma de México.

Ciudad Universitaria, Coyoacán. Mexico D.F. http://arquitectura.unam.mx

Urheilumuseo. Sport Museum of Finland.

Olympic Stadium, Fl-00250 Helsinki. http://www.urheilumuseo.fi 
